\title{
Immungenetische Marker im Wandel der Zeit
}

\author{
Molekulargenetische Analyse von \\ single nucleotide Polymorphismen \\ immungenetischer Rezeptoren und Interleukine \\ in historischen Bevölkerungen
}

\author{
DisSERTATION \\ zur Erlangung des Doktorgrades \\ Dr. rer. nat.
}

Dipl. Biol. Jutta Pepperl

geb. Pollmann

aus

Wuppertal

Göttingen 2008 
D7

Referent: Prof. Dr. B. Herrmann

Korreferent: Prof.Dr. M. Oppermann

Datum der mündlichen Prüfung: 30.04.2008 
Diese Arbeit wurde angefertigt in der Abteilung für Historische Anthropologie und Humanökologie des Johann-Friedrich-Blumenbach-Institutes für Zoologie, Anthropologie und Entwicklungsbiologie.

Sie ist Teil des Projektes: „Molekulargenetische Untersuchung immungenetischer Marker an degradierter DNA aus genetischen Archiven“, gefördert durch die DFG innerhalb des Graduiertenkollegs 1034 cancer pharmacogenomics „Die Bedeutung genetischer Polymorphismen in der Onkologie: Von den Grundlagen zur individualisierten Therapie“" 
1 Einleitung 1

$\begin{array}{llr}2 & \text { Fragestellung } & 6\end{array}$

3 Immungenetische Marker $\quad 8$

3.1 Rezeptoren der Pathogenerkennung . . . . . . . . . . . . . . . . 8

3.1 .1 TLR2 . . . . . . . . . . . . . . . . . . . . . . . . . . . . . 10

3.1 .2 TLR4 . . . . . . . . . . . . . . . . . . . . 12

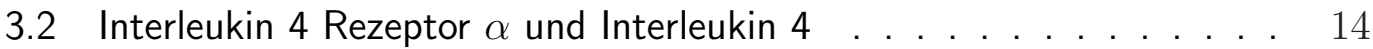

3.2 .1 Interleukin $4 \ldots \ldots \ldots \ldots . \ldots \ldots$

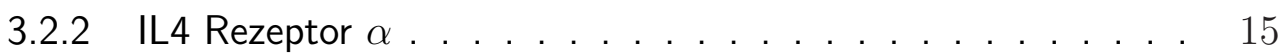

3.3 Pro- und antiinflammatorische Interleukine . . . . . . . . . . 17

3.3 .1 Interleukin $6 \ldots \ldots \ldots \ldots \ldots$

3.3.2 Interleukin $10 \ldots \ldots \ldots \ldots$

4 Einfluß demographischer Transitionen 23

4.1 Prähistorische Transition . . . . . . . . . . . . . . . . . . . 26

4.2 1. Historische Transition . . . . . . . . . . . . . . . . . . . . 26

4.3 2. historische Transition . . . . . . . . . . . . . . . . . . . . . . . . 27

4.4 3. historische Transition . . . . . . . . . . . . . . . . . . . . . . 30

4.5 4. historische Transition . . . . . . . . . . . . . . . . . . . . . . . 31

4.6 Der Schwarze Tod - War Y. pestis der Auslöser? . . . . . . . . . . . 32

5 Auswahl der Bevölkerungen 34

6 Hypothese 36

7 Historische Skelettserien $\quad 38$

7.1 Mittelalterliche Skelettserien aus Lübeck $(\mathrm{HL}) \ldots \ldots$. . . . . . . . . 38

7.1 .1 Allgemeine Informationen . . . . . . . . . . . . . . . . 38

7.1.2 Stichprobe Lübeck Pestmassengrab, jüngerer Bestattungshorizont . . . . . . . . . . . . . . . . . . . 39

7.1.3 Stichprobe Lübeck "Hungersnot", älterer Bestattungshorizont 42

7.2 Skelettserie Dorste . . . . . . . . . . . . . . . . . . . . . . . . 44

8 Methoden $\quad 47$

8.1 Allgemeine Aspekte der Kontaminationsvermeidung und Authentifizierung der Ergebnisse . . . . . . . . . . . . . . . . . . . . . . . 47

8.2 Extraktion von DNA aus Probenmaterial . . . . . . . . . . . . . . . 48

8.2.1 Probenvorbereitung . . . . . . . . . . . . . . . . . . . . . 49

8.2 .2 DNA-Extraktion . . . . . . . . . . . . . . . . . 49

8.3 Amplifikation zur Bestimmung des Genetischen Fingerabdrucks . . . 50

8.3.1 Oktaplex-PCR . . . . . . . . . . . . . . . . . 50 
8.3.2 Fragmentlängen-Analyse (FLA) . . . . . . . . . . . . . 52

8.4 Kombinierte Genotypisierung von STR und SNP . . . . . . . . . . . 52

8.4.1 Design der Primer zur DNA-Amplifikation . . . . . . . . . . . 54

8.4.2 Design der Primer für die SBE-Reaktion . . . . . . . . . . . 56

8.4.3 Primäre PCR zur DNA-Amplifikation . . . . . . . . . . . 56

8.4.4 Sekundäre PCR zur Farbmarkierung der STR-Fragmente . . . 57

8.4.5 Single-Base-Extension-Reaktion (SBE) . . . . . . . . . . 58

8.4.6 Auswertung der SNP-Analyse . . . . . . . . . . . . . . . . . 59

8.5 Sequenzierung . . . . . . . . . . . . . . . . . . . 64

8.6 Statistische Auswertung . . . . . . . . . . . . . . . . . 65

9 Ergebnis $\quad 66$

9.1 Amplifikationserfolg . . . . . . . . . . . . . . . . . . . . 66

9.2 Typisierungserfolg . . . . . . . . . . . . . . . . . . . . . . . . . 71

9.3 Auswertung der Typisierungsergebnisse . . . . . . . . . . . . . . . 77

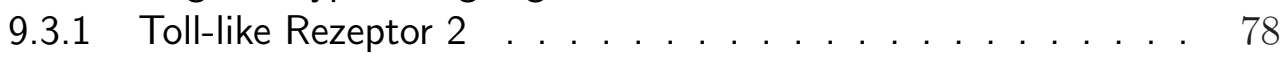

9.3.2 Toll-like Rezeptor 4 . . . . . . . . . . . . . . . . . . . . . 80

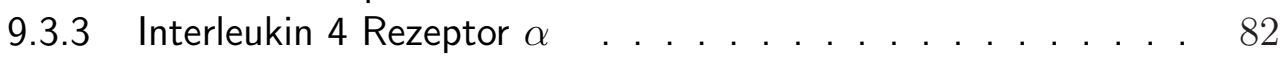

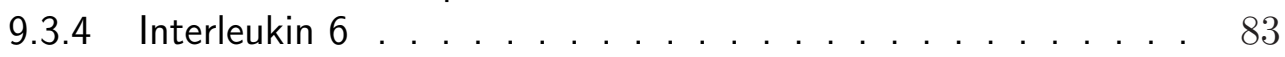

9.3 .5 Interleukin $10 \ldots \ldots \ldots$

9.3.6 Zusammenfassung der Ergebnisse . . . . . . . . . . . . . . . 90

9.4 Spezifität von PCR und SBE . . . . . . . . . . . . . . . . . . . . . . 91

9.4.1 Artefaktbildung in der SBE . . . . . . . . . . . . . . . . . . 91

9.4.2 Kontrolle der Reaktionsspezifität mittels Sequenzierung der PCR-Fragmente . . . . . . . . . . . . . . . . 94

9.5 Genetischer Fingerabdruck . . . . . . . . . . . . . . . . . . . . . . . 96

9.5.1 Individualisierung und Authentifizierung . . . . . . . . . . 96

10 Diskussion der angewandten Methoden 106

10.1 Vergleich der Single-Base-Extension-Reaktion und alternativen Methoden . . . . . . . . . . . . . . . . 106

10.2 Fehlerdiskussion der ausgeschlossene Systeme . . . . . . . . . . . . 107

10.3 Resumee . . . . . . . . . . . . . . . . . . . . . . 108

11 Ergebnisdiskussion $\quad 110$

11.1 Diskussion der beobachteten Allelfrequenzen . . . . . . . . . . . . . 110

Pathogen-Rezeptoren . . . . . . . . . . . . . . . . . . . . . . . . 111

IL4Ra . . . . . . . . . . . . . . . . . . . . . . . . . . . . . . 112

Pro- und antiinflammatorische Zytokine . . . . . . . . . . . . . . . . 113

11.2 Frequenzen antiinflammatorischer Allele . . . . . . . . . . . . . . . . 116

Langlebigkeitsallele als Vorteil in historischen Bevölkerungen . . . . . 116

Antiinflammatorische Allele in Zeiten substantieller Krisen . . . . . . 117

Eignung der modernen Population als Kontrolle . . . . . . . . . . . . 118

11.3 Aussagekraft der ausgewählten Marker . . . . . . . . . . . . . . . . 120

12 Zusammenfassung $\quad 121$ 
Literatur

Tabellenanhang

Der Fundkomplex Dorste als genetisches Archiv . . . . . . . . . . . . . . . 139

Ergebnisse der Einzelamplifikationen zur Typisierung der SNP . . . . . . . 141

Allelfrequenzen und Häufigkeiten der Genotypen . . . . . . . . . . . . . . 197

Ergebnisse der Einzelamplifikationen des genetischen Fingerabdrucks . 201

Skelettserie Dorste: Referenzdaten . . . . . . . . . . . . . . . . . . . . . 226

Ergebnisse der Sequenzierungen . . . . . . . . . . . . . . . . . . . . . . . . 229

Tabellen der statistischen Auswertung . . . . . . . . . . . . . . . . . . . . 239

Hardy-Weinberg equilibrium . . . . . . . . . . . . . . . . . . . . . . 239

Ergebnisse des Exakten Tests . . . . . . . . . . . . . . . . . . . 240

Primerübersicht . . . . . . . . . . . . . . . . . . . . . . 242

$\begin{array}{lr}\text { Anhang } & 249\end{array}$

Einheiten und Abkürzungen . . . . . . . . . . . . . . . . . . . . . . . 249

Geräte . . . . . . . . . . . . . . . . . . . . 251

Chemikalien und Kits . . . . . . . . . . . . . . . . . . . . . . . . . . 252

Einwegmaterialien und Hilfsmittel . . . . . . . . . . . . . . . . . 253

Längenstandards . . . . . . . . . . . . . . . . . . . . . . . . . . . 254

IUB-Code . . . . . . . . . . . . . . . . . . . . . 255 


\section{Einleitung}

Nothing in biology makes sense except in the light of evolution

(Dobzhansky, 1973)

Single nucleotide polymorphisms (SNP) sind Polymorphismen, die eine einzelne Basenpaar-Position der genomischen DNA betreffen. An dieser Position sind verschiedene Sequenzalternativen (Allele) vorhanden, deren seltenste mit einer Frequenz von mindestens einem Prozent in der Bevölkerung vorkommt (Brookes, 1999). SNP sind weit verbreitete Mutationen, die zumeist in biallelischer Ausprägung auftreten. Sie machen etwa $90 \%$ der interindividuellen DNA-Variation aus, etwa 10 Millionen SNP verteilen sich auf das menschliche Genom. Etwa $85 \%$ dieser Polymorphismen teilen sich die menschlichen Populationen, lediglich $15 \%$ sind nur in einzelnen Populationen vorhanden (Brookes, 1999). Die Möglichkeiten ihrer funktionellen Bedeutung werden besonders deutlich im Verhältnis zur genetischen Distanz zu einem unserer nächsten Verwandten, dem Schimpansen, die nur 10mal höher ist als zwischen verschiedenen Menschen (Brookes, 1999). Die Bedeutung von SNP in genetischen Studien sehen Riva \& Kohane (2002) in drei Ansätzen:

- Die Vererbung von einer Generation zur nächsten gibt Einblicke in die Evolution unserer Spezies.

- Ihre Frequenz und Verteilung zwischen Populationen lassen Erkenntnisse zu ihrer Geschichte und wechselseitigen Beziehungen zu.

- Ihre Untersuchung in Assoziationsstudien ermöglicht die Identifizierung von Genen, die an einem Phänotyp beteiligt sind.

Da single nucleotide polymorphisms den Großteil des Spektrums der genomischen Variabilität ausmachen, kann ein hoher Einfluß auf die genetische Komponente von Erkrankungen gefolgert werden. Etwa 100.000 bis 300.000 SNP liegen innerhalb kodierender (Rebbeck et al., 2004), weitere finden sich innerhalb regulatorischer Genregionen, z. B. den Promotorregionen. Ein besonderes Interesse kommt dabei den regulatorischen (r) und kodierenden (c) SNP innerhalb der molekular-epidemiologischen Forschung zu. Es wird erwartet, daß das Muster an SNP, das ein Individuum auf Suszeptibilitätsgenen trägt, gerade zum Risiko multifaktorielle Erkrankungen beiträgt (Brookes, 1999). Die SNP werden daher als 
Marker für Gene untersucht, die an der Krankheitsentstehung beteiligt sind. Solche Assoziationsstudien beschäftigten sich mit Diabetes (Giacconi et al., 2004), Herz-Kreislauf-Erkrankungen (Koch et al., 2001), degenerativen Bindegewebserkrankungen, Asthma und Allergien (Rosenwasser, 1999; Youn et al., 2000; Kabesch \& Lauener, 2004). Da ein Zusammenhang der Entstehung von Krebs mit der Immunantwort gefunden wurde, untersucht auch die onkologische Forschung immungenetische SNP (Kube et al., 2003; Schwartzbaum et al., 2005; Garg et al., 2006; Kube et al., 2007).

In der Pharmakologie sind SNP ebenfalls von Interesse, da starke interindividuelle Unterschiede in der Reaktion auf Medikamente beobachtet werden. Häufig resultiert daraus eine Unverträglichkeit, die eine Minimierung der Dosis nötig macht. Bisher sind solche individuellen Reaktionen auf die Therapie schwer einschätzbar, so daß für alle Patienten eine niedrigere Dosis verwendet wird, um die Nebenwirkungen einzuschränken. Eine höhere Dosis könnte jedoch bei Patienten ohne Nebenwirkungen ein bessere Heilungschance bedeuten. Das Ziel soll daher eine individualisierte Therapie sein, die an die genetischen Voraussetzungen des Patienten angepaßt ist. Single nucleotide polymorphisms wird zwar nur die Modifikation bestimmter Ausprägungen zugestanden, trotzdem werden sie als nützliche Marker für genetische Studien von pharmakogenetischen und polygenen Merkmalen angesehen (Ekstrom et al., 2002; Brockmöller \& Tzvetkov, 2008).

Was einerseits als Nachteil heterogener Erkrankungen gesehen wird, die geringe Bedeutung einzelner Faktoren wie den SNP an der Entwicklung einer Erkrankung, wertet Brookes (1999) als Vorteil. Dadurch können einige schwach benachteiligende Allele in der Selektion toleriert werden und zu einer höheren Frequenz gelangen, die in Assoziationsstudien nachweisbar wird. Die Zeiträume der Mutationsereignisse und der Selektion liegen in der Vergangenheit. Die resultierende Variabilität ist daher nicht zufällig, sondern wurde unter dem Einfluß von Infektionserkrankungen, Gründer- und bottle-neck-Effekten oder geographischer Isolation geformt. Diesen evolutionären Kontext der menschlichen Variation zu verstehen, bezeichnet Chakravarti (1999) als unerläßlich für ein besseres Verständnis der Bedeutung der heutigen Phänotyp-Variabilität. Chakravarti (1999) sieht in der jüngeren Geschichte der Menschheit mit ihrer dramatischen Expansion der Bevölkerungsgröße innerhalb der letzten Jahrhunderte ein einzigartiges Szenario, das ein hohes linkage disequilibrium über den Großteil des Genoms erwarten läßt. 
In diesem Kontext hat auch die ancientDNA-(aDNA-)Forschung der historischen Anthropologie Interesse an der Untersuchung von immungenetischen SNP gefunden. Die historische Anthropologie beschäftigt sich klassischerweise mit der Erforschung von Beziehungen innerhalb und zwischen historischen Populationen sowie zwischen Mensch und Umwelt. Dazu gehört das Forschungsinteresse an der Epidemiologie der Krankheiten des Menschen als Indikator seiner Lebensbedingungen. In ihrem historischen Teilgebiet der Paläoepidemiologie gibt sie Aufschluß über die menschliche Anpassungsfähigkeit genauso wie über die der menschlichen Pathogene (Hummel \& Herrmann, 1995). In diesem Zusammenhang erforschen die Spezialgebiete der Paläopathologie und Paläomikrobiologie die Verbreitung von Erkrankungen in historischen menschlichen Populationen. Dank der Weiterentwicklung der molekularen Genetik durch die Entwicklung der PCR (Saiki et al., 1985; Mullis \& Faloona, 1987) eröffnete sich ein neuer Zugang zu historischen Populationen als biologisches Archiv. Parallel zur histologischen Examination ist es nun möglich, das Genom von Pathogenen aus historischen Geweben zu isolieren und direkt zu studieren. Dies führte in einer Reihe von Studien zum Nachweis von Tuberkulose (Rothschild et al., 2001; Zink et al., 2003, 2005), Pest (Drancourt \& Raoult, 2002; Wiechmann \& Grupe, 2005), Lepra (Haas et al., 2000) und Diphterie (Zink et al., 2001) in historischen Individuen und Bevölkerungen. Auch die beobachtete Ablösung der Lepra als dominierende Erkrankung der europäischen Bevölkerung im Mittelalter durch die Tuberkulose wurde molekulargenetisch untersucht (Donoghue et al., 2004b). Dieser Ansatz erlaubt indirekt den Zugang zu Beziehungen zwischen menschlichen Populationen. Erreger, die in einer Population endemisch sind, verbreiten sich durch deren Kontakte und Wanderungsbewegungen (Mokrousov et al., 2005). Auch die Entstehung neuer Erkrankungen durch die Übertragung zwischen Mensch und Tier (Rothschild et al., 2001, am Beispiel der Tuberkulose) kann beleuchtet werden.

Nicht nur die genetischen Veränderungen der menschlichen Pathogene, sondern ebenso die Veränderungen des menschlichen Genoms selbst als Antwort auf den Kontakt mit Pathogenen zu untersuchen, ist ein weiterer Ansatz. In diesem Zusammenhang sind auch immungenetische Faktoren als solche in das Zentrum des Interesses getreten. Als Beispiele der molekularen Anthropologie sind hier die Arbeiten zum Auftreten der $\Delta 32$ Variante des CCR5-Rezeptors (Kremeyer et al., 2005; Hummel et al., 2005) und des Interleukin 6 Promotor-SNP G-174C (Lar- 
combe et al., 2005; Puder, 2005) zu nennen. Das Beispiel des CCR5-Rezeptors zeigt die Möglichkeiten der aDNA-Forschung: Der Nachweis von Trägern der in der HIV-Forschung relevanten $\Delta 32$ Variante in einer bronzezeitlichen Skelettserie (Hummel et al., 2005) führte zum Überdenken des postulierten Alters der Mutation und ihrer Selektionsfaktoren (Stephens et al., 1998; Hedrick \& Verrelli, 2006).

Gerade im Zusammenhang mit der Untersuchung von immungenetischen SNP gewinnt die Erforschung historischer Populationen einen weiteren Vorteil: Weltweite Assoziations-Studien zeigen die Abhängigkeit der Ergebnisse vom ethnischen Hintergrund (Hoffmann et al., 2002; Ness et al., 2004). Daher ist es wichtig, daß eine Population zugrunde liegt, die von ihrer ethnischen Zugehörigkeit und damit ihrem genetischen Hintergrund vergleichbar ist. Dies ist nicht der Fall, wenn wir Vergleiche mit rezenten Populationen anderer Kontinente oder auch verschiedenen Völkern eines Kontinentes anstellen. Die bronzezeitliche und mittelalterlichen Populationen auf heutigem deutschen Gebiet hingegen stellen unsere direkten Vorfahren und damit unseren eigenen genetischen Hintergrund dar, so daß eine größtmögliche genetische Kontinuität gewährleistet ist. Gesichert wurde diese Annahme bereits für die in dieser Arbeit verwendeten Populationen durch die Arbeiten von Schultes (2000), Schilz (2006), und Huhn (2008), die eine Übereinstimmung mit der modernen genetischen Landschaft über mt- und Y-Haplogruppen nachwiesen.

Die Bedeutung der historischen Forschung, die direkte Daten über die Beziehungen zwischen Pathogen und Wirt liefern kann, wird in den modernen Forschungszweigen weitgehend unterschätzt. Sie erlaubt uns, diese Beziehungen nicht nur rückwirkend zu betrachten, sondern sie in ihrer evolutiven Entwicklung zu sehen. Die Informationen werden in Echtzeit aufgenommen, statt sich auf statistische Modellrechnungen zu stützen. Ausgeschaltet werden zudem die Einflüsse der modernen Gesellschaft, ihrer globalisierten Beziehungen und antimikrobieller Therapie (Donoghue et al., 2004a). Die genetische Kontinuität zwischen den untersuchten Populationen kann maximiert werden. Für die modernen Forschungszweige ergeben sich damit wertvolle Informationen zur Aufklärung der Interaktion von menschlichem Wirt und Pathogen. Sie können zur Aufklärung der Erkrankungen unserer Zeit und ihrer zukünftigen Entwicklung beitragen (Donoghue et al., 2004a; Zink et al., 2002; Baum \& Bar-Gal, 2003). Cohn \& Weaver (2006) zie- 
hen gerade aus der Diskussion um den CCR5 und den Schwarzen Tod die Lehre, daß eine engere Zusammenarbeit zwischen Historikern und Naturwissenschaftlern benötigt wird, um den Selektionsdruck auf die genetischen Mutationen und die daraus entstehenden Auslöser für Änderungen der genetischen Frequenzen der letzten Jahrtausende zu verstehen. 


\section{Fragestellung}

Mit dem zunehmenden medizinischen und hygienischen Standard in den Industrieländern sind deren Einwohner bestimmten Erregern in geringerem Maße ausgesetzt als in früheren Epochen. Besonders die parasitäre Belastung (z. B. Helminthen) ist wesentlich gesunken, der Einfluß virueller Erkrankungen ist gestiegen. Gleichzeitig wird eine Zunahme an „Wohlstandserkrankungen“, wie Allergien, Autoimmunerkrankungen und chronisch-entzündliche Prozesse, beobachtet. Ein Zusammenhang wird postuliert. An der Abwehr von Parasiten sind dieselben Komponenten des Immunsystems beteiligt, die auch in atopischen Erkrankungen bedeutend sind. Die „Hygiene-“ oder „Old Friends"-Hypothese beschreibt, daß durch den Wegfall der Kontrolle des parasitären Befalls ein etabliertes Gleichgewicht verlorengegangen ist (Rook, 2007; Kabesch \& Lauener, 2004, u.a.). Van den Biggelaar et al. (2004) sehen einen Zusammenhang in der Abnahme der Belastung durch infektiöse Erkrankungen und der Zunahme onkologischer Ereignisse, wie auch chronisch-entzündliche Erkrankungen, die im fortgeschrittenen Alter einsetzen. Erst durch den Verlust der Gefahren von Infektionen des Kindesalters gewannen sie an Bedeutung.

Das Forschungsinteresse dieser Arbeit liegt in der Untersuchung von Verteilungsänderungen immungenetischer Marker im Kontext sich ändernder Umweltbedingungen und Pathogenexposition. Dafür werden genetische Daten aus historischen Populationen verschiedener Zeitstellungen miteinander verglichen. Ziel dieser Arbeit ist es, Aussagen zur Selektion gegen ausgewählte Polymorphismen zu ermöglichen. Darauf aufbauend sollen Rückschlüsse zu der Bedeutung dieser Polymorphismen für die Infektionsabwehr gezogen werden.

Der Fokus liegt auf der Untersuchung von immungenetischen Polymorphismen, deren epidemiologische Relevanz innerhalb von Assoziationsstudien an der Rezentbevölkerung bereits nachgewiesen wurde. Dazu gehören die Interleukine (IL) 6 , IL10, IL4 und die Rezeptoren IL4Ra, TLR2 und TLR4, die für diese Studie ausgewählt wurden. Die Bedeutung der Interleukine liegt in ihrer Funktion als stimulierende oder regulierende Botenstoffe des Immunsystems, besonders zwischen Leukozyten. IL4Ra ist als Rezeptor von IL4 von Interesse. Die Toll-like Rezeptoren (TLR) spielen eine wichtige Rolle als Pathogen-Erkennungs-Rezeptoren in der ersten Abwehr von Infektionen. Nähere Informationen folgen in Kapitel 3. 
Zentraler Gegenstand ist die Untersuchung eines historischen epidemiologischen Kollektivs auf seine genetische Variabilität. Als Kollektiv wurde eine Skelettserie aus einem Massengrab der Pestepidemie von 1348 bis 1350 gewählt. Eine zweite zeitstellungsnahe und ortsgleiche Serie ist eine nicht-epidemiologische Kontrolle von 1316, die für den status quo der immungenetischen Eigenschaften einer mittelalterlichen Bevölkerung steht. Eine ältere Kontrolle, und damit präepidemisch, ist der bronzezeitliche Fundkomplex der Lichtensteinhöhle bei Dorste, die moderne Bevölkerung wird als postepidemische Kontrolle herangezogen, die Daten werden der Literatur über rezente Studien entnommen. 


\section{Immungenetische Marker}

Im folgenden sollen die Loci genauer vorgestellt werden, die in dieser Studie untersucht wurden. Dazu gehören die Gene zweier Oberflächen-Rezeptoren der Pathogen-Erkennung (TLR2 und TLR4), des Komplexes des Interleukins (IL) 4 und seinem Rezeptor IL4R $\alpha$ sowie die beiden Interleukine IL6 und IL10 (Tab. 20). Diese Loci wurden aufgrund ihrer zentralen Stellung der Immunreaktion ausgewählt, die in einer Vielzahl an Studien für diverse Erkrankungen bereits nachgewiesen wurden. Ihre Bedeutung beschränkt sich dabei nicht auf die Abwehr von Infektionserkrankungen. Während die Bedeutung des IL4-Rezeptors und seines Liganden IL4 heutzutage besonders in der Entstehung von atopischen Erkrankungen zu finden ist, werden die Rezeptoren TLR2 und TLR4 sowie IL6 und IL10 in chronisch-inflammatorischen Prozessen untersucht. IL4 und IL10 wird zusätzlich eine Bedeutung bei der Entstehung von Krebs zugewiesen, aber auch TLR2 und TLR4 werden in diesem Zusammenhang untersucht. Die ausgewählten Interleukine können aufgrund ihrer physiologischen Funktion innerhalb der Immunreaktion als proinflammatorisch (IL6) beziehungsweise antiinflammatorisch (IL4 und IL10) eingeordnet werden.

Tab. 1: Übersicht der untersuchten Marker und ihrer Bedeutung in immunologischen Zusammenhängen. Nähere Beispiele und Referenzen werden in den folgenden Unterkapiteln angegeben.

\begin{tabular}{ll}
\hline Locus & Bedeutung \\
\hline TLR4 & Infektionserkrankungen, Krebs, Herz-Kreislauferkrankungen \\
TLR2 & Infektionserkrankungen, Krebs \\
IL4R $\alpha$ & atopische Erkankungen, Krebs \\
IL4 & atopische Erkrankungen, parasitäre Infektionen, Krebs \\
IL6 & Infektionserkrankungen, Autoimmunerkrankungen, Langlebigkeit \\
IL10 & Infektionserkrankungen, Autoimmunerkrankungen, Langlebigkeit, Fertilität \\
\hline
\end{tabular}

\subsection{Rezeptoren der Pathogenerkennung}

Die Familie der Toll-like Rezeptoren (TLR) umfaßt konservierte OberflächenRezeptoren, die den Typ 1 integralen Membran-Glycoproteinen zugeordnet werden. Aufgrund der Homologie ihrer zytoplastischen Domäne werden sie in eine Super-Familie mit den Interleukin 1 (IL1)-Rezeptoren gestellt. Gemeinsam ist 
ihnen die konservierte Toll/IL1-R- (TIR-) Domäne, die als Bindestelle für Adaptermoleküle in der Signalübertragung von Bedeutung ist. Charakteristisch für die extrazelluläre Antigenerkennungs-Domäne sind Leucin-reiche repetitive Motive (LRR).

Die TLR erkennen im Rahmen der first-line of defense der angeborenen Immunabwehr konservierte Oberflächenstrukturen, sogenannte PAMPs (pathogenassociated molecule patterns), die von einem weiten Spektrum an Mikroorganismen exprimiert werden. Bei Kontakt mit solchen PAMPs wird über Signalwege die Expression von proinflammatorischen Zytokinen und Aktivierung sowie Reifung von dendritischen Zellen eingeleitet (Abb. 1).

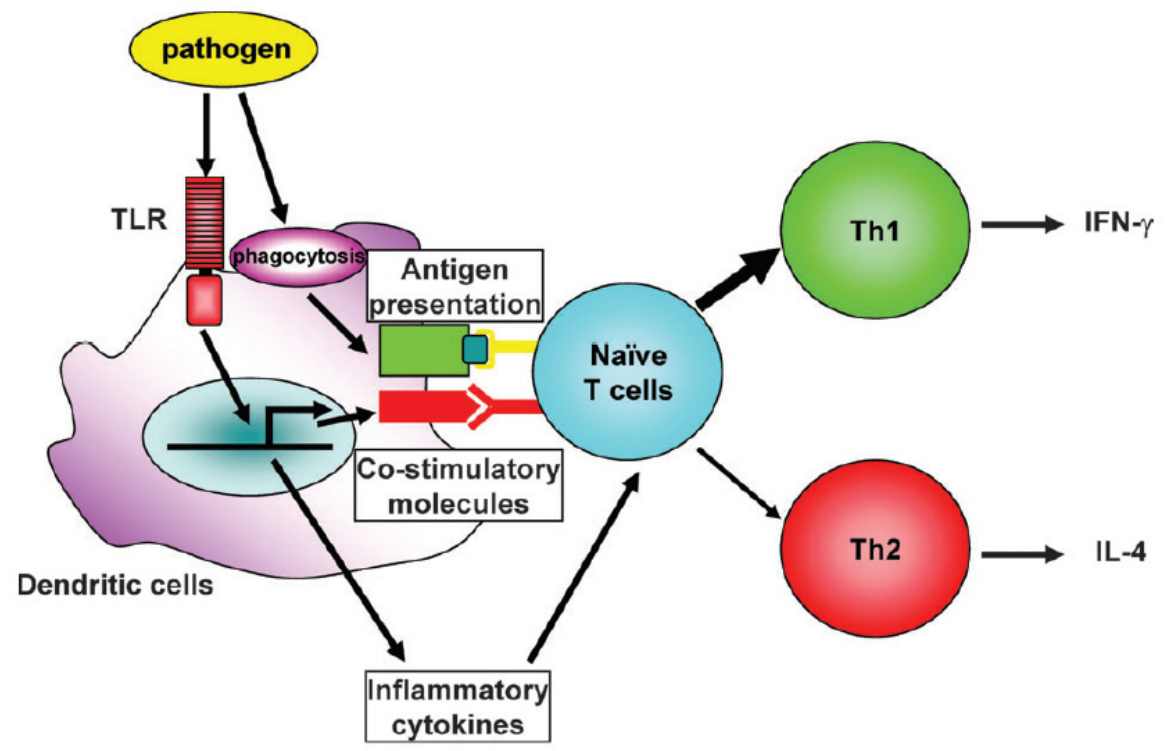

Innate immunity

Acquired immunity

Abb. 1: Schematische Darstellung der Bedeutung von Toll-like Rezeptoren in angeborener und erworbener Immunantwort. Quelle: Takeda \& Akira (2005)

Erstmals wurden diese Oberflächen-Rezeptoren als Toll-Rezeptoren in Drosophila beschrieben. Dort wurden sie mit der Anfälligkeit von Larven auf Pilzinfektionen in Verbindung gebracht. Beim Menschen sind inzwischen 11 TLR bekannt (Takeda \& Akira, 2005), die speziell auf verschiedene Untergruppen der PAMPs reagieren und unterschiedliche Expressionmuster auf verschiedenen Zelltypen aufweisen (Abb. 2). Da die einzelnen TLR verschiedene Signalwege aktivieren können, die zu 
unterschiedlichen Reaktionen führen, erreicht auch das angeborene Immunsystem eine gewisse Spezifität (Bochud et al., 2007).

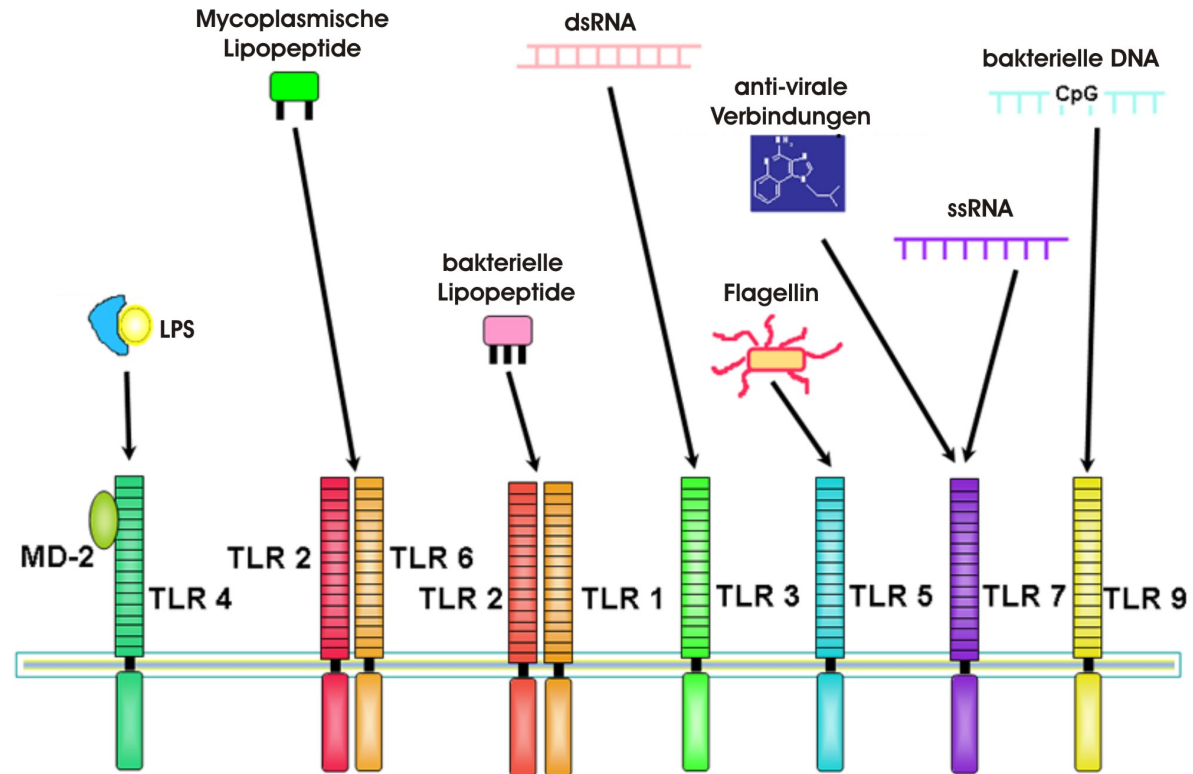

Abb. 2: Schematische Darstellung der wichtigsten Toll-like Rezeptoren und ihrer Liganden. Nach http://www.biken.osaka-n.ac.jp/act/images/akiraA.png (10.01.08)

\subsubsection{TLR2}

Der TLR2 nimmt eine besondere Stellung in der TLR-Familie ein. Er spielt eine entscheidende Rolle in der frühen Pathogenerkennung durch das angeborene Immunsystem (Medzhitov \& Janeway, 1997), gleichzeitig aber auch in der Abstimmung der Immunantwort des erworbenen Immunsystems durch die Induzierung der Th1-Reaktion. Als Homodimer oder Heterodimer mit TLR1 und TLR6 vermittelt er die Reaktion auf bakterielle Lipoproteine, Peptidoglycane, Lipoteichoinsäure und Zymosan (Ozinsky et al., 2000; Schwandner et al., 1999; Takeuchi et al., 2002; Texereau et al., 2005; Bochud et al., 2007). Er erkennt damit das weiteste Repertoir an Pathogen-Strukturen, das solche gram-positiver und gram-negativer Bakterien, von Mykobakterien, Pilzen, Viren und verschiedener Parasiten einschließt (Texereau et al., 2005). Darunter fällt neben den Erregern der Tuberkulose auch Yersinia pestis, welcher die Pest auslöst. Studien zu TLR2 beschäftigt, ob und welchen Einfluß der Rezeptor per se sowie weiterführend ge- 
netische Mutationen auf die Immunantwort haben. Das Interesse an der Bedeutung des Rezeptors ist medizinischer Natur: Aus den Erkenntnissen werden neue Ansätze für therapeutische Anwendungen wie präventive Maßnahmen, pharmakologische Interventionen und die Entwicklung von Impfungen erhofft.

Tab. 2: Liganden des TLR2, nach Texereau et al. (2005) und Bochud et al. (2007)

\begin{tabular}{lll}
\hline Dimer & Ligand & Erreger \\
\hline TLR2/TLR2 & $\begin{array}{l}\text { Lipoteichoische Säure } \\
\text { Peptidoglycan }\end{array}$ & $\begin{array}{l}\text { gram-positive Bakterien } \\
\text { gram-positive Bakterien }\end{array}$ \\
& Lipoarabinomannan & \\
& Phoshpolipomannan & Candida albicans \\
& Zymosan & Saccharomyces cerevisiae \\
& Glycosylphosphatidylinositol Mucin & Trypanosoma spp. \\
& Hämaglutinin & Masern-Virus \\
TLR2/TLR6 & Diazyl-Lipopeptide & Mycoplasma spp. \\
TLR2/TLR1 & Triazyl-Lipopeptide & \\
\hline
\end{tabular}

Das Gen des Rezeptors liegt auf Chromosom 4 in der Region 4q32. Es gliedert sich in drei Exons, wobei das dritte Exon den kompletten open reading frame (ORF) kodiert (Texereau et al., 2005). Die Literatur über funktionelle Polymorphismen im codierenden Bereich des Gens ist begrenzt. Bisher wurden 17 SNP beschrieben, davon führen neun zu einem Aminosäureaustausch. An nt2029 und nt2256 wurden zwei SNP identifiziert, die eine Veränderung der Aminosäuresequenz des Rezeptors in der cytosolischen Domäne herbeiführen (Aminosäureposition 677 und 753). Eine direkte funktionelle Beeinträchtigung der Rezeptorfunktion liegt nahe, konnte jedoch bislang nicht nachgewiesen werden. Allerdings liegen Studien vor, die signifikante Assoziationen der SNP mit verschiedenen Infektionskrankheiten zeigen, dazu gehören Tuberkulose (Ogus et al., 2003; Ben-Ali et al., 2004) und Lepra (Kang et al., 2004). Beide Erkrankungen sind auch im historischen Mitteleuropa von Bedeutung. Während der erste Polymorphismus (R677W) bislang nicht in europäischen Populationen nachgewiesen wurde und damit für diese Arbeit uninteressant ist, fanden Lorenz et al. (2000) sowie auch Folwazny et al. (2004) eine Allelfrequenz des selteneren A-Alleles des R753Q SNP von etwa 3\% in mitteleuropäischen Populationen. Schröder et al. (2003) berichten eine höhere Frequenz von 9,4\%. 
Tab. 3: Assoziationen des TLR2-Polymorphismus R753Q mit Infektionserkrankungen

\begin{tabular}{lll}
\hline Infektionsart & Risiko & Referenz \\
\hline Tuberkulose & erhöht & Ogus et al. (2003) \\
Sepsis & erhöht & Lorenz et al. (2000) \\
Sepsis & nicht nachgewiesen & Moore et al. (2004) \\
C.pneumoniae & nicht nachgewiesen & Rupp et al. (2004) \\
Borreliose & erniedrigt & Schröder et al. (2005) \\
\hline
\end{tabular}

\subsubsection{TLR4}

Mit dem TLR4 steht ein zweiter Vertreter der Toll-like-Rezeptor-Familie im Interesse dieser Arbeit. Im Gegensatz zu TLR2 bildet TLR4 ausschließlich Homodimere. Der Rezeptor erkennt Lipopolysaccharide (LPS), die auf der Oberfläche gram-negativer Bakterien exprimiert sind. Neben LPS sind weitere Liganden bekannt (Tab. 4), unter anderem wurden endogene Liganden wie HitzeschockProtein (HSP) 60 und HSP70 beschrieben. Takeda \& Akira (2005) als auch Bochud et al. (2007) konstatieren jedoch die Möglichkeit einer LPS-Kontamination dieser Proteine, die bisher nicht ausgeschlossen wurde, so daß ihre Funktion als Liganden umstritten ist.

Tab. 4: Übersicht der Liganden von TLR4, Zusammenfassung aus Bochud et al. (2007)

\begin{tabular}{ll}
\hline Ligand & Erreger \\
\hline LPS & gram-negative Bakterien \\
Mannan & Candida albicans \\
Fusions-Protein & Respiratory syncytial virus (RS-Virus) \\
$\begin{array}{l}\text { Fibrinogen, Fibronectin, Hyaluronan, Heparin-Sulfat, } \\
\text { Beta-Defensin, Hitzeschock-Proteine }\end{array}$ & endogene Liganden \\
\hline
\end{tabular}

Das Gen des Rezeptors liegt am Locus 9q32-q33. Zwei Polymorphismen werden beschrieben, für die ein Effekt auf die Funktionalität des Rezeptors angenommen wird: eine Aspartat (D)-zu-Glycin (G)-Substitution an Aminosäureposition 299 und ein Austausch von Threonin (T) gegen Isoleucin (I) an Position 399. Den Aminosäuresubstitutionen liegen SNPs an den Positionen +896 (G/A) und +1196 (C/T) zugrunde. Ihre direkte Auswirkung auf die Rezeptorfunktion ist umstritten. Arbour et al. (2000) fanden eine Assoziation mit Endotoxin-Hypo- 
responsivität, Erridge et al. (2003) und Imahara et al. (2005) konnten diese Beobachtung nicht bestätigen. Allerdings wurden die Arbeiten mit verschiedenen Zelltypen durchgeführt. Ungeachtet dessen wurden die SNP mit verschiedenen Infektionserkrankungen in Verbindung gebracht (vgl. Tab. 5). Auch mit chronischentzündlichen Erkrankungen wird der Polymorphismus assoziiert. Gleeson et al. (2006) beschreibt einen protektiven Effekt des häufigeren +896A-Alleles (299D) bei bakteriellen Infektionen des frühen Lebens, die mit einem höheren Risiko chronisch-entzündlicher Erkrankungen im späteren Leben einhergeht. Die Allelfrequenz des D299G-Polymorphismus wird mit 4 bis 6\% (Hawn et al., 2005; Schmitt et al., 2002) angegeben. Beide SNPs cosegregieren in der europäischen Bevölkerung (Hawn et al., 2005; Ferwerda et al., 2007). Ferwerda et al. (2007) führen die Cosegregation auf eine Selektion während der pandemischen Infektionen des letzten Jahrtausends zurück. Das 299G-Allel vermittelt nach Ferwerda et al. (2007) einen evolutionären Nachteil durch eine erhöhte Mortalität bei einem septischen Schock. Dieser werde durch das 399I-Allel aufgehoben.

Tab. 5: Assoziationen des TLR4-Polymorphismus D299G mit Infektionserkrankungen. Da in der europäischen Bevölkerung der Polymorphismus T399l cosegregiert, wird er in vielen Studien nicht gesondert betrachtet. In der Tabelle wird er daher nur mit angegeben $(+)$, wenn explizit auf eine Assoziation dieses SNP hingewiesen wurde.

\begin{tabular}{llll}
\hline TLR4 D299G & & & \\
\hline Infektionsart & Risiko & T399l & Referenz \\
\hline Brucellosis & erhöht & & Rezazadeh et al. (1998) \\
RS-Virus & erhöht & + & Tal et al. (2004) \\
Malaria & erhöht & + & Mockenhaupt et al. (2006) \\
Malaria & protektiv & & Ferwerda et al. (2007) \\
Osteomyelitis & erhöht & & Montes et al. (2006) \\
Rickettsiosis & erhöht & & Balistreri et al. (2005) \\
Sepsis & erhöht & & Lorenz et al. (2002) \\
C. albicans & erhöht & & Van der Graaf et al. (2006) \\
gram-negative & erhöht & & Agnese et al. (2002) \\
L. pneumophila & erniedrigt & + & Hawn et al. (2005) \\
\hline
\end{tabular}




\subsection{Interleukin 4 Rezeptor $\alpha$ und Interleukin 4}

IL4 und sein Rezeptor wurden ausgewählt, da ihre physiologische Bedeutung neben der Regulierung in der Entstehung und Aufrechterhaltung der Immuntoleranz parasitärer Infektionen liegt. In historischen Zeiten war die parasitäre Belastung eine der vorherrschenden Ursachen von Infektionen. In den heutigen Industrieländern spielen sie kaum mehr eine Rolle. In Studien der modernen Bevölkerung werden diese Marker im Zusammenhang mit Allergien und $\mathrm{Au}$ toimmunerkrankungen untersucht. Ein Zusammenhang der fehlenden parasitären und generell der abnehmenden Pathogen-Exposition durch den hygienischen Fortschritt mit der Entstehung von Allergien und Autoimmunerkrankungen wird diskutiert. Allergien werden demnach als evolutionäres Erbe eines Immunsystems gesehen, das in einer pathogenreichen Umgebung auf möglichst effektive Immunantwort selektiert wurde. Die Frage ist, ob der Umkehrschluß zulässig ist, daß die Disposition zu Allergien eine niedrigere Infektionsanfälligkit in Zeiten höherer Pathogen-Exposition bedeutet.

\subsubsection{Interleukin 4}

Das pleiotrope Typ1-Zytokin IL4 ist das Signal-Zytokin der Th2-Immunreaktion (Olver et al., 2007). Ihm wird eine wichtige Rolle in Wachstum und Differenzierung sowie Überleben von B- und T-Lymphozyten zugeschrieben (Youn et al., 2000), wie auch sein alternativer Name „B-cell stimulatory factor 1“ aussagt. Es wird von einer Untergruppe der CD4 ${ }^{+}$T-Zellen (Th2-Zellen), Basophilen und Mastzellen gebildet (Nelms et al., 1999). Über den IL4-Rezeptor $\alpha$ veranlaßt es B-Zellen, IgE zu produzieren, induziert das Endothelium, Adhäsions-Moleküle zu exprimieren, die Eosinophile spezifisch anziehen, und signalisiert T-Zellen, sich zu CD4+-Typ2 Helferzellen zu entwickeln, die zusätzliches IL4 produzieren. Seine physiologischen Funktionen umfassen zusätzlich eine Hauptrolle in der Entwicklung der protektiven Immunantwort auf Helminthen und andere extrazelluläre Parasiten (Nelms et al., 1999). Durch seine Bedeutung in der Kontrolle von IgE kommt ihm eine kritische Rolle in der Expression von Atopie und Allergien zu (Rosenwasser, 1999). Auch an der Krebsentstehung hat es einen Anteil, jedoch mit gegensätzlichen Effekten (Olver et al., 2007): Es kann die Kontrolle des Tumorwachstums sowohl behindern wie auch positiv beeinflussen. 
Das IL4-Gen liegt in vier Exons organisiert auf Chromosom 5q31 im sogenannten Th2-Zytokin-Cluster. Rosenwasser (1995) beschreibt einen Polymorphismus in der Promotorregion an nt-590 (auch als C-589T und C-524T zu finden), dem er als gain-of-function-Polymorphismus eine erhöhte IL4-Produktion und eine höhere IgE-Gesamtserumkonzentration zuordnet (s.a. Rosenwasser (1999)). In Assoziationsstudien wurde er vor allem mit atopischen Erkankungen in Verbindung gebracht (Sandford et al., 2000; Adjers et al., 2005, u.a.). Aber auch bei Infektionserkrankungen wie Malaria (Luoni et al., 2001) und HIV (Konenkov et al., 2001) wurde eine Assoziation beobachtet. Kalish et al. (2004) fanden zudem einen Einfluß auf den Verlauf von Mehrlings-Schwangerschaften: Das Vorkommen des IL4 -590T-Alleles in Mutter und Föten bedeutete ein höheres Risiko einer vorzeitigen Geburt. Die Allelfrequenz in zentraleuropäischen Populationen wird von Basehore et al. (2004) mit 14\% angegeben.

Tab. 6: IL4 C-590T: Assoziationen

\begin{tabular}{lcc}
\hline Assoziation T-Allel & Risiko & Referenz \\
\hline HIV & erniedrigt & Konenkov et al. (2001) \\
Malaria & erniedrigt & Luoni et al. (2001) \\
Asthma & erhöht & Sandford et al. (2000) \\
Asthma & erhöht & Adjers et al. (2005) \\
vorzeitige Geburt & erhöht & Kalish et al. (2004) \\
\hline
\end{tabular}

\subsubsection{IL4 Rezeptor $\alpha$}

Der IL4 Rezeptor $\alpha$ (IL4Ra) gehört zur Familie der Hämatopoietin-Rezeptoren, die eine charakteristische Typ III Fibronektin-Domäne in der extrazellulären Region tragen (Nelms et al., 1999). Als Heterodimer mit dem IL13-Rezeptor bzw. der sogenannten $\gamma$ common chain fungiert er als Rezeptor der Zytokine IL4 und IL13 (Abb. 3). Der IL4Ra wird in einer Vielzahl von Geweben exprimiert, dazu gehören hämatopoietische, Hirn- und Muskelgewebe, Endothel, Epithel, Fibroblasten sowie Hepatozyten. Seine Bedeutung wird analog zu IL4 im Zusammenhang mit parasitären Infektionen, atopischen Erkrankungen und der Immunüberwachung von Tumoren beschrieben (Terabe, 2000).

Das Gen des IL4Ra ist in Region p12.1-p11.2 des Chromosoms 16 positioniert. Im Exon 9 an Position +1902 ist ein A/G-Polymorphismus lokalisiert, bei dem 

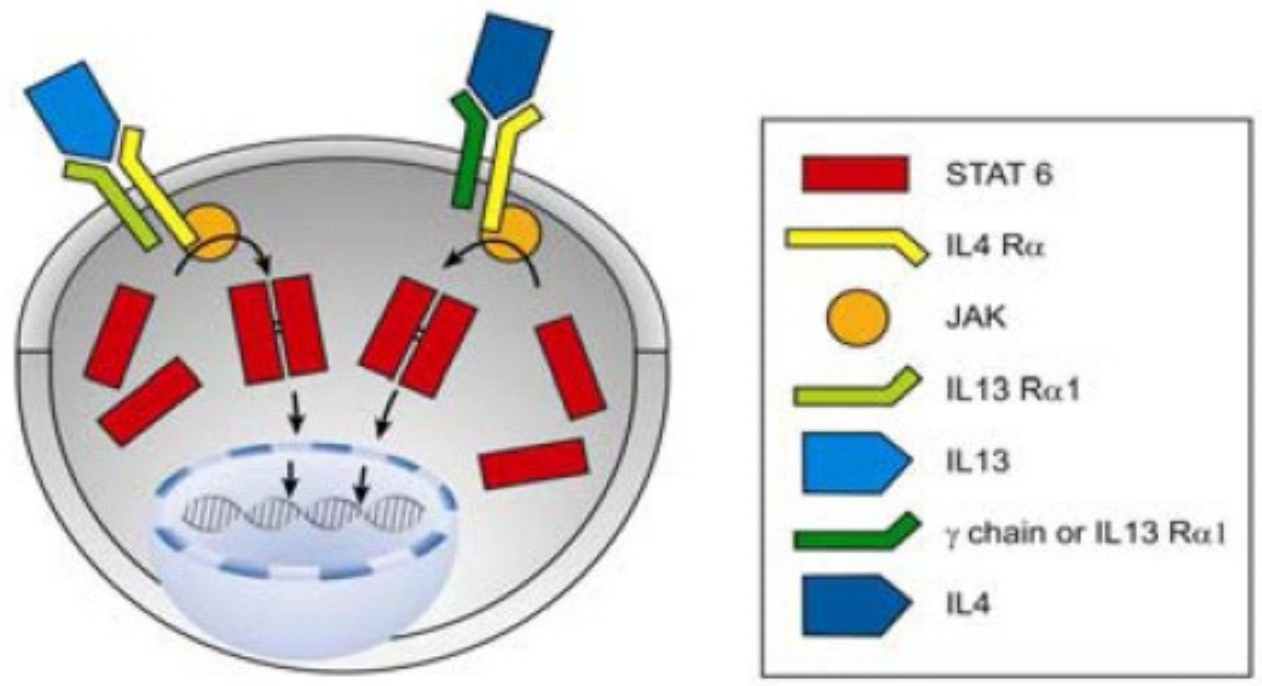

Abb. 3: Signalweg des IL4Ra und seiner Liganden IL4 und IL13. (Quelle: http://www.science.ngfn.de/6_371.htm (11.01.2008))

es zu einem Aminosäure-Austausch von Glutamin (Q) zu Arginin (R) an Aminosäureposition 576 in der intrazellulären Domäne kommt. In der Literatur ist der Q576R-SNP auch als Q551R zu finden. Als ancestral allele wird das heute seltenere G-Allel (576R) aufgeführt (vgl. ncbi SNP-Datenbank). Hershey et al. (1997) vermuten eine verstärkte Signalübertragung der 576R-Variante als Reaktion auf die Stimulierung mit IL4. Kruse et al. (1999) hingegen fanden einen Einfluß des SNP auf die Bindung und Phosphorylierung intrazellulärer Substrate, die sie auf eine zusätzliche positive Ladung durch den Austausch gegen Arginin zurückführen. Der damit assoziierte niedrigere Gesamt-IgE-Spiegel prädisponiere zu atopischen und allergischen Erkrankungen. Youn et al. (2000) assoziierten den SNP mit einem erhöhten Risiko für Bindegewebserkrankungen durch die Verschiebung des Th1/Th2-Gleichgewichts zu Th2. Forster et al. (2004) finden entsprechend eine Assoziation mit Osteoarthritis. Schwartzbaum et al. (2005) beschreiben eine weitere Assoziation mit dem multiformen Glioblastom, mit einer odds ratio (OR) von 1,61 für Träger des A-Alleles. Die Allelfrequenz des selteneren G-Alleles, das auch als ancestral allele bezeichnet wird, ist mit $24 \%$ angegeben (Nieters et al., 2001). 
Tab. 7: IL4Ra Q576R: Assoziationen

\begin{tabular}{lccc}
\hline Assoziation & Allel & Effekt & Referenz \\
\hline Gesamt-lgE & G & erniedrigt & Kruse et al. (1999) \\
Bindegewebserkrankungen & G & erhöht & Youn et al. (2000) \\
Osteoarthritis & G & erhöht (OR1,3) & Forster et al. (2004) \\
multiformes Glioblastom & AG/AA & erhöht (OR1,61) & Schwartzbaum et al. (2005) \\
\hline
\end{tabular}

\subsection{Pro- und antiinflammatorische Interleukine}

\subsubsection{Interleukin 6}

IL6 ist ein proinflammatorisches Zytokin, das zur Familie der Hämatopoetine gehört. Es wird vor allem von T-Zellen, aber auch von Makrophagen und Zellen des Endothels gebildet. Neben der Induzierung der Bildung von Akute-PhaseProteinen beeinflußt es die Aktivierung und Differenzierung von T- und B-Zellen (Janeway et al., 2005). Beteiligt ist es unter anderem auch an Blutbildung (Pschyrembel, 1994) und Hormonstoffwechsel.

Für das IL6-Gen (Genlocus 7p21) sind verschiedene Polymorphismen beschrieben. Besonders interessant erscheint der G-zu-C-SNP an Position -174 in der Promotorregion, der nach Haplotypen-Analyse als charakterisierender SNP der Promotorregion beschrieben wird (Christiansen et al., 2004). Fishman et al. (1998) beobachteten seinen Einfluß auf die Transkription des Genes; so wird dem Allel "C" eine niedrigere Genexpression zugeschrieben. Neben einem geringeren basalen IL6-Plasmalevel wurde als Folge der fehlende Anstieg als Antwort auf eine Stimulation beschrieben. Der heterozygote Genotyp bewirkte dagegen gegenüber dem Genotyp GG keine Veränderung der Genexpression. Villuendas et al. (2002) fanden einen erhöhten IL6-Spiegel bei allen G-Allel-Trägern, sowohl homo- als auch heterozygot. Auch die Studie von Rivera-Chavez et al. (2003) ergab eine niedrigere IL6-Produktion für das C-Allel.

Fishman et al. (1998) fanden weiterhin eine protektive Wirkung des C-Alleles im Zusammenhang mit juveniler rheumatischer Arthritis. Bonafe et al. (2001), Christiansen et al. (2004) und Giacconi et al. (2004) untersuchten den Polymorphismus auf seine Assoziation mit Langlebigkeit in der dänischen bzw. italienischen Bevölkerung. Unabhängig fanden sie eine Assoziation, die allerdings ent- 
gegengesetzt wirkt. Hier zeigt sich die Bedeutung der ethnischen Zugehörigkeit bei der Untersuchung immungenetischer Polymorphismen. Die Assoziationen mit Erkrankungen der Wohlstandsgesellschaft, z. B. Atherosklerose (Giacconi et al., 2004), spiegeln die Entwicklung infolge der abnehmenden Bedrohung durch Infektionserkrankungen wieder.

Tab. 8: Assoziationen des IL6 G-174C SNP

\begin{tabular}{|c|c|c|c|c|}
\hline Population & Assoziation & Effekt & Allel/Genotyp & Referenz \\
\hline PL & neonatale Infektionen & erhöht & CC & $\begin{array}{l}\text { Wojsyk-Banaszak et } \\
\text { al. (2005) }\end{array}$ \\
\hline I & $\begin{array}{l}\text { Langlebigkeit } \\
\text { (Männer) }\end{array}$ & erhöht & C & Bonafe et al. (2001) \\
\hline I & Langlebigkeit & erniedrigt & G & Giacconi et al. (2004) \\
\hline DK & Langlebigkeit & erhöht & GG & $\begin{array}{l}\text { Christiansen et al. } \\
(2004)\end{array}$ \\
\hline FIN & Langlebigkeit & kein & & Wang et al. (2001) \\
\hline \multirow[t]{3}{*}{ I } & Atherosklerose & erhöht & G & Giacconi et al. (2004) \\
\hline & Diabetes Typ 2 & erniedrigt & $\mathrm{C}$ & Huth et al. (2006) \\
\hline & Diabetes Typ 1 & früherer Beginn & $\mathrm{CC}$ & $\begin{array}{l}\text { Kristiansen et al. } \\
(2003)\end{array}$ \\
\hline USA & \multicolumn{2}{|c|}{$\begin{array}{l}\text { Überlebenswahrscheinlichkeit erhöht } \\
\text { bei Ovarial/Peritoneal } \\
\text { Krebs }\end{array}$} & GG & Garg et al. (2006) \\
\hline UK & $\begin{array}{l}\text { Juvenile rheumatoide } \\
\text { Arthritis }\end{array}$ & erhöht & G & Fishman et al. (1998) \\
\hline
\end{tabular}

Die Allelfrequenzen des G-174C-SNP weichen innerhalb der mittel- und nordeuropäischen Bevölkerung auffällig von der weltweiten Verteilung ab. Weltweit liegt die Frequenz des C-Alleles um 10\% (vgl. Tab. 9), während sie in Mitteleuropa bei $40 \%$ liegt. Für diese Abweichung postulieren Fishman et al. (1998) eine relativ junge (recent) Ursache, wobei eine genauere Definition des Terms „recent" ausbleibt. Diese Auffälligkeit macht den Polymorphismus besonders interessant. Eine Eingrenzung des historischen Zeitrahmens, zu dem es zu einer Anreicherung des C-Alleles gekommen ist, kann weitergehende Hinweise liefern. Damit beschäftigte sich bereits die Arbeit Puder (2005), die eine erste Untersuchung des IL6-SNP an den Individuen der Lichtensteinhöhle durchführte. 
Tab. 9: IL6 G-174C: Allelfrequenzen in verschiedenen Rezentpopulationen. $F_{m i n}$ : Frequenz des selteneren „C"-Alleles (minor allele); Populationen nach Angaben der Autoren, verwendet wurden die KFZ-Länderkennzeichen

\begin{tabular}{lcccccl}
\hline Population & $\mathrm{n}$ & $\mathrm{GG}$ & $\mathrm{GC}$ & $\mathrm{CC}$ & $\mathrm{F}_{\text {min }}$ & Referenz \\
\hline Eur & & & & & 0,4 & Fishman et al. (1998) \\
I & 362 & 0,5 & 0,39 & 0,11 & 0,29 & Poli et al. (2002) \\
I & 140 & 0,41 & 0,5 & 0,09 & & deCapei et al. (2003) \\
UK & 224 & 0,35 & 0,45 & 0,20 & & Smith et al. (2004) \\
CY & 100 & 0,67 & 0,29 & 0,04 & 0,185 & Costeas et al. (2003) \\
D & 111 & 0,39 & 0,44 & 0,17 & & Nieters et al. (2001) \\
\hline
\end{tabular}

\subsubsection{Interleukin 10}

IL10 ist ein pleiotropes Zytokin, das hauptsächlich von Monozyten und in geringerem Maße von Lymphozyten gebildet wird. Es nimmt eine Schlüsselrolle in der adaptiven Immunität ein. Dabei reguliert es vor allem die Expression von Th1-Zytokinen. Es stimuliert weiterhin das Überleben und Proliferieren von BZellen sowie die Produktion von Antikörpern. Aufgrund seiner antiinflammatorischen Bedeutung in der Immunregulation trägt es den Alternativnamen cytokine synthesis inhibitory factor. Unter anderem inhibiert es die Sekretion des proinflammatorischen Zytokins IL6 (Turner et al., 1997). Seine Bedeutung als Immunoregulator ist besonders in der Aufrechterhaltung des Gleichgewichts zwischen dem Schutz vor Pathogenen und der Schädigung des Gewebes zu sehen (Mocellin et al., 2004). Ein Nebenaspekt dieses Mechanismus scheint ein Einfluß auf die reproduktive Fitneß des Individuums zu sein (Van den Biggelaar et al., 2004; Westendorp et al., 2001). 


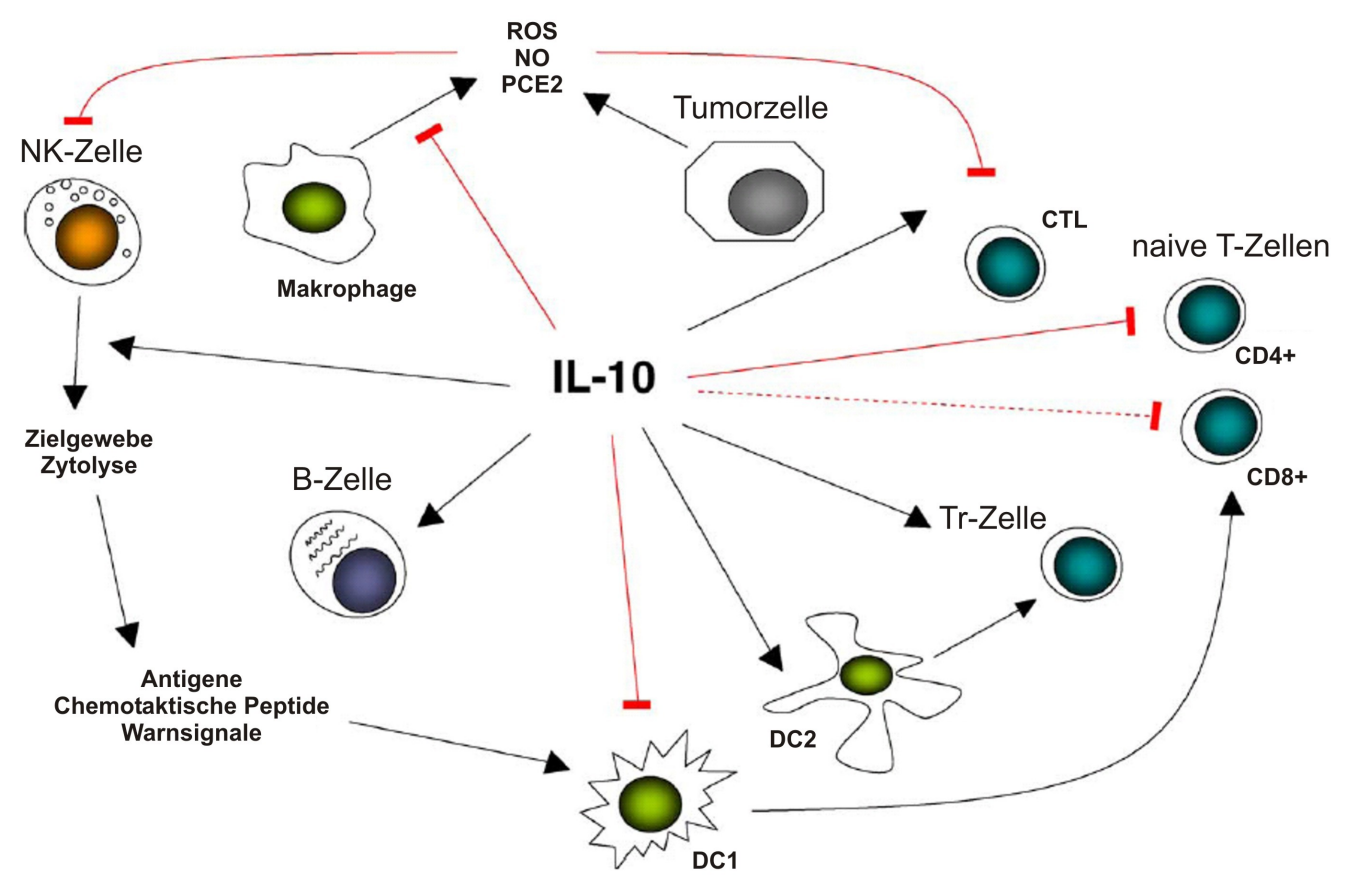

Abb. 4: Wirkung von IL10 auf die Zellen des naiven und adaptiven Immunsystems. Schwarze Linien: Stimulierende Wirkung, rote Linien: Inhibierend. ROS: reactive oxygen Species, NO: nitric oxid, PGE2: Prostaglandin E2. nach Mocellin et al. (2004)

Das IL10-Gen ist komplementär in einem Gencluster mit IL19 auf Chromosom 1q31-q32 lokalisiert. 27 SNP sind bis heute alleine für die Promotorregion des Gens beschrieben (http://www.nanea.dk/cytokinesnps). Weitere finden sich ebenfalls in der kodierenden Region. Ein SNP an der Nukleotidposition -1082 wird mit der IL10-Produktion in Zusammenhang gebracht (Turner et al., 1997). Probanden mit A-Allel zeigten eine geringere IL10-Produktion als G-Allelträger. Häufig wird dieser SNP innerhalb eines Haplotypen mit weiteren SNP, vor allem -819 und -592 untersucht (Turner et al., 1997; Eskdale et al., 1998), für den ebenfalls ein Einfluß auf die IL10-Expression nachgewiesen wurde. Kube et al. (2003) schlußfolgerten eine zentrale Rolle dieser Region des Promoters unter bestimmten Bedingungen aus der Beobachtung, daß sich die -1087 Variante trotz ihrer starken Assoziation mit verschiedenen IL10-Produktions-Kapazitäten in ihrer Ausprägung nicht signifikant unterscheidet zwischen einer deutschen und einer gabonesischen Population. Sie vermuteten daher eine Konservierung dieser Region.

Ein weiterer SNP von Interesse liegt an Position -2849 (Lard et al., 2003). Für das -2849G-Allel beobachteten Van den Biggelaar et al. (2004) einen höheren IL10-Serumlevel und einen generell protektiven Effekt. A-Homozygote hingegen 
haben ein höheres Risiko für Herz-Kreislauferkrankungen, gleichzeitig eine halb so hohe Chance auf erfolgreiche Fortpflanzung, aufgrund eines erhöhten Risikos an Spontanaborten. Heterozygote nehmen grundsätzlich eine Zwischenstellung ein (Van den Biggelaar et al., 2004). Auch Westendorp et al. (2001) beschreiben einen nachteiligen Effekt des -2849AA-Genotyps auf die Fertilität aufgrund des niedrigeren IL10-Spiegels. Die Allelfrequenzen der beiden IL10-SNP variieren zwischen verschiedenen Populationen stark (vgl. Tab. 11).

Tab. 10: Übersicht der Assoziationsstudien zu den IL10 Promoterpolymorphismen. AA+: Teil eines Haplotypen (vgl. Text). RDS: respiratory distress syndrom

\begin{tabular}{llll}
\hline Assoziation & Effekt & Allel & Referenz \\
\hline G-1087A & & & \\
\hline Langlebigkeit & & & Lio et al. (2004) \\
EBV & erniedrigt & A & Helminen et al. (1999) \\
RDS & erniedrigt & GG/AG & Capasso et al. (2007) \\
Langlebigkeit & erniedrigt & AA+ & Naumova et al. (2004) \\
Tuberkulose & erniedrigt & AA/AG & Scola et al. (2003) \\
pleurale TB & erhöht & AA & Henao et al. (2006) \\
\hline $\begin{array}{l}\text { G-2849A } \\
\text { Herz-Kreislauferkrankungen }\end{array}$ & erhöht & AA & Van den Biggelaar et al. (2004) \\
$\begin{array}{l}\text { Spontanabort } \\
\text { Gelenkdestruktion in rheumatoider Ar- } \\
\text { thritis }\end{array}$ & erhöht & G & Lard et al. (2003) \\
$\begin{array}{l}\text { Autoantikörper-Titer (Patienten) } \\
\text { Fertilität }\end{array}$ & erhöht & G & Lard et al. (2003) \\
\hline
\end{tabular}


Tab. 11: Allelfrequenzen der beiden IL10 Promoterpolymorphismen in verschiedenen Rezentpopulationen

\begin{tabular}{ccccccc}
\hline Population & $\mathrm{n}$ & AA & AG & GG & $F_{\text {min }}$ & Referenz \\
\hline \multicolumn{7}{c}{ G-1087A } \\
I & 140 & 0,34 & 0,54 & 0,12 & & deCapei et al. (2003) \\
CY & 726 & & & & 0,63 & Poli et al. (2002) \\
D & 100 & 0,4 & 0,44 & 0,16 & 0,62 & Costeas et al. (2003) \\
D & 111 & 0,3 & 0,41 & 0,29 & & Nieters et al. (2001) \\
D & 340 & 0,31 & 0,47 & 0,22 & & Koch et al. (2001) \\
NL & 321 & 0,28 & 0,48 & 0,24 & 0,52 & Moraes et al. (2003) \\
\hline & & 0,28 & 0,44 & 0,27 & & Kube et al. (2003) \\
\hline NL & 1220 & 0,08 & 0,45 & 0,47 & 0,08 & Lard et al. (2003) \\
NL & 321 & 0,08 & 0,35 & 0,57 & 0,25 & Moraes et al. (2003) \\
\hline
\end{tabular}

$\mathrm{F}_{\text {min }}$ : Frequenz des selteneren „A“-Alleles (minor allele); I: Italiener, UK: Briten, CY: griech. Zyprioten, D: Deutsche, NL: Niederländer; Populationen nach Angaben der Autoren. 


\section{Der Einfluß demographischer Transitionen auf die Infektionsgeschichte}

The very process of living is a continual interplay between the individual and his environment, often taking the form of a struggle resulting in injury or disease. (Dubos, 1987)

Weit verbreitet ist der Gedanke, daß der Mensch sich der biologischen Evolution entzogen hat und alleine einer kulturellen Evolution unterworfen ist. Mag es für viele Belange plausibel erscheinen, so ist dies mehr als fraglich bei der Betrachtung der Koexistenz von Mensch und Pathogen. Mikroorganismen, ob krankheitserregend oder harmlos, sind abundant und Infektionserkrankungen begleiten den Menschen seit jeher. Dabei trifft der Anpassungs- und Selektionsdruck sowohl das Pathogen als auch den Menschen. Es selektiert solche Pathogene, die der Immunabwehr des Menschen entkommen, bzw. den Menschen als Wirt dauerhaft nutzen können. Nur solche können sich dauerhaft in einer Population verbreiten, die ein balanciertes Maß zwischen Pathogenität und Erhalt des Wirtsreservoirs schaffen. Dieses Maß ist abhängig von der Größe der Wirtspopulation. In kleinen Populationen tötet ein grassierender hochvirulenter Erreger in relativ kurzer Zeit alle Wirte. Fehlt ihm die Möglichkeit auf andere Wirte auszuweichen, etwa über den Kontakt zwischen Wirtspopulationen oder das Übergreifen auf eine andere Spezies, ist der Erreger selbst dem Tod geweiht. Dobson (1992) erläutert die Bedeutung der demographischen Komponente „Bevölkerungsdichte“ am Beispiel der Masern: Zur endemischen Aufrechterhaltung einer Infektionskrankheit wie der Masern wird eine Population von 400.000 bis 500.000 Individuen benötigt. Diese Konzentration wird erst seit weniger als 2000 Jahren erreicht, was für die Masern einen Zeitraum von weniger als 100 Generationen als menschliches Pathogen zuläßt. Gleichzeitig verlangt die Coexistenz zum Erreichen eines Gleichgewichtes eine Anpassung des menschlichen Immunsystems. Hier ist neben der erfolgreichen Abwehr von Pathogenen und dem Erlangen von Immunität auch die Toleranz solcher gefragt, die sich an der Immunabwehr vorbei im Körper etablieren können (z. B. Helminthen (Rook, 2007)). Mocellin et al. (2004) weisen zudem auf die Bedeutung der Regulation des richtigen Maßes der Immunantwort hin. Diese kann Schäden am eigenen Organismus hervorrufen, die eventuell weitreichendere Fol- 
gen haben als die Infektion selber. Abzuwägen ist daher das Verhältnis zwischen eigenem Schaden und erfolgreicher Infektionsbekämpfung.

Die evolutionären Anpassungsprozesse, die auf genetischer Ebene abgelaufen sein müssen, lassen sich zunächst einmal nur hypothetisch erfassen. Die historische Entwicklung der demographischen Komponente in der Beziehung zwischen Mensch und Pathogen ist hingegen vielfach beschrieben (McNeill, 1976; McMichael, 2004; Frauendorf, 2001a, z. B.). In den vergangenen 10.000 Jahren nahm der zeitliche Abstand zwischen der Etablierung neuer menschlicher Entwicklungsstufen ab. Die kulturellen, sozialen, Verhaltens- oder technischen Änderungen gingen mit einer drastischen Veränderungen der Beziehung zu seiner Umwelt einher. Neuartige Kontakte entstanden zwischen dem Menschen und seinem pathogenen Umfeld. Ein Schlüsselereignis ist sicherlich in der Entwicklung der Landwirtschaft zu sehen, der eine dramatische Zunahme an Infektionserkrankungen zugesprochen wird (Mascie-Taylor, 1993; Baum \& Bar-Gal, 2003).

Anhand der Entwicklungsstufen lassen sich nach McMichael (2004) verschiedene demographische Transitionen beschreiben. Jede einzelne hat ihre spezifische Zusammensetzung der Pathogenflora (Tab. 13).

1. Jäger- und Sammlerkulturen (prähistorische Transition)

2. Ackerbau und Viehzucht (1. historische Transition)

3. Urbanisierung und Handel (2. historische Transition)

4. Kolonialismus und Industrialisierung (3. historische Transition)

5. Globalisierung (4. historische Transition)

Die Entwicklung auf jedem Kontinent und in jeder Kultur ist sehr spezifisch, auch wenn sich gewisse Parallelen zeigen, die sich unter anderem aus den Interaktionen der Bevölkerungen ergeben. Die dargestellte Einteilung bezieht sich daher nur auf die historische Entwicklung des europäischen Subkontinentes. Selbst hier ist das Einsetzen der Transitionen lokal sehr unterschiedlich. Die Regionen des nordöstlichen Mittelmeeres mit den Städten der Antike erreichen die zweite historische Transition früher, während sie innerhalb der heutigen deutschen Gebiete erst im Mittelalter einsetzt. 
Tab. 12: Entwicklung von Kultur und Größe menschlicher Gemeinschaften, Quelle: Mascie-Taylor (1993)

\begin{tabular}{|c|c|c|c|}
\hline Jahre vor 1985 & Generationen & Kultureller Status & $\begin{array}{l}\text { Größe menschlicher Siedlun- } \\
\text { gen }\end{array}$ \\
\hline $1 \mathrm{Mio.}$ & 50.000 & Jäger und Sammler & $\begin{array}{l}\text { verstreute nomadisch lebende } \\
\text { Gruppen von }<100 \text { Personen }\end{array}$ \\
\hline 10.000 & 500 & $\begin{array}{l}\text { Entwicklung der Landwirt- } \\
\text { schaft }\end{array}$ & $\begin{array}{l}\text { relativ seßhafte Dorfgemein- } \\
\text { schaften von }<300 \text { Personen }\end{array}$ \\
\hline 5500 & 220 & $\begin{array}{l}\text { Entwicklung } \\
\text { Bewässerungsanbau }\end{array}$ & $\begin{array}{l}\text { wenige Städte von } 100.000 \text {, } \\
\text { hauptsächlich Dörfer von } \\
<300 \text { Personen }\end{array}$ \\
\hline 250 & 10 & Nutzung der Dampfkraft & $\begin{array}{l}\text { wenige Städte von } 500.000 \text {, } \\
\text { einige Städte von } 100.000 \text {, ei- } \\
\text { nige Dörfer von } 1000\end{array}$ \\
\hline 130 & 6 & $\begin{array}{l}\text { Einführung der Hygiene- } \\
\text { Reformen }\end{array}$ & \\
\hline 0 & - & - & $\begin{array}{l}\text { Einige Städte von } 5 \text { Mio, vie- } \\
\text { le Städte bis } 500.000 \text {, wenige } \\
\text { Dörfer von } 1000\end{array}$ \\
\hline
\end{tabular}

Tab. 13: Krankheitsspektrum vom Frühmenschen bis heute, nach Mascie-Taylor (1993), McNeill (1976), McMichael (2004)

\begin{tabular}{|c|c|c|}
\hline & anwesend & fehlend \\
\hline \multicolumn{3}{|l|}{ Jäger und Sammler } \\
\hline nomadisch lebende Gruppen & $\begin{array}{l}\text { parasitäre Flora, Zoonosen } \\
\text { mit nichtmenschlichen Wirten } \\
\text { (z. B. Malaria), Tuberkulose }\end{array}$ & $\begin{array}{l}\text { menschliche viruelle Erkran- } \\
\text { kungen, bakterielle Infektionen } \\
\text { wie Cholera und Typhus }\end{array}$ \\
\hline \multicolumn{3}{|l|}{ Landwirtschaft } \\
\hline einfache Dörfer & $\begin{array}{l}\text { wie bei Jäger und Sammler, en- } \\
\text { terische Bakterien, Infektionen } \\
\text { der Atmungswege, Zooanthro- } \\
\text { ponosen }\end{array}$ & Masern, Pocken, Röteln \\
\hline einfache Städte & $\begin{array}{l}\text { Infektionen, die von Mensch zu } \\
\text { Mensch übertragen werden }\end{array}$ & Masern, Pocken, Röteln \\
\hline fortgeschrittene Städte & $\begin{array}{l}\text { Masern, Pocken, Röteln, Ge- } \\
\text { schlechtskrankheiten }\end{array}$ & $\begin{array}{l}\text { abhängig von Kontrollen } \\
\text { (Trinkwasserqualität), Imp- } \\
\text { fung, Medikamenten }\end{array}$ \\
\hline
\end{tabular}




\subsection{Prähistorische Transition: Jäger- und Sammlerkulturen}

Die Jäger- und Sammlergesellschaften sind charakterisiert durch eine kleine Gruppengröße und zumeist nomadische Lebensweise. Da der Mensch in dieser Phase auf ein Gleichgewicht mit seiner Umwelt angewiesen ist, ist die Bevölkerungsdichte limitiert (McNeill, 1976). Vorherrschend sind wahrscheinlich endemische Infektionen mit einem hohem Resistenzlevel innerhalb der Wirtspopulation. Darunter fallen Parasiten, die über die (fleischliche) Nahrung aufgenommen werden. Daneben ist außerdem ein hoher Einfluß durch Zoonosen mit einem nichtmenschlichen Reservoir (z. B. Malaria) denkbar, die unabhängig von der menschlichen Bevölkerungsdichte sind. Veränderungen der Pathogenflora sind bei der Eroberung neuer geographischer und klimatischer Lebensräume während der Ausbreitung des Menschen über die Kontinente anzunehmen. Die Phase der Jäger- und Sammlerkulturen erstreckte sich über einen langen Zeitraum, wodurch die Chance auf eine ausgeprägte Balance zwischen den coevolutierenden Parteien Pathogen - Mensch bestand. Dobson (1992) stuft diese Phase als eine mit relativ geringer Inzidenz von Infektionserkrankungen ein.

\subsection{Erste historische Transition: Landwirtschaftliche Revolution}

Gerade die erste historische Transition, die mit der landwirtschaftlichen Revolution und Domestikation von Tieren einherging (McNeill, 1976; Baum \& BarGal, 2003), bedeutete den erstmaligen Kontakt zu einem größeren neuen Erregerspektrum. Sie beginnt regional sehr unterschiedlich in einem Zeitraum von etwa 10.000 bis 5.000 Jahren vor heute. Für diese Phase wird eine Zunahme der enzootischen Pathogene vermutet (McMichael, 2004; Frauendorf, 2001a). Durch den engen Kontakt mit den domestizierten Tieren infizierte sich der Mensch nun auch mit tierpathogenen Erregern wie Viren und Bakterien, die eine direkte Übertragung erfordern. Die Erschließung neuer Ländereien, etwa durch Brandrodung von Waldgebieten, ließ den Menschen zu einem neuen Glied innerhalb vorher unbekannter Infektionsketten werden. Bedeutung findet auch der mit der Aufnahme der Landwirtschaft einhergehende Übergang zur Seßhaftigkeit. Die Möglichkeit der Überproduktion erlaubt die Zunahme der Gruppengröße und die 
Spezialisierung von Bevölkerungsteilen. Erstmals sind größere Siedlungen möglich und eine höhere Bevölkerungsdichte.

Die Erkrankungen sind jedoch meist chronischer Natur mit niedriger Virulenz. Dazu gehören Lepra, Tuberkulose und Leishmaniose, deren Vorkommen molekulargenetisch für verschiedene Kulturen (z. B. Zink et al. (2005)) belegt ist. Die Bevölkerungsdichte und der Kontakt von Subpopulationen untereinander bleibt zu gering, um das Überleben hochvirulenter Erreger zu erlauben.

In diese Phase fällt die europäische Bronzezeit (ca. 2200 - 800 v. Chr.) Charakteristisch ist die geringe Besiedlungsdichte der mitteldeutschen Gebiete mit kleinen Populationen auf Clanebene (Jockenhövel, 1994a). Eine Siedlung wird nur aufrechterhalten, bis die landwirtschaftliche Nutzung nach etwa drei bis vier Generationen die Böden ausgelaugt hat. Der Handel und Austausch mit anderen Populationen ist zwar anhand von archäologischen Fundstücken belegt, beschränkte sich aber wahrscheinlich auf den kleinräumigen Austausch und die Hand zu Hand Weitergabe von Einzelstücken (Jockenhövel, 1994b)

Aufgrund seiner Charakteristika wird dieser Zeitraum im Vergleich zu den folgenden Phasen von Antike, Mittelalter und Neuzeit mit virulenten und epidemisch auftretenden Erkrankungen ebenfalls als pathogenarm angesehen. Der Selektionsdruck auf die immungenetische Ausstattung des Menschen wird aufgrund fehlender Großereignisse und der geringen und langsamen Veränderung von Umwelt und Pathogenflora als eher gering eingeschätzt. Für diese Phase steht repräsentativ in dieser Arbeit die Skelettserie der Lichtensteinhöhle bei Dorste. Ihr kommt der Stellenwert einer präepidemischen Kontrolle zu.

\subsection{Zweite historische Transition: Urbanisierung und Handel}

Die zweite historische Transition beginnt etwa 1500 bis 3000 Jahre vor heute (McMichael, 2004) mit der Aufnahme von Handels- sowie kriegerischen Beziehungen der frühen europäischen Populationen. Zusätzlich zur stärkeren Vernetzung nimmt die Größe und Dichte der Bevölkerung zu. Durch die Handelskontakte nach Asien kommt es zum Vermischen des Infektionspools zwischen China, Rom und dem östlichen Mittelmeerraum. Es ist anzunehmen, daß weite Bereiche Nord- und Mitteleuropas diese Entwicklung aufgrund ihrer abgelegenen Lage zu den antiken 
Kulturen erst wesentlich später erreichten. Im Gebiet des heutigen Deutschlands gab es bis ins Mittelalter nur eine überschaubare Zahl größerer Siedlungen, die in ihrer Isolation in geringer besiedeltem Gebiet jedoch kein ausreichendes Reservoir darstellen sollten. Einzelne Infektionsereignisse sind denkbar, die sich jedoch schnell erschöpfen.

In den antiken Städten jedoch war das Wirtsreservoir nun für virulente Pathogene ausreichend, was sich am Auftreten von wiederkehrenden epidemischen Erkrankungen zeigt. 430 v. Chr. bricht eine Epidemie in Athen aus (Pest von Athen), die nach dem Bericht des griechischen Geschichtsschreibers Thukydides als Typhusepidemie eingestuft wird. Ihr folgten weitere Epidemien, die größeren sind in Tabelle 14 vorgestellt. Die Justinianische Pest, für die Y. pestis als Erreger nachgewiesen ist (Wiechmann \& Grupe, 2005), verbreitete sich aufgrund des römischen Kolonialismus bis in das germanische Rheinland (Keil, 1986, S. 112)

Tab. 14: Bedeutende Epidemien der antiken Welt

\begin{tabular}{ll}
\hline Ereignis & Datum \\
\hline Pest von Athen & 430 v. Chr. \\
Antoninische Pest & AD165 - 180 \\
Cyprianische Pest & AD250 \\
Justinianische Pest & AD541 - 542 \\
Pest von Emmaus & AD639 \\
Pest von Konstantinopel & AD747 - 748 \\
\hline
\end{tabular}

In Mitteleuropa gewann die Urbanisierung besonders ab dem 12. Jahrhundert mit der Gründung der Hanse an Bedeutung. Einige chronisch verlaufende Erkrankungen, wie Lepra und Tuberkulose, hatten sich bereits im frühen Mittelalter in Europa etabliert. Mit der Urbanisierung nahm auch der Einfluß virulenter infektiöser Erkrankungen zu. Pest, Pocken, Cholera und Typhus traten in pandemischen Wellen ab dem 14. Jahrhundert auf (Grupe et al., 2005; McNeill, 1976).

Der Schwarze Tod, wie die Pest des 14. Jahrhunderts (1348 - 1351) aufgrund ihrer hohen Sterblichkeitsrate genannt wurde, stellt die erste große Epidemie Mitteleuropas dar. Über Indien verbreitete sich die Infektion entlang der Handelswege bis an die italienische und französische Mittelmeerküste. Innerhalb weniger Jahre breitete sie sich vom Mittelmeer über ganz Mitteleuropa aus, wobei sie nur wenige Gebiete aussparte (vgl. auch Kap. 4.6). Die Pandemie beeindruck- 
te nicht nur durch ihre hohe Virulenz und Mortalität, der europaweit 30\% der Bevölkerung zum Opfer fielen (lokal bis 70\%) (McNeill, 1976; Keil, 1986; Grupe, 1986), sie zeichnete sich auch durch eine hohe Verbreitungsgeschwindigkeit aus. Es ist anzunehmen, daß der Erreger in weiten Teilen Mitteleuropas auf eine nichtimmunisierte Bevölkerung traf. Ein Zeichen hierfür ist neben der hohen Sterblichkeit (virgin soil syndrome) auch das bevorzugte Sterben der jüngeren Erwachsenen (Grupe, 1986; Herrmann et al., 1990). Parallelen finden sich im Untergang der Kulturen der Neuen Welt im 16. und 17. Jahrhundert, an dem die mit den Conquistadoren eingeschleppten europäischen Pathogene einen Anteil hatten. Begünstigt wurde das Voranschreiten der mittelalterlichen Epidemie zudem durch den schlechten Ernährungszustand der Bevölkerung (Dobson, 1992), denn klimatische Veränderungen führten im Vorfeld der Pest zu Mißernten und Hungersnöten (wie z. B. 1316 in Lübeck). Weitere Pestepidemien folgten der großen Epidemie des Schwarzen Todes in regelmäßigen Abständen, die nächste nach nur 12 Jahren. Zunehmend wurde davon nur noch der nachgewachsene, nichtimmunisierte Bevölkerungsteil betroffen, also Kinder und Jugendliche, die aus demographischer Sicht leicht zu ersetzen sind. Spätere Seuchenzüge werden daher auch als Kinderpest (Grupe, 1986) angesprochen. Hier zeigt sich ein typisches Muster, das auch bei anderen epidemischen Erkrankungen zu beobachten ist, die zunehmend als Kinderkrankheiten an bedrohlichem Charakter verloren. Die zweite Pestwelle jedoch bedeutete einen erheblichen Eingriff in die demographische Entwicklung, da nach der hohen Sterblichkeit des reproduzierenden Bevölkerungsteils der ersten Pestwelle, der Adultas, nun die nachgewachsene Generation vor Erreichen der Fortpflanzungsfähigkeit dezimiert wurde (Grupe, 1986).

Der hohe Einfluß der Pest auf die Bevölkerungsentwicklung des Mittelalters läßt auf einen hohen Selektionsdruck auf die menschliche Immungenetik schließen. Immerhin überlebten rund zwei Drittel der Bevölkerung die erste Pestwelle trotz fehlender Immunität. Eine genetische Komponente in der Suszeptibilität kann daher angenommen werden. Diese wird in einer Disposition zur verstärkten Immunreaktion mit einer höheren Frequenz proinflammatorischer Polymorphismen angenommen. 


\subsection{Dritte historische Transition: Kolonialismus und Industrialisierung}

Die dritte historische Transition beginnt mit dem 16. Jahrhundert. Sie ist charakterisiert durch den abnehmenden demographischen Einfluß der zunächst epidemisch mit hoher Mortalität auftretenden Infektionserkrankungen. McNeill (1976, S.232) spricht in diesem Zusammenhang von einer „Domestikation“ der Pathogene. Neben der Pest, die bis ins 19. Jahrhundert wiederholt auftritt, sind dies Pocken, Masern und Röteln. In diese Zeit fällt auch die erste Influenza-Epidemie (1556 - 1560), die eine Mortalität von etwa $20 \%$ mit sich brachte. Syphilis und Tuberkulose florieren in den städtischen Zentren, Cholera und Typhus sind seit dem frühen 19. Jahrhundert in wiederkehrenden Infektionswellen präsent.

Nach den verheerenden mittelalterlichen Pestwellen stellt sich trotz weiterer infektiöser Ereignisse eine Entwicklung der zunehmenden Überlebenswahrscheinlichkeit ein (McNeill, 1976; Dobson, 1992; Frauendorf, 2001a). Sie leitet das bis dato massivste Bevölkerungswachstum Europas ein (McNeill, 1976, S. 246ff). Auslöser ist eine weitere Revolutionierung der Landwirtschaft. Diese bestand aus der zunehmenden Intensivierung der Flächennutzung durch neue Methoden und (später) Maschinerie (Stichwort „Neue Landwirtschaft“/ New Husbandry). Aus den Kolonien kamen neue Feldfrüchte wie Kartoffel und Alfalfa nach Europa, die einen wesentlich höheren Ertrag erzielten als die altbekannten. Auch die Zunahme der Nutzflächen über die Kolonien war von Bedeutung. Die Überproduktion ermöglichte zum einen eine bessere Versorgung der Gesamtbevölkerung bei niedrigeren Lebensmittelpreisen. Zum anderen nahm der Anteil der Fleischveredelung zu, die Grundvoraussetzung für einen höheren Proteinanteil in der Ernährung. McNeill (1976, S. 253) beziffert die Erhöhung der Produktivität mit einem Drittel. Auf die Bedeutung des Zusammenhangs zwischen Ernährung und Infektionen weisen auch McNeill (1976, S. 253) und Grupe (1986) hin. Die qualitative Verbesserung des Nahrungsangebotes mit einem erhöhten Proteinanteil stellt die Voraussetzung für eine höhere Produktion von Immunglobulinen dar, die wiederum einen höheren Grundlevel an Infektionsresistenz zuläßt.

Traten Pocken, Masern und Röteln zu Beginn noch in Epidemien auf, hatten sich die ehemals gefürchteten Krankheitserreger im 17. und 18. Jahrhundert in den Städten bereits als Kindererkrankungen etabliert. Übertragungsorte der Erkran- 
kungen waren zumeist Schulen und das Militär. Auf die ländliche Bevölkerung, die weiterhin den bedeutenderen Anteil der Gesamtbevölkerung stellte, wurden die Erreger nur gelegentlich übertragen. Trotz der im Vergleich zur Landbevölkerung weiterhin schlechteren Ernährung der Stadtbevölkerung machte sich die höhere Pathogen-Exposition in einer höheren Immunität bemerkbar (Dobson, 1992). Noch im 18. Jahrhundert wurde die Pockenimpfung in Europa eingeführt und leitete den Niedergang der Pocken ein.

\subsection{Vierte historische Transition: Globalisierung}

Ab dem Ende des 19. Jahrhunderts gewann der medizinische Fortschritt an Bedeutung. Durch die Entdeckung der ersten Mikroorganismen als Krankheitserreger veränderte sich der Umgang mit Infektionen. Vorbeugende Maßnahmen wie Quarantäne, Desinfektionsmittel und Trinkwasseraufbereitung sowie Abwasserentsorgung zur Verbesserung der hygienischen Umstände in den Städten wurden eingeführt (McNeill, 1976, S.276ff). Die Verbesserung der Wasserqualität bedeutete eine wirksame Bekämpfung enteraler Infektionen, womit eine Hauptursache der Kindersterblichkeit ausgemerzt wurde. Die viruellen Kinderkrankheiten blieben jedoch bis in die heutige Zeit erhalten. Weitreichende Verbesserungen brachte die Einführung der pharmazeutischen Industrie ab der Mitte des 20. Jahrhunderts vor allem mit der Entwicklung der Antbiotika.

Die starke Urbanisierung und die höhere Mobilität ab dem 19. Jahrhundert führte auch eine lange Serie neuer Krankheitsbelastung ein. Die Globalisierung zog eine weltweite und kurzfristige Verbreitung neuer beziehungsweise neuer Varianten altbekannter Pathogene nach sich. Mindestens 30 neue Infektionserkrankungen sind dadurch weltweit bekannt geworden (Frauendorf, 2001b). Die Wanderung in größere und zahlreichere städtische Zentren hatte den parallelen Effekt des intensivierten Kontaktes mit alten und bekannten Infektionen (McNeill, 1976, S. 265). Auch die klimatischen Veränderungen haben ihren Anteil, in dem sie geographisch engverbreiteten Pathogenen neue Lebensräume eröffnen.

Trotz allen medizinischen Fortschritts sind Infektionen weiterhin ein Bestandteil des täglichen Lebens. Dadurch bleibt eine hohe Pathogenexposition erhalten, so daß auch dieser Zeitraum als pathogenreich einzustufen ist. Die Bedeutung des Infektionsgeschehens als Selektionsereignis ist heutzutage wahrscheinlich als ge- 
ring anzunehmen, eher im Sinne einer den status quo erhaltenden Selektion. Die genetische Grundlage des Immunsystems ist durch die Einflüsse der Epidemien, die unsere Vorfahren durchlebt haben, geprägt. Die vierte Transition ist daher eine zwar postepidemische Phase, in der die direkte Auswirkung der Infektionserkrankungen auf die Bevölkerungsentwicklung aber rückläufig ist.

\subsection{Der Schwarze Tod - War Y. pestis der Auslöser?}

Auch wenn die Epidemien des 14. Jahrhunderts als Pestepidemien beschrieben sind, ist der Erreger der heute bekannten Pestinfektion, Yersinia pestis, als Auslöser der mittelalterlichen Pest umstritten (Twigg, 1995; Scott \& Duncan, 2001; Duncan et al., 2005). Drancourt \& Raoult (2002) konnten Sequenzen, die für $Y$. pestis spezifisch sind, in mittelalterlichen Skeletten aus Frankreich nachweisen. Auch aus Skeletten, die in die Zeit der Justinianischen Pest (6. Jh.) fallen, konnte der Erreger bereits nachgewiesen werden, so geschehen für zwei Funde aus Oberbayern (Wiechmann \& Grupe, 2005). Scott \& Duncan (2001, S.389) unterscheiden zwei Pesterkrankungen, die gleichzeitig für hunderte von Jahren existierten: die hämorrhagische Pest, die für die Pestwellen in Europa verantwortlich sei, und die Beulenpest, die in Zentral- und Ostasien vorherrschte. Die Beulenpest, die durch $Y$. pestis hervorgerufen wird, komme als Erreger der europäischen Pest aufgrund ihrer Charakteristika nicht in Frage. Es fehlen Hinweise auf ein Rattensterben, das gewöhnlich mit dem Ausbruch einer Beulenpestepidemie einhergeht. Die hohe Verbreitungsgeschwindigkeit und Mortalität sowie die lange Inkubationszeit sind weitere Faktoren, die sie anführen. Sie gehen aufgrund dieser Eigenschaften von einer Viruserkrankung aus. Auch die primäre Lungenpest wird in der Argumentation als Auslöser negiert, da ihr schneller Verlauf die Übertragung von Mensch zu Mensch nur kleinräumig erlaubt. Nach der Ansteckung seien die Infizierten kaum noch in der Lage, die für die beobachtete Ausbreitung erforderliche Distanz zurückzulegen. Unbestritten ist $Y$. pestis dagegen als auslösendes Agens neuzeitlicher Pestepidemien. Die Ergebnisse von Drancourt \& Raoult (2002) erklären sie mit sporadischen Übergriffen der Beulenpest auf die Mittelmeerküste. Auch Rückschlüsse aus modernen Verteilungsmustern von immungenetisch relevanten Mutationen werden als Beweis bemüht. So postulieren Duncan et al. (2005) ein hämorrhagisches Virus als Auslöser, bei dem die CCR5 $\Delta 32$-Variante einen se- 
lektiven Vorteil verleiht. Das Verbreitungsmuster der bis 1800 wiederkehrenden Seuchen decke sich mit dem Verteilungsgradienten der Mutation. Allerdings zeigten Kremeyer et al. (2005), daß die zugrundegelegte mittelalterliche Verteilung der CCR5 32 -Variante nicht zutrifft. Für das Lübecker Pestkollektiv wurde dieselbe Häufigkeit nachgewiesen wie für die moderne Bevölkerung, weitere Untersuchungen ergaben diese Frequenz bereits in der bronzezeitlichen Skelettserie aus der Lichtensteinhöhle bei Dorste (Hummel et al., 2005). Eine Selektion durch die Seuche kann daher ausgeschlossen werden.

Nicht zu vergessen ist allerdings auch die mögliche Anpassung eines Erregers an seinen Wirt. Der mittelalterliche Pesterreger muß daher in seinen Eigenschaften nicht identisch sein mit dem heutigen, sondern kann einer anderen Serotype mit unbekannten Eigenschaften angehören. Auch zeigen sich in nichtimmunisierten Bevölkerungen bei Erstkontakt mit Erkrankungen abweichende Symptome und Krankheitsverläufe, die in ihrer Dramatik beeindrucken (Grupe, 1986).

Für diese Arbeit ist letztendlich die Art des Erregers selber nicht zwingend, auch wenn als zentrale Population ein Kollektiv von Pestopfern untersucht wird. Zwar mag die genetische Komponente der Suszeptibilität für die Erkrankung von der Art des Erregers (Virus oder Bakterium) abhängig sein. Jedoch wird das Kollektiv nicht im Zusammenhang der Assoziation von Polymorphismen mit einem bestimmten Erreger untersucht. Vielmehr ist dieses Kollektiv im diachronen Kontext der Transitionen, zwischen Bronzezeit und Moderne, sowie in der Kombination mit dem zweiten nichtepidemiologischen Kollektiv bedeutend. Entsprechend ist die Auswahl der Marker (vgl. Kap.3) weiträumig ausgelegt und nicht auf eine Assoziation mit $Y$. pestis selber oder allgemein mit bakteriellen Infektionen beschränkt. 


\section{Auswahl der Bevölkerungen}

Die Auswahl umfaßt Skelettserien aus verschiedenen Zeitstellungen der letzten 3000 Jahre. Im Zentrum der Untersuchung steht ein mittelalterliches Skelettkollektiv aus Lübeck, das Opfer der Pestepidemie umfaßt, die 1348 bis 1351 Europa überrollte. Dieses Kollektiv steht stellvertretend für ein Zeitalter rasch aufeinanderfolgender epidemischer Ereignisse (zweite historische Transition). Eine nur wenige Jahre ältere Serie aus Lübeck, die einer Hungersnot zugeordnet wird, dient mit gewissen Einschränkungen als kontemporäre Kontrolle. Hier besteht die Möglichkeit, die Bevölkerung Lübecks zwei Generationen vor Eintreffen der Pest zu untersuchen. Einer weiteren Skelettserie, dem bronzezeitlichen Fundkomplex aus der Lichtensteinhöhle bei Dorste (Harz), kommt die Rolle der präepidemischen Kontrolle zu. Sie ist gleichzeitig eine Bevölkerung der ersten historischen Transition.

Eine besondere Bedeutung kommt der genetischen Kontinuität zwischen den untersuchten Populationen zu. Sie erlaubt die Annahme, daß die beobachteten Varianzen in selektiven Ereignissen gründen. Der Einfluß des genetischen Hintergrundes zeigte sich bereits in Studien an Rezentpopulationen. In Studien über verschiedenen Kontinente und selbst innerhalb von Kontinenten zeigten sich starke abweichende Allelfrequenzen für verschiedene Marker (Hoffmann et al., 2002). Dies gilt neben immungenetischen Markern auch für STR-Marker, Y-Haplotypen und mt-Haplotypen. Diese werden sich zum Beispiel in der forensischen Genetik zu nutze gemacht, um aus SpurenDNA die ethnische Herkunft eines gesuchten Täters einzugrenzen. Im Falle der immungenetischen Marker kommt es in Abhängigkeit des genetischen Hintergrundes zu starken Abweichungen hinsichtlich ihrer Auswirkung auf Erkrankungen, die Ergebnisse von Studien verschiedener Kontinente sind teilweise widersprüchlich.

Durch ihre geringe lokale Abweichung gewährleisten die gewählten Skelettserien eine maximale genetische Kontinuität. Der Vergleich der genetischen Daten aus verschiedenen Zeitstellungen und ethnisch verwandter Populationen erlaubt die Verfolgung chronologischer genetischer Veränderungen. Ereignisse mit selektivem Charakter können zeitlich näher eingegrenzt werden, ebenso werden Marker mit Relevanz für die Immunabwehr über ihre Assoziation mit geänderten infektiologischen Bedingungen identifiziert. 


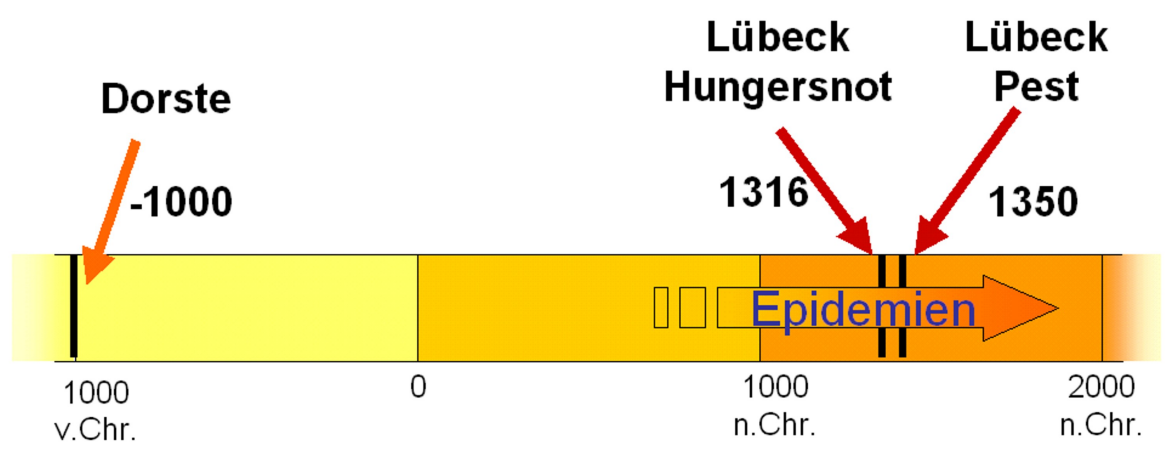

Abb. 5: Zeitskala zur Darstellung des Zeitraums, der von den untersuchten Populationen abgedeckt wird.

Während die bronzezeitliche Serie in ihrer Konformität mit der heutigen deutschen Bevölkerung bereits bestätigt ist (Schultes, 2000; Schilz, 2006), wurden die Daten für die Lübecker Serien in der Arbeit von Huhn (2008) erhoben. Demnach sind die Lübecker Skelettkollektive ein gutes Beispiel für eine urbane mitteleuropäische Bevölkerung. Allerdings wurden Unterschiede in der regionalen Herkunft zwischen den beiden Serien gefunden. Auch wenn ein Stichprobenartefakt aufgrund der geringen Probenzahl von insgesamt 27 erfolgreich typisierten Individuen nicht auszuschließen ist, muß ein möglicher Einfluß auf die Ergebnisse immungenetischer Studien berücksichtigt werden. Die Skelettserien und die Zusammensetzung der Stichproben werden in Kapitel 7 vorgestellt.

Als moderne postepidemische Kontrolle werden Stichproben der rezenten Bevölkerung herangezogen. Die Daten werden der Literatur entnommen. Für die Marker TLR4 D299G, IL10 G-1087A und IL4Ra Q576R wurden im Rahmen der Kooperation mit der Abteilung Hämatologie und Onkologie (Universitätsklinikum) von Herrn PD Dr. D. Kube zur Verfügung gestellt. Die Probanden der Stichprobe stammen aus dem Raum Göttingen und Tübingen. 


\section{Hypothese}

Humans and microbes are not 'at war'; rather, both parties are engaged in amoral, self-interested, coevolutionary struggle. (McMichael, 2004)

Die Art und Intensität der Pathogen-Exposition hat sich innerhalb der letzten 3000 Jahren mehrfach verändert (vgl. Kap. 4). Von der Dominanz parasitärer und chronischer Infektionen erfolgte eine Verschiebung hin zu hochvirulenten Erregern mit Infektionen epidemischen Charakters. Die Anpassung des Menschen innerhalb dieser Coevolution der Infektionsentwicklung wird sich in seiner Immungenetik widerspiegeln. Im Vergleich der historischen Populationen mit der Rezentbevölkerung wird daher ein Einfluß dieser Verschiebung auf die immungenetischen Eigenschaften des Menschen erwartet. Ein besonders hervorstechendes Ereignis selektiven Charakters wird in der mittelalterlichen Pestepidemie gesehen. Die Opfer der Pest sollten sich daher in ihren immungenetischen Eigenschaften von der mittelalterlichen Bevölkerung (repräsentiert durch die Opfer der Hungersnot) unterscheiden. Ebenso sollte ein Unterschied zur heutigen Bevölkerung bestehen, die sich aus den Nachfahren der Überlebenden der Pestepidemie zusammensetzt.

Die immungenetischen Eigenschaften des Individuums sind nicht zuletzt durch die Funktionalität der einzelnen Gene (Transkription) und ihrer Proteine (Effizienz) bestimmt. Einzelne Polymorphismen können weitreichende funktionelle Veränderungen im Sinne von gain of function- oder loss of function-Mutationen bedeuten. Es wird erwartet, daß entsprechend der Verschiebung der Pathogenflora eine Selektion funktionaler Varianten von Markern hin zu einer stärker proinflammatorischen Disposition des Immunsystems erfolgte. Für Marker mit proinflammatorischen Eigenschaften wird eine Anreicherung verstärkender Varianten (gain of function) innerhalb der Bevölkerung erwartet, für antiinflammatorische Marker eine Zunahme der Varianten mit abschwächender Wirkung.

Proinflammatorische Eigenschaften werden z. B. IL6 zugesprochen, während IL10 sowie der Komplex IL4 und IL4Ra durch ihre regulierende Wirkung antiinflammatorische Eigenschaften tragen. Für den Marker IL6 wird daher eine Anreicherung verstärkender Varianten (gain of function) innerhalb der Bevölkerung erwartet, für die antiinflammatorischen Marker eine Zunahme der Varianten mit 
abschwächender Wirkung. Die funktionellen Varianten der Toll-like Rezeptoren TLR2 und TLR4 beeinträchtigen die Rezeptorfunktion und sollten damit innerhalb einer pathogenreichen Umwelt einen selektiven Nachteil darstellen. Denn für die erfolgreiche Abwehr von Infektionserkrankungen ist die frühzeitige Erkennung und Einleitung der angeborenen Immunantwort von großer Bedeutung. Besonders unter den Pestopfern wird daher eine Abweichung der Frequenz erwartet. 


\section{Historische Skelettserien}

\subsection{Mittelalterliche Skelettserien aus Lübeck (HL)}

\subsubsection{Allgemeine Informationen}

Aus Lübeck sind zwei Skelettserien aus der ersten Hälfte des 14. Jahrhunderts überliefert. Aus mehreren Massengräbern auf zwei Grabungshorizonten wurden bei einer Grabung auf dem Areal des Heiligen-Geist-Hospitals zwischen 1989 und 1991 die sterblichen Überreste von mehr als 1000 Individuen geborgen. Nach Prechel (1996), die die anthropologische Befundung der Skelette durchführte, ist der jüngere Fundhorizont einer Pestepidemie zuzuordnen, die 1350 in Lübeck wütete. Insgesamt waren 696 Individuen in zwei Grabgruben bestattet, 364 in der nördlichen Grube (Befund 4528), 332 in der südlichen (Befund 4529). Der ältere Fundhorizont, der aus kleineren Grabgruben mit insgesamt 158 Individuen besteht, wird auf eine vorangegangene Hungersnot im Jahre 1316 datiert. Ein Hinweis auf epidemische Ursachen bei Massenbestattungen ist in der Abweichung des Sterblichkeitsgipfels hin zu einer sonst auf Friedhöfen unterrepräsentierten Altersgruppe zu finden. Im Falle der Pest ergibt sich eine erhöhte Sterblichkeit adulter Individuen (20 - 40 Jahre, Herrmann et al. (1990, S.52); Castex \& Friess (2001)), insbesondere der frühadulten, die auch für die jüngere Serie aus Lübeck beobachtet wurde. Hier sind entsprechend besonders die Altersklassen 15 - 25 Jahre betroffen (Prechel, 1996).

Für die Stichprobe „Pest“ wurden Individuen aus dem jüngeren Lübecker Fundhorizont ausgewählt, bei denen es sich mit hoher Wahrscheinlichkeit um Opfer der Pest handelt. Dies trifft vor allem auf die Bestatteten aus den beiden größeren Gruben zu (Befundnummern 4528 und 4529, Tab. 15). Da in der Altersklasse Adultas der höchste Anteil an Individuen zu erwarten ist, die während der Pestepidemie an der Pest selber verstorben sind, sollte das Sterbealter laut anthropologischem Befund zwischen 20 und 40 Jahren liegen. Gleichzeitig wurde Wert gelegt auf ein ausgewogenes Geschlechterverhältnis, soweit der Erhaltungszustand und die Vollständigkeit der Funde dies zuließen. Dieses Kriterium sollte gewährleisten, daß die Ergebnisse nicht durch eventuelle geschlechtsspezifische Effekte verfälscht werden. Aus der älteren Serie (Hungersnot) wurden analog zur 
Pestserie ebenfalls Individuen des Sterbealters 20 - 40 Jahre ausgewählt. Auch hier wurde ein ausgeglichenes Geschlechterverhältnis angestrebt. Die Auswahlkriterien wurden gleich gehalten, um eine größtmögliche Vergleichbarkeit der beiden mittelalterlichen Stichproben zu gewährleisten. Als Proben wurden vorzugsweise im Kiefer verbliebene Zähne oder Knochengewebe der partes petrosae verwendet. Diese Skelettelemente haben in verschiedenen Studien eine besonders gute DNAErhaltung gezeigt (Kleindorp, 2006; Westenthanner, 2006). In einigen Fällen waren diese Skelettelemente nicht erhalten, so daß auf Metatarsale zurückgegriffen wurde.

\subsubsection{Stichprobe Lübeck Pestmassengrab, jüngerer Bestattungshorizont}

Insgesamt wurden 83 Individuen ausgewählt, davon 40 Männer und 43 Frauen, womit nur ein geringer Überschuß an weiblichen Individuen vorliegt. Das jüngste Individuum wird auf 20 - 23 Jahre geschätzt, das älteste auf 36 - 40 Jahre. Eine Aufstellung der untersuchten Individuen sowie der verwendeten Skelettelemente gibt Tabelle 15.

Tab. 15: Untersuchte Individuen des Pestmassengrabes. Alters- und Geschlechtsangaben nach dem Fundkatalog, die Daten wurden von Herrn Tank (Archäologie, Stadt Lübeck) zur Verfügung gestellt. HL: Lübeck; m/w: männlich/weiblich; Z: Zahn, pp: pars petrosa, metat: metatarsale; re/li: rechts/links;

\begin{tabular}{lcccc}
\hline FNR & Alter & Geschlecht & Befund & Skelettelement \\
\hline HL 891 & $20-25$ & $\mathrm{f}$ & 4528 & Z2.7 \\
HL 927 & $20-23$ & $\mathrm{~m}$ & 4528 & Z3.7 \\
HL 934 & $25-35$ & $\mathrm{f}$ & 4528 & $\mathrm{pp} \mathrm{li}$ \\
HL 942 & $28-32$ & $\mathrm{f}$ & 4528 & Z3.7 \\
HL 945/1 & $23-40$ & $\mathrm{~m}$ & 4528 & metat \\
HL 958 & $30-37$ & $\mathrm{f}$ & 4528 & Z3.8 \\
HL 965 & $34-38$ & $\mathrm{f}$ & 4528 & Z1.6 \\
HL 972 & $20-25$ & $\mathrm{~m}$ & 4528 & Z3.7 \\
HL 994/1 & $23-35$ & $\mathrm{f}$ & 4528 & Z1.4 \\
HL1006 & $30-36$ & $\mathrm{~m}$ & 4528 & Z3.8 \\
HL1037 & $25-33$ & $\mathrm{~m}$ & 4528 & Z3.8 \\
HL1043 & $20-28$ & $\mathrm{~m}$ & 4528 & Z3.4 \\
HL1047 & $25-30$ & $\mathrm{f}$ & 4528 & Z2.6 \\
HL1081 & $23-30$ & $\mathrm{f}$ & 4528 & Z4.7 \\
HL1102 & $21-24$ & $\mathrm{~m}$ & 4529 & metat \\
HL1106 & $21-24$ & $\mathrm{~m}$ & 4528 & Z3.8 \\
\hline
\end{tabular}


Tab. 15: Fortgesetzt: Untersuchte Individuen des Pestmassengrabes.

\begin{tabular}{|c|c|c|c|c|}
\hline FNR & Alter & Geschlecht & Befund & Skelettelement \\
\hline HL1112 & 23-35 & $f$ & 4529 & Z1.5 \\
\hline HL1133 & $28-34$ & $\mathrm{~m}$ & 4529 & Z4.8 \\
\hline HL1154 & $32-36$ & $\mathrm{~m}$ & 4529 & Z2.4 \\
\hline HL1156 & $21-24$ & $\mathrm{~m}$ & 4529 & Z3.5 \\
\hline HL1188 & $20-25$ & $\mathrm{~m}$ & 4529 & metat \\
\hline HL1217 & $26-40$ & $f$ & 4528 & pp re \\
\hline HL1219 & $21-25$ & $\mathrm{~m}$ & 4528 & Z1.7 \\
\hline HL1225 & $23-30$ & $f$ & 4528 & Z2.7 \\
\hline HL1227 & $32-37$ & $\mathrm{~m}$ & 4528 & Z2.4 \\
\hline HL1232 & $20-25$ & $\mathrm{~m}$ & 4529 & pp re \\
\hline HL1234 & $20-26$ & $\mathrm{~m}$ & 4529 & $\mathrm{Z} 2.4$ \\
\hline HL1262 & $23-30$ & $f$ & 4528 & Z3.6 \\
\hline HL1270 & $32-36$ & $f$ & 4528 & $\mathrm{Z} 1.7$ \\
\hline HL1271 & $21-24$ & $\mathrm{~m}$ & 4528 & Z3.7 \\
\hline HL1273 & $22-25$ & $f$ & 4528 & Z3.6 \\
\hline HL1292 & $30-40$ & $\mathrm{~m}$ & 4528 & pp re \\
\hline HL1331 & $30-40$ & $f$ & 4528 & metat \\
\hline HL1341 & $25-34$ & $f$ & 4528 & Z4.8 \\
\hline HL1343 & $20-25$ & $\mathrm{~m}$ & 4528 & Z4.4 \\
\hline HL1355 & $23-25$ & $f$ & 4528 & $\mathrm{Z} 1.7$ \\
\hline HL1357 & $22-26$ & $f$ & 4528 & Z1.8, pp li \\
\hline HL1359 & $31-40$ & $\mathrm{~m}$ & 4528 & Z4.8 \\
\hline HL1361 & $20-25$ & $f$ & 4528 & pp li \\
\hline HL1383 & $23-28$ & $f$ & 4528 & Z3.8 \\
\hline HL1396 & $23-26$ & $f$ & 4529 & pp li \\
\hline HL1415 & $23-40$ & $\mathrm{~m}$ & 4528 & Z3.5 \\
\hline HL1422 & $20-26$ & $\mathrm{~m}$ & 4529 & pp re \\
\hline HL1443 & $29-34$ & $f$ & 4528 & Z3.8 \\
\hline HL1449 & $24-30$ & $\mathrm{~m}$ & 4528 & Z2.4 \\
\hline HL1462 & $26-32$ & $f$ & 4529 & Z4.7 \\
\hline HL1463 & $30-36$ & $\mathrm{~m}$ & 4529 & Z2.6 \\
\hline HL1464 & $30-36$ & $\mathrm{~m}$ & 4529 & pp re \\
\hline HL1486 & 23-28 & $\mathrm{m}$ & 4529 & Z3.8 \\
\hline HL1487 & $34-40$ & $f$ & 4528 & Z3.5 \\
\hline HL1489 & 23-26 & $\mathrm{m}$ & 4528 & Z1.8 \\
\hline HL1495 & $20-26$ & $f$ & 4528 & Z1.4 \\
\hline HL1497 & $31-37$ & $f$ & 4528 & Z4.6 \\
\hline HL1505 & $20-26$ & $f$ & 4528 & pp re \\
\hline HL1532 & 34-39 & $\mathrm{m}$ & 4529 & pp re \\
\hline HL1536 & $20-25$ & $\mathrm{~m}$ & 4529 & Z1.5 \\
\hline
\end{tabular}


Tab. 15: Fortgesetzt: Untersuchte Individuen des Pestmassengrabes.

\begin{tabular}{|c|c|c|c|c|}
\hline FNR & Alter & Geschlecht & Befund & Skelettelement \\
\hline HL1545 & $20-26$ & $\mathrm{~m}$ & 4529 & Z4.6 \\
\hline HL1546 & $20-26$ & $f$ & 4529 & Z4.7 \\
\hline HL1547 & $32-37$ & $f$ & 4529 & Z2.6 \\
\hline HL1553 & $20-26$ & $f$ & 4528 & Z3.4 \\
\hline HL1561 & $31-35$ & $f$ & 4528 & Z3.8 \\
\hline HL1571 & $20-26$ & $\mathrm{~m}$ & 4529 & Z2.7 \\
\hline HL1589 & $33-38$ & $f$ & 4529 & $\mathrm{Z} 3.7$ \\
\hline HL1593 & $25-30$ & $\mathrm{~m}$ & 4529 & metat \\
\hline HL1612 & $20-26$ & $\mathrm{~m}$ & 4529 & Z4.5 \\
\hline HL1683 & $34-40$ & $f$ & 4528 & Z3.6 \\
\hline HL1688 & $25-34$ & $f$ & 4528 & Z4.7 \\
\hline HL1697 & $34-40$ & $f$ & 4528 & pp re \\
\hline HL1701 & $20-26$ & $f$ & 4528 & $\mathrm{Z} 3.7$ \\
\hline HL1702 & $20-23$ & $\mathrm{~m}$ & 4528 & Z4.5 \\
\hline HL1717 & $34-40$ & $\mathrm{~m}$ & 4528 & Z2.6 \\
\hline HL1720 & $20-26$ & $f$ & 4528 & Z2.6 \\
\hline HL1730 & $29-35$ & $\mathrm{~m}$ & 4529 & Z2.8 \\
\hline HL1741 & $25-30$ & $f$ & 4528 & $\mathrm{pp}$ \\
\hline HL1749 & $31-36$ & $f$ & 4528 & Z4.5 \\
\hline HL1751 & $36-40$ & $\mathrm{~m}$ & 4528 & Z2.5 \\
\hline HL1753 & $34-40$ & $f$ & 4528 & Z3.8 \\
\hline HL1758 & $21-25$ & $f$ & 4528 & Z3.5 \\
\hline HL1759 & $30-39$ & $f$ & 4528 & Z3.6 \\
\hline HL1776 & $21-24$ & $\mathrm{~m}$ & 4528 & $\mathrm{Z} 2.7$ \\
\hline HL1780 & $24-29$ & $\mathrm{~m}$ & 4529 & Z2.5 \\
\hline HL1800 & $20-30$ & $f$ & 4528 & Z3.5 \\
\hline
\end{tabular}




\subsubsection{Stichprobe Lübeck "Hungersnot", älterer Bestattungshorizont}

Der geringere Umfang dieser Skelettserie mit 158 Skeletten bedingte eine eingeschränkte Auswahl, sodaß trotz weniger strikter Anwendung der Altersgrenze eine Stichprobengröße von 44 Individuen resultiert. Das jüngste Individuum wurde auf 16 - 20 Jahre bestimmt, die ältesten auf 38 - 44, beziehungsweise 32 - 50 Jahre. Bei Skeletten weiterer Individuen der Adultas fehlten die bevorzugten Skelettelemente, so daß zugunsten der Probenqualität auf weitere Proben verzichtet wurde. Die ausgewählten 44 Individuen teilen sich auf in 25 männliche und 19 weibliche Individuen. Damit liegt ein Männerüberschuß vor. Tabelle 16 gibt eine Übersicht über die Stichprobe.

Tab. 16: Untersuchte Individuen des Pestmassengrabes. Alters- und Geschlechtsangaben nach dem Fundkatalog, die Daten wurden von Herrn Tank (Archäologie, Stadt Lübeck) zur Verfügung gestellt. HL: Lübeck; m/w: männlich/weiblich; Z: Zahn, pp: pars petrosa, metat: metatarsale; re/li: rechts/links;

\begin{tabular}{lcccc}
\hline FNR & Alter & Geschlecht & Befund & Skelettelement \\
\hline HL1002 & $23-40$ & $\mathrm{~m}$ & 4557 & metat \\
HL1003 & $39-45$ & $\mathrm{~m}$ & 4557 & $\mathrm{pp}$ \\
HL1104 & $18-21$ & $\mathrm{~m}$ & 4557 & Z4.7 \\
HL1105 & $21-24$ & $\mathrm{~m}$ & 4557 & metat \\
HL1206 & $18-21$ & $\mathrm{~m}$ & 4557 & $\mathrm{pp}$ \\
HL1222 & $27-32$ & $\mathrm{f}$ & 4557 & $\mathrm{pp}$ \\
HL1224 & $23-40$ & $\mathrm{f}$ & 4557 & $\mathrm{pp}$ \\
HL1381 & $18-23$ & $\mathrm{f}$ & 4557 & Z3.7 \\
HL1766 & $25-50$ & $\mathrm{~m}$ & 4610 & $\mathrm{pp}$ \\
HL1817 & $20-25$ & $\mathrm{f}$ & 4616 & metat \\
HL1824 & $20-26$ & $\mathrm{~m}$ & 4619 & Z4.8 \\
HL1825 & $20-24$ & $\mathrm{~m}$ & 4619 & $\mathrm{pp}$ \\
HL1827 & $30-45$ & $\mathrm{f}$ & 4619 & Z1.8 \\
HL1828 & $19-25$ & $\mathrm{~m}$ & 4619 & Z2.7 \\
HL1838 & $31-37$ & $\mathrm{f}$ & 4617 & metat \\
HL1843 & $29-35$ & $\mathrm{~m}$ & 4617 & Z2.6 \\
HL1871 & $34-42$ & $\mathrm{~m}$ & 4608 & metat \\
HL1883 & $32-50$ & $\mathrm{f}$ & 4622 & Z2.5 \\
HL1884 & $25-40$ & $\mathrm{f}$ & 4622 & Z4.6 \\
HL1887 & $35-40$ & $\mathrm{f}$ & 4622 & Z4.8 \\
HL1896 & $18-23$ & $\mathrm{f}$ & 4534 & Z2.6 \\
HL1899 & $23-35$ & $\mathrm{f}$ & 4534 & pp \\
HL1902 & $38-44$ & $\mathrm{~m}$ & 4534 & $\mathrm{pp} \mathrm{li}$ \\
HL1909 & $30-38$ & $\mathrm{f}$ & 4534 & Z1.7 \\
\hline
\end{tabular}


Tab. 16: Fortgesetzt: Untersuchte Individuen des Pestmassengrabes.

\begin{tabular}{lcccc}
\hline FNR & Alter & Geschlecht & Befund & Skelettelement \\
\hline HL1920 & $19-25$ & $\mathrm{f}$ & 4629 & metat \\
HL1922 & $20-26$ & $\mathrm{f}$ & 4629 & Z4.7 \\
HL1938 & $32-37$ & $\mathrm{~m}$ & 4623 & Z3.7 \\
HL1973 & $21-24$ & $\mathrm{~m}$ & 4569 & Z3.7 \\
HL1974 & $35-41$ & $\mathrm{~m}$ & 4569 & Z4.8 \\
HL1976 & $16-20$ & $\mathrm{f}$ & 4569 & Z3.7 \\
HL1978 & $20-24$ & $\mathrm{~m}$ & 4569 & metat \\
HL1982 & $20-26$ & $\mathrm{~m}$ & 4642 & Z1.6 \\
HL1983 & $23-40$ & $\mathrm{f}$ & 4642 & Z1.8 \\
HL1989 & $33-38$ & $\mathrm{f}$ & 4640 & Z3.8 \\
HL1991 & $37-42$ & $\mathrm{f}$ & 4617 & metat \\
HL1996 & $35-41$ & $\mathrm{~m}$ & 4610 & Z4.6 \\
HL1999/1 & $23-40$ & $\mathrm{~m}$ & 4646 & Z1.6 \\
HL1999/2 & $20-30$ & $\mathrm{~m}$ & 4646 & Z3.6; Z3.7 \\
HL1999/3 & $23-40$ & $\mathrm{~m}$ & 4646 & Z2.7 \\
HL2001 & $27-32$ & $\mathrm{~m}$ & 4610 & Z2.6 \\
HL2045 & $21-24$ & $\mathrm{f}$ & 4639 & metat \\
HL2057 & $17-20$ & $\mathrm{~m}$ & 4639 & Z1.5 \\
HL2058 & $24-32$ & $\mathrm{~m}$ & 4639 & Z1.7 \\
\hline
\end{tabular}




\subsection{Skelettserie Dorste}

Das Skelettkollektiv der Lichtensteinhöhle bei Dorste ist die bronzezeitliche Kontrolle einer Bevölkerung geringer Pathogenexposition. Die Fundserie umfaßt mindestens 40 Individuen, die sich in eine Großfamilie einordnen lassen (Schilz, 2006; Schultes, 2000). Drei Familienlinien wurden identifiziert, die sich jeweils über drei Generationen erstrecken. Weitere Verbindungen bestehen auch zwischen diesen drei Familienlinien. Insgesamt konnten 28 Individuen in verwandtschaftliche Beziehung gesetzt werden. Die Genealogie der Fundserie (Abb. 6) ist bisher einzigartig und gleichzeitig ein Vor- und Nachteil für genetische Studien. Dank der Beziehungen zwischen den Familienmitgliedern können genetische Eigenschaften entlang der Vererbungswege rekonstruiert werden, wie es in der Arbeit von Suray (2007) für Haplotypen des IL10-Promotors geschah. Die Genotypen einzelner Individuen können mit Hilfe der Genotypen ihrer nächsten Verwandten rekonstruiert werden, selbst wenn ein direkter Nachweis aufgrund starker DNADegradierung nicht möglich ist.

Nur für neun der 40 Individuen besteht nachweislich keine biologische verwandtschaftliche Beziehung innerhalb des Kollektives (blauer Kasten). Diese können daher als Individuen mit unabhängigen Genotypen gelten, während alle anderen Individuen sich in ihren Genotypen bedingen. In jeder Familie ist nur die jeweils höchste Ebene in der Verwandtschaftslinie sowie eingeheiratete Individuen unabhängig und kann daher in statistische Berechnungen einbezogen werden. Dies gilt für weitere neun Individuen: F4, F5, M3, F1, M1, F2, F10, M10 und M19. Darüber hinaus kann jeweils ein Individuum aus den Geschwisterpaaren F12/ F13 und M11/ F9 berücksichtigt werden. Die mögliche statistische Stichprobe setzt sich damit aus nur 23 der 40 Individuen, also etwa der Hälfte der eh schon zahlenmäßig kleinen Gruppe zusammen. 


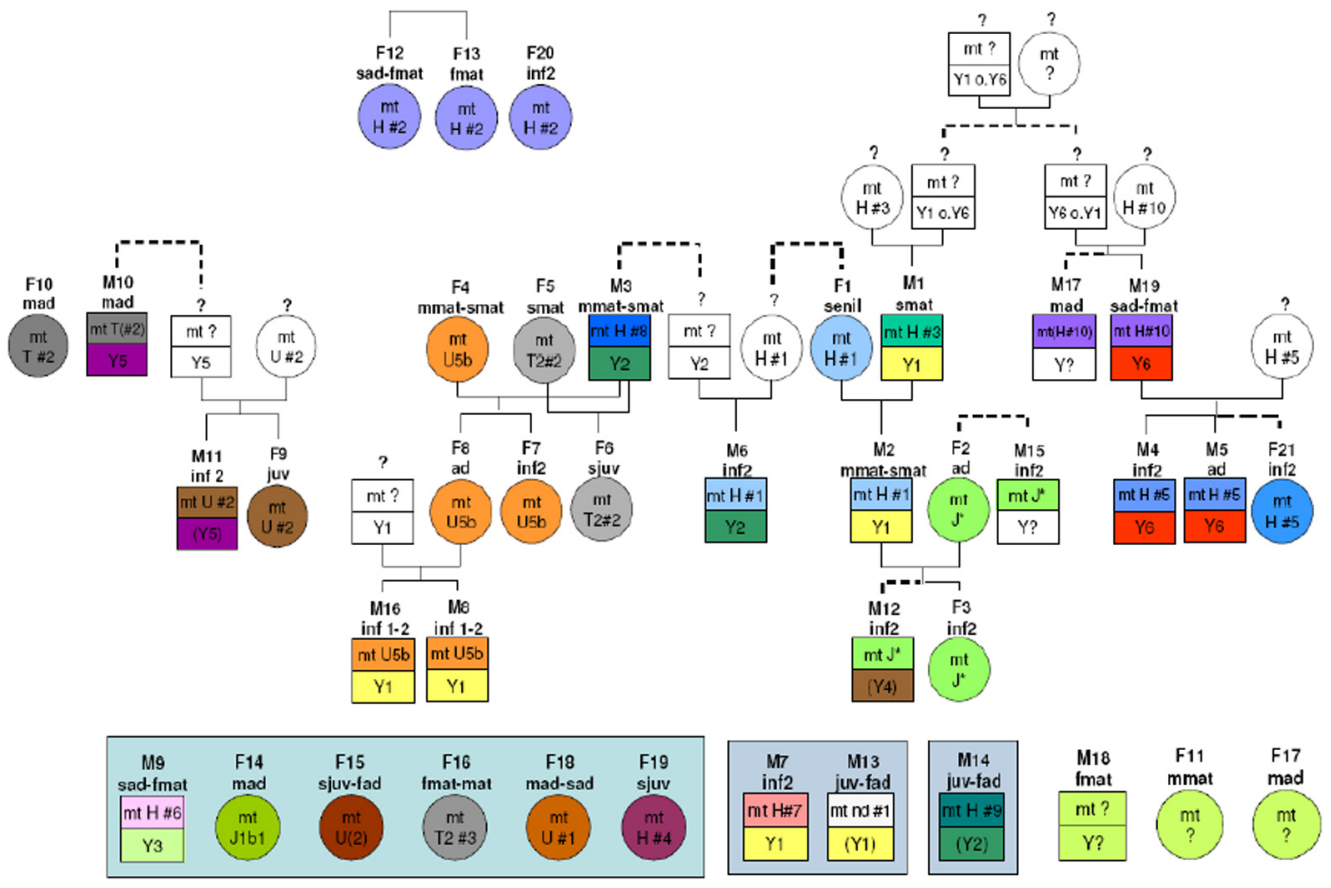

Abb. 6: Skelettserie Dorste, Lichtensteinhöhle: Rekonstruierter Stammbaum. Quelle Suray (2007) 
Tab. 17: Individuen der Skelettserie Lichtensteinhöhle (Do). Angegeben sind nur die Individuen und Fundnummern, die in dieser Arbeit untersucht wurden. Eine vollständige Liste ist in Schilz (2006) zu finden. Die Spalte „Statistik“ zeigt mit 's' die Individuen an, die in der statistischen Auswertung berücksichtigt werden. Altersangaben nach Schilz (2006). FNR: Fundnummer; sen: senil, mat: matur, ad: adult, juv: juvenil, inf1/2: infans 1/2; Ergänzung durch f/m/s: früh-/mittel-/spät-. Zur Definition der Altersklassen vgl. Herrmann et al. (1990)

\begin{tabular}{|c|c|c|c|}
\hline Ind & Alter & FNR \& Extrakt & Statistik \\
\hline $\mathrm{F} 1$ & sen & Do26 DOS Ex3, Do26 TC, Do38 DOS, Do38 DOS Ex4 & s \\
\hline F 2 & ad & Do1500 DOS Ex3, Do1500 B UB, Do1500 b SKR & s \\
\hline F 3 & inf2 & Do1746 II DOS Ex4, Do1746 I ExIF, Do1746 b SKR & \\
\hline F 4 & mmat-smat & $\begin{array}{l}\text { Do4078 DOS Ex3, Do4078 DOS Ex4, Do5516 Exl, Do5516 } \\
\text { NEU, Do } 5516 \text { II }\end{array}$ & s \\
\hline F 5 & smat & Do3706 ExIV, Do3706 ExV, Do3756 DOS Ex3, Do3756 B UB & s \\
\hline F 6 & sjuv & Do5517 Exllla, Do3709 ExIII & \\
\hline F 7 & inf2 & Do1247 DOS Ex4, Do1206 Trace Phenol & \\
\hline F 8 & ad & Do3631 DOS Ex3, Do3631 2.7 Exl, Do3631 a SKR & \\
\hline F 9 & juv & Do3705 Ex2, DO3746 a SKR, Do3746 Exll & $\mathrm{s}$ \\
\hline F10 & $\operatorname{mad}$ & Do302 Exllb, Do302 4.6 ExI, Do1046 a \& b SKR & s \\
\hline F11 & mmat & Do3713 a SKR, Do3713 b SKR & s \\
\hline F12 & sad-fmat & DoR1 Exl, DoR1 DOS Ex1 \& Ex2 & s \\
\hline F13 & fmat & Do1044 Ez16, Do1044 b Ez1, Do1078 Exll & \\
\hline F14 & mad & Do4309 Ex1, Do1103 B UB & s \\
\hline F15 & sjuv-fad & Do2589 b SKR, Do2589 Ez1.8, Do2589 1.8 & s \\
\hline F16 & fmat-mmat & DoR2 1.6b SKR, DoR2 Ex2, DoR2 ExIV & s \\
\hline F17 & $\operatorname{mad}$ & Do300 B UB & s \\
\hline F19 & sjuv & Do1176 Exl 1.6, Do1585 neu, Do1585 Ex2, Do1585 Ex4 & s \\
\hline F20 & inf2 & Do3190 neu & s \\
\hline F21 & inf2 & DoE37 Ex2 & \\
\hline M 1 & smat & Do1076 DOS Ex3, Do1076 a \& b SKR, Do1172 B UB & s \\
\hline M 2 & mmat-smat & Do1102 B UB, Do1102 DOS Ex3 & \\
\hline M 3 & mmat-smat & Do1911 a SKR, Do1911 b, Do6525 Ilb & s \\
\hline M 4 & inf2 & Do900 DOS Ex4, Do900 IIlb, Do35 Exl & \\
\hline M 5 & ad & Do3380 & \\
\hline M 6 & inf2 & Do2030 A \& B UB & s \\
\hline M 7 & inf2 & Do3 Ex1, Do3 ExIF, Do910 IIla, Do910 III FS & s \\
\hline M 8 & sinf1-finf2 & Do3757 DOS Ex1, Do3757 DOS Ex3, DOS3757 Ex4c JUST & \\
\hline M 9 & sad-fmat & Do1916 A \& B UB, Do2749 II & s \\
\hline M10 & mad & Do902 A \& B UB, Do480 Exll & $\mathrm{s}$ \\
\hline M11 & inf2 & Do183II Ez13, Do183II Ez1.12 & \\
\hline M12 & inf2 & DoE33 DOS Ex4 & \\
\hline M13 & juv-fad & Do58.3 TracePhenol, Do58.3 b SKR, Do58.3 A UB & s \\
\hline M14 & fad-mad & Do905 a, Do905 b, Do905 b SKR & s \\
\hline M16 & inf1-inf2 & Do3886 DOS Ex2, Ex3 und Ex4, Do3886 ExII, Do3886 Ex1F & \\
\hline M17 & $\operatorname{mad}$ & Do57.2 DOS Ex1, Do57.2 b SKR & \\
\hline M19 & sad-fmat & Do153 Ex2, Do153 DOS Ex2 \& Ex4, Do153 Exll & $\mathrm{s}$ \\
\hline
\end{tabular}




\section{Methoden}

\subsection{Allgemeine Aspekte der Kontaminationsvermeidung und Authentifizierung der Ergebnisse}

Die Analyse von aDNA ist aufgrund ihrer geringen target-Zahlen ganz besonders empfänglich für den Eintrag von Fremd-DNA. Eine Kontaminierung ist zu verschiedenen Zeitpunkten der Lagerung und Bearbeitung möglich. Unterschiedliche Ursachen für die Kontaminierung sind möglich:

- Kreuzkontaminationen zwischen verschiedenen Proben (Kitchin et al., 1990)

- Kontaminationen durch Bearbeiter bei der Handhabung der Proben (Kitchin et al., 1990)

- Kontaminationen aus Einwegmaterialien wie Reaktionsgefäßen und Pipettenspitzen (Schmidt et al., 1995)

- Eintrag von bereits amplifizierten Sequenzen aus vorangegangenen Reaktionen (Kwok, 1990)

Grundsätzlich gilt die räumliche und zeitliche Trennung des präPCR- und postPCR-Bereichs. Die Arbeitsbereiche dürfen von Personen und Materialien nur in Richtung präPCR zu postPCR durchlaufen werden (sog. Einbahnstraßenregel (Hummel, 2003)). Laborutensilien, Materialien und Proben aus dem postPCRBereich werden nicht in den präPCR-Bereich zurückgeführt. Plastik-Einwegmaterialien werden zur Beseitigung von möglichen Kontaminationen für 15 min mit kurzwelligem UV-Licht (254 nm) bestrahlt. Glaswaren und Kunststoff-Mehrwegmaterialien werden vor und zwischen den Verwendungen in einem Lauge- (Extran) und Säurebad $(\mathrm{HCl})$ dekontaminiert. Sämtliche Laborgeräte und Arbeitsflächen werden vor und nach der Bearbeitung mit Lauge (Alconox, Aldrich), Aqua bidest. und 70\%igem Ethanol gereinigt.

Bei der Bearbeitung des Probenmaterials von der Probennahme bis hin zur PCR (präPCR-Bereich) ist das Tragen von Schutzkleidung bestehend aus Kittel, Mundschutz, Haarhaube und Handschuhen sowie in besonderen Fällen Schutzbrillen vorgeschrieben. Um Kreuzkontaminationen und Kontaminationen durch Bearbeiter während der Bergung und Lagerung von Skeletten zu vermeiden, wer- 
den die exponierten Oberflächen von Probenstücken großzügig abgetragen. Die Extrakte werden außerdem mit Hilfe des genetischen Fingerabdrucks auf die Anwesenheit von Fremd-DNA überprüft. Für den Abgleich können die genetischen Daten der Bearbeiter herangezogen werden. Aufschluß über Kreuzkontaminationen gibt der Vergleich der individuellen Fingerabdrücke. Die genetischen Fingerabdrücke der historischen Individuen werden mit der in Kapitel 8.3.1 vorgestellten STR-Multiplex-PCR erstellt.

\subsection{Extraktion von DNA aus Probenmaterial}

Bei der Arbeit mit alter DNA kommt der Extraktionsmethode ein zentraler Stellenwert zu, mit Hilfe derer die DNA des Probenmaterials isoliert wird. Experimente wie z. B. Hummel (2003, S.58ff) und Anslinger et al. (2005) zeigen die Abhängigkeit des Analyseerfolges von der Extraktionsmethode bzw. den Extraktionskomponenten. Während dies zum einen auf den Erfolg der Isolierung der DNA selber zurückzuführen ist, sollte auch die Entfernung von Bestandteilen, die spätere Analysen stören, nicht vergessen werden. Zu nennen sind insbesondere Inhibitoren enzymatischer Reaktionen, wie zum Beispiel Huminsäuren und zweiwertige Kationen, besonders Kupfer. Über rein chemische Vorgänge sind diese nur unzureichend von der DNA zu trennen, gerade wasserlösliche Huminsäuren und Kupfer werden zusammen mit der wasserlöslichen DNA am Ende der Extraktion ausgefällt. Dadurch erweisen sich Extraktionsprotokolle von Vorteil, bei denen die DNA selber z. B. über Bindung an Glasperlen mit magnetischem Kern aus der Lösung herausgezogen wird. Ein solches Protokoll auf der Grundlage einer Guanidiniumthiocyanat/Guanidiniumhydrochlorat-Extraktion in Verbindung mit einem Extraktionsroboter (EZ1-Biorobot, Qiagen) fand für die in dieser Arbeit hergestellten Extrakte Verwendung. Diese Extrakte zeichnen sich grundsätzlich durch ihre hohe Klarheit und Farblosigkeit aus, Hinweis auf die gründliche Beseitigung von Beimengungen. Ältere Extrakte der Lübecker Kollektive, die bis 2003 bearbeitet wurden (Kremeyer et al., 2005), wurden nach einem automatisierten Phenol-Chloroform-Silikat-Protokoll erstellt. Obwohl dieses Protokoll eine höhere Ausbeute erzielen mag, zeigen die Extrakte häufig bräunlich-rote oder grünliche Verfärbungen, die auf coextrahierte PCR-Inhibitoren zurückzuführen sind. 
Neben der DNA-Ausbeute ist ein weiterer essentieller Punkt der Extraktion das kontaminationsfreie Arbeiten. Besondere Bedeutung kommt dabei der Vermeidung von Einbringung exogener DNA während der Bearbeitung zu. Die automatisierte, maschinelle Extraktion trägt dem Rechnung, da sie die nötigen Manipulationsschritte während der Bearbeitung minimiert.

\subsubsection{Probenvorbereitung}

Für die DNA-Extraktion wurde Probenmaterial aus Hartgeweben verwendet, hierbei wurden Zähne soweit vorhanden als Material bevorzugt. Die Zähne wurden vorsichtig aus dem Kiefer gelöst und ihre Wurzel mit einer Dentalbohrmaschine (Typ K10, KaVo) von der Zahnkrone abgetrennt. Die Zahnkrone kann später wieder in der Alveole plaziert werden, so daß die Beschädigung des Fundstückes nicht sichtbar ist. Bei der Probennahme aus Knochen wurden ca. $1 \mathrm{~cm}^{2}$ große Blöcke ausgesägt. Dabei wurde beachtet, daß Meßstrecken für morphometrische Untersuchungen nicht beeinträchtigt wurden. Von allen Probenstücken wurden die exponierten Oberflächen abgetragen. Anschließend wurde das Probenmaterial in einem Stahlmörser zerkleinert und in einer Kugelschwingmühle (Retsch) homogenisiert.

\subsubsection{DNA-Extraktion}

Die Extraktion wurde mit standardisierten Parametern durchgeführt, die von Wenzel (2006) empfohlen werden. 0,1 g des gewonnenen Zahn- oder Knochenpulvers wurde in einer Inkubation mit $500 \mu \mathrm{l}$ EDTA (0,5 M; pH 8) für $18 \mathrm{~h}$ in einem Über-Kopf-Rotator bei $37^{\circ} \mathrm{C}$ dekalcifiziert. Für die anschließende Zelllyse wurden $10 \mu \mathrm{l}$ ProteinaseK (20 mg/ml, Qiagen) zugesetzt und für weitere $60 \mathrm{~min}$ im Thermorüttler $\left(56^{\circ} \mathrm{C} ; 300 \mathrm{rpm}\right)$ inkubiert. Nach einer Zentrifugation von $6000 \mathrm{rpm}$ für 3 min wurden $200 \mu \mathrm{l}$ des Überstands in den EZ1-Extraktor eingesetzt. Die DNAExtraktion erfolgte mit dem Programm trace-protocol der Forensic Card, das Elutionsvolumen betrug $100 \mu \mathrm{l}$. 


\subsection{Amplifikation zur Bestimmung des Genetischen Fingerabdrucks}

Die Bestimmung des genetischen Fingerabdrucks aus Probenmaterial hat ihre Bedeutung im Nachweis von authentischer DNA, dem Ausschluß von Kontaminationen durch Bearbeiter sowie der Kreuzkontamination durch andere Proben. Sie dient darauf aufbauend der Authentifizierung aller weiteren Daten. Die Individuen der beiden zentralen Skelettserien wurden in Massengräbern mit bis zu 360 anderen Leichnamen bestattet. Eine räumliche und zeitliche Trennung der Einzelbestattungen, wie es bei Regelbestattungen der Fall ist, ist nicht gegeben. Daher ist eine Kreuzkontamination des Probenmaterials bereits während der Bodenlagerung möglich. In diesem Kontext erlangt die Absicherung der Ergebnisse über den genetischen Fingerabdruck besondere Bedeutung. Mischspuren, wie sie für Kreuzkontaminationen charakteristisch sind, werden nachgewiesen und aus der Analyse ausgeschlossen. Besondere Bedeutung kommt dem genetischen Fingerabdruck aber auch für den Ausschluß rezenten DNA-Eintrags zu. Extrakte, deren Ergebnisse Übereinstimmungen zu den genetischen Profilen von Mitarbeitern zeigen, können ebenfalls aus der Analyse ausgeschlossen werden. Die Integration der STR-Typisierung ist weiterhin unerläßlich für die Aufdeckung von Ort und Zeitpunkt einer Kontamination, so daß zwischen verunreinigten Einzelamplifikaten, Extrakten und dem Probenmaterial per se unterschieden und die Kontaminationsquelle in vielen Fällen bei der weiteren Bearbeitung ausgeschlossen werden kann. Für die Generierung von STR-Allelprofilen, des „genetischen Fingerabdrucks“, stand ein Multiplex-System zur Verfügung, das verschiedene STR-Systeme mit hoher Variabilität in einem Reaktionsansatz zur gleichzeitigen Amplifikation vereint.

\subsubsection{Oktaplex-PCR}

Die verwendete Multiplex stellt einen verkleinerten Ansatz der für aDNA optimierten 17plex (Schilz et al., 2004) dar, zusätzlich wurde der STR-Marker VWA eingefügt. Die resultierende Oktaplex enthält die in Tabelle 18 vorgestellten STRSysteme. Sieben der acht Systeme sind auch in kommerziellen STR-Kits enthalten (z. B. AmpFlSTR ProfilerPlus), die innerhalb früherer Projekte zur Anwendung 
Tab. 18: Primersequenzen der Oktaplex-PCR

\begin{tabular}{llll}
\hline STR & Primer & Markierung & Primersequenz $\left(5^{\prime} \rightarrow 3^{\prime}\right)$ \\
\hline D3S1358 & upper & NED & AGG AGT TTG AGG CTG TAG TGA G \\
& lower & & CAT CTC TTA TAC TCA TGA AAT CAA CA \\
FGA & upper & 6-FAM & CAT AGG TTT TGA ACT CAC AGA TTA A \\
& lower & & CTG AAA TCG AAA ATA TGG TTA TTG \\
D5S818 & upper & NED & GGT ATC CTT ATG TAA TAT TTT GAA GAT \\
& lower & & ATC ATA GCC ACA GTT TAC AAC ATT \\
CSF1PO & upper & 6-FAM & TAA CCA CCC TGT GTC TCA GTT \\
& lower & & ACA GCA TTT CCT GTG TCA GAC \\
VWA & upper & & CTT CCA GAA GAA GAA ACA GGT C \\
& lower & HEX & GAC AGA TGA TAA ATA CAT AGG ATG G \\
D13S317 & upper & 6-FAM & CTA ACG CCT ATC TGT ATT TAC AAA TA \\
& lower & & AGC CCA AAA AGA CAG ACA GA \\
D21S11 & upper & NED & ACT TTT CTC AGT CTC CAT AAA TAT GT \\
& lower & & GGA GGT AGA TAG ACT GGA TAG ATA GAC \\
Amelo & upper & HEX & CCC TGG GCT CTG TAA AGA ATA GTG \\
& lower & & ATC AGA GCT TAC ACT GGG AAG CTG \\
\hline
\end{tabular}

Amelo: Amelogenin, Geschlechtsmarker; 6-FAM, Ned, HEX: Fluoreszenz-Farbstoffe, Primersequenzen nach Schilz et al. (2004)

kamen. Deren Daten können somit als Referenzen herangezogen werden (Schilz, 2006).

$25 \mu$ l Reaktionsansatz: 2,5 $\mu \mathrm{l} 10 \times \mathrm{PCR}$ Buffer, $2 \mu \mathrm{l} \mathrm{MgCl}_{2}(2,5 \mathrm{mM}), 4 \mu \mathrm{l} \mathrm{dNT}$ Ps (je $200 \mu \mathrm{M}), 0,3 \mu \mathrm{l}$ AmpliTaq Gold (1,5 U), 0,2 $\mu \mathrm{M}$ je Primer D13S317 upper und lower, 0,2 $\mu \mathrm{M}$ je Primer VWA upper und lower, $0,15 \mu \mathrm{M}$ je Primer CSF1PO upper und lower, $0,15 \mu \mathrm{M}$ je Primer D5S818 upper und lower, 0,2 $\mu \mathrm{M}$ je Primer Amelogenin upper und lower, $0,25 \mu \mathrm{M}$ je Primer D21S11 upper und lower, $0,25 \mu \mathrm{M}$ je Primer FGA upper und lower, $0,3 \mu \mathrm{M}$ je Primer D3S1358 upper und lower, max. $9 \mu$ l DNA-Extrakt

Cycling Parameter: Initialisierung $94^{\circ} \mathrm{C} 11 \mathrm{~min} ; 48$ Zyklen mit $94^{\circ} \mathrm{C} 30 \mathrm{sec}$, $58^{\circ} \mathrm{C} 1 \mathrm{~min} 30 \mathrm{sec}, 72^{\circ} \mathrm{C} 1 \mathrm{~min}$; Delay $60^{\circ} \mathrm{C} 30 \mathrm{~min}$; Temperaturänderung $\mathrm{r}=1 \mathrm{~K} / \mathrm{s}$.

Die Produkte wurden zur Kontrolle des Amplifikationserfolges auf einem 2,5\%igen Agarosegel mit Ethidiumbromidfärbung aufgetrennt und photographisch dokumentiert (Hummel, 2003, S.205f). Dazu wurde neben einer Polaroid ${ }^{\mathrm{TM}}$-Kamera ein digitales Geldokumentationssystem (INTAS) eingesetzt. 


\subsubsection{Fragmentlängen-Analyse (FLA)}

Für die Fragmentlängen-Analyse wurden die Produkte über eine denaturierende hochaufösende Elektrophorese aufgetrennt. Dazu kamen zwei Verfahren zum Einsatz, die im folgenden beschrieben werden.

Vertikale Platten-Elektrophorese: Je nach Stärke des Produktes auf dem Agarosegel wurden 0,1 bis $2,5 \mu \mathrm{l}$ mit $2 \mu \mathrm{l}$ Formamid und $0,25 \mu$ GeneScan $^{T M} 500$ ROX Standard (Applied Biosystems) vermischt und bei $94^{\circ} \mathrm{C}$ über 2 min denaturiert. Anschließend wurden die Proben auf Eis abgekühlt. Die Auftrennung wurde auf einem ABI DNA Sequencer 373 Stretch mit 6\%igen Polyacrylamid-Gelen $(0,4 \mathrm{~mm}$ Stärke und $12 \mathrm{~cm}$ well-to-read lenght) durchgeführt. Die Datenaufnahme erfolgte mit der AbiPrism ${ }^{\top M} 672$ Collection Software (Applied Biosystems). Die Auswertung der Daten wurde mit der AbiPrism ${ }^{\text {TM }}$ GeneScan Software 2.1 vorgenommen.

Kapillarelektrophorese: Je nach Produktstärke auf dem Agarosegel wurden 0,5 oder $1 \mu \mathrm{l}$ des PCR-Produktes mit $12 \mu \mathrm{l}$ HiDiFormamid und 0,25 $\mu \mathrm{l}$ GeneScan $^{T M} 500$ ROX Standard (Applied Biosystems) angesetzt. Zur Denaturierung wurden die Proben 5 min bei $95^{\circ} \mathrm{C}$ erhitzt und anschließend auf Eis gekühlt. Die Auftrennung erfolgte auf einem ABI 310 Genetic Analyzer (Applied Biosystems) mit POP4 bei einer Kapillarlänge von $45 \mathrm{~cm}$. Die Datenerfassung erfolgte mit AbiPrism $^{\text {TM }} 310$ Collection Software (Applied Biosystems). Für die Datenanalyse wurde die Software AbiPrism ${ }^{T M}$ GeneScan 2.1 verwendet. Die Auswertung wurde nach dem Kriterienkatalog durchgeführt, der in Schilz (2006) vorgestellt wurde.

\subsection{Kombinierte Genotypisierung von STR und SNP}

SNP weisen nur eine geringe Variabilität auf, die Mehrzahl findet sich in biallelischer Ausprägung. Bei einigen der untersuchten SNP ist zudem jeweils ein Allel, das sogenannte minor allele, mit einer Frequenz von weniger als $10 \%$ in der rezenten Bevölkerung vertreten (z. B. TLR2 Arg753Gln). Identische Ergebnisse selbst bei simultaner Analyse mehrere SNPs sind zu erwarten. Diese geringe Variabilität erlaubt keine individuelle Abgrenzung von Genotypisierungsergebnissen. Gerade im Zusammenhang mit aDNA-Analysen ist dies problematisch, die 


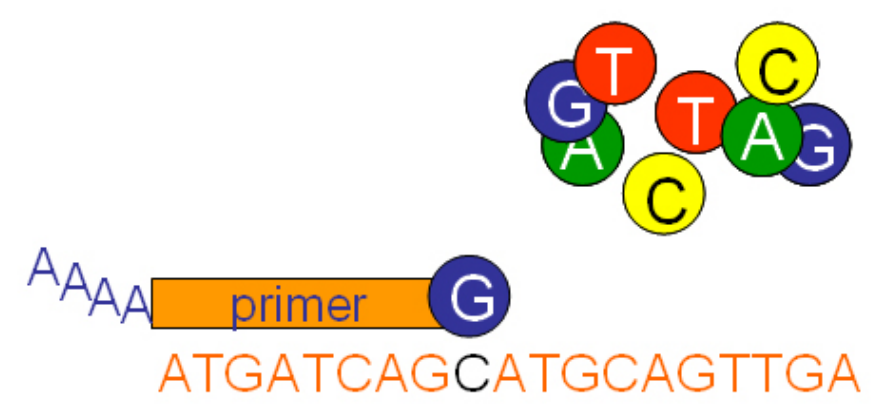

Abb. 7: Prinzip der SBE-Reaktion. Ein kurzer Primer mit nicht-hybridisierendem Schwanz, dem sogenannten tail bindet an die Zielsequenz. Aus einem Gemisch der verschiedenen farbmarkierten ddNTP wird das entsprechende Nukleotid an den Primer angehängt. Eine weitere Elongation des Produktes bleibt aus.

besonders anfällig für Kontaminationen sind. Über die Kombination der SNPAnalyse mit einer PCR zur Generierung des genetischen Fingerabdrucks wird die simultane Abgrenzung bis hin zur Individualisierung möglich. Dies bedeutet die Absicherung der Ergebnisse gegen Kontaminationen (Kap. 8.3). Die Amplifikation der SNP-Loci wird daher mit STR kombiniert, die in der Multiplex zur Bestimmung des genetischen Fingerabdrucks (Kap. 8.3.1) verwendet werden (Pepperl et al., in prep). Sequenzierungen einzelner Positivkontrollen zur Überprüfung der Typisierungsergebnisse ermöglichen es leicht, diese Fehlerquelle auszuschließen.

Verschiedene Arbeiten haben die Eignung der SBE-Reaktion in der Analyse von degradierter DNA sowohl aus aDNA (Larcombe et al., 2005; Liebert, 2007) als auch forensischen Ansätzen gezeigt (Quintans et al., 2004). Gerade die geringen Fragmentlängen, die für die primäre PCR benötigt werden, sind im Zusammenhang mit degradierter DNA von großem Vorteil. Nach der primären PCR werden mit neuen Primern die Fragmente in einer linearen Amplifikation sequenziert. Das Sequenzierprodukt besteht im Gegensatz zum Taq-Cycle-Sequencing allerdings nur aus einem Primer, an den ein ddNTP angehängt wird (Abb.7). Da ausschließlich ddNTP im Reaktionsmix enthalten sind, kommt es zu keiner Sequenzverlängerung. Ein Längenunterschied der Produkte wird über einen nicht hybridisierenden Schwanz, dem sogenannten tail erreicht. Die STR werden nach der primären PCR unter erneuter Zugabe der Primer weiteren 5 Zyklen der PCRParameter unterzogen. Dabei ist ein Primer jeweils farbmarkiert. Anschließend 
können beide Produkte getrennt einer Fragment-Längen-Analyse (FLA) unterzogen werden.

\subsubsection{Design der Primer zur DNA-Amplifikation}

Das Design der PCR-Primer folgte den in Hummel (2003, S.90ff) erläuterten Prinzipien zur Steigerung der PCR-Spezifität. Wo möglich wurden Primerpaare gewählt, die kurze Fragmente von 100 bis maximal 170 bp einschließen und damit bei der Untersuchung von degradierter DNA höhere Erfolgschancen bieten. Die Primersequenzen sind in Tabelle 19 aufgeführt. Das Primerpaar des IL6Polymorphismus wurde aus der Arbeit Puder (2005) verwendet.

Besondere Vorsicht war in bezug auf den SNP IL10 G-2849A geboten, der am Rande einer Alu-Repeat-Sequenz liegt (D. Kube und T.W. Huizinga, pers. Mitteilung). Um die Spezifität des PCR-Produktes zu garantieren, wurde der vordere Primer außerhalb des Alu-Repeats plaziert. Die Systeme (je vier) wurden auf zwei Heptaplex-Systeme verteilt, in jeder sind außerdem die beiden STR-Systeme FGA und D13S317 enthalten. Die Systeme IL6 -174, TLR2 753, TLR4 399 und IL10 -2849 werden in Multiplex A, die Systeme IL4 -524, IL4Ra 576, IL10 -1087 und TLR4 299 in Multiplex B amplifiziert. Bei der Aufteilung der Markersysteme wurde beachtet, daß durch den geringen Abstand der beiden TLR4-SNP, die nur 300 bp auseinanderliegen, in Konkurrenz zu den gewünschten zwei kurzen Fragmenten ein langes Fragment zwischen den beiden äußeren Primern amplifiziert werden kann. Diese Systeme wurden daher auf verschiedene Ansätze verteilt. Ein weiterer Faktor war die Entstehung unspezifischer Produkte. So konnten sie minimiert werden, in dem IL10 -2849 in die Multiplex A eingefügt wurde, TLR4 299 in Multiplex B. Die Vermeidung unspezifischer Produkte gab auch den Ausschlag für die Bevorzugung der Heptaplex-Ansätze gegenüber einer Dekaplex, in der alle acht Systeme mit den beiden STR koamplifiziert werden. Tabelle 20 gibt eine Übersicht über die untersuchten Polymorphismen. 
Tab. 19: Sequenzdaten und Fragmentlängen der PCR-Primer

\begin{tabular}{|c|c|c|c|}
\hline SNP & Primer & Primersequenz $\left(5^{\prime} \rightarrow 3^{\prime}\right)$ & Länge \\
\hline \multicolumn{4}{|l|}{ Multiplex A } \\
\hline \multirow{2}{*}{ IL6 G-174C } & upper & CTA GCC TCA ATG ACG ACC TAA & \multirow{2}{*}{$161 \mathrm{bp}$} \\
\hline & lower & GGA AAA TCC CAC ATT TGA TAA & \\
\hline \multirow{2}{*}{ TLR4 399} & upper & AAG GTT GCT GTT CTC AAA GTG A & \multirow{2}{*}{$127 \mathrm{bp}$} \\
\hline & lower & TGA AAT CCA GAT GTT CTT AGT TG & \\
\hline \multirow{2}{*}{ TLR2 753} & upper & TGA GTG GTG CAA GTA TGA ACT G & \multirow{2}{*}{$164 \mathrm{bp}$} \\
\hline & lower & GCC ACT CCA GGT AGG TCT TG & \\
\hline \multirow{2}{*}{ IL10 G-2849A } & upper & TCT CGA TCT CCT GAC CTT ATG AT & \multirow{2}{*}{$142 \mathrm{bp}$} \\
\hline & lower & CAG CAA ATG GCT TGA GAT AAT TAG & \\
\hline \multicolumn{4}{|l|}{ Multiplex B } \\
\hline \multirow{2}{*}{ IL10 G-1087A } & upper & CAC AAA TCC AAG ACA ACA CTA CTA AG & \multirow{2}{*}{$137 \mathrm{bp}$} \\
\hline & lower & GGG TGG AAG AAG TTG AAA TAA CA & \\
\hline \multirow{2}{*}{ TLR4 D299G } & upper & AAT TCC GAT TAG CAT ACT TAG ACT AC & \multirow{2}{*}{$109 \mathrm{bp}$} \\
\hline & lower & ACC CTT TCA ATA GTC ACA CTC AC & \\
\hline \multirow{2}{*}{ IL4Ra 576} & upper & CCCAACCTGAGCCAGAAACC & \multirow{2}{*}{$123 \mathrm{bp}$} \\
\hline & lower & GCTCCACCGCATGTACAAACT & \\
\hline \multirow{2}{*}{ IL4 C-524T } & upper & AACTAGGCCTCACCTGATACGA & \multirow{2}{*}{$161 \mathrm{bp}$} \\
\hline & lower & CATCTTGGAAACTGTCCTGTCAT & \\
\hline
\end{tabular}

Tab. 20: Übersicht der Polymorphismen. Angegeben wird bei den Rezeptoren neben den namengebenden Aminosäuresubstitutionen (AS) die Nukleotidposition (nt) des zugrundeliegenden SNP in der coding region des Rezeptorgens. Die rs-Nummer dient der Identifizierung und Erfassung der SNP in Datenbanken (z. B. SNP-Entrez, NCBI).

\begin{tabular}{lcccc}
\hline Locus & AS & nt & rs-Nummer & Allele \\
\hline TLR4 & D299G & +896 & rs4986790 & G/A \\
TLR4 & T399I & +1196 & rs4986791 & C/T \\
TLR2 & R753Q & +2256 & rs5743708 & A/G \\
IL4R $\alpha$ & Q576R & +1902 & rs1801275 & G/A \\
IL4 & & -590 & rs2243250 & C/T \\
IL6 & & -174 & rs1800795 & G/C \\
IL10 & & -2849 & rs6703630 & G/A \\
IL10 & & -1087 & rs1800896 & G/A \\
\hline
\end{tabular}




\subsubsection{Design der Primer für die SBE-Reaktion}

Das Design der SBE-Primer hat weniger Freiheitsgrade, da der Endpunkt des Primers mit der an den untersuchten SNP angrenzenden Position festgelegt ist. Gleichzeitig gibt es weniger Anforderungen an die Spezifität, da die Zielsequenz spezifisch im Überschuß vorliegt, genomische DNA ist mengenmäßig nicht von Bedeutung. Das Hauptaugenmerk liegt auf der Bildung unspezifischer Produkte, soweit es die Positionierung des Primers zuläßt. Über Länge und Auswahl des forward oder reverse Primer können elongierbaren Produkten aus Dimeren und hairpins vermieden werden. Ihre Signale sind in der Analyse nicht von Allelsignalen trennbar, wenn sie sowohl in Farbe als auch Länge den erwarteten Produkten entsprechen. Ihr Auftreten wird in Leer-Ansätzen (no template controls) überprüft. Toleriert werden schwache Nebenprodukte, wenn unumgänglich, die ein anderes Farbsignal als die Allele des untersuchten SNP zeigen. In diesem Falle ergibt sich nur eine Konkurrenz um Resourcen, als Ursache für falsche Allelbestimmungen sind sie ausgeschlossen. Die Primerlänge wird nach der Entstehung von Nebenprodukten und auf eine ähnliche Schmelztemperatur $\mathrm{T}_{m}$ mit weiteren Primern des Multiplex-Ansatzes gewählt, damit möglichst ähnliche Amplifikationsbedingungen vorliegen. Der endgültige Unterschied in den Fragmentlängen wird über das Anfügen eines Poly-A oder Poly-C-Schwanz am 5'-Ende des Oligonukleotids erreicht. Tab. 21 führt die Sequenzen und Eigenschaften der verwendeten Primer auf. Die Längen der SBE-Primer wurden so gewählt, daß die acht Systeme auch in einem Oktaplex-Ansatz analysiert werden können.

\subsubsection{Primäre PCR zur DNA-Amplifikation}

Die Amplifikation der acht SNP- und zwei STR-Loci wurde in Heptaplex-Ansätzen zu je $25 \mu$ l durchgeführt.

Multiplex A - Amplifikation von IL6 -174, TLR2 753, TLR4 399, IL10 -2849: 12,5 $\mu$ l Qiagen Multiplex PCR MasterMix, 0,25 $\mu \mathrm{M}$ je SNP-Primer, 0,3 $\mu \mathrm{M}$ je Primer FGA (upper/lower), 0,1 $\mu \mathrm{lM}$ je Primer D13S317 (upper/lower, $50 \mathrm{pmol}$ ), 1 - 9,5 $\mu$ l DNA-Extrakt, auf $25 \mu \mathrm{l}$ mit Wasser auffüllen 
Tab. 21: Darstellung der Primer, die in der SNaPshot-Analyse verwendet wurden. Gezeigt werden die Primersequenzen nach Loci, zusätzlich wird die Richtung, in der sequenziert wird, mit angegeben, so wie die erwarteten Farbsignale in der Analyse.

\begin{tabular}{lll}
\hline Bezeichnung & Primersequenz & nt \\
\hline TLR2 753 R & TTT TTT TTG GTC TTG GTG TTC ATT ATC TTC & 29 \\
TLR4 299 F & ccc ccc ccc ccc ccc ccc TAG CAT ACT TAG ACT ACT ACC TCG ATG & 45 \\
TLR4 399 R & CAG ATC TAA ATA CTT TAG GCT GGT T & 25 \\
IL4R $2576 \mathrm{R}$ & aaa aaa aaa aaa aaa aaa aaa aaa aGC TCC ACC GCA TGT ACA AAA CTC C & 48 \\
IL6 -174 F & TCC CCC TAG TTG TGT CTT GC & 20 \\
IL10 -1082 R & aaa aaa aaa aaa CTC TTA CCT ATC CCT ACT TCC CC & 34 \\
IL10 -2849 R & aaa aaa aaa aaa aaa aaa TCG ATC TCC TGA CCT TAT GAT C & 38 \\
IL4 -524 F & aaa aaa aaa aaa aaa aaa aaa aaa aaa aaC CTA AAC TTG GGA GAA CAT TGT C & 52 \\
\hline
\end{tabular}

F: forward, R: reverse; nt: Nukleotide, Primerlänge; kleine Buchstaben in der Primersequenz stehen für den nichtbindenden tail zur Primerverlängerung

\section{Multiplex B - Amplifikation von IL4 -524, IL4Ra 576, TLR4 399, IL10 -1087:}

$12,5 \mu \mathrm{l}$ Qiagen Multiplex PCR MasterMix, 0,25 $\mu \mathrm{M}$ je SNP-Primer, $0,3 \mu \mathrm{M}$ je Primer FGA (upper/lower), 0,1 $\mu \mathrm{lM}$ je Primer D13S317 (upper/lower, 50 pmol), 1 - 9,5 $\mu$ l DNA-Extrakt, auf $25 \mu$ l mit Wasser auffüllen

Cycling Parameter: Initialisierung $95^{\circ} \mathrm{C} 15 \mathrm{~min} ; 40-45$ Zyklen mit $94^{\circ} \mathrm{C} 30 \mathrm{sec}$, $58^{\circ} \mathrm{C} 1 \mathrm{~min} 30 \mathrm{sec}, 72^{\circ} \mathrm{C} 1 \mathrm{~min}$; Temperaturänderung $\mathrm{r}=1 \mathrm{~K} / \mathrm{s}$.

Die Bewertung des Amplifikationserfolges der PCR erfolgte auf 2,5\%igen Agarosegelen mit Ethidiumbromid-Färbung. Eine nähere Beschreibung findet sich bei Hummel (2003, S.205f).

\subsubsection{Sekundäre PCR zur Farbmarkierung der STR-Fragmente}

Für die Fragmentlängen-Analyse der Systeme D13S317 und FGA wurde über die Zugabe des jeweiligen fluoreszenzmarkierten upper-Primers (vgl. Tab.18) zum Amplifikat in weiteren 5 Zyklen die Farbmarkierung der Produkte erreicht. Da$\mathrm{zu}$ wurde ein Aliquot von $4 \mu \mathrm{l}$ mit 2 pmol Primer D13S317 und 3 pmol Primer FGA versetzt. Nach weiteren fünf Zyklen der PCR-Reaktionsparameter wurde ein Delay von 30 min bei $60^{\circ} \mathrm{C}$ zur Adenylierung angehängt. Die FragmentlängenAnalyse wird in Kap. 8.3.2 beschrieben. War die Nachamplifikation nicht ohne erneute Zugabe von Polymerase möglich, wurde dem Aliquot zur Farbmarkierung 
0,1 $\mu \mathrm{l}$ AmpliTaq-Gold zugesetzt. Dies war insbesondere der Fall bei Proben, die nicht direkt anschließend an die PCR weiterbearbeitet werden konnten.

\subsubsection{Single-Base-Extension-Reaktion (SBE)}

Die PCR-Produkte wurden vor der weiteren Bearbeitung mit $2 \mathrm{U}$ Exonuclease I (ExoI) und $5 \mathrm{U}$ Shrimp Alkaliner Phosphatase (SAP) bei $37^{\circ} \mathrm{C}$ für $1 \mathrm{~h}$ inkubiert. Dieser Schritt dient der enzymatischen Aufreinigung der PCR-Produkte, bei der freie ddNTP und Primer degradiert und damit von der folgenden Amplifikation ausgeschlossen werden. Die Enzyme wurden anschließend über $15 \mathrm{~min}$ bei $75^{\circ} \mathrm{C}$ deaktiviert.

Die Minisequencing Reaktion erfolgte mit dem SNaPshot Kit, Applied Biosystems. Dieses enthält ein Reaktionsgemisch aus ddNTPs, Polymerase und Puffer. Abweichend von den vom Hersteller empfohlenen Reaktionsparameter wurde ein halber Ansatz $(5 \mu \mathrm{L})$ verwendet, die Annealingtemperatur wurde auf $55^{\circ} \mathrm{C}$ hochgesetzt, um Artefaktbildung zu verringern. Wenn möglich wurde die SBE mit gepoolten PCR-Produkten aus den beiden Multiplex-PCR durchgeführt (Kap. 8.4.3). Die Primerkonzentrationen bleiben gleich, unabhängig von der Anzahl der beigefügten Primer.

Reaktionsansatz: SNaPshot Reaction Mix 2,5 $\mu$ l, Primer IL10-2849 0,4 $\mu \mathrm{M}$, Primer IL10-1087 0,4 $\mu \mathrm{M}$, Primer IL6-174 0,6 $\mu \mathrm{M}$, Primer IL4-524 0,6 $\mu \mathrm{M}$, Primer IL4R $\alpha$ 0,2 $\mu \mathrm{M}$, Primer TLR4 299 0,4 $\mu \mathrm{M}$, Primer TLR4 399 0,2 $\mu \mathrm{M}$, Primer TLR2 $7530,4 \mu \mathrm{M}$, PCR-Produkt je 0,5 - $2 \mu \mathrm{l}$. Das Gesamtvolumen betrug $5 \mu \mathrm{l}$. Der Ansatz wurde auf Eis angesetzt.

Cycling-Parameter: $\quad 30$ Zyklen von $96^{\circ} \mathrm{C}$ für $10 \mathrm{sec}, 55^{\circ} \mathrm{C}$ für $5 \mathrm{sec}$ und $60^{\circ} \mathrm{C}$ für $30 \mathrm{sec}$.

Für die abschließende Aufreinigung folgte die Inkubation der Produkte bei $37^{\circ} \mathrm{C}$ für $1 \mathrm{~h}$ mit je $1 \mathrm{U}$ SAP. Mit weiteren $15 \mathrm{~min}$ bei $75^{\circ} \mathrm{C}$ wurde das Enzym deaktiviert. Die Produkte werden bei $4^{\circ} \mathrm{C}$ für bis zu $24 \mathrm{~h}$, für längere Zeit bei $-20^{\circ} \mathrm{C}$ aufbewahrt. 
Die Auftrennung der SBE-Produkte wurde auf einem ABI 310 Genetic Analyzer (Applied Biosystems) durchgeführt unter Verwendung von POP4 bei einer Kapillarlänge von $45 \mathrm{~cm}$. Für die Elektrophorese wurden je 0,5 - $1 \mu \mathrm{l}$ des SBE-Produktes in $12 \mu \mathrm{l} \mathrm{HiDiFormamid} \mathrm{mit} \mathrm{0,25} \mu$ GeneScan $^{\text {TM }} 120$ LIZ Standard (Applied Biosystems) versetzt. Die Datenaufnahme und -analyse erfolgte mit AbiPrism 310 Collection und GeneScan Software, Version 3.1 (Applied Biosystems).

\subsubsection{Auswertung der SNP-Analyse}

Entsprechend der Auswertung der STR-Analysen wurden Regeln für die SNPAnalyse erstellt. Zu berücksichtigen waren hierbei die besonderen Charakteristika der SNaPshot-Reaktion: Hintergrundsignale, unterschiedliche peak-Höhen und Nebenprodukte. Durch die Verlängerung der bindenden Primersequenz durch einen sogenannten tail kommt es zu einem Hintergrund aus „Primer - n“-Produkten. Diese Produkte haben aufgrund unausweichlicher Aufreinigungsdefizite der Primer auf Herstellerseite und Degradierungsphänomenen während der Lagerung Nukleotide des tails verloren und treten als verkürzte Produkte mit geringer Signalintensität im Hintergrund in Erscheinung. Nebenprodukte, die auch in Leerkontrollen auftreten, wurden versucht, durch effizientes Primerdesign zu umgehen. Allerdings erlauben die geringen Freiheitsgrade der Positionierung der Primer den Polymorphismus flankierend kaum Optimierungen. Toleriert wurden solche Produkte mäßiger Signalintensität und mit einer Farbmarkierung, die nicht denen der zu typisierenden Allele entsprachen. Für die erfolgreiche Zuordnung der einzelnen Signale in Multiplex-Ansätzen wurden zunächst die Produkte aus Singleplex-Ansätzen analysiert. Die dort beobachteten Fragmentlängen (Tab. 22) wurden als Grundlage für die Zuordnung verwendet. 
Tab. 22: Laufeigenschaften der SBE-Produkte in Abhängigkeit des gebundenen ddNTP. nt: Nukleotide

\begin{tabular}{ccccccccc}
\hline Locus & IL6 & TLR4 & TLR2 & IL10 & IL10 & TLR4 & IL4Ra & IL4 \\
& -174 & 399 & 753 & -1082 & -2849 & 299 & 576 & -524 \\
\hline Länge & $20 \mathrm{nt}$ & $25 \mathrm{nt}$ & $30 \mathrm{nt}$ & $35 \mathrm{nt}$ & $38 \mathrm{nt}$ & $43 \mathrm{nt}$ & $48 \mathrm{nt}$ & $52 \mathrm{nt}$ \\
\hline $\mathrm{A}$ & & & & & & $45 \mathrm{nt}$ & & \\
$\mathrm{C}$ & $28 \mathrm{nt}$ & $29 \mathrm{nt}$ & $33 \mathrm{nt}$ & $36 \mathrm{nt}$ & $40 \mathrm{nt}$ & & $46 \mathrm{nt}$ & $50 \mathrm{nt}$ \\
$\mathrm{G}$ & $28 \mathrm{nt}$ & & & & & $44 \mathrm{nt}$ & & \\
$\mathrm{T}$ & & $30 \mathrm{nt}$ & $34 \mathrm{nt}$ & $37 \mathrm{nt}$ & $41 \mathrm{nt}$ & & $47 \mathrm{nt}$ & $52 \mathrm{nt}$ \\
\hline
\end{tabular}

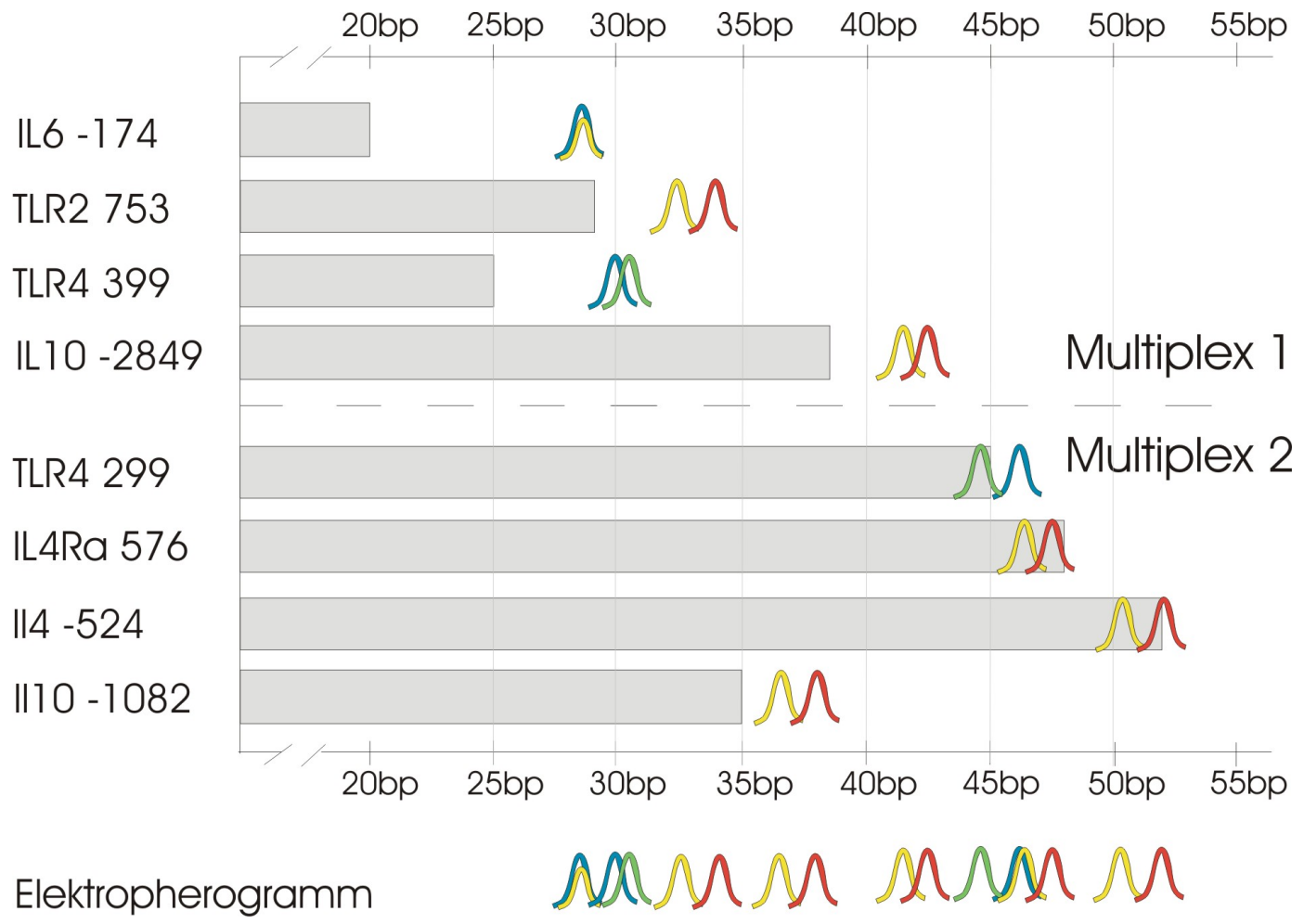

Abb. 8: Design der SBE-Analyse. Übereinander sind die Produkte der acht untersuchten Polymorphismen dargestellt. Die grauen Blöcke signalisieren die Länge des jeweiligen Produktes, die farbigen peaks geben die beobachtete Lauflänge des Produktes abhängig von der Farbmarkierung an. Die Lauflänge der Produkte unterscheidet sich besonders bei kürzeren Produkten um bis zu 5 bp von der echten Länge (Primer +1 ). Zu sehen ist auch, daß sich alle Produkte beider SBE-Multiplexes in ihrer Länge deutlich unterscheiden. Dadurch besteht die Möglichkeit, die Produkte beider Tetraplexes zu poolen und in einem Oktaplex-Ansatz zu analysieren.

Die beobachteten Fragmentlängen errechnet die GeneScan-Software automatisch mit Hilfe des lane-internen Längenstandards GeneScan Liz 120. Sie entsprechen dabei nur unzureichend den wirklichen Fragmentlängen. Die Gesamtlänge und 
Zusammensetzung des Primers wirkt sich allerdings auf die Laufeigenschaften der Produkte aus. So laufen alle Fragmente unter 30 nt deutlich langsamer als erwartet, während über $30 \mathrm{nt}$ sich die errechnete Länge in der Analyse der echten Länge des Produktes annähert. Aufgrund der insgesamt kurzen Produktlängen (hier 20 bis 50 nt) bewirken die verschiedenen Farbstoffe mit ihren individuellen Laufeigenschaften zusätzlich mobility shifts der SBE-Produkte, die bei der Auswertung berücksichtigt werden müssen. Charakteristischerweise zeigen blaumarkierte Produkte die höchste Mobilität, vor schwarz- und grün-markierten, während rot-markierte Produkte die geringste Mobilität zeigen. Bei der Analyse von heterozygoten Ausprägungen erscheinen die verschiedenfarbigen Signale daher nebeneinander statt übereinander (Abb. 8 und Tab. 23), wobei rotmarkierte Produkte scheinbar die größte Produktlänge zeigen.

Tab. 23: Auswertungsschema für die SNaPshot-Analyse. In der Tabelle ist für die einfachere Analyse jedes Allel der entsprechenden Farbkodierung direkt zugeordnet worden. Die Farbkodierung ist von der Primerorientierung abhängig. SNP: Polymorphismus; ddNTP: angehängtes Nukleotid; Or: Orientierung des Primers, F-forward, R-reverse

\begin{tabular}{cccclc}
\hline Länge & SNP & ddNTP & Or & Farbe & Allel \\
\hline ca. 28 & IL6-174 & G & F & blau & G \\
ca. 28 & & C & F & gelb & C \\
ca. 29 & TLR4 399 & G & R & blau & C \\
ca. 30 & & A & R & grün & T \\
ca. 33 & TLR2 753 & C & R & gelb & G \\
ca. 34 & & T & R & rot & A \\
ca. 36 & IL10-1082 & C & R & gelb & G \\
ca. 37 & & T & R & rot & A \\
ca. 40 & IL10-2849 & C & F & gelb & G \\
ca. 41 & & T & F & rot & A \\
ca. 45 & TLR4 299 & A & F & grün & A \\
ca. 44 & & G & F & blau & G \\
ca. 46 & IL4R $\alpha 76$ & T & R & rot & A \\
ca. 47 & & C & R & gelb & G \\
ca. 50 & IL4 -524 & C & F & gelb & C \\
ca. 52 & & T & F & rot & T \\
\hline
\end{tabular}


Kriterien der Alleldetermination: Ein sensibler Punkt in der Analyse von aDNA ist die Interpretation der gewonnenen Daten. Aufgrund verschiedener Phänomene, die für aDNA typisch sind, werden wiederholte Amlifikationen aus mehreren Extrakten nötig, um die Authentizität der Ergebnisse sicherzustellen. Dazu gehört neben möglichen Kontaminationen verschiedener Ursachen auch das Phänomen des allelic dropout. Es beschreibt das falsch homozygote Erscheinen von heterozygoten Ausprägungen. Ursache ist die geringe Anzahl von DNAMatrizen als Ausgangsmaterial für die PCR. Westenthanner (2006) zeigte, daß bei der Analyse von aDNA häufig templates nur im einstelligen Mengenbereich zur Verfügung steht. Folge kann ein allelic dropout sein, bei dem in der Amplifikation eines heterozygoten Locus nur eines der beiden Allele amplifiziert wird und es zur Generierung falsch homozygoter Ergebnisse kommt (Schmerer et al., 2000; Hummel, 2003).

Signale wurden als Allel gewertet,

- wenn sie eine regelmäßige peak-Morphologie zeigten. Diese sollte annähernd symmetrisch und spitz zulaufend sein. Signale mit einer unregelmäßigen Morphologie (unsymmetrisch, oder rund) wurden als Artefakte gewertet.

- wenn sie deutlich aus dem Hintergrundrauschen als peak heraustraten. Signale kürzerer SBE-Produkte wurden als Allel gewertet, wenn sie deutlich als peak aus dem Hintergrund gleichfarbiger längerer SBE-Produkte heraustraten

- und wenn ihre Position innerhalb eines Bereiches von +/- 1 bp der erwarteten Länge lag. Verschiebungen sollten alle Fragmente des SBE-Produktes gleichermaßen betreffen. Signale, die außerhalb dieses Bereiches lagen, und solche, die uncharakteristische Verschiebungen zeigten, wurden nicht als Allele aufgenommen. Sie werden auf unspezifische Produkte zurückgeführt. Signale, die nicht deutlich vom Hintergrund getrennt werden konnten, wurden zunächst in Klammern als unsicheres Allel gewertet.

Kriterien der Zusammenführung der Endergebnisse: Neben der grundsätzlich unvoreingenommenen Auswertung der Rohdaten wurden zusätzlich Kriterien erstellt, nach denen die Daten wiederholter Einzeltypisierungen zu Ergebnissen zusammengefaßt werden. Zu berücksichtigen ist hier, daß die Analyse im Gegen- 
satz zu der der STR des genetischen Fingerabdrucks jeweils nur zwei mögliche Ausprägungen hat (biallelisch). Auch die Art der Artefakte weicht von der STRAnalyse ab. Die besonderen Anforderungen der SNP-Analyse bilden die Grundlage der Auswertekriterien.

- Allele, die in mindestens zwei Analysen als sicher typisiert wurden, werden als Allele im Endergebnis berücksichtigt.

- Ergebnisse werden als sicher homozygot angesehen, wenn die Homozygotie mehrfach reproduziert ist (vier Ergebnisse aus zwei Extrakten). Damit soll ein allelic dropout ausgeschlossen werden.

- Ergebnisse sind heterozygot, wenn beide Allele gemeinsam oder abwechselnd einzeln typisiert werden.

Die Möglichkeit der Probenvertauschung kann über die integrierten STR ausgeschlossen werden. In zweifelhaften Fällen wird die Qualität der Amplifikate und der Analyse in die Beurteilung mit einbezogen. Allele, die einmalig beobachtet wurden, wurden im Endergebnis nicht berücksichtigt, wenn

- das zweite Allel in jeder Amplifikation auftrat und

- die anderen Systeme der Amplifikation gute Ergebnisse zeigen (kein allelic dropout, Einzeltypisierungen vollständig) oder

- sie nur aus einer Amplifikation typisiert wurden, die viele Artefakte zeigte (PCR oder SBE).

Mit diesen Kriterien soll das Risiko, fälschlicherweise Artefakte als Allel zu werten und in die endgültige Typisierung aufzunehmen, minimiert werden. 


\subsection{Sequenzierung}

Die Sequenzierung diente zur Validierung der Spezifität neuer Primerpaare sowie zur stichprobenartigen Überprüfung einzelner Genotypisierungen. Die primäre PCR wurde mit den oben genannten Primern (Tab.19) im Singleplex-Ansatz durchgeführt. Die Sequenzierung folgte der Methode des taq-Cycle-Sequencing (Sanger et al., 1977).

Für die Sequenzierung wurden Restkomponenten der PCR-Reaktion von den PCR-Produkten über einen Aufreinigungsschritt mit dem MinElute ${ }^{\circledR}$ Kit (Qiagen) entfernt. Das Protokoll folgte den Angaben des Herstellers, das Eluat wurde bei einem $25 \mu$ l PCR-Ansatz auf $30 \mu$ l eingestellt.

Der Ansatz der Sequenzierreaktion bestand aus $3 \mu$ l Sequenzier-Puffer $(5 \times), 2 \mu \mathrm{l}$ BigDye ${ }^{T M}$ Terminator Ready Reaction Mix, 0,6 $\mu$ l Primer $(5 \mu \mathrm{M}), 0,5-2 \mu$ l aufgereinigtes PCR-Produkt. Das Endvolumen von $20 \mu \mathrm{l}$ wurde durch Auffüllen mit HPLC-Wasser (Merck) erreicht.

Das cycling erfolgte über 25 bis 30 Zyklen bei $96^{\circ} \mathrm{C}$ für $10 \mathrm{sec}, 50^{\circ} \mathrm{C}$ für $5 \mathrm{sec}$ und $60^{\circ} \mathrm{C}$ für 4 min. Das Sequenzierprodukt wurde mit NucleoSeq-Säulchen (Macherey \& Nagel) entsprechend der Herstellerangaben aufgereinigt.

Die Auftrennung der Produkte wurde auf einem ABI 310 Genetic Analyzer (Applied Biosystems) durchgeführt unter Verwendung von POP6 bei einer Kapillarlänge von $45 \mathrm{~cm}$. Die Datenerfassung erfolgte mit AbiPrism ${ }^{T M} 310$ Collection Software (Applied Biosystems). Nach der automatischen Bearbeitung der Rohdaten mit AbiPrism ${ }^{T M}$ Sequencing-Analysis Software 3.0 (Applied Biosystems) wurden die resultierenden Sequenzen mit den Programmen SeqMan ${ }^{\top M}$ und MegAlign $^{T M}$ des DNAStar Software Paketes (Lasergene) ausgewertet und mit Referenzsequenzen der NCBI-Sequenzdatenbank abgeglichen. 


\subsection{Statistische Auswertung}

Für die statistische Auswertung wurde das Programm Arlequin ver3.11 (Excoffier et al., 2005) verwendet. Die Berechnungen wurden unabhängig für die einzelnen Loci durchgeführt. Als Grundlage der Berechnungen wurden die beobachteten Genotyphäufigkeiten der Populationen angegeben. Folgende Parameter wurden untersucht:

- Hardy-Weinberg-Gleichgewicht, exact test

- Exact test of population differentiation

Das Hardy-Weinberg-Gleichgewicht ist die Grundlage für alle weiteren Tests. Ausgehend von einer Modellbevölkerung wird eine Genotypenverteilung postuliert. Diese wird aus den Allelfrequenzen mit folgender Formel berechnet:

$$
\frac{p^{2}+2 p q+q^{2}}{2 N}
$$

Getestet wird die Hypothese $\mathrm{H}_{0}$ : Die beobachtete Heterozygotenrate unterscheidet sich nicht von der erwarteten. Das Signifikanzniveau beträgt $\mathrm{p}=0,05$. Die Hypothese $\mathrm{H}_{0}$ wird verworfen, wenn $\mathrm{p}<0,05$. Abweichungen vom Hardy-WeinbergGleichgewicht können auftreten, wenn eine Stratifizierung der Bevölkerung vorliegt, das heißt die Bedingung der Panmixie ist nicht erfüllt, oder einzelne Genotypen einem Selektionsdruck unterliegen. Auch methodische Fehler kommen als Ursache in Betracht.

Der Exact test of population differentiation vergleicht die beobachteten Frequenzen verschiedener Populationen nach Raymond \& Rousset (1995). Getestet wird die Hypothese einer zufälligen Verteilung $r$ verschiedener Genotypen in $k$ untersuchten Populationen. Der Test basiert auf dem Fisher Exakt-Test, der zu einer $r \times k$-Kontingenztafel ausgeweitet ist. Die Kontingenztafel wird aus den GenotypFrequenzen der Proben aufgebaut (Goudet et al., 1996). Das Signifikanzniveau beträgt $\mathrm{p}=0,05$. Die Hypothese $\mathrm{H}_{0}$ „Die Populationen unterscheiden sich nicht" wird verworfen, wenn $\mathrm{p}<0,05$. 


\section{Ergebnis}

\subsection{Amplifikationserfolg}

Innerhalb dieser Studie wurden insgesamt 3645 Loci amplifiziert. Dies ergibt sich aus der Zahl der Gesamtamplifikationen multipliziert mit der Anzahl der untersuchten Loci. 26,9\% der Loci zeigten kein Ergebnis, damit liegt die Erfolgsrate bei $73,1 \%$. Auf die einzelnen Loci bezogen konnten im Schnitt für 74,2\% Allelsignale detektiert werden. Der Amplifikationserfolg war in der Skelettserie „HL Kontrolle“ geringfügig besser als in den Skelettserien „HL Pest“ und „Do“. Hier konnten im Schnitt für $78 \%$ der amplifizierten Loci ein Ergebnis verzeichnet werden. Der Amplifikationserfolg schwankt in der Serie „Do“ am stärksten (zwischen 58 und $98 \%$ ), während die Serie HL Hungersnot auch den gleichmäßigsten Amplifikationserfolg über alle Systeme zeigte.

Den höchsten Amplifikationserfolg erbrachten insgesamt die Systeme IL10 -2849 und IL4Ra mit 89 bzw. 86\%, den niedrigsten IL10 -1087 (62\%) und IL6 (65\%). Das System IL10 -2849 wurde seltener amplifiziert, als die übrigen Systeme. Dies ergab sich aus zeitlichen Gründen. Der Locus IL10 wurde erst nachträglich in die Studie aufgenommen. Da er mit der Multiplex B aufgrund von unspezifischen Produkten unvereinbar war, wurde er in die bereits etablierte Multiplex A aufgenommen. Aus den bereits untersuchten Proben der Skelettserie „HL Pest“ wurden Individuen mit guter DNA-Erhaltung ausgewählt und erneut amplifiziert. Dadurch konnte die Zahl erfolgloser Amplifikationen von vornherein reduziert werden. Als Folge zeigt dieses System eine besonders hohe Erfolgsquote.

Tab. 24: Amplifikationserfolg, dargestellt in der Anzahl der erfolgreichen Amplifizierungen jedes Locus. Der Locus IL10 G-2849A unterlag einer geringeren Anzahl an Amplifikationen (s. Text).

\begin{tabular}{lcccccc}
\hline Serie & IL6 & TLR2 & TLR4 & IL10 & IL10 & IL4Ra \\
& G-174C & R753Q & D299G & G-2849A & G-1087A & Q576R \\
\hline Do & $70 \%$ & $76 \%$ & $58 \%$ & $98 \%$ & $58 \%$ & $78 \%$ \\
HL Kontrolle & $68 \%$ & $73 \%$ & $78 \%$ & $87 \%$ & $72 \%$ & $89 \%$ \\
HL Pest & $62 \%$ & $68 \%$ & $76 \%$ & $86 \%$ & $59 \%$ & $86 \%$ \\
\hline Gesamt & $65 \%$ & $71 \%$ & $74 \%$ & $89 \%$ & $62 \%$ & $86 \%$ \\
\hline
\end{tabular}


Abbildung 9 zeigt das Ergebnis einer Amplifikation mit dem Multiplex-Sytem A. In dieser Reaktion wurden die Proben HL 1751 bis 1800 der Serie „HL Pest“ amplifiziert, die sich durch einen gleichbleibend guten Amplifikationserfolg auszeichneten. Die PCR-Produkte sind über den gesamten Bereich von 100 bis 260 bp sehr gleichmäßig amplifiziert. Auch unspezifische Produkte, die sich in der Anwesenheit zusätzlicher Banden ober- und unterhalb des erwarteten Längenbereiches zeigen, fehlen. Diese PCR ist daher ein Beispiel für gute Proben- und Reaktionsqualität, die auf gute SBE-Ergebnisse hoffen läßt.

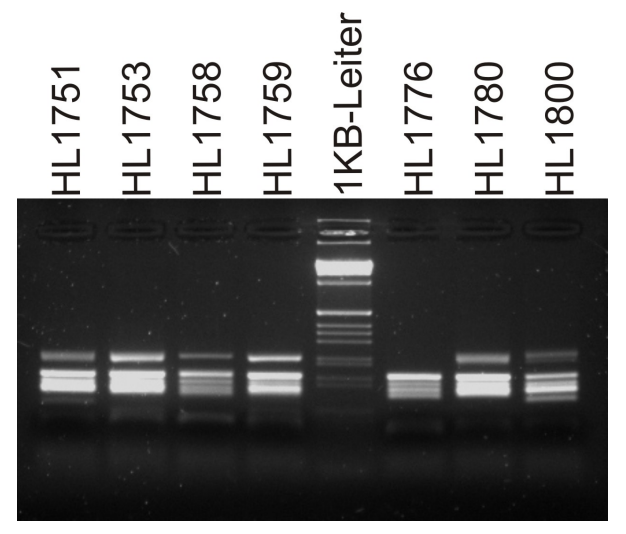

Abb. 9: Agarosegel mit Amplifikaten der Multiplex A zur Typisierung von vier SNPs der Loci TLR2, TLR4, IL6 und IL10 sowie der beiden STR-System D13S317 und FGA. Die Extrakte dieser Proben zeichnen sich durch gleichbleibend gute DNA-Qualität aus. Entsprechend zeigen sie sehr gleichmäßige Produkte im erwarteten Längenbereich zwischen ca. 100 und 260 bp.

Abbildung 10 zeigt eine Amplifikation der Multiplex B mit Proben der Serie „HL Hungersnot“. Die mitgeführte Positivkontrolle in der ersten Spalte (PK) gibt einen Eindruck des erwarteten Ergebnisses. Die gute Extraktqualität der Mehrzahl der mitgeführten Proben hat sich über wiederholte Amplifikationen gezeigt. Trotzdem kommt es zu einem Hintergrund unspezifischer Produkte. 


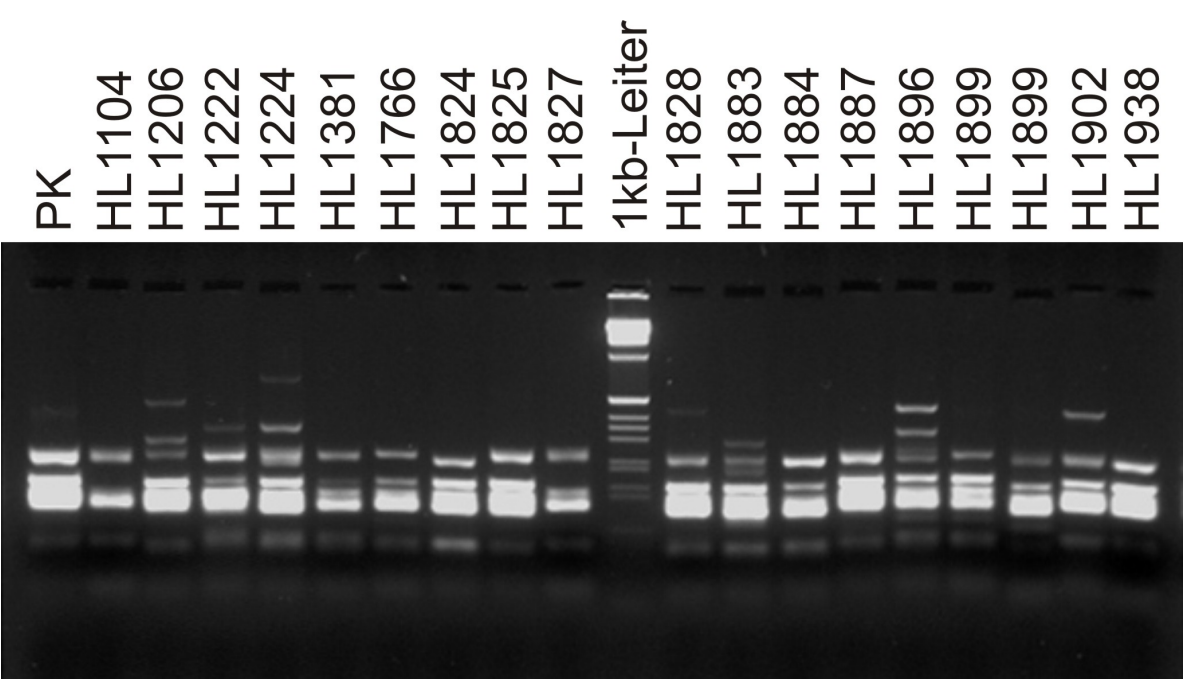

Abb. 10: Agarosegel mit Amplifikaten der Multiplex B zur Typisierung von vier SNP der Loci IL10, TLR4, IL4Ra und IL4 sowie der beiden STR-System D13S317 und FGA. Erwartet werden Produkte zwischen 100 und 260 bp. Oberhalb der 260 bp sind einzelne unspezifische Produkte zu sehen. Das PCR-Produkt in der ersten Spalte (PK) stammt von einer Rezentprobe. Die mit „HL“ gekennzeichneten Proben gehören zur Lübecker Skelettserie „HL Hungersnot".

Die SBE-Reaktion wurde in Quadruplex oder Oktapex-Ansätzen durchgeführt. Eine Quadruplex-SBE aus der Multiplex A ist in Abbildung $11 \mathrm{zu}$ sehen. Für die Oktaplex-Ansätze wurden PCR-Produkte einer Probe aus den beiden MultiplexPCR-Ansätzen A und B in den Reaktionsansatz eingesetzt. Das Ergebnis wird in Abbildung 12 am Beispiel der Probe HL1553 vorgestellt. In dieser Probe konnten alle acht Systeme erfolgreich nachgewiesen werden. Die verschiedenen Signalstärken werden durch PCR-Produktstärke, Leuchtkraft der Farbstoffe und Primereigenschaften bedingt. 


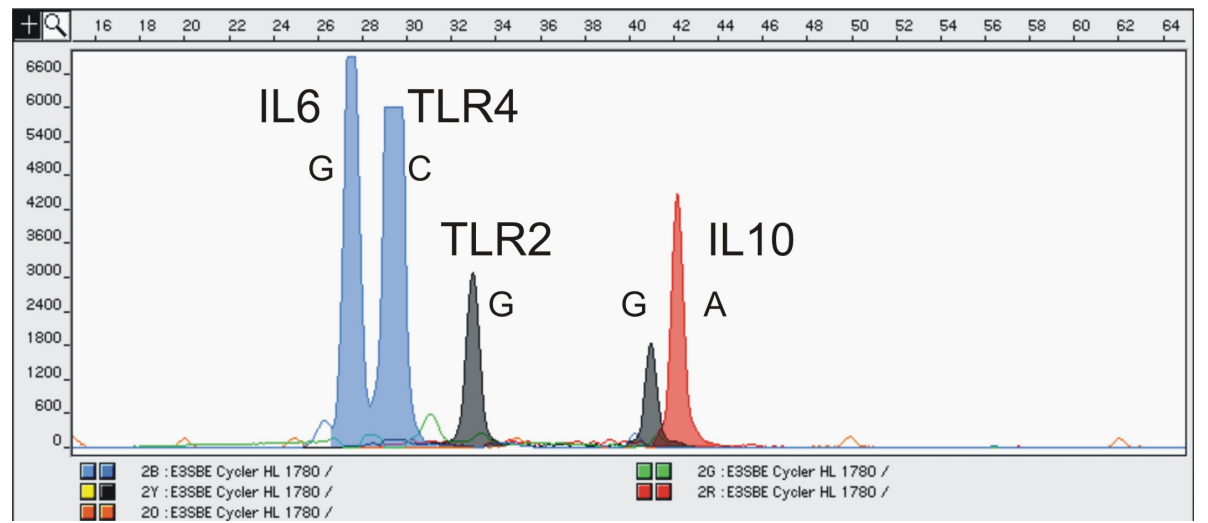

Abb. 11: HL1780: Elektropherogramm einer SBE-Reaktion in der die vier Systeme der Multiplex A untersucht wurden. Die Allelsignale in schwarz, blau, rot sind ausgefüllt, in orange ist der spurinterne Standard GeneScan 120 Liz hinterlegt. Die Unterschied der Signalfarbe der G-Allele resultiert aus der Orientierung der Primer. Der Primer IL10-2849 bindet als reverse-Primer am komplementären Strang.

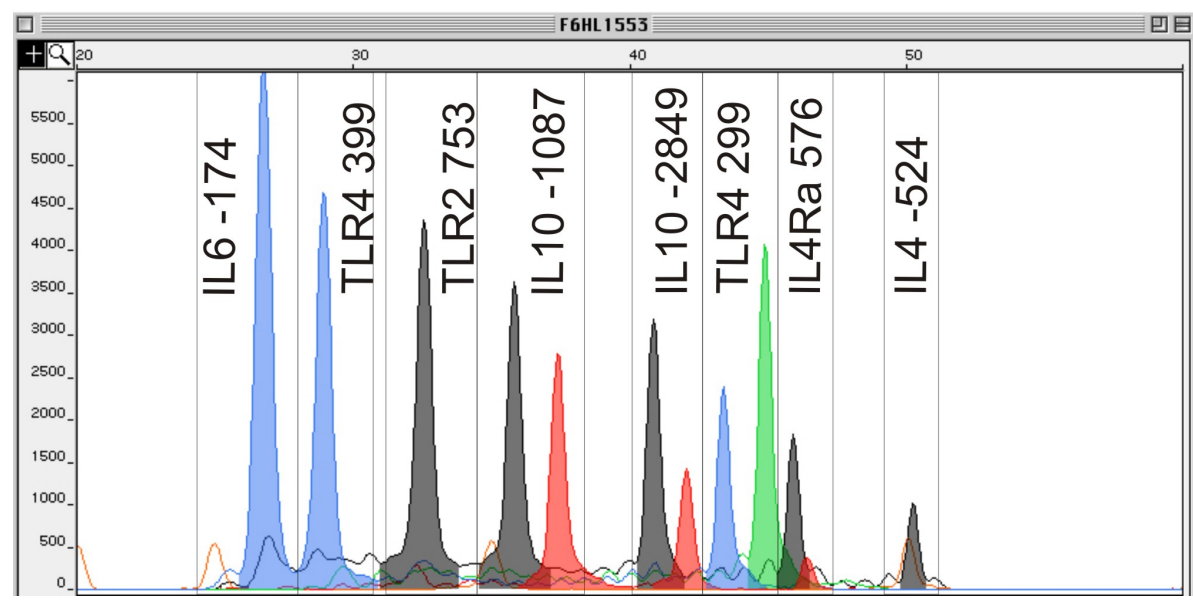

Abb. 12: HL1553: Elektropherogramm einer SBE-Reaktion in der alle acht Systeme simultan untersucht wurden. Die PCR-Produkte der beiden Multiplex-PCR wurden dafür gepoolt. Die Allelsignale in schwarz, blau, rot, grün sind ausgefüllt, in orange ist der spurinterne Standard GeneScan 120 Liz hinterlegt.

Insgesamt zeigt die Aufstellung einen für die Bearbeitung historischer Skelettserien sehr guten Amplifikationserfolg mit mindestens $80 \%$ erfolgreicher Amplifikationen. Dabei ist die Zahl der Ausfälle auf wenige Proben beschränkt, die dann 
jedoch meist über wiederholte Amplifikationen hinweg keine Ergebnisse erbrachten. Für HL1683 zum Beispiel konnte aus beiden Extrakten über 4 PCR jeweils nur ein Ergebnis für das System IL4Ra erzielt werden. Auch die STR-Analyse blieb bis auf zwei Ausnahmen erfolglos (Tab. 25).

Tab. 25: Ergebnisse der Amplifikationen für HL1683 als Beispiel einer Probe mit schlechtem DNAErhalt. D13: D13S317, IL10A: IL10 -2849, IL10B: IL10 -1087, TLR4: TLR4 299

\begin{tabular}{llllllllll}
\hline PCR & Extrakt & D13 & FGA & IL6 & TLR2 & IL10A & IL10B & TLR4 & IL4Ra \\
\hline $4-03$ & Ez1 & $-/-$ & $24 /-$ & & & & $-/-$ & $-/-$ & A $/-$ \\
$4-10$ & Ez1 & $-/-$ & $-/-$ & & & & $-/-$ & $-/-$ & $-/-$ \\
$4-11$ & Ez2 & $-/-$ & $-/-$ & & & & $-/-$ & $-/-$ & A/- \\
$4-15$ & Ez2 & $-/-$ & $-/-$ & & & & $-/-$ & $-/-$ & $\mathrm{A} /-$ \\
$6-05$ & Ez1 & $-/-$ & $-/-$ & $-/-$ & $-/-$ & $-/-$ & & & \\
$6-07$ & Ez2 & $-/-$ & $-/-$ & $-/-$ & $-/-$ & $-/-$ & & & \\
$6-12$ & Ez1 & $-/-$ & $-/-$ & $-/-$ & $-/-$ & $-/-$ & & & \\
$6-12$ & Ez2 & $9 / 11$ & $-/-$ & $-/-$ & $-/-$ & $-/-$ & & & \\
\hline
\end{tabular}

Tabelle 26 zeigt am Beispiel der Probe HL1828 das Beispiel einer vollständigen Typisierung. In allen vier Amplifikationen aus beiden Extrakten wurden nur identische Ergebnisse beobachtet. Diese Probe gibt keinen Hinweis auf allelic dropout. Die Homozygotie aller Systeme außer IL10 -2849 wird damit als sicher angesehen.

Tab. 26: Ergebnisse der Amplifikationen für HL1828 als Beispiel einer Probe mit gutem DNA-Erhalt. D13: D13S317, IL10A: IL10 -2849, IL10B: IL10 -1087, TLR4: TLR4 299, n.a.: nicht analysiert

\begin{tabular}{llcccccccc}
\hline PCR & Extrakt & D13 & FGA & IL6 & TLR2 & IL10A & IL10B & TLR4 & IL4Ra \\
\hline $4-06$ & Ez1 & $11 /-$ & $23 / 24$ & & & & A $/-$ & A $/-$ & A $/-$ \\
$4-08$ & Ez1 & $11 /-$ & $23 / 24$ & & & & A/- & A/- & A/- \\
$4-12$ & Ez2 & $11 /-$ & $24 /-$ & & & & A/- & A/- & A/- \\
$4-13$ & Ez2 & $11 /-$ & $23 / 24$ & & & & A/- & A/- & A/- \\
$6-21$ & Ez1 & $(8) / 11$ & $23 / 24$ & C/- & G/- & G/A & & & \\
$6-24$ & Ez1 & $(11) /-$ & $23 / 24$ & C/- & G/- & G/A & & & \\
$6-28$ & Ez2 & n.a & n.a & C/- & G/- & G/A & & & \\
$6-29$ & Ez2 & $11 /-$ & $23 / 24$ & C/- & G/- & G/A & & & \\
\hline
\end{tabular}

Bei Proben von durchschnittlichem DNA-Erhalt konnten die Ergebnisse in unterschiedlichem Maße reproduziert werden. Häufig wurde in diesem Zusammenhang allelic dropout beobachtet. Als Beispiel werden die Ergebnisse der Probe HL1702 
in Tabelle 27 vorgestellt. Für die Loci IL6 und beide IL10-Loci wurden abwechselnd ein oder beide möglichen Allele beobachtet. Einzelne Ergebnisse der Loci IL10 -1087, TLR2 und TLR4 fehlen komplett. Auch das längere STR-System FGA zeigt einzelne Amplifikationsausfälle.

Tab. 27: Ergebnisse der Amplifikationen für HL1702 als Beispiel einer Probe mit allelic dropout. D13: D13S317, IL10A: IL10 -2849, IL10B: IL10 -1087, TLR4: TLR4 299

\begin{tabular}{llcccccccc}
\hline PCR & Extrakt & D13 & FGA & IL6 & TLR2 & IL10A & IL10B & TLR4 & IL4Ra \\
\hline $4-22$ & Ez1 & $12 /-$ & $-/-$ & & & & $-/-$ & $\mathrm{A} /-$ & $\mathrm{A} /-$ \\
$4-23$ & Ez1 & $10 /-$ & $21 /(23.2)$ & & & & $\mathrm{G} /-$ & $-/-$ & $\mathrm{A} /-$ \\
$4-23$ & Ez2 & $10 / 12$ & $-/-$ & & & & $-/-$ & $-/-$ & $\mathrm{A} /-$ \\
$4-23$ & Ez2 & $10 / 12$ & $-/-$ & & & & $\mathrm{G} / \mathrm{A}$ & $\mathrm{A} /-$ & $\mathrm{A} /-$ \\
$6-34$ & Ez1 & $10 / 12$ & $-/-$ & $-/-$ & $-/-$ & $\mathrm{G} / \mathrm{A}$ & & & \\
$6-36$ & Ez1 & $10 / 12$ & $21 / 23$ & $\mathrm{G} /-$ & $-/-$ & $-/-$ & & & \\
$6-36$ & Ez2 & $12 /-$ & $-/-$ & $\mathrm{G} /-$ & $-/-$ & $\mathrm{G} / \mathrm{A}$ & & & \\
$6-36$ & Ez2 & $10 / 12$ & $-/-$ & $\mathrm{G} / \mathrm{C}$ & $\mathrm{G} /-$ & $\mathrm{A} /-$ & & & \\
\hline
\end{tabular}

\subsection{Typisierungserfolg}

Aus den Ergebnissen der einzelnen Amplifikationen wurden die Genotypisierungen erstellt. Entsprechend der Erfolge der Einzelamplifikationen zeigen die Systeme IL10 -2849 und IL4Ra den größten Typisierungserfolg (Tab. 28). Hier konnte für alle Individuen ein Ergebnis erzielt werden. Den schlechtesten Analyseerfolg zeigte der SNP IL10 -1087 mit 84,3 bzw. 83,7\% erfolgreich typisierten Individuen. Zwischen den Skelettserien zeigte IL6 -174 Abweichungen: Während in der Pestserie nur 68 von 82 der Individuen (81,9\%) typisiert werden konnten, gelang dies bei 39 von 43 Individuen aus dem Kollektiv „Hungersnot“, was 90,7\% entspricht. Betrachtet man das Endergebnis, so war der Typisierungserfolg mit über $80 \%$ hoch. Die Typisierungsergebnisse sind in den Tabellen 29, 30 und 40 zusammengefaßt. 
Tab. 28: Erfolgreiche Typisierungen. Angegeben ist die Zahl an erfolgreichen Typisierungen pro Anzahl der untersuchten Individuen. In der Serie „HL Pest" wurde eine kleinere Stichprobe der Untersuchung des IL10 SNP -2849 unterzogen. In Klammern ist der Amplifikationserfolg in Prozent angegeben.

\begin{tabular}{lllllllll}
\hline \multirow{2}{*}{ Serie } & IL6 & TLR2 & TLR4 & TLR4 & IL10 & IL10 & IL4Ra & IL4 \\
& -174 & 753 & 299 & 399 & -1087 & -2849 & 576 & -590 \\
\hline \multirow{2}{*}{ Hungersnot } & $39 / 43$ & $37 / 43$ & $40 / 43$ & $39 / 43$ & $36 / 43$ & $43 / 43$ & $43 / 43$ & $36 / 43$ \\
\multirow{3}{*}{ Pest } & $(90,7)$ & $(86,0)$ & $(93,0)$ & $(90,7)$ & $(83,7)$ & $(100)$ & $(100)$ & $(83,7)$ \\
& $68 / 82$ & $72 / 82$ & $75 / 82$ & $74 / 82$ & $70 / 82$ & $52 / 55$ & $82 / 82$ & $71 / 82$ \\
& $(82,9)$ & $(87,8)$ & $(91,5)$ & $(90,2)$ & $(85,4)$ & $(94,5)$ & $(100)$ & $(86,6)$ \\
\hline
\end{tabular}

Tab. 29: Skelettserie Lübeck Pest: Ergebnisse der SNP-Genotypisierungen

\begin{tabular}{|c|c|c|c|c|c|c|c|c|}
\hline FNR & $\begin{array}{c}\text { IL6 } \\
-174\end{array}$ & $\begin{array}{c}\text { TLR2 } \\
753\end{array}$ & $\begin{array}{c}\text { TLR4 } \\
299\end{array}$ & $\begin{array}{c}\text { TLR4 } \\
399\end{array}$ & $\begin{array}{c}\text { IL10 } \\
-1087\end{array}$ & $\begin{array}{c}\text { IL10 } \\
-2849\end{array}$ & $\begin{array}{c}\text { IL4Ra } \\
576\end{array}$ & $\begin{array}{c}\text { IL4 } \\
-524\end{array}$ \\
\hline HL0891 & $(G / C)$ & $\mathrm{G} / \mathrm{G}$ & $\mathrm{A} / \mathrm{A}$ & $\mathrm{C} / \mathrm{C}$ & $\mathrm{A} / \mathrm{A}$ & & $G / A$ & $\mathrm{C} /-$ \\
\hline HL0927 & $-/-$ & $(G) /-$ & $(A) /-$ & $-/-$ & $-/-$ & & $(G) / A$ & $-/-$ \\
\hline HL0934 & $-/-$ & $(G) /-$ & $\mathrm{A} / \mathrm{A}$ & $\mathrm{C} / \mathrm{C}$ & $(\mathrm{A}) /-$ & $G /(A)$ & $\mathrm{A} / \mathrm{A}$ & (C)/- \\
\hline HL0942 & $\mathrm{G} / \mathrm{C}$ & $G / G$ & $\mathrm{~A} / \mathrm{A}$ & $\mathrm{C} / \mathrm{C}$ & $G / A$ & & $(G) / A$ & $\mathrm{C} / \mathrm{T}$ \\
\hline HL0945/1 & $-/-$ & $-/-$ & $-/-$ & $-/-$ & (A)/- & & $G /(A)$ & (C)/- \\
\hline HL0958 & $(G) / C$ & $\mathrm{G} /-$ & $\mathrm{A} /-$ & $C /(T)$ & $(G) / A$ & $(G) /-$ & $G / A$ & $\mathrm{C} /-$ \\
\hline HL0965 & $G / G$ & $G / G$ & $\mathrm{~A} / \mathrm{G}$ & $C / C$ & $G / A$ & & $G / A$ & $\mathrm{C} /-$ \\
\hline HL0972 & $\mathrm{G} /(\mathrm{C})$ & $(G) /-$ & $\mathrm{A} / \mathrm{A}$ & $C /(C)$ & $\mathrm{A} /-$ & & $\mathrm{A} / \mathrm{A}$ & (C)/- \\
\hline HL0994/1 & $C /(C)$ & $\mathrm{G} / \mathrm{G}$ & $\mathrm{A} / \mathrm{A}$ & $\mathrm{C} / \mathrm{C}$ & $\mathrm{G} / \mathrm{A}$ & $(\mathrm{G} / \mathrm{A})$ & $\mathrm{A} / \mathrm{A}$ & $\mathrm{C} /-$ \\
\hline HL1006 & $\mathrm{G} / \mathrm{C}$ & $\mathrm{G} / \mathrm{G}$ & $\mathrm{A} / \mathrm{A}$ & $\mathrm{C} / \mathrm{C}$ & $\mathrm{G} / \mathrm{G}$ & $(G) / A$ & $\mathrm{~A} / \mathrm{A}$ & $\mathrm{C} / \mathrm{C}$ \\
\hline HL1037 & $-/-$ & $-/-$ & $(A) /-$ & (C)/- & $-/-$ & & $\mathrm{G} / \mathrm{A}$ & $\mathrm{C} /-$ \\
\hline HL1043 & $-/-$ & $(G) / A$ & $\mathrm{~A} /(\mathrm{A})$ & (C)/- & $\mathrm{G} /-$ & & $\mathrm{A} /-$ & $\mathrm{C} /-$ \\
\hline HL1047 & $\mathrm{G} / \mathrm{C}$ & $\mathrm{G} / \mathrm{G}$ & $\mathrm{A} / \mathrm{A}$ & $\mathrm{C} / \mathrm{T}$ & $\mathrm{G} /-$ & $\mathrm{A} /-$ & $G / A$ & $C /(C)$ \\
\hline HL1081 & $\mathrm{G} / \mathrm{C}$ & $G / G$ & $\mathrm{~A} / \mathrm{A}$ & $C /(C)$ & $G /(G)$ & & $(G) / A$ & $C /(C)$ \\
\hline HL1102 & $(G) /-$ & $-/-$ & $\mathrm{A} /-$ & (C)/- & $(A) /-$ & & $(G) / A$ & $-/-$ \\
\hline HL1106 & $(\mathrm{C}) /-$ & $-/-$ & $(\mathrm{A}) /-$ & $-/-$ & $-/-$ & & $\mathrm{A} /-$ & $-/-$ \\
\hline HL1112 & $G /(G)$ & $G /(A)$ & $\mathrm{A} /(\mathrm{A})$ & $\mathrm{C} / \mathrm{C}$ & G/- & & $\mathrm{A} / \mathrm{A}$ & C/- \\
\hline HL1133 & $G /(C)$ & $\mathrm{G} / \mathrm{G}$ & $\mathrm{A} /(\mathrm{A})$ & $\mathrm{C} / \mathrm{C}$ & $G /(G)$ & $\mathrm{G} / \mathrm{A}$ & $\mathrm{A} / \mathrm{A}$ & $C /(C)$ \\
\hline HL1154 & $\mathrm{G} / \mathrm{C}$ & $G /(A)$ & $A / G$ & $\mathrm{C} / \mathrm{C}$ & $\mathrm{A} / \mathrm{A}$ & $G / A$ & $\mathrm{~A} / \mathrm{A}$ & $\mathrm{C} / \mathrm{C}$ \\
\hline HL1156 & G/- & $(A) /-$ & $-/-$ & (C)/- & $-/-$ & & $(G) / A$ & $-/-$ \\
\hline HL1188 & $-/-$ & (G)/- & $-/-$ & $-/-$ & $-/-$ & & $\mathrm{A} /-$ & $-/-$ \\
\hline HL1217 & G/- & $\mathrm{G} /-$ & $\mathrm{A} / \mathrm{A}$ & $C /(C)$ & $\mathrm{G} / \mathrm{A}$ & $\mathrm{A} /-$ & $\mathrm{A} / \mathrm{A}$ & $\mathrm{C} /-$ \\
\hline HL1219 & $\mathrm{G} / \mathrm{C}$ & $\mathrm{G} / \mathrm{G}$ & $\mathrm{A} / \mathrm{A}$ & $\mathrm{C} /(\mathrm{C})$ & $\mathrm{G} / \mathrm{A}$ & & $\mathrm{A} / \mathrm{A}$ & $\mathrm{C} / \mathrm{C}$ \\
\hline HL1225 & $\mathrm{G} / \mathrm{G}$ & $\mathrm{G} / \mathrm{G}$ & $\mathrm{A} / \mathrm{G}$ & $C / C$ & $\mathrm{G} / \mathrm{A}$ & $\mathrm{A} /-$ & $\mathrm{A} / \mathrm{A}$ & $\mathrm{C} /(\mathrm{T})$ \\
\hline HL1227 & $\mathrm{C} / \mathrm{C}$ & $\mathrm{G} / \mathrm{G}$ & $\mathrm{A} / \mathrm{G}$ & $\mathrm{C} /(\mathrm{T})$ & $\mathrm{G} / \mathrm{A}$ & $G /(A)$ & $\mathrm{A} / \mathrm{A}$ & $\mathrm{C} /(\mathrm{T})$ \\
\hline HL1232 & $\mathrm{C} / \mathrm{C}$ & $\mathrm{G} / \mathrm{G}$ & $\mathrm{A} /(\mathrm{A})$ & $\mathrm{C} / \mathrm{C}$ & $A /-$ & & $\mathrm{A} / \mathrm{A}$ & $C /(C)$ \\
\hline HL1234 & $\mathrm{G} / \mathrm{C}$ & $G /(A)$ & $\mathrm{A} / \mathrm{A}$ & $\mathrm{C} / \mathrm{C}$ & $\mathrm{G} / \mathrm{A}$ & $\mathrm{G} / \mathrm{A}$ & $\mathrm{G} / \mathrm{A}$ & C/- \\
\hline
\end{tabular}


Tab. 29: Skelettserie Lübeck Pest: Typisierungsergebnisse fortgesetzt

\begin{tabular}{|c|c|c|c|c|c|c|c|c|}
\hline FNR & $\begin{array}{c}\text { IL6 } \\
-174\end{array}$ & $\begin{array}{c}\text { TLR2 } \\
753\end{array}$ & $\begin{array}{c}\text { TLR4 } \\
299\end{array}$ & $\begin{array}{c}\text { TLR4 } \\
399\end{array}$ & $\begin{array}{c}\text { IL10 } \\
-1087\end{array}$ & $\begin{array}{c}\text { IL10 } \\
-2849\end{array}$ & $\begin{array}{c}\text { IL4Ra } \\
576\end{array}$ & $\begin{array}{c}\text { IL4 } \\
-524\end{array}$ \\
\hline HL1262 & (G)/- & $-/-$ & $\mathrm{A} /(\mathrm{A})$ & C/- & (A)/- & & $\mathrm{A} / \mathrm{A}$ & (C)/- \\
\hline HL1270 & G/- & $(\mathrm{G}) /-$ & $\mathrm{A} /-$ & $C /(C)$ & $-/-$ & & $(G) /-$ & $\mathrm{C} /-$ \\
\hline HL1271 & $\mathrm{G} /-$ & $\mathrm{G} /-$ & $A /(G)$ & (C)/- & $(G) /-$ & & $\mathrm{G} / \mathrm{A}$ & (C)/- \\
\hline HL1273 & $-/-$ & $-/-$ & $(A) /-$ & $-/-$ & (G)/- & $-/-$ & $G /(A)$ & (C)/- \\
\hline HL1292 & $\mathrm{G} /(\mathrm{G})$ & $\mathrm{G} / \mathrm{G}$ & $A / G$ & $\mathrm{C} / \mathrm{C}$ & $\mathrm{G} / \mathrm{A}$ & $\mathrm{A} /-$ & $G / A$ & $C /(C)$ \\
\hline HL1331 & $-/-$ & $-/-$ & $-/-$ & $-/-$ & $-/-$ & $-/-$ & $\mathrm{A} / \mathrm{A}$ & $-/-$ \\
\hline HL1341 & G/- & $\mathrm{G} /(\mathrm{G})$ & $\mathrm{A} /(\mathrm{A})$ & $C / C$ & G/- & $A /-$ & $\mathrm{A} / \mathrm{A}$ & $\mathrm{C} /-$ \\
\hline HL1343 & $\mathrm{G} / \mathrm{C}$ & $\mathrm{G} /(\mathrm{G})$ & $\mathrm{A} / \mathrm{A}$ & $\mathrm{C} / \mathrm{C}$ & $G /(A)$ & $\mathrm{A} /-$ & $(G) / A$ & $C /(C)$ \\
\hline HL1355 & $\mathrm{G} / \mathrm{C}$ & $\mathrm{G} / \mathrm{G}$ & $\mathrm{A} / \mathrm{A}$ & $\mathrm{C} / \mathrm{C}$ & $G /(A)$ & $(G / A)$ & $\mathrm{G} / \mathrm{A}$ & $\mathrm{C} / \mathrm{C}$ \\
\hline HL1357 & $\mathrm{G} / \mathrm{C}$ & $G /(G)$ & $\mathrm{A} / \mathrm{A}$ & $\mathrm{C} / \mathrm{C}$ & $\mathrm{G} / \mathrm{A}$ & $\mathrm{G} / \mathrm{A}$ & $\mathrm{A} / \mathrm{A}$ & $\mathrm{C} / \mathrm{C}$ \\
\hline HL1359 & $-/-$ & $-/-$ & $\mathrm{A} /-$ & $-/-$ & $-/-$ & $(G / A)$ & $(G) / A$ & $-/-$ \\
\hline HL1361 & G/- & $G / G$ & $\mathrm{~A} /(\mathrm{A})$ & $\mathrm{C} / \mathrm{C}$ & $G / A$ & $(A) /-$ & $G / A$ & (C)/- \\
\hline HL1383 & $(G) / C$ & $G /(G)$ & $\mathrm{A} /(\mathrm{A})$ & $\mathrm{C} / \mathrm{C}$ & $\mathrm{G} / \mathrm{A}$ & $\mathrm{G} / \mathrm{A}$ & $\mathrm{A} /(\mathrm{A})$ & $\mathrm{C} /-$ \\
\hline HL1396 & $-/-$ & $-/-$ & $-/-$ & (C)/- & $-/-$ & & $(G / A)$ & $-/-$ \\
\hline HL1415 & $\mathrm{G} / \mathrm{C}$ & $\mathrm{G} / \mathrm{G}$ & $\mathrm{A} / \mathrm{A}$ & $\mathrm{C} / \mathrm{C}$ & $\mathrm{G} / \mathrm{A}$ & $G /(A)$ & $\mathrm{A} / \mathrm{A}$ & $\mathrm{C} / \mathrm{C}$ \\
\hline HL1422 & $-/-$ & G/- & $-/-$ & $-/-$ & $-/-$ & $(G) /-$ & $\mathrm{A} /-$ & $(\mathrm{C} / \mathrm{T})$ \\
\hline HL1443 & $\mathrm{G} /-$ & $G / G$ & $\mathrm{~A} / \mathrm{A}$ & $C / C$ & $\mathrm{G} / \mathrm{A}$ & $\mathrm{A} /-$ & $\mathrm{A} / \mathrm{A}$ & $\mathrm{C} / \mathrm{C}$ \\
\hline HL1449 & $\mathrm{G} / \mathrm{G}$ & G/- & $\mathrm{A} / \mathrm{A}$ & $C / C$ & $(\mathrm{G}) / \mathrm{A}$ & $G / A$ & $\mathrm{G} / \mathrm{A}$ & $C /(C)$ \\
\hline HL1462 & $\mathrm{G} / \mathrm{C}$ & $\mathrm{G} / \mathrm{G}$ & $\mathrm{A} / \mathrm{A}$ & $\mathrm{C} / \mathrm{C}$ & $G / A$ & $\mathrm{~A} /-$ & $\mathrm{G} / \mathrm{A}$ & $C /(C)$ \\
\hline HL1463 & $\mathrm{G} / \mathrm{G}$ & $\mathrm{G} / \mathrm{G}$ & $\mathrm{A} / \mathrm{A}$ & $\mathrm{C} / \mathrm{C}$ & $\mathrm{G} / \mathrm{A}$ & G/- & $\mathrm{G} / \mathrm{A}$ & $\mathrm{C} / \mathrm{C}$ \\
\hline HL1464 & $-/-$ & $(G / A)$ & $\mathrm{A} /(\mathrm{A})$ & $\mathrm{C} /-$ & $(G / A)$ & & $(G) / A$ & (C) $/-$ \\
\hline HL1486 & $\mathrm{G} /(\mathrm{C})$ & $\mathrm{G} / \mathrm{G}$ & $A /(G)$ & $C /(T)$ & $\mathrm{A} /-$ & & $\mathrm{A} / \mathrm{A}$ & $C / C$ \\
\hline HL1487 & $(\mathrm{G}) / \mathrm{C}$ & G/- & $A /(G)$ & C/- & $G /(A)$ & $\mathrm{A} /(\mathrm{A})$ & $\mathrm{A} /(\mathrm{A})$ & $\mathrm{C} /-$ \\
\hline HL1489 & $-/-$ & $(\mathrm{G}) /-$ & $(G) /-$ & $\mathrm{C} /-$ & $-/-$ & & $(G) / A$ & $-/-$ \\
\hline HL1495 & $\mathrm{G} / \mathrm{C}$ & $G / G$ & $A /(G)$ & $\mathrm{C} / \mathrm{C}$ & $G / A$ & $\mathrm{~A} /-$ & $\mathrm{A} / \mathrm{A}$ & $\mathrm{C} /(\mathrm{T})$ \\
\hline HL1497 & $\mathrm{G} / \mathrm{C}$ & $\mathrm{G} / \mathrm{G}$ & $\mathrm{A} / \mathrm{G}$ & $\mathrm{C} / \mathrm{C}$ & $G / A$ & $G / A$ & $G / A$ & $\mathrm{C} / \mathrm{T}$ \\
\hline HL1505 & $\mathrm{G} / \mathrm{G}$ & $\mathrm{G} / \mathrm{G}$ & $\mathrm{A} / \mathrm{A}$ & $\mathrm{C} / \mathrm{T}$ & $\mathrm{G} / \mathrm{A}$ & $\mathrm{A} /-$ & $\mathrm{A} / \mathrm{A}$ & $\mathrm{C} / \mathrm{C}$ \\
\hline HL1532 & $\mathrm{G} / \mathrm{C}$ & $\mathrm{G} / \mathrm{A}$ & $\mathrm{G} / \mathrm{G}$ & $C /(C)$ & $\mathrm{G} / \mathrm{A}$ & $G / A$ & $\mathrm{G} / \mathrm{A}$ & $\mathrm{C} / \mathrm{C}$ \\
\hline HL1536 & $\mathrm{G} / \mathrm{G}$ & $\mathrm{G} / \mathrm{G}$ & $\mathrm{A} /(\mathrm{A})$ & $\mathrm{C} / \mathrm{C}$ & $\mathrm{G} / \mathrm{A}$ & $\mathrm{A} /-$ & $\mathrm{A} /(\mathrm{A})$ & $C /(C)$ \\
\hline HL1545 & $\mathrm{G} /-$ & G/- & $\mathrm{A} /(\mathrm{A})$ & $\mathrm{C} / \mathrm{C}$ & $-/-$ & & $\mathrm{A} /(\mathrm{A})$ & C/- \\
\hline HL1546 & $\mathrm{C} / \mathrm{C}$ & $\mathrm{G} /(\mathrm{G})$ & $\mathrm{A} /(\mathrm{A})$ & $\mathrm{C} /-$ & $(A) /-$ & & $(G) / A$ & $\mathrm{C} /-$ \\
\hline HL1547 & $\mathrm{G} / \mathrm{C}$ & $\mathrm{G} / \mathrm{G}$ & $\mathrm{A} / \mathrm{G}$ & $\mathrm{C} / \mathrm{C}$ & $G / A$ & & $(G) / A$ & $\mathrm{C} /-$ \\
\hline HL1553 & $\mathrm{G} / \mathrm{C}$ & $\mathrm{G} / \mathrm{G}$ & $\mathrm{A} / \mathrm{G}$ & $C /(C)$ & $G /(A)$ & & $G /(A)$ & $\mathrm{C} / \mathrm{C}$ \\
\hline HL1561 & $(\mathrm{G}) /-$ & G/- & $(\mathrm{A}) /-$ & $\mathrm{C} / \mathrm{C}$ & $G /(G)$ & & $\mathrm{A} /(\mathrm{A})$ & (C)/- \\
\hline HL1571 & $\mathrm{C} / \mathrm{C}$ & $\mathrm{G} / \mathrm{G}$ & $\mathrm{A} / \mathrm{A}$ & $\mathrm{C} / \mathrm{C}$ & $G / A$ & & $\mathrm{~A} / \mathrm{A}$ & $C / C$ \\
\hline HL1589 & $\mathrm{G} / \mathrm{G}$ & $G /(A)$ & $\mathrm{A} / \mathrm{A}$ & $\mathrm{C} / \mathrm{T}$ & $G /(A)$ & & $\mathrm{G} / \mathrm{A}$ & $\mathrm{C} /(\mathrm{T})$ \\
\hline HL1593 & $-/-$ & $-/-$ & $-/-$ & $-/-$ & $(G) /-$ & & $(G) / A$ & $-/-$ \\
\hline HL1612 & $(\mathrm{G} / \mathrm{C})$ & $\mathrm{A} /(\mathrm{A})$ & $\mathrm{A} / \mathrm{A}$ & $\mathrm{C} / \mathrm{C}$ & $\mathrm{A} /(\mathrm{A})$ & & $G / A$ & (C)/- \\
\hline HL1683 & $-/-$ & $-/-$ & $-/-$ & $-/-$ & $-/-$ & & $\mathrm{A} /(\mathrm{A})$ & $-/-$ \\
\hline
\end{tabular}


Tab. 29: Skelettserie Lübeck Pest: Typisierungsergebnisse fortgesetzt

\begin{tabular}{|c|c|c|c|c|c|c|c|c|}
\hline FNR & $\begin{array}{c}\text { IL6 } \\
-174\end{array}$ & $\begin{array}{c}\text { TLR2 } \\
753\end{array}$ & $\begin{array}{c}\text { TLR4 } \\
299\end{array}$ & $\begin{array}{c}\text { TLR4 } \\
399\end{array}$ & $\begin{array}{c}\text { IL10 } \\
-1087\end{array}$ & $\begin{array}{c}\text { IL10 } \\
-2849\end{array}$ & $\begin{array}{c}\text { IL4Ra } \\
576\end{array}$ & $\begin{array}{c}\text { IL4 } \\
-524\end{array}$ \\
\hline HL1688 & $-/-$ & $-/-$ & (A)/- & (C)/- & (G)/- & & $\mathrm{A} /-$ & $-/-$ \\
\hline HL1697 & $\mathrm{C} /-$ & G/- & $\mathrm{A} / \mathrm{A}$ & $\mathrm{C} / \mathrm{C}$ & $G /(A)$ & $\mathrm{A} /(\mathrm{A})$ & $\mathrm{A} / \mathrm{A}$ & $\mathrm{C} /-$ \\
\hline HL1701 & $\mathrm{G} / \mathrm{C}$ & $\mathrm{G} / \mathrm{G}$ & $\mathrm{A} / \mathrm{A}$ & $\mathrm{C} / \mathrm{C}$ & $G / G$ & $(G) / A$ & $\mathrm{~A} / \mathrm{A}$ & $C /(C)$ \\
\hline HL1702 & $\mathrm{G} / \mathrm{C}$ & $(G) /-$ & $A /-$ & $C /(C)$ & $\mathrm{G} /(\mathrm{A})$ & $(G) / A$ & $\mathrm{~A} / \mathrm{A}$ & $\mathrm{C} / \mathrm{C}$ \\
\hline HL1717 & $G / G$ & $G / G$ & $\mathrm{~A} / \mathrm{A}$ & $\mathrm{C} /(\mathrm{T})$ & $G / A$ & $\mathrm{G} / \mathrm{A}$ & $\mathrm{A} / \mathrm{A}$ & $C /(C)$ \\
\hline HL1720 & $\mathrm{G} / \mathrm{C}$ & $\mathrm{G} / \mathrm{A}$ & $\mathrm{A} / \mathrm{G}$ & $\mathrm{C} /(\mathrm{T})$ & $\mathrm{G} / \mathrm{G}$ & $G / A$ & $\mathrm{~A} / \mathrm{A}$ & $\mathrm{C} / \mathrm{C}$ \\
\hline HL1730 & $\mathrm{G} / \mathrm{C}$ & $G / A$ & $\mathrm{~A} / \mathrm{A}$ & $\mathrm{C} / \mathrm{C}$ & $G / A$ & $(G) / A$ & $\mathrm{G} / \mathrm{A}$ & $\mathrm{C} / \mathrm{C}$ \\
\hline HL1741 & $C /(C)$ & $(\mathrm{A}) /-$ & $\mathrm{A} /(\mathrm{A})$ & $\mathrm{C} / \mathrm{C}$ & $\mathrm{G} / \mathrm{G}$ & $(\mathrm{G}) / \mathrm{A}$ & $(G) / A$ & $\mathrm{C} /-$ \\
\hline HL1749 & $\mathrm{G} / \mathrm{C}$ & $\mathrm{G} / \mathrm{G}$ & $\mathrm{A} / \mathrm{G}$ & $\mathrm{C} / \mathrm{C}$ & $\mathrm{G} /(\mathrm{G})$ & A/- & $\mathrm{A} /(\mathrm{A})$ & $C /(T)$ \\
\hline HL1751 & $G / G$ & $\mathrm{G} / \mathrm{G}$ & $\mathrm{A} / \mathrm{G}$ & $\mathrm{C} /(\mathrm{T})$ & $\mathrm{G} / \mathrm{A}$ & $\mathrm{G} / \mathrm{A}$ & $\mathrm{A} / \mathrm{A}$ & $\mathrm{C} / \mathrm{C}$ \\
\hline HL1753 & $\mathrm{G} / \mathrm{C}$ & $G /(G)$ & $\mathrm{A} / \mathrm{A}$ & $\mathrm{C} / \mathrm{C}$ & $G / A$ & $\mathrm{~A} /-$ & $\mathrm{A} / \mathrm{A}$ & $C /(C)$ \\
\hline HL1758 & $\mathrm{G} / \mathrm{C}$ & $\mathrm{G} / \mathrm{G}$ & $\mathrm{A} / \mathrm{A}$ & $\mathrm{C} / \mathrm{C}$ & $G / A$ & $\mathrm{~A} /-$ & $\mathrm{A} / \mathrm{A}$ & $\mathrm{C} /-$ \\
\hline HL1759 & $\mathrm{G} / \mathrm{G}$ & $\mathrm{G} / \mathrm{G}$ & $\mathrm{A} / \mathrm{A}$ & $\mathrm{C} / \mathrm{C}$ & $\mathrm{G} / \mathrm{G}$ & $(G) / A$ & $(G) / A$ & $C /(C)$ \\
\hline HL1776 & $\mathrm{G} / \mathrm{G}$ & $G / G$ & $\mathrm{~A} / \mathrm{A}$ & $\mathrm{C} /(\mathrm{T})$ & $\mathrm{G} / \mathrm{A}$ & $\mathrm{A} /-$ & $\mathrm{A} / \mathrm{A}$ & $\mathrm{C} / \mathrm{C}$ \\
\hline HL1780 & $G / G$ & $G / G$ & $\mathrm{~A} / \mathrm{A}$ & $C /(T)$ & $\mathrm{G} / \mathrm{A}$ & $(G) / A$ & $\mathrm{~A} / \mathrm{A}$ & $\mathrm{C} / \mathrm{C}$ \\
\hline HL1800 & $\mathrm{G} / \mathrm{C}$ & $G / G$ & $\mathrm{~A} / \mathrm{A}$ & $\mathrm{C} / \mathrm{C}$ & $\mathrm{G} / \mathrm{A}$ & $\mathrm{G} / \mathrm{A}$ & $\mathrm{A} / \mathrm{A}$ & $C /(C)$ \\
\hline
\end{tabular}

Tab. 30: Skelettserie Lübeck Hungersnot: Ergebnisse der SNP-Genotypisierungen

\begin{tabular}{|c|c|c|c|c|c|c|c|c|}
\hline FNR & $\begin{array}{c}\text { IL6 } \\
-174\end{array}$ & $\begin{array}{c}\text { TLR2 } \\
753\end{array}$ & $\begin{array}{c}\text { TLR4 } \\
299\end{array}$ & $\begin{array}{c}\text { TLR4 } \\
399\end{array}$ & $\begin{array}{c}\text { IL10 } \\
-1087\end{array}$ & $\begin{array}{c}\text { IL10 } \\
-2849\end{array}$ & $\begin{array}{c}\text { IL4Ra } \\
576\end{array}$ & $\begin{array}{c}\text { IL4 } \\
-524\end{array}$ \\
\hline HL1002 & $-/-$ & $(A) /-$ & $-/-$ & (C)/- & $-/-$ & $(G) / A$ & (A)/- & $-/-$ \\
\hline HL1003 & $\mathrm{G} /(\mathrm{C})$ & $G /(A)$ & $\mathrm{A} / \mathrm{A}$ & $C /(T)$ & $G / A$ & $(G) / A$ & $(G) / A$ & $C / C$ \\
\hline HL1104 & $\mathrm{G} /(\mathrm{G})$ & $G /(A)$ & $\mathrm{A} / \mathrm{A}$ & $\mathrm{C} / \mathrm{C}$ & $G / A$ & $\mathrm{G} / \mathrm{A}$ & $\mathrm{G} / \mathrm{A}$ & (C)/- \\
\hline HL1105 & $(G) /-$ & $(G) /-$ & $A /-$ & $-/-$ & $-/-$ & $(\mathrm{G} / \mathrm{A})$ & $\mathrm{G} / \mathrm{A}$ & C/- \\
\hline HL1206 & $\mathrm{G} /(\mathrm{G})$ & $\mathrm{G} / \mathrm{G}$ & $\mathrm{A} / \mathrm{A}$ & $C /(T)$ & $G / A$ & $\mathrm{G} / \mathrm{A}$ & $\mathrm{G} / \mathrm{A}$ & $\mathrm{C} / \mathrm{C}$ \\
\hline HL1222 & $\mathrm{C} /(\mathrm{C})$ & $\mathrm{G} / \mathrm{G}$ & $\mathrm{A} / \mathrm{A}$ & $C / C$ & $\mathrm{~A} / \mathrm{A}$ & $\mathrm{G} / \mathrm{A}$ & $\mathrm{G} / \mathrm{A}$ & $\mathrm{C} / \mathrm{C}$ \\
\hline HL1224 & $\mathrm{C} / \mathrm{C}$ & $\mathrm{G} / \mathrm{G}$ & $A / A$ & $C / C$ & $\mathrm{G} / \mathrm{G}$ & $\mathrm{G} / \mathrm{A}$ & $\mathrm{A} / \mathrm{A}$ & $\mathrm{C} / \mathrm{C}$ \\
\hline HL1381 & $\mathrm{G} / \mathrm{G}$ & $\mathrm{G} / \mathrm{G}$ & $A / G$ & $\mathrm{C} / \mathrm{T}$ & $G / A$ & $\mathrm{G} / \mathrm{A}$ & $\mathrm{G} / \mathrm{A}$ & $\mathrm{C} / \mathrm{C}$ \\
\hline HL1766 & $\mathrm{G} /(\mathrm{C})$ & $G /(A)$ & $\mathrm{A} /(\mathrm{G})$ & $\mathrm{C} /(\mathrm{T})$ & $G / A$ & $G /(A)$ & $\mathrm{A} / \mathrm{A}$ & $\mathrm{C} /(\mathrm{T})$ \\
\hline HL1817 & $(G) /-$ & $-/-$ & $-/-$ & $(C) /-$ & $-/-$ & $(G) / A$ & $(G) /-$ & $-/-$ \\
\hline HL1824 & $\mathrm{C} / \mathrm{C}$ & $\mathrm{G} / \mathrm{G}$ & $\mathrm{A} / \mathrm{A}$ & $\mathrm{C} / \mathrm{C}$ & $G / A$ & $\mathrm{G} / \mathrm{G}$ & $\mathrm{G} / \mathrm{A}$ & $\mathrm{C} / \mathrm{C}$ \\
\hline HL1825 & $C /(C)$ & $\mathrm{G} / \mathrm{G}$ & $\mathrm{A} / \mathrm{A}$ & $\mathrm{C} / \mathrm{C}$ & $\mathrm{G} / \mathrm{G}$ & $\mathrm{A} /-$ & $\mathrm{A} / \mathrm{A}$ & $\mathrm{C} / \mathrm{C}$ \\
\hline HL1827 & $(\mathrm{G} / \mathrm{C})$ & $\mathrm{G} /(\mathrm{G})$ & $A /-$ & $C /(C)$ & G/- & $\mathrm{A} / \mathrm{A}$ & $\mathrm{A} /(\mathrm{A})$ & (C)/- \\
\hline HL1828 & $\mathrm{C} / \mathrm{C}$ & $G / G$ & $\mathrm{~A} / \mathrm{A}$ & $\mathrm{C} / \mathrm{C}$ & $\mathrm{A} / \mathrm{A}$ & $G / A$ & $\mathrm{~A} / \mathrm{A}$ & $C / C$ \\
\hline HL1838 & $(G) /-$ & $-/-$ & $(A) /-$ & $(T) /-$ & $(G) /-$ & $\mathrm{A} /-$ & $\mathrm{A} /-$ & $-/-$ \\
\hline HL1843 & $\mathrm{G} /(\mathrm{G})$ & $\mathrm{G} /(\mathrm{G})$ & $\mathrm{A} / \mathrm{A}$ & $\mathrm{C} /(\mathrm{C})$ & $G / A$ & $(G) / A$ & $\mathrm{G} / \mathrm{A}$ & $\mathrm{C} / \mathrm{C}$ \\
\hline HL1871 & $(G) /-$ & $-/-$ & $(A) /-$ & $(\mathrm{C} / \mathrm{T})$ & $-/-$ & $\mathrm{A} /(\mathrm{A})$ & $A /-$ & $-/-$ \\
\hline
\end{tabular}


Tab. 30: Skelettserie Lübeck Hungersnot: Typisierungsergebnisse fortgesetzt

\begin{tabular}{|c|c|c|c|c|c|c|c|c|}
\hline FNR & $\begin{array}{c}\text { IL6 } \\
-174\end{array}$ & $\begin{array}{c}\text { TLR2 } \\
753\end{array}$ & $\begin{array}{c}\text { TLR4 } \\
299\end{array}$ & $\begin{array}{c}\text { TLR4 } \\
399\end{array}$ & $\begin{array}{c}\text { IL10 } \\
-2849\end{array}$ & $\begin{array}{l}\text { IL10 } \\
-1087\end{array}$ & $\begin{array}{c}\text { IL4Ra } \\
576\end{array}$ & $\begin{array}{c}\text { IL4 } \\
-524\end{array}$ \\
\hline HL1883 & $\mathrm{G} / \mathrm{C}$ & $\mathrm{G} / \mathrm{G}$ & $\mathrm{A} /-$ & $C / T$ & G/- & $G / A$ & $\mathrm{~A} /-$ & (C)/- \\
\hline HL1884 & $\mathrm{G} / \mathrm{C}$ & $G / G$ & $\mathrm{~A} / \mathrm{A}$ & $C / C$ & $\mathrm{~A} / \mathrm{A}$ & G/- & $\mathrm{A} / \mathrm{A}$ & $\mathrm{C} / \mathrm{C}$ \\
\hline HL1887 & $G / G$ & $G / G$ & $\mathrm{~A} / \mathrm{A}$ & $C / T$ & $\mathrm{~A} / \mathrm{A}$ & $\mathrm{G} /-$ & $\mathrm{A} / \mathrm{A}$ & $\mathrm{C} / \mathrm{C}$ \\
\hline HL1896 & $\mathrm{C} /-$ & G/- & $\mathrm{A} /(\mathrm{A})$ & $\mathrm{C} /-$ & $G /(A)$ & $\mathrm{A} /-$ & $\mathrm{A} /(\mathrm{A})$ & $C /(C)$ \\
\hline HL1899 & $\mathrm{G} /(\mathrm{G})$ & $G / G$ & $\mathrm{~A} / \mathrm{A}$ & $\mathrm{C} / \mathrm{C}$ & $\mathrm{G} / \mathrm{A}$ & $\mathrm{G} / \mathrm{A}$ & $\mathrm{A} / \mathrm{A}$ & $\mathrm{C} / \mathrm{C}$ \\
\hline HL1902 & $\mathrm{G} / \mathrm{G}$ & $\mathrm{G} / \mathrm{A}$ & $\mathrm{A} / \mathrm{A}$ & $\mathrm{C} / \mathrm{C}$ & $\mathrm{A} / \mathrm{A}$ & $G / A$ & $\mathrm{~A} / \mathrm{A}$ & $\mathrm{C} / \mathrm{C}$ \\
\hline HL1909 & $\mathrm{C} / \mathrm{C}$ & $G / G$ & $\mathrm{~A} / \mathrm{A}$ & $\mathrm{C} / \mathrm{C}$ & $G / A$ & $G / A$ & $\mathrm{G} / \mathrm{A}$ & $\mathrm{C} / \mathrm{C}$ \\
\hline HL1920 & $(G) /-$ & $(\mathrm{G}) /-$ & $(\mathrm{A}) /-$ & $-/-$ & $-/-$ & $(G) / A$ & $\mathrm{~A} /-$ & $-/-$ \\
\hline HL1922 & $\mathrm{G} /(\mathrm{G})$ & $\mathrm{G} / \mathrm{G}$ & $\mathrm{A} / \mathrm{A}$ & $\mathrm{C} / \mathrm{T}$ & $\mathrm{A} / \mathrm{A}$ & $(\mathrm{G}) / \mathrm{A}$ & $\mathrm{A} / \mathrm{A}$ & $C / C$ \\
\hline HL1938 & $\mathrm{C} / \mathrm{C}$ & $\mathrm{G} / \mathrm{G}$ & $\mathrm{A} / \mathrm{A}$ & $\mathrm{C} / \mathrm{C}$ & $G / A$ & $\mathrm{G} / \mathrm{A}$ & $\mathrm{A} / \mathrm{A}$ & $\mathrm{C} / \mathrm{C}$ \\
\hline HL1973 & $\mathrm{G} / \mathrm{C}$ & $A /(G)$ & $\mathrm{A} / \mathrm{A}$ & $C / C$ & $G / G$ & $A /-$ & $\mathrm{A} / \mathrm{A}$ & $C / C$ \\
\hline HL1974 & $\mathrm{G} / \mathrm{G}$ & $\mathrm{G} / \mathrm{G}$ & $\mathrm{A} / \mathrm{G}$ & $C / C$ & $\mathrm{G} / \mathrm{A}$ & $\mathrm{G} / \mathrm{A}$ & $\mathrm{G} / \mathrm{A}$ & $\mathrm{C} / \mathrm{C}$ \\
\hline HL1976 & $(\mathrm{G}) / \mathrm{C}$ & $G / G$ & $\mathrm{~A} / \mathrm{A}$ & $\mathrm{C} / \mathrm{C}$ & $\mathrm{G} / \mathrm{A}$ & $\mathrm{G} / \mathrm{A}$ & $\mathrm{A} / \mathrm{A}$ & $C / C$ \\
\hline HL1978 & $(G) /-$ & $-/-$ & $-/-$ & (C)/- & $-/-$ & $\mathrm{A} /-$ & $(G) / A$ & $-/-$ \\
\hline HL1982 & $\mathrm{G} /(\mathrm{C})$ & $G / G$ & $\mathrm{~A} / \mathrm{A}$ & $\mathrm{C} / \mathrm{C}$ & $\mathrm{G} / \mathrm{A}$ & $\mathrm{G} / \mathrm{A}$ & $\mathrm{G} / \mathrm{A}$ & $C / C$ \\
\hline HL1983 & $\mathrm{G} / \mathrm{C}$ & $G / G$ & $\mathrm{~A} / \mathrm{A}$ & $\mathrm{C} / \mathrm{C}$ & $G / G$ & $\mathrm{~A} / \mathrm{A}$ & $\mathrm{A} / \mathrm{A}$ & $\mathrm{C} / \mathrm{C}$ \\
\hline HL1989 & $\mathrm{G} / \mathrm{C}$ & $G / G$ & $\mathrm{~A} / \mathrm{A}$ & $C / C$ & $\mathrm{G} / \mathrm{G}$ & $\mathrm{A} /(\mathrm{A})$ & $\mathrm{A} / \mathrm{A}$ & $\mathrm{C} / \mathrm{C}$ \\
\hline HL1991 & $-/-$ & $-/-$ & (A)/- & $-/-$ & $(G / A)$ & $\mathrm{A} /-$ & $\mathrm{A} /-$ & (C)/- \\
\hline HL1996 & $\mathrm{G} / \mathrm{C}$ & $G / G$ & $\mathrm{~A} /(\mathrm{A})$ & $\mathrm{C} / \mathrm{C}$ & $\mathrm{A} /(\mathrm{A})$ & G/- & $A /(A)$ & $C /(C)$ \\
\hline HL1999/1 & $\mathrm{G} / \mathrm{G}$ & $G / G$ & $\mathrm{~A} / \mathrm{A}$ & $C /(T)$ & $G / G$ & $\mathrm{~A} / \mathrm{A}$ & $\mathrm{A} / \mathrm{A}$ & $\mathrm{C} / \mathrm{C}$ \\
\hline HL1999/2 & $(\mathrm{G} / \mathrm{C})$ & G/- & $\mathrm{A} /(\mathrm{A})$ & $C /(C)$ & $(G) / A$ & $\mathrm{~A} /(\mathrm{A})$ & $\mathrm{A} /-$ & $C /(C)$ \\
\hline HL1999/3 & $\mathrm{C} / \mathrm{C}$ & $G / G$ & $A / G$ & $C / C$ & $\mathrm{G} / \mathrm{A}$ & $\mathrm{G} / \mathrm{A}$ & $\mathrm{A} / \mathrm{A}$ & $\mathrm{C} / \mathrm{C}$ \\
\hline HL2001 & $\mathrm{C} / \mathrm{C}$ & $\mathrm{G} / \mathrm{G}$ & $\mathrm{A} / \mathrm{A}$ & $\mathrm{C} / \mathrm{C}$ & $\mathrm{A} / \mathrm{A}$ & $G / A$ & $\mathrm{G} / \mathrm{A}$ & $\mathrm{C} / \mathrm{C}$ \\
\hline HL2045 & $-/-$ & $-/-$ & $(A / G)$ & $(\mathrm{C}) /-$ & $-/-$ & $\mathrm{G} / \mathrm{A}$ & $G / A$ & $-/-$ \\
\hline HL2057 & $\mathrm{G} / \mathrm{C}$ & $\mathrm{G} / \mathrm{G}$ & $\mathrm{A} /(\mathrm{A})$ & $C /(T)$ & $(G / A)$ & $\mathrm{G} / \mathrm{A}$ & $G / A$ & $C / C$ \\
\hline HL2058 & $G / G$ & $(G) / A$ & $\mathrm{~A} / \mathrm{A}$ & $\mathrm{C} / \mathrm{C}$ & $\mathrm{G} / \mathrm{A}$ & $\mathrm{G} / \mathrm{A}$ & $\mathrm{A} / \mathrm{A}$ & $\mathrm{C} / \mathrm{C}$ \\
\hline
\end{tabular}

Tab. 31: Skelettserie Dorste: Ergebnisse der SNP-Genotypisierungen. Angegeben sind nur die Ergebnisse der Stichprobe, die in die statistische Auswertung eingeht.

\begin{tabular}{lcccccccc}
\hline Ind & IL6 & TLR2 & TLR4 & TLR4 & IL10 & IL10 & IL4Ra & IL4 \\
& -174 & 753 & 299 & 399 & -1087 & -2849 & 576 & -524 \\
\hline Do F1 & G/G & G/G & A/(A) & C/C & G/(A) & G/A & G/A & $-/-$ \\
Do F 2 & G/(C) & $(\mathrm{G}) /-$ & $(\mathrm{A}) /-$ & $(\mathrm{C}) /-$ & $-/-$ & $(\mathrm{G} / \mathrm{A})$ & $(\mathrm{G}) / \mathrm{A}$ & $-/-$ \\
Do F 4 & $\mathrm{C} / \mathrm{C}$ & $\mathrm{G} / \mathrm{G}$ & $\mathrm{A} /(\mathrm{A})$ & $\mathrm{C} / \mathrm{C}$ & $\mathrm{G} /(\mathrm{G})$ & $\mathrm{A} /-$ & $\mathrm{A} /(\mathrm{A})$ & $(\mathrm{C}) /-$ \\
Do F 5 & $\mathrm{C} /-$ & $\mathrm{G} / \mathrm{G}$ & $\mathrm{A} /(\mathrm{A})$ & $\mathrm{C} / \mathrm{C}$ & $\mathrm{(G)/-}$ & $\mathrm{G} / \mathrm{A}$ & $\mathrm{A} /(\mathrm{A})$ & $\mathrm{C} /(\mathrm{C})$ \\
Do F 9 & $\mathrm{G} / \mathrm{C}$ & $\mathrm{G} /(\mathrm{G})$ & $\mathrm{A} /(\mathrm{A})$ & $\mathrm{C} /(\mathrm{C})$ & $\mathrm{G} / \mathrm{A}$ & $\mathrm{G} / \mathrm{A}$ & $\mathrm{G} / \mathrm{A}$ & $\mathrm{C} /(\mathrm{C})$ \\
Do F10 & $\mathrm{G} /(\mathrm{C})$ & $\mathrm{G} / \mathrm{G}$ & $\mathrm{A} /-$ & $\mathrm{C} / \mathrm{C}$ & $\mathrm{G} / \mathrm{G}$ & $\mathrm{G} / \mathrm{A}$ & $\mathrm{G} / \mathrm{A}$ & $\mathrm{C} /-$ \\
\hline
\end{tabular}


Tab. 31: Skelettserie Dorste: Typisierungsergebnisse fortgesetzt

\begin{tabular}{|c|c|c|c|c|c|c|c|c|}
\hline Ind & $\begin{array}{c}\text { IL6 } \\
-174\end{array}$ & $\begin{array}{c}\text { TLR2 } \\
753\end{array}$ & $\begin{array}{c}\text { TLR4 } \\
299\end{array}$ & $\begin{array}{c}\text { TLR4 } \\
399\end{array}$ & $\begin{array}{c}\text { IL10 } \\
-1087\end{array}$ & $\begin{array}{c}\text { IL10 } \\
-2849\end{array}$ & $\begin{array}{c}\text { IL4Ra } \\
576\end{array}$ & $\begin{array}{c}\text { IL4 } \\
-524\end{array}$ \\
\hline Do F11 & $-/-$ & $-/-$ & $A /-$ & (C)/- & $-/-$ & (G)/- & (A)/- & $-/-$ \\
\hline Do F12 & $\mathrm{C} / \mathrm{C}$ & $\mathrm{G} / \mathrm{G}$ & $A /-$ & $\mathrm{C} / \mathrm{C}$ & $A /-$ & $\mathrm{G} / \mathrm{A}$ & $\mathrm{A} /-$ & $-/-$ \\
\hline Do F14 & $C /(C)$ & $G /(A)$ & $\mathrm{A} /(\mathrm{A})$ & $\mathrm{C} / \mathrm{C}$ & $\mathrm{A} /(\mathrm{A})$ & $G / A$ & $G / A$ & $\mathrm{C} /-$ \\
\hline Do F15 & $-/-$ & G/- & A/- & $\mathrm{C} /-$ & $-/-$ & $(G / A)$ & $(\mathrm{G}) / \mathrm{A}$ & $-/-$ \\
\hline Do F16 & $-/-$ & G/- & $(\mathrm{A} / \mathrm{G})$ & $C /-$ & $\mathrm{A} /-$ & $(G / A)$ & $\mathrm{A} /-$ & (C)/- \\
\hline Do $F$ & (G)/- & $(G / A)$ & $(A) /-$ & $\mathrm{C} /-$ & $-/-$ & (A)/- & $(\mathrm{G}) / \mathrm{A}$ & (C)/- \\
\hline Do $F$ & $\mathrm{G} / \mathrm{C}$ & $\mathrm{G} /(\mathrm{G})$ & $(\mathrm{A}) /-$ & $\mathrm{C} /(\mathrm{C})$ & $(G / A)$ & $\mathrm{A} /-$ & $\mathrm{A} /(\mathrm{A})$ & (C)/- \\
\hline Do F & $-/-$ & $-/-$ & $-/-$ & $-/-$ & $-/-$ & (A) $/-$ & A/- & $-/-$ \\
\hline Do $N$ & $\mathrm{G} / \mathrm{C}$ & $G /(A)$ & $(\mathrm{A}) /-$ & $\mathrm{C} / \mathrm{C}$ & $\mathrm{A} /-$ & $\mathrm{G} / \mathrm{A}$ & $\mathrm{G} / \mathrm{A}$ & (C)/- \\
\hline Do I & $\mathrm{C} / \mathrm{C}$ & $\mathrm{G} / \mathrm{G}$ & $\mathrm{A} /-$ & $\mathrm{C} / \mathrm{C}$ & (A)/- & $\mathrm{G} / \mathrm{A}$ & $\mathrm{A} /-$ & (C)/- \\
\hline Do $M$ & $-/-$ & $(G) /-$ & $(G) /-$ & (C)/- & $(G / A)$ & $(G / A)$ & $-/-$ & $\mathrm{C} /-$ \\
\hline Do M 7 & $\mathrm{G} / \mathrm{C}$ & $G /(G)$ & $\mathrm{A} /-$ & $\mathrm{C} /(\mathrm{C})$ & $\mathrm{G} / \mathrm{A}$ & (G)/A & $\mathrm{G} / \mathrm{A}$ & $\mathrm{C} /-$ \\
\hline Do M 9 & $\mathrm{G} / \mathrm{G}$ & $\mathrm{G} / \mathrm{G}$ & $A /-$ & $\mathrm{C} / \mathrm{C}$ & $(G) /-$ & $\mathrm{G} / \mathrm{A}$ & $\mathrm{A} /-$ & (C)/- \\
\hline Do M10 & $C /(C)$ & $\mathrm{G} /(\mathrm{G})$ & $\mathrm{A} / \mathrm{G}$ & $\mathrm{C} /(\mathrm{C})$ & $G / A$ & $\mathrm{~A} /-$ & $\mathrm{G} / \mathrm{A}$ & $\mathrm{C} /-$ \\
\hline Do M13 & $\mathrm{G} /(\mathrm{G})$ & $\mathrm{G} /(\mathrm{G})$ & $A /-$ & $\mathrm{C} /(\mathrm{C})$ & $\mathrm{A} /-$ & $\mathrm{G} / \mathrm{A}$ & $\mathrm{A} /-$ & (C)/- \\
\hline Do M14 & $-/-$ & $(G) /-$ & $-/-$ & $-/-$ & $-/-$ & $(G / A)$ & $(G) /-$ & (C)/- \\
\hline Do M19 & $(G) / C$ & G/- & $-/-$ & C/- & $(\mathrm{A}) /-$ & (G)/A & $\mathrm{A} /(\mathrm{A})$ & $-/-$ \\
\hline
\end{tabular}




\subsection{Auswertung der Typisierungsergebnisse}

Die Tabelle 32 faßt die beobachteten Allelfrequenzen des in der Literatur als minor allele angegebenen Alleles in den historischen Stichproben zusammen.

Tab. 32: Allelfrequenzen in den untersuchten historischen Populationen. Angegeben ist jeweils die Frequenz des Allels, das in der rezenten Bevölkerung die geringere Frequenz aufweist.

\begin{tabular}{lllllll}
\hline SNP & IL6 & TLR2 & TLR4 & IL10 & IL10 & IL4Ra \\
& -174 C & R753Q A & D299G & G-1087A & G-2849A & Q576R \\
\hline Allel & C & A & G & G & A & G \\
\hline Do & 0,53 & 0,07 & 0,1 & 0,41 & 0,59 & 0,27 \\
HL Hungersnot & 0,42 & 0,11 & 0,06 & 0,51 & 0,59 & 0,21 \\
HL Pest & 0,37 & 0,11 & 0,13 & 0,54 & 0,66 & 0,24 \\
\hline
\end{tabular}

Im folgenden werden die Verteilungen der Genotypen und die daraus bestimmten Allelfrequenzen der einzelnen SNP vorgestellt. Daran schließen die Ergebnisse der statistischen Auswertung an. Für diese Darstellung wurden jeweils die reproduziert Homozygoten und unsicheren Homozygoten eines Alleles zusammengefasst. Der Allelfrequenz $F_{(G G)}$ liegen demnach sowohl die Ergebnisse G/G, G/(G) als auch G/- zugrunde. Den Genotypenhäufigkeiten der einzelnen SNP liegen unterschiedliche Individuenzahlen zugrunde, da Individuen bei denen ein Locus aufgrund mangelnden Amplifikationserfolgs nicht typisiert werden konnte (im Endergebnis durch -/- gekennzeichnet), für diesen einen Locus ausgeschlossen wurden. Dadurch entstehen Subpopulationen, die sich zwischen den einzelnen Loci unterscheiden. Da die Loci nicht miteinander verglichen werden, dient der Ausschluß der fehlenden Ergebnisse der Stärkung der Aussagekraft der statistischen Tests. Unterschiede zwischen den Subpopulationen hingegen sind in diesem Zusammenhang weniger relevant. Als Folge ergeben sich unter anderem auch unterschiedliche Individuenzahlen für die einzelnen Subpopulationen, je nach Typisierungserfolg der einzelnen Marker (vgl. Tab. 33).

Als rezente Kontrolle wurden Arbeiten aus der Literatur herangezogen (vgl. Referenzen). Die Vergleichsdaten des IL10 G-2849A stammen aus einer niederländischen Bevölkerung (Moraes et al., 2003). Daten einer deutschstämmigen Bevölkerung standen nicht zur Verfügung. Für die Marker IL10 G-1087A, TLR4 D299G und IL4Ra Q576R wurden Daten aus einer Kontrollkohorte aus dem 
Raum Göttingen und Tübingen herangezogen. Die Daten wurden von der Abteilung Hämatologie und Onkologie, PD Dr. D. Kube, Universitätsklinikum Göttingen überlassen. Die übrigen Vergleichsdaten wurden ebenfalls in der deutschen Bevölkerung erhoben (Schröder et al., 2003; Nieters et al., 2001).

Tab. 33: Anzahl der Individuen, die in die Stichproben für die statistische Auswertung eingeflossen sind. Angegeben sind auch die Stichprobengrößen der Rezentpopulationen

\begin{tabular}{lcccccc}
\hline & IL6 -174 & TLR2 753 & TLR4 299 & IL10-1087 & IL10 -2849 & IL4Ra 576 \\
\hline Dorste & 17 & 21 & 20 & 17 & 23 & 22 \\
HL Hungersnot & 39 & 37 & 40 & 36 & 43 & 43 \\
HL Pest & 67 & 71 & 74 & 69 & 46 & 82 \\
Rezent & 224 & 319 & 263 & 264 & 315 & 262 \\
\hline
\end{tabular}

\subsubsection{Toll-like Rezeptor 2}

In beiden mittelalterlichen Skelettserien wurden Homozygote für das variant allele gefunden. Diese sind in der modernen Bevölkerung nicht vertreten (Schröder et al., 2003, z. B.). Die Genotypenhäufigkeiten unterscheiden sich allerdings mit maximal 10\% nur gering. Jedoch kann die höchste Häufigkeit für G-Homozygote in der Rezentbevölkerung, die geringste im Kollektiv der Hungersnot verzeichnet werden. Die Skelettserien „HL Pest“ und Dorste liegen in ihren Häufigkeiten zwischen diesen. Die Verschiebungen der Genotypen liegt in einer Zunahme der A-Träger, vor allem der heterozygoten begründet. Hier zeigt sich der umgekehrte Trend der G-Homozygoten. 


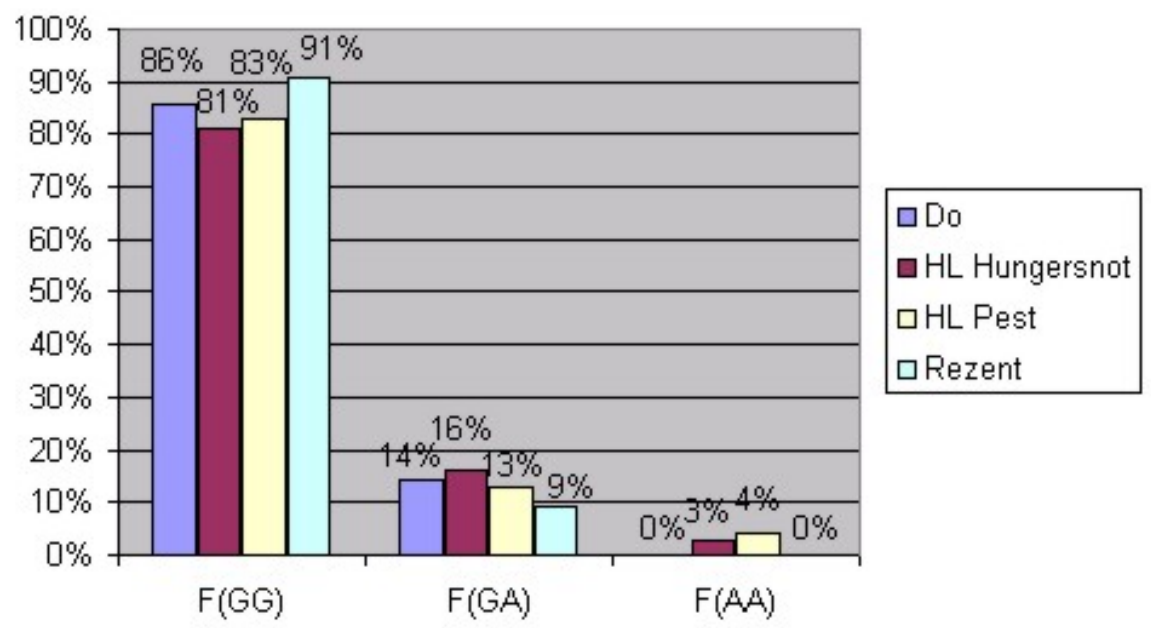

Abb. 13: Genotypen des SNP TLR2 R753G: Die Verteilung in den drei historischen Populationen im Vergleich zur deutschen Rezentbevölkerung (Konstanz/Berlin). Quelle der Rezentdaten: Schröder et al. (2003)

In den Allelfrequenzen stehen hingegen die beiden mittelalterlichen Serien mit einer Frequenz des A-Allels von 0,11 der bronzezeitlichen Serie $(0,07)$ und der Rezentbevölkerung $(0,05)$ gegenüber. Der Unterschied der mittelalterlichen Serien liegt also nur in der Verteilung der Genotypen.

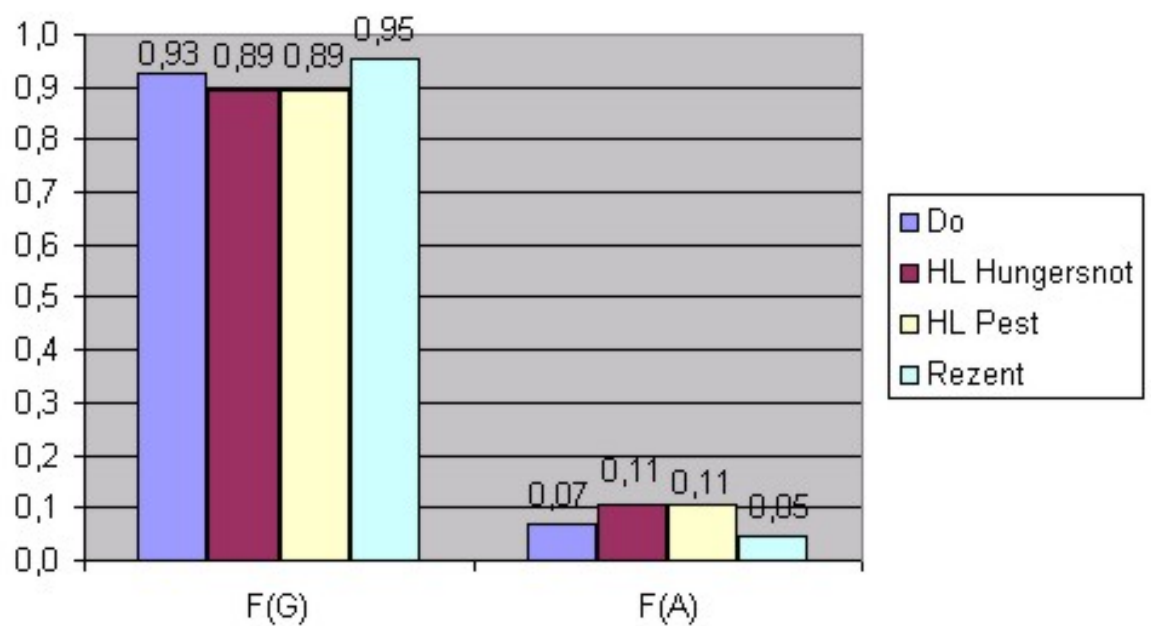

Abb. 14: Allelfrequenzen des SNP TLR2 R753G: Die drei historischen Populationen im Vergleich zur deutschen Rezentbevölkerung (Konstanz/Berlin). Quelle der Rezentdaten: Schröder et al. (2003)

Der Unterschied der mittelalterlichen Stichproben „HL Pest“ und „HL Hungersnot" zur modernen Stichprobe ist signifikant ( $p=0,018$ bzw. $p=0,033)$. Zwischen 
den Stichproben aller historischen Skelettserien sowie zwischen moderner und bronzezeitlicher Stichprobe sind keine signifikanten Unterschiede zu verzeichnen. Die Stichprobe der Lübecker Pestserie weicht vom HWE ab $(p=0,024)$. Hintergrund ist ein Heterozygotendefizit. Nach Hardy-Weinberg wäre eine Heterozygotenrate von 0,19 zu erwarten, beobachtet wurde nur eine Rate von 0,13. Alle anderen Stichproben liegen im HWE.

Der Marker TLR2 R753Q unterscheidet sich damit in beiden mittelalterlichen Populationen signifikant von der modernen Bevölkerung. Sie zeigen häufiger das Allel A, das die Variante $753 \mathrm{Q}$ kodiert. Für die Pest-Serie wurde dieses Ergebnis erwartet, da das A-Allel mit einem erhöhten Risiko für Infektionserkrankungen assoziiert wird. Sie sollte jedoch auch von der zweiten mittelalterlichen Serie abweichen, die als Kontrollkohorte ohne epidemiologischen Hintergrund eingesetzt wurde. Die Paarung der beiden mittelalterlichen Serien kommt daher unerwartet.

\subsubsection{Toll-like Rezeptor 4}

Auch für den SNP TLR4 D299G wurden homozygote Träger des minor alleles in den historischen Serien („Dorste“ und „HL Pest“) gefunden. In der Rezentbevölkerung und in der bronzezeitlichen Stichprobe fehlen diese. Die Serie „HL Pest" fällt durch die höchste Heterozygoten-Rate auf, die mit $20 \%$ doppelt so hoch ist, wie die der übrigen Populationen. Die Allelfrequenzen sind sich sehr ähnlich, der Unterschied entsteht alleine durch die Verteilung der G-Träger auf Homozygote und Heterozygote. Die höchste G-Allelfrequenz wird in der Stichprobe „HL Pest“ beobachtet. Mit 0,13 ist sie doppelt so hoch wie die der Stichprobe „HL Hungersnot“ und der rezenten Bevölkerung (beide 0,06). 


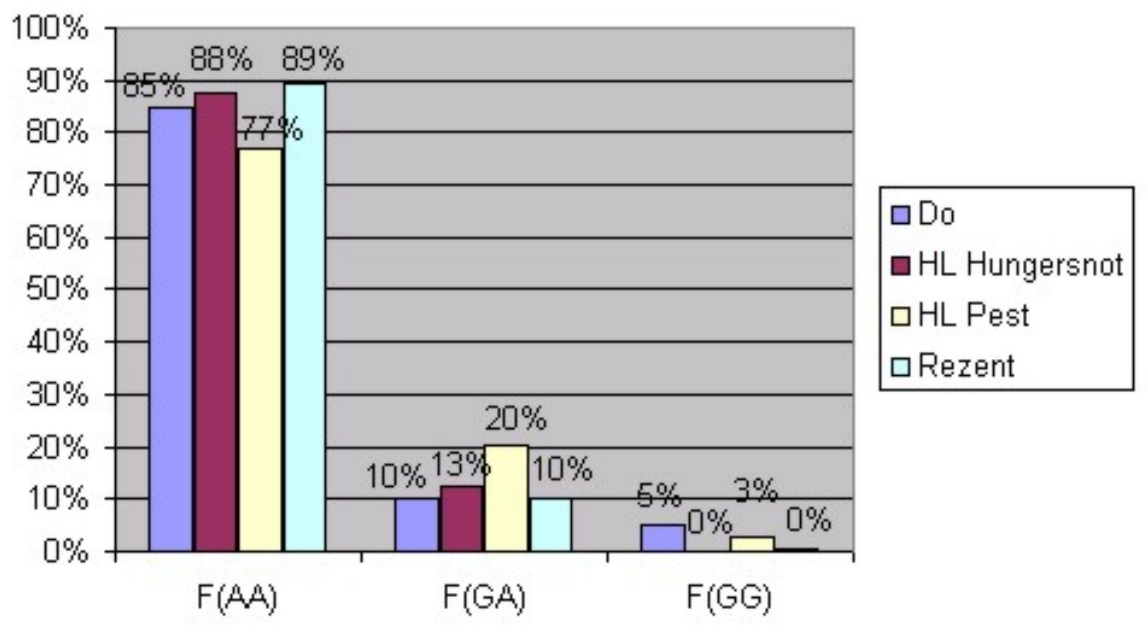

Abb. 15: TLR4 D299G: Genotypenhäufigkeiten der drei historischen Populationen im Vergleich zur deutschen Rezentbevölkerung (Tübingen/Göttingen)

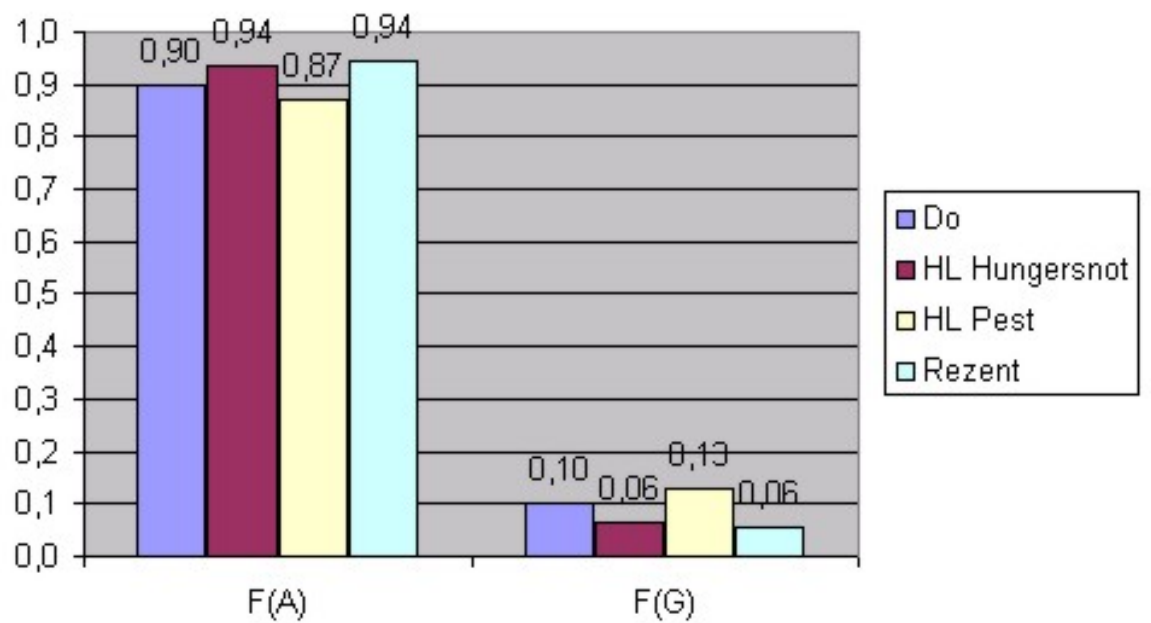

Abb. 16: TLR4 D299G: Allelfrequenzen der drei historischen Populationen im Vergleich zur deutschen Rezentbevölkerung (Tübingen/Göttingen)

Die Allelverteilung in der Stichprobe „HL Pest“ entspricht den Ergebnissen der statistischen Auswertung. Hier zeigt sich ein signifikanter Unterschied zur modernen Stichprobe $(p=0,015)$. Die Ergebnisse der übrigen Serien zueinander erreichen nicht das Signifikanzniveau. Die Stichproben erfüllen alle das HWE.

Der Trend der Allelfrequenzen des TLR4 D299G-Polymorphismus von höherer G-Allelfrequenz in der Stichprobe „Dorste“ hin zu niedriger Frequenz in der Rezentbevölkerung entspricht den Erwartungen. Die TLR4 Variante 299G (G-Allel) 
wird in verschiedenen Arbeiten als LPS-hyporesponsiv beschrieben. Die erhöhte Frequenz unter den Pestopfern und die Signifikanz dieser Abweichung zur modernen Bevölkerung entspricht der Erwartung.

\subsubsection{Interleukin 4 Rezeptor $\alpha$}

Bei den Genotypen der A-Allelträger (AA und GA) paaren sich die Stichproben „HL Pest" und Dorste sowie die Serie „HL Hungersnot" und die moderne Bevölkerung (Daten von D. Kube). Die Paarung „HL Pest“/„Dorste“ zeigt eine bis zu $10 \%$ niedrigere Häufigkeit der A-Homozygoten (50 und 54\%). Die Heterozygotenrate verhält sich entgegengesetzt. Der Unterschied ist in den Allelfrequenzen weniger auffällig. Hier schwankt die Frequenz des minor alleles zwischen 0,21 und 0,27 .

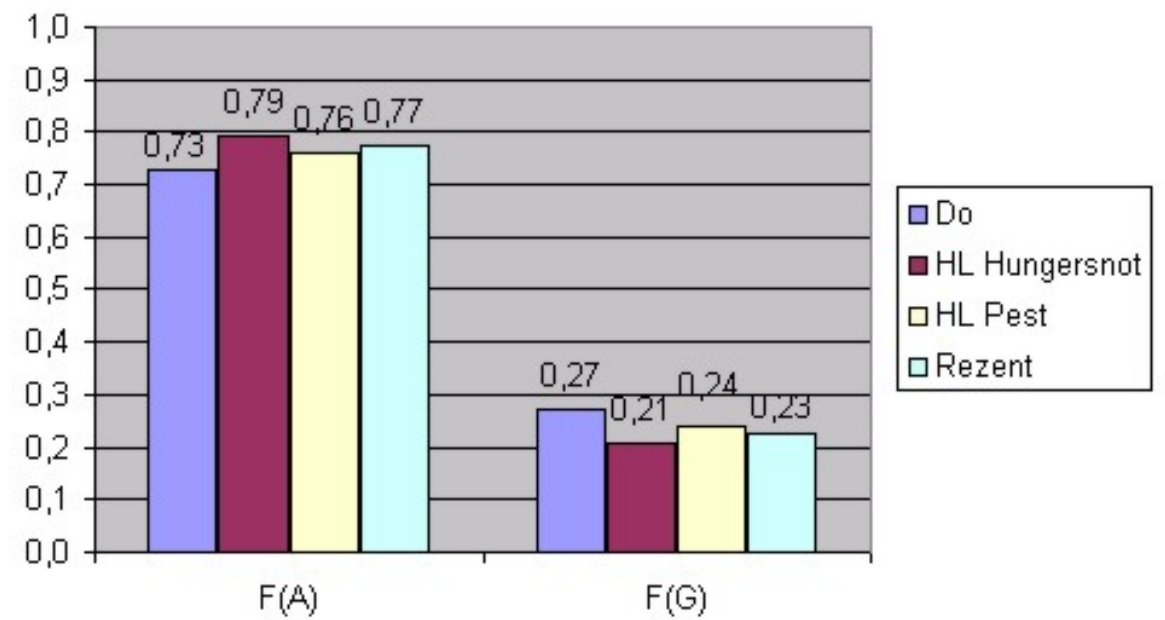

Abb. 17: IL4Ra Q576R: Allelfrequenzen der drei historischen Populationen. Rezentdaten: Tübingen/Göttingen

Für den Locus IL4Ra werden keine signifikanten Unterschiede beobachtet, auch wenn die Unterschiede in der Genotypen-Verteilung zunächst eine Signifikanz erwarten lassen. Die Serie „HL Pest“ weicht auch bei diesem Locus vom HWE ab $(p=0,034)$. Es wurden mehr Heterozygote beobachtet $(0,45)$ als nach HardyWeinberg zu erwarten sind (0,36). Die beobachtete Paarung der Allelfrequenzen der Serie „Dorste“ und „HL Pest" entspricht den Erwartungen. Zu beachten ist allerdings der Heterozygotenüberschuß innerhalb der Serie „HL Pest“, ohne den 
sich die Verteilung innerhalb der Pestserie möglicherweise der zweiten mittelalterlichen und der modernen Bevölkerung annähert.

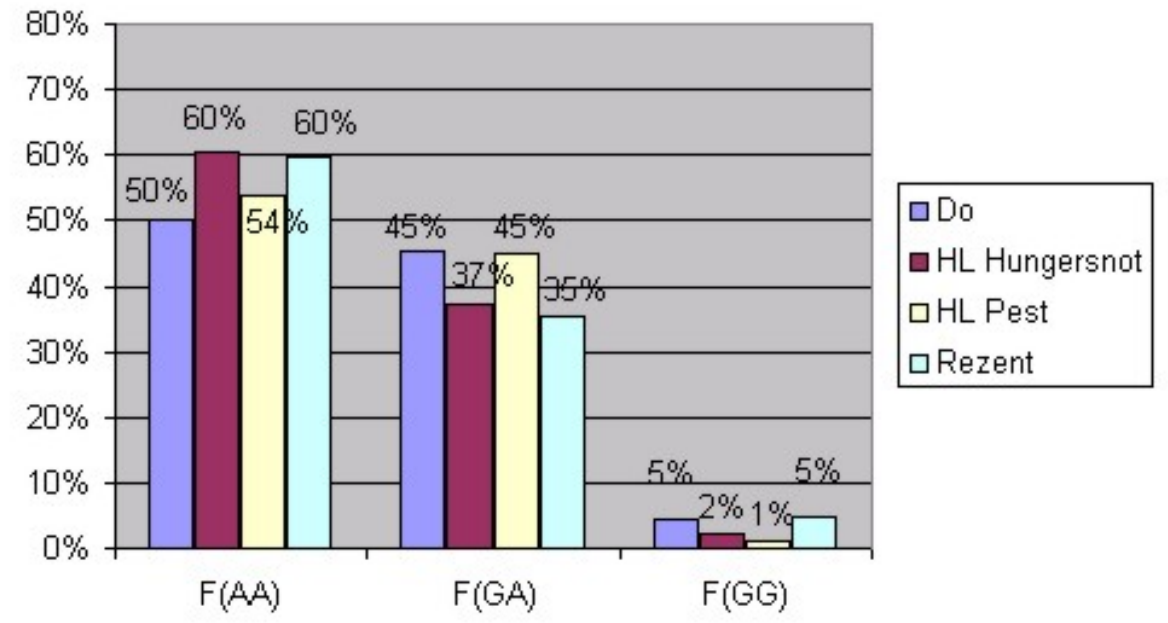

Abb. 18: IL4Ra Q576R: beobachtete Häufigkeit der Genotypen der drei historischen Populationen. Rezentdaten: Tübingen/Göttingen

\subsubsection{Interleukin 6}

Die Stichprobe „HL Pest“ fällt durch die geringste Anzahl homozygoter C-Träger auf. Diese geht mit der höchsten Heterozygotenrate einher. Insgesamt zeigt diese Stichprobe die größten Schwankungen in der Genotypenverteilung. Bei der Stichprobe „Dorste“ hingegen sind die Genotypfrequenzen sehr ausgeglichen, sie schwanken um ein Drittel. Die Heterozygotenrate der Stichprobe „HL Hungersnot“ entspricht der der Stichprobe „Dorste“. Die Verteilung der Homozygoten ist entgegengesetzt. Die Allelfrequenzen schwanken in allen Populationen um 50\%. Die Serie „Dorste“ zeigt einen umgekehrten Trend zu den übrigen Populationen, mit einer höheren Anzahl an C-Allelträgern. Die vorgestellten Rezentdaten stammen aus der Arbeit von Nieters et al. (2001).

Die Allelfrequenzen aller Populationen sind für den SNP IL6 G-174C im HardyWeinberg-Gleichgewicht. Die beobachteten Abweichungen erreichen nicht das Signifikanzniveau $(\mathrm{p}=0,05)$. Damit kann ein Unterschied zwischen den Populationen nicht nachgewiesen werden.

Das C-Allel wird mit einem erniedrigten IL6-Spiegel assoziiert, was eine Abschwächung der proinflammatorischen Wirkung des Zytokins bewirkt. In einer 


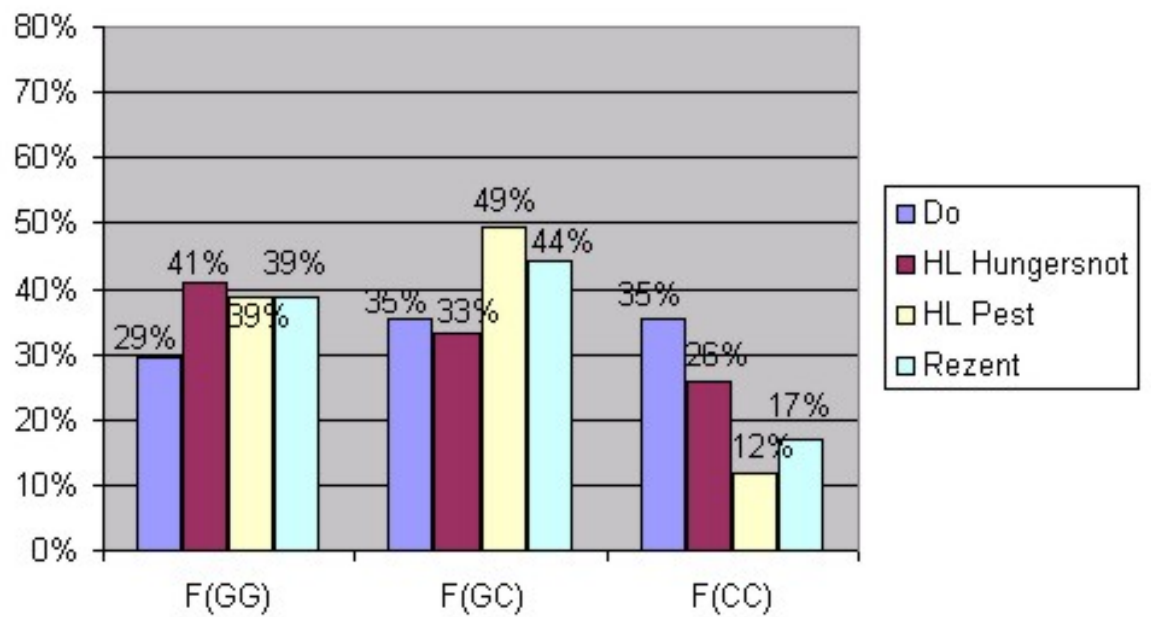

Abb. 19: IL6 G-174C: beobachtete Genotypenhäufigkeiten der drei historischen Populationen im Vergleich zur deutschen Rezentbevölkerung. Quelle der Rezentdaten: Nieters et al. (2001)

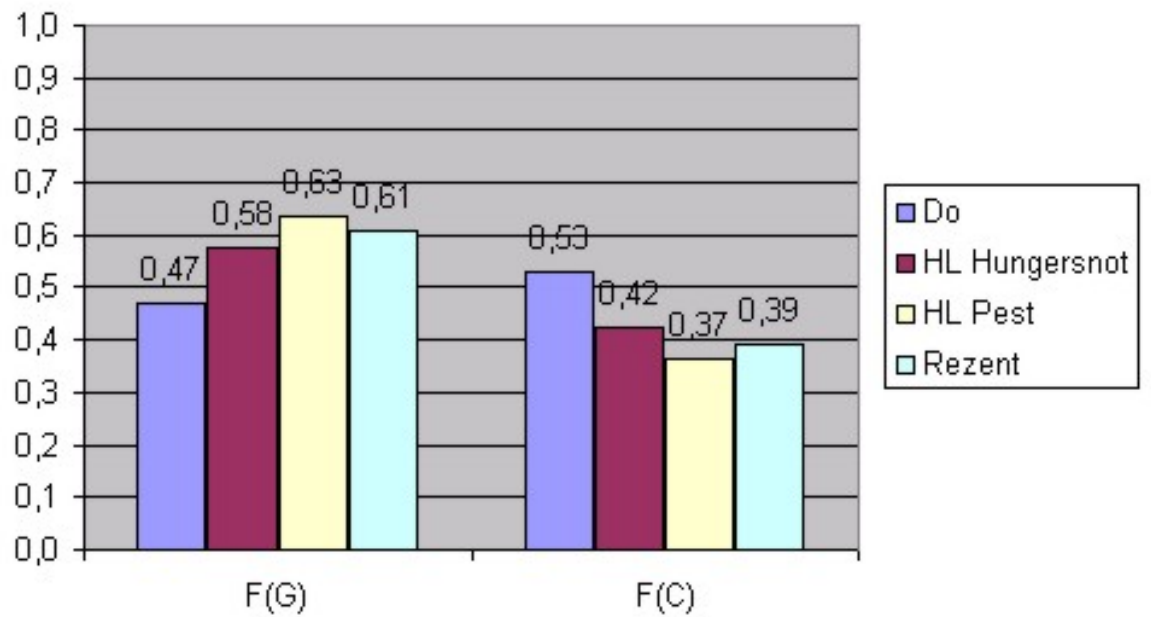

Abb. 20: IL6 G-174C: Allelfrequenzen der drei historischen Populationen im Vergleich zu einer deutschen Rezentpopulation. Quelle der Rezentdaten: Nieters et al. (2001) 
pathogenreichen Umwelt sollte dieses Allel gegenüber Trägern des häufigeren Alleles einen Nachteil bedeuten. Während einer Epidemie wie der Pest von 1350 sollten also vermehrt die Individuen versterben, die das C-Allel tragen. Daher wurde eine höhere Frequenz dieser Variante unter den Pestopfern erwartet. Ein dahingehender Trend kann nicht verzeichnet werden. Für die Skelettserie „Dorste" wurde ebenfalls ein höherer Anteil an C-Allelträgern erwartet. Die Individuen dieser Serie waren zu Lebzeiten einer geringeren Pathogenbelastung ausgesetzt, als es heutzutage der Fall ist. Das C-Allel kann in einer solchen Umwelt weniger einen Nachteil vermitteln. Während der zweiten historischen Transition sollte dieser Nachteil an Bedeutung gewonnen haben, eine Selektion zugunsten des G-Allel wird daher angenommen. Die Folge wäre eine Abnahme der C-Allel-Frequenz bis zur Neuzeit. Diese Entwicklung wird tendentiell in den vorliegenden Ergebnissen beobachtet.

\subsubsection{Interleukin 10}

Für den SNP G-1087A ist die beobachtetet Heterozygotenrate der Stichprobe „HL Pest“ mit 59\% am höchsten. Wie auch bei der zweiten mittelalterlichen Stichprobe ist der Anteil der AA-Homozygoten im Vergleich der Genotypen am geringsten. Auffällig ist die Häufigkeit der Heterozygoten in allen Stichproben außer der bronzezeitlichen: Besonders in den mittelalterlichen Serien ist sie mit 53 bzw. 59\% doppelt so hoch wie die der homozygoten Ausprägungen. Nur in der Stichprobe „Dorste“ stellen die AA-Homozygoten die größte Gruppe. Der Anteil der G-Homozygoten ist in allen Populationen mit ca. 25\% ausgeglichen. Die Unterschiede zwischen den Stichproben gehen von der Verteilung des A-Allels auf die Genotypen AA und AG aus. Die Anzahl der G-Allelträger (Genotyp GG und GA) ist dadurch größer als die der Nicht-G-Allelträger (Genotyp AA). 


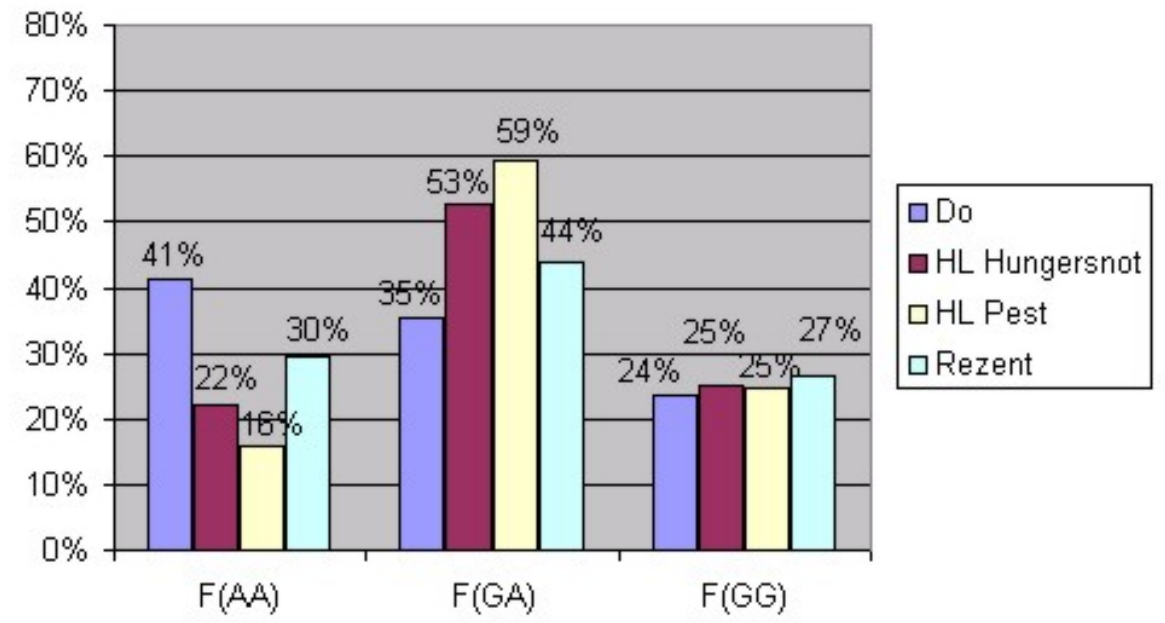

Abb. 21: IL10 G-1087A: beobachtete Genotypenhäufigkeiten der drei historischen Populationen im Vergleich zur deutschen Rezentbevölkerung (Tübingen/Göttingen)

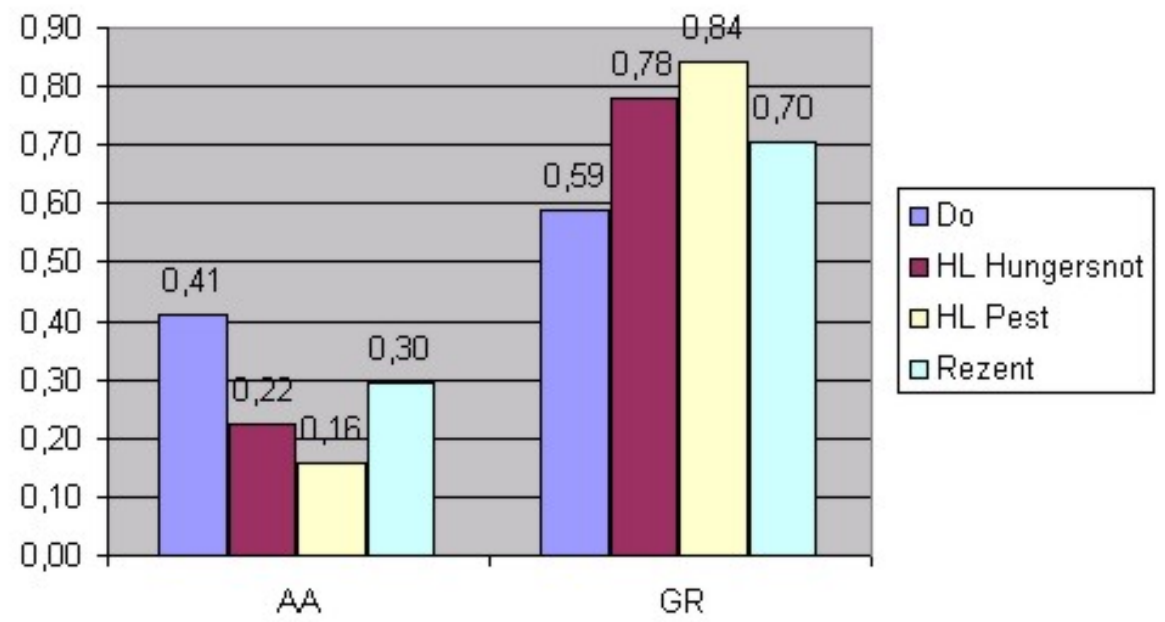

Abb. 22: IL10 G-1087A: Auftragung der G-Allelträger (Genotyp GG und GA) gegen Nicht-GAllelträger (Genotyp AA).

Die Unterschiede zwischen der Pestserie und der modernen Bevölkerung erreichen das Signifikanzniveau ( $\mathrm{p}=0.03890)$. Die Allelfrequenzen sind in allen Serien relativ ausgeglichen, die höchste A-Allelfrequenz zeigt sich in der bronzezeitlichen Serie $(0,59)$, die niedrigste in der Pestserie $(0,46)$. Die Allelfrequenzen weichen nicht vom Hardy-Weinberg-Gleichgewicht ab. 


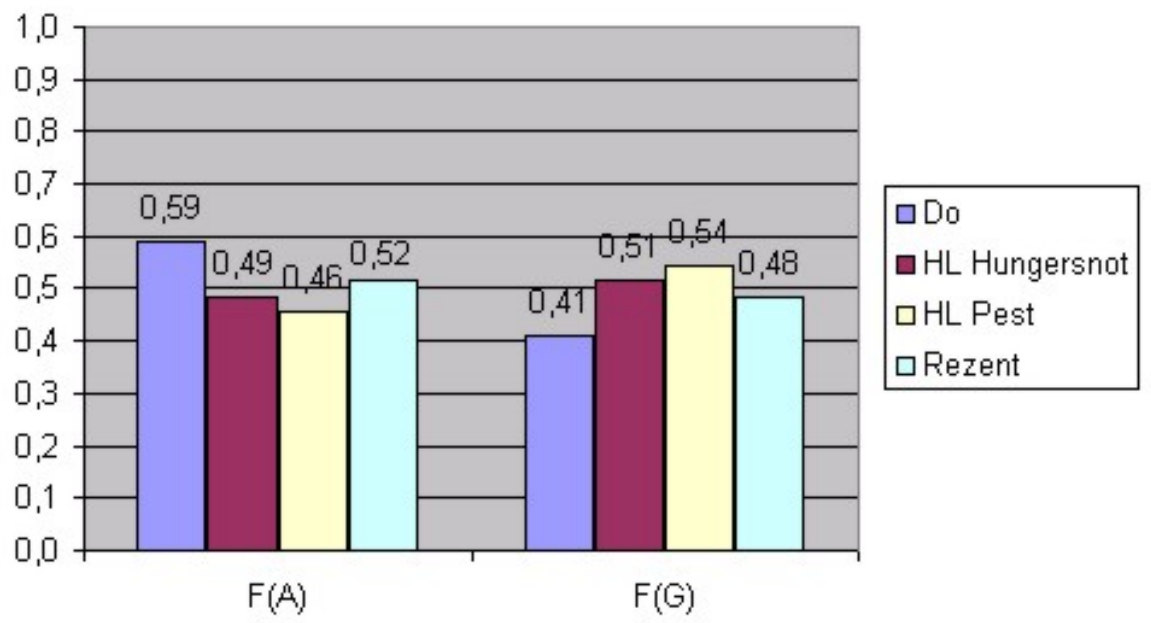

Abb. 23: IL10 G-1087A: Allelfrequenzen der drei historischen Populationen im Vergleich zur deutschen Rezentbevölkerung (Tübingen/Göttingen)

Für den SNP G-2849A unterscheiden sich die historischen Stichproben signifikant $(\mathrm{p}=0,000)$ von der modernen Bevölkerung (Moraes et al., 2003, Niederlande). Sie zeigen eine höhere Frequenz des A-Alleles (0,59 bis 0,66), während in der rezenten Bevölkerung das G-Allel vorherrscht $(0,70)$. Sowohl in der modernen als auch in den historischen Bevölkerungen ist eine große Anzahl an Heterozygoten zu finden. Die Verteilung der Homozygoten der historischen Bevölkerungen ist entgegengesetzt zur modernen, mit einer höheren Rate an A-Homozygoten und einer geringen Rate von G-Homozygoten (unter 10\%). Der größte Anteil an AHomozygoten ist unter den Pestopfern (39\%) zu finden. 


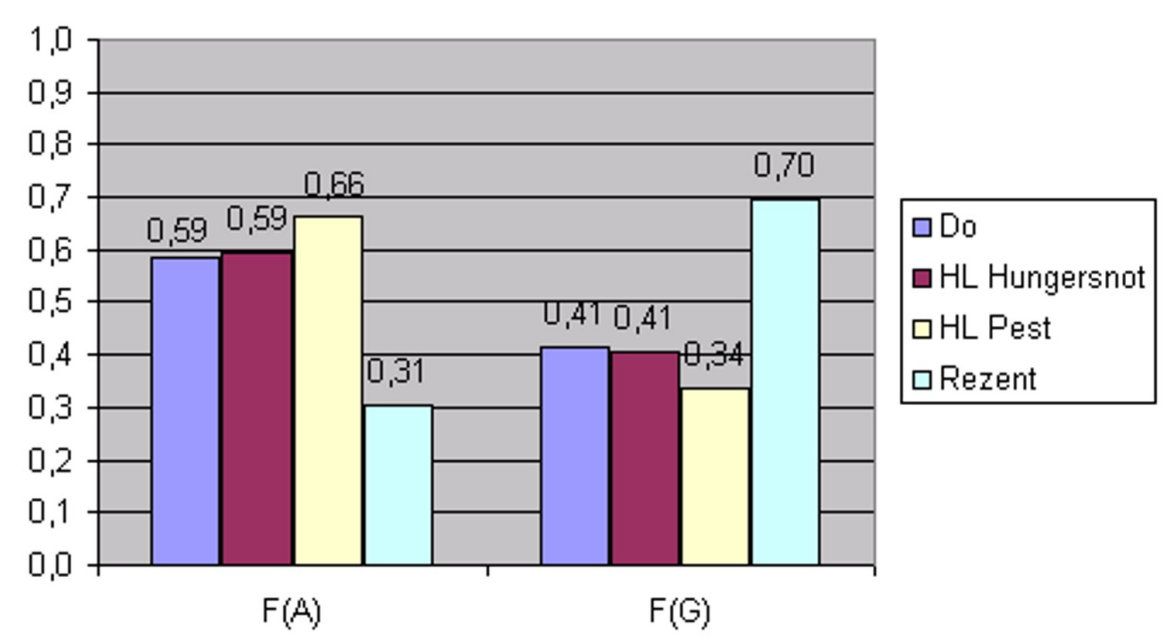

Abb. 24: IL10 G-2849A: Allelfrequenzen der drei historischen Populationen im Vergleich mit der Rezentbevölkerung. Quelle der Rezentdaten: Moraes et al. (2003)

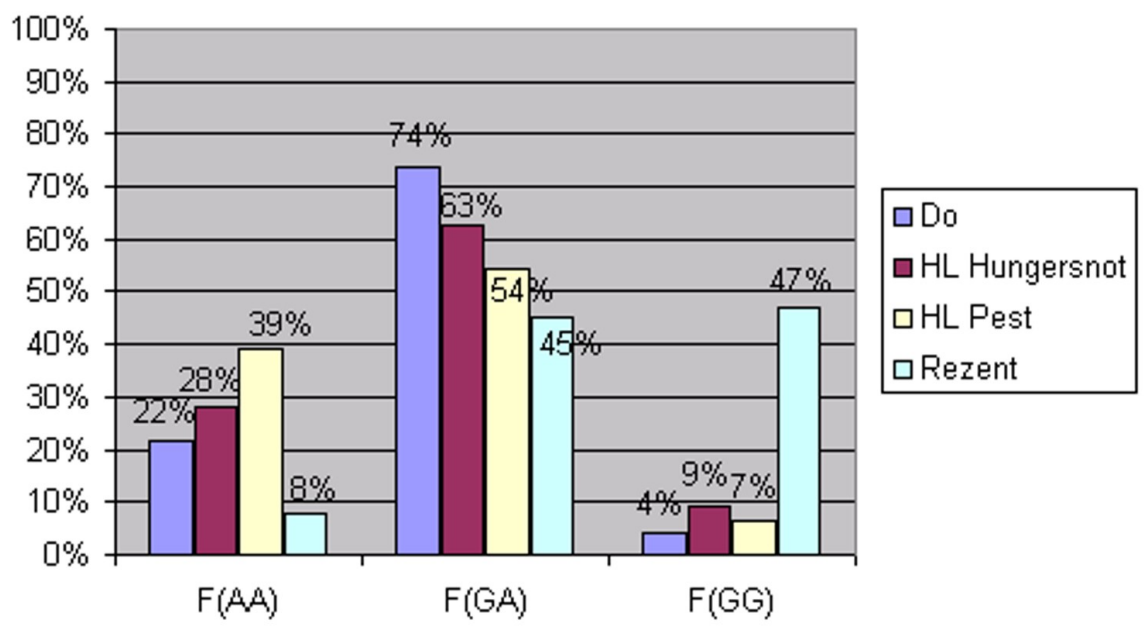

Abb. 25: IL10 G-2849A: beobachtete Genotypenhäufigkeiten der drei historischen Populationen im Vergleich zur deutschen Rezentbevölkerung. Quelle der Rezentdaten: Moraes et al. (2003)

Die Ergebnisse der Stichprobe der bronzezeitlichen Bevölkerung befinden sich nicht im Hardy-Weinberg-Gleichgewicht $(\mathrm{p}=0,030)$. Die Heterozygotenrate ist mit 0,74 signifikant höher als nach Hardy-Weinberg zu erwarten ist $(0,50)$.

Das proinflammatorische A-Allel beider IL10 Polymorphismen sollte in der Serie der Pestopfer im Vergleich zur zweiten mittelalterlichen Serie unterrepräsentiert sein. Auch in der bronzezeitlichen Serie wird eine höhere Frequenz des G-Alleles erwartet, als in der heutigen Bevölkerung, die durch die mittelalterlichen und 
frühneuzeitlichen Epidemien geprägt ist. Die Frequenzen beider Allele schwanken um 0,5 des SNP G-1087A und sind damit unerwartet ausgeglichen. Die beobachtete Allelverteilung des SNP G-1087A entspricht jedoch den Erwartungen für die Pestopfer: Das „antiinflammatorische“ G-Allel ist in der Pestserie in der Anzahl der G-Allelträger am stärksten verbreitet, die Zahl der Nicht-G-Allelträger ist am niedrigsten. Die Frequenzen der bronzezeitlichen Serie zeigen jedoch tendentiell eine höhere Frequenz des „proinflammatorischen“ A-Alleles. Das „proinflammatorische“ A-Allel des SNP G-2849A ist in allen historischen Bevölkerungen vorherrschend. Auch die Stichprobe der Pestopfer zeigt entgegen der Erwartung eine hohe Frequenz dieses Alleles, während sie in der modernen Bevölkerung deutlich geringer ist. 


\subsubsection{Zusammenfassung der Ergebnisse}

Die Allelfrequenzen aller Loci entsprechen dem Hardy-Weinberg-Gleichgewicht (HWE). Eine Ausnahme stellen die Heterozygotenraten der Stichprobe „HL Pest“ dar, die für die SNP der Loci IL4R $\alpha$ und TLR2 vom HWE abweichen. Ebenfalls weichen die Ergebnisse des SNP IL10 G-2849A in der bronzezeitlichen Stichprobe ab. Signifikante Unterschiede zwischen den Populationen wurden für die beiden TLR-Loci beobachtet, so wie für IL10. Zwischen allen anderen Stichproben sind keine signifikanten Unterschiede nachweisbar.

Die Verteilung des Locus TLR2 zeigt signifikante Abweichungen der modernen Kontrolle zu beiden mittelalterlichen Skelettserien. Die moderne Kontrolle zeigt hingegen keinen Unterschied zu der bronzezeitlichen Serie. Auch die Abweichungen zwischen den historischen Populationen liegen außerhalb des Signifikanzbereichs. Hier ist zu beachten, daß die Stichprobe „HL Pest“ vom HWE abweicht. In der zweiten mittelalterlichen Stichprobe „HL Hungersnot“ ist das HWE hingegen erfüllt.

Signifikant ist auch die Abweichung zwischen der Stichprobe „HL Pest“ und der modernen Bevölkerung für den SNP TLR4 D299G. Die postulierte Hypothese lautete, daß unter pathogenreichen Bedingungen eine höhere Frequenz an proinflammatorischen Allelen zu beobachten ist, als unter pathogenarmen Bedingungen. Gleichzeitig sollte die Frequenz der proinflammatorischen Allele unter den Opfern der Pest von 1350 niedriger sein, als in der vergleichbaren Bevölkerung der Hungersnot und der modernen Bevölkerung. Die höchste Frequenz proinflammatorischer Allele wird in der modernen Bevölkerung erwartet. Die Pestopfer hingegen sollten in ihrer Allelfrequenz denen einer pathogenarmen Umwelt am nächsten kommen. Die Ergebnisse der TLR-Polymorphismen entsprechen den Erwartungen in der Hinsicht, daß die mit Infektionserkrankungen assoziierten Allele in der Serie der mittelalterlichen Pestopfer signifikant erhöht sind im Vergleich zur modernen Bevölkerung.

Für die pro- und antiinflammatorischen Zytokine IL6 und IL10 wurde eine Verschiebung der Allelfrequenzen von einer eher antiinflammatorischen Disposition in der Bronzezeit hin zu einer eher proinflammatorischen in der heutigen Zeit erwartet. Das proinflammatorische Allel des SNP IL10 G-2849A ist in allen historischen Bevölkerungen vorherrschend, während in der modernen Bevölkerung das 
antiinflammatorische Allel häufiger ist. Die moderne Population zeigt eine tendentiell höhere Frequenz des proinflammatorischen Allels des IL6 G-174C SNP, für den Marker IL10 G-1087A hingegen sind die Allelfrequenzen relativ ausgeglichen. Die Opfer der Pestepidemie sollten eine entgegengesetzte Verteilung zeigen, analog zu der bronzezeitlichen Bevölkerung. Die Frequenz des IL6 -174C und der IL10 G-Allele wäre demnach in der Pestserie höher als in der Moderne zu erwarten, da beide Allele die Zytokin-Ausschüttung jeweils hin zu einer verstärkt antiinflammatorischen Reaktion beeinflussen. Ein entsprechender Unterschied der Allelfrequenzen kann für IL10 G-1087A verzeichnet werden, nicht jedoch parallel für die drei Marker. Die Pestserie zeigt eine höhere Frequenz des proinflammatorischen IL10 -2849A-Alleles und gleichzeitig einen Trend zu der proinflammatorischen G-Variante des IL6- Polymorphismus. Ein Defizit an IL10 -2849A und IL6 -174G-Allelträgern wurde erwartet. Die bronzezeitliche Serie hat die höchste Frequenz der IL10 A-Allele, die für einen geringeren antiinflammatorischen Effekt steht. Gleichzeitig zeigt sie eine höhere Frequenz des antiinflammatorischen IL6 -174 C-Allels.

Da dem IL4 Rezeptor ebenfalls eine antiinflammatorische Bedeutung zugesprochen werden kann, wurde entsprechend eine geringere Frequenz des proinflammatorischen A-Allels in den Serien „Dorste“ und „HL Pest" erwartet. Diese Erwartung wurde für beide Serien als Trend zu einer geringeren A-Homozygotenfrequenz beobachtet. Beide Serien stehen damit den Stichproben „HL Hungersnot" und „Rezent" gegenüber. Für die Heterozygotenhäufigkeit der Pestserie ist außerdem eine signifikante Abweichung vom Hardy-Weinberg-Gleichgewicht nachgewiesen.

\subsection{Spezifität von PCR und SBE}

\subsubsection{Artefaktbildung in der SBE}

Die Produkte der SBE zeigten trotz der Anpassung und Überprüfung von Primereigenschaften und Reaktionsparametern wiederkehrende Nebenprodukte. Der SBE-Primer IL10_-2849R etwa neigte zur Bildung von elongierbaren Homodimeren, in Singleplex-Ansätzen selbst in Leerkontrollen als distinktes blaues Farbsignal entsprechend der Base "G" zu erkennen (Abb. 26). Trotzdem wurde der Primer beibehalten, da der forward-Primer schlechtere Eigenschaften zeigte und 
die Amplifikation der erwarteten Produkte der Farben schwarz (C) und rot (T) nicht beeinträchtigt wurde. In Multiplex-Ansätzen zeigte sich seltener auch ein grünes Farbsignal (A), für das allerdings ebenfalls keine Beeinträchtigung der korrekten Darstellung des Genotyps beobachtet werden konnte. Das Auftreten dieses Artefaktes schien im Zusammenhang mit der Qualität des PCR-Amplifikates zu stehen. So entstand es besonders, wenn der SBE ein PCR-Produkt mit unspezifischen Produkten zugrunde lag (vgl. Abb. 27).

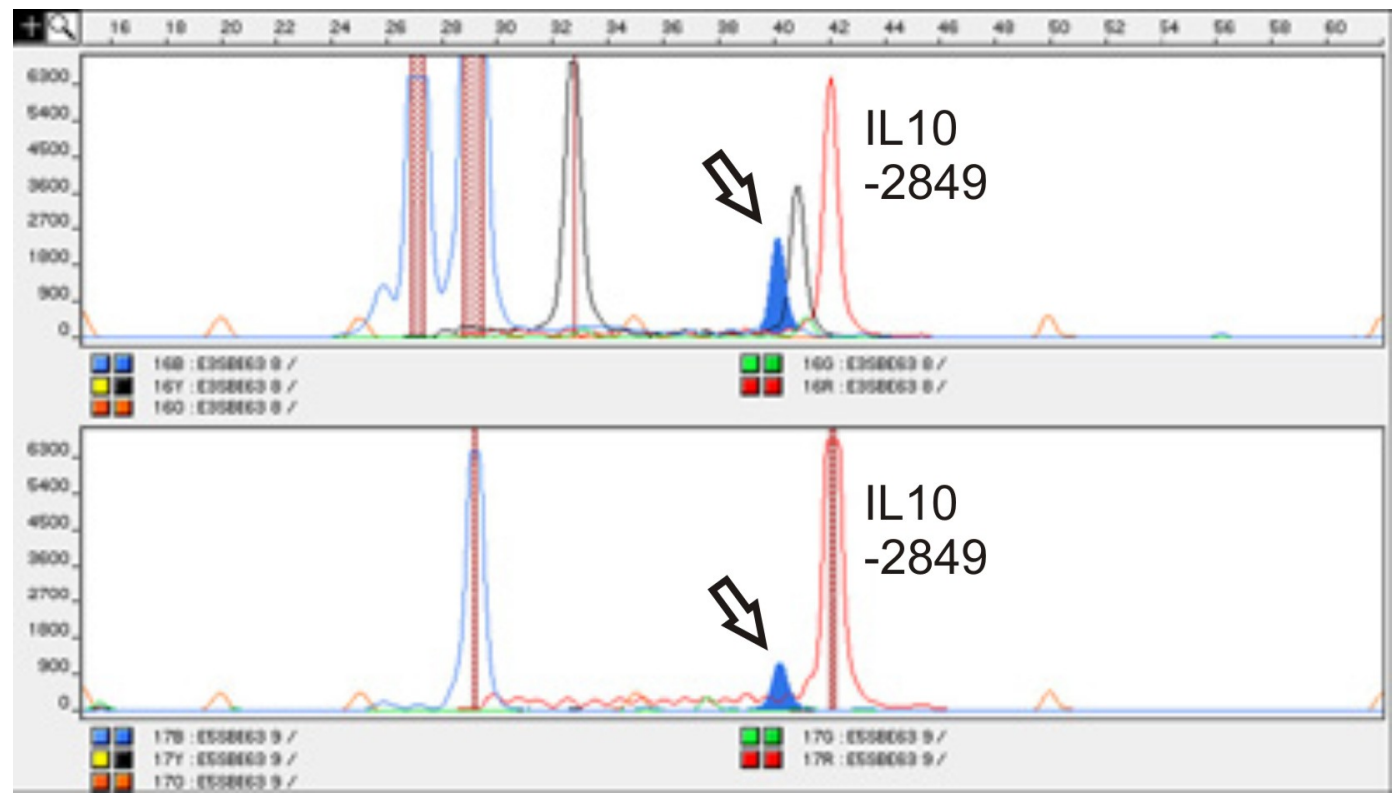

Abb. 26: Das Elektropherogramm zeigt das Ergebnis einer SNP-Analyse im Tetraplex-Ansatz. Bei beiden Proben trat im System IL10-2849 unabhängig vom Genotyp das blau markierte unspezifische Produkt auf (Pfeil). 


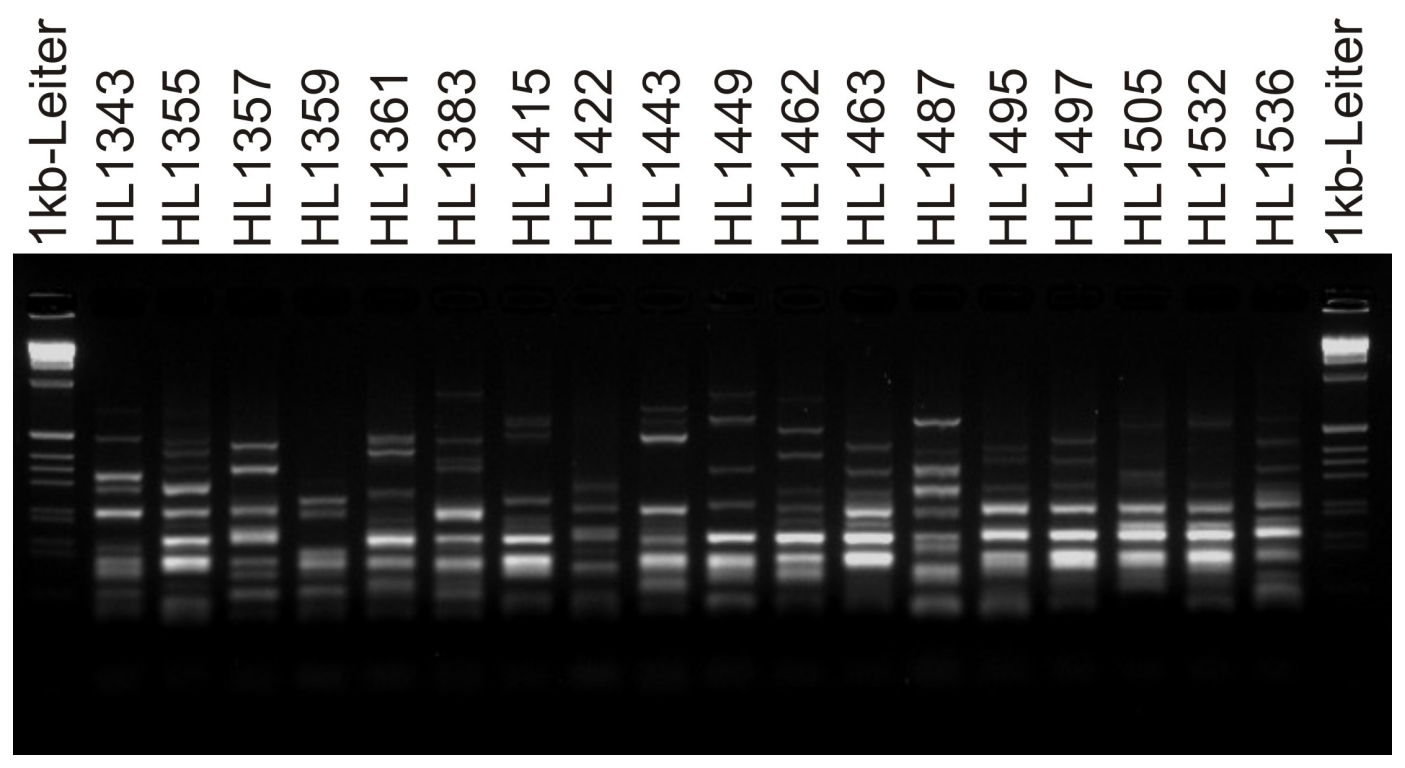

Abb. 27: Agarosegel einer Heptaplex-PCR. Erwartet wurden Fragmente zwischen 100 und 280 bp, so wie die starken Banden der Proben HL1497 bis HL1532. Die Banden oberhalb und unterhalb dieses Längenbereichs sind unspezifische Produkte, die in verschiedenen Amplifikationen auftraten. Im Zusammenhang mit diesen Produkten wurden auch vermehrt unspezifische Produkte in der SNP-Analyse beobachtet.

Im Hintergrund des Signals des TLR2_753R G-Allels (schwarz für C in der reversen Sequenz) konnte ein roter peak an derselben Position (32 bp) erscheinen. Als Nebenprodukt des Primers selber kommt es allerdings nicht in Frage, da dessen rot-markiertes Produkt aufgrund der schlechteren Mobilität bei ca. 34 bp detektiert wird. Die Herkunft des roten peaks bei 32 bp bleibt ungeklärt, möglicherweise läßt es sich durch ein rot-markiertes Nebenprodukt des vorangehenden Systems TLR4_399R erklären. Sein Auftreten scheint jedoch ebenfalls im Zusammenhang mit der Spezifität der PCR-Produkte zu stehen.

Ein Artefakt der SBE ist analog zur Sequenzierung der nicht gleichberechtigte Einbau der ddNTP. Im System IL6_-174F unterschied sich die Signalintensität deutlich zugunsten des blau-markierten dGTP. Trotzdem konnte das schwarzmarkierte dCTP problemlos typisiert werden. Darauf gibt das allelic dropout Hinweis, das bei dem heterozygoten Individuum HL0942 beide Allele gleichmäßig betraf.

Besonderheiten bei der Auswertung Bei der Auswertung der Elektropherogramme und darauf basierend die Allelzuordnung wurde in einzelnen Fällen von 
den vorgegebenen Kriterien abgewichen. Darauf aufbauend auch bei der Bestimmung der Genotypen aus den Ergebnissen der Einzelamplifikationen zu Sonderfällen, die im folgenden beschrieben werden sollen.

1. Aus insgesamt 5 Amplifikationen wird viermal homozygot dasselbe Allel bestimmt, nur in einer PCR wird neben dem ersten heterozygot das zweite Allel beobachtet. Die Entscheidung, ob das zweite Allel aufgenommen wird, wird abhängig gemacht von der Qualität des Extraktes einerseits, der Rohdaten andererseits. Das zweite Allel wird nicht berücksichtigt

- bei einem Extrakt guter DNA-Qualität, der ansonsten kein allelic dropout zeigt

- in Anwesenheit unspezifischer Produkte in PCR oder SBE.

Die Probe wird als homozygot für das erste Allel beschrieben. Das zweite Allel wird berücksichtigt

- bei einem Extrakt der auch für andere Loci allelic dropout zeigt

- in Abwesenheit unspezifischer Produkte in PCR oder SBE.

Die Probe wird dann als heterozygot beschrieben.

2. Allele, die in den Einzelergebnissen in Klammern angegeben werden, sind unsichere Allele. Diese werden nur bei wiederholtem Auftreten berücksichtigt. Treten sie nur einmalig auf, werden sie im Endergebnis ignoriert. Die Probe wird dann als homozygot für das sichere Allel beschrieben.

Die Analyse des SNP IL10 G-2849A zeigte im Zusammenhang mit PCR-Artefakten häufig unspezifische Produkte. Um falsch-positive Signale auszuschließen, wurden bei der Auswertung die peak-Höhen erfaßt. Peaks mit einer Signalintensität von weniger als $30 \%$ des Hauptsignals wurden als Artefakt gewertet. Bei der abschließenden Zusammenführung der Einzeltypisierungen wurden Ergebnisse ohne Artefakte stärker bewertet als solche mit Artefakten.

\subsubsection{Kontrolle der Reaktionsspezifität mittels Sequenzierung der PCR-Fragmente}

Für jeden Locus wurden bei der Etablierung der Systeme Sequenzierungen der PCR-Fragmente durchgeführt, um die Spezifität der PCR-Primer zu überprüfen. 
Deren Genotyp diente gleichzeitig als Kontrolle für die Spezifität der SBE-Reaktion. Im weiteren Verlauf der Arbeit wurden Sequenzierungen durchgeführt, um stichprobenartig den über die SBE-Reaktion ermittelten Genotypen zu überprüfen. Für die SNP IL6 G-174C, IL10 G-1087A und G-2849A, TLR2 R753Q, TLR4 D299G und IL4Ra Q576R bestätigten auch die stichprobenartigen Sequenzierungen die Ergebnisse der SBE. Abweichungen entstanden vereinzelt bei Extrakten, die grundsätzlich durch allelic dropout auffielen. Die Sequenzierung vieler Proben blieb aufgrund der schwankenden DNA-Qualität und PCR-Produktstärke trotz wiederholter Versuche ergebnislos. Die Ergebnisse der erfolgreichen Sequenzierungen sind im Tabellenanhang zu finden.

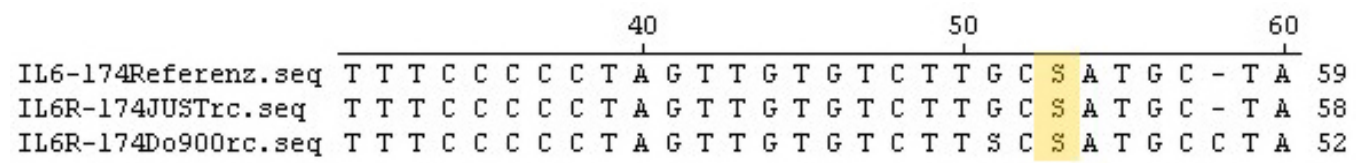

Abb. 28: IL6 C-174G: Darstellung der flankierenden Sequenzen und des SNP am Beispiel der rezenten Probe JUST und der historischen Do900 (Ausschnitt aus der Sequenz). Für beide Individuen wurde die heterozygote Ausprägung auch in der SBE reproduziert. Mit eingeblendet ist eine Referenzsequenz (NCBI: http://www.ncbi.nlm.nih.gov/SNP/snp_ref.cgi?rs=1800795)

Für die SNP IL4 C-524T und TLR4 T399I war die Reproduzierung der SBEErgebnisse nicht ausreichend möglich. Bei beiden wurde sichergestellt, daß die Primersysteme spezifisch die gewünschte Zielsequenz amplifizierten. Bei der stichprobenartigen Sequenzierung zur Überprüfung der Genotypen kam es jedoch zu Abweichungen zwischen Sequenzierung und SBE. Sie wurden daher aus der weiteren Bearbeitung der Ergebnisse ausgeschlossen.

Im System IL4 C-524T konnte das in der SBE auftretende deutliche Signal des minor alleles „T" des Individuums HL1497 nicht in der Sequenzierung nachgewiesen werden. Möglicherweise ist dies ein Problem des allelic dropout. Gleichzeitig kann die per Sequenzierung festgestellte Heterozygotie des Individuums HL0891 aufgrund mangelnder DNA-Qualität und mehrfachen erfolglosen Amplifikationsversuchen in der SBE nicht dargestellt werden. Auch eine später zur Verfügung stehende heterozygote Positivkontrolle (JA) zeigte in der SBE nur das C-Allel.

Für das System TLR4 D399I konnte bei der Einrichtung des Analysesystems der heterozygote Status einer Kontrollprobe (Do 900) erfolgreich nachgewiesen werden. Für das Individuum HL1381 wurde in einer SBE aller acht Systeme 


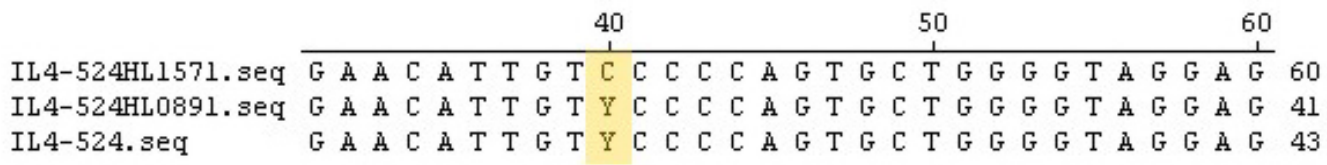

Abb. 29: IL4 C-524T: Darstellung der flankierenden Sequenzen und des SNP am Beispiel der Proben HL_891 und HL1571 (Ausschnitt aus der Sequenz). HL_0891 zeigt die heterozygote Ausprägung „Y“ für den SNP (gelb hinterlegt). Mit eingeblendet ist die Sequenz des Referenz-SNP Cluster Reports (NCBI: http://www.ncbi.nlm.nih.gov/SNP/snp_ref.cgi?rs=2243250)

gleichzeitig die heterozygote Ausprägung beider TLR4-SNP beobachtet (Abb.

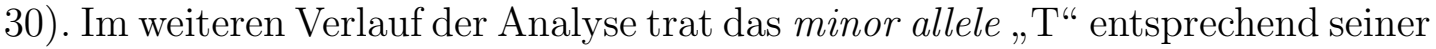
geringen Frequenz erwartungsgemäß selten auf. Bei der abschließenden Auswertung fiel sein sporadisches Erscheinen und die fehlende Cosegregation (angegeben mit $93 \%$, vgl. Kap. 3) mit dem minor allele des Systems TLR4 D299G auf. Die Kontrollsequenzierungen zeigen ebenfalls Abweichungen, die sich nicht durch das Phänomen des allelic dropouts erklären lassen.

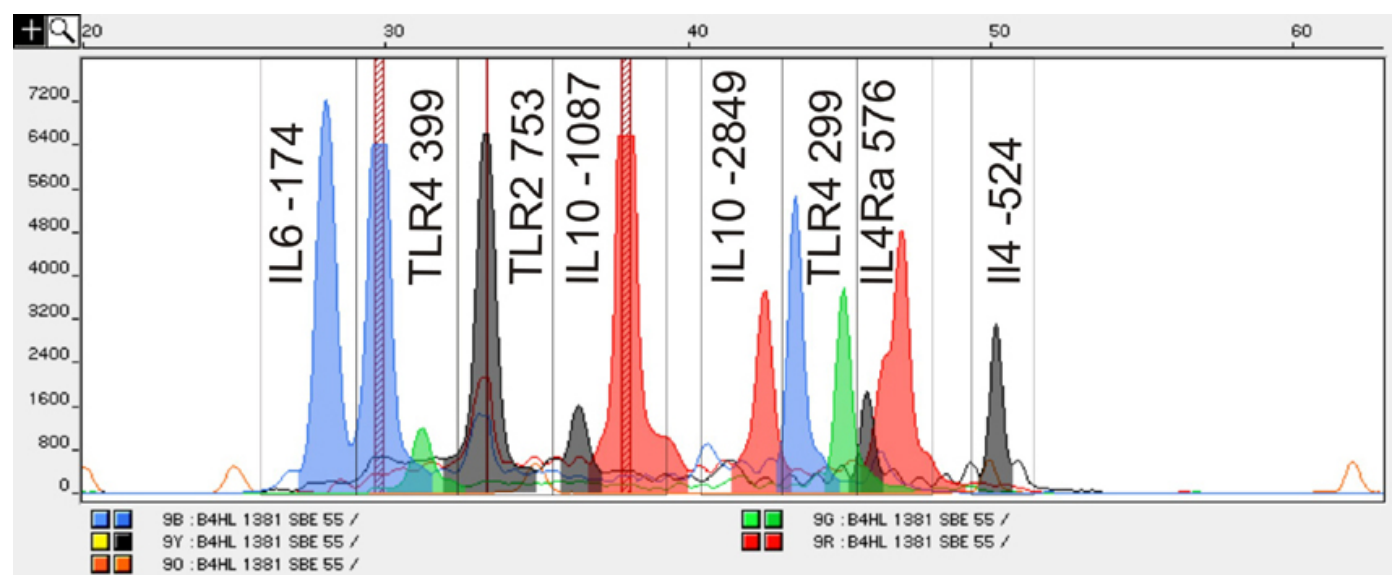

Abb. 30: HL1381: Elektropherogramm der Analyse einer Oktaplex-SBE-Reaktion. Sehr schön ist die heterozygote Ausprägung beider TLR4-SNPs zu erkennen. In der Horizontalen ist die rechnerische Produktlänge aufgetragen, in der Vertikalen die rfu (relative fluorescence units).

\subsection{Genetischer Fingerabdruck}

\subsubsection{Individualisierung und Authentifizierung}

Alle Individuen der Stichproben aus den Skelettserien Lübeck wurden mit der Oktaplex-PCR zur Bestimmung des genetischen Fingerabdrucks typisiert. Vergleichsdaten lagen für die Individuen des Fundkomplex Lichtensteinhöhle bereits 
vor (Schultes, 2000; Schilz, 2006) (vgl. Tab.12, S.226). Aufgrund des großen Probenumfangs konnte die doppelte Reproduktion der Ergebnisse im gegebenen Zeitrahmen nicht erreicht werden. Für zukünftige Studien sollten daher die Ergebnisse vervollständigt werden. Für den Ausschluß von Kontaminationen und die Individualisierung der SNP-Typisierungen ist die Datenlage jedoch ausreichend.

Bei Proben mit guter DNA-Erhaltung wurde mindestens je eine PCR aus zwei Extrakten angefertigt. Bei unvollständigen Ergebnissen wurden weitere Amplifikationen mit verändertem Extrakt-Einsatz durchgeführt. Blieb die Amplifikation nach zwei Amplifikationen erfolglos, wurde auf weitere Versuche verzichtet. Aus den angefertigten Extrakten konnte für 32,6\% der Individuen der Serie „HL Hungersnot" und 32,9\% der Serie „HL Pest" ein kompletter genetischer Fingerabdruck erstellt werden. Alle acht Systeme wurden erfolgreich typisiert. Für weitere 20,7\% waren die Ergebnisse nahezu vollständig, einzelne Allele bzw. Systeme wurden nicht reproduziert. Bei 16,3\% („HL Hungersnot“) und 6,1\% („HL Pest") waren die Amplifikationen erfolglos. Für die übrigen Individuen blieben die Ergebnisse unvollständig. Der Amplifikationserfolg war insgesamt besser für die Individuen der Serie „HL Hungersnot“. Der geringere Anteil an fehlenden Ergebnissen ist auf die Tatsache zurückzuführen, daß bei den Individuen der Serie „HL Pest" zunächst mehrere Amplifikationsversuche auch bei geringem Amplifikationserfolg durchgeführt wurden. Die erfolgreich typisierten zwei bis vier Systeme stammen dabei häufig aus verschiedenen Amplifikationen. Eine genauere Aufschlüsselung des Amplifikationserfolges geht aus Tabelle 34 hervor.

Tab. 34: Amplifikationserfolg der STR-Genotypisierung zur Erstellung des genetischen Fingerabdrucks. Dargestellt wird der Anteil der Proben in denen 0 bis 1,2 bis 4, 5 bis 7, 7 bis 8 oder alle acht Systeme mit mindestens einem sicheren Allel typisiert werden konnten. In die Kategorie 7-8 fallen die Proben, die mindestens in sieben Systemen sichere sowie weitere unsichere Allele zeigen.

\begin{tabular}{llllll}
\hline Serie & $0-1$ & $2-4$ & $5-7$ & $7-8$ & 8 \\
\hline HL Hungersnot & $16,3 \%$ & $2,3 \%$ & $25,6 \%$ & $20,7 \%$ & $32,6 \%$ \\
HL Pest & $6,1 \%$ & $14,6 \%$ & $25,6 \%$ & $20,7 \%$ & $32,9 \%$ \\
\hline
\end{tabular}

Als Beispiel der Analyse der coamplifizierten STR zeigt Abb. 31 das Elektropherogramm der STR-Fragmente der Probe HL1976, die in der in Abb. 10 gezeigten PCR (Multiplex B) amplifiziert wurde. Beide STR-Systeme konnten erfolgreich farbmarkiert und analysiert werden. Die Allele treten durch deutliche peaks in 
Erscheinung. Eine Verstärkung des Phänomens der stutter-alleles gegenüber der herkömmlichen STR-Multiplex-PCR konnte trotz der zweiten PCR mit nur 5 Zyklen nicht beobachtet werden.

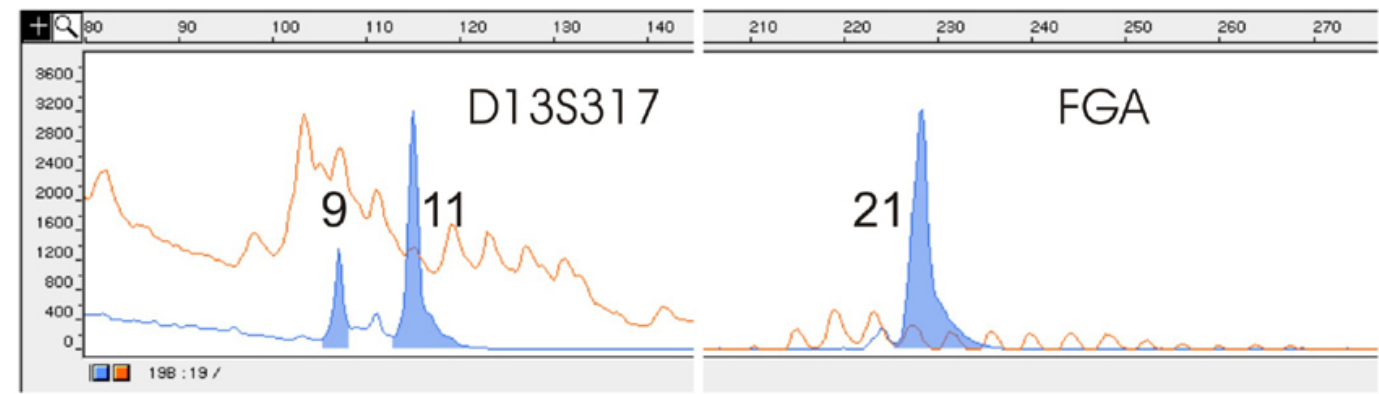

Abb. 31: HL1976: Elektropherogramm zur STR-Analyse. Beide amplifizierte Systeme treten durch deutliche peaks in Erscheinung. In orange ist eine Allelleiter für die Loci hinterlegt.

Die STR-Systeme D13S317 und FGA wurden für die Authentifizierung der SNPDaten verwendet. Der Amplifikationserfolg des STR D13S317 war geringfügig höher, wie es seine geringere Fragmentlänge erwarten läßt. In sieben Proben der Serie „HL Hungersnot" fiel das System D13S317 jedoch komplett aus, dies war für acht Proben im System FGA der Fall. In sechs Proben waren beide Systeme gleichzeitig betroffen. Für die übrigen 20,9\% („HL Hungersnot“) bzw. 30,5\% („HL Pest“) konnten beide Systeme erfolgreich bestimmt werden.

Die Tabellen 36 und 37 geben eine Übersicht der erstellten genetischen Fingerabdrücke. Die Ergebnisse der Einzeltypisierungen werden im Anhang in den Tabellen 49 und 48 vorgestellt.

Die genetischen Fingerabdrücke sind die Grundlage zur Bewertung der Authentizität der SNP-Typisierungen. Die Übereinstimmung der mit den SNP koamplifizierten STR D13S317 und FGA mit den genetischen Fingerabdrücken lassen die Bewertung der Authentizität zu sowie der Überprüfung der korrekten Zuordnung der Einzeltypisierungen zu den beprobten Individuen. In einem Fall (HL1999/2 Extrakt 1, Tab. 35) zeigte der typisierte Fingerabdruck in einer Oktaplex-PCR Übereinstimmung mit dem eines Bearbeiters. Weitere Amplifikationen und die SNP-Multiplex dieses Extraktes zeigten jedoch die Übereinstimmung der STR mit dem Fingerabdruck des historischen Individuums. Als Ursache der Abweichung kommt damit nur die einmalige Kontamination des Oktaplex-PCR-Ansatzes in 
Frage, bei der die Speichelprobe des Bearbeiters als Positivkontrolle verwendet wurde. Der Extrakt wurde daher nicht aus der Untersuchung ausgeschlossen.

Tab. 35: HL 1999/2: Einzelamplifikationen der Oktaplex-PCR als Beispiel einer aufgedeckten Kontamination des PCR-Ansatzes in der ersten PCR.

\begin{tabular}{cccccccccc}
\hline Extrakt & PCR & $\begin{array}{c}\text { D13 } \\
\text { S317 }\end{array}$ & $\begin{array}{c}\text { CSF } \\
\text { 1PO }\end{array}$ & FGA & $\begin{array}{c}\text { Amelo- } \\
\text { genin }\end{array}$ & VWA & $\begin{array}{c}\text { D5 } \\
\text { S818 }\end{array}$ & $\begin{array}{c}\text { D3 } \\
\text { S1358 }\end{array}$ & $\begin{array}{c}\text { D21 } \\
\text { S11 }\end{array}$ \\
\hline PK & & $11 / 12$ & $11 / 12$ & $20 / 22.2$ & X/- & $14 / 18$ & $10 / 11$ & $14 / 15$ & $28 / 32.2$ \\
\hline Ez1 Z37 & 1 & $11 / 12$ & $11 / 12$ & $20 / 22.2$ & $X /-$ & $14 / 18$ & $10 / 11$ & $14 / 15$ & $28 / 32.2$ \\
Ez1 Z37 & 2 & $8 / 11$ & $(11) /-$ & $-/-$ & $X / Y$ & $16 / 18$ & $11 / 13$ & $18 /-$ & $-/-$ \\
Ez3 Z37 & 3 & $8 / 11$ & $-/-$ & $-/-$ & $X / Y$ & $16 / 18$ & $11 / 13$ & $18 /-$ & $-/-$ \\
Ez1 Z36 & 4 & $8 / 11$ & $11 / 12$ & $22 / 27$ & $X / Y$ & $15 / 16 / 18$ & $11 / 13$ & $(17) / 18$ & $29 /-$ \\
\hline
\end{tabular}

Die Extrakte der Proben HL1999/1 und HL1999/2 aus der zweiten Extraktionsserie (Ez2) wurden vertauscht, konnten jedoch mangels Vollständigkeit der Fingerabdrücke nicht eindeutig zugeordnet werden. Die STR-Systeme D13S818 und FGA konnten zwar wiederholt amplifiziert werden. Die Individuen tragen zu ähnliche Allele, um die Extrakte alleine nach diesen Systemen sicher zuzuordnen. Sie wurden aus der Untersuchung ausgeschlossen und neue Extrakte (Ez3) angefertigt. 


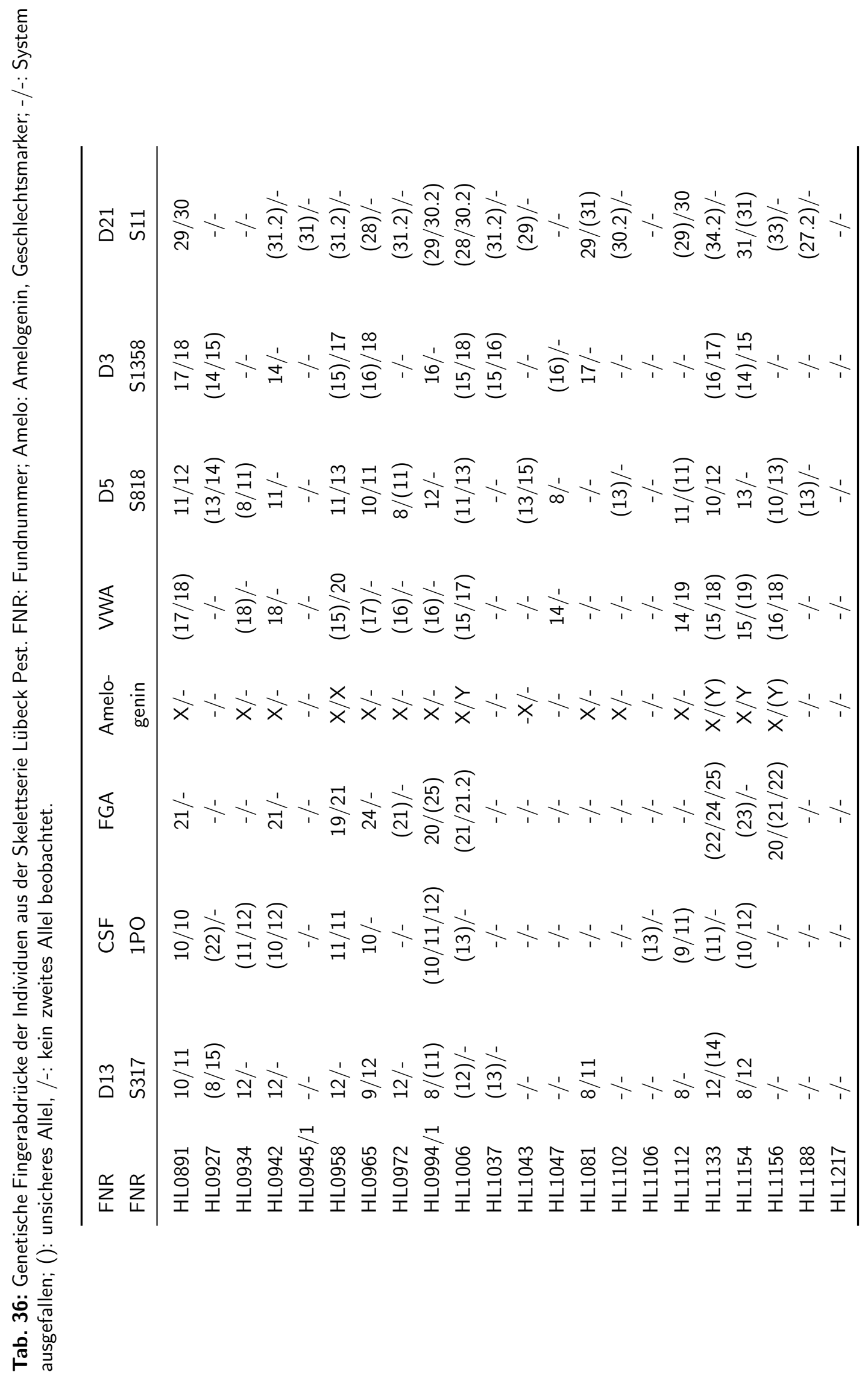




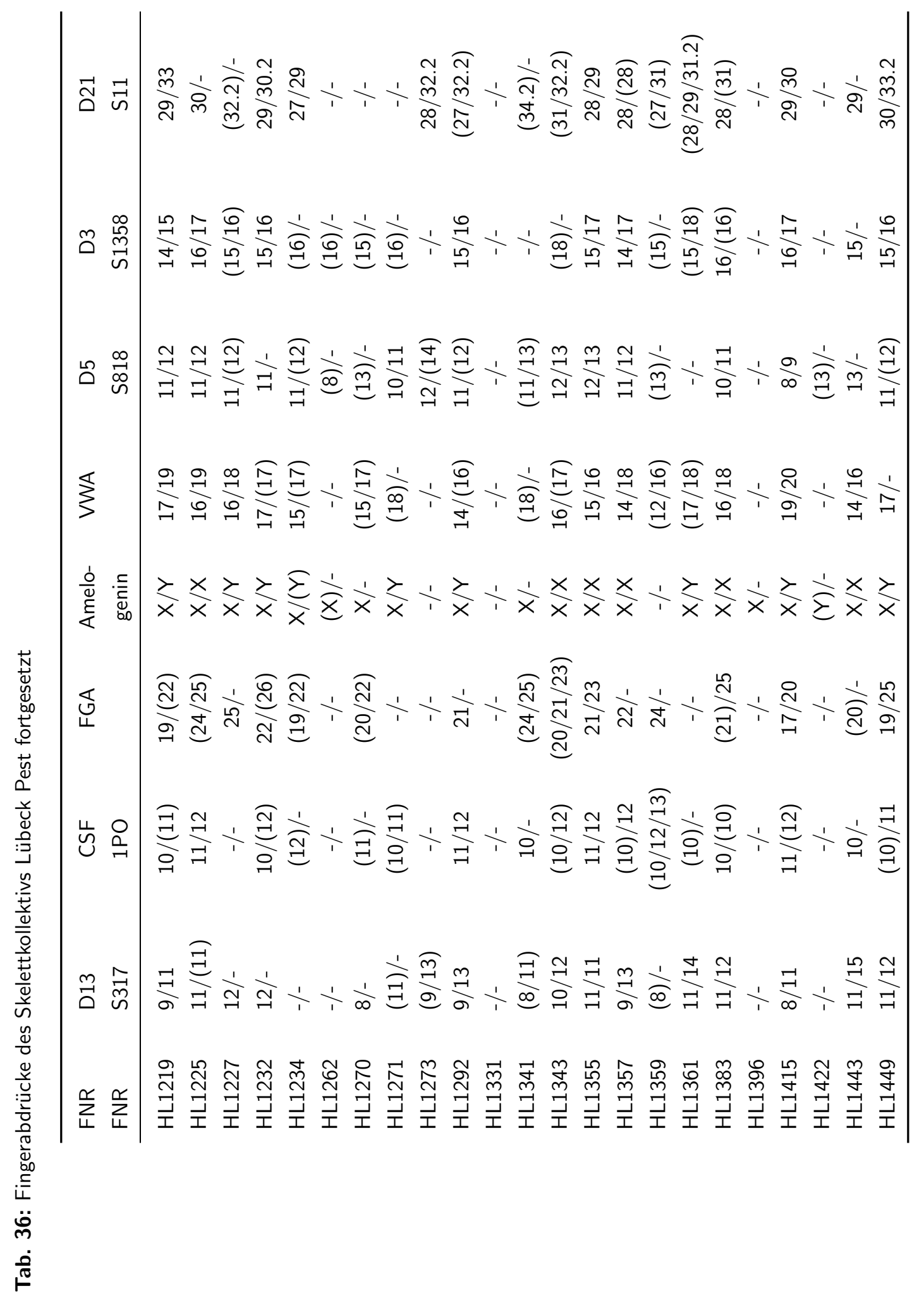




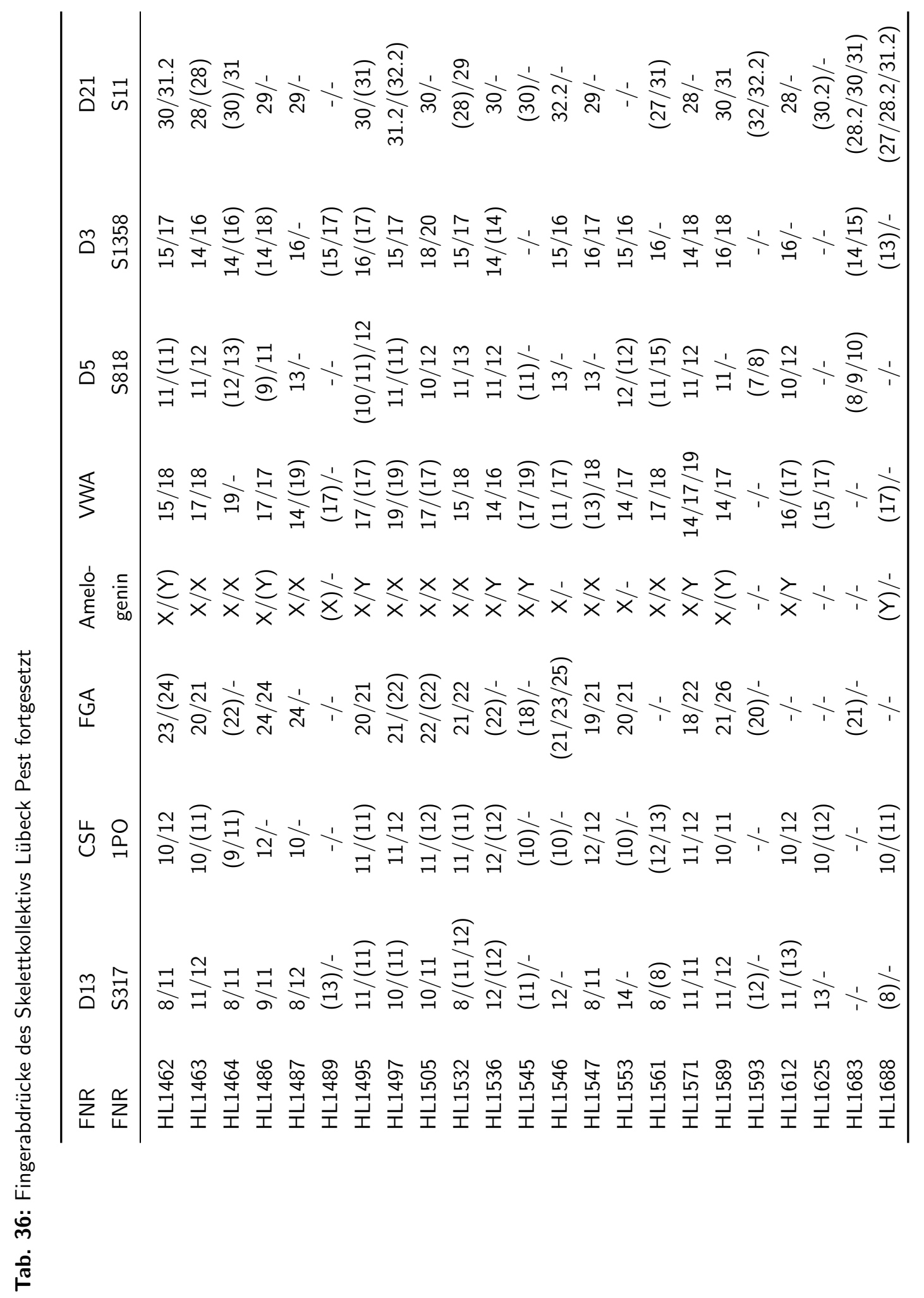




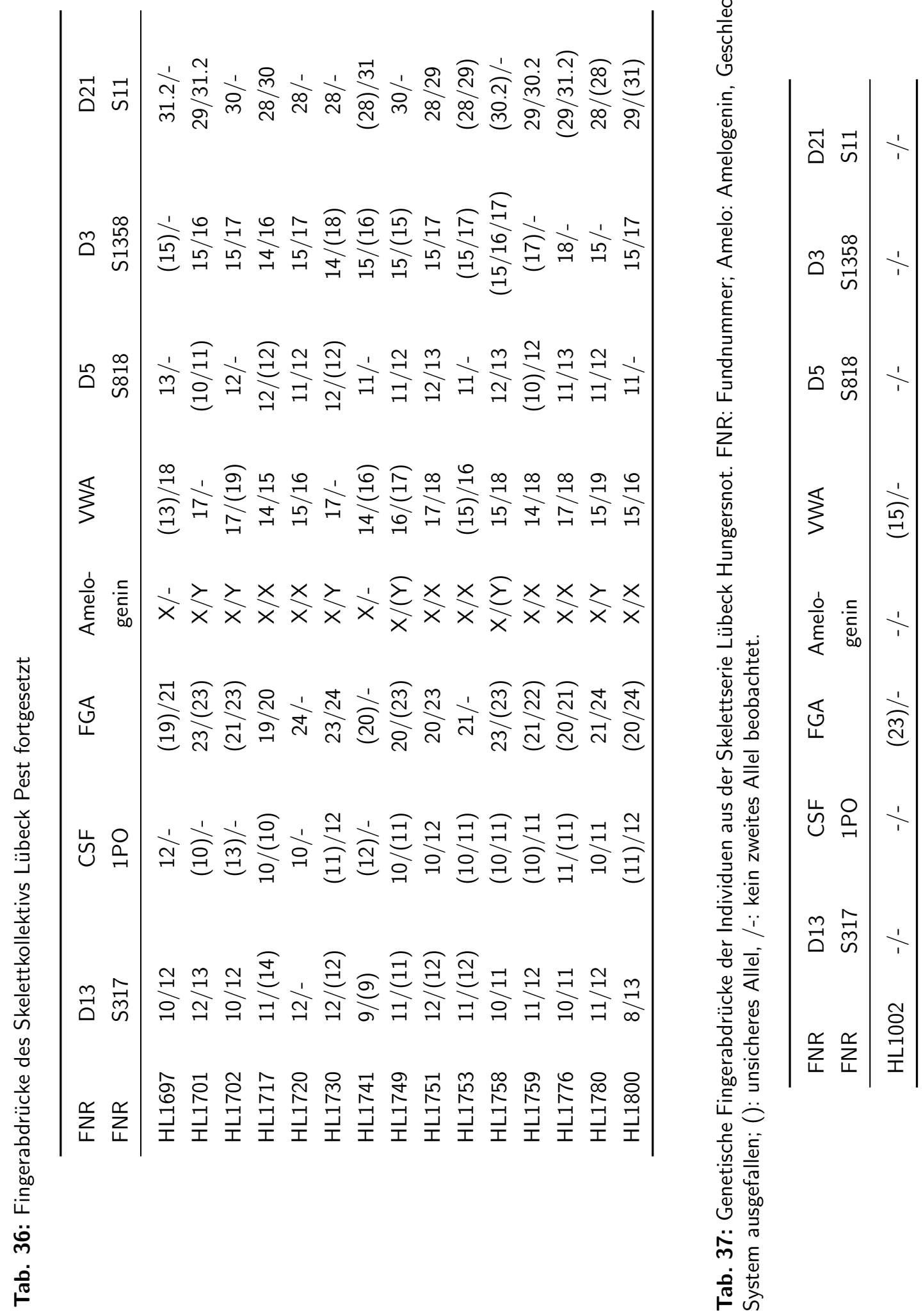




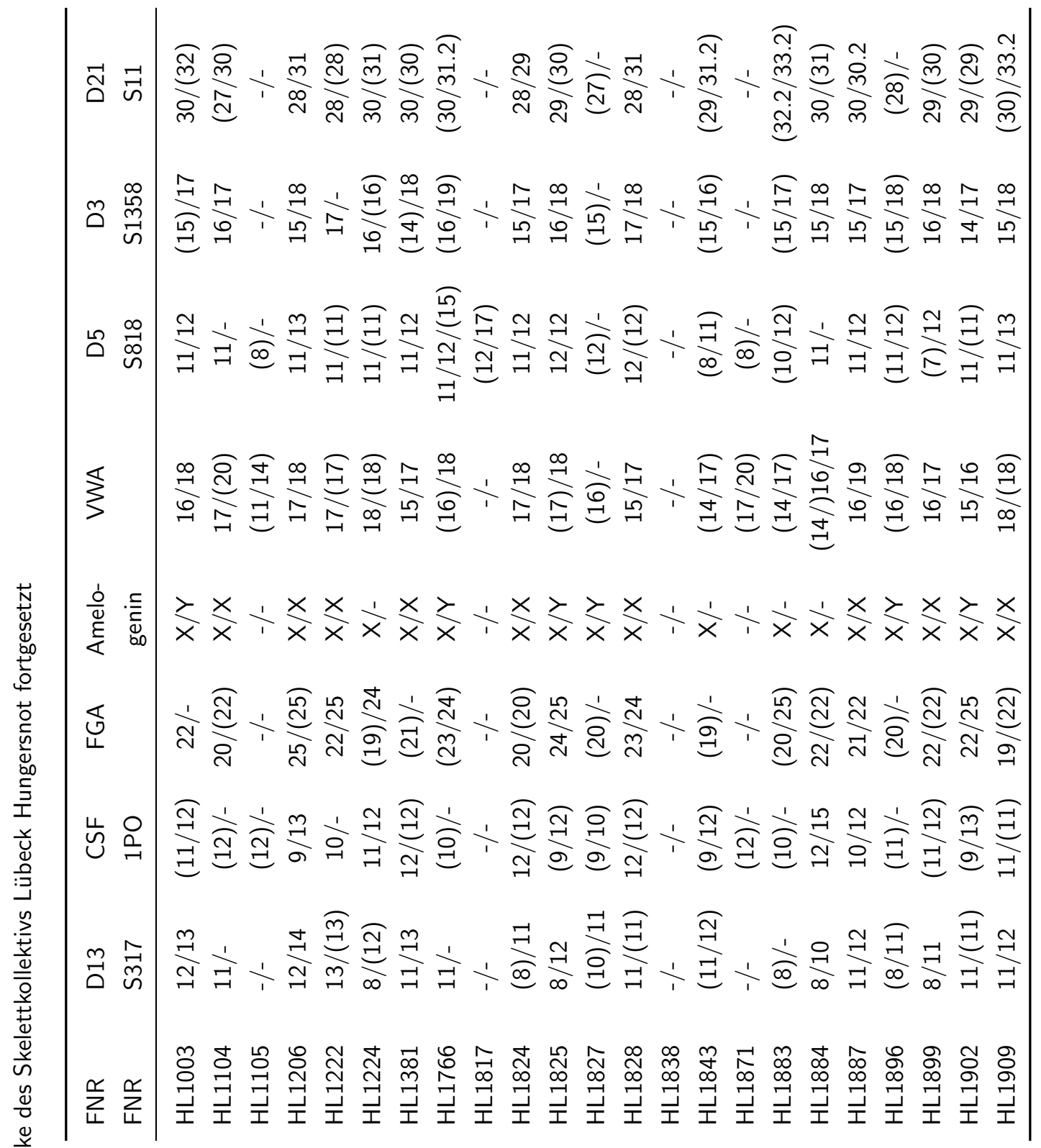




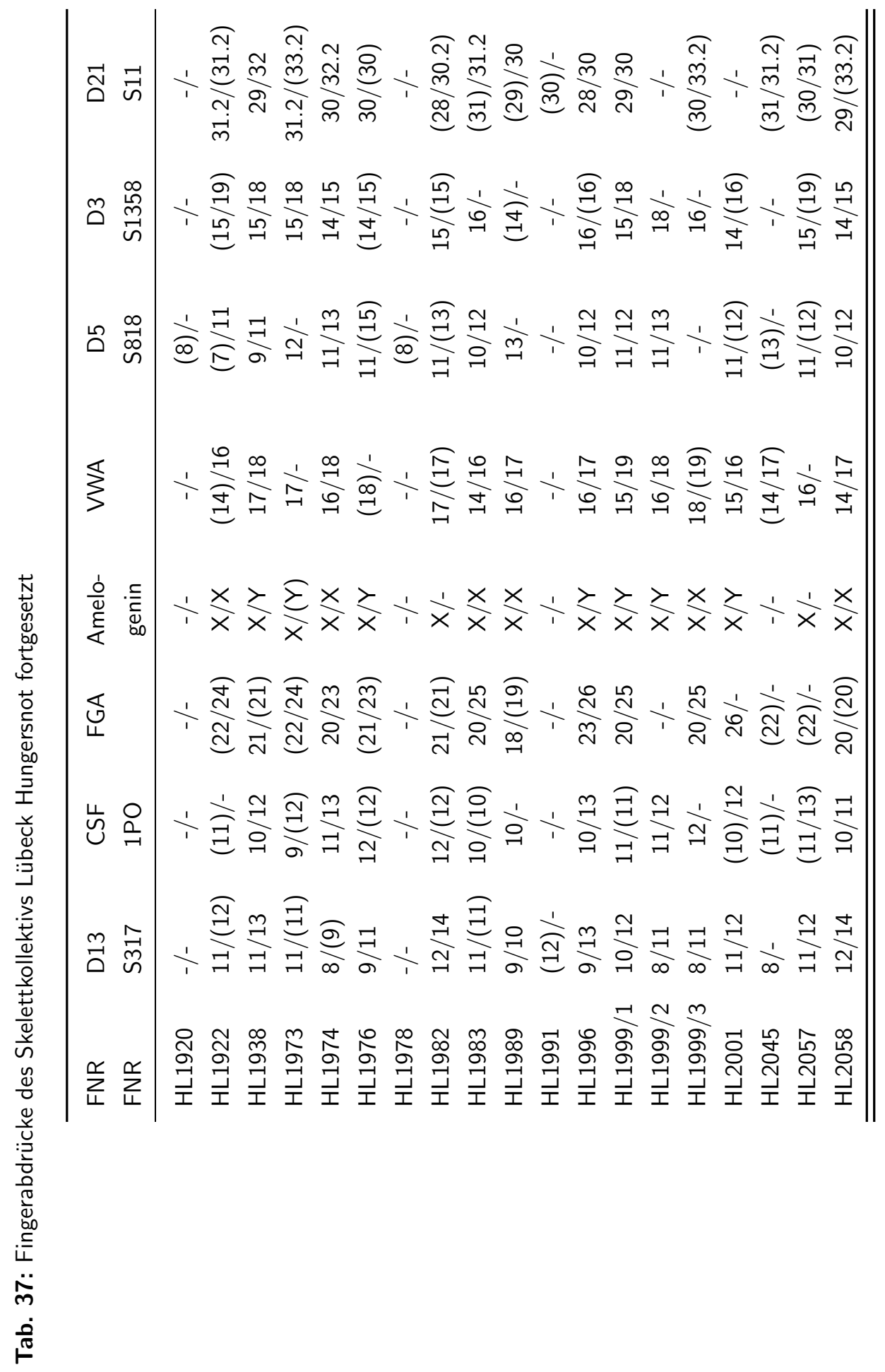




\section{Diskussion der angewandten Methoden}

\subsection{Vergleich der Single-Base-Extension-Reaktion und alternativen Methoden}

Zwei Methoden wurden in unserer Arbeitsgruppe zur Analyse von SNP verwendet, die mit einer Multiplex vereinbar sind: Zum einen die Restriktions-FragmentLängen-Polymorphismus-Analyse (RFLP), wie sie in der Arbeit von Puder (2005) zum Einsatz kam, zum anderen die SBE-Reaktion (Mini-Sequenzierung) in der vorliegenden Arbeit.

Während die RFLP methodenbedingt nur die Analyse einzelner SNPs erlaubt, ist die Single-Base-Extension (SBE) die Methode der Wahl zur simultanen Analyse mehrerer SNPs. Bis zu 16 verschiedene SNP wurden bereits im MultiplexAnsatz unter Verwendung des SNaPshot Kits (Applied Biosystems) untersucht. Bei der Kombination der SNP-Analyse mit STR-Systemen des genetischen Fingerabdrucks macht sich ein zweiter Nachteil der RFLP-Analyse bemerkbar: Da auch die STR-Fragmente Schnittstellen für die verwendeten Restriktionsenzyme enthalten können, muß das PCR-Produkt für die STR-Alleldetermination jeweils vor und nach der RFLP analysiert werden. Werden zwei SNP in einer PCR gemeinsam untersucht, muß trotz Multiplex PCR jeder SNP im eigenen Ansatz analysiert werden. Die Enzyme sind teilweise in ihren Reaktionsbedingungen nicht kompatibel bzw. verursachen auch ungewünschte Schnitte in simultan analysierten SNP-Fragmenten. Mehrfache elektrophoretische Auftrennungen der Produkte sind daher unumgänglich. Obwohl der Kostenaufwand der Restriktionsanalyse mäßig ist, bedeutet sie daher einen hohen Zeitaufwand.

Ein weiterer Vorteil gegenüber der RFLP-Analyse liegt in der gleichwertigen Darstellung der möglichen Allele einer polymorphen Position. In der SBE werden beide Allele durch verschiedene Farbsignale positiv nachgewiesen. Die RFLP erlaubt nur den positiven Nachweis des geschnittenen Alleles. Ein Ausbleiben des Schnittes hingegen läßt keinen sicheren Nachweis des Gegenalleles zu. Ein Teilschnitt oder ausgebliebener Schnitt kann unter anderem Ursachen wie z. B. Degradierung der Sequenz oder unzureichende Enzymaktivität haben. Bei Veränderungen der Sequenz durch Degradierungsereignisse genügt im schlimmsten Falle der Defekt einer einzelnen Base, um die Restriktionsstelle unkenntlich zu machen. Eine SBE- 
Reaktion zeigte hier je nach Ausmaß der Degradierung keine Beeinträchtigung. Bei Veränderung mehrerer Basen gerade im 3'-Bindungsbereich kann es jedoch zum kompletten Ausfall des Produktes kommen, da die Bindung des Primers an das Template durch Mismatches gestört werden kann.

Falsch-negative Ergebnisse sind in Einzelfällen trotzdem möglich. So verweist das Manual des Herstellers auf die Behinderung des Einbaus eines dATP, wenn ein Poly-T-tail zur Verlängerung des Primers angehängt wird. Daher wurden für die Primer dieser Arbeit Poly-A- und Poly-C-tails eingesetzt. Auch ein präferierter Einbau eines bestimmten ddNTP und damit einer vermeintlich homozygoten Ausprägung soll bereits beobachtet worden sein (C. Matheson, pers. Mitteilung), ein Artefakt, das durch Spiken der Lösung mit dem benachteiligten ddNTP behoben wurde. Dieser Ansatz sollte für die beiden ausgeschlossenen Marker verfolgt werden, bei denen das zweite Allel nicht zuverlässig nachgewiesen werden konnte.

\subsection{Fehlerdiskussion der ausgeschlossene Systeme}

Für die beiden ausgeschlossenen Polymorphismen ist die Frequenz des jeweiligen minor allele sehr gering. Gleichzeitig ist IL4 das System, das am schlechtesten amplifiziert. Selbst in den Proben, in denen die selteneren T-Allele auftraten, erschienen sie nur hin und wieder, oftmals in geringerer Signalintensität als das häufigere Allel. Vielleicht liegt in dieser Kombination die Ursache des Problems. Für TLR4 kann eine Beurteilung der Zuverlässigkeit allerdings über die beschriebene Kosegregation mit dem zweiten TLR4 Polymorphismus erfolgen. Andererseits ist das Ausbleiben der Kosegregation kein Beweis, wenn sie ein Überbleibsel von Selektionsereignissen sind, wie es von Ferwerda et al. (2007) postuliert wird. Wird als Selektionsereignis die Phase der Epidemien der historischen Transitionen angenommen, kann sich die hohe Kosegregationsrate erst nach der Pestepidemie von 1350 etabliert haben. Damit wäre sie innerhalb der untersuchten historischen Skelettserien nicht nachweisbar. Auch die Methode des Taq-cyclesequencing unterliegt den Artefakten der DNA-Degradierung. Es besteht daher ferner die Möglichkeit, daß die fehlende Reproduktion zwischen Sequenzierungsund SBE-Ergebnissen der historischen Proben im allelic dropout begründet ist. Die Zahl der modernen Kontrollen ist aufgrund der geringen Frequenz der Allele eingeschränkt. Zufällige Fehltypisierungen der wenigen Kontrollen können daher 
leicht zu einer Fehleinschätzung der Zuverlässigkeit der Methode führen. Für die während der Etablierung der Methode eingesetzten historischen Proben konnte das zweite Allel zunächst nachgewiesen werden. Die Probleme im weiteren Verlauf der Arbeit können daher auch Folge der zunehmenden Probleme mit der Qualität der PCR durch unspezifische Produkte sein. Hier sind weitere Versuche ratsam, die einen Aufschluß über die Ursache der Fehler geben.

\subsection{Resumee}

In der Literatur erfolgt eine Bewertung der SBE als geeignetes und robustes Analysesystem auch für die Anwendung mit degradierter DNA (Larcombe et al., 2005; Quintans et al., 2004). In der Praxis allerdings erweist sich eine sorgfältige Voranalyse mit alternativen Methoden als nötig, die einen gewissen Aufwand mit sich bringt. Eine größere Anzahl an Rezentproben muß sequenziert werden, um eine Auswahl an Positivkontrollen aller Genotypen zu erlangen. Gerade bei geringfrequenten Markern (unter $10 \%$ ) kann dieses Vorgehen in einer großen Anzahl zu sequenzierender Proben resultieren, wenn nicht auf bekannte Positivkontrollen zurückgegriffen werden kann. Die Übertragung auf aDNA muß mit weiteren Kontrollen einhergehen, um den Einfluß von allelic dropout sowohl in der SBE als auch in der Kontrollsequenzierung zu überprüfen. Beide Methoden unterliegen gleichermaßen der Anfälligkeit für dieses Artefakt. Abweichende Ergebnisse sind also nicht direkt als Fehler der einen oder anderen Methode zu werten. Veränderungen der PCR-Qualität, wie in dieser Arbeit, können zusätzlich während der Bearbeitung Veränderungen der Spezifität der SBE-Reaktion nach sich ziehen. Ein „Monitoring" der Reaktion über den gesamten Verlauf einer Untersuchung ist daher unter Umständen anzuraten. Wie in der vorgestellten Arbeit kann es über eine abschließende Sequenzierung geschehen, in der die in der SBE-Analyse determinierten Genotypen stichprobenartig überprüft werden.

Grundsätzlich ist anzumerken, daß Typisierungen aus degradierter DNA einem anderen Fehler unterliegen, als Typisierungen aus rezenter DNA. Die Degradierung der DNA kann die Allele eines Locus zufällig in unterschiedlichem Ausmaß betreffen. Das resultierende allelic dropout oder auch Basensubstitutionen können im Zweifelsfall selbst bei wiederholten Analysen nicht nachgewiesen werden. Gleichzeitig werden die Analysen mit einem geringen Probenumfang durch- 
geführt. Dadurch ist die Gefahr von Stichprobenartefakten aufgrund der kleinen Probenzahl gegeben. Die erhaltenen Allelfrequenzen sind daher stets unter diesem Aspekt zu betrachten.

Trotz der diskutierten Einschränkungen ist die SBE die Methode der Wahl, um gerade aus aDNA als beschränkter Ressource eine Vielzahl an Markern zu untersuchen. Nicht zu unterschätzende Probleme existieren bei den Alternativmethoden: Die RFLP-Analyse ist kostengünstig aber zeitaufwendig, da sie im Multiplex-Ansatz wiederholte Analysen desselben PCR-Produktes erfordert. Sequenzierungen mit der taq-cycle-sequencing-Methode sind nur in Singleplex-Ansätzen möglich. Neben einem hohen Materialbedarf bedeutet sie einen hohen Zeit- und Kostenaufwand. Als Resumee dieser Studie ist zu sagen, daß ohne die SBE-Analyse diese Zahl an Markern und historischen Proben weder aus finanziellen noch aus zeitlichen Gründen bearbeitbar gewesen wäre. 


\section{Ergebnisdiskussion}

\subsection{Diskussion der beobachteten Allelfrequenzen}

Erwartet wurde aufgrund der epidemiologischen Entwicklung der letzten 3000 Jahre eine Abweichung in der Allelhäufigkeit der untersuchten Polymorphismen. Die mittelalterlichen und frühneuzeitlichen Infektionskrankheiten sollte einen Selektionsdruck zu einer verstärkten Immunantwort erzeugen. Die höchste Allelfrequenz von Polymorphismen, die diese verstärkte Immunantwort nachsichziehen, wäre damit für die rezente Bevölkerung zu erwarten. Kongruent zu dieser Annahme laufen die Beobachtungen, daß eine Zunahme an inflammatorischen Erkrankungen mit der Abnahme der Bedeutung von Infektionskrankheiten einhergeht. Als genetischer Hintergrund wird das Fortbestehen eines auf die effektive Immunabwehr selektierten Immunsystems diskutiert. Für die bronzezeitliche Serie wurde eine im Vergleich niedrigere Frequenz dieser Allele erwartet, da die Selektion durch die mittelalterlichen Epidemien noch bevorstand. Die demographischen Charakteristika dieser Epoche lassen zudem auf ein pathogenarmes Umfeld schließen. Die Opfer der Pest wiederum sollten die Opfer einer Selektion auf eine verstärkte Immunantwort darstellen. Eine erhöhte Frequenz antiinflammatorischer Polymorphismen wurde daher für diese Skelettserie postuliert. Für die mittelalterliche Lübecker Serie der Hungersnot hingegen wurde eine Zwischenstellung angenommen. Ihre zeitliche Stellung vor den Epidemien, gleichzeitig aber bereits in einem Alter zunehmender Bevölkerungsdichte und -vernetzung, läßt bereits eine Zunahme der Pathogenbelastung erwarten. Für alle historischen Skelettserien wurde zusammenfassend im Vergleich zur postepidemischen modernen Bevölkerung eine niedrigere Frequenz der proinflammatorischen Allelvarianten erwartet.

Tab. 38: Zusammenfassung der Marker und ihrer Bedeutung für die Immunantwort sowie des funktionellen Einflusses ihrer Polymorphismen.

\begin{tabular}{lllcc}
\hline Protein & Funktion & Allel & Effekt & Auswirkung \\
\hline IL6 & proinflammatorisch & $-174 \mathrm{C}$ & $\downarrow$ & antiinflammatorisch \\
IL10 & antiinflammatorisch & $-1082 \mathrm{~A}$ & $\downarrow$ & proinflammatorisch \\
IL4Ra & antiinflammatorisch & $576 \mathrm{R}(\mathrm{G})$ & $\downarrow$ & proinflammatorisch \\
TLR2 & proinflammatorisch & $753 \mathrm{Q}(\mathrm{A})$ & $\downarrow$ & antiinflammatorisch \\
TLR4 & proinflammatorisch & $299 \mathrm{I}(\mathrm{G})$ & $\downarrow$ & antiinflammatorisch \\
\hline
\end{tabular}




\section{Pathogen-Rezeptoren}

Besonders für die Toll-like Rezeptoren wurde eine Assoziation mit der Pestepidemie erwartet. Sie stellen den ersten Kontakt mit Erregern dar und leiten die Erstantwort des Immunsystems ein. Die die mittelalterlichen Pestopfer umfassende Serie „HL Pest“ zeigt der Hypothese entsprechend eine höhere Allelfrequenz des A-Alleles des TLR4-Polymorphismus D299G. Der Unterschied der Verteilung zur modernen Bevölkerung ist signifikant. Eine Beeinträchtigung der Aktivierung der direkten Immunantwort als Reaktion auf LPS ist anzunehmen und zeigt sich auch in der Assoziation mit Infektionserkrankungen. Ferwerda et al. (2007) argumentiert für das A-Allel des TLR4 D299G einen Nachteil durch eine verstärkt proinflammatorische Immunantwort, die eine erhöhte Mortalität durch Zytokinämie bedeutet. Daß die Pestopfer eine erhöhte Frequenz zeigen, ist in beiden Zusammenhängen eingängig und mag als Hinweis auf die Selektion durch die Infektion gedeutet werden. Der Trend zu einer erhöhten Frequenz im Vergleich zur mittelalterlichen Kontrollkohorte („HL Hungersnot“) läßt auf eine höhere Mortalität von Trägern der 299G-Variante schließen. Eine direkte Assoziation des Polymorphismus und der mittelalterlichen Pestinfektion selber kann nicht nachgewiesen werden. Dazu wäre ein signifikanter Unterschied zu der zweiten mittelalterlichen Serie nötig gewesen. Die Unterschiede zwischen mittelalterlicher und moderner Bevölkerung in ihrem Verhalten und ihrer Umwelt sind zu groß, um weitere Einflüsse auf die Allelfrequenzen auszuschließen. Um die Theorie von Ferwerda et al. (2007) zu überprüfen, sollte ferner die Cosegregation des SNP mit dem TLR4 T399I-Polymorphismus untersucht werden.

Die Ergebnisse des TLR2 Polymorphismus R753Q hingegen erscheinen zunächst unerwartet. Eine signifikante Abweichung zur modernen Bevölkerung infolge der Selektion durch die Pest und die nachfolgenden Epidemien entspricht zwar der Hypothese. Für die Serie „HL Hungersnot“ wurde als Kontrollkohorte allerdings eine Abweichung zur Pestserie erwartet. Eine mögliche Ursache ist das beobachtete Heterozygotendefizit der Pestopfer. Da die übrigen historischen Skelettserien dieses Defizit nicht zeigen, ist ein methodisches Artefakt als Ursache unwahrscheinlich. Denkbar ist hingegen eine Beeinträchtigung der Ergebnisse durch die DNA-Degradierung, die in der Serie „HL Pest“ zu einer stärkeren Beeinflussung des Amplifikationserfolges geführt hat, als in der Serie „HL Hungersnot“. Aus 
den Ergebnis-Diagrammen (Abb. 13) läßt sich jedoch folgern, daß die erwartete Heterozygotenfrequenz von $19 \%$ gegenüber der beobachteten (13\%) die Signifikanz der Ergebnisse nicht beeinträchtigt hätte, da der Unterschied zur modernen Bevölkerung erhalten bleibt.

Abschließend läßt sich sagen, daß das A-Allel des TLR2 R753Q im Mittelalter häufiger war, als in der heutigen Zeit. Eine Selektion gegen dieses Allel zwischen Mittelalter und Moderne ist daher wahrscheinlich. Ein direkter Einfluß der Pestepidemie von 1350 auf die Allelfrequenz ist nach diesen Ergebnissen unwahrscheinlich.

\section{IL4Ra}

Auffällig ist die Abweichung der Allelfrequenzen der Serie „HL Pest“ vom HWE. Dieser kommt durch einen Heterozygotenüberschuß auf Kosten der A-Homozygotenrate zustande. Methodische Artefakte außer einer höheren DNA-Degradierung können wiederum als Ursache ausgeschlossen werden, da die übrigen Serien nicht vom HWE abweichen. Dagegen ist eine stärkere Selektion während der Pestepidemie gegen Heterozygote denkbar. Nach dem Trend der niedrigeren A-Homozygotenhäufigkeit der Serien „Dorste“ und „HL Pest" wird ein Vorteil des G-Allels unter pathogenarmen Bedingungen angenommen sowie ein Vorteil des A-Alleles in einer pathogenreichen Umwelt. Übereinstimmend findet sich auch in der modernen Bevölkerung tendentiell eine höhere Frequenz an A-Homozygoten, die GAllelträger (Genotyp GG und GA) sind seltener. Das G-Allel wird als gain-offunction-Variante des Rezeptors beschrieben (Hershey et al., 1997), ebenso wie das T-Allel des IL4 SNP C-590T (Rosenwasser, 1995). Die antiinflammatorische Einordnung des IL4/IL4Ra-Komplexes findet sich auch in den Trends der vorgestellten Ergebnissen wieder. Die Assoziation der antiinflammatorischen Varianten mit Allergien (Kruse et al., 1999, z. B.) erscheint in diesem Zusammenhang widersprüchlich. Allergien und Atopien werden auf die verminderte Auseinandersetzung mit Infektionserkrankungen zurückgeführt (Hygiene-Hypothese) (Rook, 2007; Kabesch \& Lauener, 2004, u.a.). Die beobachteten Trends zeigen jedoch, daß die mit Allergien assoziierten Allele in der modernen Bevölkerung zumindest nicht häufiger sind als in den historischen Populationen. Eine Selektion durch die Zunahme der Pathogenbelastung zwischen Bronzezeit und Neuzeit konnte somit nicht nachgewiesen werden. 


\section{Pro- und antiinflammatorische Zytokine}

Die Zytokine IL6 und IL10 nehmen eine zentrale Stellung in der Immunantwort ein. Für beide Zytokine wurde in verschiedenen Studien nachgewiesen, daß die Promotorpolymorphismen über die Transkription den Zytokin-Spiegel und damit die Immunantwort beeinflussen (Eskdale et al., 1998; Turner et al., 1997; Fishman et al., 1998; Rivera-Chavez et al., 2003). Entsprechend werden die Polymorphismen mit der Suszeptibilität für Infektionserkrankungen assoziiert (WojsykBanaszak et al., 2005; Schlüter et al., 2002; Henao et al., 2006). In der heutigen Bevölkerung kommt ihnen eine Bedeutung in den Krankheiten der Wohlstandsgesellschaften zu: So sind sie Teil der genetischen Disposition für verschiedene chronische Erkrankungen (Fishman et al., 1998; Giacconi et al., 2004; Lio et al., 2004) und Diabetes Mellitus (Huth et al., 2006), während die antiinflammatorischen Allele vermehrt in Studien an Langlebigen (Überachtzigjährige) gefunden wurden (Lio et al., 2004; Westendorp et al., 2001; Bonafe et al., 2001). Krabbe et al. (2004) und Franceschi et al. (2005) diskutieren IL6 sogar als Marker für erfolgreiches, beschwerdefreies Altern.

Für die historischen Stichproben untereinander oder im Vergleich zur modernen Bevölkerung kann trotz der Assoziationen kein Unterschied für den Marker IL6 G-174C. Unterschiede bestehen jedoch für den Marker IL10 G-1087A zwischen der Pestserie und der modernen sowie für IL10 G-2849A von allen historischen Stichproben zur modernen Bevölkerung. Die Abweichung der modernen Bevölkerung als postepidemische Kontrolle entspricht zunächst der Erwartung, daß die Epidemien des Mittelalters und der frühen Neuzeit eine Verschiebung der Allelfrequenz nach sich zogen. Erwartet wurde jedoch eine Erhöhung der Frequenz der proinflammatorischen Allele durch die epidemischen Ereignisse. Beobachtet wird mit der Zunahme des Anteils des antiinflammatorischen Allels des SNP IL10 G-2849A die entgegengesetzte Entwicklung. Als Ursache wird die eingeschränkte Eignung der modernen Bevölkerung als postepidemische Kontrolle gesehen. Der Einfluß der hygienischen und medizinischen Fortschritte der letzten 150 Jahre kann zu einer Erhöhung der Frequenz antiinflammatorischer Allele geführt haben (vgl. Kap. 11.2). Die Beurteilung der postepidemischen Entwicklung ist durch diesen gegenläufigen Trend möglicherweise maskiert. Als moderne Vergleichsbevölkerung lagen zudem nur Daten aus niederländischen Veröffentlichungen vor (Lard et al., 
2003; Moraes et al., 2003). Eine Diskrepanz der Allelverteilung zwischen der niederländischen und der mittel- bis norddeutschen Bevölkerung kann sich auf die Zuverlässigkeit der Ergebnisse auswirken. Eine Rezentbevölkerung aus demselben Hintergrund wie die historischen Individuen sollte zur Überprüfung der Datenlage herangezogen werden. Es bietet sich an, die Analyse der Vergleichsbevölkerung Tübingen/Göttingen, die auch für den SNP G-1087A herangezogen wurde, auf diesen Marker auszuweiten.

Die Frequenz der proinflammatorischen A-Allele der IL10 SNP ist in der bronzezeitlichen Serie höher als die der antiinflammatorischen G-Allele. Suray (2007) untersuchte den IL10 Polymorphismus G-1087A als Teil des Haplotypen -1087/ -819/-592 in der Skelettserie „Dorste“. Auch dort war der proinflammatorische Haplotyp ATA entgegen der Erwartungen in allen Familienlinien der Serie verbreitet. Das proinflammatorische IL10 -2849A-Allel herrscht in der Pestserie vor. Auch die Frequenz des proinflammatorischen IL6-Alleles war tendentiell die höchste unter allen Populationen. In einer pathogenreichen Situation wie der Pestepidemie hätten diese Allele jedoch einen protektiven Charakter vermitteln sollen. Auffallend ist die hohe Heterozygotenrate des SNP IL10 G-1087A in beiden mittelalterlichen Serien, während der Anteil der G-Homozygoten zwischen allen Serien konstant bleibt. Der Heterozygotenvorteil mag in einer im Verhältnis zu den homozygoten Genotypen ausgeglichenen IL10-Produktion liegen. Ein Einfluß der Pest auf die Verteilung der Genotypen kann nicht nachgewiesen werden, da die Verteilung innerhalb der Pestserie nicht von der mittelalterlichen Kontrolle abweicht.

In allen historischen Stichproben kommen die antiinflammatorischen Allele mit einer unerwartet hohen Häufigkeit vor. IL6 G-174C und IL10 G-1087A zeigen fast ausgeglichene Frequenzen der beiden Allele der SNP, nur bei IL10 G-2849A ist die Frequenz des antiinflammatorischen deutlich geringer als die des proinflammatorischen. Ergänzend zu den bereits vorgestellten Ergebnissen von $\mathrm{Pu}-$ der (2005) wurde jedoch ein Trend zu einer erhöhten Zahl an IL6-C-Allelträgern (antiinflammatorisch) innerhalb der bronzezeitlichen Skelettserie gegenüber den übrigen Populationen gefunden. Dies ist konform mit der Eingangshypothese, daß in einer vergleichsweise pathogenarmen Umgebung, wie sie für die Bronzezeit angenommen wird, das C-Allel keinen Nachteil vermittelt. Allerdings ist zu berücksichtigen, daß angesichts der geringen Stichprobengröße der Unterschied 
zwischen den Allelen nur durch wenige Individuen ausgemacht wird. Eine Vergrößerung der Stichprobe könnte daher diesen Trend sowohl verstärken als auch aufheben. Der Trend scheint zunächst im Gegensatz zu der Verteilung der IL10SNP zu stehen, bei der die proinflammatorischen Allele in dieser Serie überwiegen. Die Verteilung der Genotypen der bronzezeitlichen Serie entspricht außerdem nicht dem HWE. Ein Heterozygotenüberschuß liegt vor. Als Ursache ist bei der geringen Individuenzahl ein Stichprobenartefakt wahrscheinlich.

Die Ergebnisse lassen annehmen, daß weder anti- noch proinflammatorische Eigenschaften per se einen Vorteil vermitteln. Vielmehr scheint die erfolgreiche Balancierung proinflammatorischer und antiinflammatorischer Eigenschaften in historischen Bevölkerungen einen entscheidenden Vorteil bedeuten. Mocellin et al. (2004) weist im Zusammenhang mit IL10 auf die Bedeutung einer Immunregulation zur Aufrechterhaltung eines Gleichgewichtes zwischen dem Schutz vor Pathogenen und der Schädigung des Gewebes hin. Die Vorteile antiinflammatorischer Allele in historischen Bevölkerungen werden in Kapitel 11.2 eingehender diskutiert.

Aus den vorliegenden Daten können weitergehende Analysen durchgeführt werden, die zur Klärung der Fragestellung beitragen. Die vorgestellte Auswertung beschäftigt sich mit den Allel- und Genotypfrequenzen der einzelnen Marker. Weitergehend sollte die Kombination der anti- und proinflammatorischen Allele der untersuchten Marker in den Individuen der einzelnen Populationen verglichen werden. Daraus kann sich ein Aufschluß über die Bedeutung der Kombination von gegensätzlichen Ausprägungen verschiedener Polymorphismen ergeben. Dies ist gerade für die beiden IL10 SNP interessant. Für eine Stärkung der Aussagekraft der IL10-Polymorphismen sollte die Untersuchung auf bekannte Haplotypen ausgeweitet werden, wie bereits in der Arbeit Suray (2007) für die bronzezeitliche Skelettserie Dorste geschehen. 


\subsection{Diskussion der Frequenzen der antiinflammatorischen} Allele in den historischen Populationen

Während für die Polymorphismen der Toll-like Rezeptoren die Allelfrequenzen in der heutigen Bevölkerung mit weniger als $10 \%$ sehr niedrig sind, fallen die pro- und antiinflammatorischen Marker IL4Ra, IL6 und IL10 durch ihre hohe Häufigkeit der jeweiligen minor alleles auf. Ohne die heute mögliche medizinische Prävention und Therapie ist eine erfolgreiche Immunabwehr alleine durch die optimale Adaption des Immunsystems an die existierende Pathogenflora möglich. Erwartet wurde daher eine Adaption in Form einer Selektion auf proinflammatorische Eigenschaften, die eine besonders starke Immunantwort bedingen sollten. Die Präsenz von antiinflammatorischen Eigenschaften muß demnach auch in historischen Zeiten einen Vorteil vermittelt haben.

\section{Langlebigkeitsallele als Vorteil in historischen Bevölkerungen}

In der modernen Bevölkerung wird ein Vorteil der antiinflammatorischen Allele in der Chance zum beschwerdefreien Altern gesehen. Scola et al. (2003) und Franceschi et al. (2005) vermuten aufgrund ihrer Ergebnisse eine höhere Überlebenserwartung für Individuen mit einem ausgewogenen Verhältnis pround antiinflammatorischer Moleküle. Dadurch soll die Einleitung von biologischen Schäden verhindert werden, die eine Reduktion der Lebenserwartung nach sich ziehen können. Die Übertragung dieses Aspektes auf Selektionsereignisse in historischen Bevölkerungen erscheint zunächst uneingängig. Die Bedeutung der Abwehr des akuten Sterberisikos durch Infektionen scheint die der später auftretenden degenerativen Erkrankungen angesichts der geringeren Lebenserwartung zu überwiegen. Mocellin et al. (2004) weisen darauf hin, daß grundsätzlich durch eine überschießende Immunreaktion Gewebeschäden auftreten können. Je nach Stärke der Schädigung wird die Infektion mit bleibenden Beeinträchtigungen überlebt. Auch in einer historischen Bevölkerung bedeutet dies einen Nachteil. Weiterhin werden diese Allele mit einer höheren Chance auf erfolgreiche Reproduktion verbunden (Westendorp et al., 2001). Dieses Ungleichgewicht in der Fortpflanzungswahrscheinlichkeit (genetic drift) zwischen Trägern proinflammatorischer und antiinflammatorischer Allele kann über einen Heterozygotenvorteil den Erhalt der antiinflammatorischen Allele in der Bevölkerung sichern. Nach ei- 
ner Epidemie haben die verbliebenen Träger der antiinflammatorischen Allele die Möglichkeit, durch eine höhere Fortpflanzungsrate den Verlust auszubalancieren. Pawelec (2003) zweifelt angesichts der langen postreduktiven Phase und hohen Abhängigkeit unseres Nachwuchses die Abwesenheit einer Selektion im fortgeschrittenen Lebensalter an. Ein Aspekt der (beschwerdefreien) Langlebigkeit in historischen Populationen ist demzufolge in der Präsenz einer Großelterngeneration zu sehen. Selbst wenn die Langlebigkeit nicht der heutigen von über 80 Jahren entspricht, steht mit den Großeltern eine größere Zahl an Personen zur Betreuung des Nachwuchses zur Verfügung. Ihr Erfahrungsschatz, der mehrere Generationen überspannt, kann ebenfalls zum Erfolg einer Population beitragen. Pawelec (2003) schließt daraus: „It may not be idiotic after all to search for longevity-promoting genes".

\section{Antiinflammatorische Allele in Zeiten substantieller Krisen}

Grupe (1986) und McNeill (1976) weisen auf den Komplex Ernährung/Infektion hin, ein Zusammenhang, der auch aus individueller Erfahrung einleuchtend ist. Die Funktionen des Immunsystems stellen besondere Anforderungen an die Proteinsynthese des Organismus. Eine unzureichende Versorgung an Proteinen über die Nahrung kann daher im Infektionsfall zu Eiweißmangelerscheinungen führen. Das Kwashiorkor-Syndrom, das in den heutigen Entwicklungsländern nach MasernEpidemien bei Kindern zu beobachten ist, ist nur ein Beispiel. Auch die basale Aktivität des Immunsystems kann abhängig von der Ernährungssituation sein. Dies führt auch McNeill (1976) an, indem er eine höhere Grundresistenz mit der verbesserten Ernährungslage der Neuzeit verbindet. Parallel zur epidemiologischen Entwicklung ist die zweite historische Transition durch wiederkehrende Hungersnöte gekennzeichnet, die sich während der Unruhen und Kriege der dritten Transition fortsetzen. Grupe (1986) spricht den substantiellen Krisen zwar das Maß des Bevölkerungsregulativs ab, sie sieht diese eher bei den Infektionskrankheiten. Andererseits können sie im Zusammenspiel zumindest in einer balancierenden Selektion resultieren, die die bestehende Allelfrequenz eines antiinflammatorischen Alleles wie im Falle des IL6 G-174C erhält. In diesem Kontext ist auch die Eignung der älteren Lübecker Skelettserie („HL Hungersnot“) zu diskutieren. Unklar ist neben dem grundsätzlichen Aspekt der gegenseitigen Beeinflussung 
von Immunantwort und Ernährung, in wieweit die Sterblichkeit während einer Hungersnot durch opportunistische Erkrankungen bedingt wird.

Die Selektionsereignisse, die während einer Hungersnot auf die betroffene Bevölkerung wirken, sind daher in ihrem Einfluß auf die Allelfrequenz schwer abzuschätzen. Die Frage ist, ob ein Nachteil in niedrigerem Basallevel der Immunreaktion oder in höherem Basallevel mit geringerer Infektanfälligkeit aber höherem Ressourcenverbrauch zu sehen ist. Der erste Zustand, in Zusammenhang zu bringen mit antiinflammatorischen Polymorphismen, bedeutet zwar grundsätzlich eine höhere Anfälligkeit für Infektionen. Gleichzeitig birgt er den Vorteil eines geringeren Ressourcenverbrauchs und eines geringeren Proteinbedarfs. In Abwesenheit einer infektiösen Bedrohung könnte dies tatsächlich einen Vorteil darstellen, während der höhere Proteinbedarf einer verstärkt proinflammatorischen Immunantwort bei einer schlechteren Ernährungsgrundlage früher zu Engpässen führen kann.

\section{Eignung der modernen Population als Kontrolle}

Bei der Beurteilung der modernen Bevölkerung als postepidemische Kontrolle darf ein möglicher Einfluß der Medizin nicht vernachlässigt werden. Seit 1850 nimmt die Bedeutung der Medizin in ihrem Einfluß auf die Bevölkerungsentwicklung zu. Dieser Zeitraum erscheint zunächst nicht lange gemessen an der Entstehungsgeschichte des Menschen, entspricht aber immerhin etwa 5 Generationen. Einige wichtige Errungenschaften wurden bereits vor 1850 erreicht. Die Pockenimpfung ist für Großbritannien ab 1721 belegt, gängig wurde sie ab etwa 1770 (McNeill, 1976). Im restlichen Europa wurde sie erst ab dem 19. Jahrhundert eingeführt. McNeill (1976, S. 258f) mißt der effektiven Kontrolle der Pocken einen substantiellen Stellenwert als Voraussetzung der Bevölkerungsexplosion im 19. Jahrhundert bei. Ab etwa 1880 begann der Triumphzug der Medizin (Tab. 39): Die Entdeckung und Identifizierung von Erregern führte zu Hygienevorschriften, die sich vor allem in der Unterbrechung von Transmissionsketten auswirkten (McNeill, 1976, S. 265). Unter anderem gehörte dazu die Abwasserentsorgung und die Einführung des Pasteurisierens. Damit wurde eine der Hauptursachen der Kindersterblichkeit ausgemerzt, die in den heutigen Entwicklungsländern immer noch $30 \%$ der Mortalität in den ersten fünf Lebensjahren ausmacht. 
Tab. 39: Errungenschaften der Medizin des späten 19. Jahrhunderts. Nach Keil (1986) und McNeill (1976)

\begin{tabular}{|c|c|c|c|}
\hline \multirow{2}{*}{$\begin{array}{l}\text { Erkrankung } \\
\text { Cholera }\end{array}$} & \multicolumn{3}{|c|}{ Entdeckung } \\
\hline & 1883 & Identifizierung & R. Koch \\
\hline & & Wirkung von Desinfektionsmitteln & \\
\hline & 1893 & Impfung & \\
\hline \multirow[t]{2}{*}{ Typhus } & 1896 & $\begin{array}{l}\text { Erreger-Identifizierung und Impfung, Laus als } \\
\text { Wirt identifiziert }\end{array}$ & \\
\hline & 1910er & Massenimpfung & \\
\hline \multirow[t]{3}{*}{ Tuberkulose } & 1882 & Erreger-Identifizierung & R. Koch \\
\hline & & $\begin{array}{l}\text { Isolierungsmaßnahmen, Verbot öffentlichen } \\
\text { Spuckens, Schlachten von Tuberkulose-tragen- } \\
\text { den Milchkühen }\end{array}$ & \\
\hline & 1921 & Impfung & \\
\hline \multirow[t]{2}{*}{ Diphterie } & 1883 & Erreger-Identifizierung & \\
\hline & 1891 & Antitoxin & \\
\hline Lepra & 1873 & Erreger-Identifizierung & A. Hansen \\
\hline \multirow[t]{2}{*}{ Malaria } & $1890 \mathrm{er}$ & Erreger-Identifizierung & \\
\hline & seit 1854 & Chinin gegen Malaria & \\
\hline Pest & 1894 & Erreger-Identifizierung & Yersin \\
\hline enterale Infektionen & $1900 \mathrm{er}$ & $\begin{array}{l}\text { Einführung des Pasteurisieren, milchübertragene } \\
\text { Infektionen verloren an Bedeutung noch vor dem } \\
\text { ersten Weltkrieg }\end{array}$ & \\
\hline
\end{tabular}

Die diskutierte Entwicklung zu inflammatorischen, onkologischen und atopischen Erkrankungen läßt auf die Persistenz der proinflammatorischen Genotypen schliessen. Gleichzeitig kann im steigenden Anteil der Langlebigen die Zunahme der antiinflammatorischen Genotypen gesehen werden. Ohne medizinische Betreuung hätten sie ein erhöhtes Risiko vermittelt, an Infektionserkrankungen vor allem während der frühen Kindheit zu versterben. Mit der Eindämmung der Kindersterblichkeit sollte ein Hauptfaktor der Selektion antiinflammatorischer Genotypen verlorengegangen sein. Fraglich ist, ob innerhalb von fünf Generationen die Auswirkungen der veränderten Selektion innerhalb der Bevölkerung nachweisbar werden. Andererseits wird eine Abnahme der Sterblichkeit an Herz-KreislaufErkrankungen und Herzinfarkten in den 1960ger Jahren bereits als Folge der reduzierten Kindersterblichkeit diskutiert (Finch \& Crimmins, 2004). Interessant wäre daher die Einbindung eines Vergleichskollektivs aus der prämedizinischen Ära der Neuzeit. Eine Verschiebung zwischen prämedizinischer und heutiger Po- 
pulation hin zu den antiinflammatorischen Genotypen ließe darauf schließen, daß der Einfluß der Medizin nicht zu vernachlässigen ist.

\subsection{Aussagekraft der ausgewählten Marker}

Eine Vielzahl von Polymorphismen des Immunsystems mit ähnlichen Eigenschaften ist bekannt. Ein Einfluß eines einzelnen Polymorphismus auf die erfolgreiche Auseinandersetzung mit Erregern erscheint daher zunächst unwahrscheinlich. Daraus mag gefolgert werden, daß selektive Prozesse nur bei der simultanen tausender Marker nachweisbar sind. Brookes (1999) allerdings sieht gerade in dem geringen Einfluß des einzelnen SNP einen Vorteil, da sich dadurch auch Allele, die einen Nachteil vermitteln, in der Bevölkerung anreichern können. Bei einem stärkeren Einfluß würden sie dagegen der Selektion zum Opfer fallen. In Kapitel 3 (S. 8) wurden die Eigenschaften der Marker beschrieben, die die Auswahl bestimmten. Für alle Marker hatten zuvor bereits Studien an der Rezentbevölkerung ihre epidemiologische Relevanz nachgewiesen. Trotzdem ist es möglich, daß die Einflüsse auf diese speziellen Marker während der letzten 3000 Jahre nicht gravierend genug waren, um eine Selektion nachweisbar zu machen. Um einen selektiven Effekt zu vermitteln, muß ein Vor- oder Nachteil für einen Phänotyp bei den vorherrschenden Erkrankungen bestehen. So wie IL10 und IL6 interagieren, ist dies ebenso der Fall für viele weitere Komponenten, die im Netzwerk der Komponenten des Immunsystems wirken. Es bleibt außerdem ungewiß, inwiefern weitere SNP innerhalb der Genregionen eines Markers die Effekte der untersuchten SNP beeinflussen und maskieren können. Selbst wenn Assoziationen innerhalb von Gruppen Erkrankter im Vergleich zu einer Kontrollgruppe nachweisbar sind - die Einflüsse des alltäglichen Lebens sind allgemeiner mit ihrer Vielzahl an Erregern und Umwelteinflüssen, auf die täglich und simultan reagiert werden muß. Jedoch wurden für drei Marker Veränderungen der Allelfrequenzen gefunden. Ebenso können auch weitere Marker gefunden werden, für die eine Selektion nachweisbar ist. Die letztendliche Ursache bzw. ein selektierender Faktor (z. B. die Pestepidemie des 14. Jhs.) konnte allerdings nicht eingegrenzt werden. 


\section{Zusammenfassung}

In der vorliegenden Studie wurden die Allelfrequenzen von single nucleotide polymorphisms (SNP) der Genregionen immungenetischer Marker in drei historischen Populationen im Vergleich mit der Rezentbevölkerung untersucht. Der Zeitrahmen umfaßt 3000 Jahre, von der Bronzezeit bis zur Moderne. Aus der Untersuchung wurden Aufschlüsse über den Einfluß der Coevolution von Mensch und Pathogen sowie Selektionsereignisse auf die immungenetische Ausstattung europäischer Individuen erhofft.

Die historischen Populationen stammen aus zwei verschiedenen Zeitstellungen, die unterschiedlichen epidemiologischen Phasen zuzuordnen sind. Die älteste Serie aus der Bronzezeit steht für ein Zeitalter geringer Pathogenexposition. Eine weitere Serie umfaßt Opfer des „Schwarzen Todes“, der Pestepidemie von 1350. Sie steht für einen Zeitraum hoher Pathogenexposition. 82 Individuen wurden aus dieser Serie in die Untersuchung einbezogen. Die dritte zeitstellungsnahe Serie (AD 1316) mit einer Stichprobengröße von 43 Individuen dient als kontemporäre Kontrolle. Aus der modernen Literatur und einer Kontrollkohorte für onkologische Studien wurden Vergleichsdaten über die moderne Bevölkerung als postepidemische Kontrolle gewonnen.

$\mathrm{Zu}$ den untersuchten Markern gehören die zentralen Interleukine IL6, IL10 und IL4 sowie sein Rezeptor IL4R $\alpha$ und die beiden Pathogen-Rezeptoren TLR2 und TLR4. Die Auswahl der Marker richtete sich nach ihrer Relevanz in immunologischen Prozessen und den typischen Erkrankungen der modernen industriellen Gesellschaft. Sie war unabhängig von der Assoziation der Marker mit einem bestimmten Pathogen. Der Nachweis von Selektionsereignissen, die sich auf die gewählten Marker auswirkten, erscheint daher im Kontext der historischen Transitionen wahrscheinlich. Erwartet wurde eine Verschiebung der Allelfrequenzen von antiinflammatorischen Allelen in der pathogenarmen Bronzezeit hin zu proinflammatorischen Allelen in der heutigen Zeit. Für die Pestserie wurde eine höhere Frequenz an antiinflammatorischen Allelen als Ergebnis eines selektiven Nachteils erwartet.

Die Ergebnisse ergeben geringe Abweichungen in den Allelfrequenzen zwischen damals und heute. Obwohl Trends beobachtbar sind, bestehen signifikante Ab- 
weichungen nur zwischen einzelnen historischen und der modernen Bevölkerung in der Verteilungen der Allele der Pathogen-Rezeptoren und des Markers IL10. Auffallend ist die hohe Frequenz der antiinflammatorischen Allele der Marker IL6, IL10 und IL4R $\alpha$ in allen Zeitstellungen. Sie wird als Hinweis auf eine Bedeutung antiinflammatorischer Eigenschaften in historischen Bevölkerungen gewertet. Kontinuierliche Veränderungen über alle Serien wurden nicht beobachtet. Der Einfluß der Epidemiologie der letzten 3000 Jahre auf die immungenetischen Marker ist damit geringer als erwartet.

In der Pestserie unterscheiden sich die Verteilungen der Allele des TLR4 D299G und des IL10 G-1087A von der der modernen Bevölkerung. Eine Selektion durch die Pestepidemie wird diskutiert. Die Frequenz des minor alleles 753Q des TLR2 ist in beiden mittelalterlichen Serien höher als in der modernen Bevölkerung. Eine Selektion durch die Pest ist daher unwahrscheinlich, jedoch ist eine Selektion mit Reduktion der Allelfrequenz des minor alleles zwischen Mittelalter und Neuzeit anzunehmen. Der SNP G-2849A des Markers IL10 zeigt eine signifikante Abweichung der historischen Stichproben zur modernen Bevölkerung. Das heute seltenere proinflammatorische Allel überwiegt in den historischen Serien.

Diese Studie zeigt die Möglichkeiten eines Screenings historischer Populationen über mehrere Marker. Die verwendete Methode der single-base-extension-Reaktion (SBE), auch Minisequencing oder "SNaPshot" genannt, kam zum Einsatz, um alle Marker simultan untersuchen zu können. Sie wurde mit der Analyse von STR des genetischen Fingerabdrucks kombiniert, wodurch der direkte Nachweis der Authentizität der Ergebnisse möglich war.

Zwei SNP mußten aus der Auswertung der Ergebnisse ausgeschlossen werden, da die Spezifität der Typisierungen nicht gewährleistet werden konnte. Die Ursache konnte bisher nicht hinreichend geklärt werden. Eine weitere Analyse ist vonnöten, um für folgende Projekte die Fehlerquelle auszuschließen. Sechs weitere Systeme zeigten Ergebnisse, die über eine alternative Methode verifiziert werden konnten. Trotz der ungeklärten Probleme bei der Analyse zweier Marker ist die Methode der SBE die Methode der Wahl. Ohne sie wäre eine Untersuchung in diesem Umfang nicht möglich gewesen.

Aus den Ergebnissen dieser Studie entstehen folgende Fragen für weitere Untersuchungen: 
- Wird die Bedeutung der historischen epidemiologischen Transitionen überbewertet?

- Ist die moderne Bevölkerung als postepidemische Kontrolle geeignet?

- Wird die Untersuchung von Populationen überanstrengt? Kommt der Untersuchung einer Vielzahl von SNP auf individueller Ebene eine stärkere Aussagekraft zu?

Um diese Fragen zu beantworten sollte in folgenden Untersuchungen die Auswahl der Marker angepaßt und eine frühneuzeitliche Population als postepidemische Kontrolle einbezogen werden. Ferner sollte die individuelle Kombination der pround antiinflammatorischen Allele der untersuchten Marker auf einen Vor- oder Nachteil in der Infektabwehr untersucht werden. Ein weiterer Ansatz ist die Ausweitung der Untersuchung auf eine Vielzahl von Markern auf individueller Ebene, um den Einfluß der individuellen Immungenetik auf das Krankheitsgeschehen zu bewerten. 


\section{Literatur}

Adjers K, Karjalainen J, Pessi T, Eklund C, Hurme M (2005) Epistatic effect of TLR4 and IL4 genes on the risk of asthma in females. Int Arch Allergy Immunol. 138(3):251-6.

Agnese DM, Calvano JE, Hahm SJ, Coyle SM, Corbett SA, Calvano SE, Lowry SF (2002) Human Toll-like Receptor 4 Mutations but Not CD14 Polymorphisms Are Associated with an Increased Risk of Gram-Negative Infections. J. Inf. Dis. 186: $1522-1525$

Arai N, Nomura D, Villaret D, DeWaal Malefijt R, Seiki M, Yoshida M, Minoshima S, Fukuyama R, Maekawa M, Kudoh J, Shimizu N, Yokota K, Abe E, Yokota T, Takebe Y, Arai K (1989) J.Immun. 142:274-282.

Arbour NC, Lorenz E, Schutte BC, Zabner J, Kline JN, Jones M, Frees K, Watt JL, Schwartz DA (2000). TLR4 mutations are associated with endotoxin hyporesponsiveness in humans. Nat Genet. 25(2):187-191

Anslinger K, Bayer B, Rolf B, Keil W, Eisenmenger W (2005) Application of the BioRobot EZ1 in a forensic laboratory. Leg Med (Tokyo). 7(3):164-8

Balistreri CR, Candore G, Lio D, Colonna-Romano G, Di Lorenzo G, Mansueto P, Rini G, Mansueto S, Cillari E, Franceschi C, Caruso C (2005) Role of TLR4 receptor polymorphisms in Boutonneuse fever. Int J Immunopathol Pharmacol. $18(4): 655-60$.

Basehore MJ, Howard TD, Lange LA, Moore WC, Hawkins GA, Marshik PL, Harkins MS, Meyers DA, Bleecker ER (2004) A comprehensive evaluation of IL4 variants in ethnically diverse populations: association of total serum IgE levels and asthma in white subjects. J Allergy Clin Immunol. 114(1):80-7.

Baum J. Bar-Gal GK (2003). Emergence and Coevolution of Human Pathogens. In: Emerging Pathogens - The Archaeology, Ecology and Evolution of Infectious Disease. Greenblatt \& Spiegelman (Hrsg). Oxford Press 2003

Ben-Ali M, Barbouche MR, Bousnina S, Chabbou A, Dellagi K (2004) TollLike Receptor 2 Arg677Trp Polymorphism Is Associated with Susceptibility to Tuberculosis in Tunisian Patients. Clin Diagn Lab Immunol. 11(3):625-626

Bonafè M, Olivieri F, Cavallone L, Giovagnetti S, Marchegiani F, Cardelli M, Pieri C, Marra M, Antonicelli R, Lisa R, Rizzo MR, Paolisso G, Monti D, Franceschi C (2001). A gender-dependent genetic predisposition to produce high levels of IL-6 is detrimental for longevity. Eur J Immunol. 31:2357-2361

Bochud PY, Bochud M, Telenti A, Calandra T (2007). Innate immunogenetics: a tool for exploring new frontiers of host defence. Lancet Infect Dis. 7(8):531-42 
Brockmöller J, Tzvetkov M (2008) Pharmacogenetics: data, concepts and tools to improve drug discovery and drug treatment. Eur J Clin Pharmacol. 64:133-157

Brookes AJ (1999) The essence of SNPs. Gene 234:177-186

Capasso M, Avvisati RA, Piscopo C, Laforgia N, Raimondi F, de Angelis F, Iolascon A (2007) Cytokine gene polymorphisms in Italian preterm infants: association between interleukin-10 -1082 G/A polymorphism and respiratory distress syndrome. Pediatr Res. 61(3):313-317

Castex D \& Friess M (2001). Ein Pestsommer in der Provence. Demographische Verzerrungen im Zusammenhang mit Epidemien. In: Pein und Plagen. Aspekte einer Historischen Epidemiologie. Hrsg. Kemkes-Grottenthaler A. und Henke W. Edition Archaea - Gelsenkirchen/ Schwelm 2001. S.97 - 108

Chakravarti A (1999) Population genetics - making sense out of sequence. Nat Genet. 21(1 Suppl):56-60

Christiansen L., Bathum L, Andersen-Ranberg K, Jeune B, Christensen K (2004). Modest implication of inteleukin-6 promoter polymorphisms in longevity. Mech Ageing Dev. 125(5):391-5.

Cohn SK, Weaver LT (2006) The Black Death and AIDS: CCR5- $\delta 32$ in genetics and history. Q J Med. 99:497-503

Collins FS, Brooks LD, Chakravarti A (1998) A DNA Polymorphism Discovery Resource for Research on Human Genetic Variation. Genome Res. 8: 1229-1231

Costeas PA, Koumas L, Koumouli A, Kyriakou-Giantsiou A, Papaloizou A(2003) Cytokine polymorphism frequencies in the Greek Cypriot population. Eur J Immunogenet. 30(5):341-3.

de Capei MU, Dametto E, Fasano ME, Rendine S, Curtoni ES (2003) Genotyping for cytokine polymorphisms: allele frequencies in the Italian population. Eur J Immunogenet. 30:5-10

Dobson A (1992). People and disease. In: The Cambridge Encyclopedia of Human Evolution. Richards P (Hrsg). Cambridge University Press 1992

Donoghue HD, Spigelman M, Greenblatt CL, Lev-Maor G, Bar-Gal GK, Matheson C, Vernon K, Nerlich AG, Zink AR (2004) Tuberculosis: From prehistory to Robert Koch, as revealed by ancient DNA. Lancet Infect Dis. 4:584-592

Donoghue HD, Marcsik A, Matheson C, Vernon K, Nuorala E, Molto JE, Greenblatt CL, Spigelman M (2004) Co-infection of Mycobacterium tuberculosis and Mycobacterium leprae in human archaeological samples: a possible explanation for the historical decline of leprosy. Proc R Soc B. doi: 10.1098/rsbp.2004.2966

Drancourt M, Raoult D (2002). Molecular insights into the history of plague. Microbes Infect. 4(1):105-9 
Dubos R (1987). The mirage of health: utopias, progress and biological change. New Ed edition. Rutgers University Press.

Duncan SR, Scott S, Duncan CJ (2005) Reappraisal of the historical selective pressures for the CCR5-Delta32 mutation. J Med Genet. 42(3):205-8.

Scott S, Duncan CJ (2001) Biology of Plagues: Evidence from Historical Populations. Cambridge University Press

Ekstrom PO, Bjorheim J, Gaudernack G, Giercksky KE (2002) Population Screening of Single-Nucleotide Polymorphisms Exemplified by Analysis of $8000 \mathrm{Al}-$ leles. J Biomol Screen. 7(6):501-505

Erridge C, Stewart J, Poxton IR( 2003) Monocytes Heterozygotes for the Asp299Gly and Thr399Ile Mutations in the Toll-like Receptor 4 Gene Show No Deficit in Lipopolysaccharide Signalling. J Exp Med. 197(12):1787-1791

Eskdale J, Gallagher G, Verweij CL, Keijsers V, Westendorp RGJ, Huizinga TWJ (1998) Interleukin 10 secretion in relation to human IL-10 locus haplotypes. P Natl Acad Sci USA 95: 9465-9470

Excoffier L, Laval LG, Schneider S (2005). Arlequin ver. 3.0: An integrated software package for population genetics data analysis. Evolutionary Bioinformatics Online 1:47-50.

Ferwerda B. (2007). TLR4 polymorphisms, infectious diseases, and evolutionary pressure during migration of modern humans. PNAS 104(42)16645-16650

Fishman D, Faulds G, Jeffery R, Mohamed-Ali V, Yudkin JS, Humphries S, Woo $\mathrm{P}$ (1998) The effect of novel polymorphisms in the interleukin-6 (IL-6) gene on IL-6 transcription and plasma IL-6 levels, and an association with systemiconset juvenile chronic arthritis. J Clin Invest. 102(7):1369-76

Finch CA \& Crimmins EM (2004) Inflammatory Exposure and Historical Changes in Human Life-Spans. Science 305:1736-1739

Folwaczny M, Glas J, Török HP, Limbersky O, Folwaczny C (2004) Toll-like receptor (TLR) 2 and 4 mutations in periodontal disease. Clin Exp Immunol. $135(2): 330-5$.

Forster T, Chapman K, Loughlin J (2004) Common variants within the interleukin 4 receptor alpha gene (IL4R) are associated with susceptibility to osteoarthritis. Hum Genet. 114(4):391-5.

Franceschi C, Olivieri F, Marchegiani F, Cardelli M, Cavallone L, Capri M, Salvioli S, Valensin S, De Benedictis G, Di Iorio A, Caruso C, Paolisso G, Monti D (2005) Genes involved in immune response/inflammation, IGF1/insulin pathway and response to oxidative stress play a major role in the genetics of human longevity: the lesson of centenarians. Mech Ageing Dev. 126(2):351-61. 
Frauendorf E. (2001). Mehr Menschen - mehr Krankheiten. Zur Evolution parasitärer Erkrankungen im populationsbiologischen Kontext. In: Pein und Plagen. Aspekte einer Historischen Epidemiologie. Kemkes-Grottenthaler A und Henke W (Hrsg.). Edition Archaea - Gelsenkirchen/Schwelm 2001, S.21-37

Frauendorf E. (2001). Infektionskrankheiten im diachronen Trend. Probleme gestern, heute morgen. In: Pein und Plagen. Aspekte einer Historischen Epidemiologie. Kemkes-Grottenthaler A und Henke W (Hrsg.). Edition Archaea Gelsenkirchen/Schwelm 2001, S.137-55

Friess M. \& Castex D. (2001). Ein Pestsommer in der Provence. Demographische Verzerrungen im Zusammenhang mit Epidemien. In: Pein und Plagen. Aspekte einer Historischen Epidemiologie. Kemkes-Grottenthaler A und Henke W (Hrsg.). Edition Archaea - Gelsenkirchen/Schwelm 2001, S.97-108

Garg R, Wollan M, Galic V, Garcia R, Goff BA, Gray HJ, Swisher E (2006). Common polymorphism in interleukin 6 influences survival of women with ovarian and peritoneal carcinoma. Gynecol Oncol. 103(3):793-6

Giacconi R, Cipriano C, Albanese F, Boccoli G, Saba V, Olivieri F, Franceschi C, Mocchegiani E (2004). The $-174 \mathrm{G} / \mathrm{C}$ polymorphism of IL6 is useful to screen old subjects at risk for atherosclerosis or to reach successful ageing. Exp Gerontol. 39:621-628

Gleeson M, McFarlin B, Flynn M (2006) Exercise and Toll-like Receptors. Exerc Immunol Rev. 12:34-53.

Goudet J, Raymond M, de Meeüs T, Rousset F (1996) Testin differentiation in diploid populations. Genetics 144:1933-1940

Grupe G (1986). Umwelt und Bevölkerungsentwicklung im Mittelalter. In: Mensch und Umwelt im Mittelalter. Herrmann B (Hrsg). Fourier Verlag Wiesbaden 1996. S.24 - 34

Grupe G, Christiansen K, Schröder I, Wittwer-Backofen U (2005) Anthropologie: Ein einführendes Lehrbuch. Springer, Berlin

Haas CJ, Zink A, Pálfi G, Szeimies U, Nerlich AG (2000) Detection of leprosy in ancient human skeletal remains by molecular identification of Mycobacterium leprae. Am J Clin Pathol. 114(3):428-436

Hawn TR, Verbon A, Janer M, Zhao LP, Beutler B, Aderem A (2005). Tolllike receptor 4 polymorphisms are associated with resistance to Legionnaires' disease. PNAS 102(7):2487-2489

Helminen M, Lahdenpohja N, Hurme M (1999) Polymorphism of the interleukin10 gene is associated with susceptibility to Epstein-Barr virus infection. J Infect Dis. 180(2):496-9. 
Henao MI, Montes C, París SC, García LF (2006). Cytokine gene polymorphisms in Colombian patients with different clinical presentations of tuberculosis. Tuberculosis 86: 11-19

Herrmann B, Grupe G, Hummel S, Piepenbrink H, Schutkowski H (1990). Prähistorische Anthropologie. Leitfaden der Feld- und Labormethoden. Springer-Verlag Berlin, Heidelberg, New York.

Herrmann B (1987). Anthropologische Zugänge zu Bevölkerung und Bevölkerungsentwicklung im Mittelalter. In: Herrmann B, Sprandel R (eds) Determinanten der Bevölkerungsentwicklung im Mittelalter. Acta Humaniora, VCH, Weihnheim, pp55-72

Herrmann B, Schilz S, Fehren-Schmitz L, Renneberg R, Pollmann J, Hummel S (2007) Der Knochen als molekulares Archiv. Nova Acta Leopoldina 94(348):2127

Hershey GK, Friedrich MF, Esswein LA, Thomas ML, Chatila TA (1997) The association of atopy with a gain-of-function mutation in the alpha subunit of the interleukin-4 receptor. N Engl J Med. 337(24):1720-5

Hoffmann SC, Stanley EM, Cox ED, DiMercurio BS, Koziol DE, Harlan DM, Kirk AD, Blair PJ (2002) Ethnicity Greatly Influences Cytokine Gene Polymorphism Distribution. Am J Transplant. 2(6):560-7

Huhn S (2007) Slawen oder Deutsche? Ethnische Zuordnung des mittelalterlichen Kollektivs aus Lübeck über paternale Verwandtschaftslinien. Diplomarbeit. Universität Göttingen

Hummel S, Herrmann B (1995). aDNA analysis in paleopathology: mini-review and prospects. paleopathol Newsl. 1995 Sep (91):6-9

Hummel S (2003). Ancient DNA Typing. Methods, Strategies and Applications. Springer Verlag Berlin, Heidelberg, New York

Hummel S, Schmidt D, Kremeyer B, Herrmann B, Oppermann M (2005) Detection of the CCR5- $\Delta 32 \mathrm{HIV}$ resistance gene in Bronze Age skeletons. Genes Immun. 6(4):371-374

Hedrick PW \& Verrelli BC (2006) 'Ground truth' for selection on CCR5- $\Delta 32$. Trends in Genetics 22(6):293-296

Huth C, Heid IM, Vollmert C, Gieger C, Grallert H, Wolford JK, Langer B, Thorand B, Klopp N, Hamid YH, Pedersen O, Hansen T, Lyssenko V, Groop L, Meisinger C, Döring A, Löwel H, Lieb W, Hengstenberg C, Rathmann W, Martin S, Stephens JW, Ireland H, Mather H, Miller GJ, Stringham HM, Boehnke M, Tuomilehto J, Boeing H, Möhlig M, Spranger J, Pfeiffer A, Wernstedt I, Niklason A, López-Bermejo A, Fernandez-Real JM, Hanson RL, Gallart L, Vendrell J, Tsiavou A, Hatziagelaki E, Humphries SE, Wichmann HE, Herder 
C, Illig T (2006) IL6 gene promoter polymorphisms and type 2 diabetes: joint analysis of individual participants' data from 21 studies. Diabetes 55(10):291521.

Imahara SD, Jelacic S, Junker CE, O'Keefe GE (2005) The TLR4 +896 polymorphism is not associated with lipopolysaccharide hypo-responsiveness in leukocytes. Genes Immun. 6(1):37-43

Janeway CA, Travers P, Walport M, Shlomchik M (2005) Immunobiology: The Immune System in Health and Disease. 6th Edition. Garland Science New York \& London

Jockenhövel A (1994) Raum und Zeit - Gliederung der Bronzezeit. In: Jockenhövel A, Kubach W (Hrsg) Bronzezeit in Deutschland. C. Konrad Theiss GmbH \& Co., Stuttgart, S.11 - 14

Jockenhövel A (1994) Ortsfest und mobil - Haus und Handwerk, Handel und Verkehr. In: Jockenhövel A, Kubach W (Hrsg) Bronzezeit in Deutschland. C. Konrad Theiss GmbH \& Co., Stuttgart, S.41 - 44

Kalish RB, Vardhana S, Gupta M, Perni SC, Witkin SS (2004) Interleukin-4 and 10 gene polymorphisms and spontaneous preterm birth in multifetal gestations. Am J Obstet Gynecol. 190(3):702-6.

Kabesch M, Lauener RP (2004) Why Old McDonalds had a farm but no allergies: genes, environments, and the hygiene hypothesis. J Leuk Biol. 75:383-387

Kang TJ, Yeum CE, Kim BC, You EY, Chae GT(2004) Differential production of interleukin-10 and interleukin-12 in mononuclear cells from leprosy patients with a Toll-like receptor 2 mutation. Immunology 112(4):674-680

Kaur G, Rapthap CC, Kumar N, Kumar S, Neolia S, Mehra NK (2007) Frequency distribution of cytokine gene polymorphisms in the healthy North Indian population. Tissue Antigens 69(2):113-20

Keil G (1986) Seuchenzüge des Mittelalters. In: Mensch und Umwelt im Mittelalter. Herrmann B (Hrsg). Fourier Verlag Wiesbaden 1996. S.109-128

Kitchin PA, Szotyori Z, Fromholc C, Almond N (1990) Avoidance of false positives. Nature 344:201

Kleindorp R (2006) Vergleichende Untersuchung der DNA-Erhaltung in verschiedenen Skelettelementen. Diplomarbeit. Universität Göttingen

Kolek MJ, Carlquist JF, Muhlestein JB, Whiting BM, Horne BD, Bair TL, Anderson JL (2004) Toll-like receptor 4 gene Asp299Gly polymorphism is associated with reductions in vascular inflammation, angiographic coronary artery disease, and clinical diabetes. Am Heart J. 1q48(6):1034-40 
Konenkov VI, Prokofiev VF, Shevchenko AV, Golovanova OV, Smolnikova MV (2001) Polymorphism of Immune Response Genes as a Factor for Predisposition to Development of Diseases. Russ J Immunol. 2001 Jul;6(2):123-130.

Krabbe KS, Pedersen M, Bruunsgaard H (2004) Inflammatory mediators in the elderly. Exp Gerontol. 2004 May;39(5):687-99

Kremeyer B, Hummel S, Herrmann B (2005) Frequency analysis of the delta32ccr5 HIV resistance allele in a medieval plague mass grave. Anthropol Anz. 63(1):1322

Kristiansen OP, Nolsøe RL, Larsen L, Gjesing AM, Johannesen J, Larsen ZM, Lykkesfeldt AE, Karlsen AE, Pociot F, Mandrup-Poulsen T; DIEGG; DSGD (2003) Association of a functional 17beta-estradiol sensitive IL6-174G/C promoter polymorphism with early-onset type 1 diabetes in females. Hum Mol Genet. 2003 May 15;12(10):1101-10.

Kruse S, Japha T, Tedner M, Sparholt SH, Forster J, Kuehr J, Deichmann KA (1999) The polymorphisms S503P and Q576R in the interleukin-4 receptor alpha gene are associated with atopy and influence the signal transduction. Immunology 96(3):365-71.

Kruse S, Braun S, Deichmann KA (2002) Distinct signal transduction processes by IL- 4 and IL-13 and influences from the Q551R variant of the human IL-4 receptor alpha chain. Respir Res. 3:24.

Koch W, Kastrati A, Böttiger C, Mehilli J, von Beckerath N, Schömig A (2001) Interleukin-10 and tumor necrosis factor gene polymorphisms and risk of coronary artery disease and myocardial infarction. Atherosclerosis 159: 137-144

Kube D, Mörmann M, Tomiuk J, Rieth H, Hua TD, Kremsner PG, Vockerodt M (2003) Simultaneous analysis of interleukin-10 gene microsatellites and single-nucleotide polymorphisms in parallel with tumour necrosis factor and interferon-gamma short tandem repeats by fluorescence-based polymerase chain reaction. Genes Immun. 4:459-468

Kube D, Hua TD, Klöss M, Kulle B, Brockmöller J, Wojnowski L, Löffler M, Pfreundschuh M, Trümper L (2007): The interleukin-10 gene promoter polymorphism -1087AG does not correlate with clinical outcome in non-Hodgkin's lymphoma. Genes Immun. 8(2):164-167

Kurreeman FAS, Schonkeren JJM, Heijmans BT, Toes REM, Huizinga TWJ (2004) Transcription of the IL10 gene reveals allele-specific regulation at the mRNA level. Hum Mol Gen. 13(16):1755-1762

Kwok S (1990) Procedure to minimize PCR product carry over. In: Innis MA, Gelfand DH, Sninsky JJ, White TJ (Hrsg.). PCR protocols - A Guide to Methods and Applications. Academic Press San Diego, S. 142-145 
Larcombe LA, Nickerson P, Hoppa RD, Matheson C (2005) Detection of a single nucleotide polymorphism in the IL-6 promoter region of ancient nuclear DNA. Infect Genet Evol. 5(2):117-22.

Lard LR, van Gaalen FA, Schonkeren JJ, Pieterman EJ, Stoeken G, Vos K, Nelissen RG, Westendorp RG, Hoeben RC, Breedveld FC, Toes RE, Huizinga TW (2003) Association of the -2849 interleukin-10 promoter polymorphism with autoantibody production and joint destruction in rheumatoid arthritis. Arthritis Rheum. 48(7):1841-8.

Liebert A (2007) Bestimmung mitochondrialer Haplogruppen an stark degradierter DNA durch RFLP- und SNaPshot - Analysen am Beispiel südamerikanischer Bestattungen aus Los Molinos (Peru). Diplomarbeit. Universität Göttingen.

Lio D, Candore G, Crivello A, Scola L, Colonna-Romano G, Cavallone L, Hoffmann E, Caruso M, Licastro F, Caldarera CM, Branzi A, Franceschi C, Caruso $\mathrm{C}$ (2004) Opposite effects of interleukin 10 common gene polymorphisms in cardiovascular diseases and in successful ageing: genetic background of male centenarian is protective against coronary heart disease. J Med Genet. 41: 790-794

Lorenz E, Mira JP, Cornish KL, Arbour NC, Schwartz DA (2000) A novel polymorphism in the toll-like receptor 2 gene and its potential association with staphylococcal infection. Infect Immun. 68(11):6398-401.

Lorenz E, Mira JP, Frees Kl, Schwartz DA (2002) Relevance of mutations in the TLR4 receptor in patients with Gram-negative septic shock. Arch Intern Med. 162:1028-1032

Luoni G, Verra F, Arcà B, Sirima BS, Troye-Blomberg M, Coluzzi M, Kwiatkowski D, Modiano D (2001) Antimalarial antibody levels and IL4 polymorphism in the Fulani of West Africa. Genes Immun. 2(7):411-4.

Mascie-Taxlor CGN (1993) The Biological Anthropology of Disease. In: The Anthropology of Disease. Mascie-Taylor CGN (Hrsg). Oxford University Press, Oxford - New York - Tokyo. Reprint 1995. S.1 - 72

McMichael AJ (2004) Environmental and social influences on emerging infectious diseases: past, present and future. Phil Trans R Soc Lond. 359:1049-1058

McNeill WH (1976). Plagues and Peoples. Anchor Books, New York. Edition 1998

Medzhitov R \& Janeway CA Jr (1997) Innate immunity: impact on the adaptive immune response. Curr Opin Immunol. 1997 Feb;9(1):4-9.

Mitsuyasu H, Yanagihara Y, Mao XQ, Gao PS, Arinobu Y, Ihara K, Takabayashi A, Hara T, Enomoto T, Sasaki S, Kawai M, Hamasaki N, Shirakawa T, Hopkin 
JM, Izuhara K (1999) Cutting edge: dominant effect of Ile50Val variant of the human IL-4 receptor alpha-chain in IgE synthesis. J Immunol. 162(3):1227-31.

Mocellin S, Marincola F, Rossi CR, Nitti D, Lise M (2004). The multifaceted relationship between IL-10 and adaptive immunity: putting together the pieces of a puzzle. Cytokine \& Growth Factor Reviews 15:61-76

Mokrousov I, Ly HM, Otten T, Lan NN, Vyshnevskyi B, Hoffner S, Narvskaya O (2005) Origin and primary dispersal of the Mycobacterium tuberculosis Beijing genotype: Clues from human phylogeography. Genome Research 15:1357-1364

Mockenhaupt FP, Cramer JP, Hamann L, Stegemann MS, Eckert J, Oh NR, Otchwemah RN, Dietz E, Ehrhardt S, Schröder NW, Bienzle U, Schumann RR (2006) Toll-like receptor (TLR) polymorphisms in African children: Common TLR-4 variants predispose to severe malaria. PNAS 103(1):177-182

Moore CE, Segal S, Berendt AR, Hill AV, Day NP (2004) Lack of association between Toll-like receptor 2 polymorphisms and susceptibility to severe disease caused by Staphylococcus aureus. Clin Diagn Lab Immunol. 11(6):1194-7.

Montes AH, Asensi V, Alvarez V, Valle E, Ocana MG, Meana A, Carton JA, Paz J, Fierer J, Celada A (2006) The Toll-like receptor 4 (Asp299Gly) polymorphism is a risk factor for Gram-negative and haematogenous osteomyelitis. Clin Exp Immunol. 143(3):404-413

Moraes MO, Santos AR, Schonkeren JJ, Vanderborght PR, Ottenhoff TH, Moraes ME, Moraes JR, Sampaio EP, Sarno EN, Huizinga TW (2003) Interleukin10 promoter haplotypes are differently distributed in the Brazilian versus the Dutch population. Immunogenetics 2003 Mar. 54(12):896-9.

Mullis KB, Faloona FA (1987) Specific Synthesis of DNA in vitro via a Polymerase-Catalysed Chain Reactin. Meth Enzymol. 155:335-350

Müller-Wille M (2006) Slawenmission in Mitteleuropa. Mainz: Akademie der Wissenschaften und der Literatur. Stuttgart : Steiner, 2006.

Naumova E, Mihaylova A, Ivanova M, Michailova S, Penkova K, Baltadjieva D (2004) Immunological markers contributing to successful aging in Bulgarians. Exp Geront. 39:637-644

Nelms K, Keegan AD, Zamorano J, Ryan JJ, Paul WE (1999) The IL-4 Receptor: Signaling Mechanisms and Biologic Functions. Annu.Rev.Immunol. 17:701-38

Ness RB, Haggerty CL, Harger G, Ferrell R. (2004) Differential distribution of allelic variants in cytokine genes among African Americans and White Americans. Am J Epidemiol. 160(11):1033-8.

Nieters A, Brems S, Becker N (2001) Cross-sectional study on cytokine polymorphisms, cytokine production after T-cell stimulation and clinical parameters in a random sample of a German population. Hum Genet. 108:241-248 
Ogus AC, Yoldas B, Ozdemir T, Uguz A, Olcen S, Keser I, Coskun M, Cilli A, Yegin O (2004) The Arg753Gln polymorphism of the human toll-like receptor 2 gene in tuberculosis disease. Eur Respir J. 23(2):219-223

Olver S, Apte S, Baz A, Kienzle N (2007) The duplicitous effects of interleukin 4 on tumour immunity: how can the same cytokine improve or impair control of tumour growth? Tissue Antigens 69(4):293-8.

Ozinsky A et al (2000) The repertoire for pattern recognition of pathogens by the innate immune system is defined by cooperation between toll-like receptors. Proc Natl Acad Sci USA 97:13766-13771

Pawelec G (2003) Immunosenescence and human longevity. Biogerontolgy 4:167170

Pepperl J, Herrmann B, Hummel S (in prep) Individualizing Data from SNPAnalysis by Coamplification of STRs.

Poli F, Nocco A, Berra S, Scalamogna M, Taioli E, Longhi E, Sirchia G (2002) Allele frequencies of polymorphisms of TNFA, IL-6, IL-10 and IFNG in an Italian Caucasian population. Eur J Immunogenet. 29(3):237-40.

Prechel M (1996) Anthropologische Untersuchungen der Skelettreste aus einem Pestmassengrab am Heiligen-Geist-Hospital zu Lübeck. Lübecker Schriften zur Archäologie und Kulturgeschichte (LSAK), 24:323-339

Pschyrembel Klinisches Wörterbuch. 257., neu bearbeitete Auflage. de Gruyter Berlin - New York 1994.

Puder Y (2005) Molekulargenetische Identifikation der Allelhäufigkeit eines immungenetischen Markers der IL-6-Promotorregion bei bronzezeitlichen Individuen aus Mitteleuropa. Diplomarbeit. Universität Göttingen

Quintans B, Alvarez-Iglesias V, Salas A, Phillips C, Lareu M.V, Carracedo A (2004) Typing of mitochondrial DNA coding region SNPs of forensic and anthropological interest using SNaPshot minisequencing. Forensic Sci Int. 140(2$3): 251-7$

Raymond M, Rousset F (1995) An exact test for population differentiation. Evolution 49:1280-1283

Rebbeck TR, Spitz M, Wu X (2004) Assessing the Function of Genetic Variants in Candidate Gene Association Studies. Nature Reviews Genetics 5:589-597

Reiling N, Hölscher C, Fehrenbach A, Kröger S, Kirschning CJ, Goyert S, Ehlers S (2002) Cutting Edge: Toll-like Receptor (TLR)2- and TLR4-Mediated Pathogen Recognition in Resistance to Airborne Infection with Mycobacterium tuberculosis. J Immunol. 169:3480-3484 
Rezazadeh M, Hajilooi M, Rafiei A et al. (1998) TLR4 polymorphisms in Iranian patients with brucellosis. J Infect. 53:206-210

Riva A \& Kohane IS (2002) SNPper: retrieval and analysis of human SNPs. Bioinformatics 18(12):1681-1685

Rivera-Chavez FA, Peters-Hybki DL, Barber RC, O'Keefe GE (2003) Interleukin6 Promoter Haplotypes and Interleukin-6 cytokine responses. Shock 20(3):218223

Rook GAW (2007) The hygiene hypothesis and the increasing prevalence of chronic inflammatory disorders. Trans Roy Soc Trop Med Hyg, doi:10.1016/j.trstmh.2007.05.014

Rosenwasser LJ, Klemm DJ, Dresback JK, Inamura H, Mascali JJ, Klinnert M, Borish L (1995) Promoter polymorphisms in the chromosome 5 gene cluster in asthma and atopy. Clin Exp Allergy. 25 Suppl 2:74-8; discussion 95-96

Rosenwasser LJ (1999) Promotor Polymorphism in the Candidate Genes, IL-4, IL-9, TGF- $\beta 1$, for Atopy and Asthma. Int Arch Allergy Immunol. 118:268-270

Rothschild BM, Martin LD, Lev G, Bercovier H, Bar-Gal GK, Greenblatt C, Donoghue H, Spigelman M, Brittain D (2001) Mycobacterium tuberculosis Complex DNA from an Extinct Bison Dated 17,000 Years before the Present. CID 33:305-311

Rupp J, Goepel W, Kramme E, Jahn J, Solbach W, Maass M (2004) CD14 promoter polymorphism $-159 \mathrm{C}>\mathrm{T}$ is associated with susceptibility to chronic Chlamydia pneumoniae infection in peripheral blood monocytes. Genes Immun. $5(5): 435-438$

Saiki RK, Scharf S, Faloona F, Mullis KB, Horn GT, Erlich HA, Arnheim N (1985) Enzymatic amplification of P-globulin genomic sequences and restriciton site analysis for diagnosis of sickle cell anemia. Science 230:1350-1354

Sandford AJ, Chagani T, Zhu S, Weir TD, Bai TR, Spinelli JJ, Fitzgerald JM, Behbehani NA, Tan WC, Paré PD (2000) Polymorphisms in the IL4, IL4RA, and FCERIB genes and asthma severity. J Allergy Clin Immunol. 106(1 Pt 1):135-40.

Sanger F, Nockolson S, Coulson AR (1977) DNA sequencing with chaintermination inhibitors. Proc Natl Acad Sci USA 74:5463-5467

Scheller H (2003).Entwicklung eines Analysesystems zum Nachweis von Krankheitserregern aus Skeletten historischer Pestopfer. Diplomarbeit. Universität Göttingen

Schilz F, Hummel S, Herrmann B (2004) Design of a multiplex PCR for genotyping 16 short tandem repeats in degraded DNA samples. Anthropol Anz. 62(4): 369- 78 
Schilz F (2006) Molekulargenetische Verwandtschaftsanalysen am prähistorischen Skelettkollektiv der Lichtensteinhöhle. Dissertation. Universität Göttingen

Schlüter B, Raufhake C, Erren M, Schotte H, Kipp F, Rust S, Van Aken H, Assmann G, Berendes E (2002) Effect of the interleukin-6 promoter polymorphism $(-174 \mathrm{G} / \mathrm{C})$ on the incidence and outcome of sepsis. Crit Care Med. 30(1):32-7

Schmerer WM, Hummel S, Herrmann B (2000) STR-genotyping of archaeological human bone: experimental design to improve reproducibility by optimisation of DNA extraction. Anthrop Anz. 58: 29-35

Schmidt T, Hummel S, Herrmann B (1995) Evidence of contamination in PCR laboratory disposables. Naturwissenschaften 82:423-431

Schmitt C, Humeny A, Becker CM, Brune K, Pahl A (2002) Polymorphisms of TLR4: Rapid Genotyping and Reduced Response to Lipopolysaccharide of TLR4 Mutant Alleles. Clin Chem. 48(10): 1661-1667

Schröder NWJ, Herrmann C, Hamann L, Göbel UB, Hartung T, Schumann RR (2003) High frequency of polymorphism Arg753Gln of the Toll-like receptor-2 gene detected by a novel allele-specific PCR. J Mol Med. 81:368-372

Schröder NW, Diterich I, Zinke A, Eckert J, Draing C, von Baehr V, Hassler D, Priem S, Hahn K, Michelsen KS, Hartung T, Burmester GR, Göbel UB, Hermann C, Schumann RR (2005) Heterozygous Arg753Gln polymorphism of human TLR-2 impairs immune activation by Borrelia burgdorferi and protects from late stage Lyme disease. Crit Care Med. 30(1):32-7

Schultes T (2000) Typisierung alter DNA zur Rekonstruktion von Verwandtschaft in einem bronzezeitlichen Skelettkollektiv. Dissertation. Universität Göttingen. Cuvellier Verlag

Schwandner R, Dziarski R, Wesche H, Rothe M, Kirschning CJ (1999) Peptidoglycan- and lipoteichoic acid-induced cell activation is mediated by tolllike receptor 2. J Biol Chem. 274:17406-9

Schwartzbaum J, Ahlbom A, Malmer B, Lönn S, Brookes AJ, Doss H, Debinski W, Henriksson R, Feychting M (2005) Polymorphisms Associated with Asthma Are Inversely Related to Glioblastoma Multiforme. Cancer Res. 65(14):64596465

Scola L, Crivello A, Marino V, Gioia V, Serauto A, Candore G, Colonna-Romano G, Caruso C, Lio D (2003) IL-10 and TNF- $\alpha$ polymorphsisms in a sample of Sicilian patients affected by tuberculosis: implication for ageing and life span expectancy. Mech Ageing Dev. 124:569-572

Smith KC, Bateman AC, Fussell HM, Howell WM (2004) Cytokine gene polymorphism and breast cancer susceptibility and prognosis. Eur J Immunogenet. $31: 167-173$ 
Stephens JC, Reich DE, Goldstein DB, Shin HD, Smith MW, Carrington M, Winkler C, Huttley GA, Allikmets R, Schriml L, Gerrard B, Malasky M, Ramos MD, Morlot S, Tzetis M, Oddoux C, di Giovine FS, Nasioulas G, Chandler D, Aseev M, Hanson M, Kalaydjieva L, Glavac D, Gasparini P, Kanavakis E, Claustres M, Kambouris M, Ostrer H, Duff G, Baranov V, Sibul H, Metspalu A, Goldman D, Martin N, Duffy D, Schmidtke J, Estivill X, O'Brien SJ, Dean M (1998) Dating the Origin of the CCR5- $\triangle 32$ AIDS-Resistance Allele by the Coalescence of Haplotypes. Am J Hum Genet. 62:1507 - 1515

Suray D (2007) Interleukin-10-Haplotypen eines bronzezeitlichen Skelettkollektivs aus dem Harzer Vorland. Diplomarbeit, Universität Göttingen

Takeda K, Kaisho T, Akira S (2003) Toll-like Receptors. Annu Rev Immunol. 21:335-376

Takeda K and Akira S (2005) Toll-like receptors in innate immunity. Int Immunol. $17: 1-14$

Takeuchi O, Sato S, Horiuchi T, Hoshino K, Takeda K, Dong Z, Modlin RL, Akira S (2002) Cutting edge: role of Toll-like receptor 1 in mediating immune response to microbial lipoproteins. J Immunol. 169:10-14

Tal G, Mandelberg A, Dalal I, Cesar K, Somekh E, Tal A, Oron A, Itskovich S, Ballin A, Houri S, Beigelman A, Lider O, Rechavi G, Amariglio N (2004) Association between common Toll-like receptor 4 mutations and severe respiratory syncytial virus disease. J Infect Dis. 189(11):2057-63

Terabe M, Matsui S, Noben-Trauth N, Chen H, Watson C, Donaldson DD, Carbone DP, Paul WE, Berzofsky JA (2000) NKT cell-mediated repression of tumor immunosurveillance by IL-13 and the IL-4R-STAT6 pathway. Nat Immunol. 1(6):515-20

Texereau J, Chiche JD, Taylor W, Choukroun G, Comba B, Mira JP (2005) The importance of Toll-like Receptor 2 Polymorphisms in Severe Infections. Clin Inf Dis. 41:408-415

Turner DM, Williams DM, Sankaran D, Lazarus M, Sinnott PJ, Hutchinson IV (1997) An Investigation of polymorphism in the Interleukin-10 gene promoter. Eur J Immunogen. 24:1-8

Twigg G (1995) Bubonic plague: doubts and diagnosis. J Med Microbiol. 42:383385

Van den Biggelaar AHJ, de Craen AJM, Gussekloo J, Huizinga TWJ, Heijmans BT, Frölich M, Kirkwood TBL, Westendorp RGJ (2004) Inflammation underlying cardiovascular mortality is a late consequence of evolutionary programming. FASEB journal. doi 10.1096/fj.03-1162fje. 
Van der Graaf CA, Netea MG, Morré SA, Den Heijer M, Verweij PE, Van der Meer JW, Kullberg BJ (2006) Differential cytokine production and Toll-like receptor 4 Asp299Gly/Thr399Ile polymorphisms are a risk factor for Candida bloodstream infection. Eur Cytokine Netw. 17(1):29-34.

Villuendas G, San Millán JL, Sancho J, Escobar-Morreale HF (2002) The -597 $\mathrm{G} \rightarrow \mathrm{A}$ and $-174 \mathrm{G} \rightarrow \mathrm{C}$ polymorphisms in the promoter of the IL-6 gene are associated with hyperandrogenism. J Clin Endocrinol Metab. 87(3):1134-41

Wang XY, Hurme M, Jylhä M, Hervonen A (2001) Lack of association between human longevity and polmorphisms of Il1 cluster, IL6, IL10 and TNF- $\alpha$ genes in Finnish nonagenarians. Mech Ageing Dev. 123:29-38

Wenzel M (2006) Optimierung der Parameter der Probenvorbereitung und Extraktion mit dem BioRobotEZ1. Diplomarbeit, Universität Göttingen

Westendorp RGJ, Van Dunne FM, Kirkwood TBL, Helmerhorst FM, Huizinga TWJ (2001) Optimizing human fertility and survival. Nat Med. 7(8):873

Westendorp RGJ, Langermans JAM, Huizinga TWJ, Elouali AH, Verweij CL, Boomsma DI, Vandenbrouke JP (1997) Genetic influence on cytokine production and fatal meningococcal disease. Lancet 349: 170-173

Westenthanner M (2006) Optimierung der Real Time PCR zur Charakterisierung der Degradation von ancient DNA (aDNA) in ausgewählten Skelettelementen. Diplomarbeit. Universität Göttingen

Wiechmann I, Grupe G (2005) Detection of Yersinia pestis DNA in Two Early Medieval Skeletal Finds From Aschheim (Upper Bavaria, 6th Century A.D.). Am J Phys Anthr. 123:48-55

Wojsyk-Banaszak I, Seremak-Mrozikiewicz A, Szczapa J, Drews K, ZandeckaDziubak J, Mrozikiewicz PM (2005) The significance of $-174 \mathrm{G} / \mathrm{C}$ polymorphism of the gene coding for interleukin-6 in neonatal infections. Ginekol Pol. $76(2): 127-134$

Youn J, Hwang SH, Cho CS, Min JK, Kim WU, Park SH, Kim HY (2000) Association of the interleukin-4 receptor $\alpha$ variant Q576R with Th1/Th2 imbalance in connective tissue disease. Immunogenetics 51:743-746

Zink A, Reischl U, Wolf H, Nerlich AG, Miller R (2001) Corynebacterium in ancient Egypt. Med Hist. 45(2):267-72

Zink AR, Reischl U, Wolf H, Nerlich AG (2002) Molecular analysis of ancient microbial infections. FEMS Microbiology 213:141-147

Zink AR, Sola C, Reischl U, Grabner W, Rastogi N, Wolf H, Nerlich AG (2003) Characterization of Mycobacterium tuberculosis complex DNAs from Egyptian mummies by spoligotyping. J Clin Microbiol. 41(1):359-67. 
Zink AR, Grabner W, Nerlich AG (2005) Molecular Identification of Human Tuberculosis in Recent and Historic Bone Tissue Samples: The Role of Molecular Techniques for the Study of Historic Tuberculosis. Am J Phys Anthropol. 126:32-47

\section{Internetadressen}

Abb. 2, S. 10:

http://www.biken.osaka-n.ac.jp/act/images/akiraA.png (10.01.08)

Abb. 3, S. 16:

http://www.science.ngfn.de/6_371.htm (11.01.2008)

Short Tandem Repeat DNA Internet Database, NIST Standard Reference Database SRD 130:

http://www.cstl.nist.gov/biotech/strbase/

Entrez Nucleotide:

http://www.ncbi.nlm.nih.gov/sites/entrez?-db=nucleotide

Entrez SNP:

http://www.ncbi.nlm.nih.gov/sites/entrez?-db=snp

Cytokine Gene Polymorphism in Human Disease, Genes and Immunity http://www.nanea.dk/cytokinesnps 


\section{Tabellenanhang}

\section{Der Fundkomplex Dorste als genetisches Archiv}

Die bisher vorliegenden genetischen Daten über den Fundkomplex Dorste (Schilz, 2006) können nun um Informationen zu sechs SNP der fünf immungenetischen Marker TLR2, TLR4, IL4Ra, IL10 und IL6 erweitert werden. Die Tabelle 40 zeigt die Genotypen aller bearbeiteten Individuen. Da nicht alle Individuen in der statistische Auswertung berücksichtigt wurden, wurden nicht alle Ergebnisse ausreichend reproduziert. Daraus ergibt sich eine höhere Anzahl an ausgefallenen (-/-) Typisierungen beziehungsweise unsicheren Allelen und unsicher homozygoten Ergebnissen (N/-). Weitere Analysen zur Absicherung der vorgestellten Ergebnisse sind nötig.

Tab. 40: Skelettserie Dorste: Ergebnisse der SNP-Genotypisierungen für alle untersuchten Individuen

\begin{tabular}{|c|c|c|c|c|c|c|c|c|}
\hline Ind & $\begin{array}{c}\text { IL6 } \\
-174\end{array}$ & $\begin{array}{c}\text { TLR2 } \\
753\end{array}$ & $\begin{array}{c}\text { TLR4 } \\
299\end{array}$ & $\begin{array}{c}\text { TLR4 } \\
399\end{array}$ & $\begin{array}{c}\text { IL10 } \\
-1082\end{array}$ & $\begin{array}{c}\text { IL10 } \\
-2849\end{array}$ & $\begin{array}{c}\text { IL4Ra } \\
576\end{array}$ & $\begin{array}{c}\text { IL4 } \\
-524\end{array}$ \\
\hline $\mathrm{F} 1$ & $\mathrm{G} / \mathrm{G}$ & $\mathrm{G} / \mathrm{G}$ & $\mathrm{A} / \mathrm{A}$ & $\mathrm{C} / \mathrm{C}$ & $\mathrm{G} / \mathrm{A}$ & $\mathrm{G} / \mathrm{A}$ & $\mathrm{G} / \mathrm{A}$ & $-/-$ \\
\hline F 2 & $\mathrm{G} / \mathrm{C}$ & G/- & $\mathrm{A} /-$ & C/- & $-/-$ & $\mathrm{G} / \mathrm{A}$ & $G / A$ & $-/-$ \\
\hline F 3 & $\mathrm{C} / \mathrm{C}$ & $G / G$ & $\mathrm{~A} /-$ & $\mathrm{C} / \mathrm{C}$ & $-/-$ & $\mathrm{G} / \mathrm{A}$ & $G / A$ & $\mathrm{C} /-$ \\
\hline F 4 & $\mathrm{G} / \mathrm{C}$ & $\mathrm{G} / \mathrm{G}$ & $\mathrm{A} / \mathrm{A}$ & $\mathrm{C} / \mathrm{C}$ & $\mathrm{G} / \mathrm{G}$ & $\mathrm{G} / \mathrm{A}$ & $\mathrm{A} / \mathrm{A}$ & $\mathrm{C} /-$ \\
\hline F 5 & $\mathrm{G} / \mathrm{C}$ & $G / G$ & $\mathrm{~A} / \mathrm{A}$ & $\mathrm{C} / \mathrm{C}$ & G/- & $\mathrm{G} / \mathrm{A}$ & $\mathrm{A} / \mathrm{A}$ & $\mathrm{C} / \mathrm{C}$ \\
\hline F 6 & $\mathrm{C} /-$ & G/- & $\mathrm{A} /-$ & $\mathrm{C} /-$ & $\mathrm{G} / \mathrm{A}$ & $G / A$ & $\mathrm{~A} /-$ & $C /-$ \\
\hline F 7 & $\mathrm{C} /-$ & $-/-$ & $A /-$ & $\mathrm{C} /-$ & $G / A$ & $\mathrm{G} / \mathrm{A}$ & $\mathrm{A} /-$ & $\mathrm{C} /-$ \\
\hline F 8 & $\mathrm{C} /-$ & $G / G$ & $\mathrm{~A} /-$ & C/- & $\mathrm{G} / \mathrm{A}$ & & $\mathrm{A} /-$ & $C /-$ \\
\hline F 9 & $\mathrm{G} / \mathrm{C}$ & $\mathrm{G} / \mathrm{G}$ & $\mathrm{A} / \mathrm{A}$ & $\mathrm{C} / \mathrm{C}$ & $\mathrm{G} / \mathrm{A}$ & $\mathrm{G} / \mathrm{A}$ & $\mathrm{G} / \mathrm{A}$ & $\mathrm{C} / \mathrm{C}$ \\
\hline F10 & $\mathrm{G} / \mathrm{C}$ & $\mathrm{G} / \mathrm{G}$ & $\mathrm{A} / \mathrm{A}$ & $\mathrm{C} / \mathrm{C}$ & $\mathrm{G} / \mathrm{G}$ & $G / A$ & $G / A$ & $\mathrm{C} / \mathrm{C}$ \\
\hline F11 & $-/-$ & $-/-$ & $A /-$ & $\mathrm{C} /-$ & $-/-$ & $\mathrm{G} /-$ & $\mathrm{A} /-$ & $-/-$ \\
\hline F12 & $\mathrm{C} / \mathrm{C}$ & $\mathrm{G} / \mathrm{G}$ & $\mathrm{A} / \mathrm{A}$ & $\mathrm{C} / \mathrm{C}$ & $\mathrm{A} / \mathrm{A}$ & $\mathrm{G} / \mathrm{A}$ & $\mathrm{A} / \mathrm{A}$ & $-/-$ \\
\hline F13 & $-/-$ & $\mathrm{G} /-$ & $-/-$ & $\mathrm{C} /-$ & $-/-$ & $\mathrm{G} / \mathrm{A}$ & $\mathrm{A} /-$ & $\mathrm{C} /-$ \\
\hline F14 & $\mathrm{C} / \mathrm{C}$ & $G / A$ & $\mathrm{~A} / \mathrm{A}$ & $\mathrm{C} / \mathrm{C}$ & $\mathrm{A} / \mathrm{A}$ & $G / A$ & $G / A$ & $\mathrm{C} /-$ \\
\hline F15 & $-/-$ & G/- & $\mathrm{A} /-$ & $\mathrm{C} /-$ & $-/-$ & $G / A$ & $G / A$ & $-/-$ \\
\hline F16 & $-/-$ & G/- & $\mathrm{A} / \mathrm{G}$ & $\mathrm{C} /-$ & $\mathrm{A} /-$ & $G / A$ & $\mathrm{~A} /-$ & $\mathrm{C} /-$ \\
\hline F17 & G/- & $G / A$ & $\mathrm{~A} /-$ & $\mathrm{C} /-$ & $-/-$ & $G / A$ & $G / A$ & $\mathrm{C} /-$ \\
\hline F19 & $\mathrm{G} / \mathrm{C}$ & $G / G$ & $A /-$ & $\mathrm{C} / \mathrm{C}$ & $G / A$ & $\mathrm{G} / \mathrm{A}$ & $\mathrm{A} / \mathrm{A}$ & $\mathrm{C} /-$ \\
\hline F20 & $-/-$ & $-/-$ & $-/-$ & $-/-$ & $-/-$ & $\mathrm{G} / \mathrm{A}$ & $\mathrm{A} /-$ & $-/-$ \\
\hline $\mathrm{F} 21$ & $-/-$ & $-/-$ & $A /-$ & $-/-$ & $-/-$ & $(G) / A$ & $\mathrm{~A} /-$ & $-/-$ \\
\hline M 1 & $\mathrm{G} / \mathrm{C}$ & $\mathrm{G} / \mathrm{A}$ & $\mathrm{A} /-$ & $\mathrm{C} / \mathrm{C}$ & $\mathrm{A} /-$ & $\mathrm{G} / \mathrm{A}$ & $G / A$ & $\mathrm{C} /-$ \\
\hline M 2 & $\mathrm{G} / \mathrm{C}$ & $G /(A)$ & $\mathrm{A} /-$ & $\mathrm{C} /-$ & $-/-$ & $\mathrm{G} / \mathrm{A}$ & $\mathrm{A} /-$ & $-/-$ \\
\hline
\end{tabular}


Tab. 40: Skelettserie Dorste: Typisierungsergebnisse fortgesetzt

\begin{tabular}{ccccccccc}
\hline Ind & IL6 & TLR2 & TLR4 & TLR4 & IL10 & IL10 & IL4Ra & IL4 \\
& -174 & 753 & 299 & 399 & -1082 & -2849 & 576 & -524 \\
\hline M 3 & C/C & G/G & A/- & C/C & A/- & G/A & A/- & C/- \\
M 4 & G/C & G/- & (A)/- & C/- & $-/-$ & G/A & A/- & $-/-$ \\
M 5 & $-/-$ & $-/-$ & $-/-$ & $-/-$ & $-/-$ & G G/A & A/- & $-/-$ \\
M 6 & $-/-$ & G/- & G/- & C/- & G/A & G/A & $-/-$ & $\mathrm{C} /-$ \\
M 7 & G/C & G/G & A/- & C/C & G/A & G/A & G/A & C/- \\
M 8 & C/- & G/G & A/- & C/C & G/A & G/A & A/- & C/- \\
M 9 & G/G & G/G & A/- & C/C & G/- & G/A & A/- & C/- \\
M10 & C/- & G/G & A/G & C/C & G/A & G/A & G/A & C/- \\
M11 & C/- & G/- & $-/-$ & C/- & A/- & G/A & A/- & $-/-$ \\
M12 & $-/-$ & G/- & $-/-$ & C/- & $-/-$ & A/- & A/- & $-/-$ \\
M13 & G/G & G/G & A/- & C/C & A/- & G/A & A/- & C/- \\
M14 & $-/-$ & G)/- & $-/-$ & $-/-$ & $-/-$ & A/- & G/- & C/- \\
M16 & G/C & G/G & A/- & C/C & G/A & G/A & A/- & C/- \\
M17 & C/- & $-/-$ & $-/-$ & $-/-$ & A/- & G/A & G/A & C/- \\
M19 & G/C & G/- & $-/-$ & C/- & A/- & G/A & A/A & $-/-$ \\
\hline
\end{tabular}




\section{Ergebnisse der Einzelamplifikationen zur Typisierung der SNP}

Auf den folgenden Seiten sind die Ergebnisse der Einzelamplifikationen aufgeführt, die der Genotypisierung der immungenetischen Marker zugrunde liegen. 


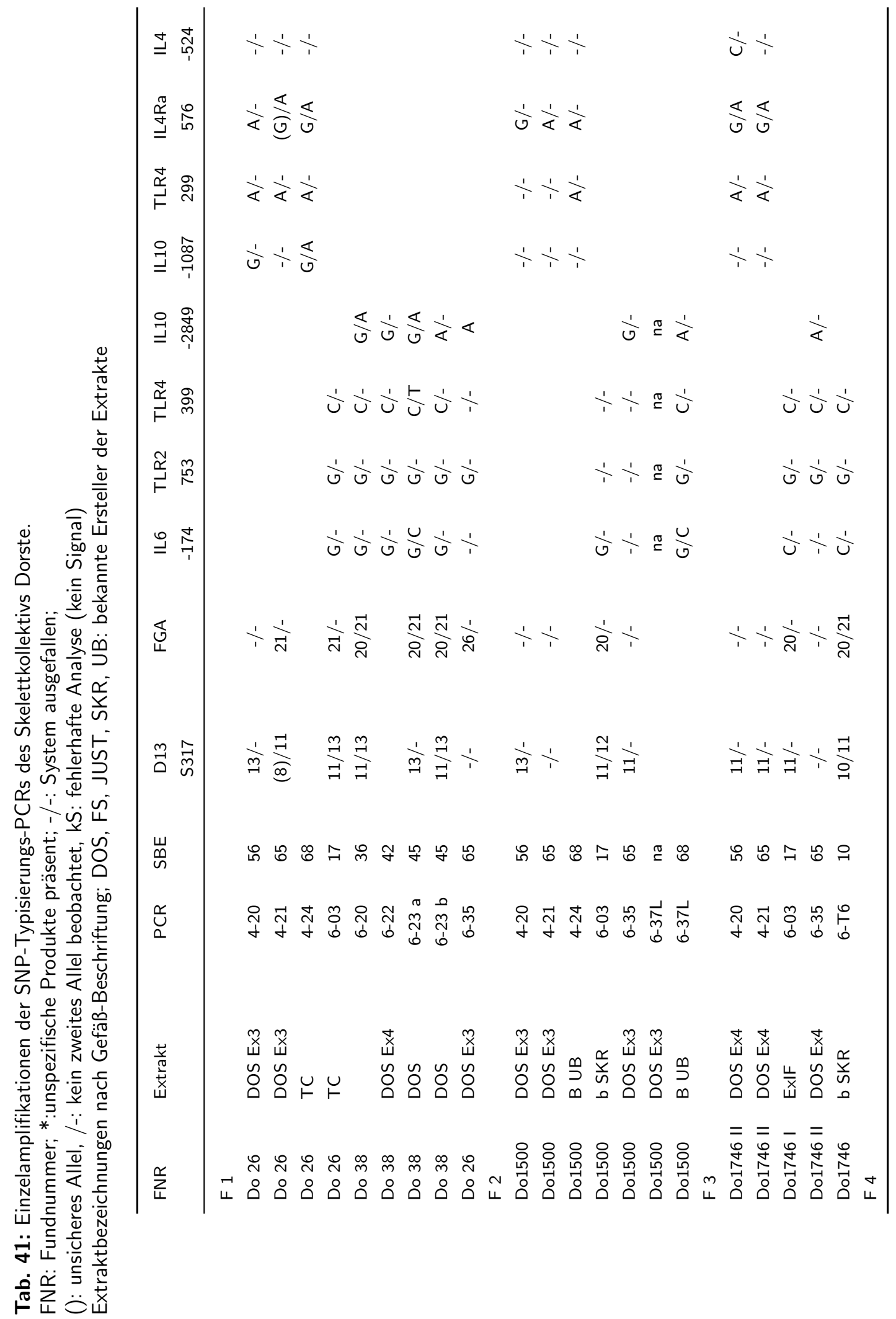




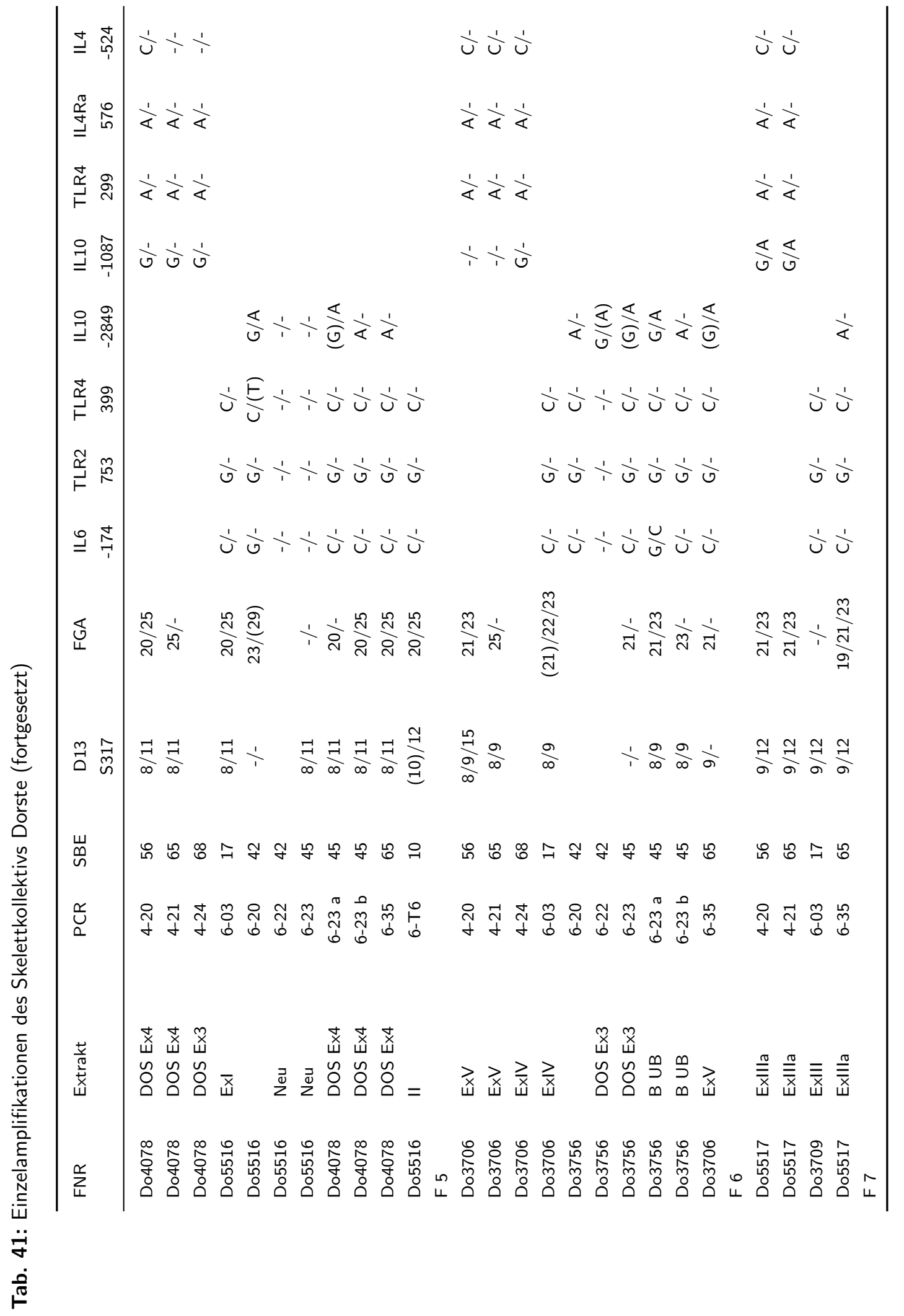




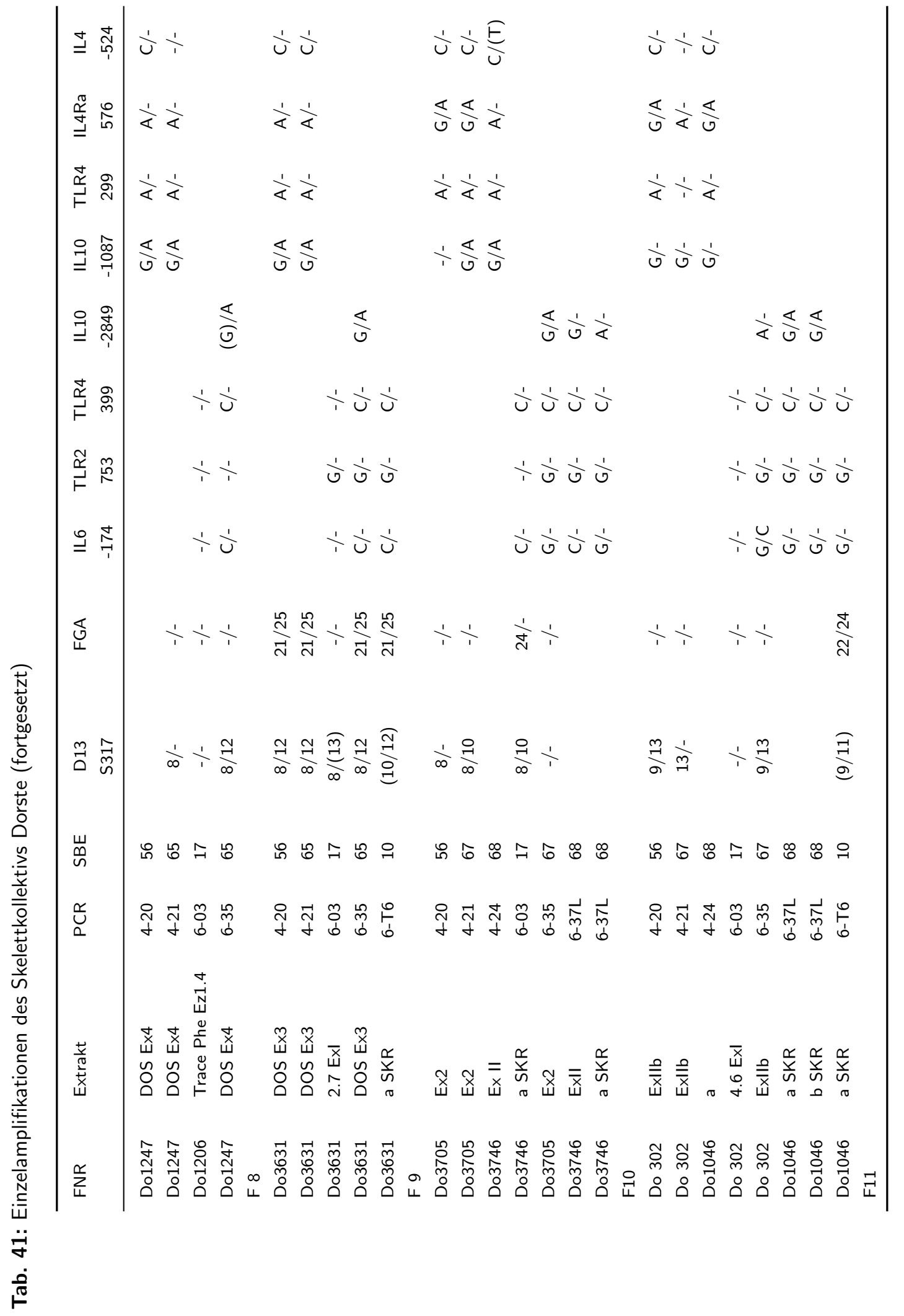




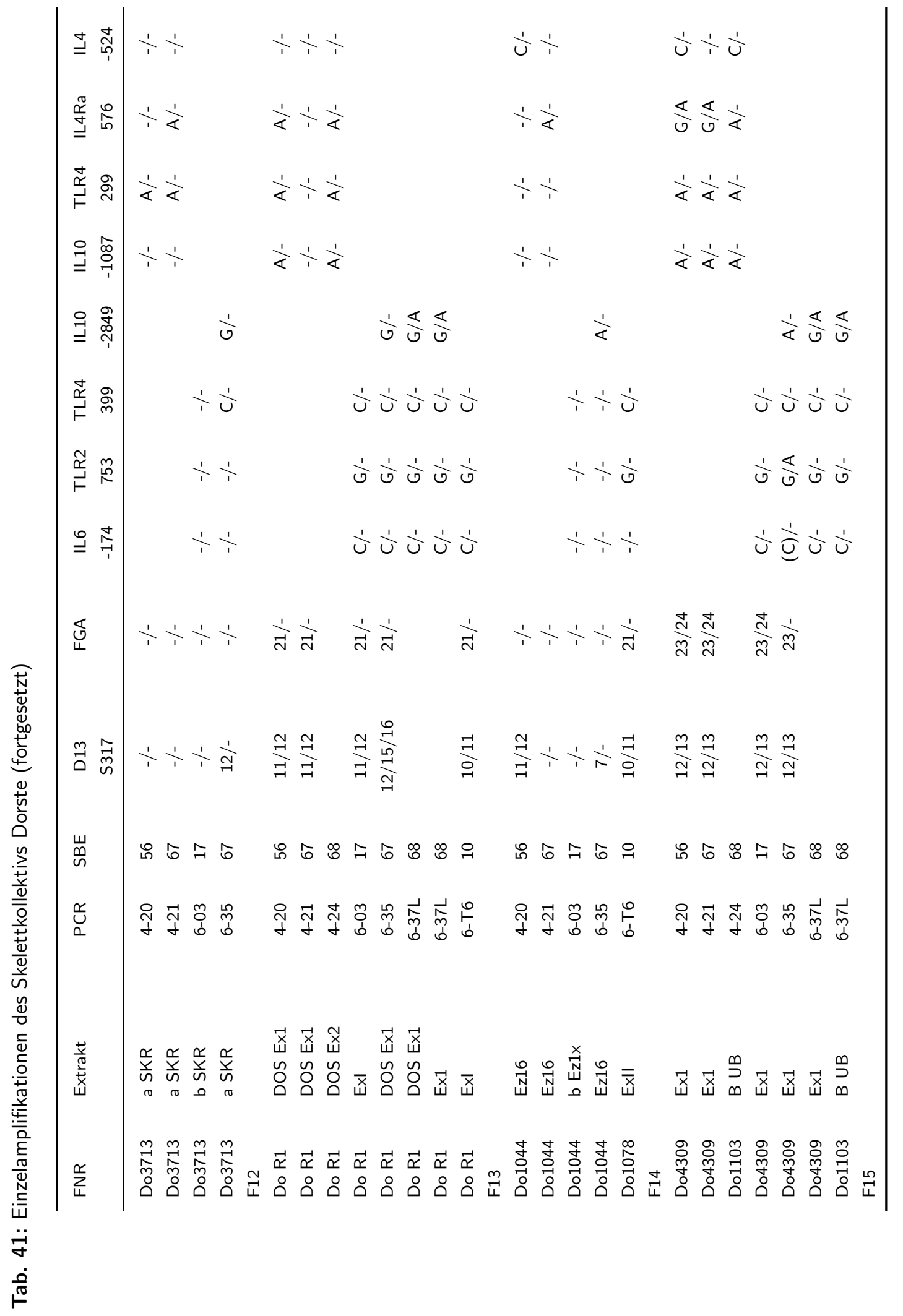




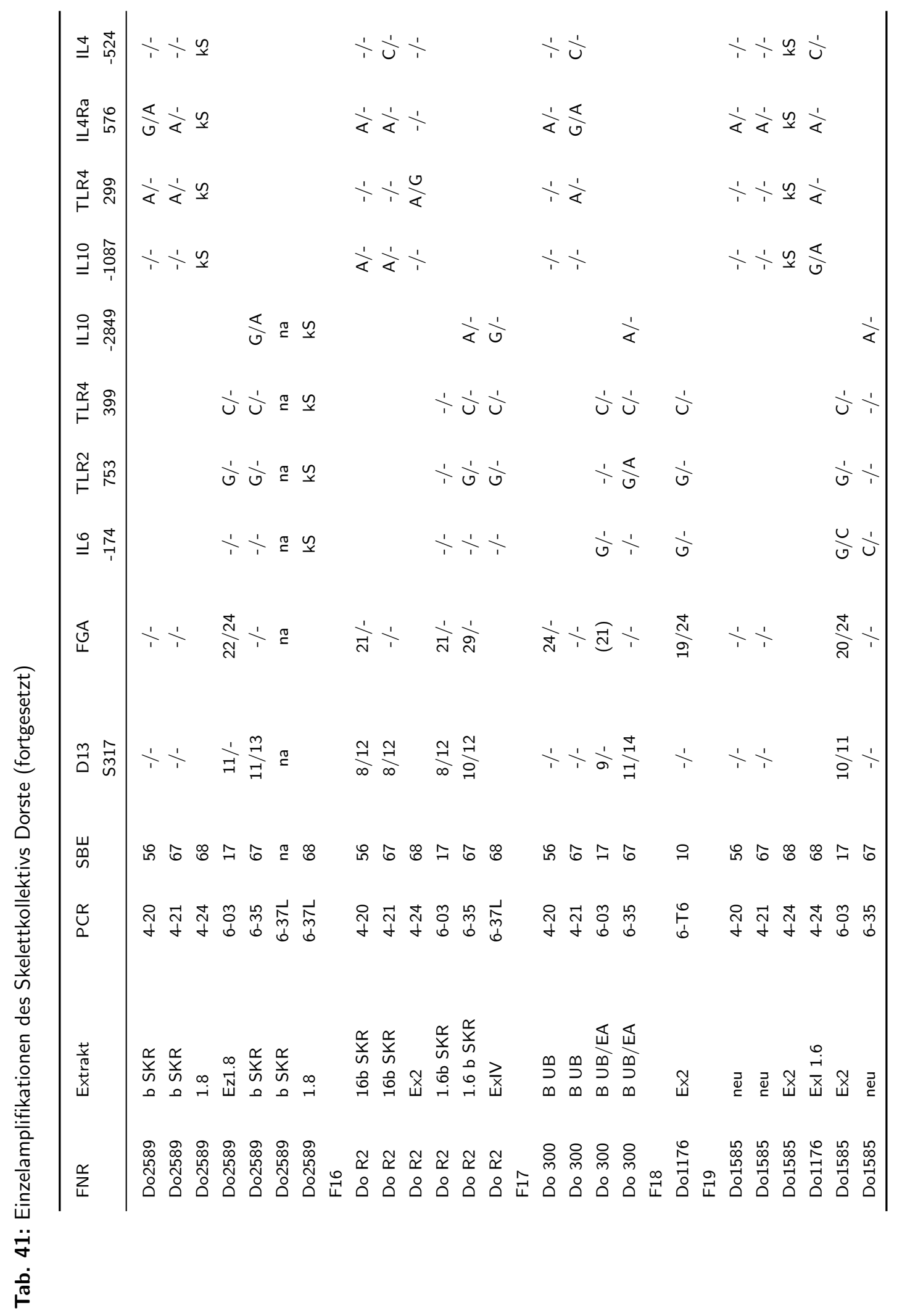




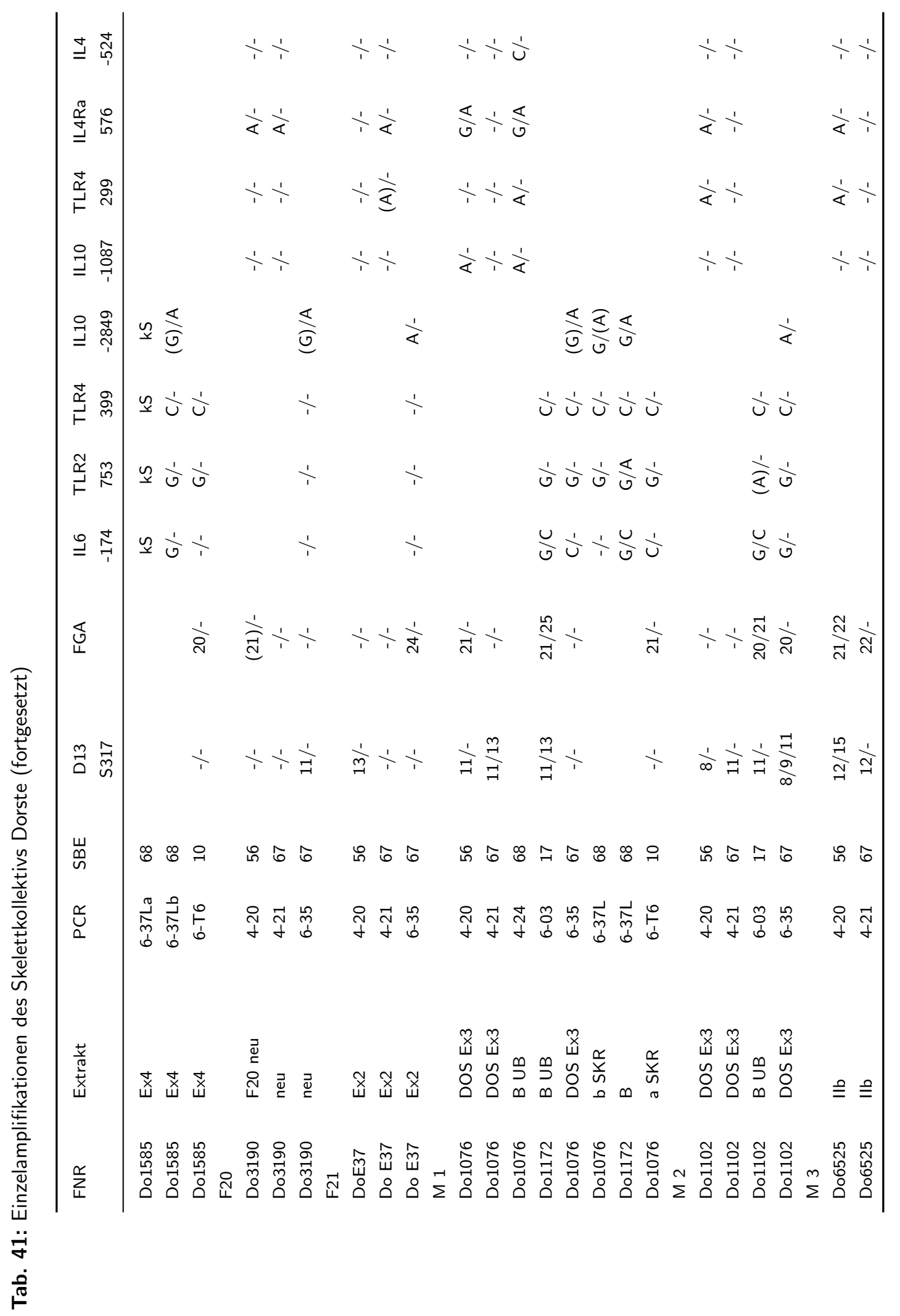




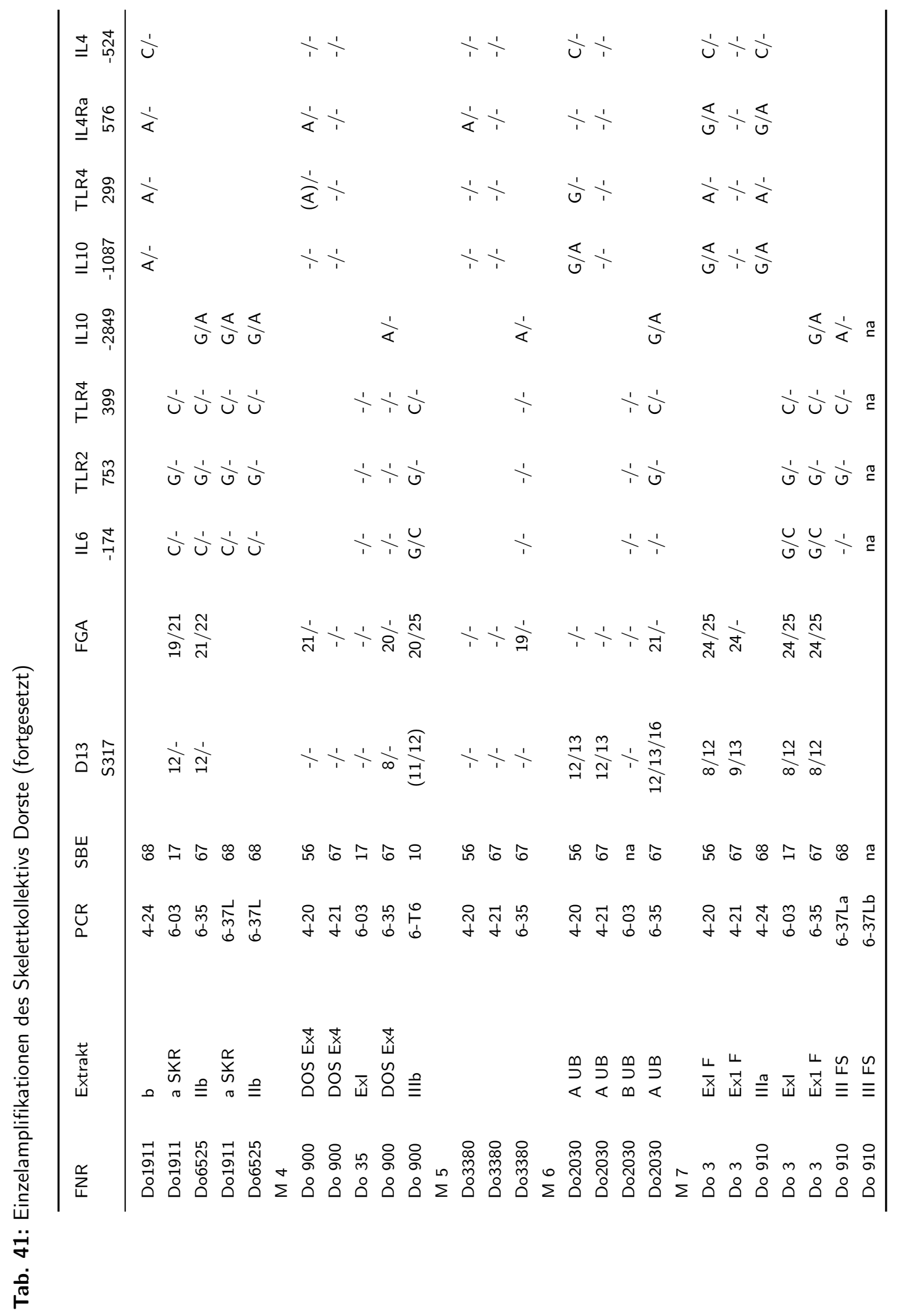




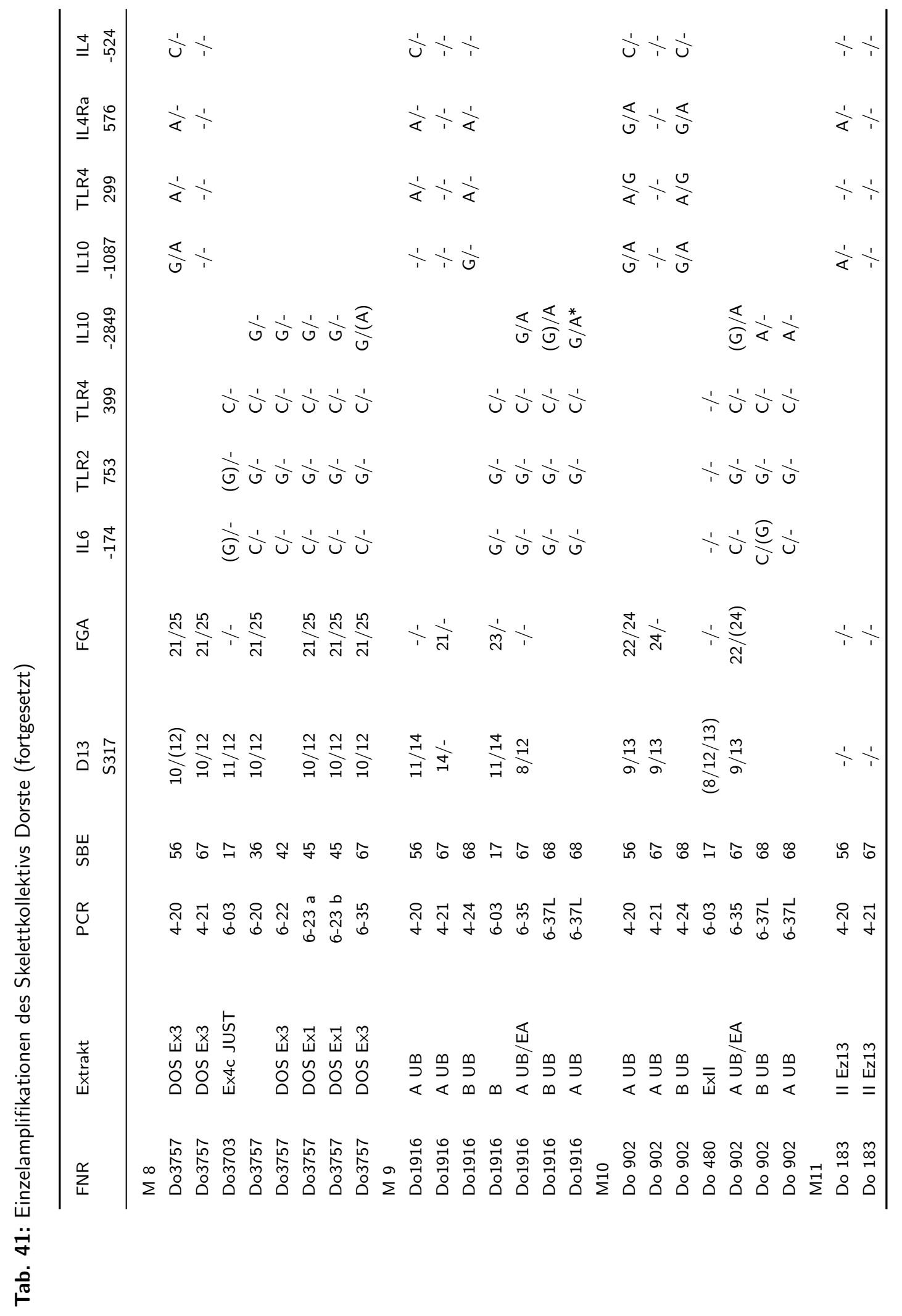




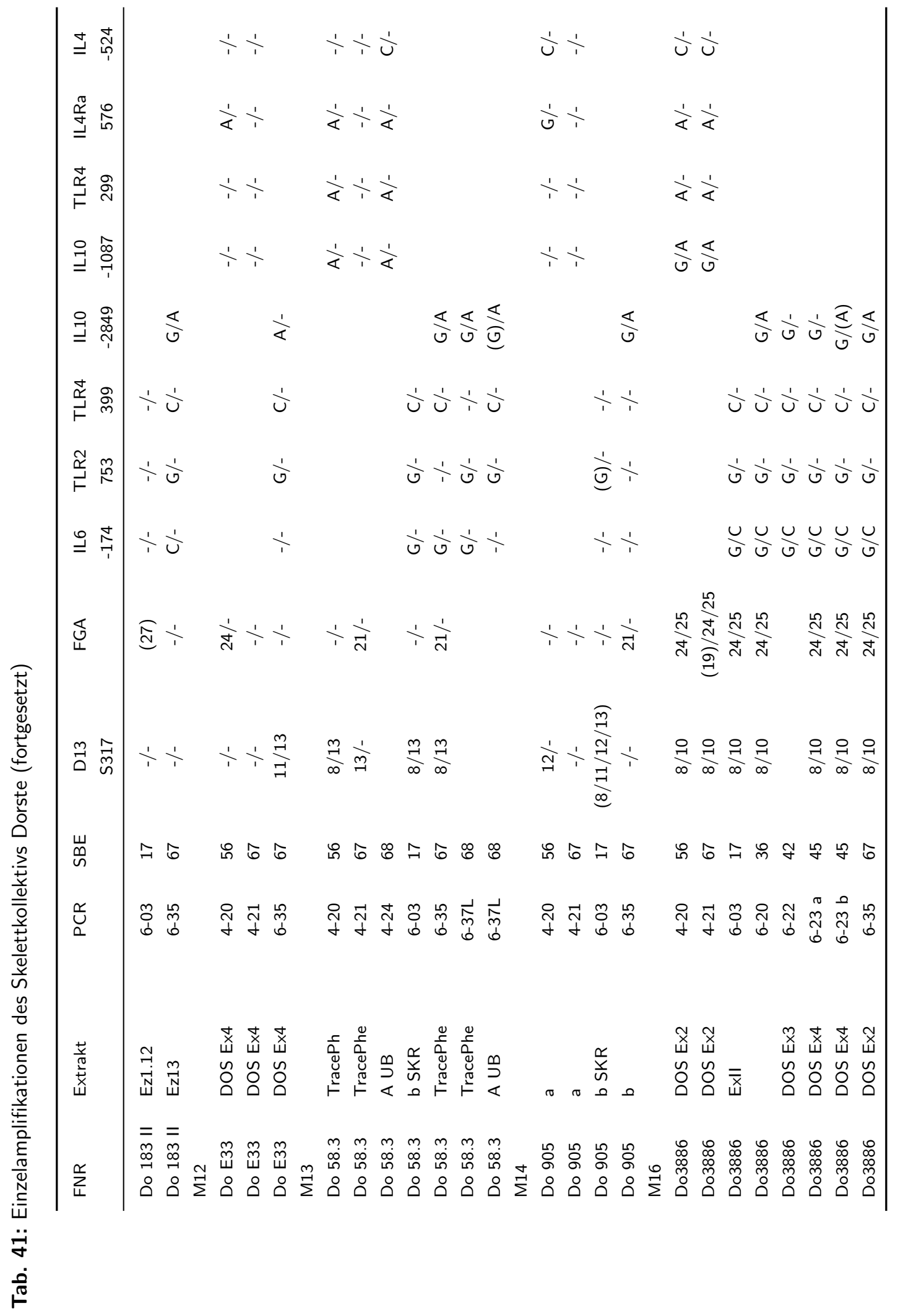




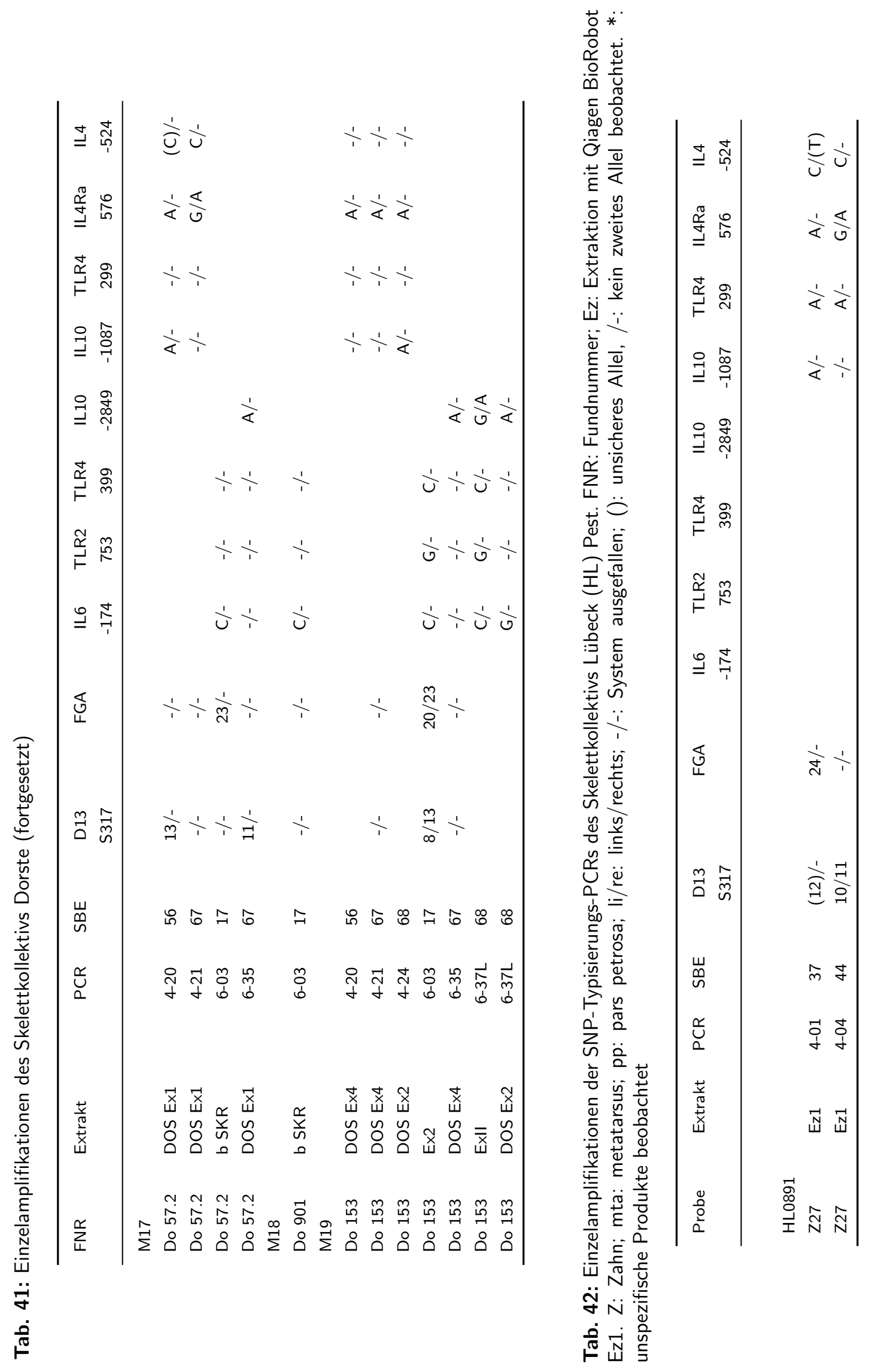




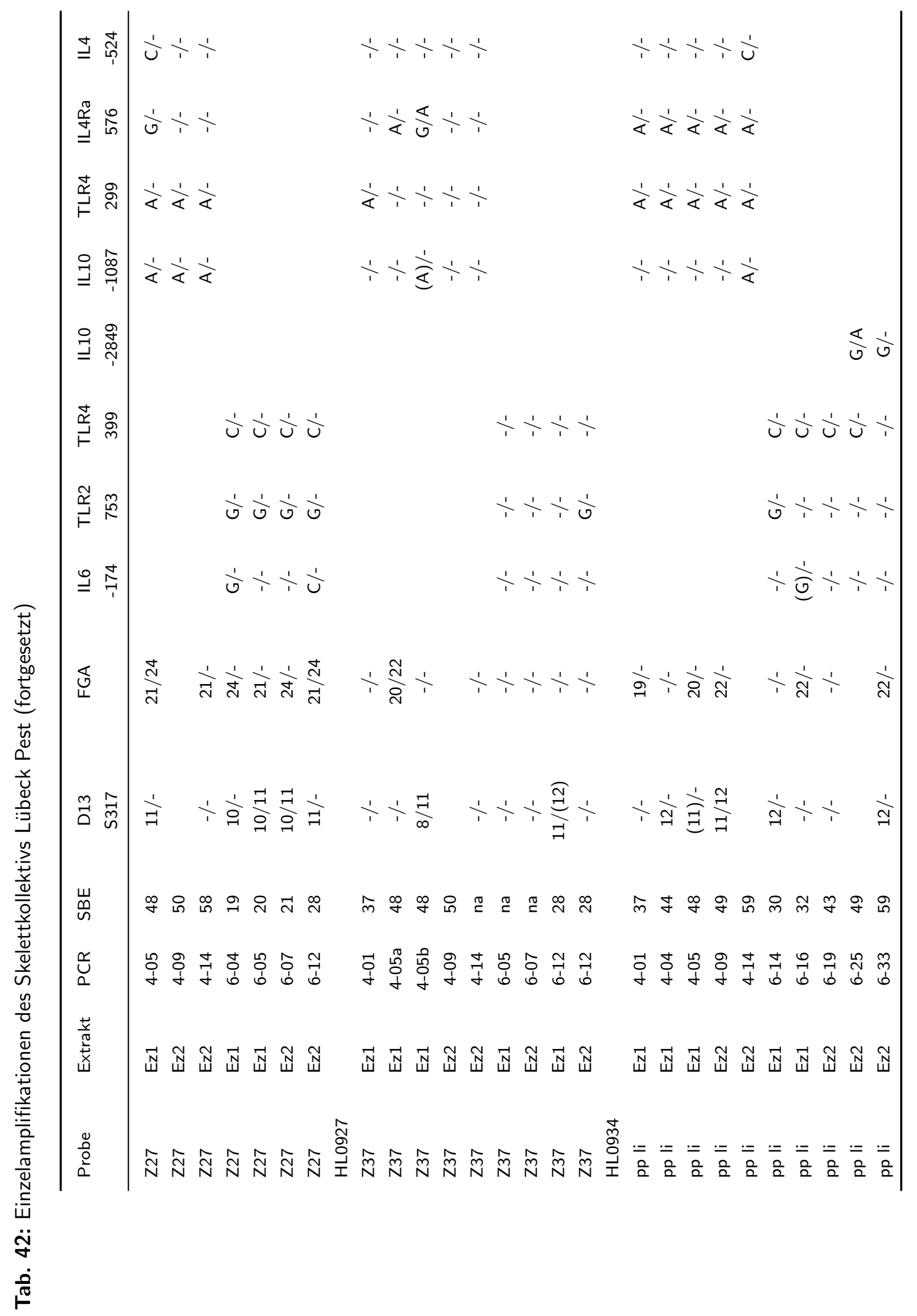




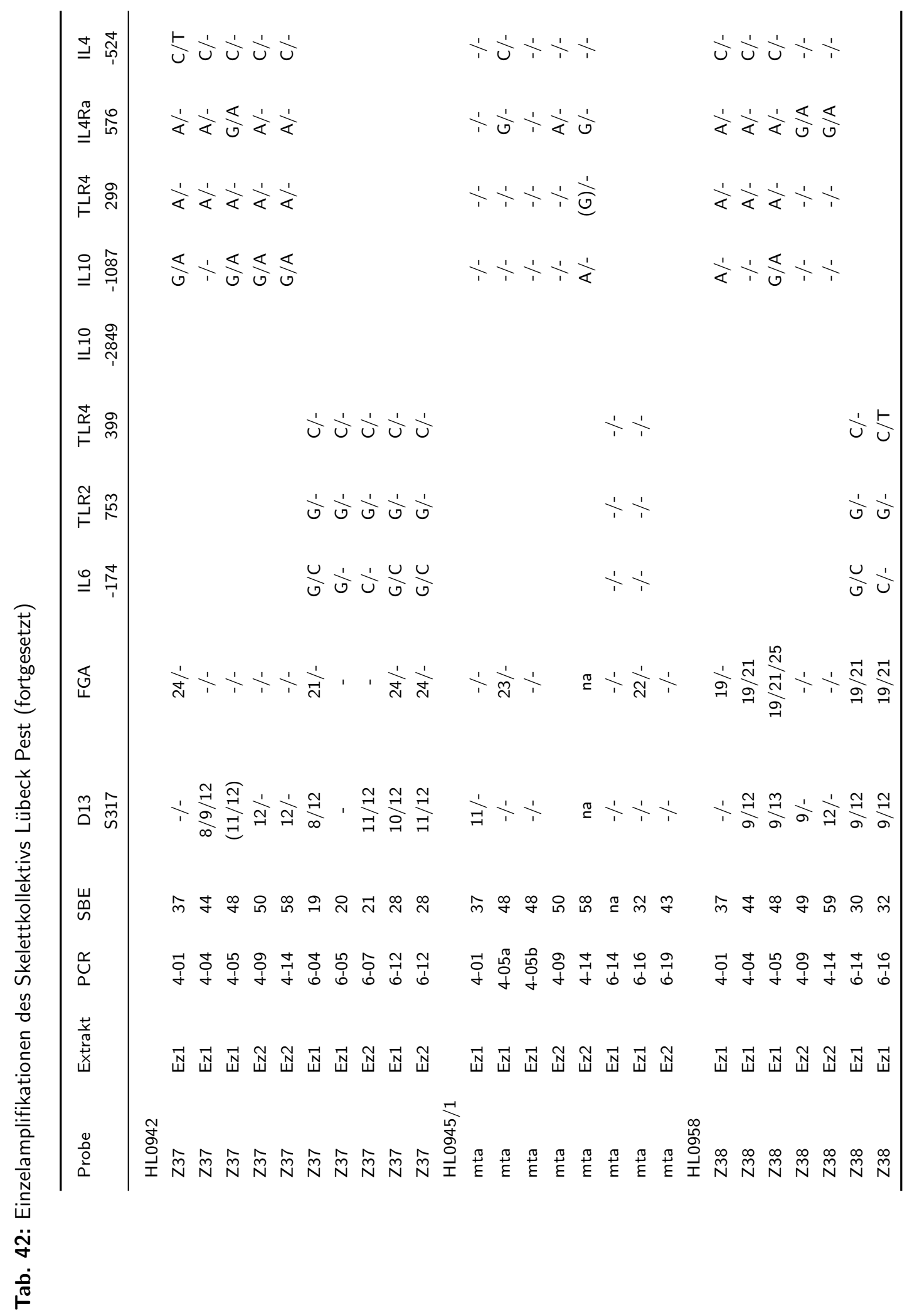




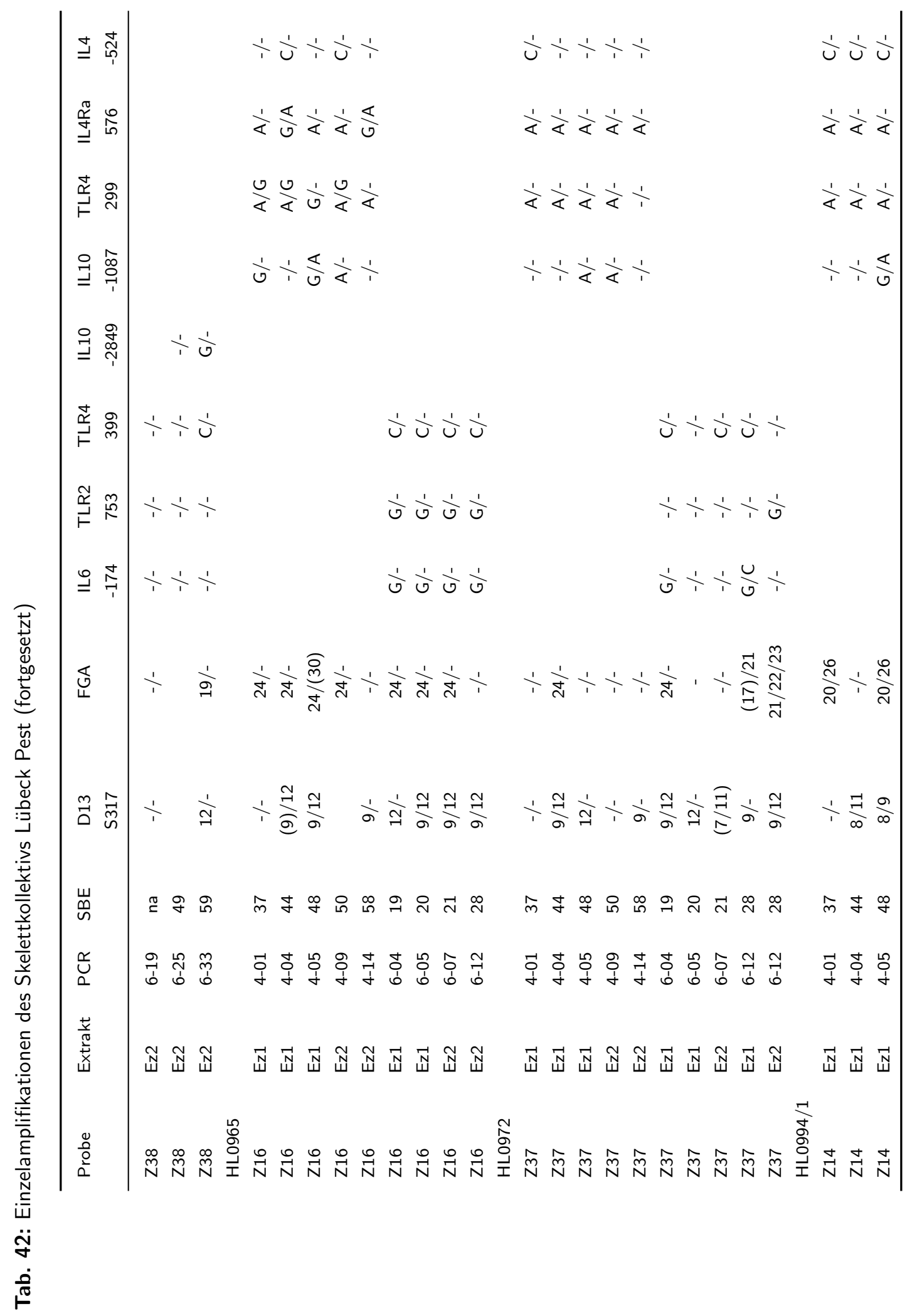




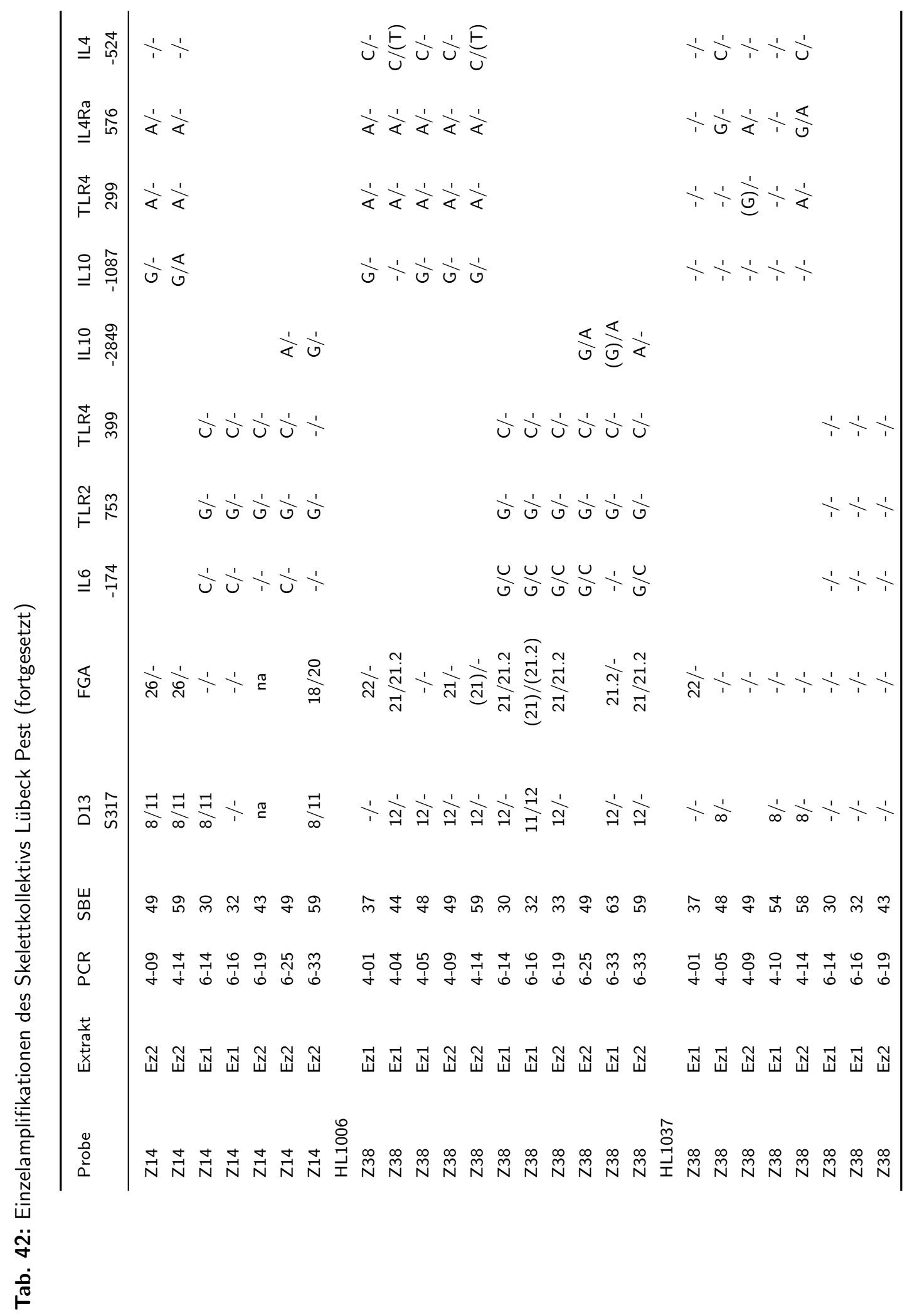




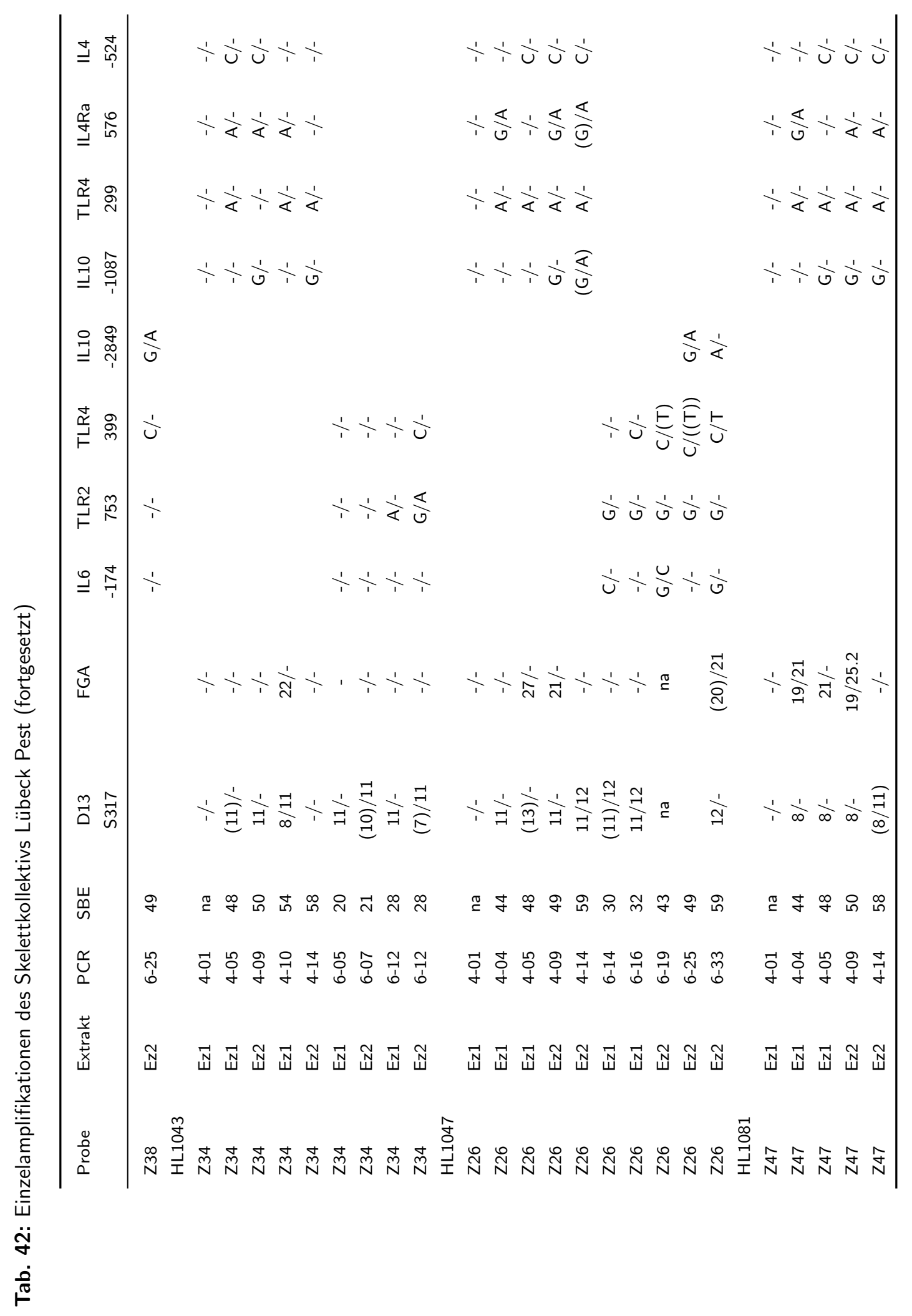




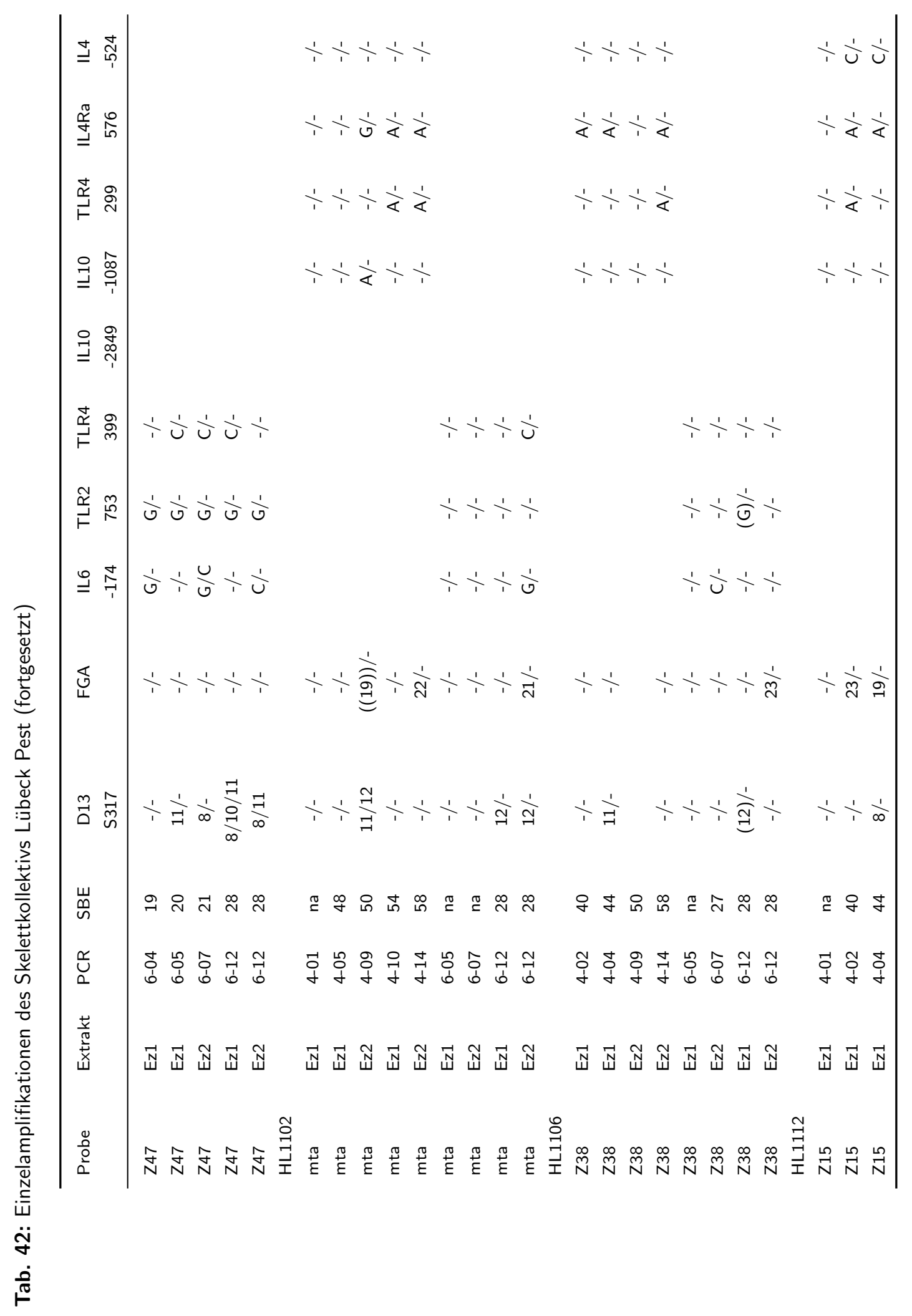




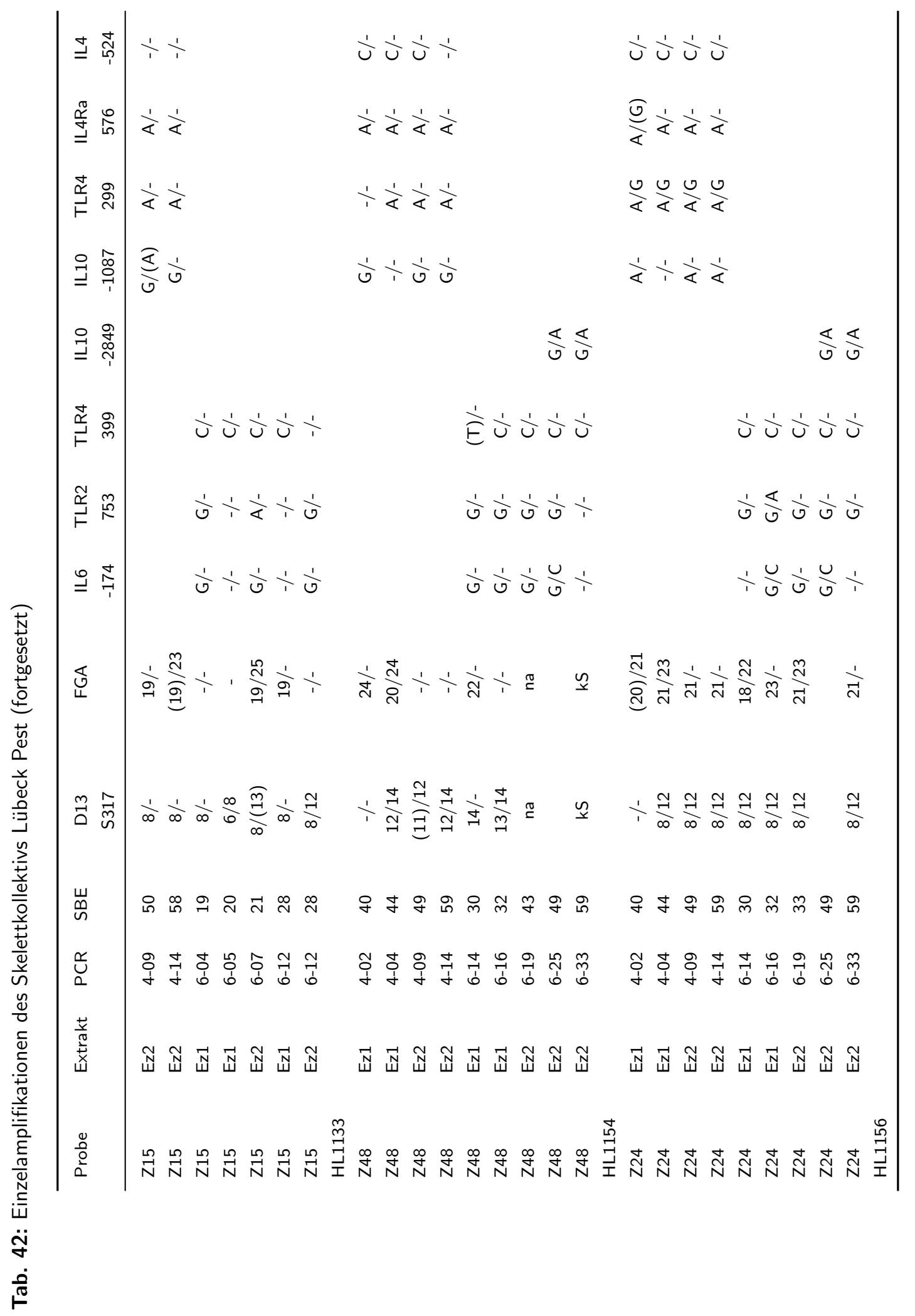




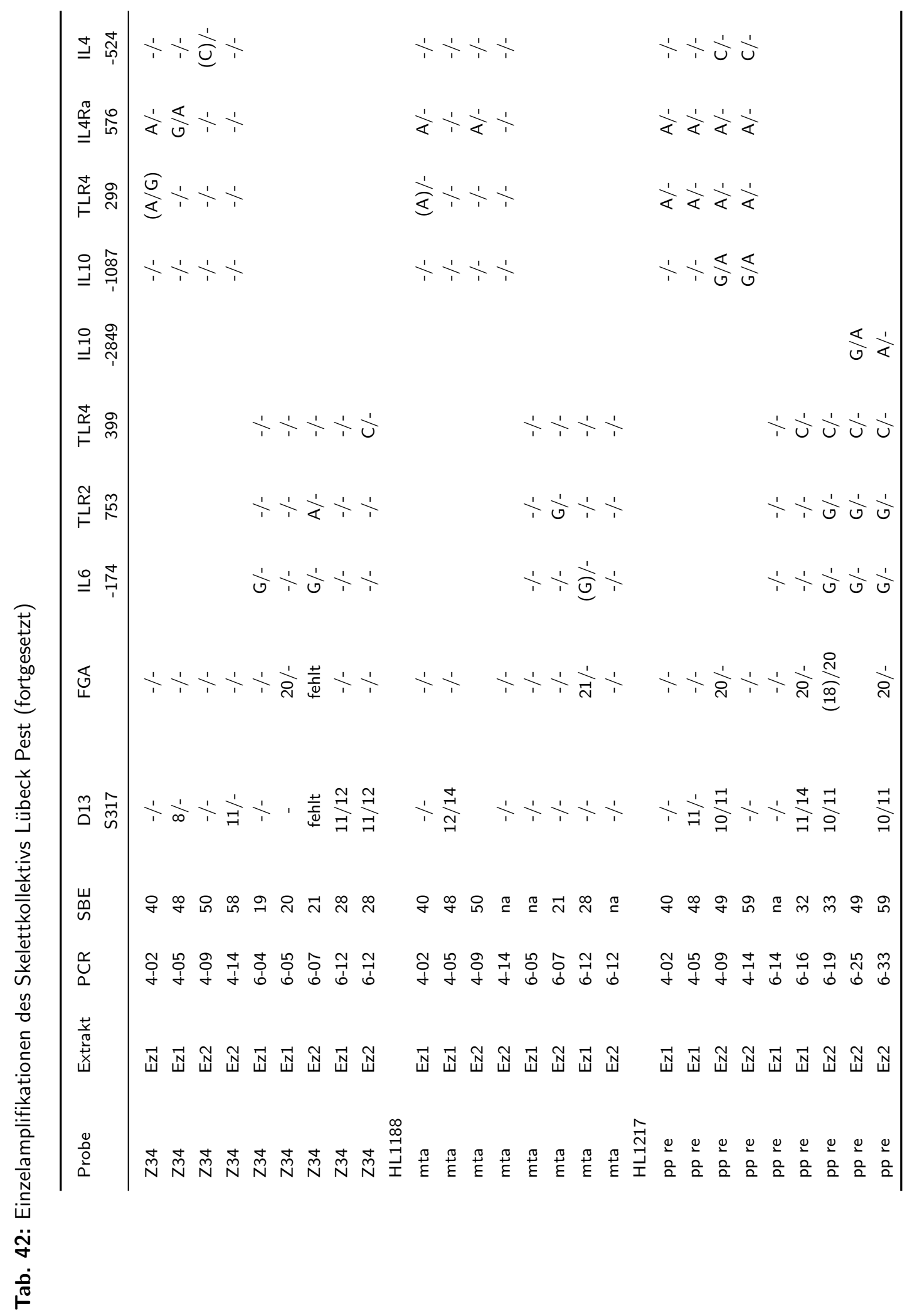




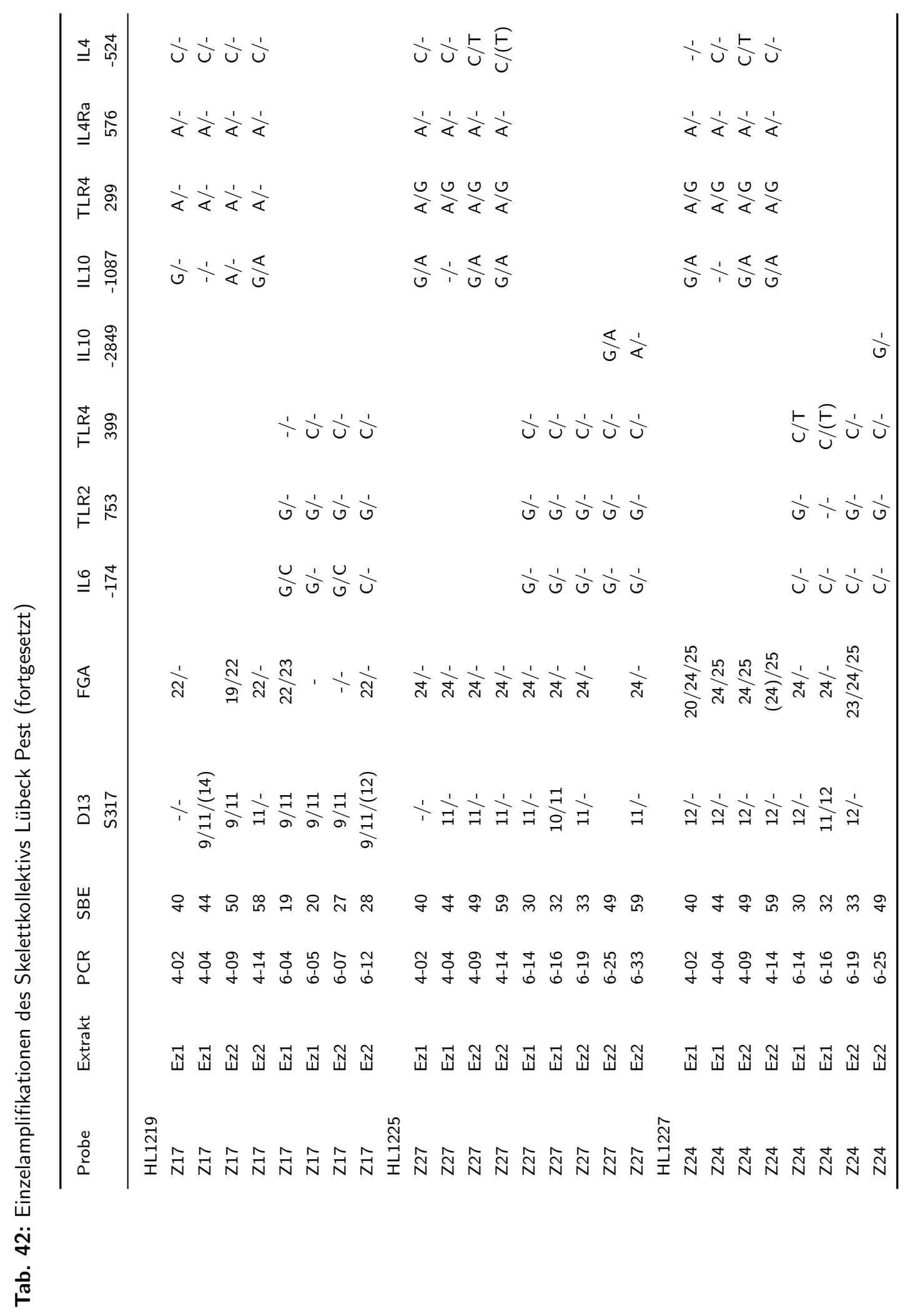




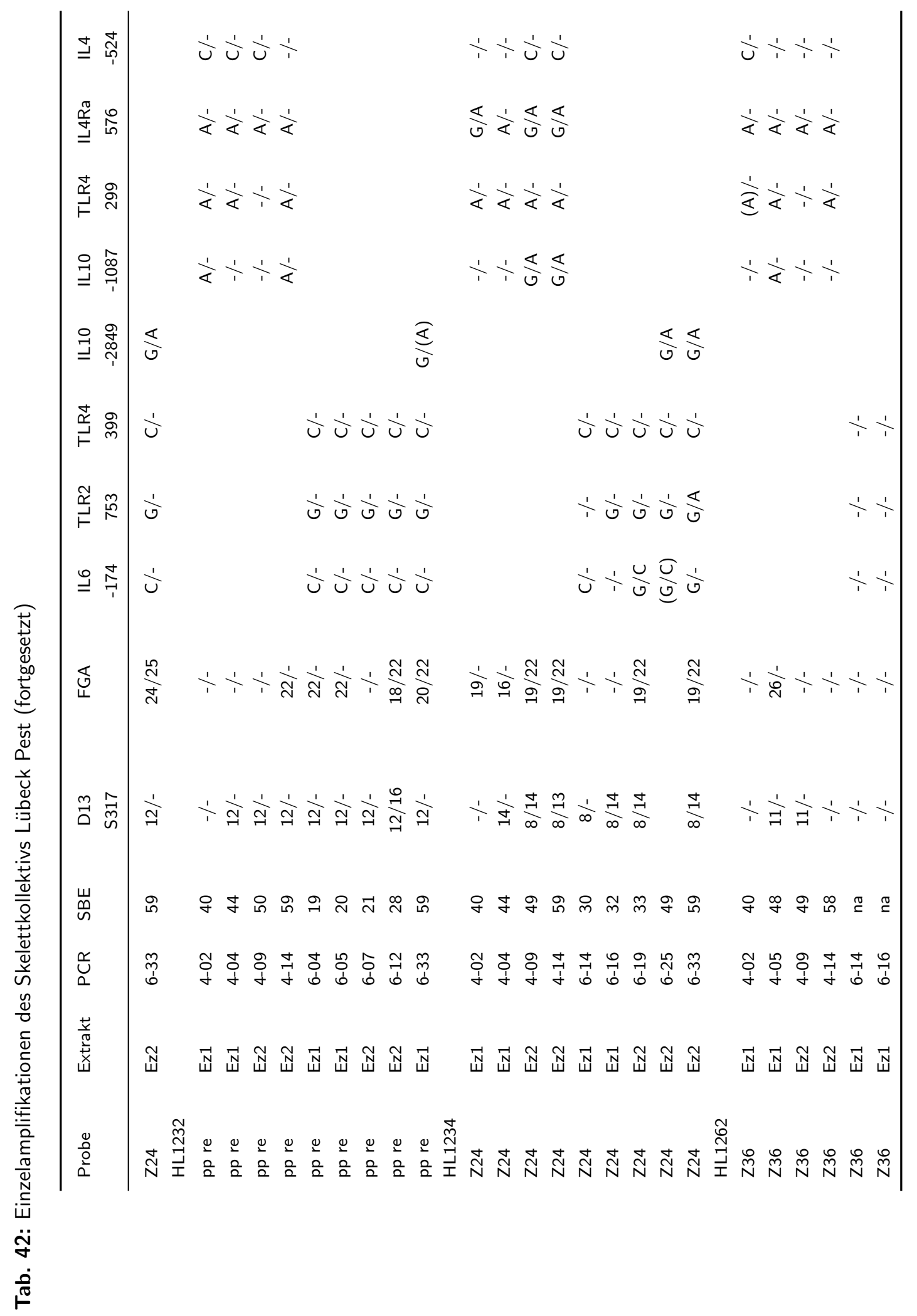




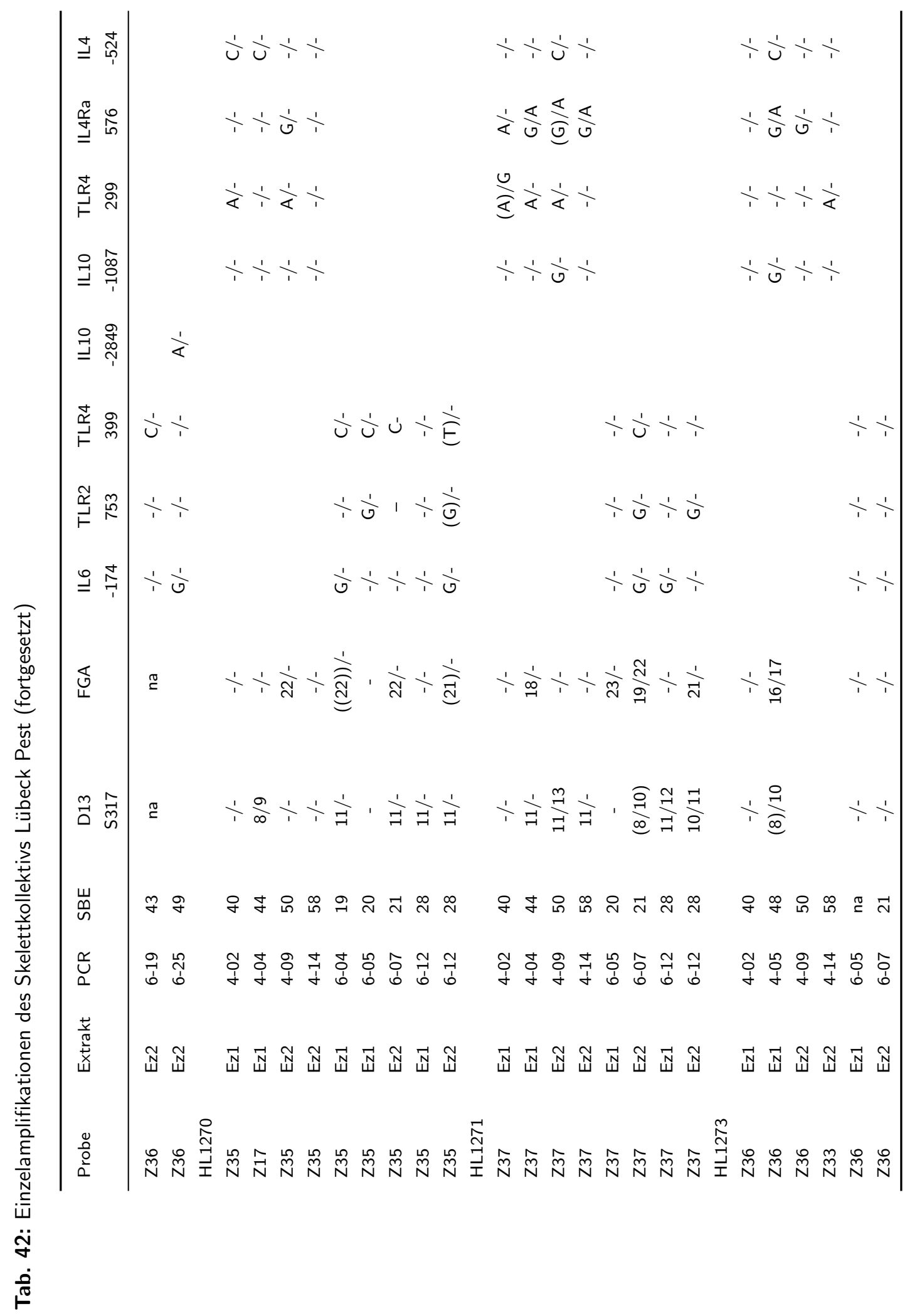




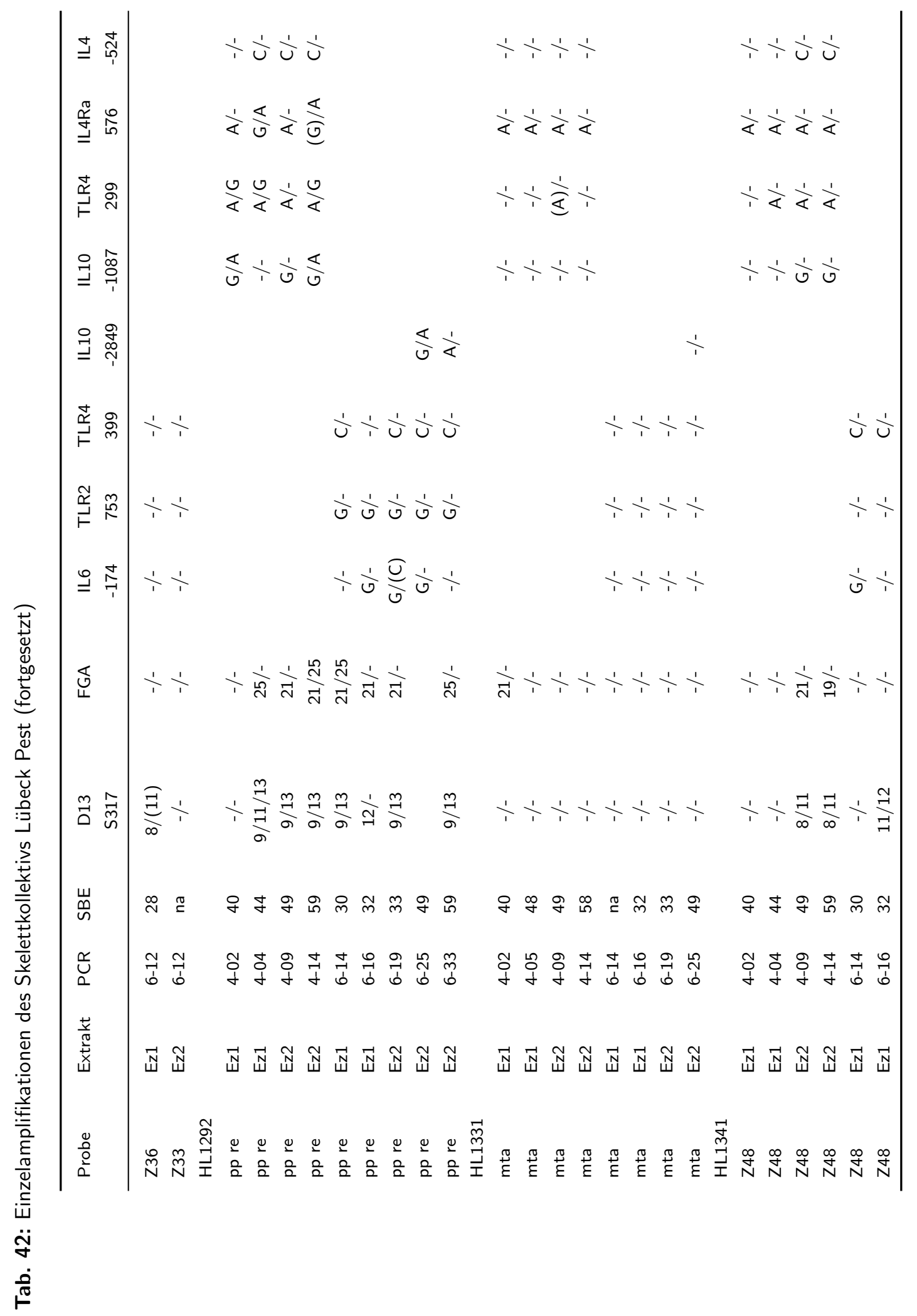




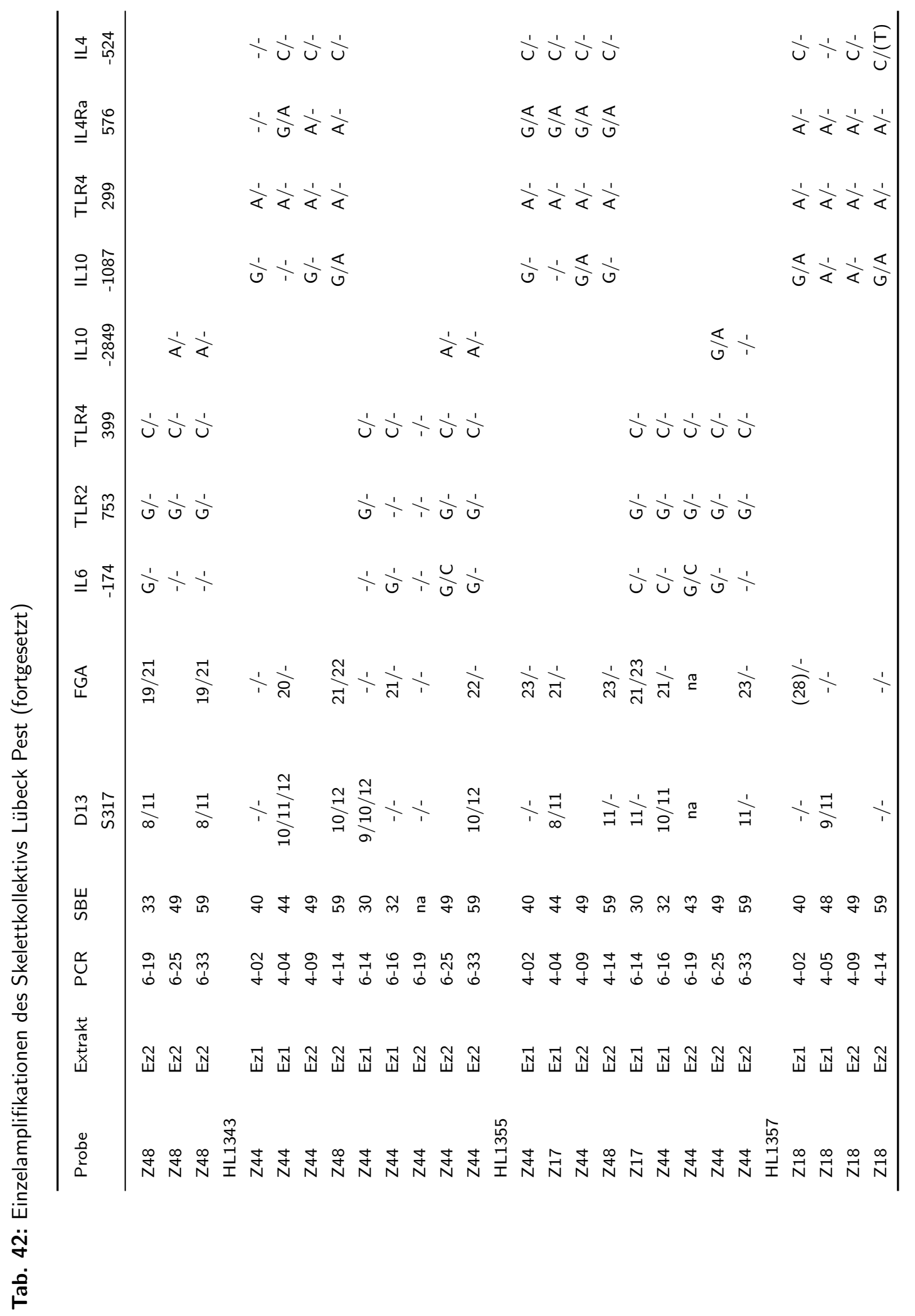




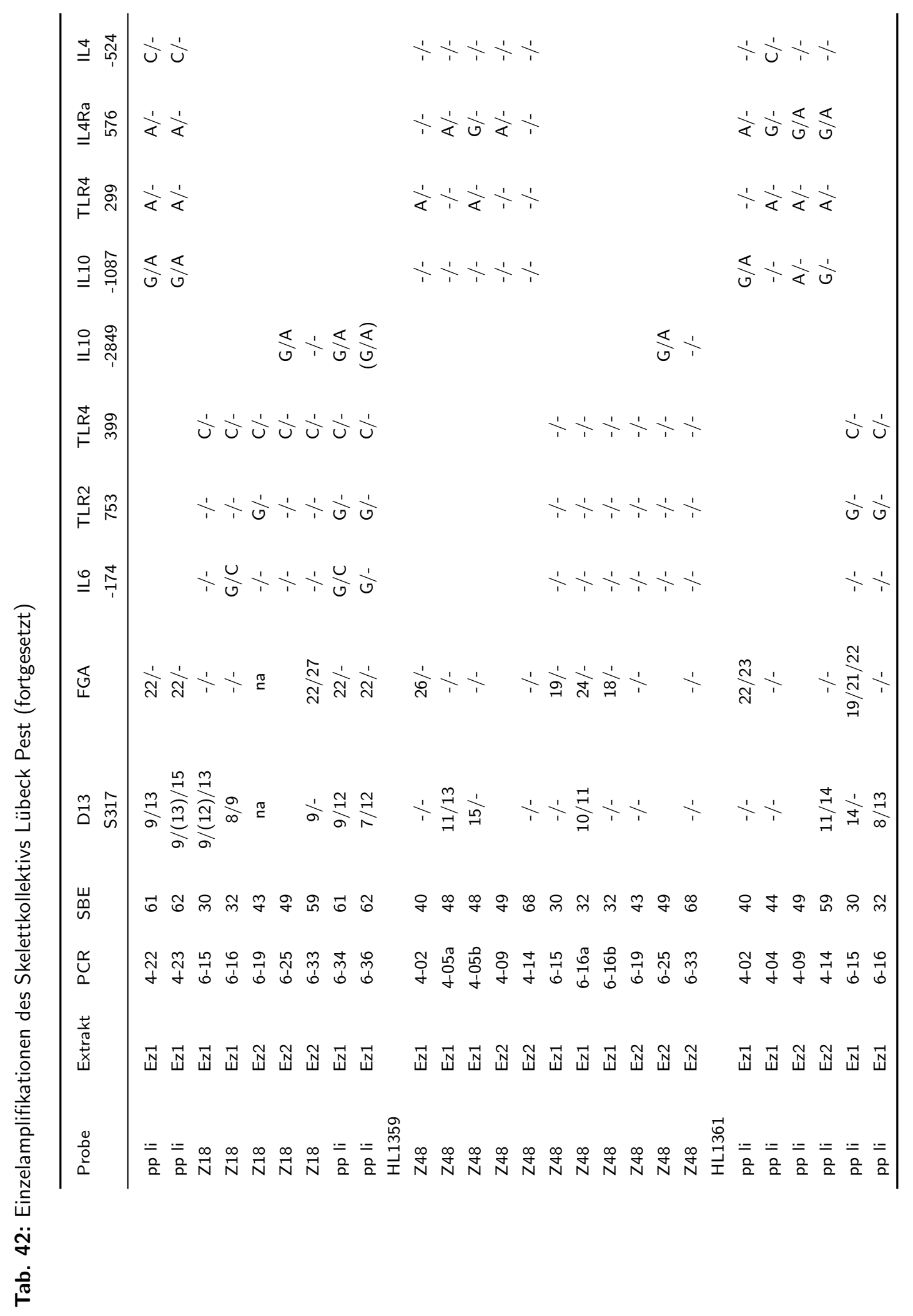




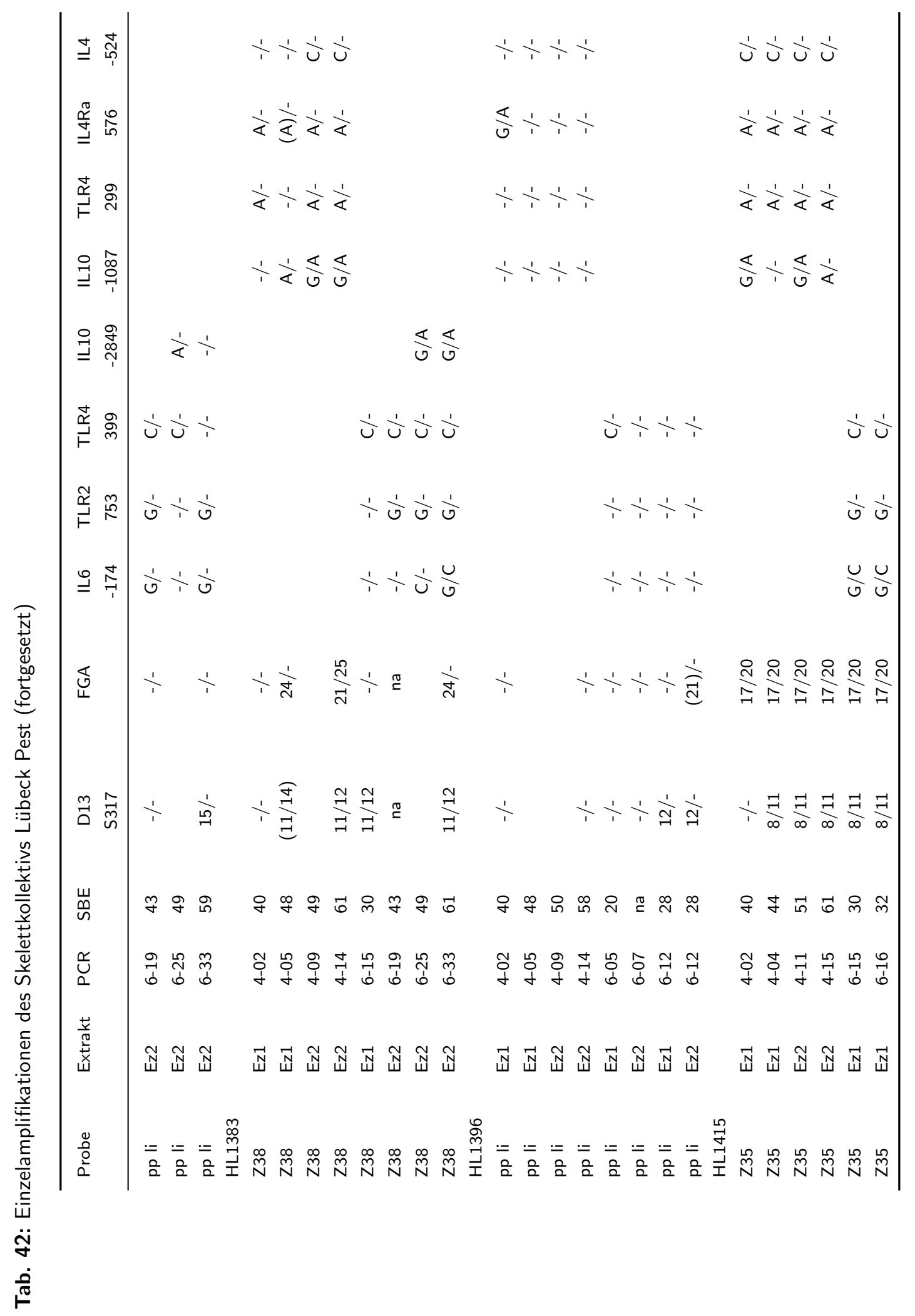




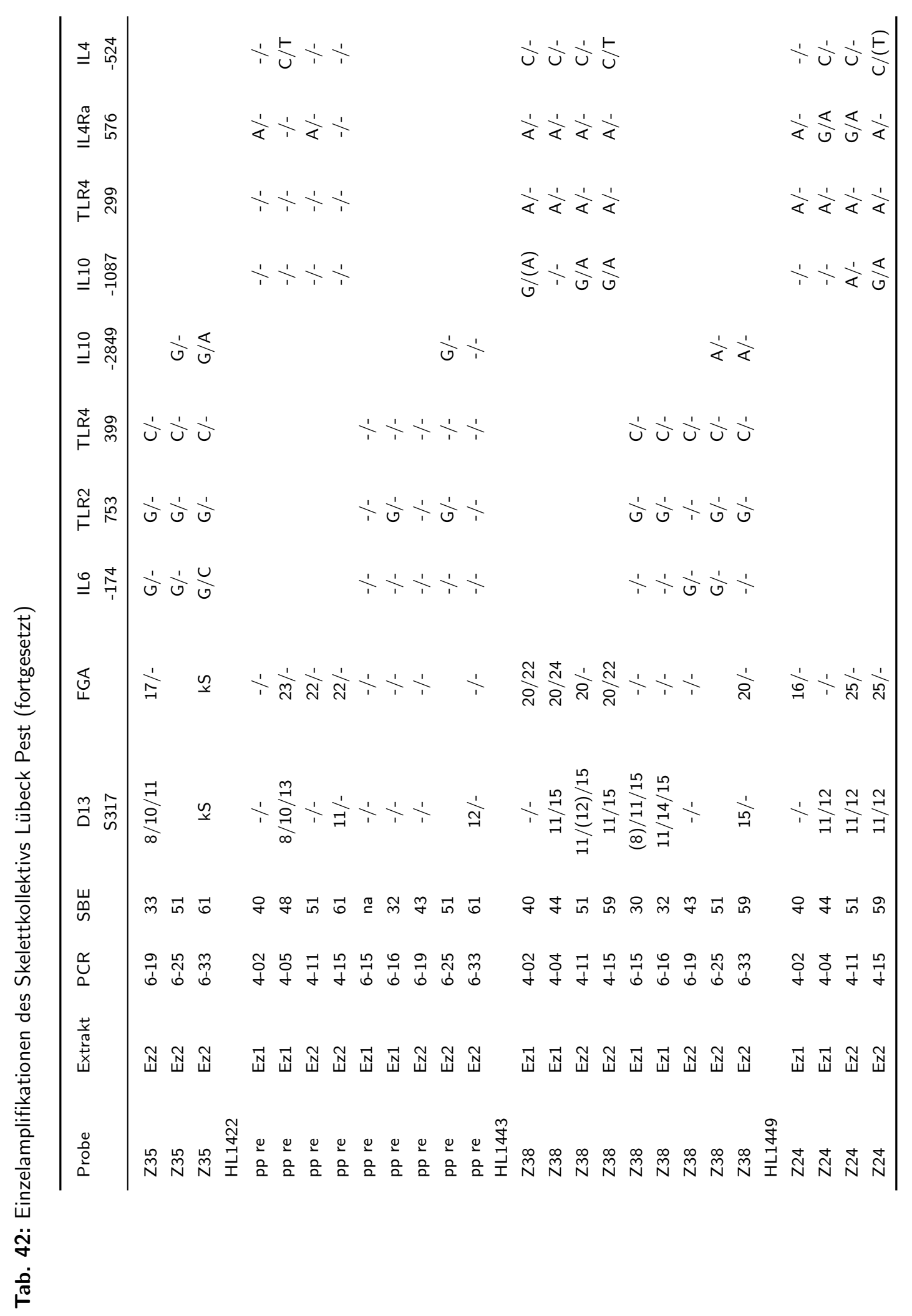




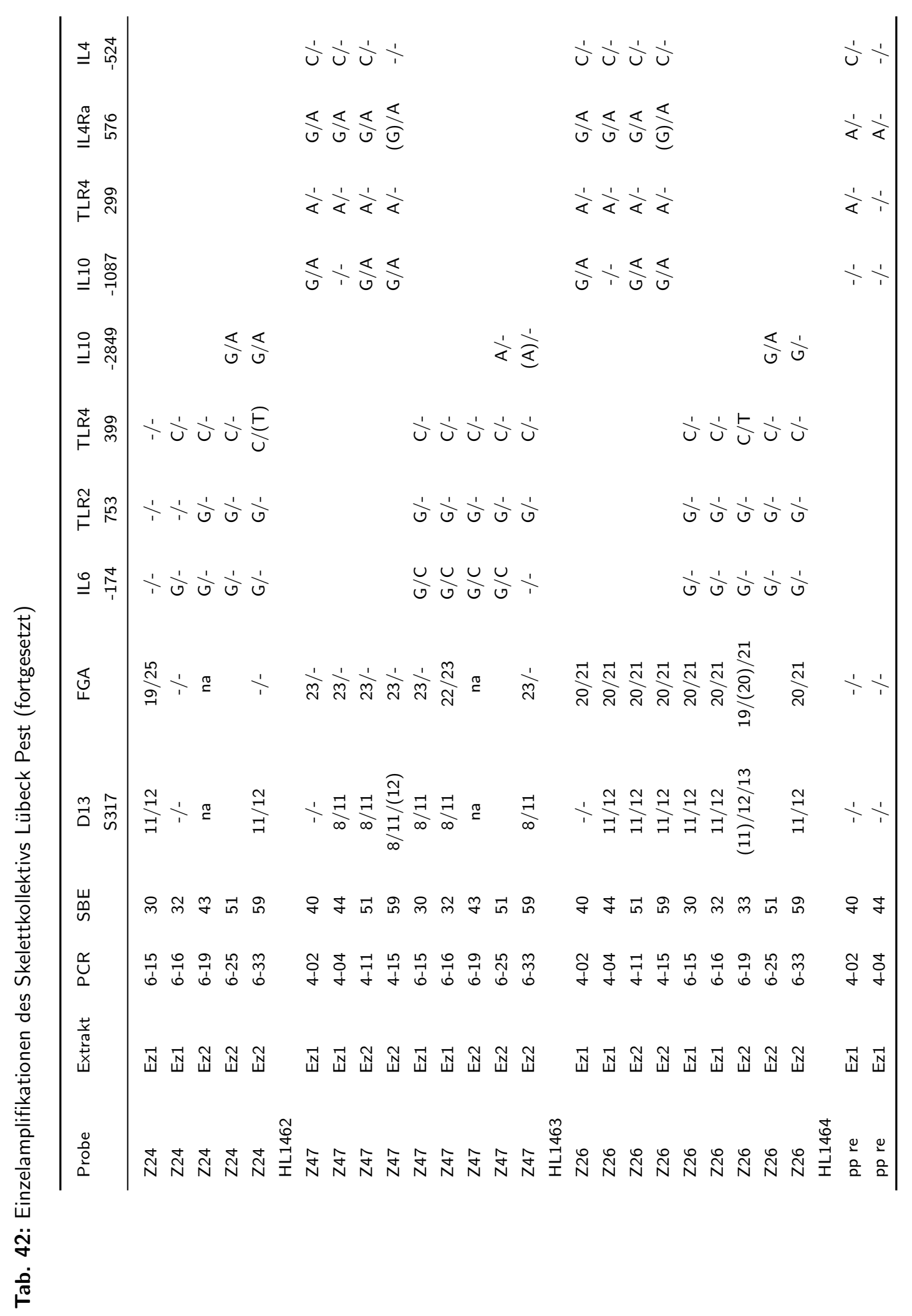




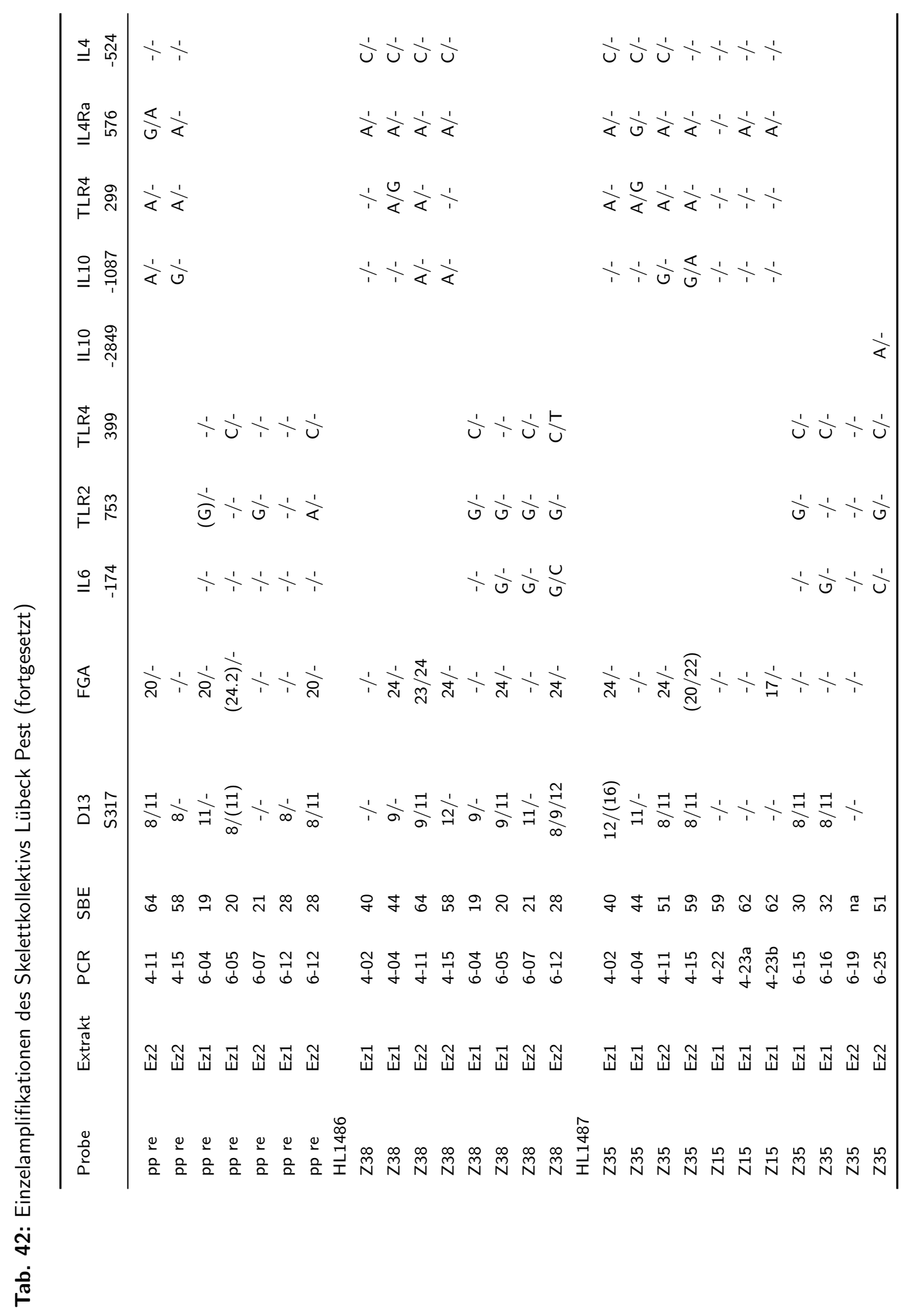




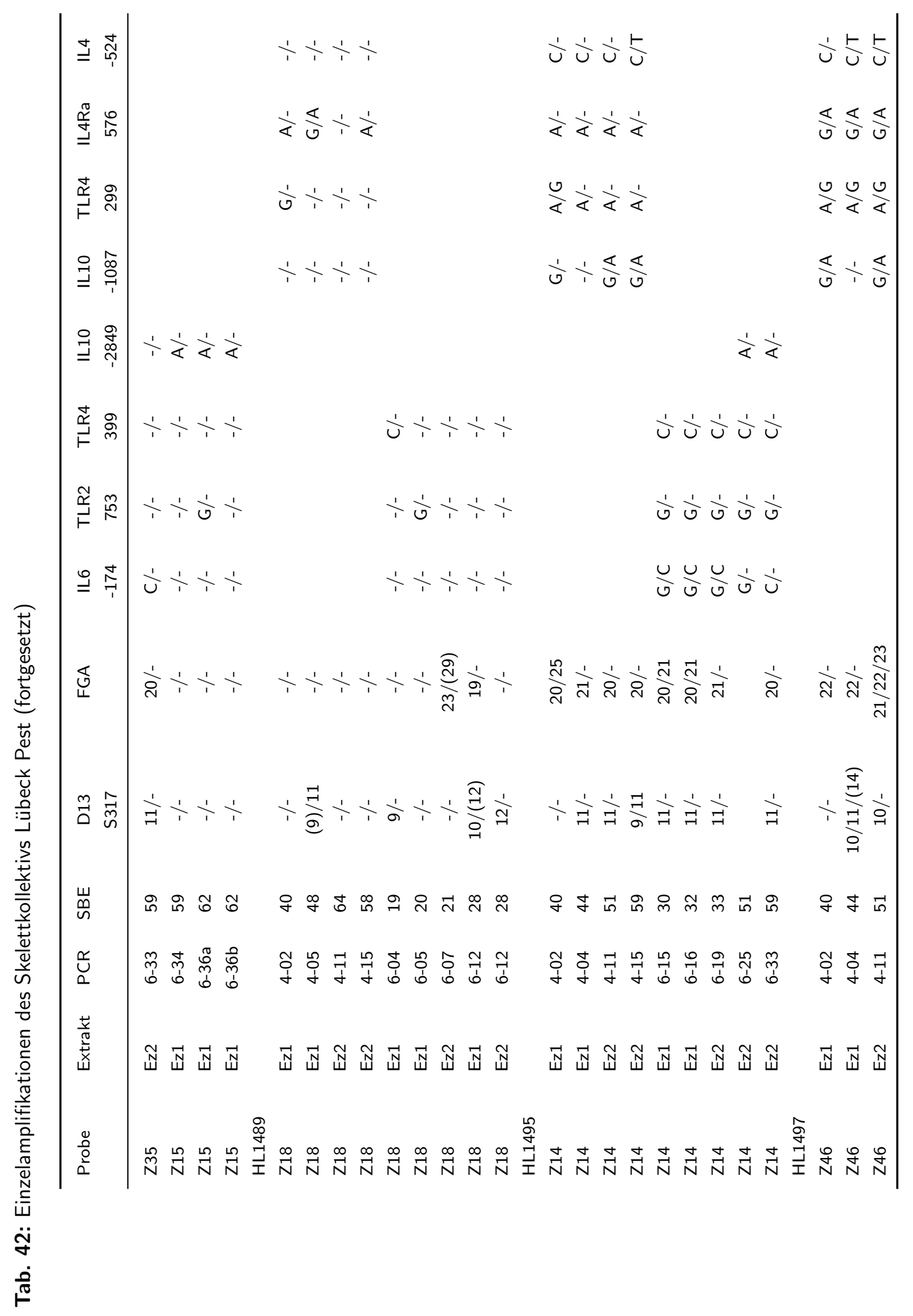




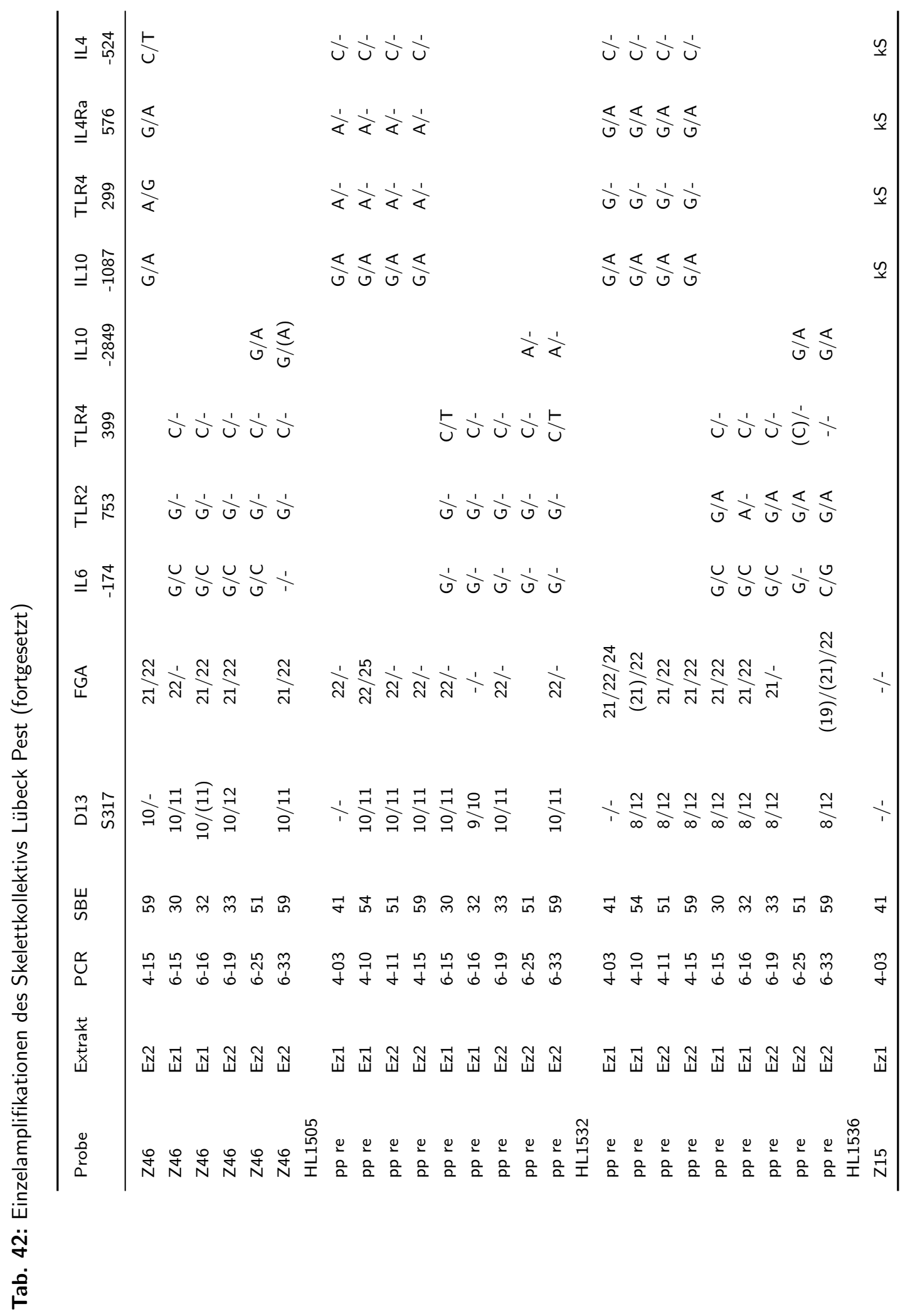




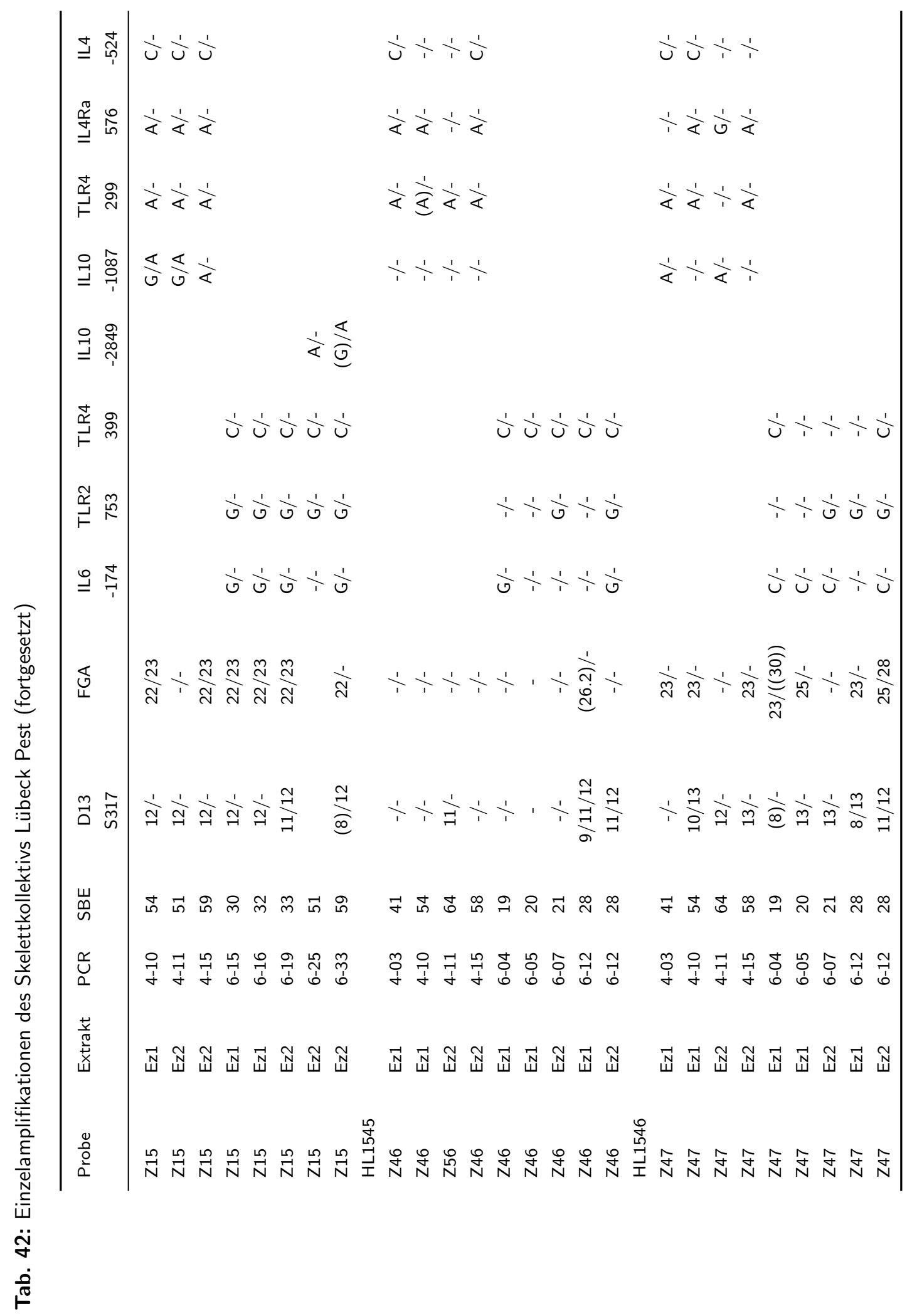




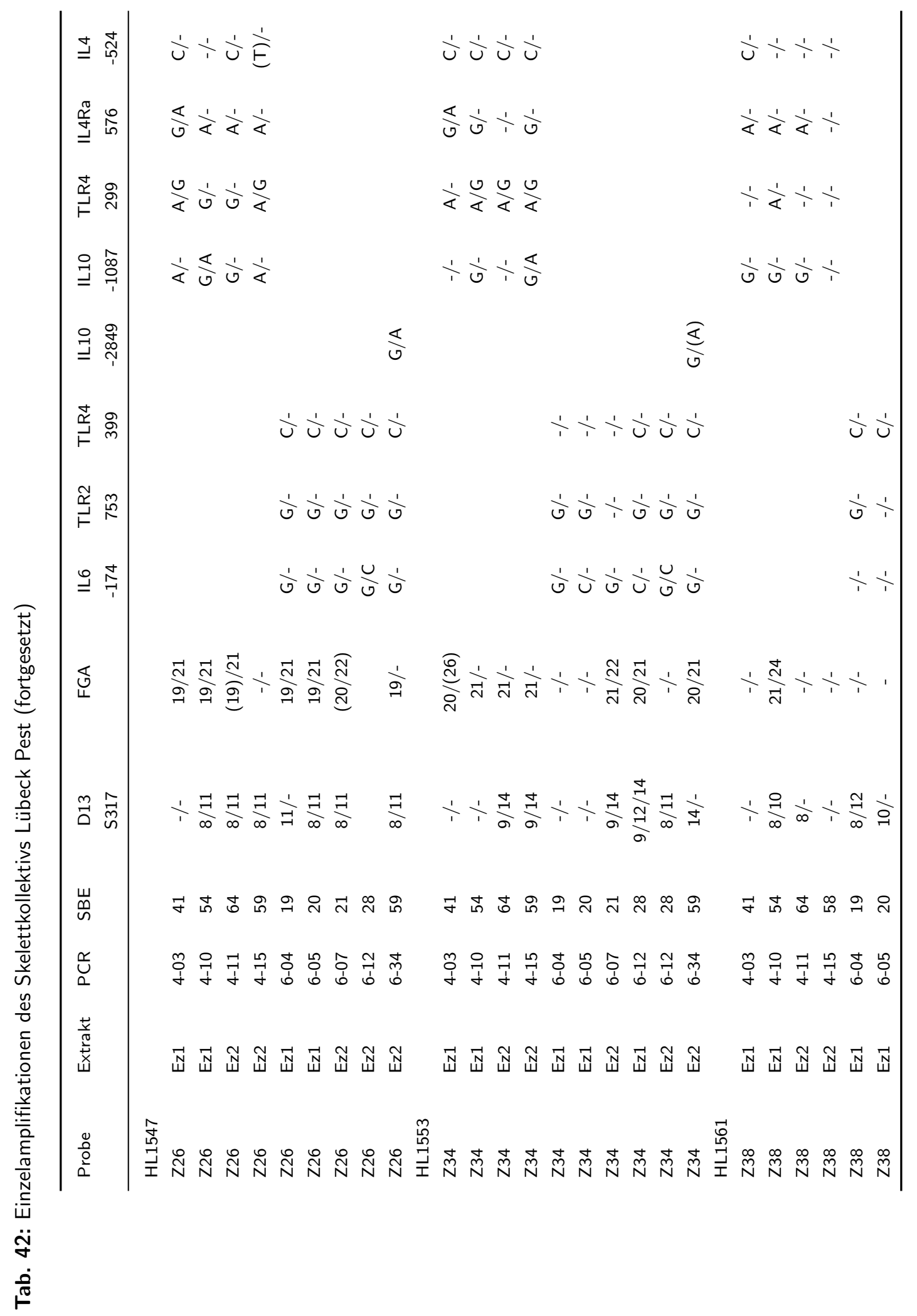




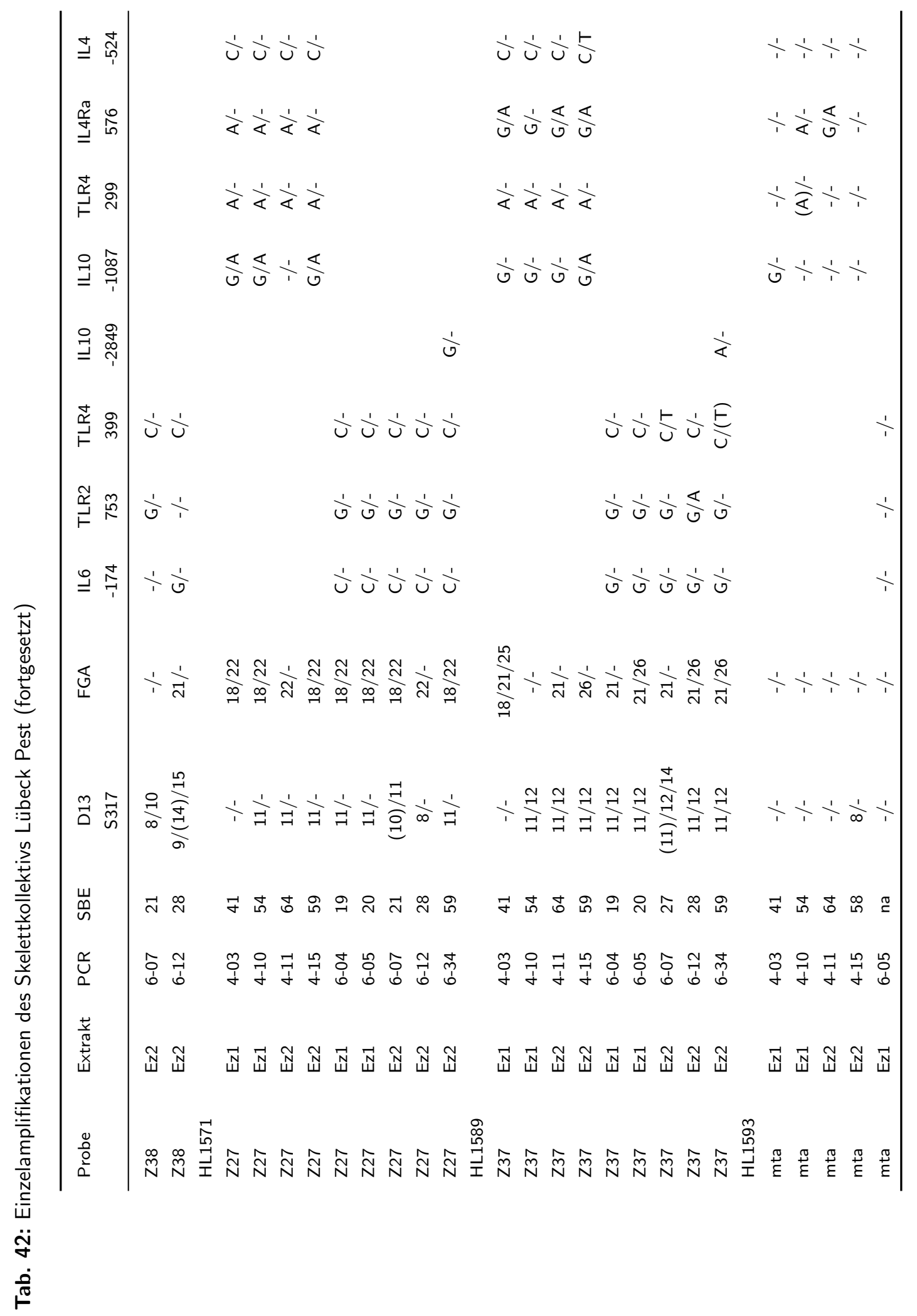




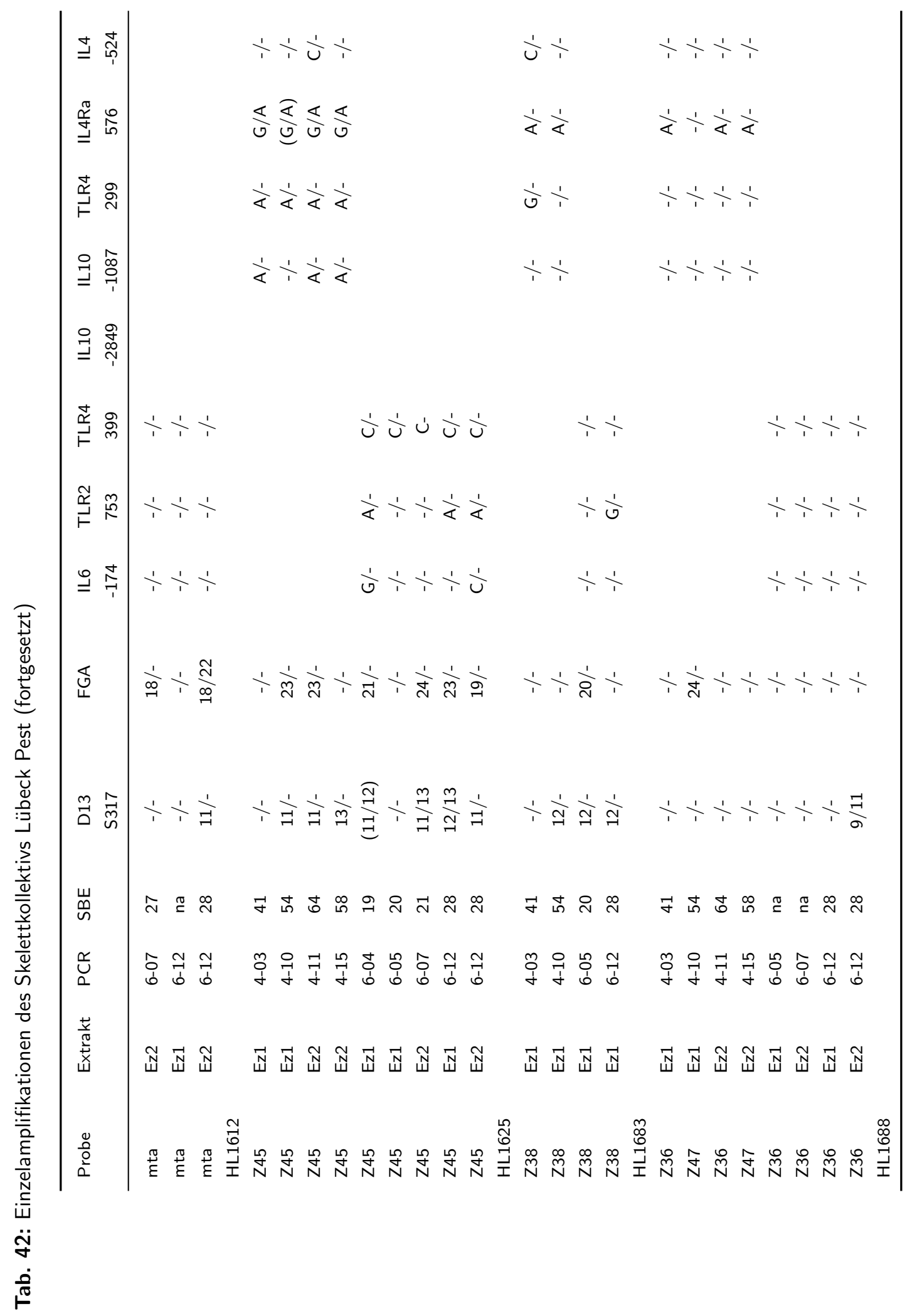




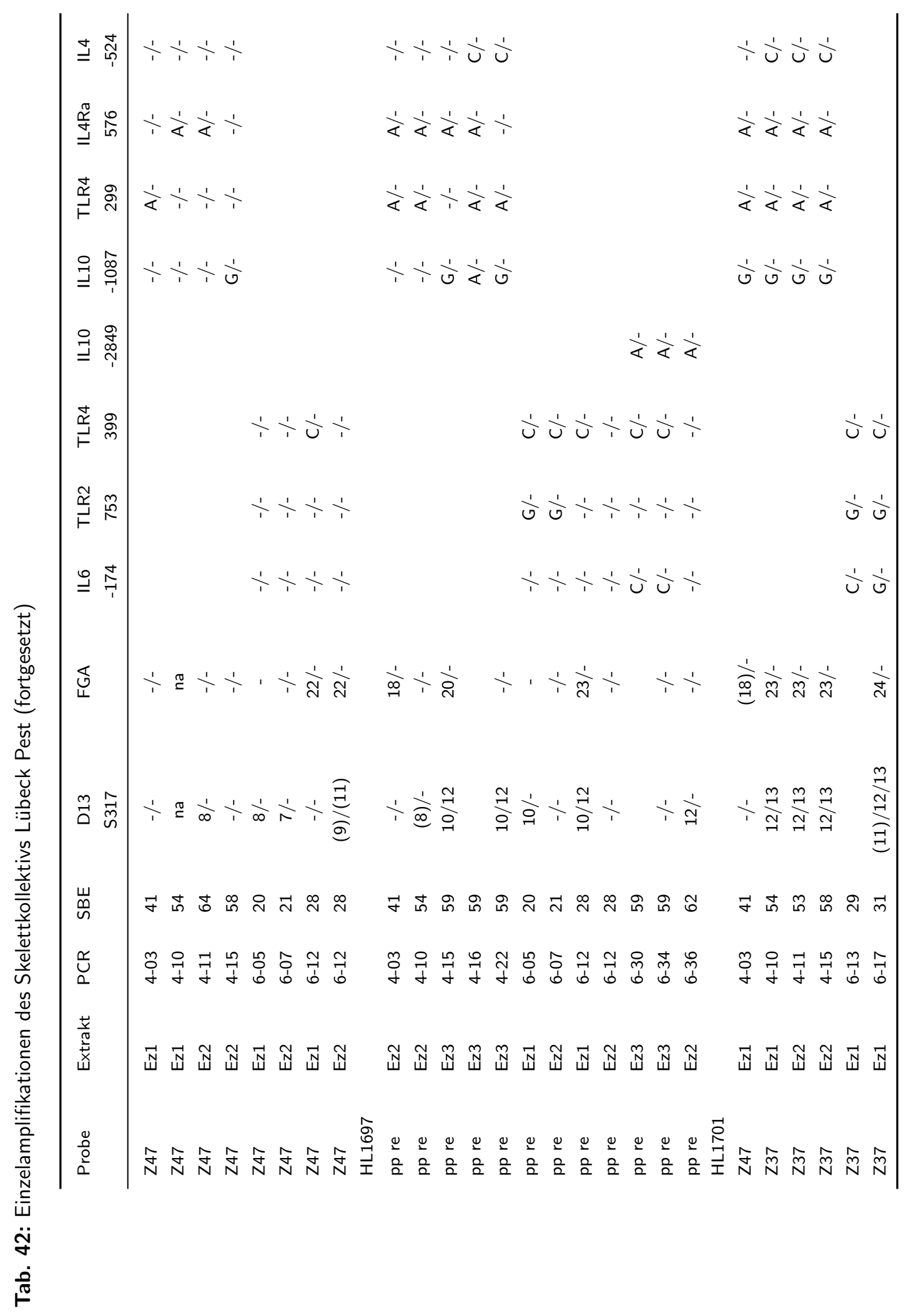




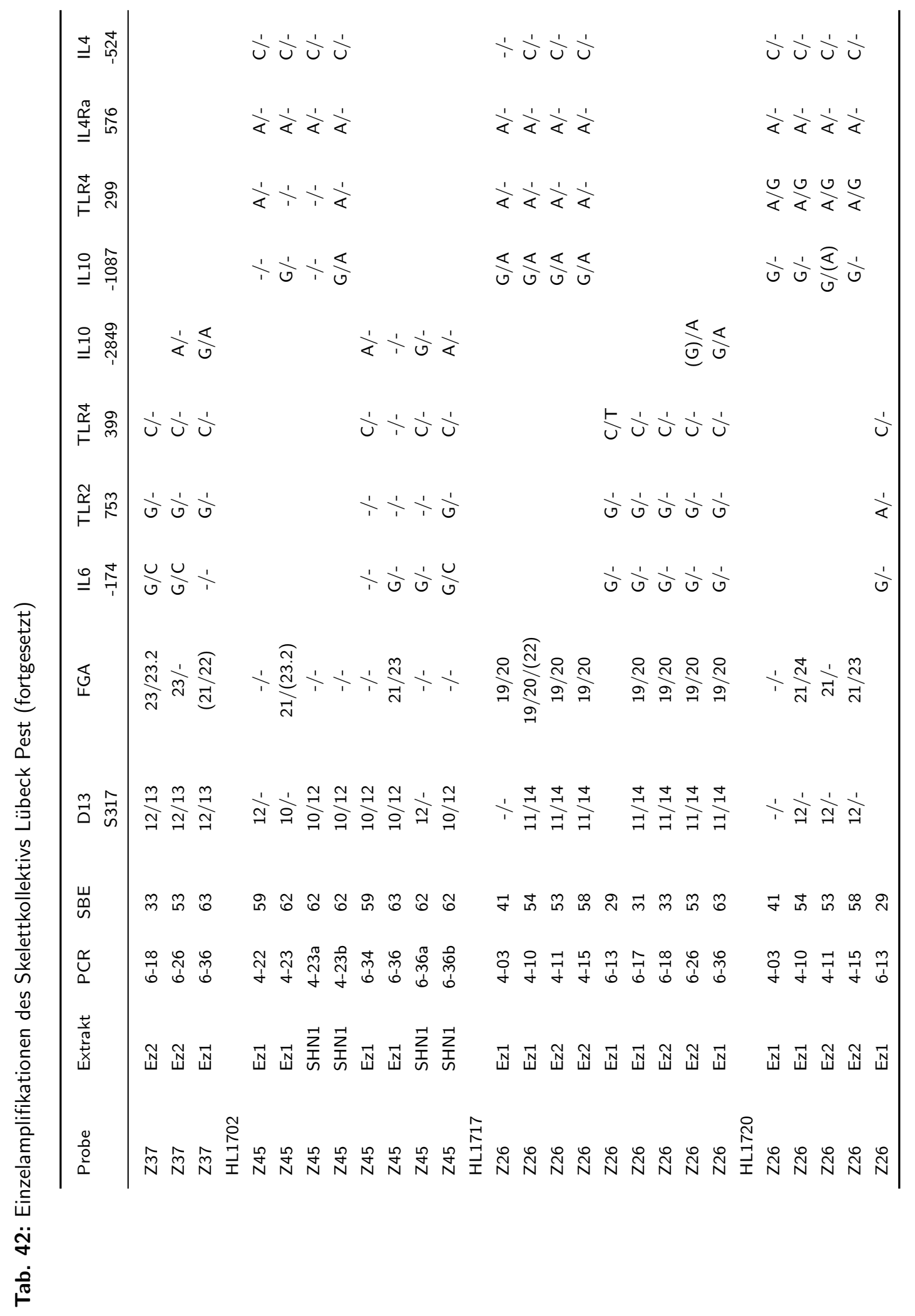




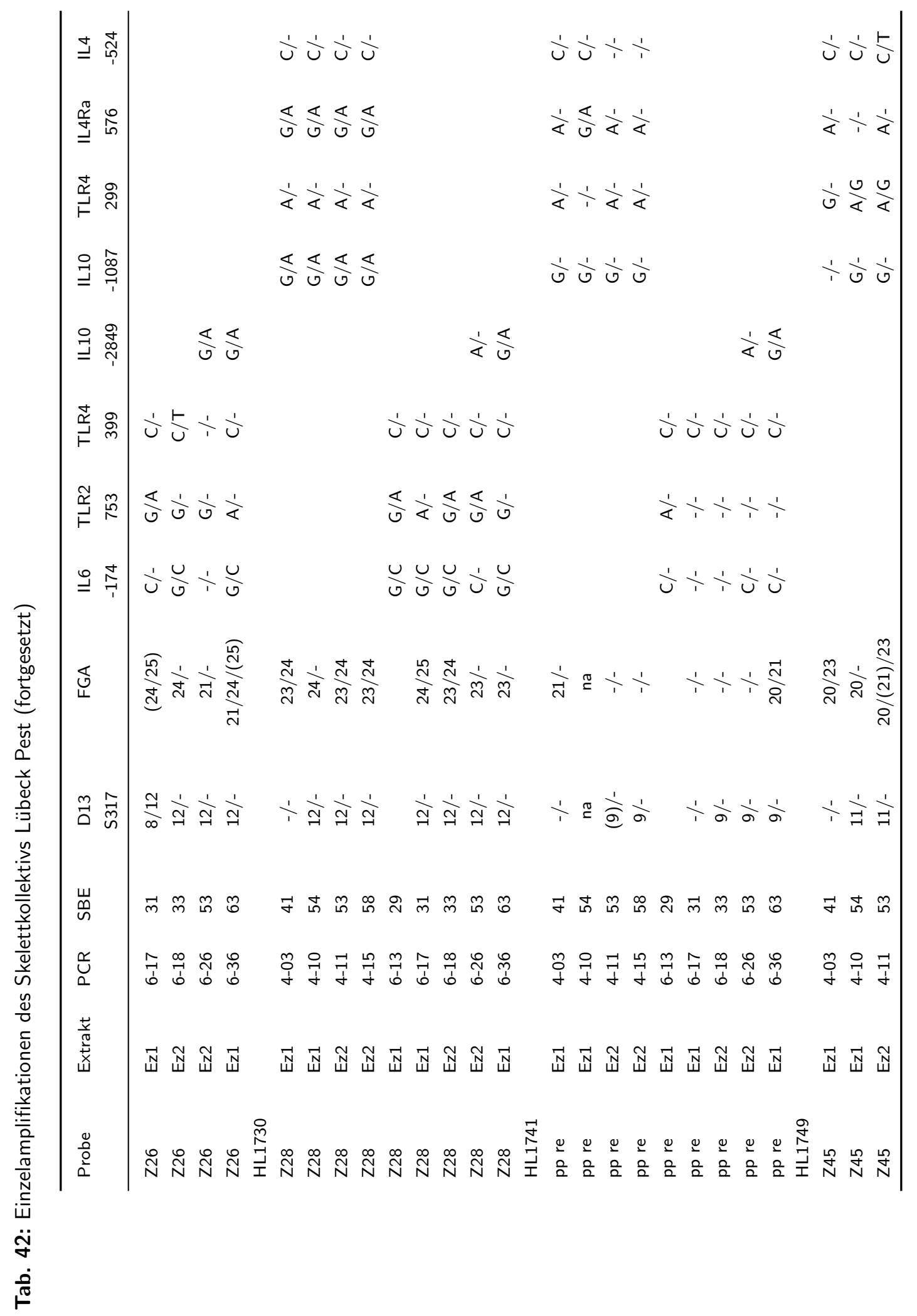




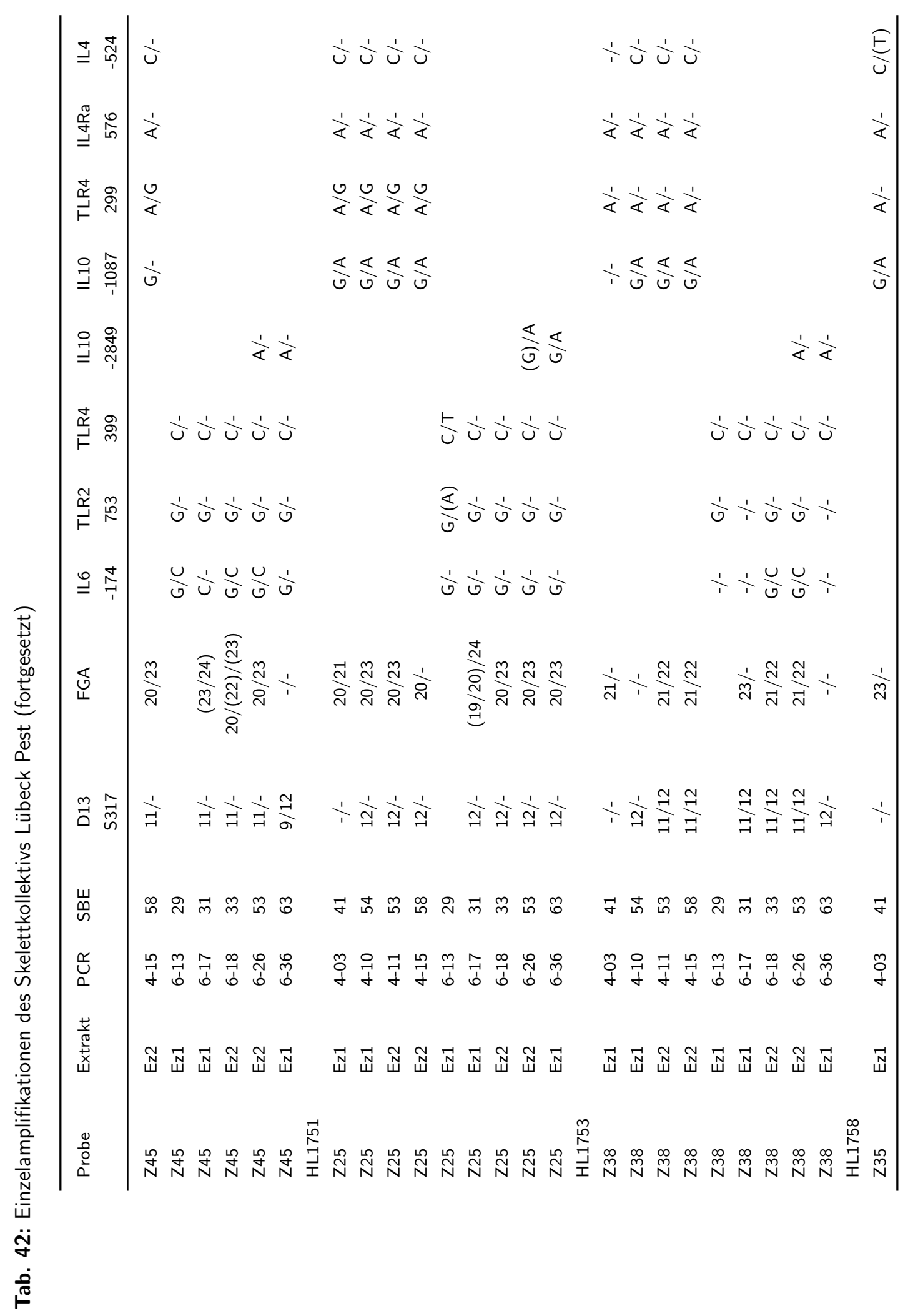




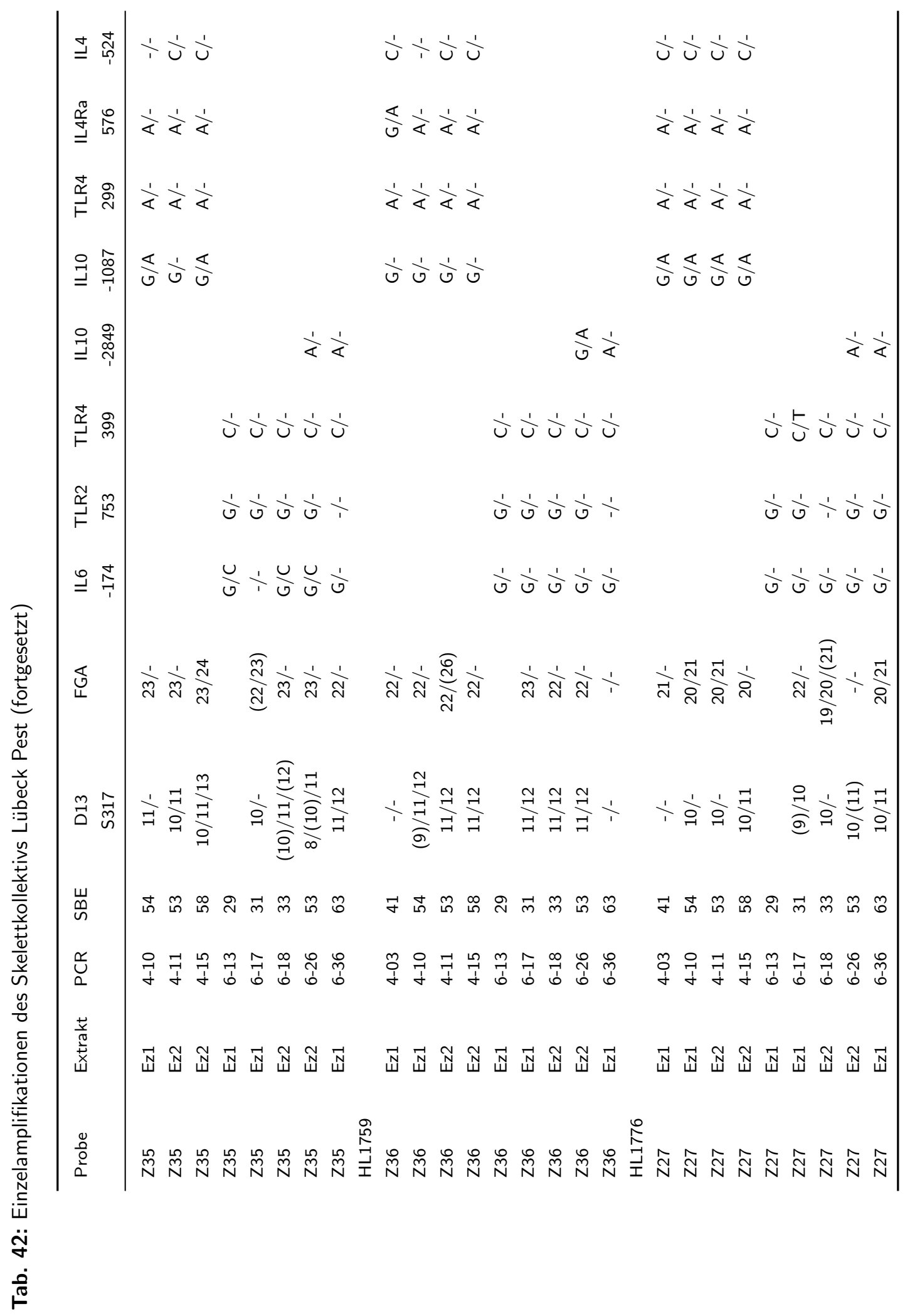




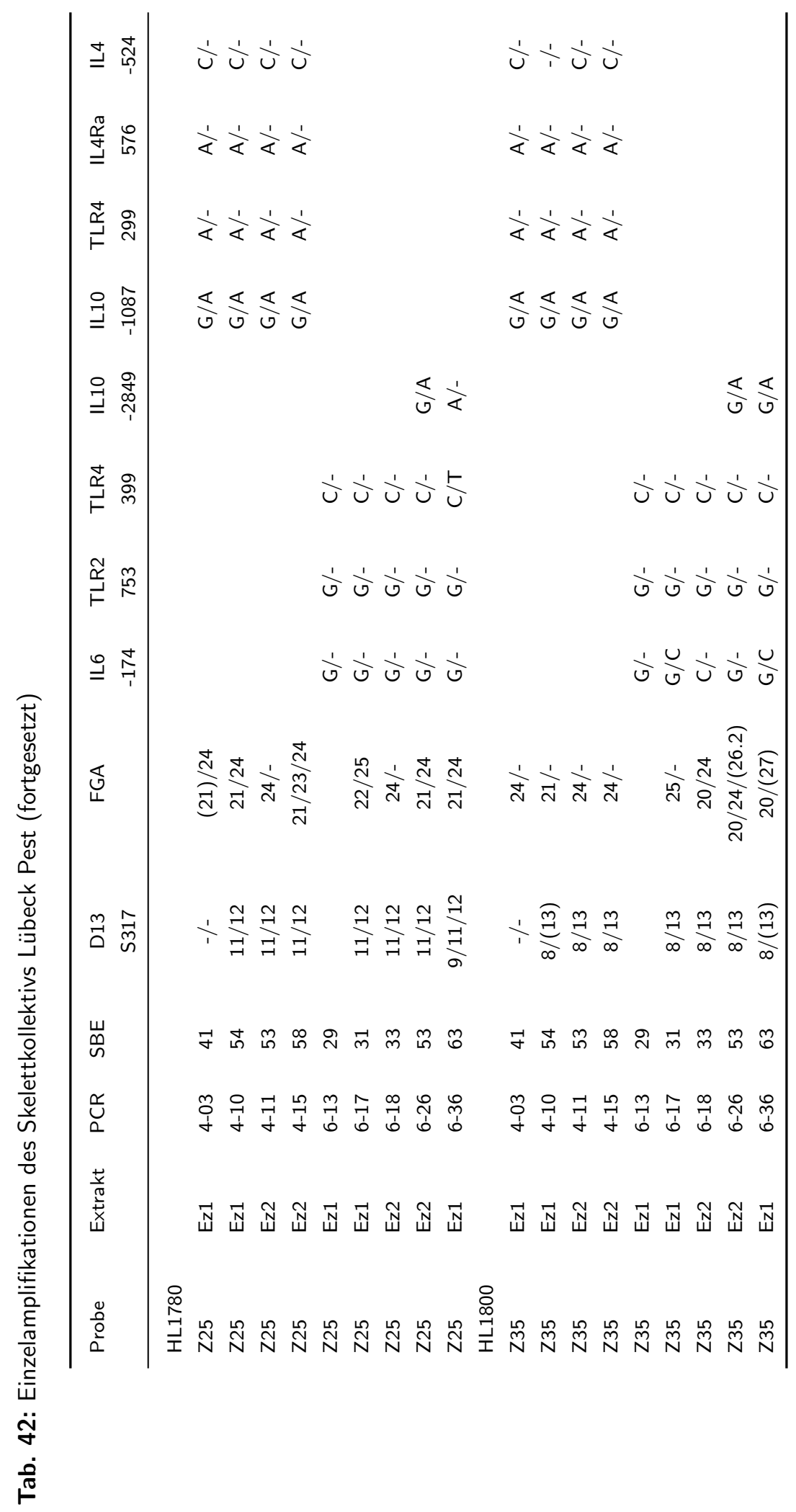




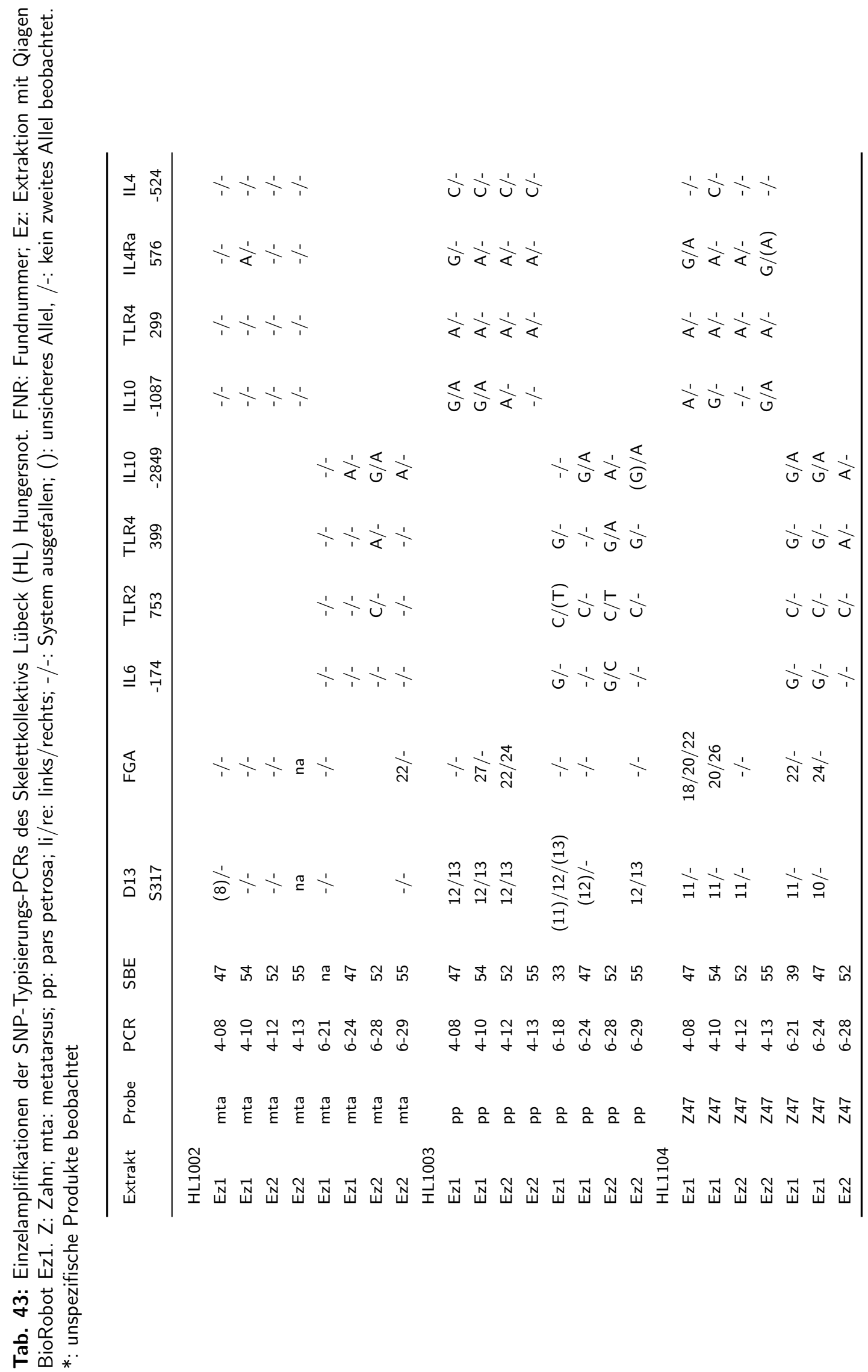




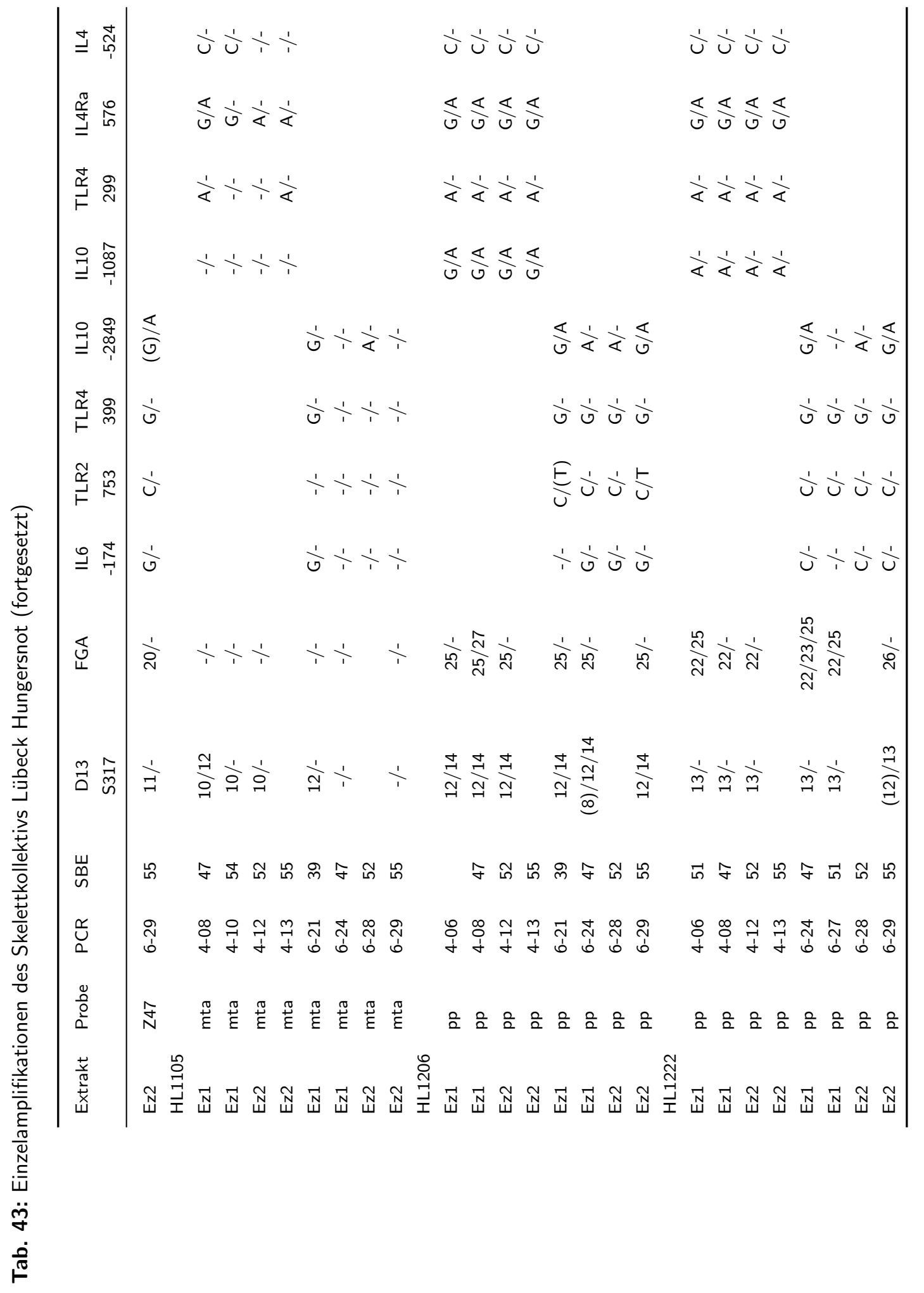




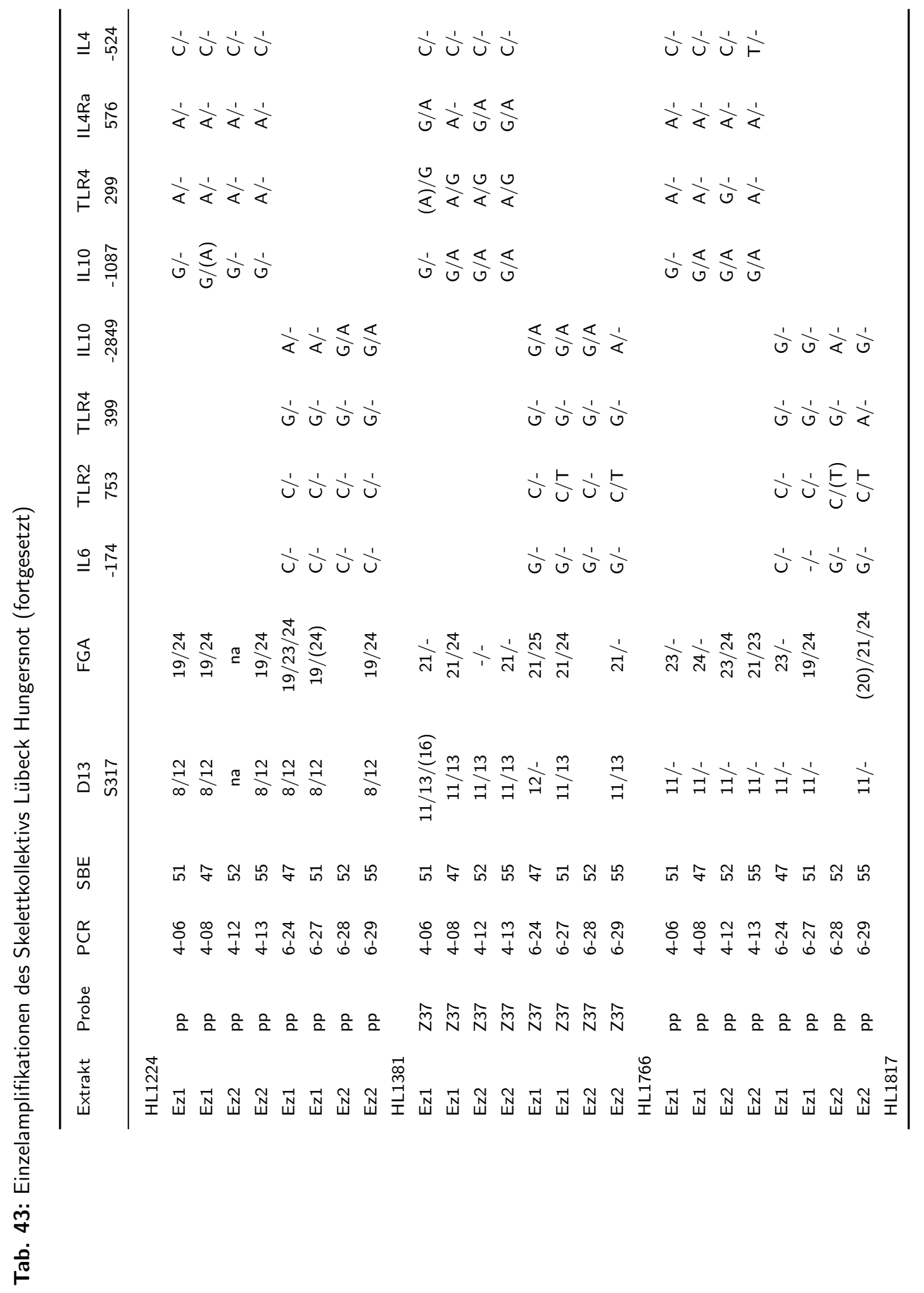




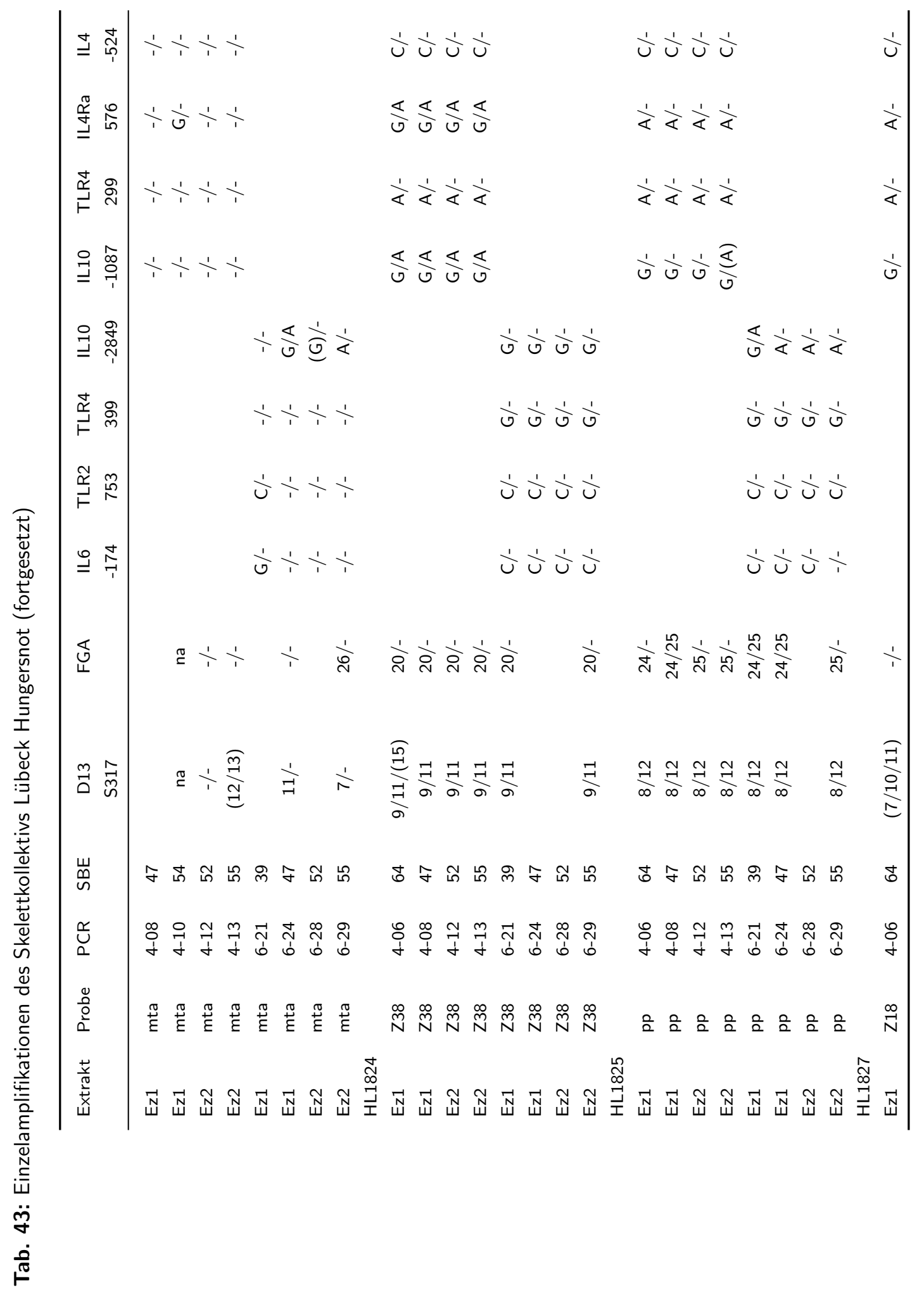




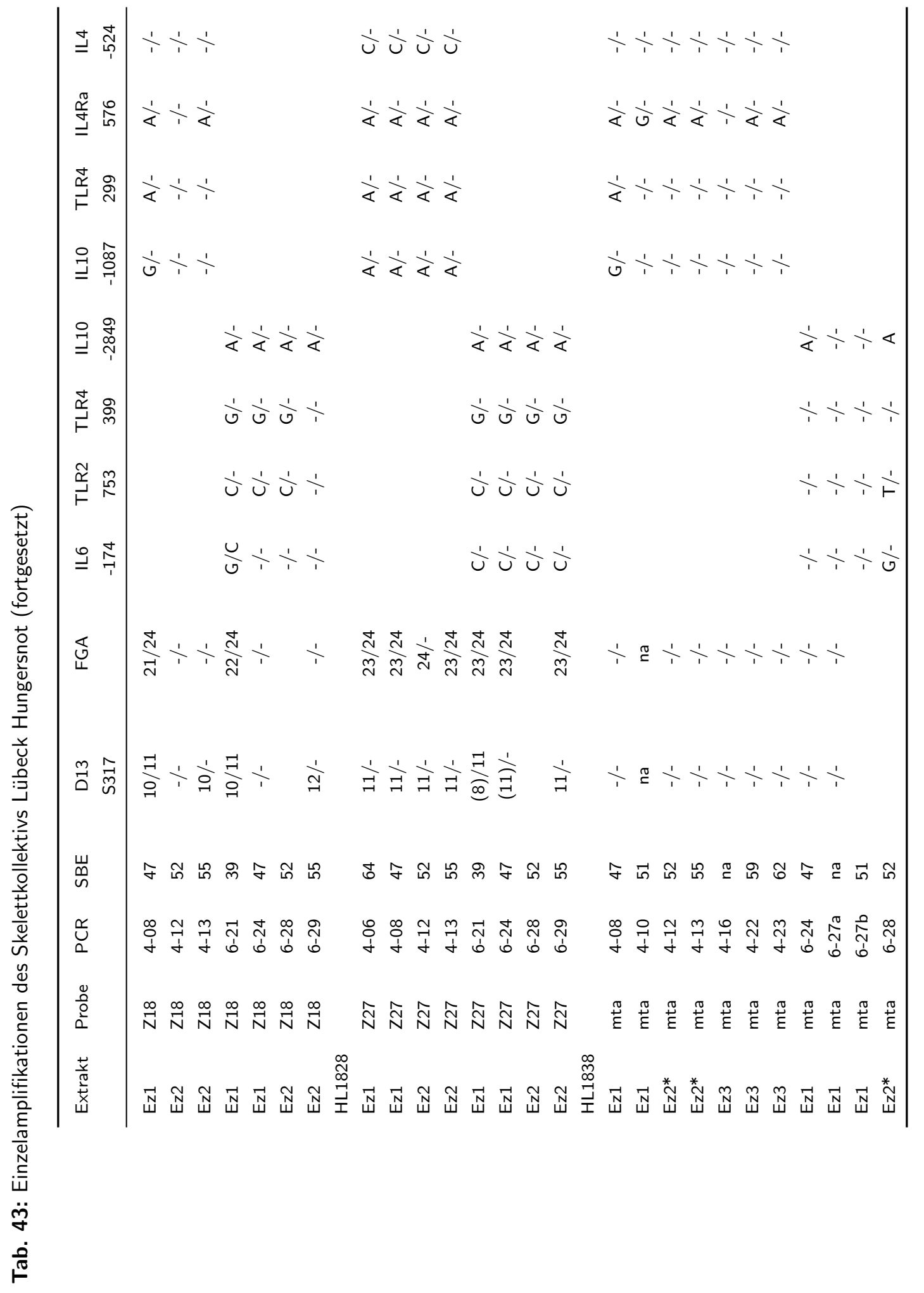




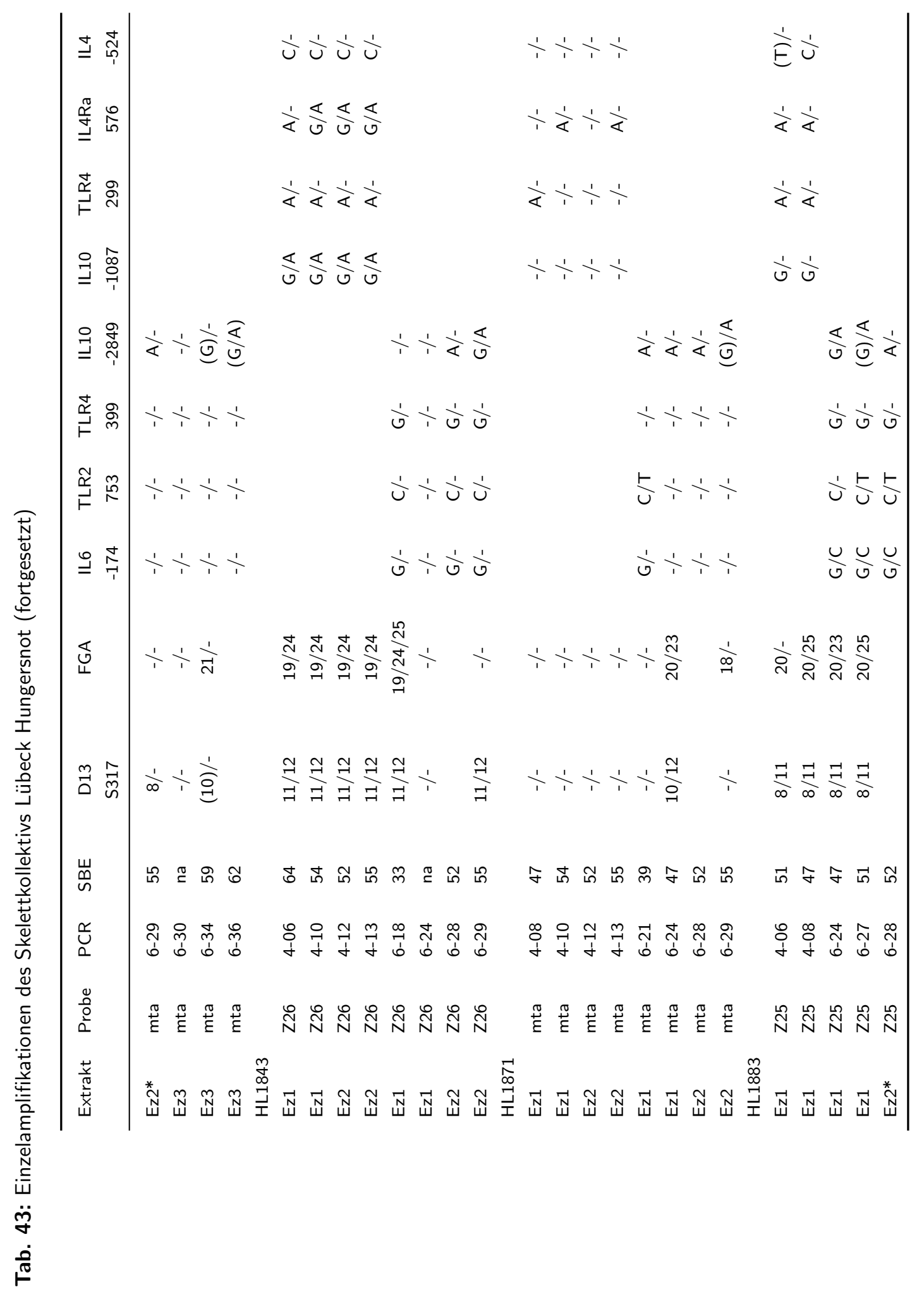




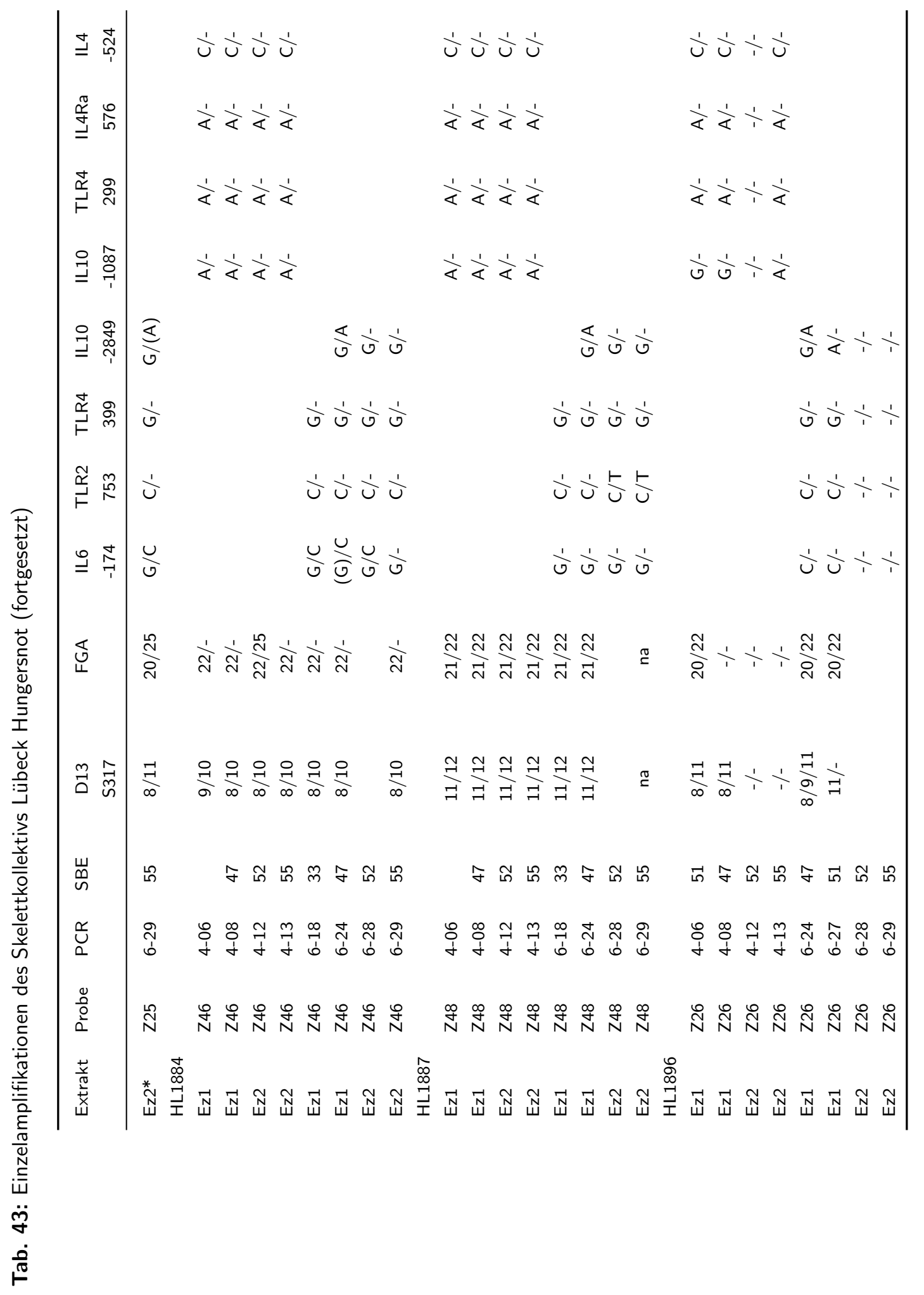




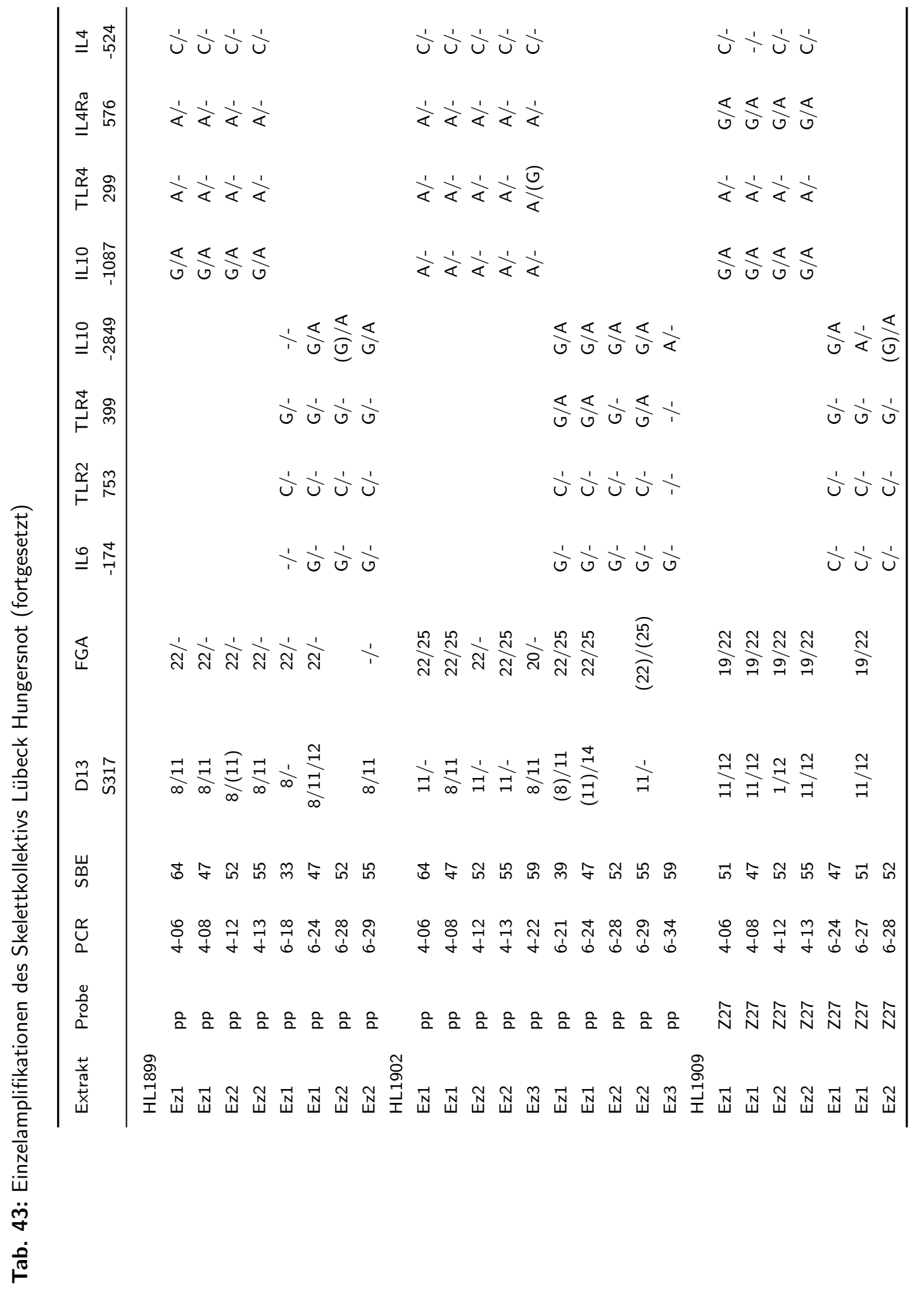




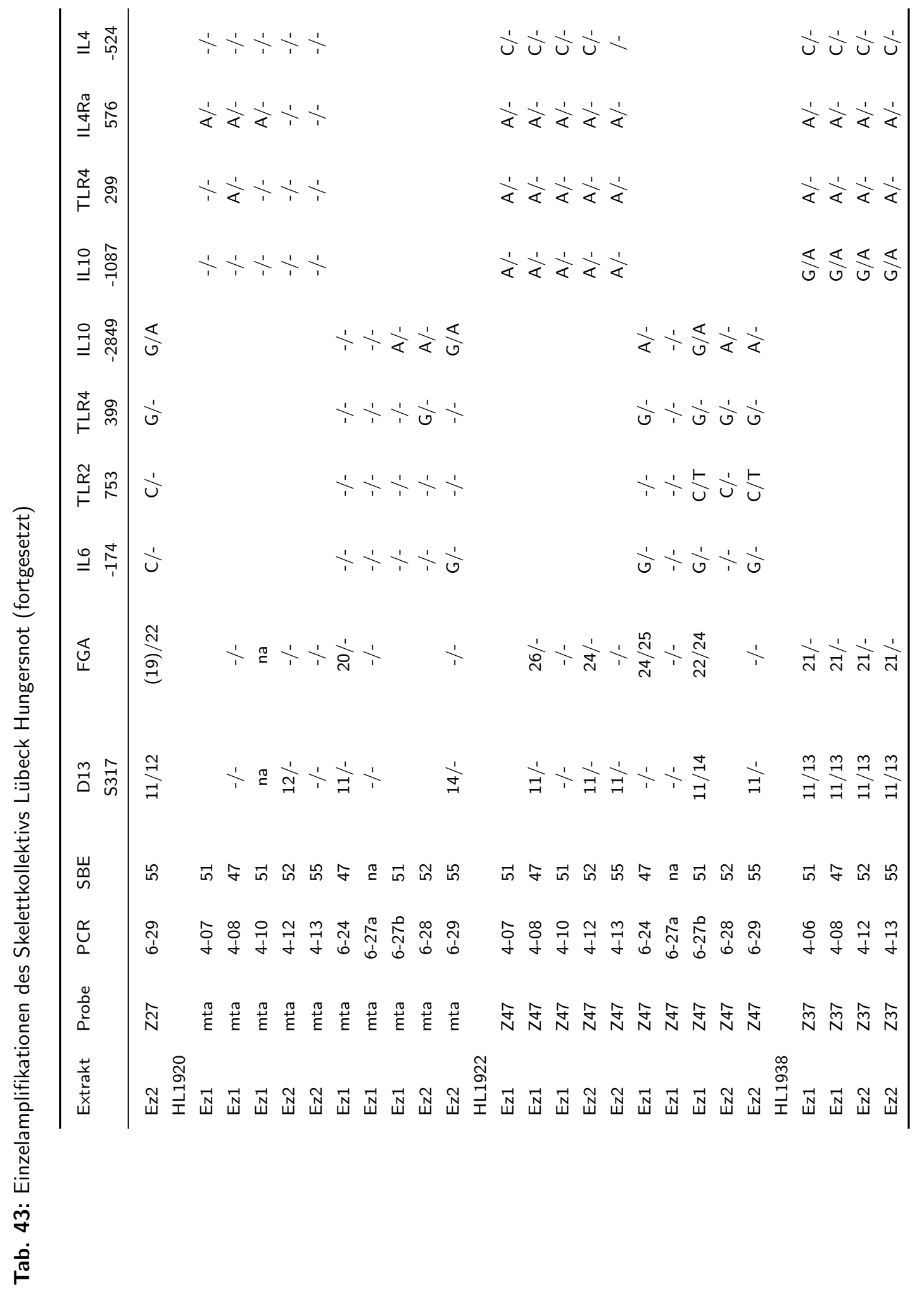




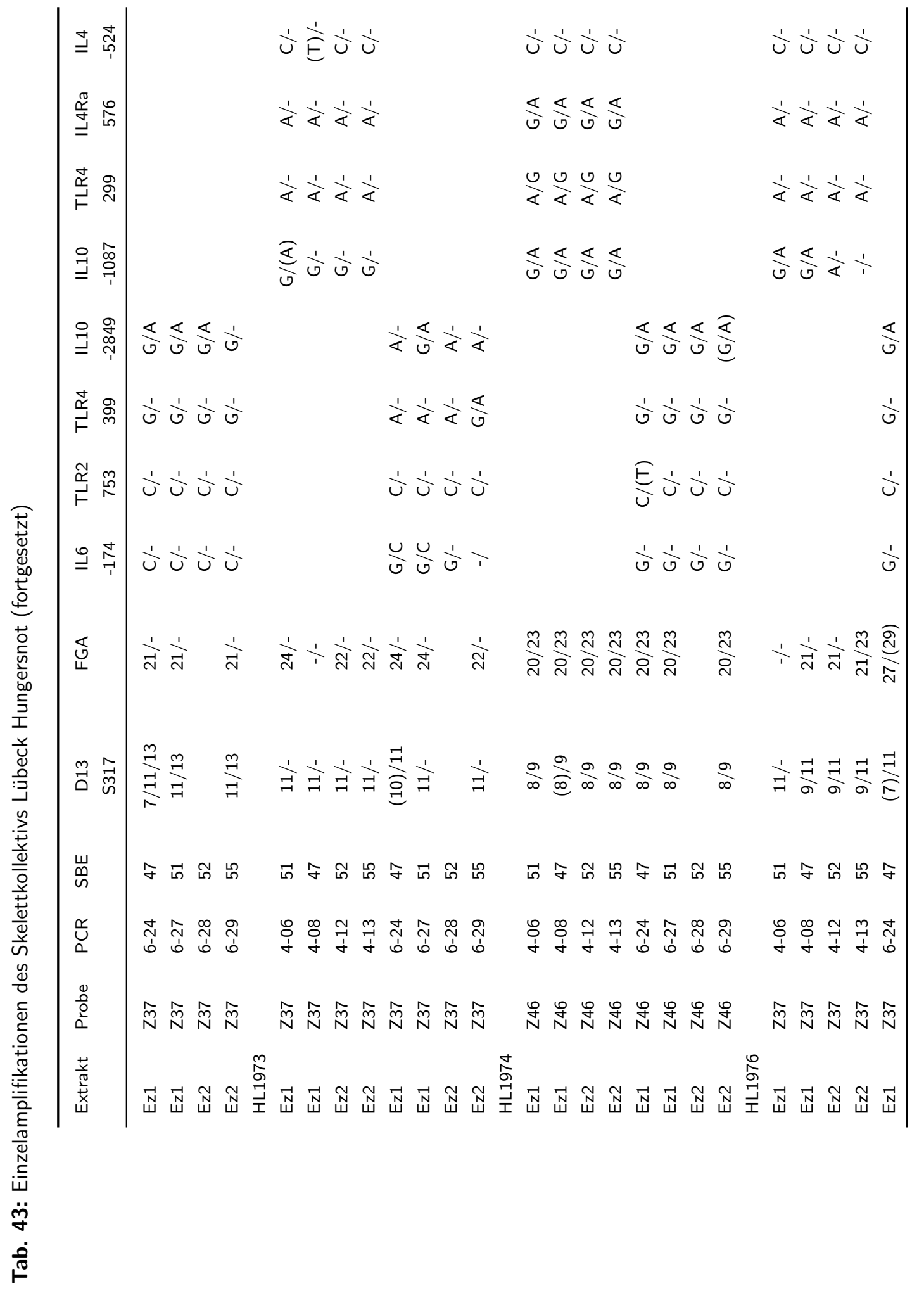




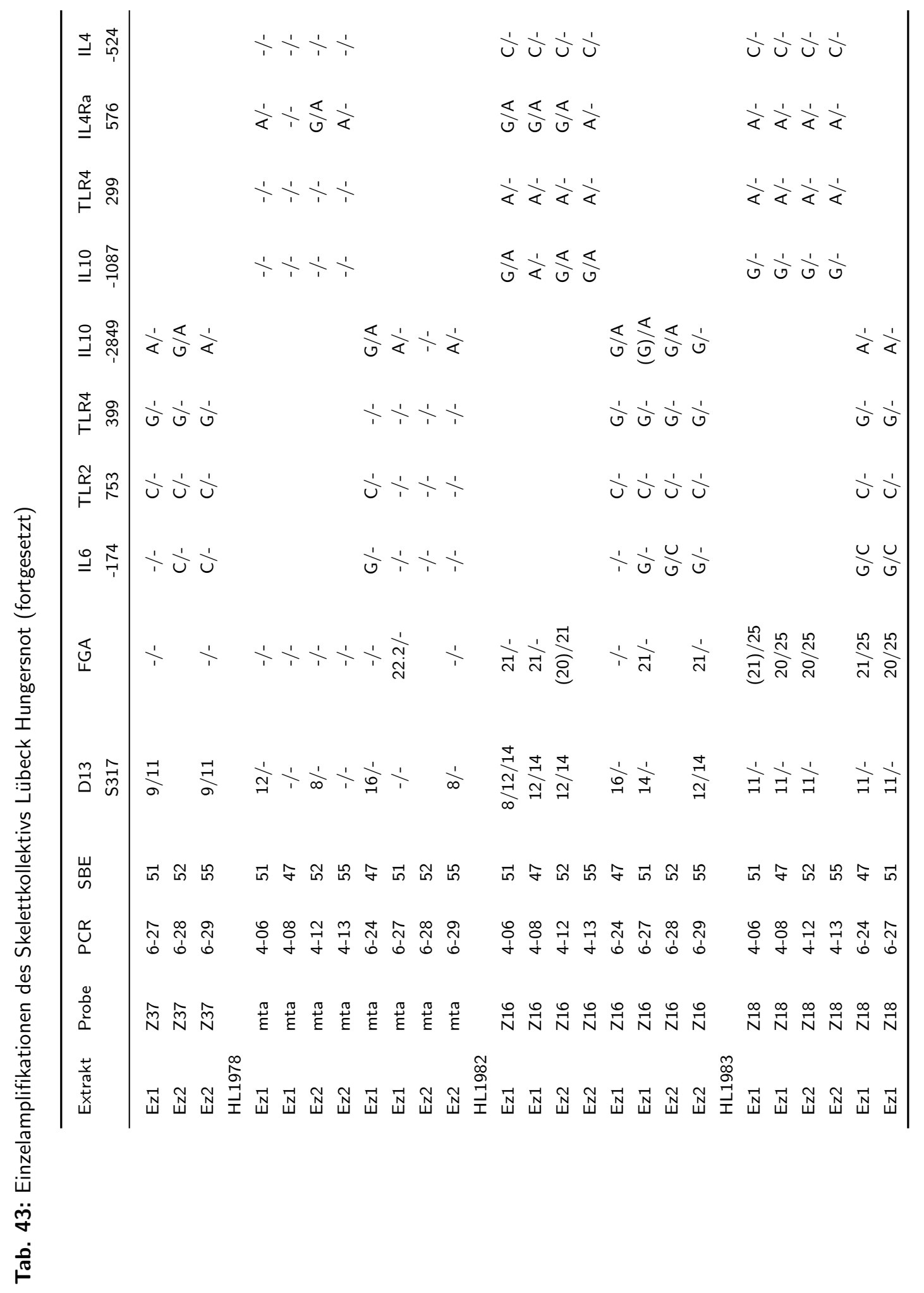




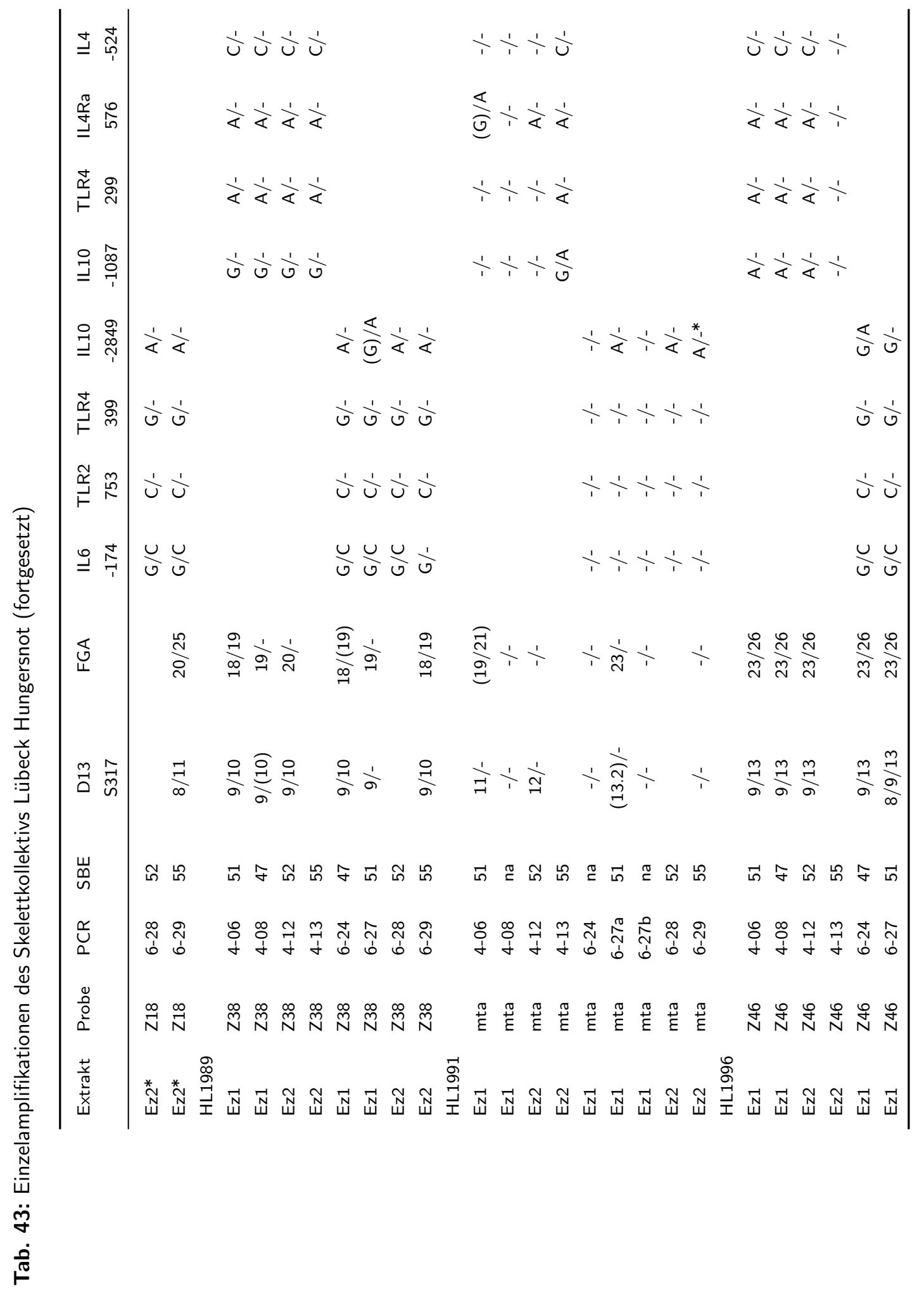




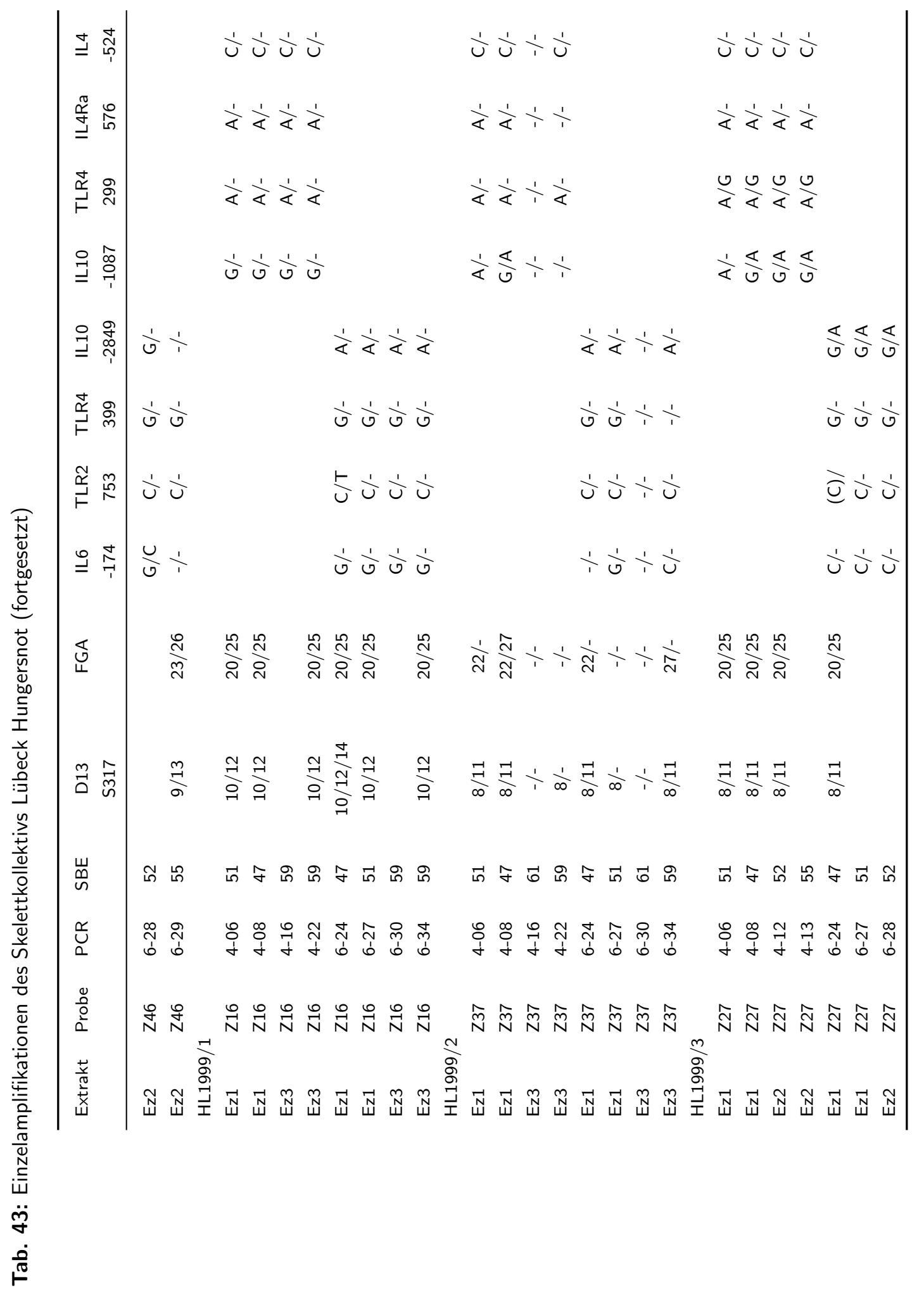




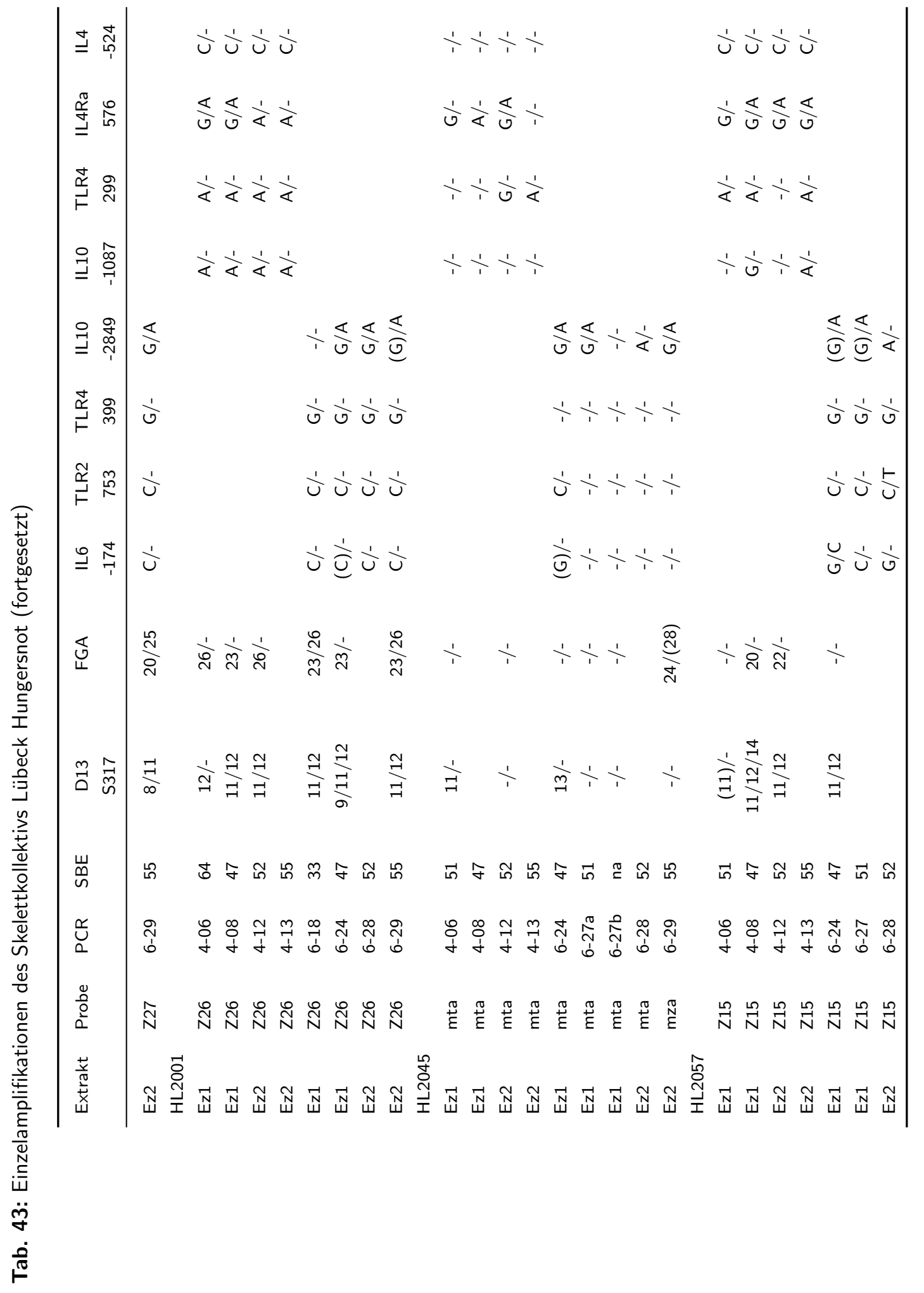




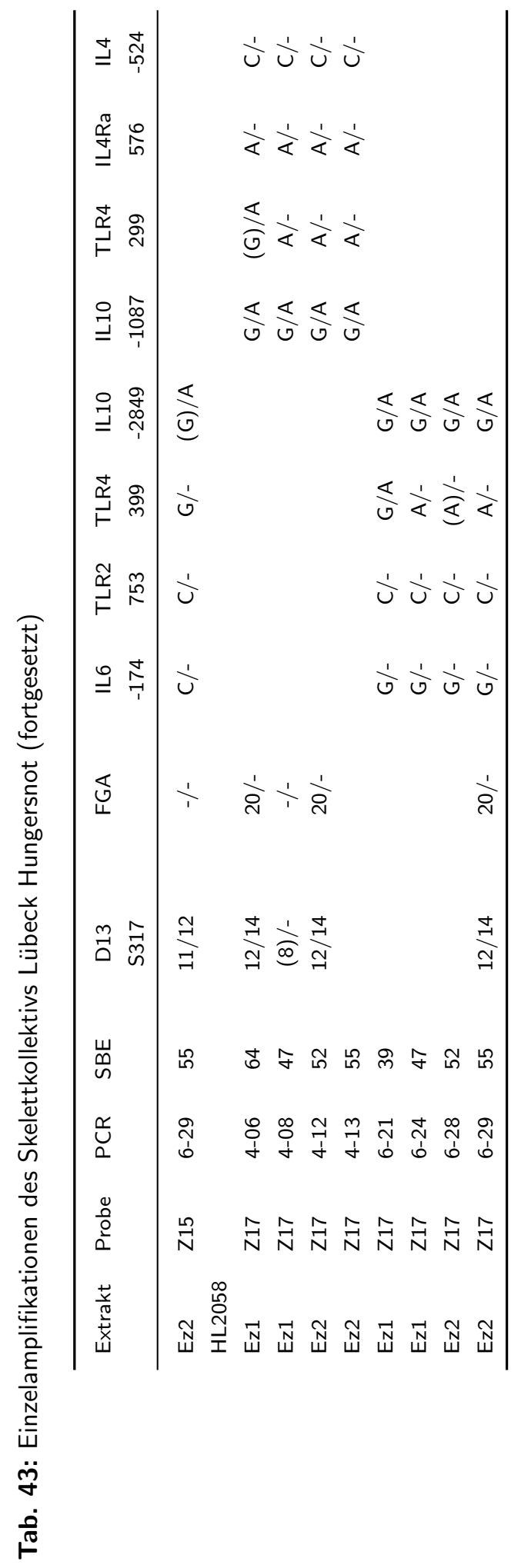




\section{Allelfrequenzen und Häufigkeiten der Genotypen}

Die folgenden Tabellen geben eine detaillierte Übersicht über die Zusammensetzung der Populationen in Allelverteilung und Häufigkeit der Genotypen. 
Tab. 44: Skelettserie HL Pest: Übersicht zu Allelfrequenzen und Genotypverteilung. n:Gesamtzahl typisierter Individuen für Locus; $\sum$ : Summe der Genotypen, -/-: Zahl nicht bestimmbarer Genotypen; $\mathrm{F}_{(N)}$ : Allelfrequenz; $\mathrm{F}_{(N N)}$ Häufigkeit der Genotypen

\begin{tabular}{|c|c|c|c|c|c|c|c|c|c|c|c|}
\hline \multicolumn{2}{|c|}{$\begin{array}{c}\text { IL6 } \\
\text { G-174C }\end{array}$} & \multicolumn{2}{|c|}{$\begin{array}{r}\text { TLR2 } \\
\text { R753Q }\end{array}$} & \multicolumn{2}{|c|}{$\begin{array}{c}\text { TLR4 } \\
\text { D299G }\end{array}$} & \multicolumn{2}{|c|}{$\begin{array}{c}\text { IL10 } \\
\text { G-1082A }\end{array}$} & \multicolumn{2}{|c|}{$\begin{array}{c}\text { IL10 } \\
\text { G-2849A }\end{array}$} & \multicolumn{2}{|c|}{ IL4Ra } \\
\hline \multicolumn{12}{|c|}{ beobachtete Zahl der Genotypen } \\
\hline GG & 26 & GG & 59 & AA & 57 & AA & 11 & $\mathrm{AA}$ & 18 & AA & 44 \\
\hline GC & 33 & GA & 9 & $A G$ & 15 & $A G$ & 41 & AG & 25 & $A G$ & 37 \\
\hline $\mathrm{CC}$ & 8 & AA & 3 & GG & 2 & GG & 17 & GG & 3 & GG & 1 \\
\hline$\sum$ & 67 & & 71 & & 74 & & 69 & & 46 & & 82 \\
\hline$-/-$ & 15 & & 11 & & 8 & & 13 & & 0 & & 0 \\
\hline $\mathrm{n}$ & 82 & & 82 & & 82 & & 82 & & 46 & & 82 \\
\hline \multicolumn{12}{|c|}{ beobachtete Zahl der Allele } \\
\hline G & 85 & G & 127 & $A$ & 129 & $A$ & 63 & $A$ & 61 & A & 125 \\
\hline C & 49 & A & 15 & G & 19 & G & 75 & G & 31 & G & 39 \\
\hline \multicolumn{12}{|c|}{ Allelfrequenz } \\
\hline $\mathrm{F}_{(G)}$ & 0,63 & $\mathrm{~F}_{(G)}$ & 0,89 & $\mathrm{~F}_{(A)}$ & 0,87 & $\mathrm{~F}_{(A)}$ & 0,46 & $\mathrm{~F}_{(A)}$ & 0,66 & $\mathrm{~F}_{(A)}$ & 0,76 \\
\hline $\mathrm{F}_{(C)}$ & 0,37 & $\mathrm{~F}_{(A)}$ & 0,11 & $\mathrm{~F}_{(G)}$ & 0,13 & $\mathrm{~F}_{(G)}$ & 0,54 & $\mathrm{~F}_{(G)}$ & 0,34 & $\mathrm{~F}_{(G)}$ & 0,24 \\
\hline \multicolumn{12}{|c|}{ Häufigkeit der Genotypen } \\
\hline GG & $38,8 \%$ & GG & $83,1 \%$ & $\mathrm{AA}$ & $77,0 \%$ & $\mathrm{AA}$ & $15,9 \%$ & $\mathrm{AA}$ & $39,1 \%$ & $\mathrm{AA}$ & $53,7 \%$ \\
\hline GC & $49,3 \%$ & GA & $12,7 \%$ & GA & $20,3 \%$ & GA & $59,4 \%$ & GA & $54,3 \%$ & GA & $45,1 \%$ \\
\hline $\mathrm{CC}$ & $11,9 \%$ & AA & $4,2 \%$ & GG & $2,7 \%$ & GG & $24,6 \%$ & GG & $6,5 \%$ & GG & $1,2 \%$ \\
\hline
\end{tabular}


Tab. 45: Skelettserie HL Hungersnot: Übersicht zu Allelfrequenzen und Genotypverteilung. n:Gesamtzahl typisierter Individuen für Locus; $\sum$ : Summe der Genotypen, -/-: Zahl nicht bestimmbarer Genotypen; $\mathrm{F}_{(N)}$ : Allelfrequenz; $\mathrm{F}_{(N N)}$ Häufigkeit der Genotypen

\begin{tabular}{|c|c|c|c|c|c|c|c|c|c|c|c|}
\hline \multicolumn{2}{|c|}{$\begin{array}{c}\text { IL6 } \\
\text { G-174C }\end{array}$} & \multicolumn{2}{|c|}{$\begin{array}{r}\text { TLR2 } \\
\text { R753Q }\end{array}$} & \multicolumn{2}{|c|}{$\begin{array}{c}\text { TLR4 } \\
\text { D299G }\end{array}$} & \multicolumn{2}{|c|}{$\begin{array}{c}\text { IL10 } \\
\text { G-1082A }\end{array}$} & \multicolumn{2}{|c|}{$\begin{array}{c}\text { IL10 } \\
\text { G-2849A }\end{array}$} & \multicolumn{2}{|c|}{$\begin{array}{l}\text { IL4Ra } \\
\text { Q576R }\end{array}$} \\
\hline \multicolumn{12}{|c|}{ Genotypen absolut } \\
\hline GG & 16 & GG & 30 & $A A$ & 35 & $A A$ & 8 & $\mathrm{AA}$ & 12 & $A A$ & 26 \\
\hline GC & 13 & GA & 6 & AG & 5 & $A G$ & 19 & AG & 27 & $A G$ & 16 \\
\hline $\mathrm{CC}$ & 10 & AA & 1 & GG & 0 & GG & 9 & GG & 4 & GG & 1 \\
\hline $\mathrm{n}$ & 39 & & 37 & & 40 & & 36 & & 43 & & 43 \\
\hline \multirow[t]{2}{*}{$-/-$} & 4 & & 6 & & 3 & & 7 & & 0 & & 0 \\
\hline & 43 & & 43 & & 43 & & 43 & & 43 & & 43 \\
\hline \multicolumn{12}{|c|}{ Allele absolut } \\
\hline G & 45 & G & 66 & $A$ & 75 & $A$ & 35 & $A$ & 51 & $A$ & 68 \\
\hline C & 33 & $A$ & 8 & G & 5 & G & 37 & G & 35 & G & 18 \\
\hline \multicolumn{12}{|c|}{ Allelfrequenz } \\
\hline $\mathrm{F}_{(G)}$ & 0,58 & $\mathrm{~F}_{(G)}$ & 0,89 & $\mathrm{~F}_{(A)}$ & 0,94 & $\mathrm{~F}_{(A)}$ & 0,49 & $\mathrm{~F}_{(A)}$ & 0,59 & $\mathrm{~F}_{(A)}$ & 0,79 \\
\hline $\mathrm{F}_{(C)}$ & 0,42 & $\mathrm{~F}_{(A)}$ & 0,11 & $\mathrm{~F}_{(G)}$ & 0,06 & $\mathrm{~F}_{(G)}$ & 0,51 & $\mathrm{~F}_{(G)}$ & 0,41 & $\mathrm{~F}_{(G)}$ & 0,21 \\
\hline \multicolumn{12}{|c|}{ Genotypverteilung } \\
\hline GG & $41,0 \%$ & GG & $81,1 \%$ & $\mathrm{AA}$ & $87,5 \%$ & AA & $22,2 \%$ & AA & $27,9 \%$ & AA & $60,5 \%$ \\
\hline GC & $33,3 \%$ & GA & $16,2 \%$ & GA & $12,5 \%$ & GA & $52,8 \%$ & GA & $62,8 \%$ & GA & $37,2 \%$ \\
\hline $\mathrm{CC}$ & $25,6 \%$ & $A A$ & $2,7 \%$ & GG & $0,0 \%$ & GG & $25,0 \%$ & GG & $9,3 \%$ & GG & $2,3 \%$ \\
\hline
\end{tabular}


Tab. 46: Skelettserie Do: Übersicht zu Allelfrequenzen und Genotypverteilung. n:Gesamtzahl typisierter Individuen für Locus; $\sum$ : Summe der Genotypen, -/-: Zahl nicht bestimmbarer Genotypen; $\mathrm{F}_{(N)}$ : Allelfrequenz; $\mathrm{F}_{(N N)}$ Häufigkeit der Genotypen

\begin{tabular}{|c|c|c|c|c|c|c|c|c|c|c|c|}
\hline \multicolumn{2}{|c|}{$\begin{array}{c}\text { IL6 } \\
\text { G-174C }\end{array}$} & \multicolumn{2}{|c|}{$\begin{array}{r}\text { TLR2 } \\
\text { R753Q }\end{array}$} & \multicolumn{2}{|c|}{$\begin{array}{c}\text { TLR4 } \\
\text { D299G }\end{array}$} & \multicolumn{2}{|c|}{$\begin{array}{c}\text { IL10 } \\
\text { G-1082A }\end{array}$} & \multicolumn{2}{|c|}{$\begin{array}{c}\text { IL10 } \\
\text { G-2849A }\end{array}$} & \multicolumn{2}{|c|}{$\begin{array}{l}\text { IL4Ra } \\
\text { Q576R }\end{array}$} \\
\hline \multicolumn{12}{|c|}{ beobachtete Zahl der Genotypen } \\
\hline GG & 4 & GG & 18 & AA & 17 & AA & 7 & $\mathrm{AA}$ & 5 & AA & 11 \\
\hline GC & 9 & GA & 3 & $A G$ & 2 & AG & 6 & AG & 17 & AG & 10 \\
\hline $\mathrm{CC}$ & 4 & AA & 0 & GG & 1 & GG & 4 & GG & 4 & GG & 1 \\
\hline$\sum$ & 17 & & 21 & & 20 & & 17 & & 23 & & 22 \\
\hline$-/-$ & 6 & & 2 & & 3 & & 6 & & 0 & & 1 \\
\hline $\mathrm{n}$ & 23 & & 23 & & 23 & & 23 & & 23 & & 23 \\
\hline \multicolumn{12}{|c|}{ beobachtete Zahl der Allele } \\
\hline G & 17 & G & 39 & $A$ & 36 & $A$ & 20 & A & 27 & A & 32 \\
\hline C & 17 & A & 3 & G & 4 & G & 14 & G & 19 & G & 12 \\
\hline \multicolumn{12}{|c|}{ Allelfrequenz } \\
\hline $\mathrm{F}_{(G)}$ & 0,50 & $\mathrm{~F}_{(G)}$ & 0,93 & $\mathrm{~F}_{(A)}$ & 0,90 & $\mathrm{~F}_{(A)}$ & 0,59 & $\mathrm{~F}_{(A)}$ & 0,59 & $\mathrm{~F}_{(A)}$ & 0,73 \\
\hline $\mathrm{F}_{(C)}$ & 0,50 & $\mathrm{~F}_{(A)}$ & 0,07 & $\mathrm{~F}_{(G)}$ & 0,10 & $\mathrm{~F}_{(G)}$ & 0,41 & $\mathrm{~F}_{(G)}$ & 0,41 & $\mathrm{~F}_{(G)}$ & 0,27 \\
\hline \multicolumn{12}{|c|}{ Häufigkeit der Genotypen } \\
\hline GG & $23,5 \%$ & GG & $85,7 \%$ & $\mathrm{AA}$ & $85,0 \%$ & $\mathrm{AA}$ & $41,2 \%$ & $\mathrm{AA}$ & $21,7 \%$ & $\mathrm{AA}$ & $50,0 \%$ \\
\hline GC & $52,9 \%$ & GA & $14,3 \%$ & GA & $10,0 \%$ & GA & $35,3 \%$ & GA & $73,9 \%$ & GA & $45,5 \%$ \\
\hline $\mathrm{CC}$ & $23,5 \%$ & AA & $0,0 \%$ & GG & $5,0 \%$ & GG & $23,5 \%$ & GG & $4,3 \%$ & GG & $4,5 \%$ \\
\hline
\end{tabular}




\section{Ergebnisse der Einzelamplifikationen des genetischen Fingerabdrucks}

Auf den folgenden Seiten finden sich die Übersichtstabellen der einzelnen Amplifikationen, die der Bestimmung des genetischen Fingerabdrucks zugrunde liegen. 


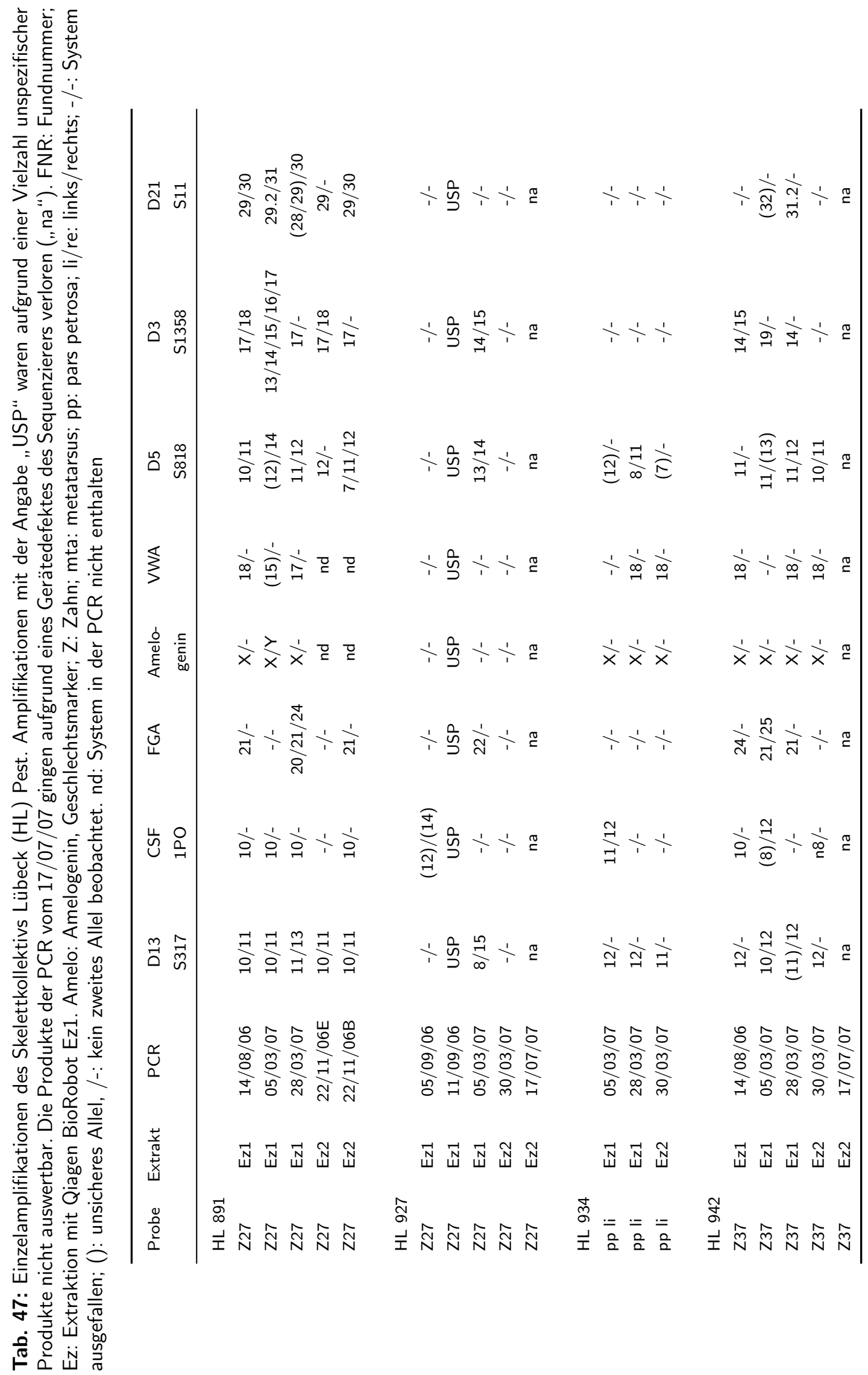




\begin{tabular}{|c|c|c|c|c|c|}
\hline$\vec{N} \vec{n}$ & $\frac{1}{\vec{m}} \stackrel{0}{=}+$ & $+\frac{1}{\stackrel{1}{m}}+$ & $\frac{1}{1}+\frac{1}{1}+\frac{1}{\infty}$ & $+\underset{m}{\stackrel{\frac{1}{m}}{\vec{m}}+\frac{1}{\longrightarrow}}$ & 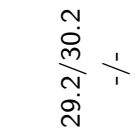 \\
\hline 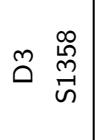 & $\stackrel{0}{1} \stackrel{1}{1}$ & 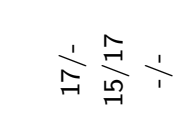 & 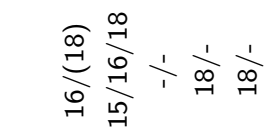 & 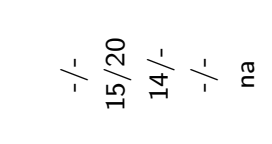 & $\frac{1}{0} \frac{1}{0}$ \\
\hline 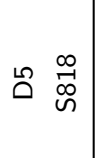 & 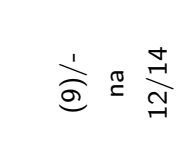 & 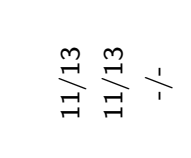 & 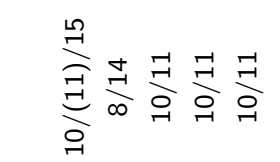 & 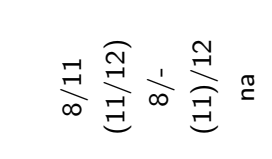 & 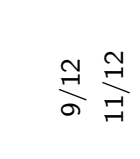 \\
\hline$\xi_{3}^{\pi}$ & $\stackrel{1}{\Gamma} \stackrel{1}{=}$ & 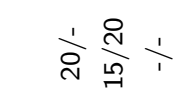 & $\frac{1}{1}+\frac{1}{\hat{~}}$ & $\frac{1}{0}+\frac{1}{1}+\frac{1}{0} \stackrel{0}{=}$ & 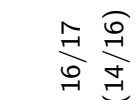 \\
\hline 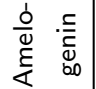 & $+\stackrel{0}{\perp} \frac{1}{1}$ & $\frac{1}{x} \frac{1}{x} \frac{1}{1}$ & $\stackrel{1}{\prime} \frac{1}{x} \frac{1}{x} \frac{1}{1}+\frac{1}{1}$ & $\frac{1}{x} \frac{1}{x}+\frac{1}{x} \stackrel{0}{x}$ & $\frac{1}{x} \frac{1}{x}$ \\
\hline 过 & $+\stackrel{0}{=}$ & $\underset{\text { Iิ }}{\vec{N}} \stackrel{\vec{N}}{\Omega}+$ & 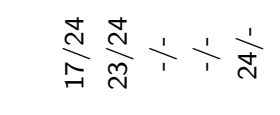 & $\frac{1}{\dot{A}}+\frac{1}{\dot{d}} \stackrel{0}{=}$ & $\stackrel{\stackrel{\llcorner}{N}}{\stackrel{\sim}{े}}+$ \\
\hline 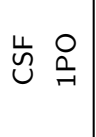 & $+\stackrel{0}{1} \stackrel{1}{0}$ & 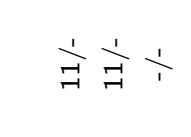 & 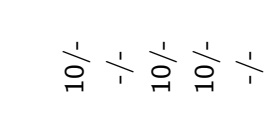 & $\stackrel{1}{+}+\frac{1}{1} \stackrel{0}{=}$ & 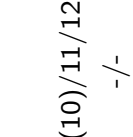 \\
\hline$\stackrel{m}{\vec{n}}$ & $+\stackrel{0}{=} \frac{1}{\Rightarrow}$ & 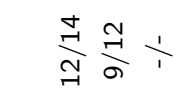 & 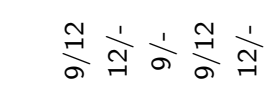 & 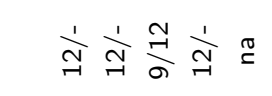 & $\underset{\infty}{\stackrel{\vec{E}}{\vec{F}}} \underset{\infty}{\vec{\sigma}}$ \\
\hline ֻ̛ & 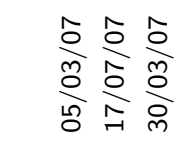 & 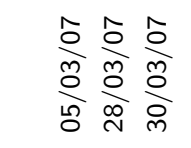 & 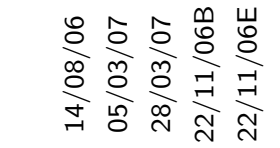 & 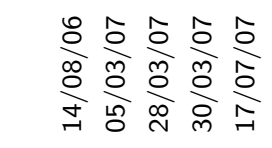 & 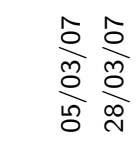 \\
\hline 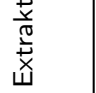 & $\vec{\Psi}$ บี & N $\vec{N} \underset{N}{N}$ & $\vec{N} \vec{N} \vec{N} \underset{\uplus}{N}$ & 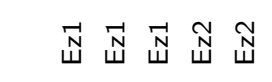 & 氙 \\
\hline 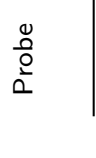 & 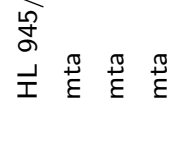 & $\begin{array}{l}\stackrel{\infty}{\Omega} \\
\stackrel{\infty}{I} \stackrel{\infty}{N} \stackrel{\infty}{N} \stackrel{\infty}{N}\end{array}$ & 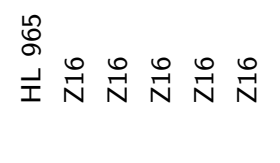 & 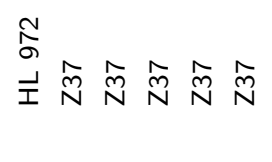 & 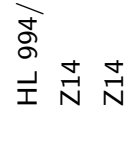 \\
\hline
\end{tabular}




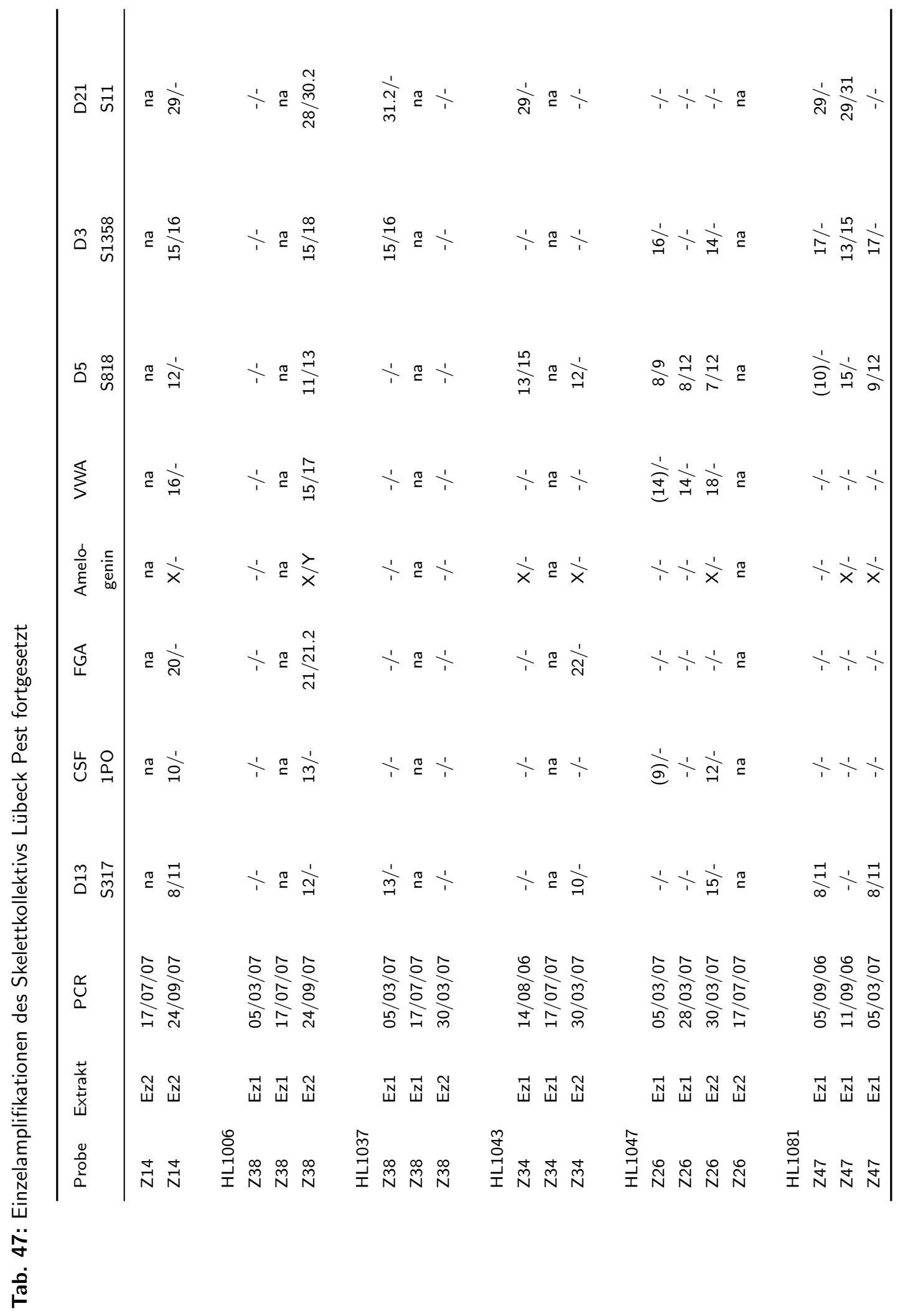




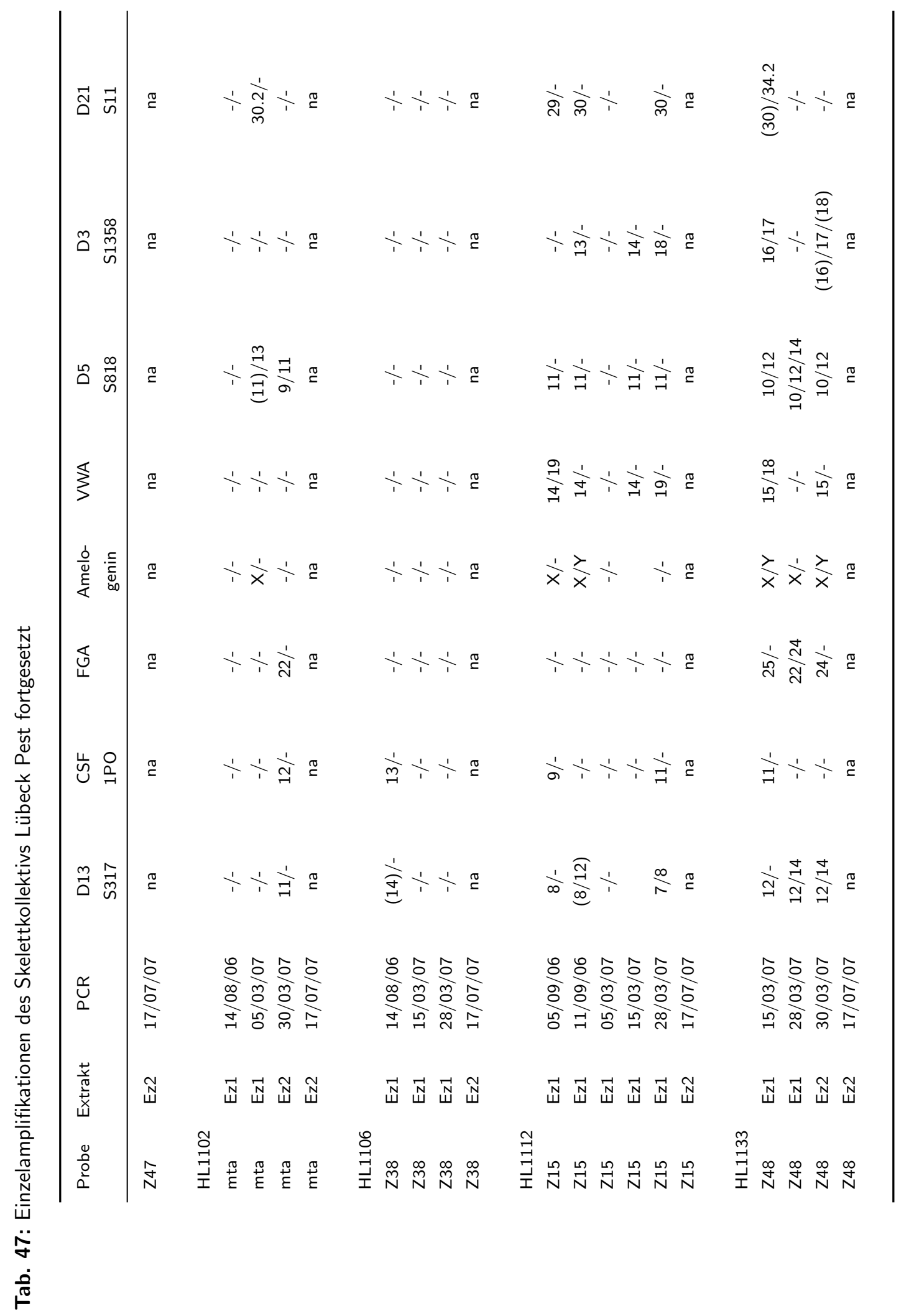




\begin{tabular}{|c|c|c|c|c|c|}
\hline $\overrightarrow{\tilde{D}} \vec{\sim}$ & 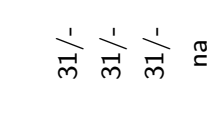 & 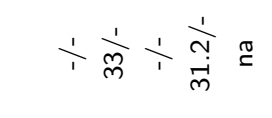 & 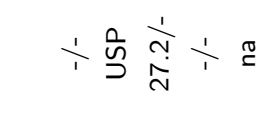 & $\stackrel{n}{1}$ & 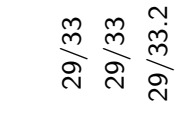 \\
\hline 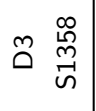 & 学总点 & $\stackrel{1}{+}+\frac{1}{1} \stackrel{0}{=}$ & $+\stackrel{n}{\stackrel{\text { I }}{\Xi}}+\stackrel{0}{=}$ & 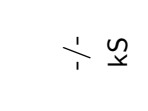 & 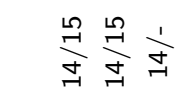 \\
\hline 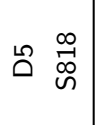 & 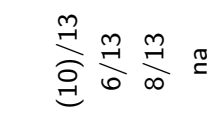 & 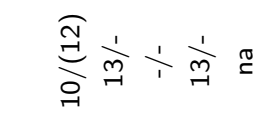 & 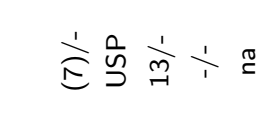 & $\stackrel{n}{1}$ & $\stackrel{1}{\Rightarrow} \frac{1}{\sigma} \frac{\text { I }}{\Rightarrow}$ \\
\hline$\xi_{3}^{\pi}$ & 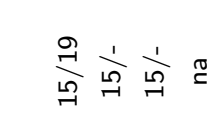 & 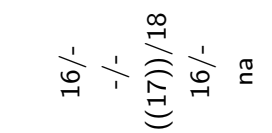 & $+\stackrel{n}{n}+\frac{0}{5}$ & $+\underline{\varphi}$ & 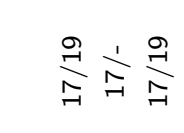 \\
\hline 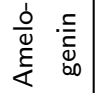 & $\underset{x}{>} \frac{\nu}{x} \underset{x}{x} \stackrel{0}{=}$ & $\frac{1}{x} \frac{1}{x} \frac{1}{x} \div \stackrel{0}{x}$ & 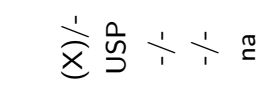 & $\div \underline{\varphi}$ & $\frac{1}{1} \geq \frac{z}{x}$ \\
\hline 过 & 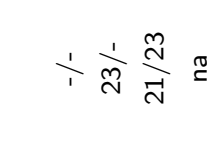 & 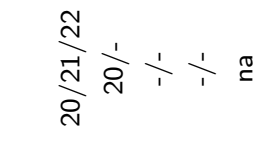 & $\stackrel{n}{n} \div \stackrel{0}{=}$ & $\stackrel{n}{1}$ & $\frac{\text { ลิ }}{3} \frac{1}{9}$ \\
\hline 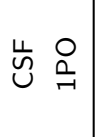 & 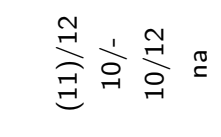 & $\stackrel{1}{\stackrel{1}{Y}} \div \stackrel{0}{=}$ & $\stackrel{n}{n} \div \stackrel{0}{=}$ & $+\underset{x}{1}$ & 皇 \\
\hline$\stackrel{m}{\overrightarrow{0}} \overrightarrow{\hat{n}}$ & $\underset{\infty}{\mathbb{Z}} \underset{\infty}{\mathbb{N}} \frac{\mathbb{T}}{\infty} \stackrel{0}{=}$ & 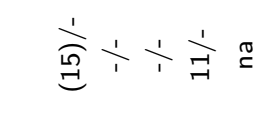 & $+\frac{n}{n}+\frac{1}{1}$ & $+\underset{x}{1}$ & $\frac{\overrightarrow{1}}{\sigma} \frac{\overrightarrow{1}}{\sigma} \frac{1}{\sigma}$ \\
\hline 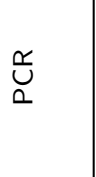 & 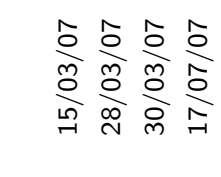 & 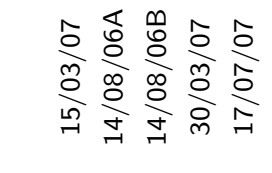 & 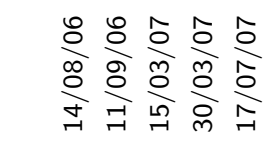 & 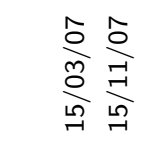 & 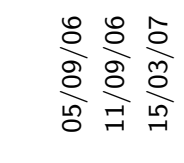 \\
\hline 离 & 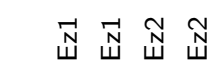 & $\vec{N} \vec{N} \vec{N} \mathbb{N}$ & 氙氙芯出 & 氙 & Ш艹 \\
\hline $\begin{array}{l}0 \\
\stackrel{2}{0} \\
0 \\
0\end{array}$ & 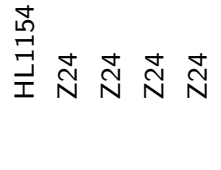 & 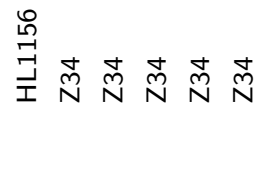 & 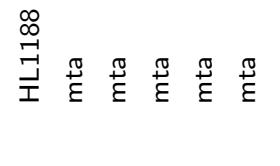 & 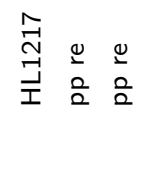 & $\stackrel{\vec{I}}{\vec{I}} \hat{N} \hat{N}$ \\
\hline
\end{tabular}




\begin{tabular}{|c|c|c|c|c|c|}
\hline $\overrightarrow{\text { ปี }}$ & बे & 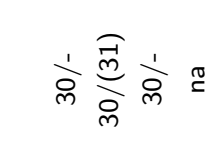 & 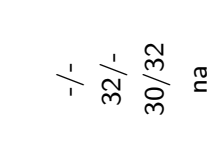 & 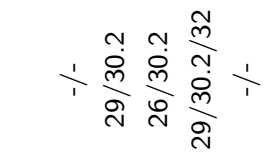 & 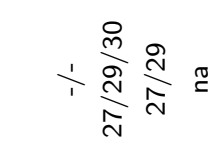 \\
\hline 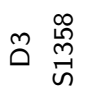 & 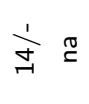 & 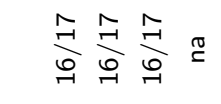 & 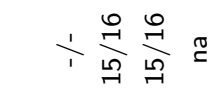 & 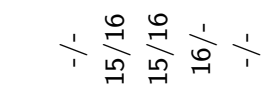 & $+\frac{1}{1}+\frac{0}{0}$ \\
\hline 卯 & 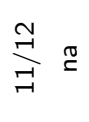 & 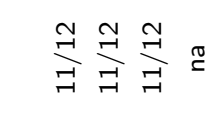 & 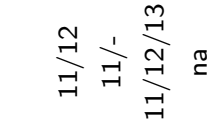 & 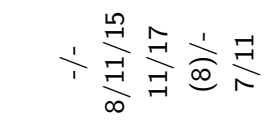 & 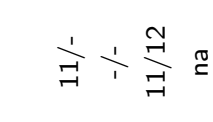 \\
\hline$\sum_{3}^{\$}$ & $\underset{\overbrace{}}{\stackrel{2}{ }} \stackrel{0}{\simeq}$ & 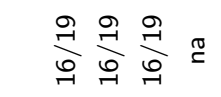 & $\stackrel{\infty}{\stackrel{\infty}{\rightarrow}} \stackrel{\infty}{\stackrel{\infty}{0}} \frac{1}{0} \stackrel{0}{0}$ & 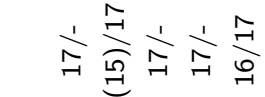 & 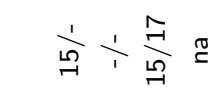 \\
\hline 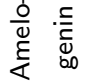 & $\frac{1}{x} \stackrel{0}{x}$ & $\frac{1}{x} \frac{1}{x} \frac{1}{x} \stackrel{0}{=}$ & $\underset{x}{x}>\grave{x} \times \stackrel{0}{x}$ & 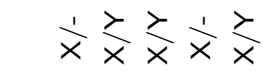 & $\dot{z} \frac{1}{x} \grave{x}_{x} \stackrel{0}{=}$ \\
\hline 志 & $+\stackrel{0}{=}$ & 空 & $\frac{1}{\stackrel{N}{N}} \frac{1}{N} \div \stackrel{0}{=}$ & 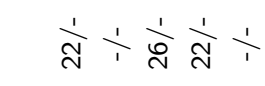 & $\frac{1}{1}+\frac{\pi}{\sqrt{2}} \stackrel{0}{=}$ \\
\hline 岕 인 & $\stackrel{0}{=}$ & 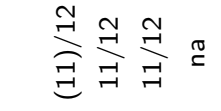 & $+\frac{1}{1}+\frac{0}{=}$ & 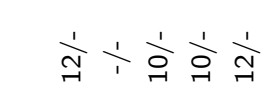 & $\stackrel{1}{1} \stackrel{1}{\frac{1}{y}} \stackrel{0}{=}$ \\
\hline$\stackrel{m}{\overrightarrow{0}} \overrightarrow{\tilde{n}}$ & $\stackrel{\overrightarrow{1}}{\sigma} \stackrel{0}{=}$ & 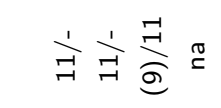 & 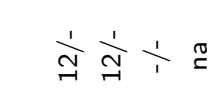 & 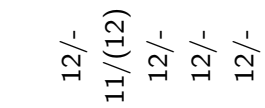 & $\underset{\infty}{\frac{N}{\infty}} \frac{1}{\sigma} \stackrel{+}{\frac{d}{\infty}} \stackrel{0}{=}$ \\
\hline 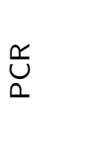 & 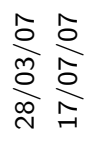 & 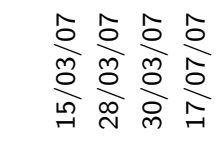 & 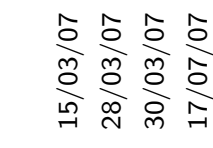 & 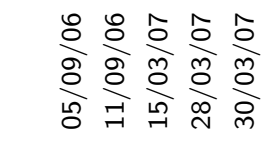 & 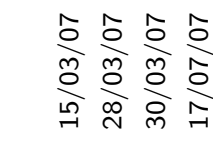 \\
\hline 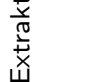 & $\stackrel{N}{\mathbb{N}}$ & $\vec{N} \underset{N}{\mathbb{N}}$ & 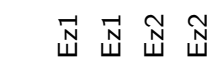 & 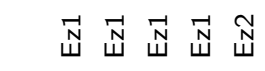 & $\vec{N} \stackrel{N}{\mathbb{N}} \underset{N}{\mathbb{N}}$ \\
\hline $\begin{array}{l}0 \\
\stackrel{0}{0} \\
\frac{0}{2}\end{array}$ & $\hat{N} \hat{N}$ & $\stackrel{\stackrel{\sim}{N}}{\vec{I}} \stackrel{N}{N} \stackrel{N}{N} \stackrel{N}{N}$ & $\underset{\mathbb{N}}{\stackrel{N}{N}} \stackrel{⿱}{N} \underset{N}{N} \stackrel{ \pm}{N}$ & 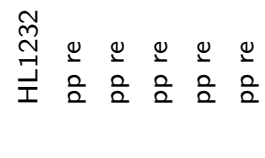 & 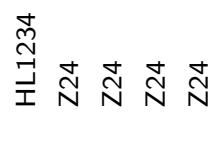 \\
\hline
\end{tabular}




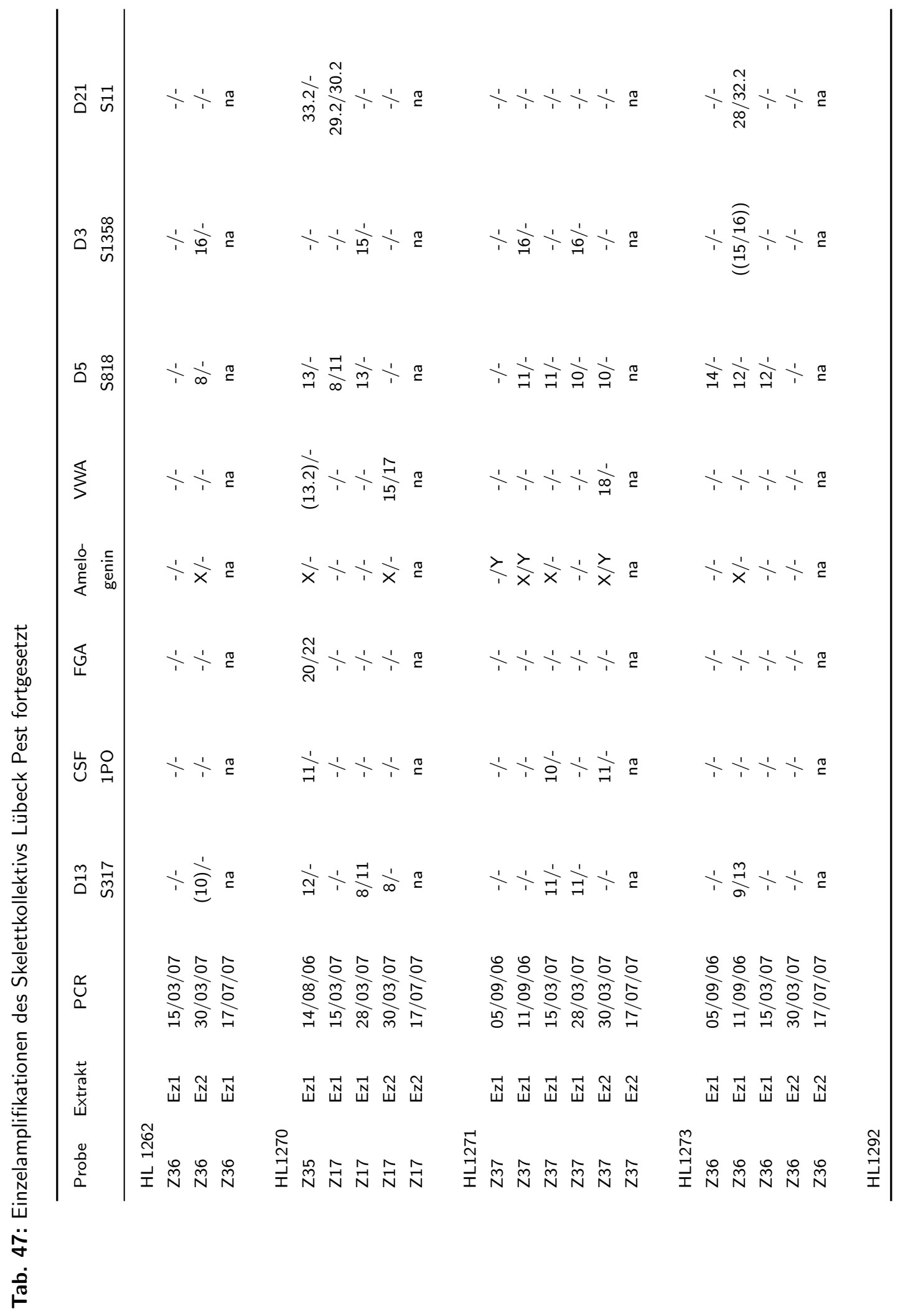




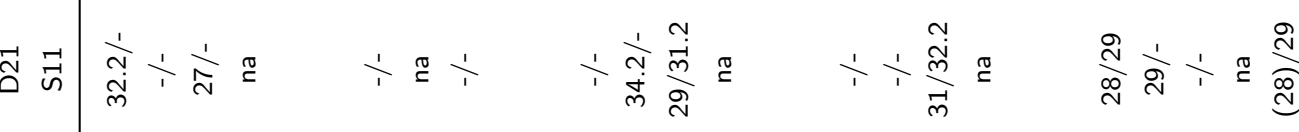

m

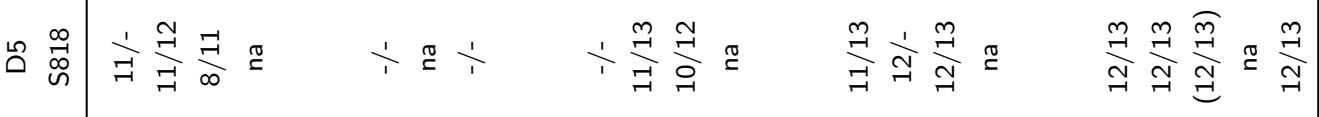

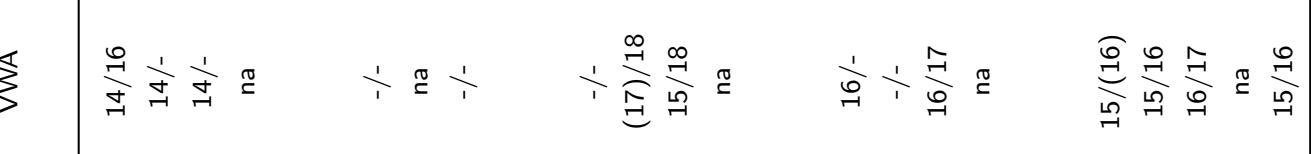

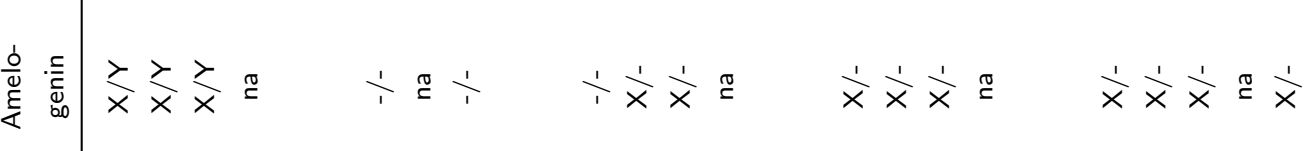

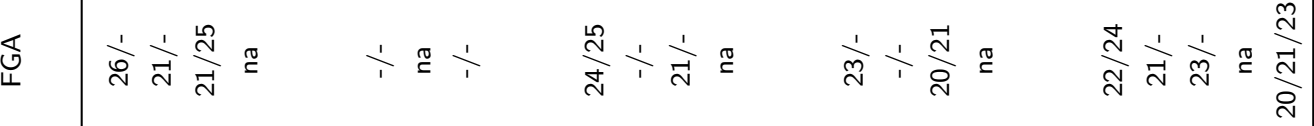

药

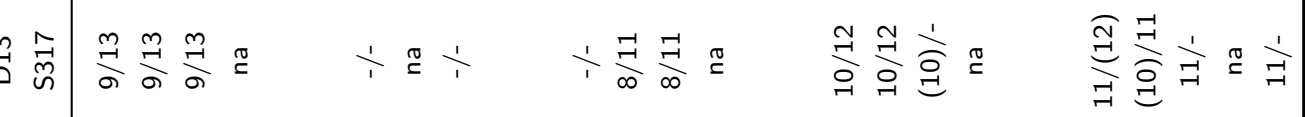

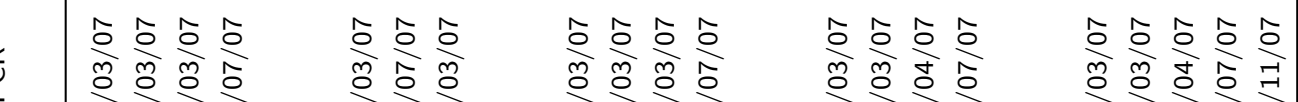

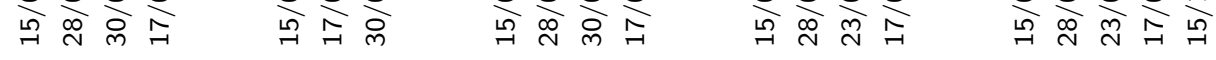

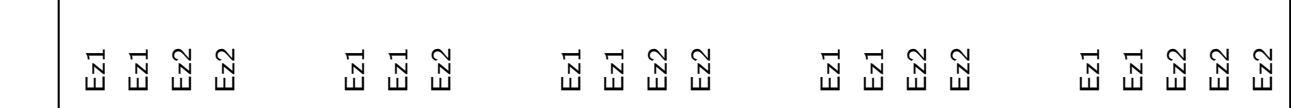

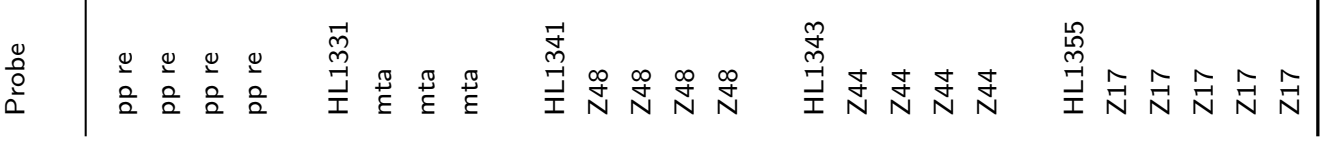




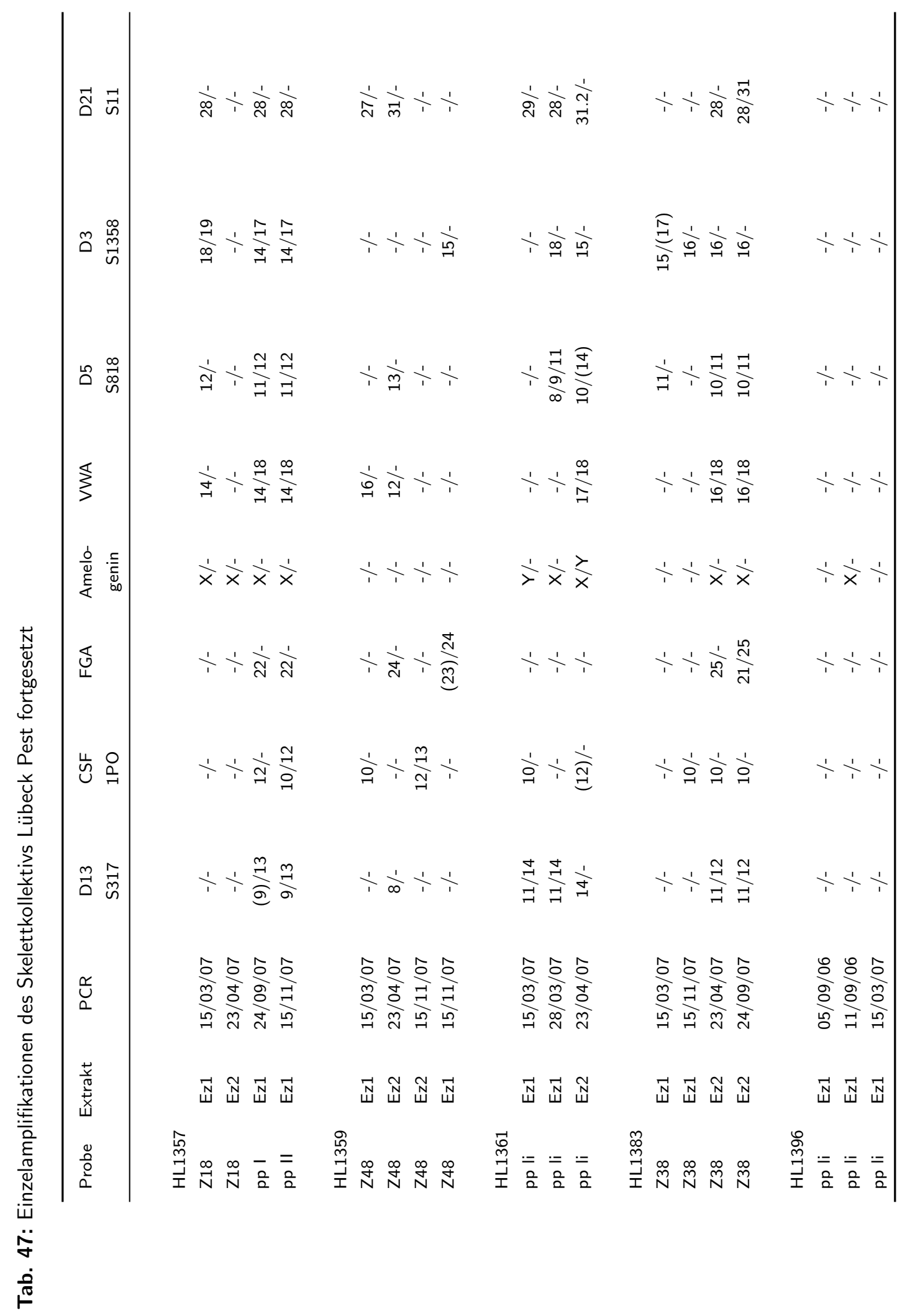




\begin{tabular}{|c|c|c|c|c|c|c|c|}
\hline$\vec{n} \vec{n}$ & $\stackrel{1}{1}$ & 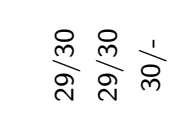 & $\frac{1}{1}$ & के & $+\div \frac{\tilde{m}}{\stackrel{m}{m}}$ & 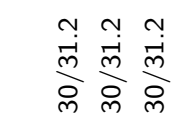 & $\stackrel{\infty}{\sim}$ \\
\hline 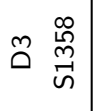 & $\stackrel{1}{+}$ & 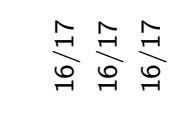 & $\div \div$ & 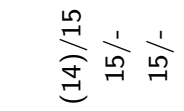 & $\div \div \frac{0}{1}$ & 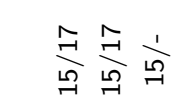 & 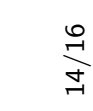 \\
\hline 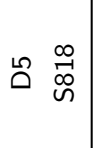 & $\stackrel{1}{+}$ & $\frac{a}{\infty} \underset{\frac{a}{\sigma}}{\stackrel{\frac{m}{\sigma}}{\stackrel{\sigma}{\sigma}}}$ & $\stackrel{1}{m} \div$ & $\underset{m}{\frac{1}{m}} \frac{1}{m} \underset{\sim}{\stackrel{m}{i}}$ & 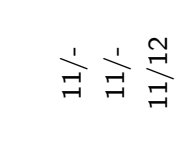 & $\stackrel{1}{\Rightarrow} \vec{y}$ & $\underset{ }{\stackrel{ }{ }}$ \\
\hline 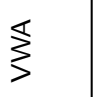 & $\stackrel{1}{i}$ & 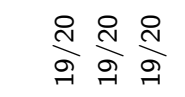 & $\frac{1}{1}$ & 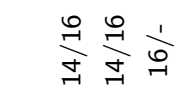 & $\div \frac{1}{1}$ & 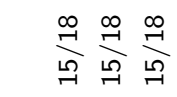 & $\stackrel{\infty}{\stackrel{\infty}{I}}$ \\
\hline 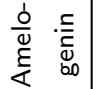 & $\stackrel{+}{i}$ & $z_{x}>\bar{x}$ & $\frac{1}{2} \div$ & $\frac{1}{x} \frac{1}{x} \frac{1}{x}$ & $+\frac{z}{x}$ & $\frac{1}{x} \frac{1}{x} \frac{\bar{x}}{x}$ & $\frac{1}{x}$ \\
\hline 㜽 & $\stackrel{1}{1}$ & 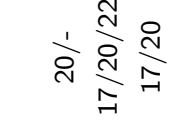 & $\frac{1}{1}$ & $\stackrel{1}{\grave{2}} \div \frac{1}{1}$ & $\frac{1}{\grave{N}} \div \frac{\stackrel{n}{\Omega}}{9}$ & $\frac{1}{\vec{d}} \frac{1}{\grave{d}}$ & $\frac{\text { d }}{\text { d }}$ \\
\hline $\begin{array}{ll}\frac{u}{0} & 0 \\
& 0 \\
-1\end{array}$ & $\stackrel{1}{i}$ & 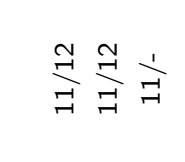 & $\div$ & 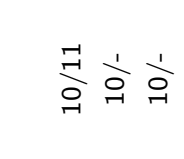 & $\frac{1}{1} \frac{1}{1}$ & 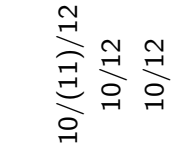 & 官 \\
\hline $\begin{array}{ll}m & \hat{n} \\
0 & \vec{n}\end{array}$ & $\stackrel{1}{i}$ & $\underset{\infty}{\vec{I}} \frac{1}{\infty} \frac{\vec{I}}{\infty}$ & $\frac{1}{1}$ & 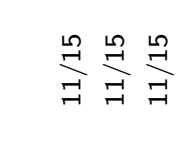 & 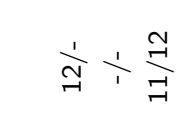 & ${\underset{\infty}{\vec{I}}}_{\infty}^{\vec{d}} \underset{\infty}{\overrightarrow{1}} \frac{\vec{I}}{\infty}$ & $\stackrel{\text { I }}{-1}$ \\
\hline 胥 & $\frac{\hat{o}}{\frac{0}{\partial}}$ & 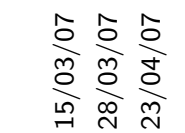 & 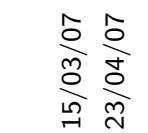 & 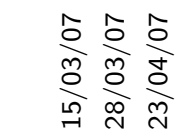 & 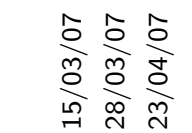 & 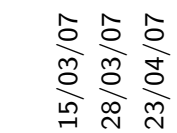 & 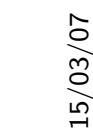 \\
\hline 童 & N & تี & $\vec{N} \tilde{N}$ & $\vec{N} \mathbb{W}$ & $\overrightarrow{\tilde{W}} \vec{N}$ & $\overrightarrow{\mathcal{W}} \overrightarrow{\tilde{N}}$ & $\vec{N}$ \\
\hline 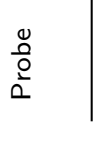 & $=$ & 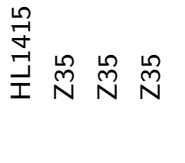 & 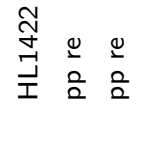 & 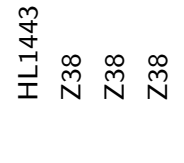 & $\stackrel{g}{\stackrel{g}{I}} \underset{N}{\mathbb{N}} \stackrel{d}{N}$ & 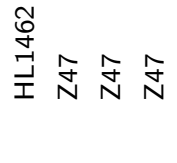 & 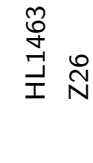 \\
\hline
\end{tabular}




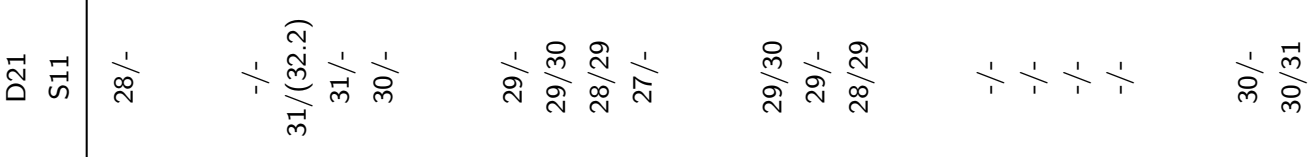

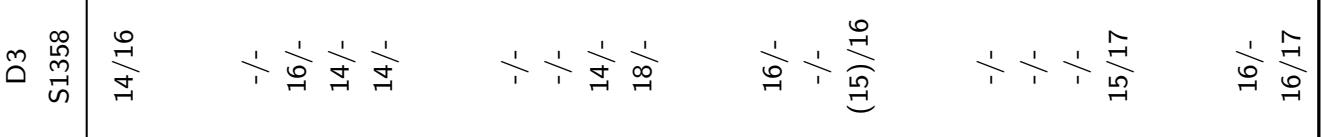

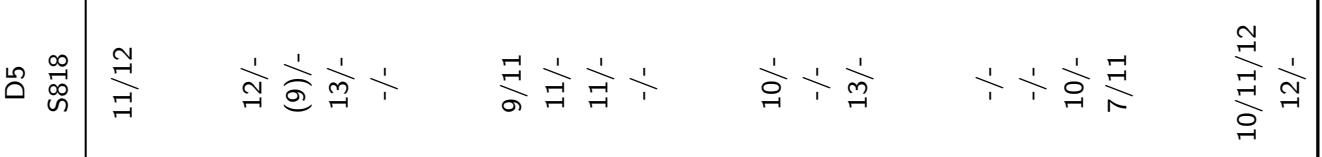

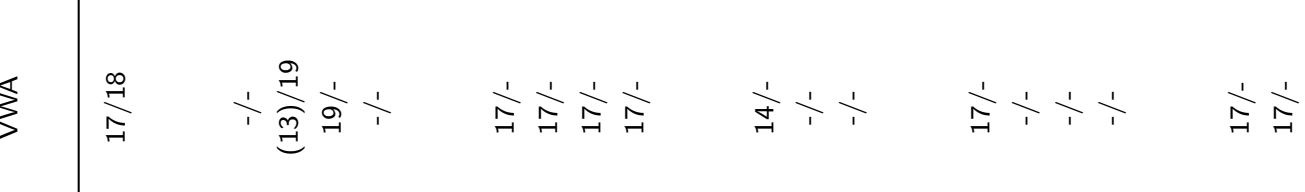

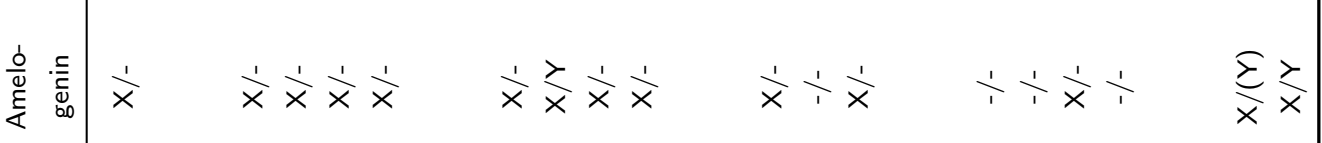

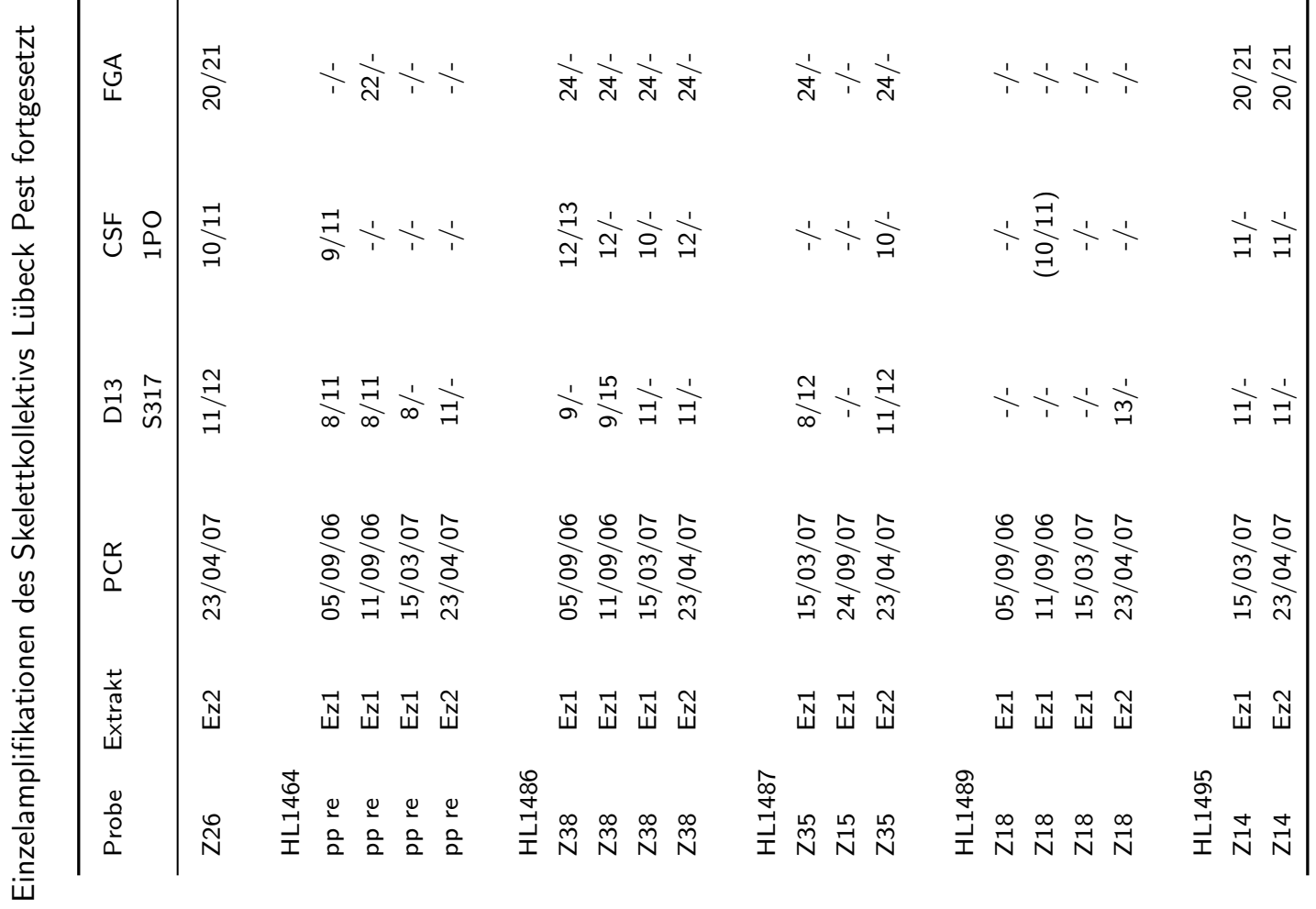




\begin{tabular}{|c|c|c|c|c|c|c|}
\hline $\overrightarrow{\text { ปे }}$ & 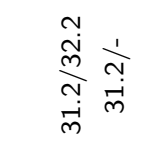 & 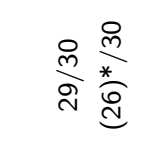 & 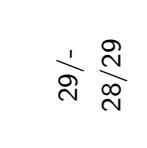 & 商 & $\stackrel{i}{\perp} \stackrel{1}{\perp} \div$ & 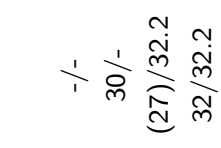 \\
\hline 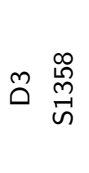 & 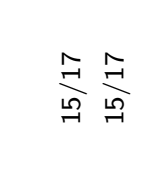 & 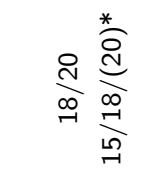 & 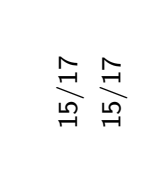 & $\stackrel{1}{\stackrel{y}{\vec{J}}}$ & $\perp \stackrel{n}{s}+\frac{1}{\supset}$ & 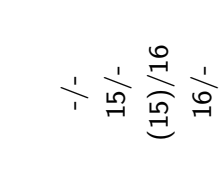 \\
\hline$\stackrel{\llcorner}{\circ} \underset{\infty}{\infty}$ & $\stackrel{1}{\vec{y}} \frac{1}{\xi}$ & 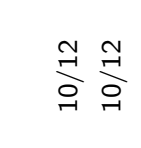 & 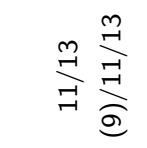 & $\underset{\exists}{\stackrel{I}{I} \underset{ন}{\overparen{I}}}$ & $+\frac{\hat{n}}{\partial} \stackrel{1}{\prime}$ & $\stackrel{1}{m}+\underbrace{\stackrel{\infty}{=}}_{\vec{m}} \underset{\infty}{\stackrel{m}{\infty}}$ \\
\hline 3 & 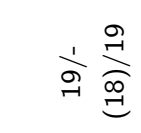 & $\stackrel{\text { 공 }}{\stackrel{1}{\Xi}}$ & 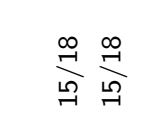 & 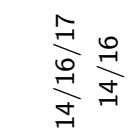 & 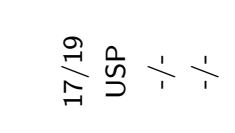 & 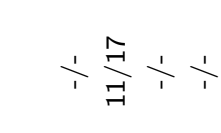 \\
\hline 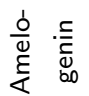 & $\frac{1}{x} \frac{1}{x}$ & $\frac{1}{x} \frac{1}{x}$ & $\frac{1}{x} \frac{1}{x}$ & $\frac{z}{x}$ & $\frac{\dot{n}}{x} \stackrel{\frac{1}{x}}{x}$ & $+\frac{\sum}{x} \frac{1}{x}+$ \\
\hline 芯 & $\frac{\sqrt{N}}{\vec{\lambda}} \frac{1}{\sqrt{n}}$ & สิ่ & $\frac{\pi}{\sqrt{n}} \frac{\pi}{\sqrt{n}}$ & $\frac{1}{\text { ปิ }}+$ & $+\frac{n}{n} \div \stackrel{1}{\infty}$ & 1 $\frac{1}{\vec{N}} \stackrel{\stackrel{N}{N}}{N}_{\text {1 }}^{1}$ \\
\hline 岂 운 & $\underset{F}{\stackrel{ }{7} \underset{7}{\mathcal{F}}}$ & $\underset{7}{\vec{y}} \underset{-}{\mathcal{I}}$ & $\vec{y}$ & $\underset{ }{\stackrel{1}{\Im}}$ & $+\stackrel{n}{n} \stackrel{1}{\circ}+$ & $\stackrel{1}{+} \div \frac{1}{\circ}$ \\
\hline$\stackrel{m}{\overrightarrow{0}} \stackrel{\tilde{n}}{n}$ & $\underset{0}{\overrightarrow{1}} \frac{1}{0}$ & $\underset{0}{\overrightarrow{1}} \underset{0}{\vec{I}}$ & $\underset{\infty}{\stackrel{ }{*}} \frac{\overrightarrow{1}}{\infty}$ & 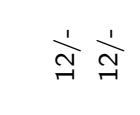 & $+\frac{n}{n} \stackrel{1}{\Rightarrow}+$ & 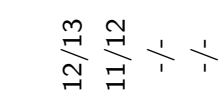 \\
\hline 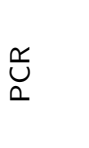 & 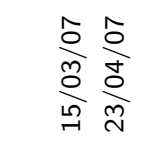 & 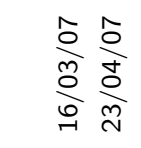 & 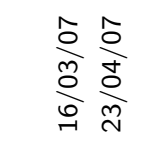 & 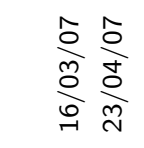 & 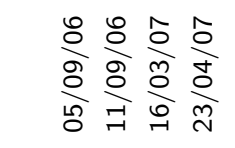 & 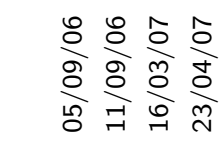 \\
\hline 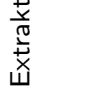 & $\vec{N} \underset{\amalg}{\mathbb{N}}$ & $\vec{N} \underset{N}{ }$ & บี & $\vec{N} \underset{N}{\mathbb{N}}$ & $\vec{W}$ 胥 $\vec{N}$ & $\vec{N} \vec{N} \vec{N} \underset{W}{N}$ \\
\hline 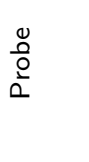 & 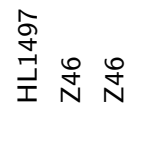 & 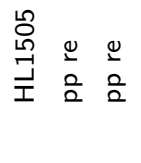 & 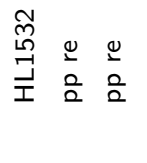 & 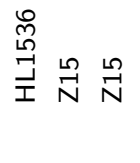 & 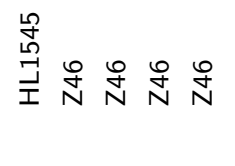 & 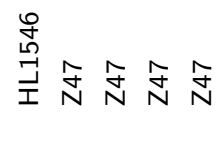 \\
\hline
\end{tabular}




\begin{tabular}{|c|c|c|c|c|c|}
\hline $\overrightarrow{\tilde{D}} \vec{\sim}$ & 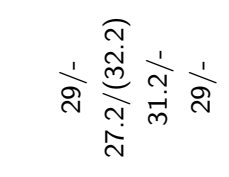 & 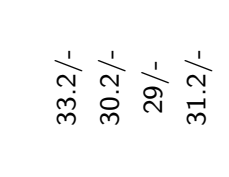 & 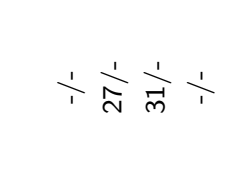 & 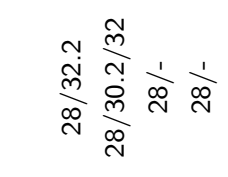 & 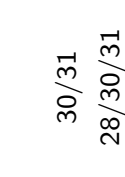 \\
\hline 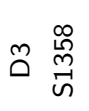 & 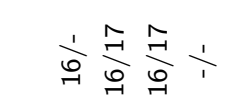 & 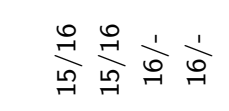 & $\frac{1}{0} \frac{1}{0} \div \frac{1}{1}+1$ & 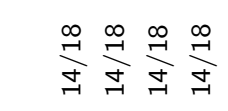 & के \\
\hline 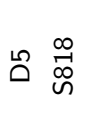 & 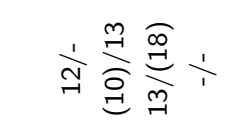 & $\underset{\Im}{1}+\frac{1}{\Im}$ & 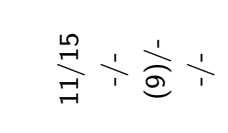 & & $\Rightarrow \stackrel{0}{\Rightarrow}$ \\
\hline$\xi$ & 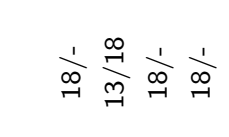 & 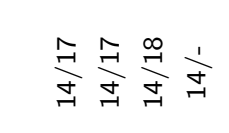 & 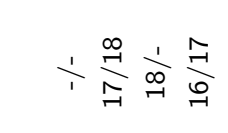 & 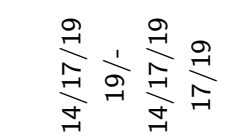 & $\underset{\text { J }}{\sqrt{7}}+$ \\
\hline 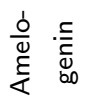 & $\frac{1}{x} \frac{1}{x} \frac{\varepsilon}{x} \frac{1}{x}$ & $\frac{1}{x} \frac{1}{x} \frac{1}{x} \frac{1}{x}$ & $\frac{1}{x} \frac{1}{x} \frac{1}{x}$ & $\underset{x}{>} \frac{\succ}{x} \frac{\nu}{x} \frac{1}{>}$ & $\frac{z}{x} \frac{1}{x}$ \\
\hline 芯 & $\underset{N}{\vec{N}} \frac{1}{\sigma} \underset{न}{\stackrel{N}{g}} \frac{\vec{N}}{\sigma}$ & 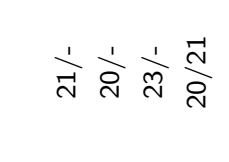 & 离突守 & 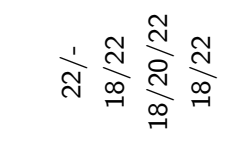 & 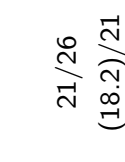 \\
\hline 讪 & 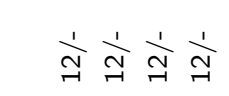 & $+\frac{\widehat{a}}{a}+\frac{1}{\sigma}$ & 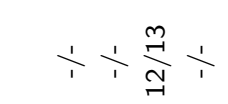 & 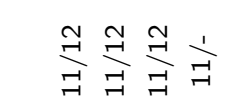 & 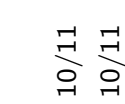 \\
\hline$\stackrel{m}{a} \stackrel{\tilde{n}}{\Delta}$ & 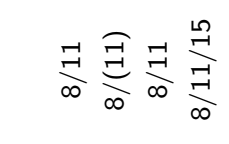 & 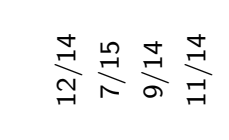 & $\frac{1}{\infty} \frac{\infty}{\wedge} \frac{1}{\infty} \frac{1}{\infty}$ & 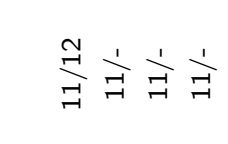 & $\underset{ }{\mathcal{I}} \underset{7}{\stackrel{7}{7}}$ \\
\hline 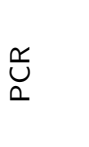 & 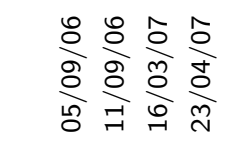 & 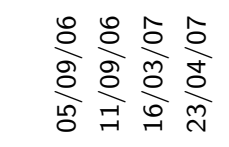 & 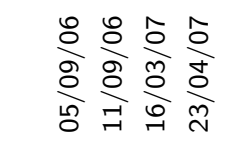 & 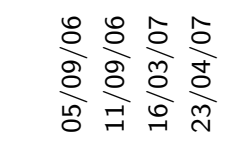 & $\begin{array}{ll}8 & 0 \\
0 & 8 \\
0 & 0 \\
0 & 0 \\
0 & =\end{array}$ \\
\hline 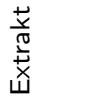 & 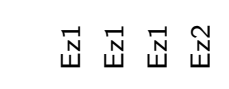 & $\vec{W} \underset{N}{\mathbb{N}} \vec{N}$ & $\vec{W} \underset{W}{\mathbb{N}} \vec{N}$ & 岀氙芯 & $\vec{N}$ \\
\hline $\begin{array}{l}0 \\
\stackrel{0}{0} \\
\stackrel{0}{0}\end{array}$ & 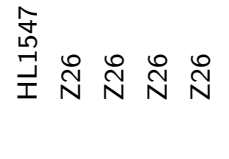 & 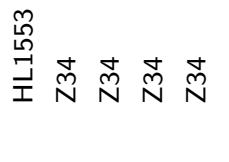 & 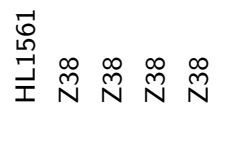 & 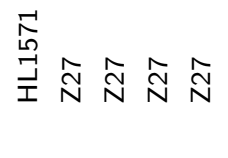 & 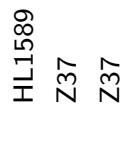 \\
\hline
\end{tabular}




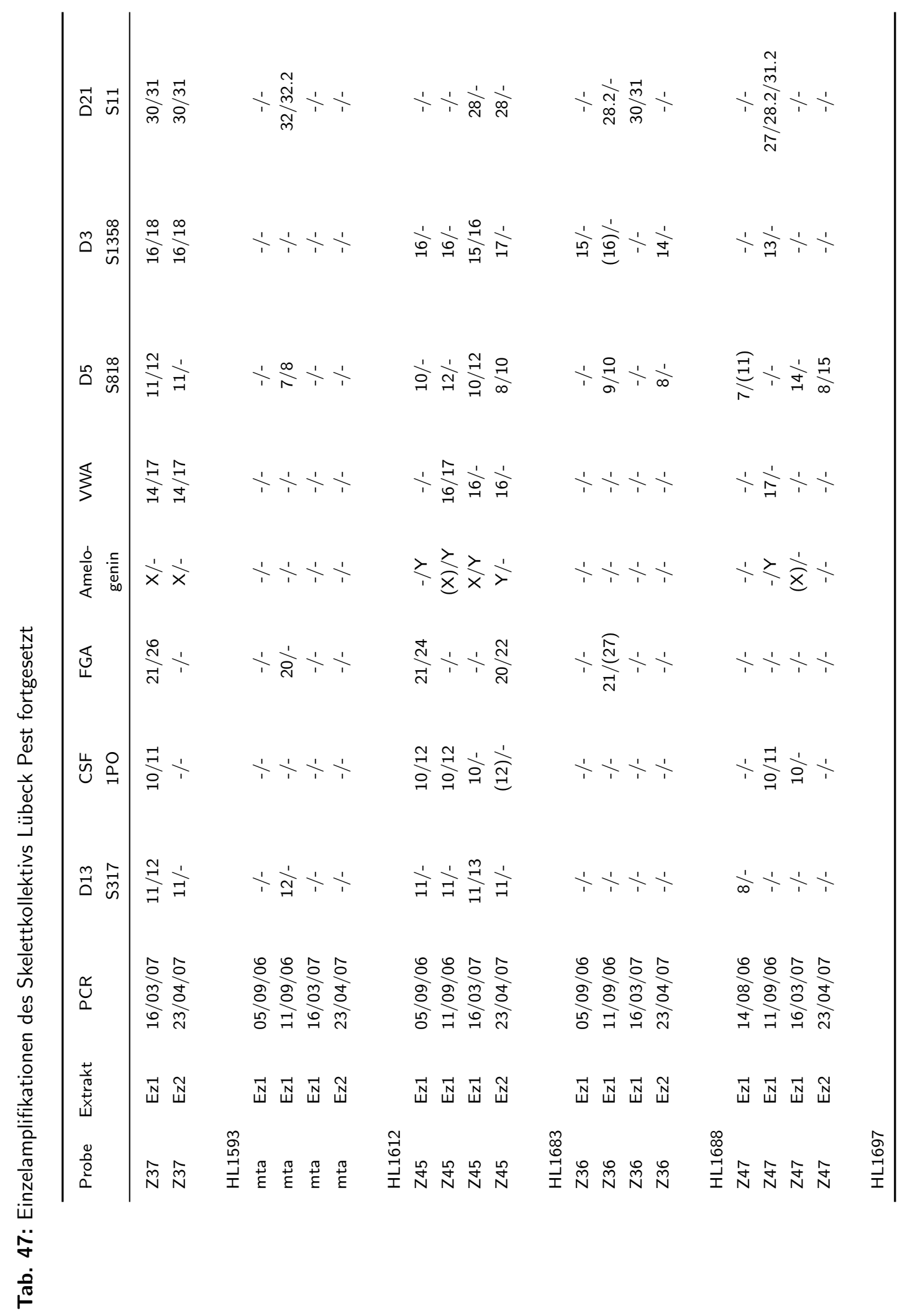




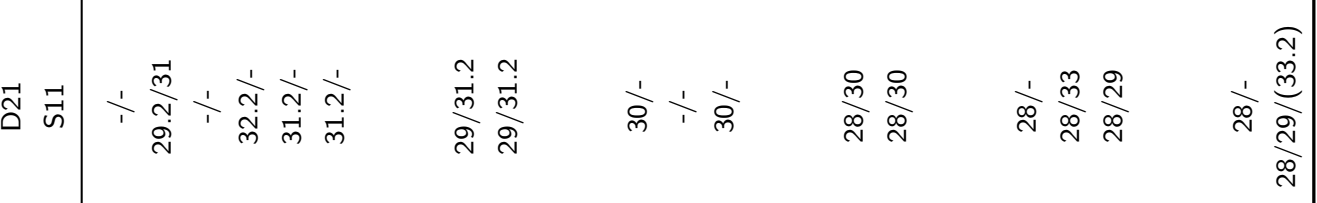

ڤ

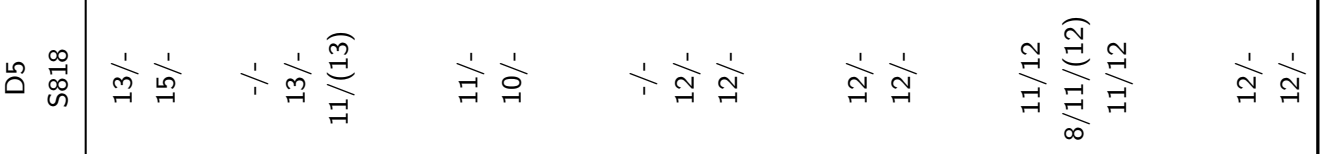

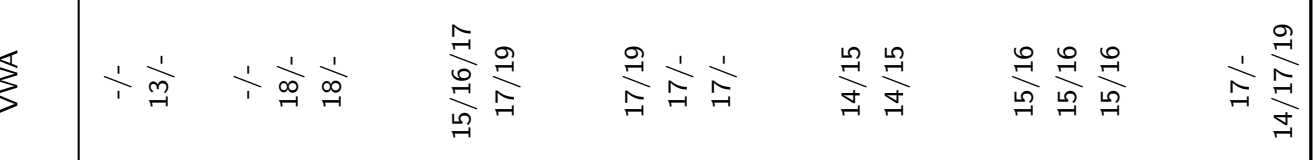

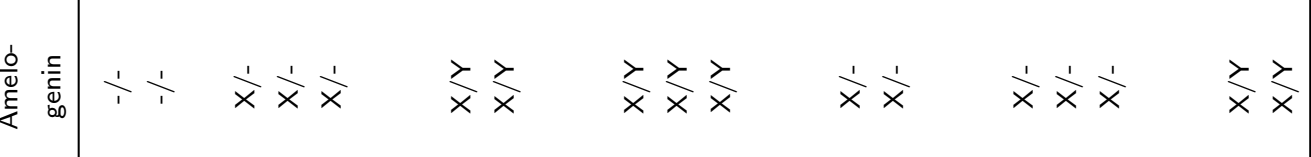

ए ए

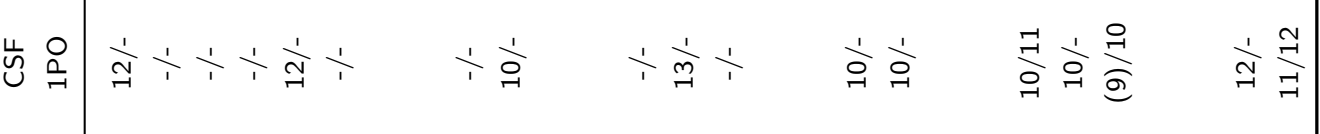

崩

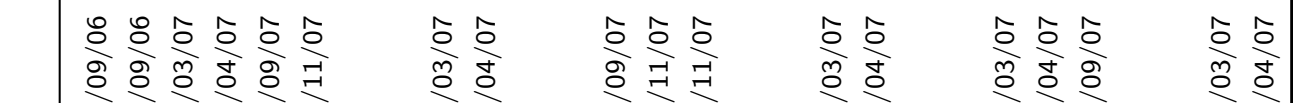

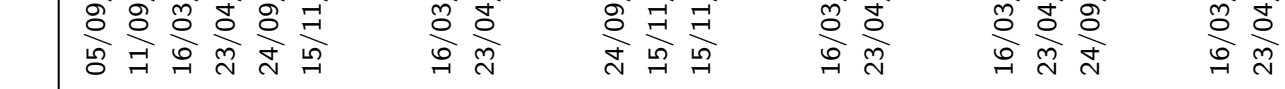

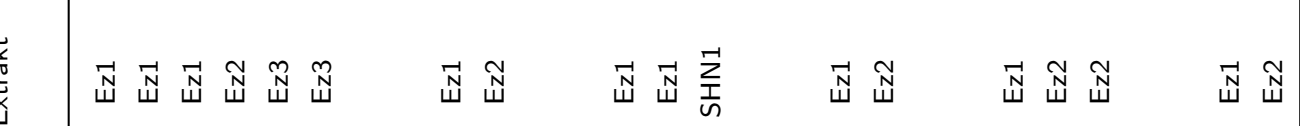

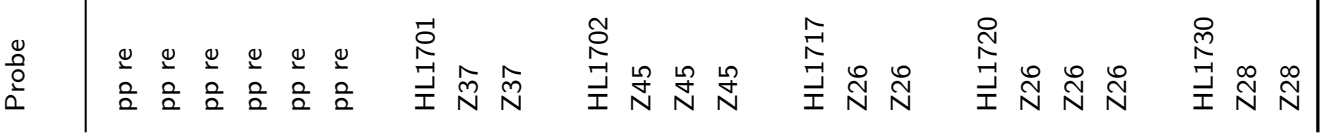




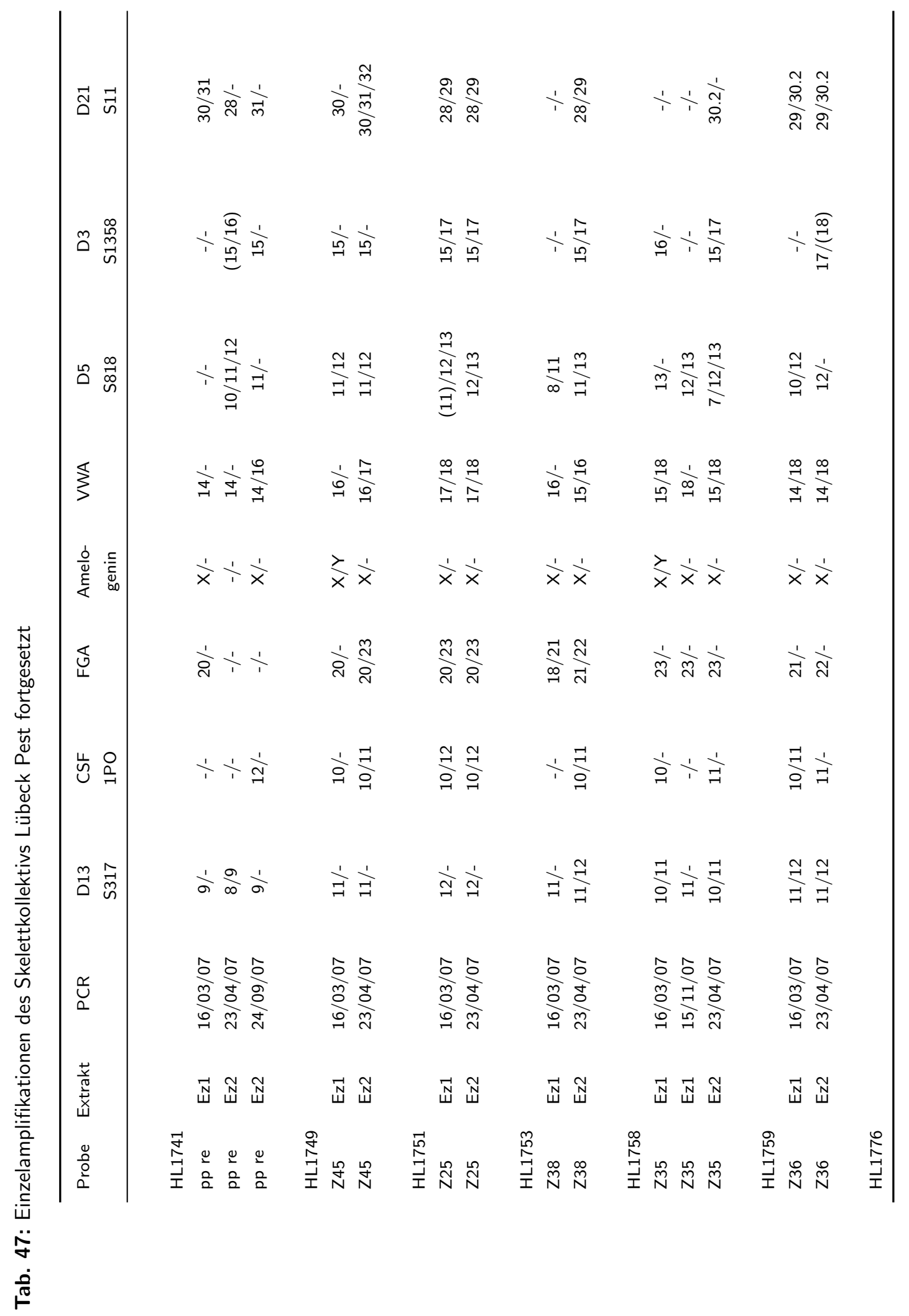




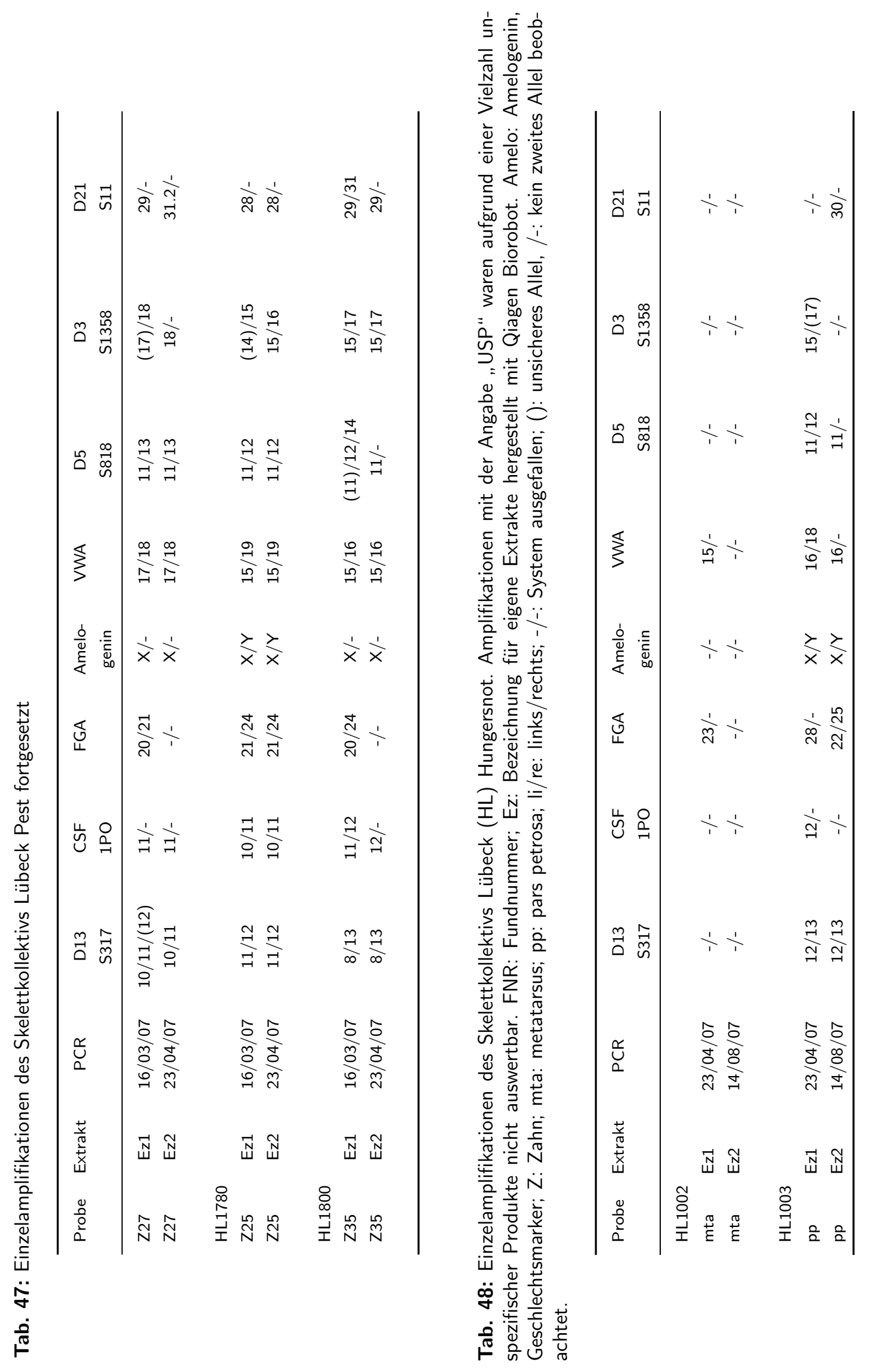




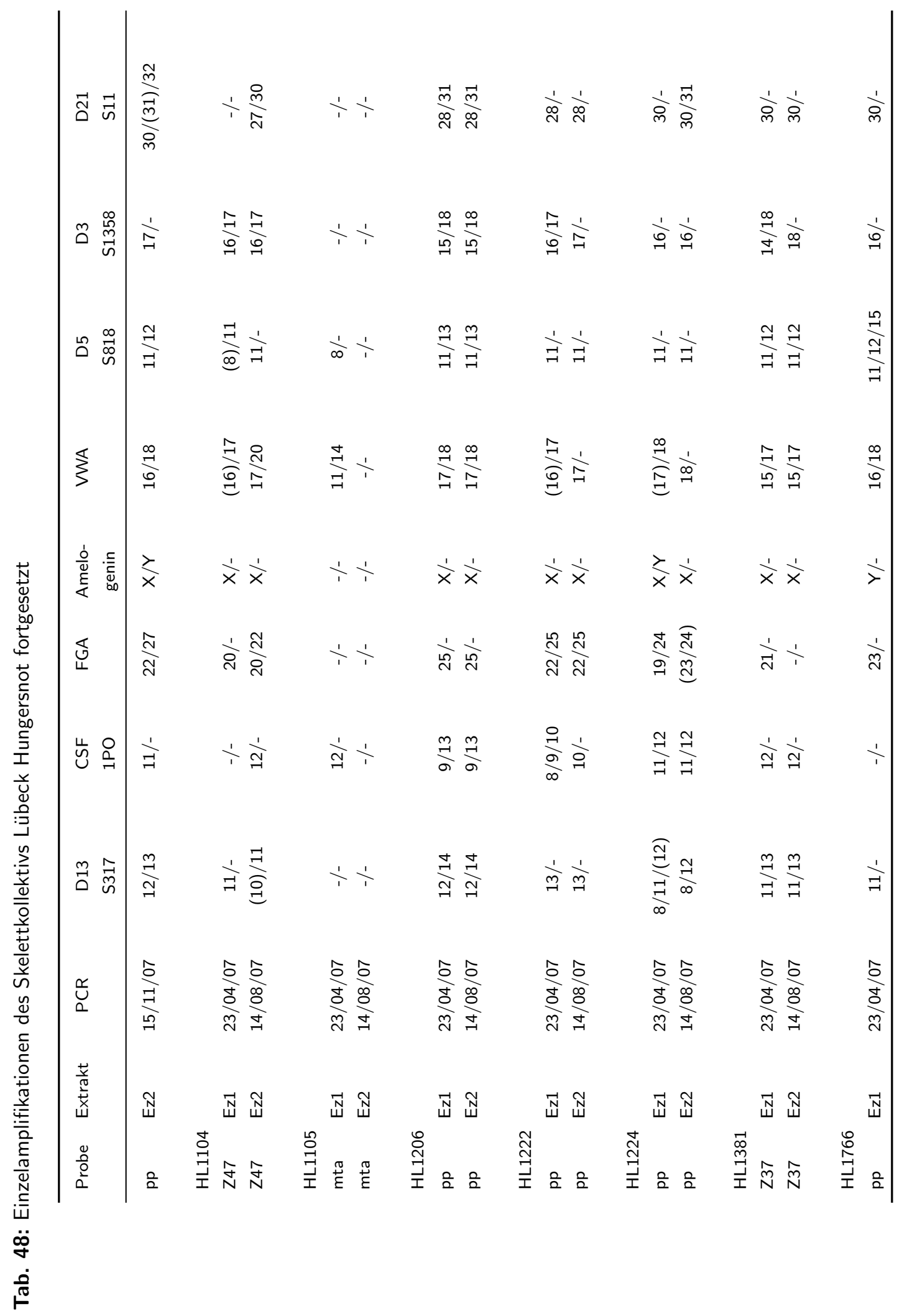




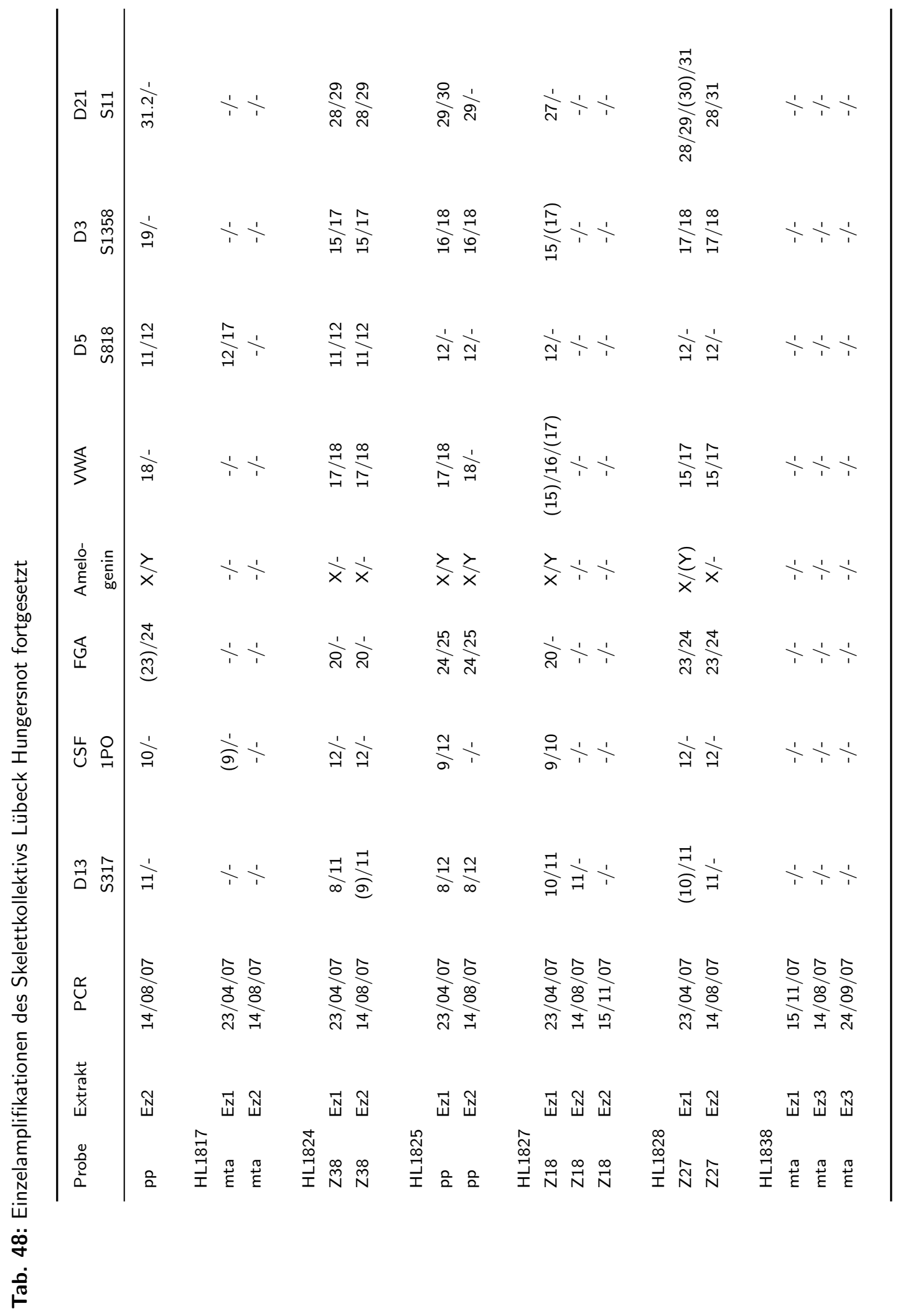




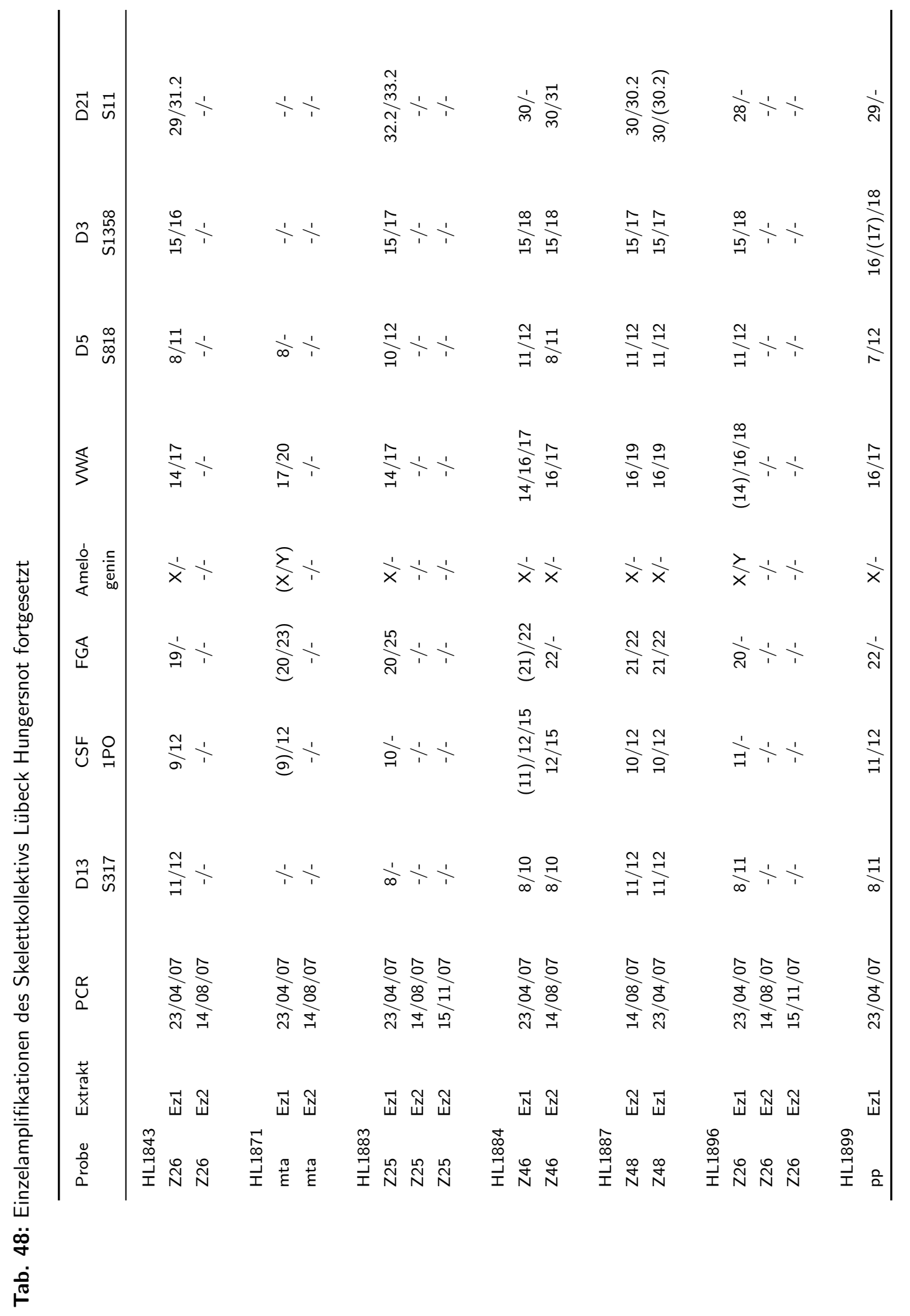




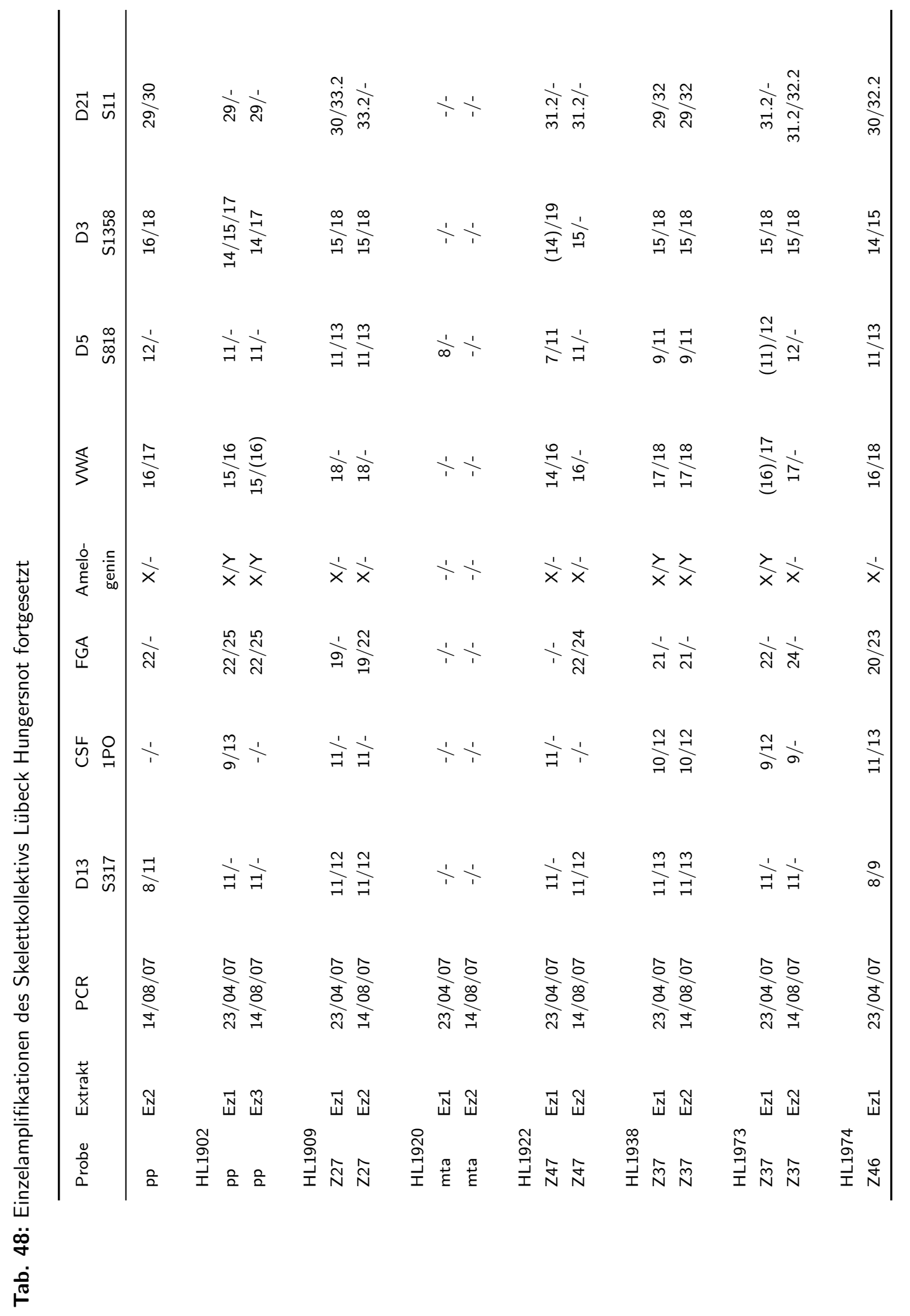




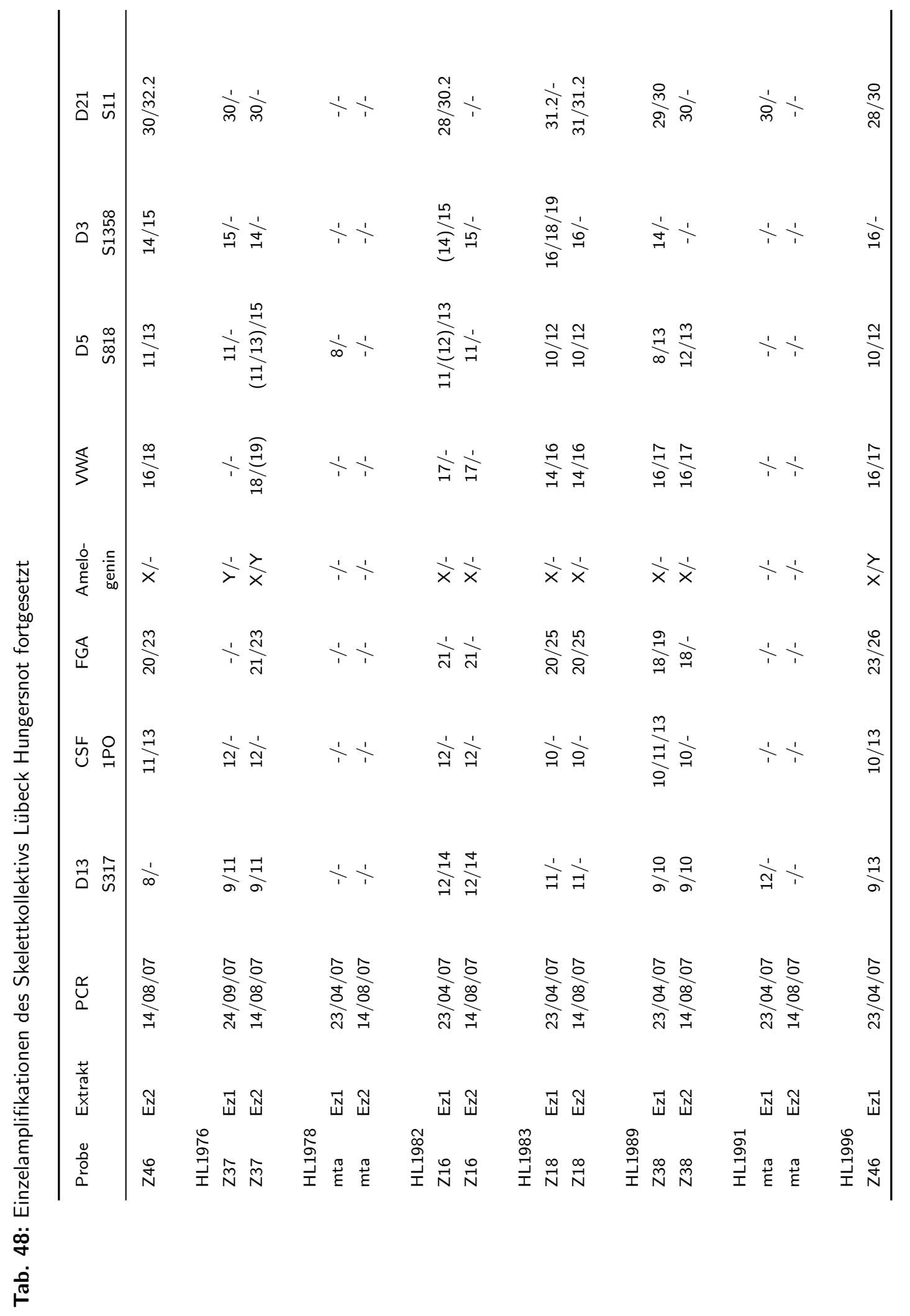




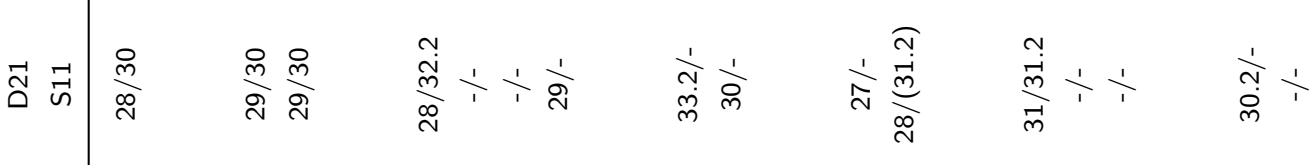

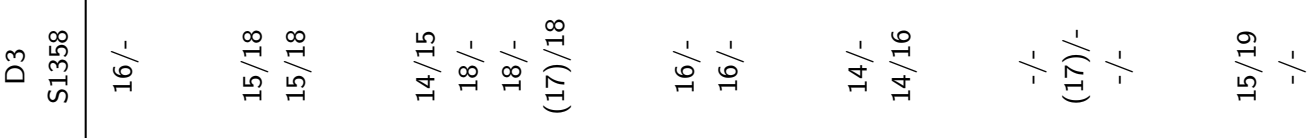

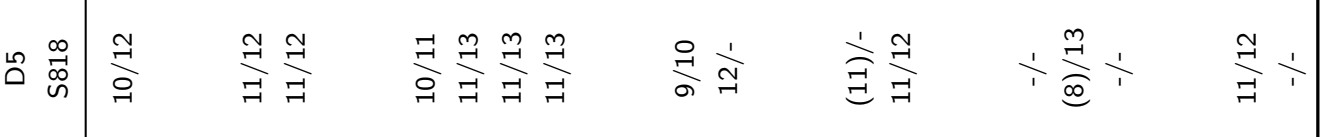

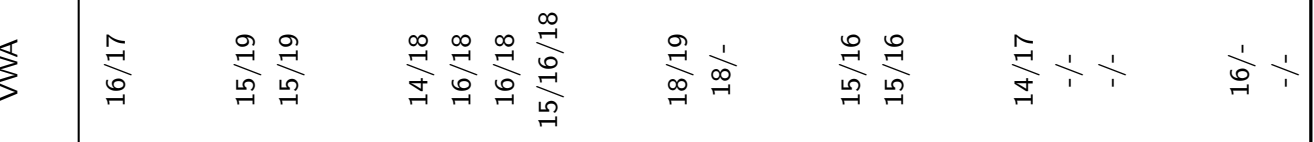

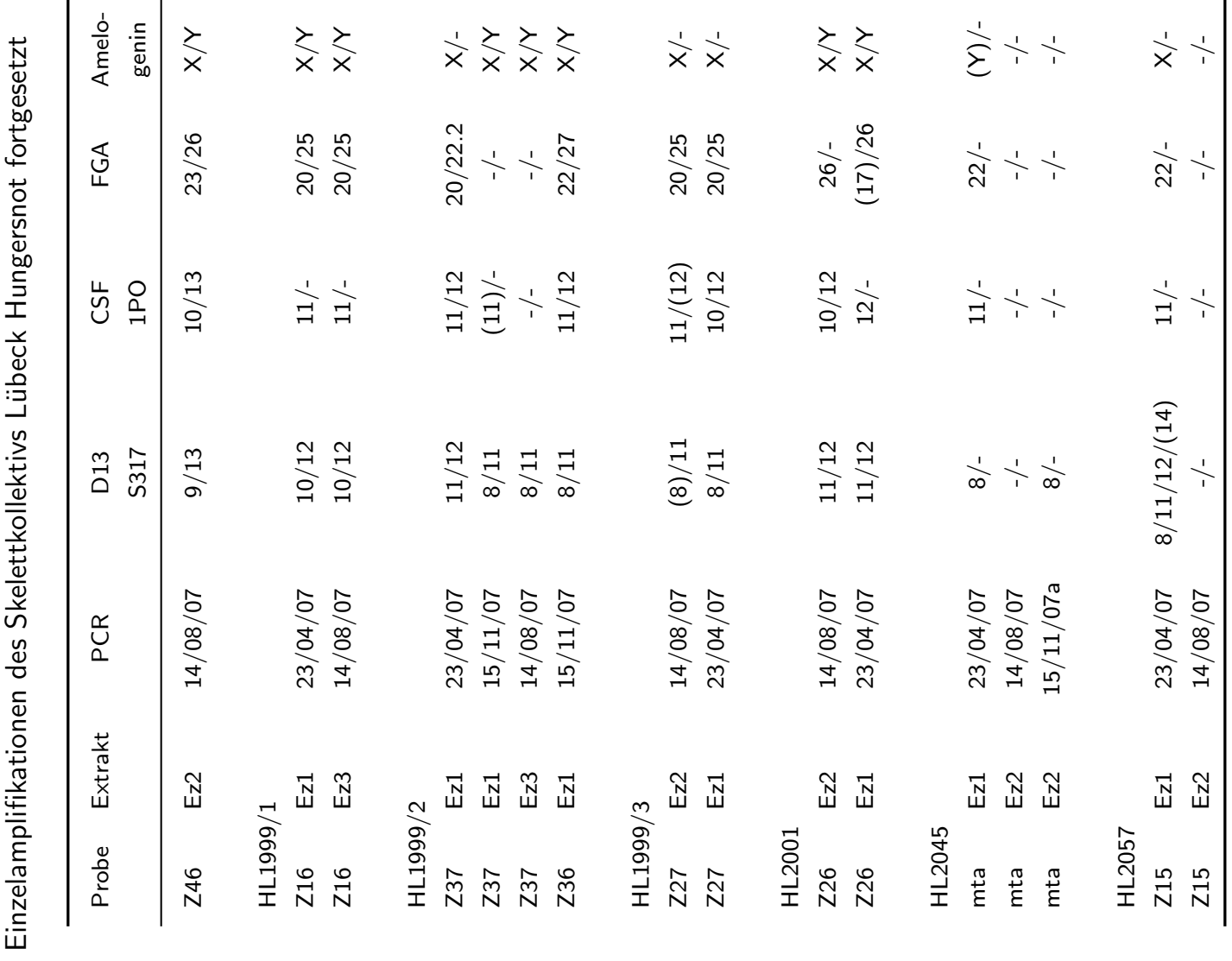


Allelfrequenzen und Häufigkeiten der Genotypen

225

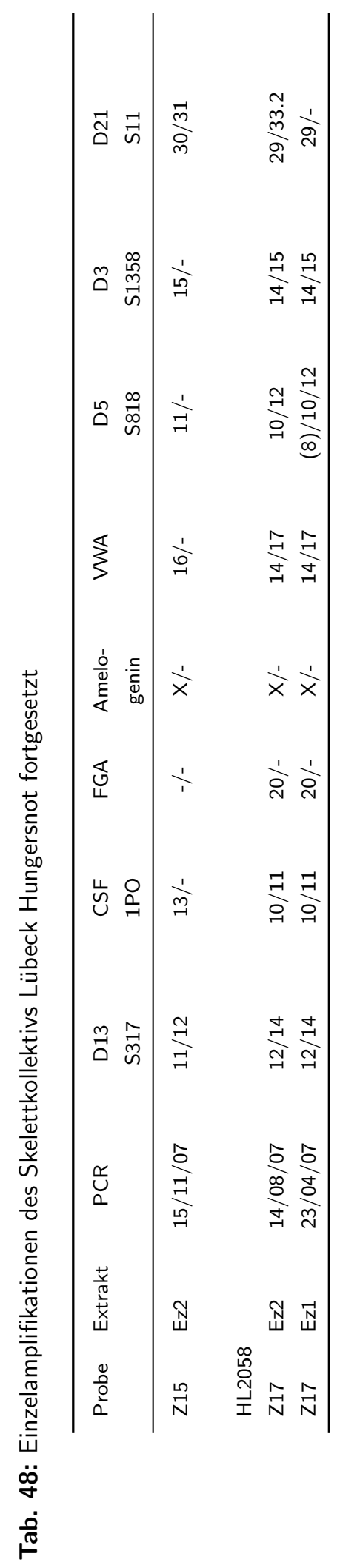




\section{Skelettserie Dorste: Referenzdaten}

Auf den folgenden Seiten werden die genetischen Fingerabdrücke der Individuen aus der Skelettserie Dorste vorgestellt, die als Referenz für diese Arbeit dienten. Die Daten wurden der Arbeit Schilz (2006) entnommen. Rohdaten und Ergebnisse nach Fundnummern können dort nachgeschlagen werden. 


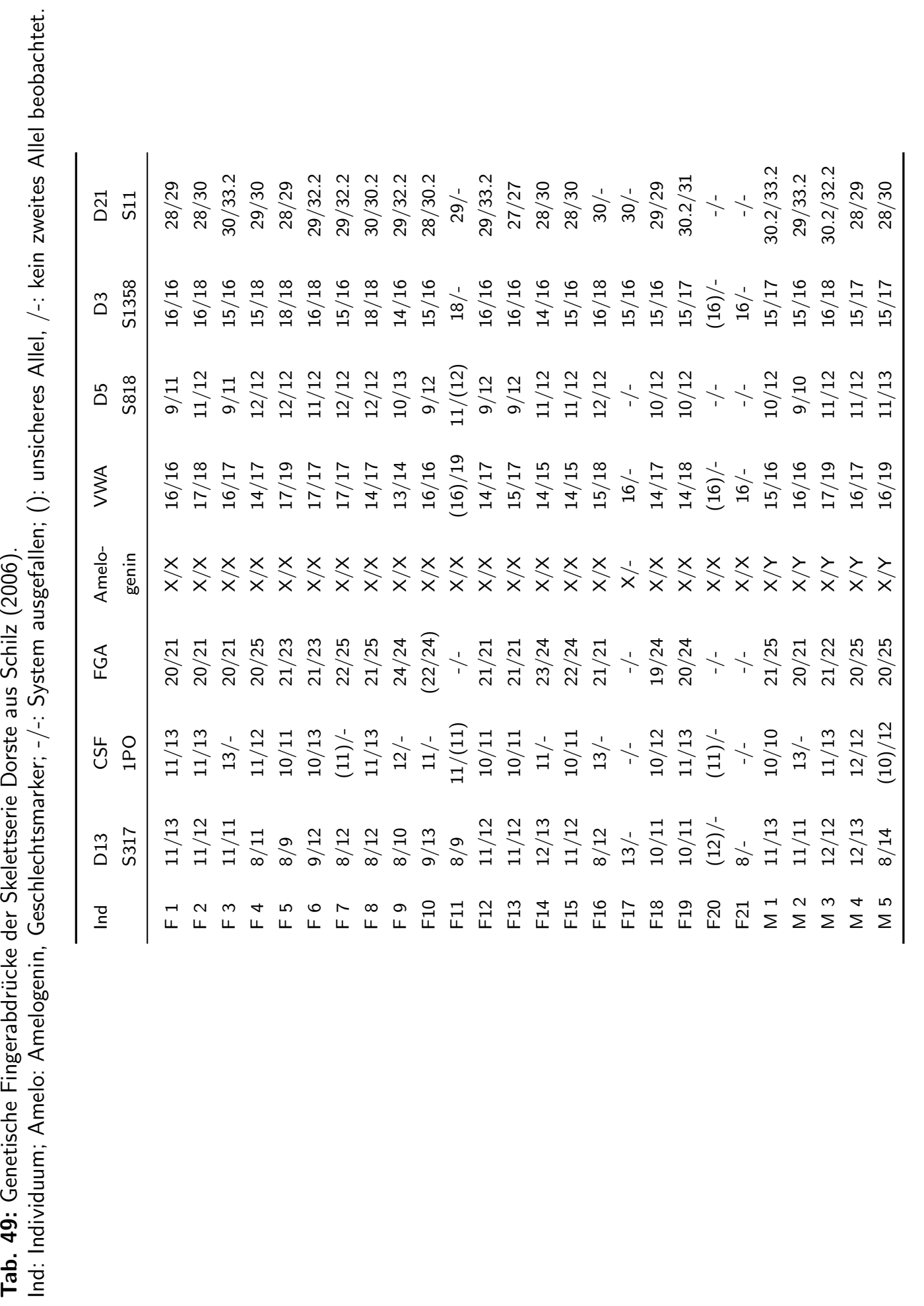




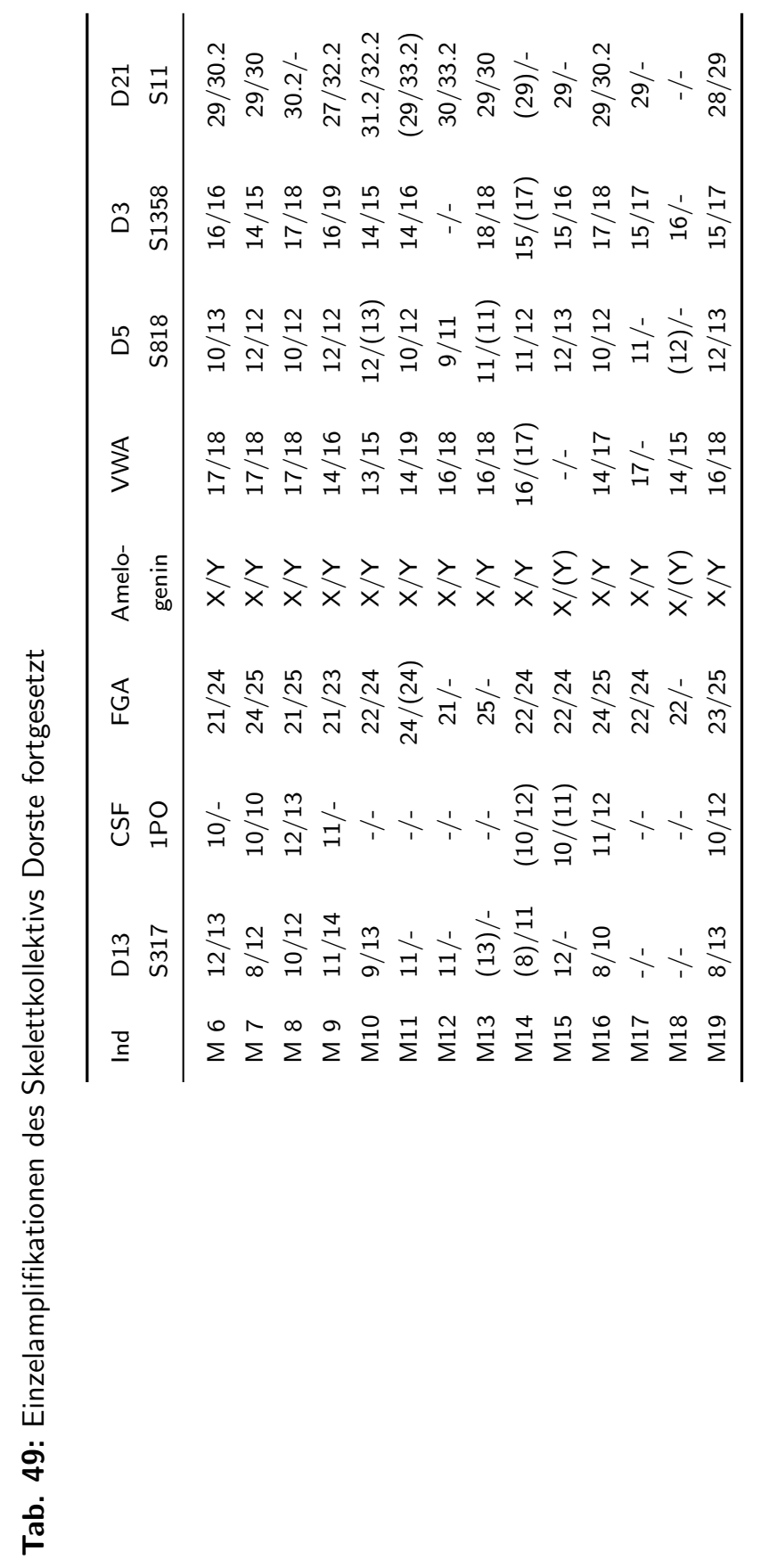




\section{Ergebnisse der Sequenzierungen}

Auf den folgenden Seiten sind die Ergebnisse der erfolgreichen Sequenzierungen aufgeführt. Als Grundlage des Alignments wurde jeweils die Referenzsequenz des Polymorphismus aus der Entrez-SNP-Datenbank (NCBI) verwendet. 


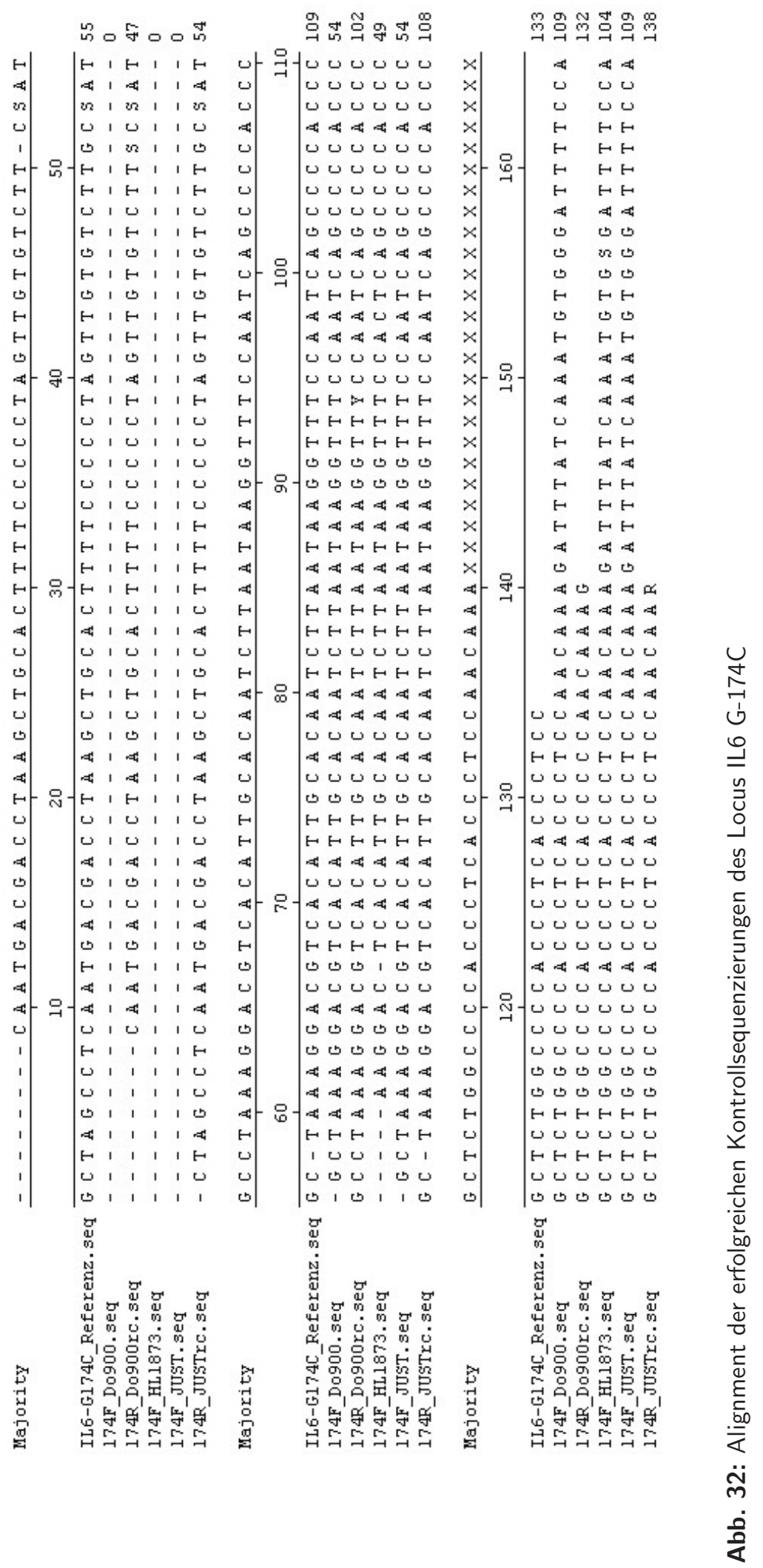




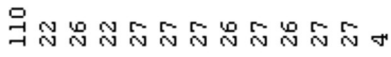

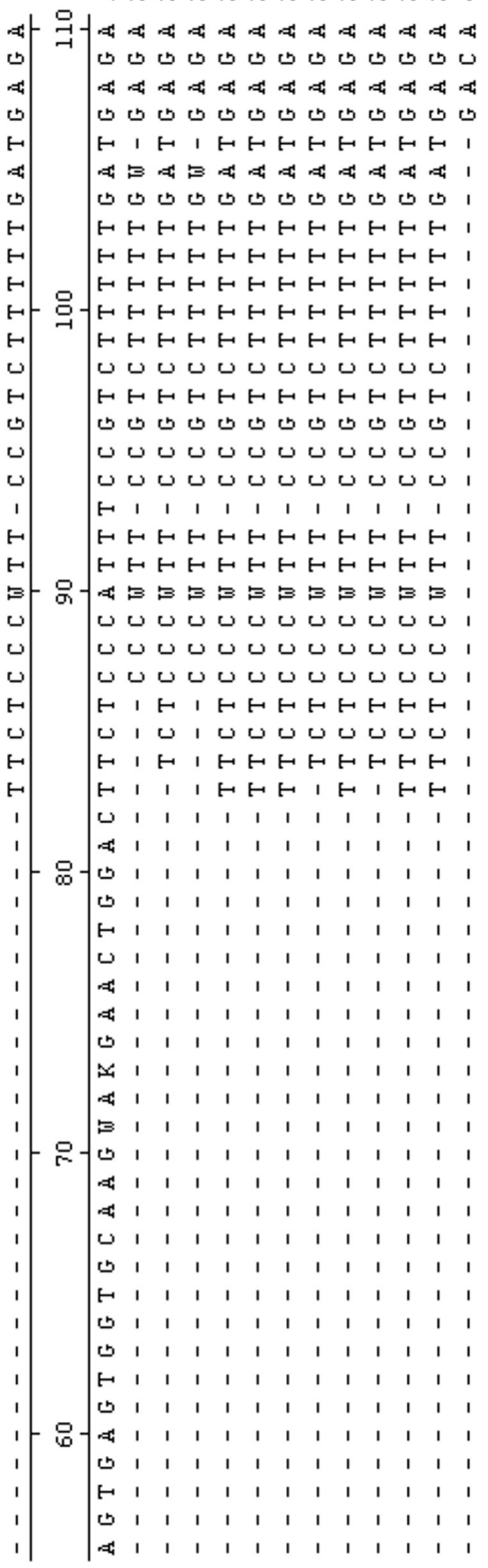

要

苟

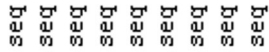

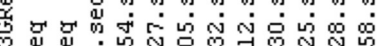
管

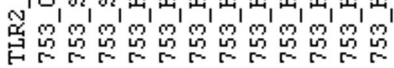

武只品只

D) 0000000000000 HトHトHトHトHトHト HHHHHHHHHHHHH

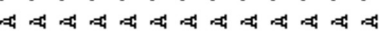

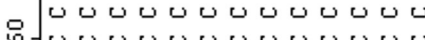

-00000000000 b b b b b b b b b

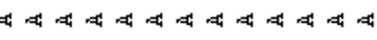

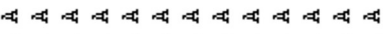

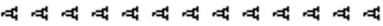

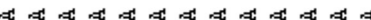

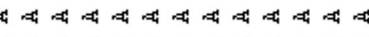

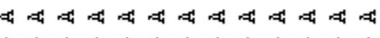
b b b b b b b b b b

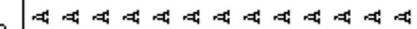
际 b b b b b b b b b b b b b H HHHHHHHHHH

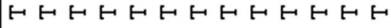

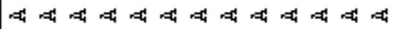

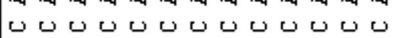
ט०0000000000 ט b b b b b b b b b b b b

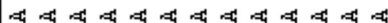
b b b b b b b b b b

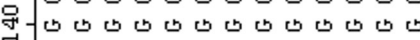

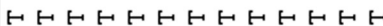
○ण $000 \cup 00 \cup 00$ H H H H H H H H HHHHHHHHHHHHH

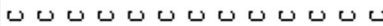
Нトトトトトトトトトトトト

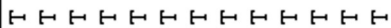

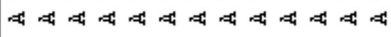
- uucuoucuououo

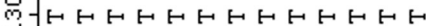
○ण 000000000 НHトHトHトHトHトHH

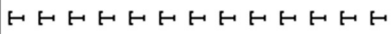

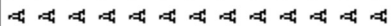

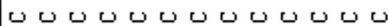
ט 00000000000

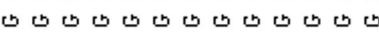

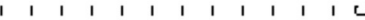

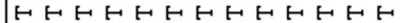

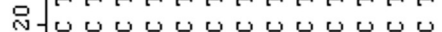

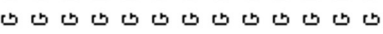
HトHトHトHトHトHトH

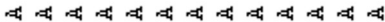

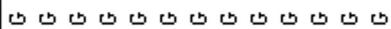
HHトHHHトHHHHHH

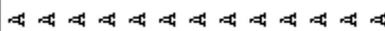

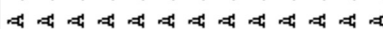

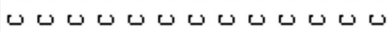

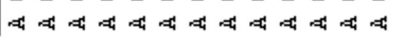

品

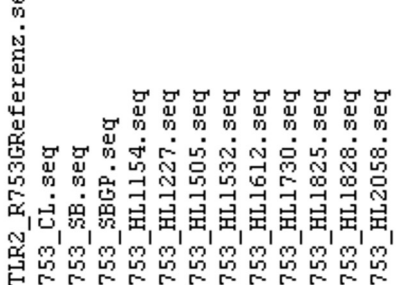




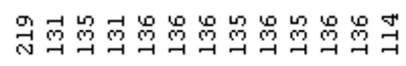

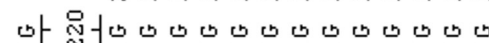

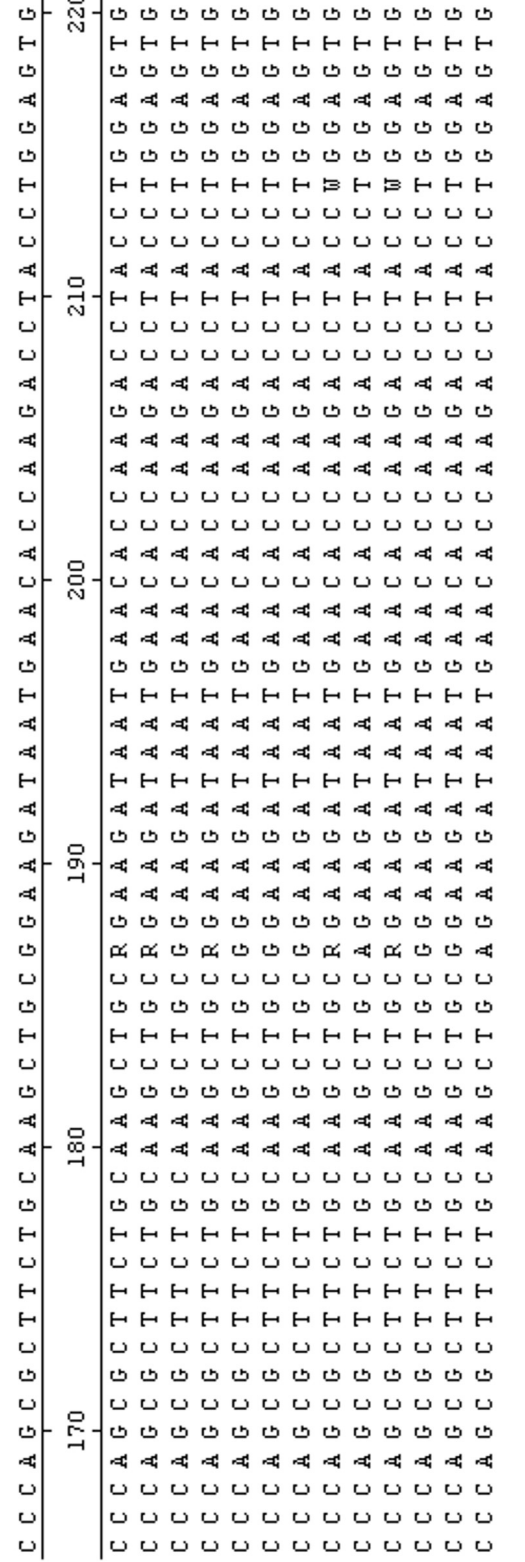

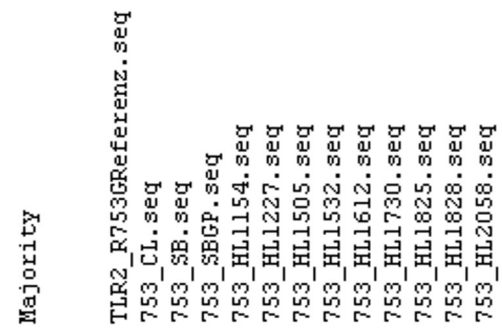
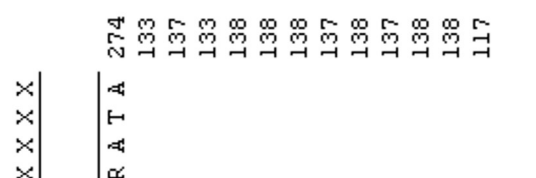


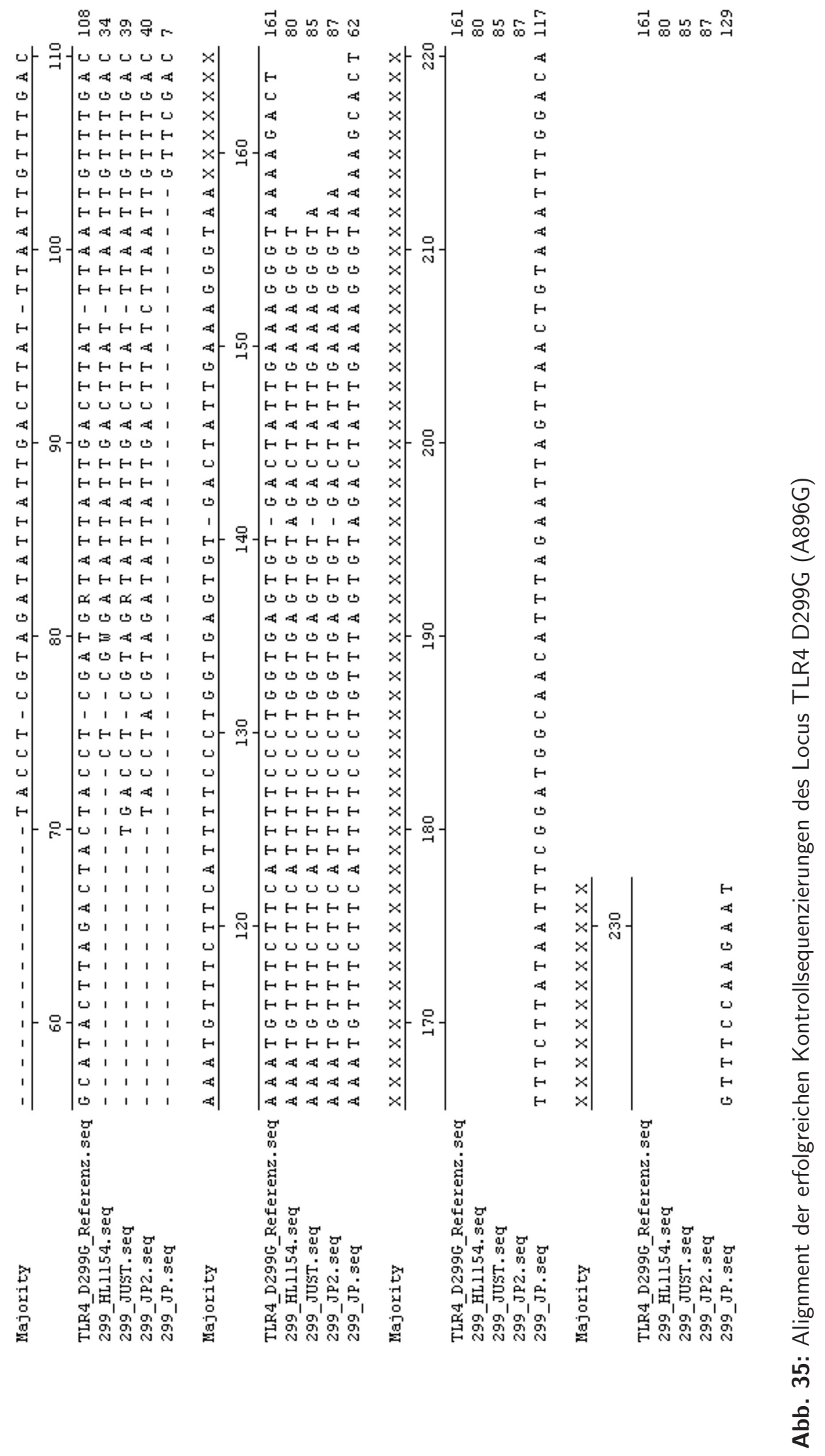




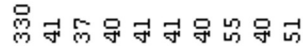

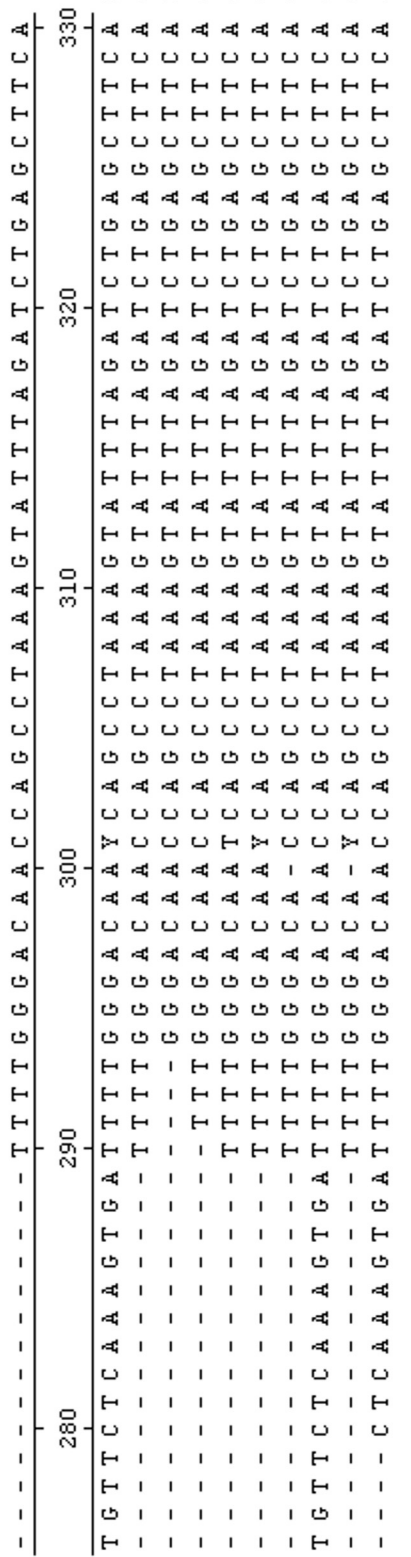

:

ن$$
\text { 通 }
$$

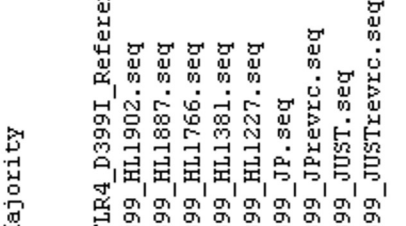

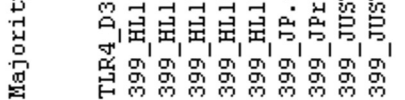

总品赑品品品员员员品

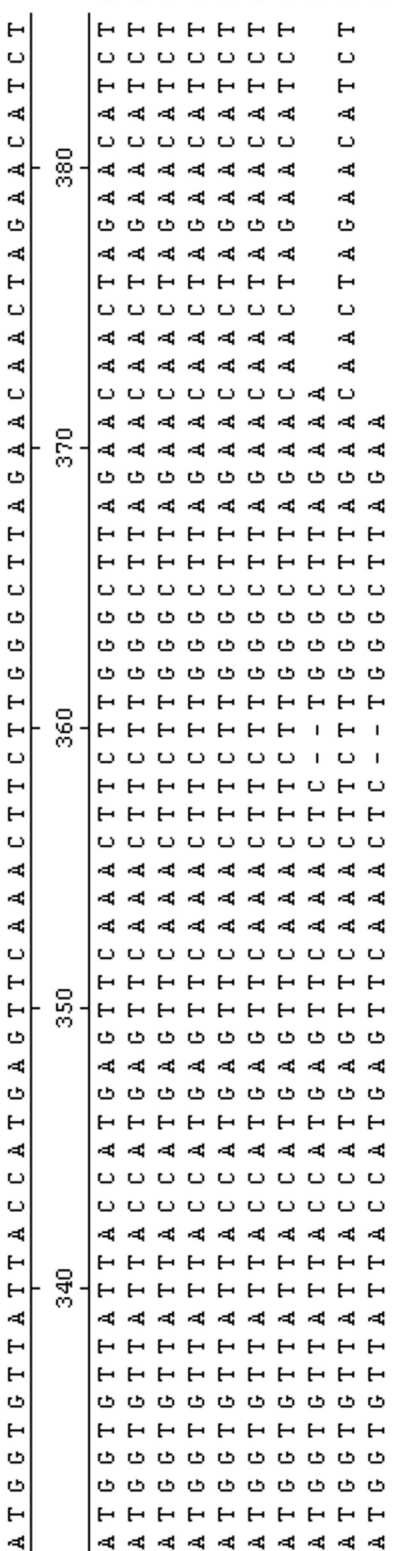

$g$

离

苞

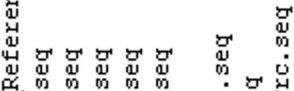

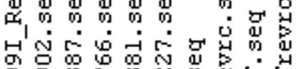

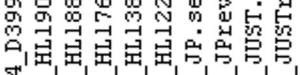

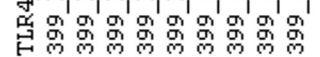

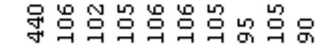
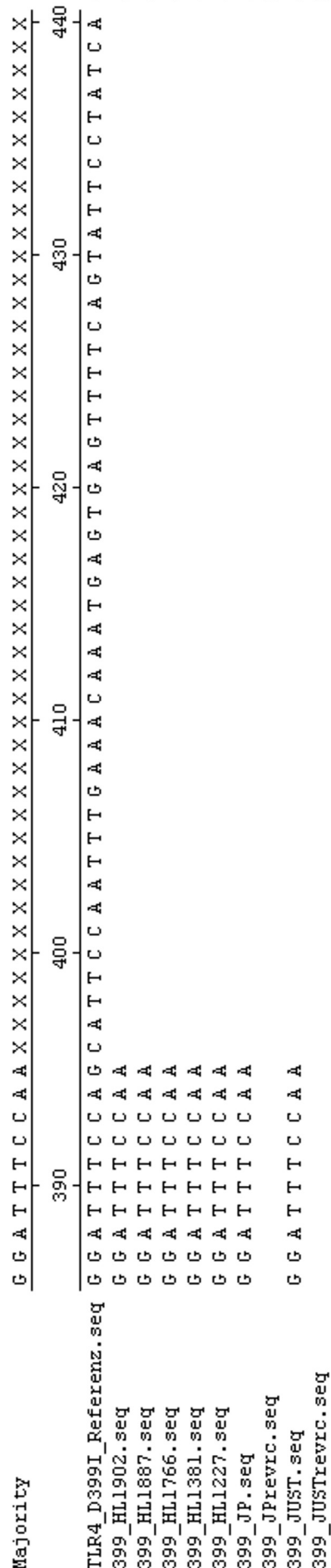


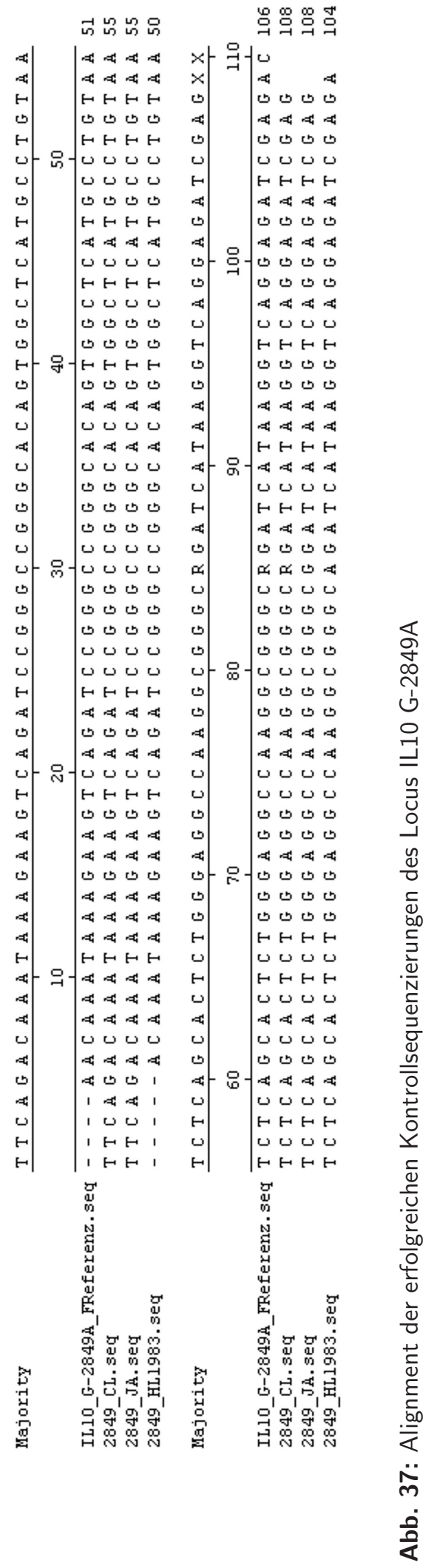



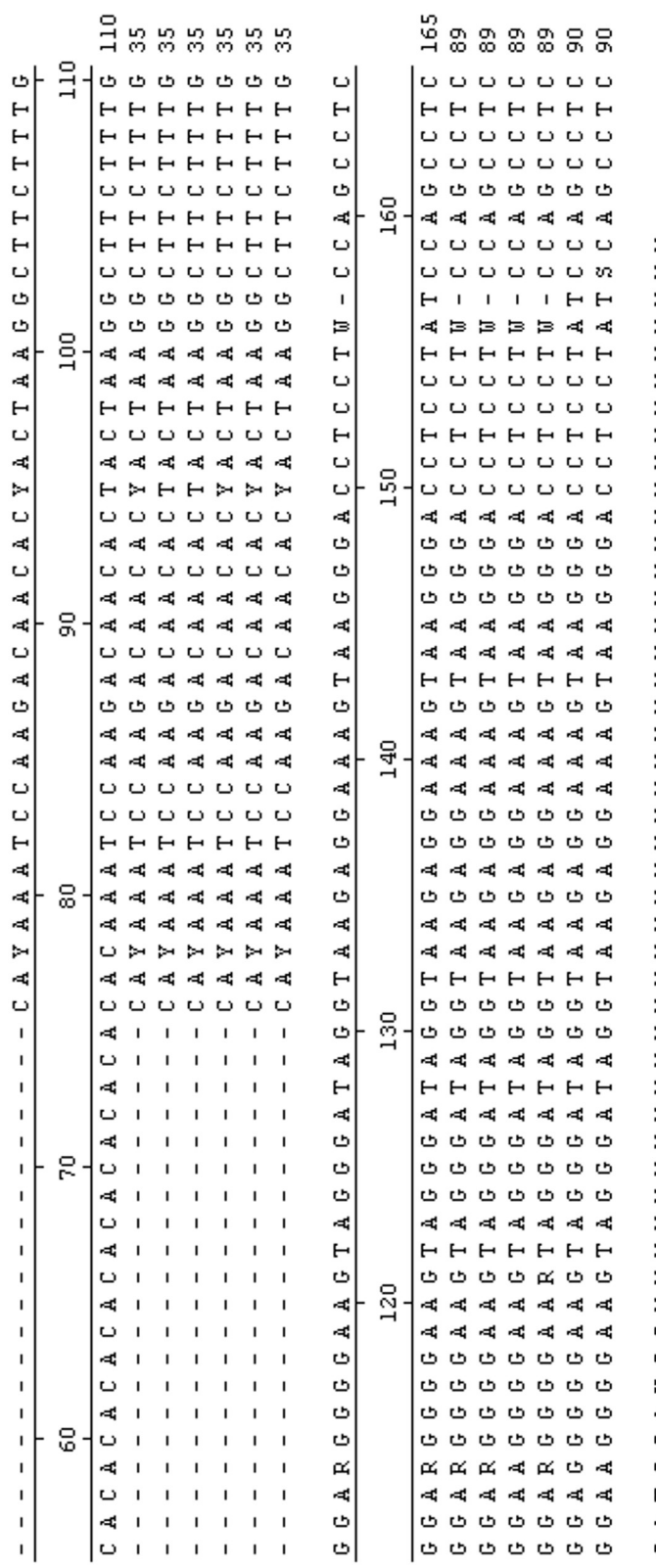

志品声吉品品
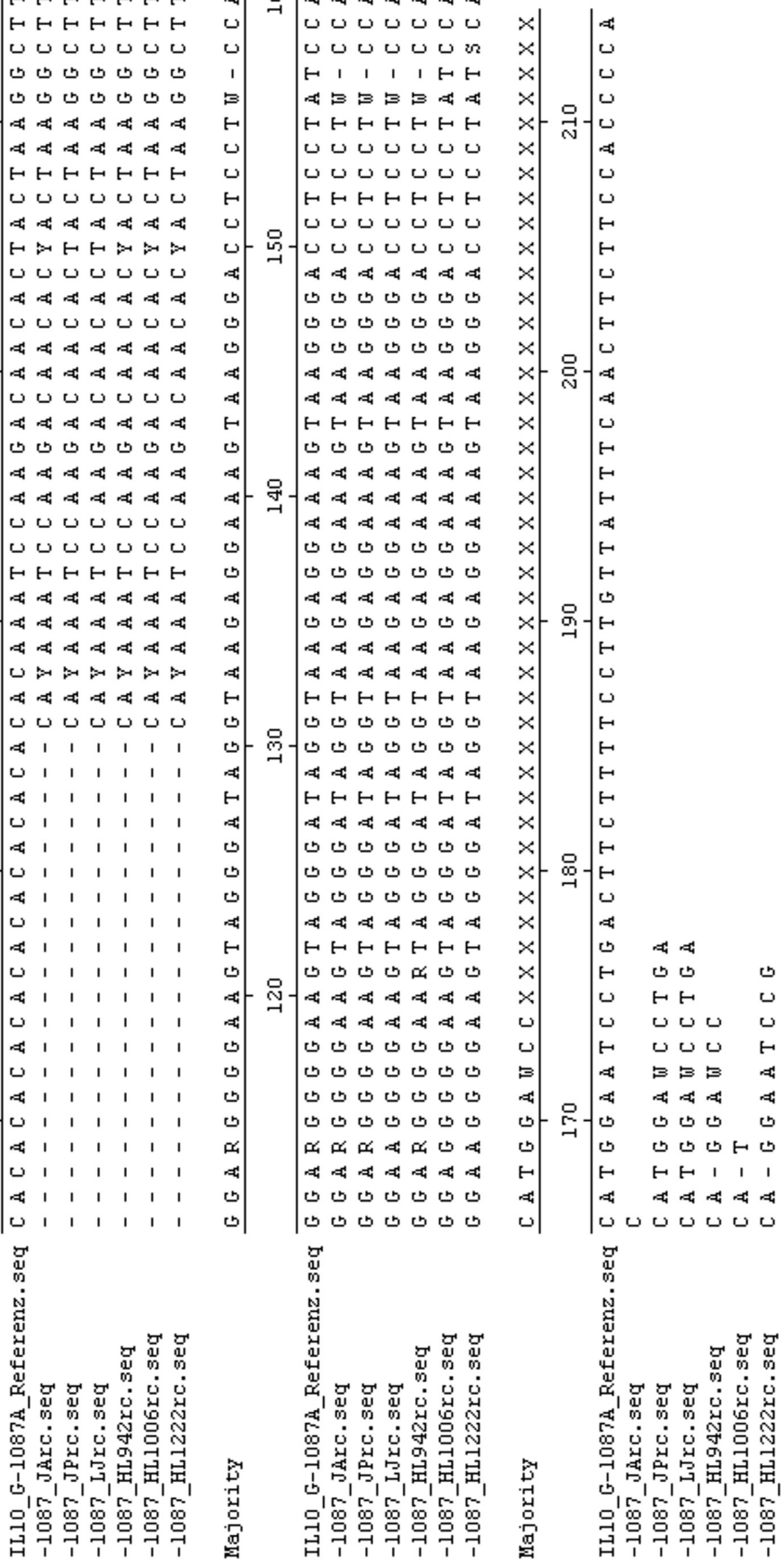


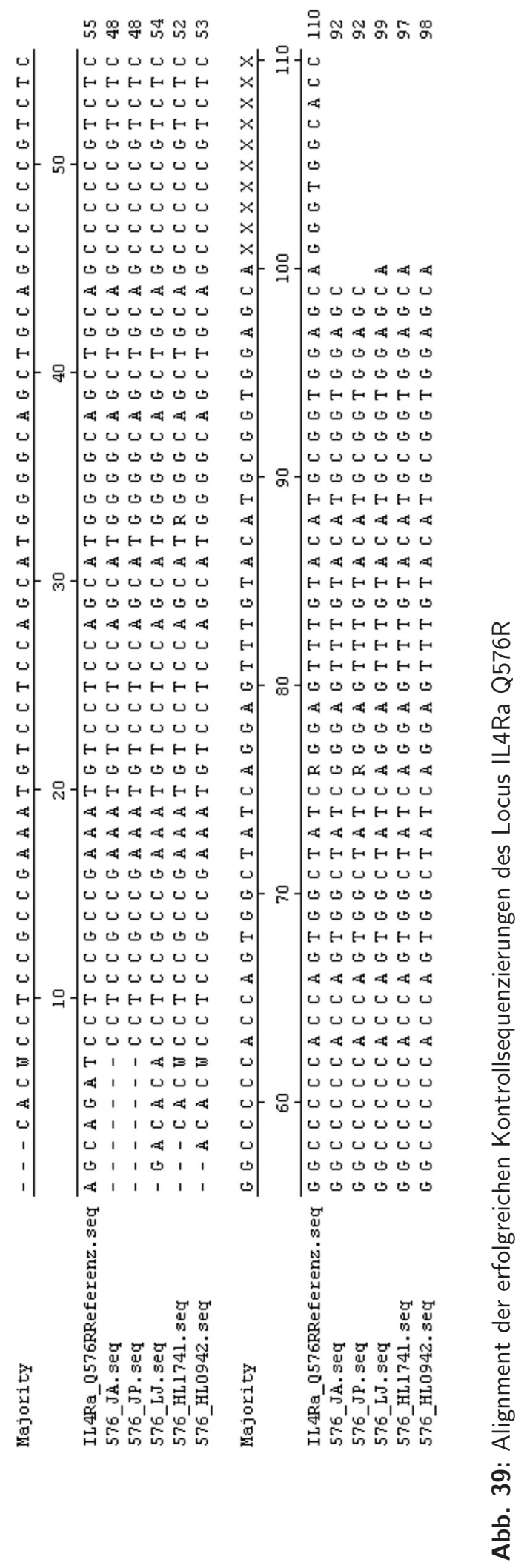




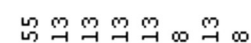

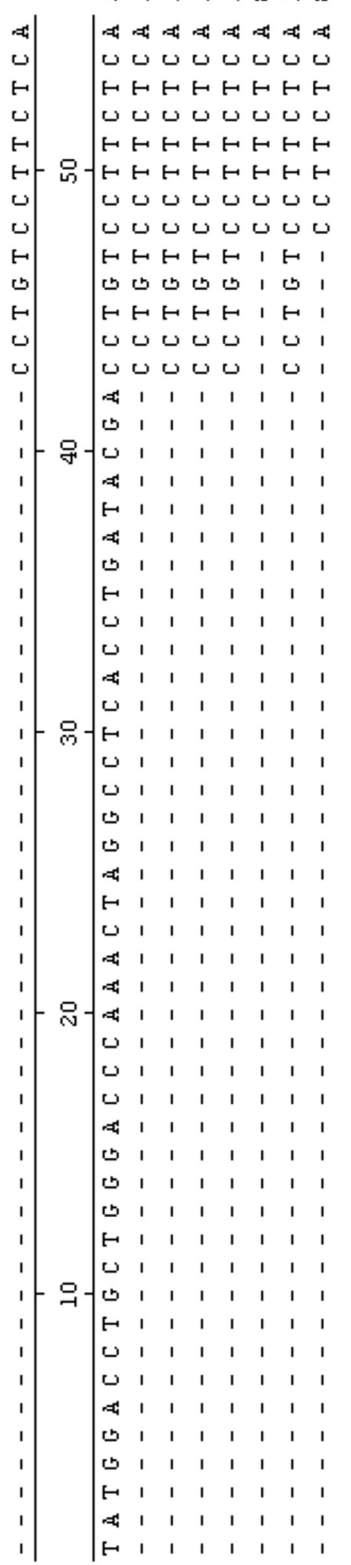

响

:

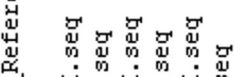

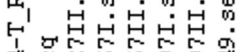

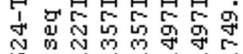

总

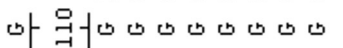
HHHHHHH OUOU⿴囗十丁0 HHHHHHH b t b b b

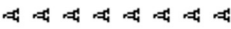

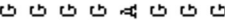

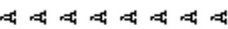
b 0 b 0 b

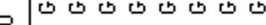

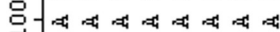
$H H H H H H H$

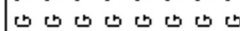
D员

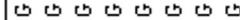
b b b b b b b HHHHHHH

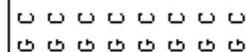
H $H$ H H H H

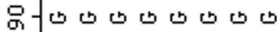

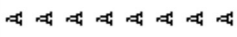

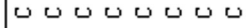
00000000 00000000 ००000000

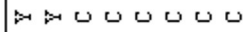
H H H H H b b b b b b HHHHHHH 盟HHHHHH

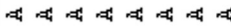
U U U U U U U

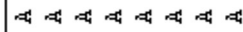

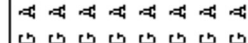
b b b b b b b

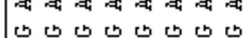

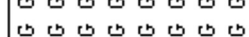

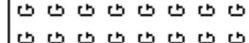

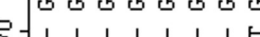
HHHHHHH HHHHHHH

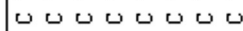

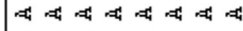

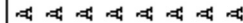

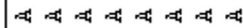
HHHHHHH

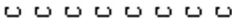
0u0u0u00

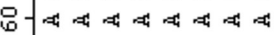
U 0 U $\cup \cup \cup \cup 0$

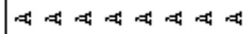

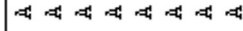

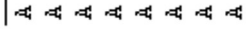
焉<smiles>[Hg]=[Hg]</smiles><smiles>[Li][Mg]</smiles>
岕 出

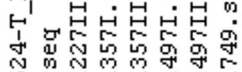

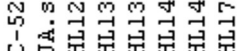

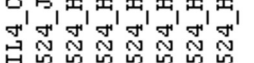

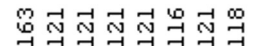

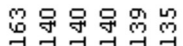

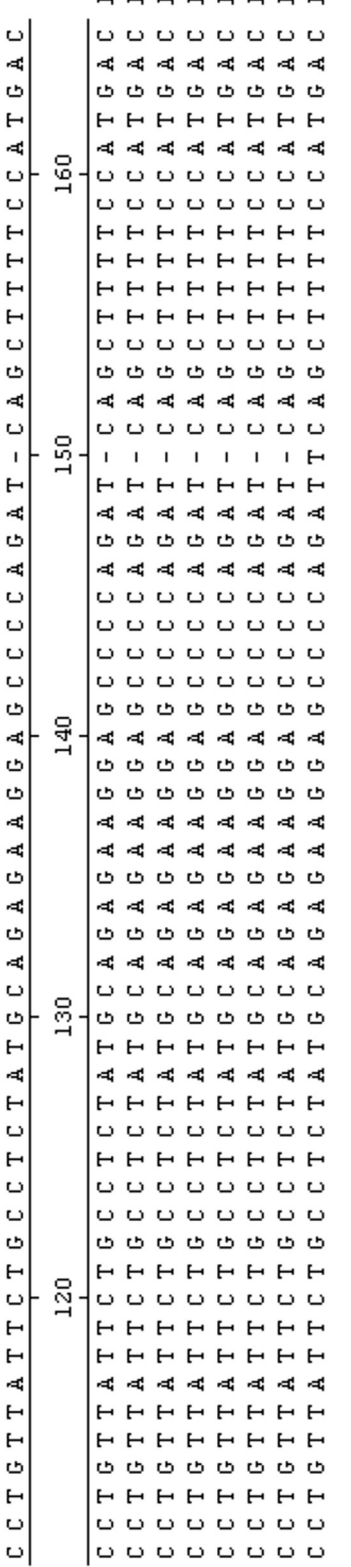

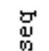

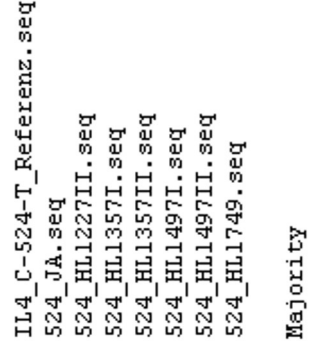




\section{Tabellen der statistischen Auswertung}

\section{Hardy-Weinberg equilibrium}

Die folgenden Tabellen geben die Ergebnistabellen des Programmes Arlequin wieder. Untersucht wurde jeweils nur ein Locus, die Zahl der berücksichtigten Individuen wird unter "N" angegeben. Getestet wird die beobachtete Heterozygotenrate (Obs.Het.) gegen die erwartete (Exp.Het.). Der P-value zeigt die Signifikanz der Ergebnisse, das Signifikanzniveau beträgt $\mathrm{p} \leq 0,05$. Weiter werden die Standardabweichung (s.d.) und durchlaufene Zahl an Berechnungen (Steps done) angegeben.

Tab. 50: TLR2 R753Q: Ergebnisübersicht des Programmes Arlequin

\begin{tabular}{lccccccc}
\hline Serie & Locus & $\mathrm{N}$ & Obs.Het. & Exp.Het. & P-value & s.d. & Steps done \\
\hline Dorste & 1 & 21 & 0.14286 & 0.13589 & 1.00000 & 0.00000 & 100172 \\
HL Hungersnot & 1 & 37 & 0.16216 & 0.19548 & 0.34642 & 0.00152 & 100172 \\
HL Pest & 1 & 71 & 0.12676 & 0.19029 & 0.02384 & 0.00040 & 100172 \\
Rezent & 1 & 319 & 0.09404 & 0.08976 & 1.00000 & 0.00000 & 100172 \\
\hline
\end{tabular}

Tab. 51: TLR4 D299G: Ergebnisübersicht des Programmes Arlequin

\begin{tabular}{lccccccc}
\hline Serie & Locus & $\mathrm{N}$ & Obs.Het. & Exp.Het. & P-value & s.d. & Steps done \\
\hline Dorste & 1 & 20 & 0.10000 & 0.18462 & 0.15208 & 0.00120 & 100172 \\
HL Hungersnot & 1 & 40 & 0.12500 & 0.11867 & 1.00000 & 0.00000 & 100172 \\
HL Pest & 1 & 74 & 0.20270 & 0.22532 & 0.33589 & 0.00152 & 100172 \\
Rezent & 1 & 263 & 0.10266 & 0.10439 & 0.55590 & 0.00153 & 100172 \\
\hline
\end{tabular}

Tab. 52: IL4Ra Q576R: Ergebnisübersicht des Programmes Arlequin

\begin{tabular}{lccccccc}
\hline Serie & Locus & N & Obs.Het. & Exp.Het. & P-value & s.d. & Steps done \\
\hline Dorste & 1 & 22 & 0.45455 & 0.40592 & 1.00000 & 0.00000 & 100172 \\
HL Hungersnot & 1 & 43 & 0.37209 & 0.33488 & 0.66005 & 0.00145 & 100172 \\
HL Pest & 1 & 82 & 0.45122 & 0.36473 & 0.03435 & 0.00062 & 100172 \\
Rezent & 1 & 262 & 0.35496 & 0.35172 & 1.00000 & 0.00000 & 100172 \\
\hline
\end{tabular}


Tab. 53: IL6 G-174C: Ergebnisübersicht des Programmes Arlequin

\begin{tabular}{lccccccc}
\hline Serie & Locus & $\mathrm{N}$ & Obs.Het. & Exp.Het. & P-value & s.d. & Steps done \\
\hline Dorste & 1 & 17 & 0.52941 & 0.51515 & 1.00000 & 0.00000 & 100172 \\
HL Hungersnot & 1 & 39 & 0.33333 & 0.49451 & 0.05246 & 0.00078 & 100172 \\
HL Pest & 1 & 67 & 0.49254 & 0.46740 & 0.79465 & 0.00123 & 100172 \\
Rezent & 1 & 111 & 0.44144 & 0.47878 & 0.43553 & 0.00145 & 100172 \\
\hline
\end{tabular}

Tab. 54: IL10 G-1087A: Ergebnisübersicht des Programmes Arlequin

\begin{tabular}{lccccccc}
\hline Serie & Locus & $\mathrm{N}$ & Obs.Het. & Exp.Het. & P-value & s.d. & Steps done \\
\hline Dorste & 1 & 17 & 0.35294 & 0.49911 & 0.32558 & 0.00150 & 100172 \\
HL Hungersnot & 1 & 36 & 0.52778 & 0.50665 & 1.00000 & 0.00000 & 100172 \\
HL Pest & 1 & 69 & 0.59420 & 0.49984 & 0.14098 & 0.00105 & 100172 \\
Rezent & 1 & 264 & 0.43939 & 0.50049 & 0.05210 & 0.00075 & 100172 \\
\hline
\end{tabular}

Tab. 55: IL10 G-2849A: Ergebnisübersicht des Programmes Arlequin

\begin{tabular}{lccccccc}
\hline Serie & Locus & $\mathrm{N}$ & Obs.Het. & Exp.Het. & P-value & s.d. & Steps done \\
\hline Dorste & 1 & 23 & 0.73913 & 0.49565 & 0.03012 & 0.00056 & 100172 \\
HL Hungersnot & 1 & 43 & 0.62791 & 0.48837 & 0.06841 & 0.00089 & 100172 \\
HL Pest & 1 & 46 & 0.54348 & 0.45174 & 0.19826 & 0.00125 & 100172 \\
Rezent & 1 & 315 & 0.34603 & 0.38110 & 0.11001 & 0.000792 & 100172 \\
\hline
\end{tabular}

\section{Ergebnisse des Exakten Tests}

Die folgenden Tabellen geben die Ergebnisse des Exakten Tests wieder. Ein signifikanter Unterschied zwischen zwei Populationen ist bei $\mathrm{p} \leq 0,05$ nachgewiesen. Die Populationen sind wie folgt codiert: 1: Dorste, 2: HL Hungersnot, 3: HL Pest, 4: rezent.

Tab. 56: TLR2 R753Q: p-Werte der paarweisen Berechnung von Unterschieden zwischen den Populationen

$\begin{array}{llll}1 & 2 & 3 & 4\end{array}$

$$
\begin{array}{llll}
2 & 1.00000+-0.0000 & & \\
3 & 1.00000+-0.0000 & 0.90690+-0.0040 & \\
4 & 0.43635+-0.0182 & 0.03320+-0.0072 & 0.01802+-0.0036
\end{array}
$$


Tab. 57: TLR4 D299G : p-Werte der paarweisen Berechnung von Unterschieden zwischen den Populationen

$\begin{array}{ccccc} & 1 & 2 & 3 & 4 \\ 2 & 0.47410+-0.0107 & & \\ 3 & 0.41745+-0.0090 & 0.35840+-0.0104 & \\ 4 & 0.16695+-0.0087 & 0.76577+-0.0093 & 0.01540+-0.0039\end{array}$

Tab. 58: IL4 Q576R: p-Werte der paarweisen Berechnung von Unterschieden zwischen den Populationen

$\begin{array}{ccccc} & 1 & 2 & 3 & 4 \\ 2 & 0.53095+-0.0099 & & \\ 3 & 0.52580+-0.0108 & 0.48680+-0.0129 & \\ 4 & 0.58085+-0.0121 & 0.87700+-0.0018 & 0.13990+-0.0125\end{array}$

Tab. 59: IL6 G-174C: p-Werte der paarweisen Berechnung von Unterschieden zwischen den Populationen

$\begin{array}{ccccc} & 1 & 2 & 3 & 4 \\ 2 & 0.35050+-0.0063 & & \\ 3 & 0.29830+-0.0081 & 0.11895+-0.0064 & \\ 4 & 0.51635+-0.0154 & 0.39810+-0.0107 & 0.66105+-0.0147\end{array}$

Tab. 60: IL10 G-1087A: p-Werte der paarweisen Berechnung von Unterschieden zwischen den Populationen

$\begin{array}{ccccc} & 1 & 2 & 3 & 4 \\ 2 & 0.32570+-0.0120 & & \\ 3 & 0.07525+-0.0070 & 0.71040+-0.0094 & \\ 4 & 0.58815+-0.0087 & 0.58415+-0.0219 & 0.03890+-0.0077\end{array}$

Tab. 61: IL10 G-2849A : p-Werte der paarweisen Berechnung von Unterschieden zwischen den Populationen

$\begin{array}{ccccc} & 1 & 2 & 3 & 4 \\ 2 & 0.63540+-0.0105 & & \\ 3 & 0.32675+-0.0124 & 0.51755+-0.0074 & \\ 4 & 0.00000+-0.0000 & 0.00000+-0.0000 & 0.00000+-0.0000\end{array}$




\section{Primerübersicht}

\begin{tabular}{|c|c|c|c|c|}
\hline $\begin{array}{l}\text { Upper Primer: TLR4_299K_U } \\
\text { Lower Primer: TLR4_299K_L }\end{array}$ & $\begin{array}{l}\text { 26-mer } \\
23-\text { mer }\end{array}$ & $\begin{array}{l}\text { AGCATACTTAG } \\
\text { TAGTCACACTO }\end{array}$ & $\begin{array}{l}A C T A C \\
A C\end{array}$ & $\begin{array}{l}3^{\prime} \\
3^{\prime}\end{array}$ \\
\hline DNA250 pM, Salt $50 \mathrm{~mm}$ & & Upper Primer & \multicolumn{2}{|c|}{ Lower Primer } \\
\hline $\begin{array}{l}\text { Primer Tm } \\
\text { Primer Overall Stability } \\
\text { Primer Location }\end{array}$ & & $\begin{array}{l}49.3^{\circ} \mathrm{C} \\
-42.7 \mathrm{kcim} \\
229.254\end{array}$ & \multicolumn{2}{|c|}{$\begin{array}{l}49.3^{\circ} \mathrm{C} \\
-38.2 \mathrm{kchm} \\
337.315\end{array}$} \\
\hline $\begin{array}{l}\text { Product Tm - Primer Tm } \\
\text { Primers Tm Difference } \\
\text { Optimal Annealing Temperature }\end{array}$ & & \multicolumn{3}{|c|}{$\begin{array}{l}18.0^{\circ} \mathrm{C} \\
0.0^{\circ} \mathrm{C} \\
47.0^{\circ} \mathrm{C}\end{array}$} \\
\hline $\begin{array}{l}\text { Product Length } \\
\text { Product Tm (\$GC Method) } \\
\text { Product GC Content } \\
\text { Product Tm at } 6 \text { XSSC }\end{array}$ & & \multicolumn{3}{|c|}{$\begin{array}{l}109 \mathrm{bp} \\
67.3^{\circ} \mathrm{C} \\
33.0^{\circ} \mathrm{C} \\
88.8^{\circ} \mathrm{C}\end{array}$} \\
\hline
\end{tabular}

Product Melting Temperature ('GC Method)

\begin{tabular}{|c|c|c|c|c|c|c|}
\hline \multicolumn{3}{|c|}{ Salt } & \multicolumn{4}{|c|}{ Formamide } \\
\hline $\mathrm{m} M \mathrm{M}$ & $x \mathrm{ssc}$ & $x S S P E$ & $0 \%$ & $10 \%$ & $20 \%$ & $50 \%$ \\
\hline 1 & 0.005 & 0.006 & 39.0 & 32.5 & 26.0 & 6.5 \\
\hline 10 & 0.051 & 0.062 & 55.6 & 49.1 & 42.6 & 23.1 \\
\hline 50 & 0.256 & 0.312 & 67.3 & 60.8 & 54.3 & 34.8 \\
\hline 165 & 0.846 & 1.031 & 75.9 & 69.4 & 62.9 & 43.4 \\
\hline 330 & 1.692 & 2.062 & 80.9 & 74.4 & 67.9 & 48.4 \\
\hline 500 & 2.564 & 3.125 & 83.9 & 77.4 & 70.9 & 51.4 \\
\hline 1000 & 5.128 & 6.250 & 88.8 & 82.3 & 75.8 & 56.3 \\
\hline 195 & 1.000 & 1.219 & 0.0 & sforman & $m 77$. & \\
\hline
\end{tabular}

Abb. 41: Amplification summary des Primerpaares TLR4 299 


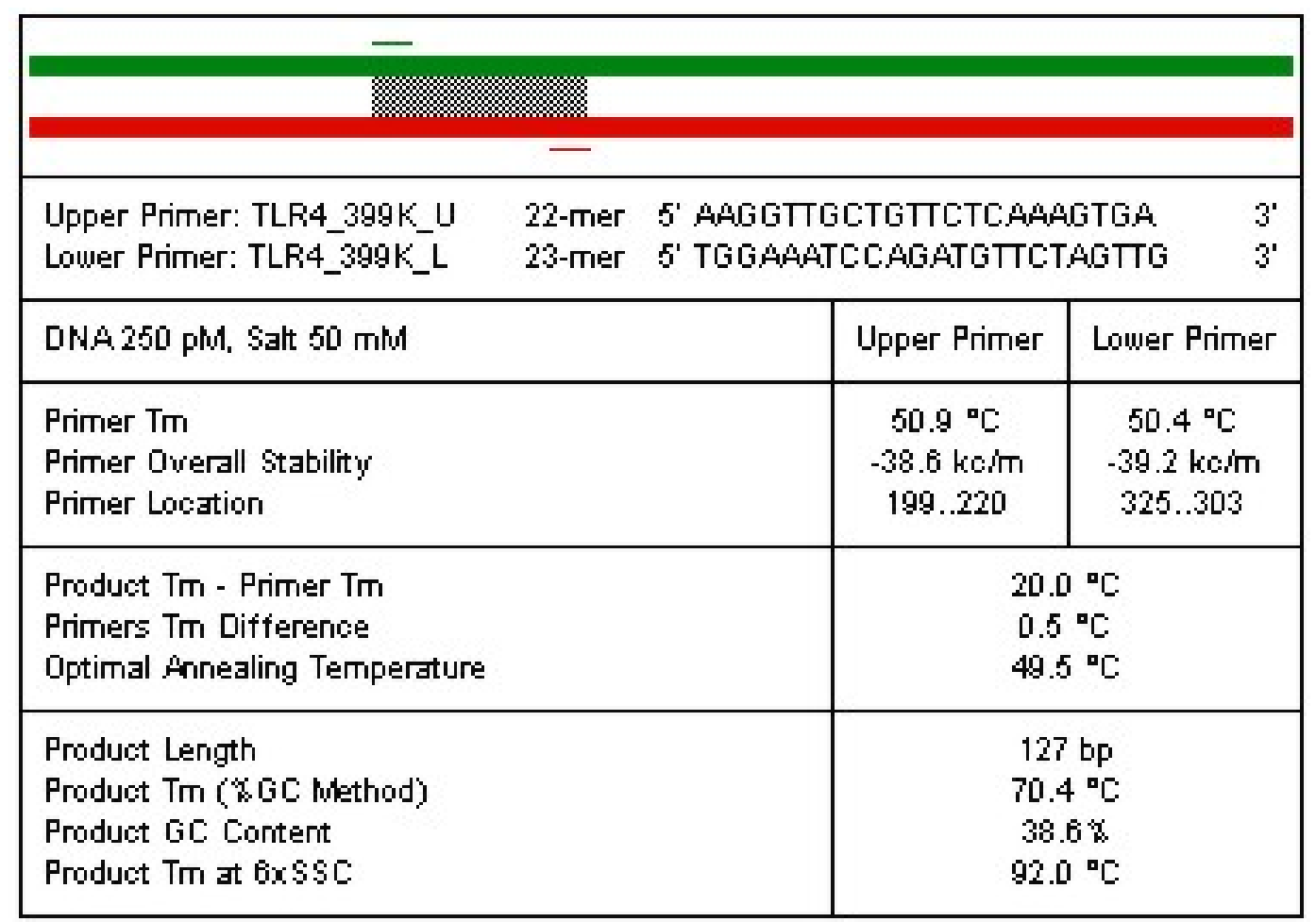

\begin{tabular}{|c|c|c|c|c|c|c|}
\hline \multicolumn{3}{|c|}{ Salt } & \multicolumn{4}{|c|}{ Formamide } \\
\hline milut & $x \mathrm{SSC}$ & $x$ SSPE & $0 \%$ & $10 x$ & $20 \%$ & $50 \%$ \\
\hline 1 & 0.005 & 0.006 & 42.2 & 35.7 & 29.2 & 9.7 \\
\hline 10 & 0.051 & 0.062 & 58.8 & 52.3 & 45.8 & 26.3 \\
\hline 50 & 0.256 & 0.312 & 70.4 & 63.9 & 57.4 & 37.9 \\
\hline 165 & 0.846 & 1.031 & 79.0 & 72.5 & 66.0 & 46.5 \\
\hline 330 & 1.692 & 2.062 & 84.0 & 77.5 & 71.0 & 51.5 \\
\hline 500 & 2.564 & 3.125 & 87.0 & 80.5 & 74.0 & 54.5 \\
\hline 1000 & 5.128 & 6.250 & 92.0 & 85.5 & 79.0 & 59.5 \\
\hline 195 & 1.000 & 1.219 & +0.0 & iforma & Tm 8 & \\
\hline
\end{tabular}

Abb. 42: Amplification summary des Primerpaares TLR4 399 


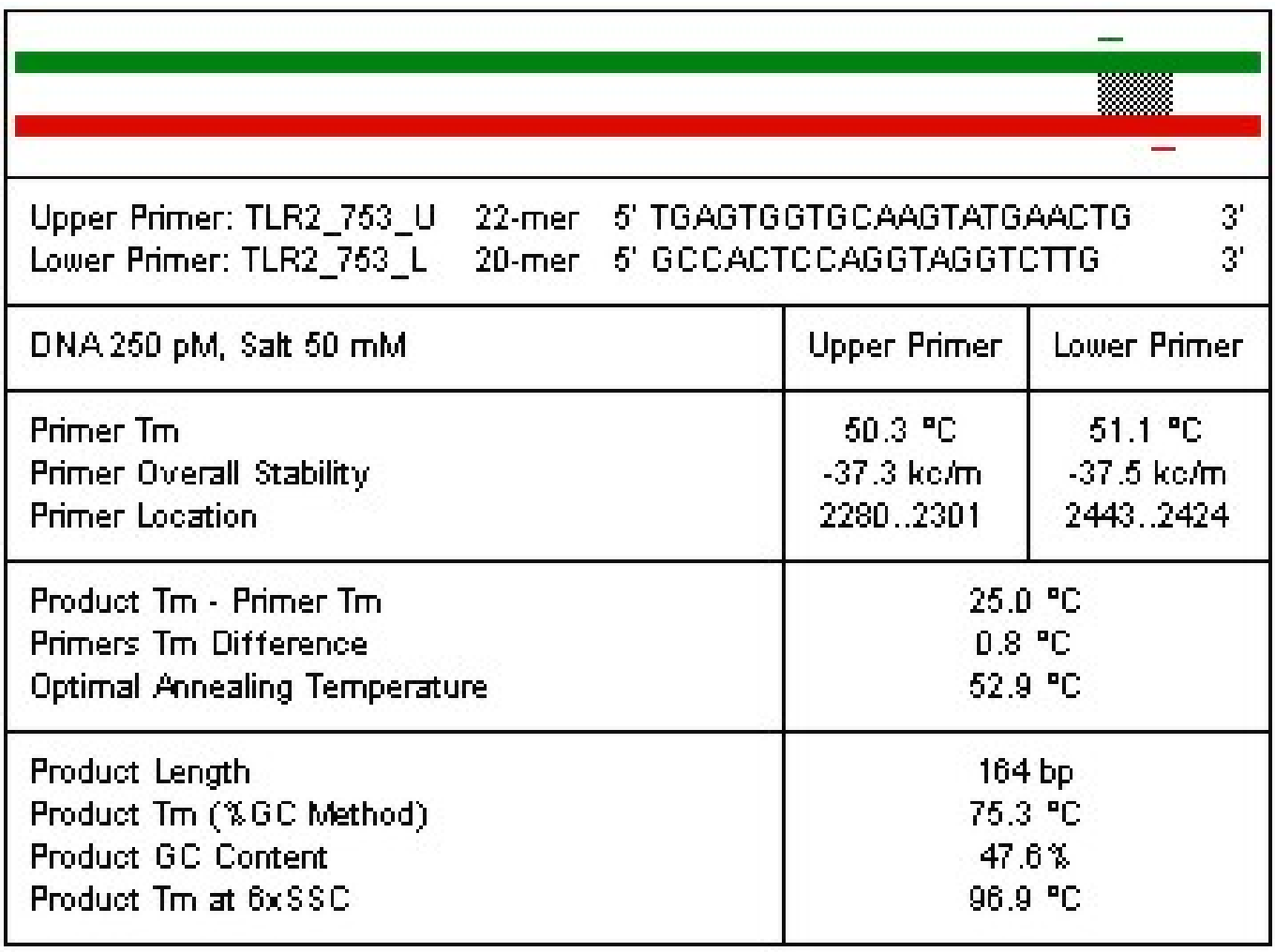

Product Melting Temperature (\%GC Method)

\begin{tabular}{|c|c|c|c|c|c|c|}
\hline \multicolumn{3}{|c|}{ Salt } & \multicolumn{4}{|c|}{ Formamide } \\
\hline milu & $x \operatorname{ssc}$ & $x S S P E$ & $0 \%$ & $10 \%$ & $20 \%$ & $50 \%$ \\
\hline 1 & 0.005 & 0.006 & 47.1 & 40.6 & 34.1 & 14.6 \\
\hline 10 & 0.051 & 0.062 & 63.7 & 57.2 & 50.7 & 31.2 \\
\hline 50 & 0.256 & 0.312 & 75.3 & 68.8 & 62.3 & 42.8 \\
\hline 165 & 0.846 & 1.031 & 83.9 & 77.4 & 70.9 & 51.4 \\
\hline 330 & 1.692 & 2.062 & 88.9 & 82.4 & 75.9 & 56.4 \\
\hline 500 & 2.564 & 3.125 & 91.9 & 85.4 & 78.9 & 59.4 \\
\hline 1000 & 5.128 & 6.250 & 96.9 & 90.4 & 83.9 & 64.4 \\
\hline 195 & 1.000 & 1.219 & +0.0 & Sorman & $\operatorname{Tm} 85$ & \\
\hline
\end{tabular}

Abb. 43: Amplification summary des Primerpaares TLR2 753 


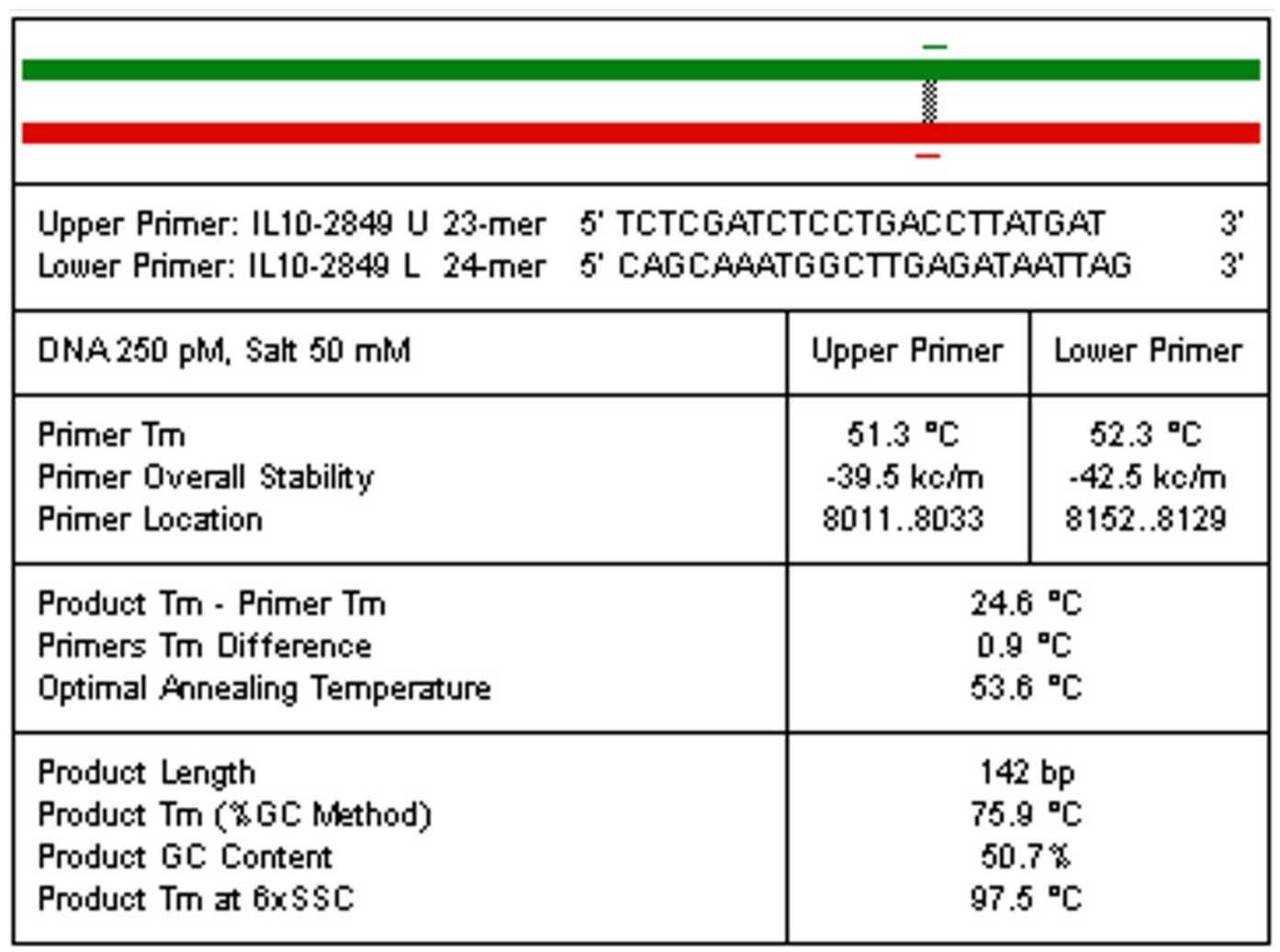

Product Melting Temperature (" GC Method)

\begin{tabular}{|c|c|c|c|c|c|c|}
\hline \multicolumn{3}{|c|}{ Salt } & \multicolumn{4}{|c|}{ Formamide } \\
\hline $\mathrm{mlw}$ & $x \operatorname{ssc}$ & $X S S P E$ & $0 x$ & $10 x$ & $20 x$ & $50 \%$ \\
\hline 1 & 0.005 & 0.006 & 47.7 & 41.2 & 34.7 & 15.2 \\
\hline 10 & 0.051 & 0.062 & 64.3 & 57.8 & 51.3 & 31.8 \\
\hline 50 & 0.256 & 0.312 & 75.9 & 69.4 & 62.9 & 43.4 \\
\hline 165 & 0.846 & 1.031 & 84.5 & 78.0 & 71.5 & 52.0 \\
\hline 330 & 1.692 & 2.062 & 89.5 & 83.0 & 76.5 & 57.0 \\
\hline 500 & 2.564 & 3.125 & 92.5 & 86.0 & 79.5 & 60.0 \\
\hline 1000 & 5.128 & 6.250 & 97.5 & 91.0 & 84.5 & 65.0 \\
\hline 195 & 1.000 & 1.219 & +0.0 & xforman & $\operatorname{Tm} 86$ & \\
\hline
\end{tabular}

Abb. 44: Amplification summary des Primerpaares IL10 -2849 


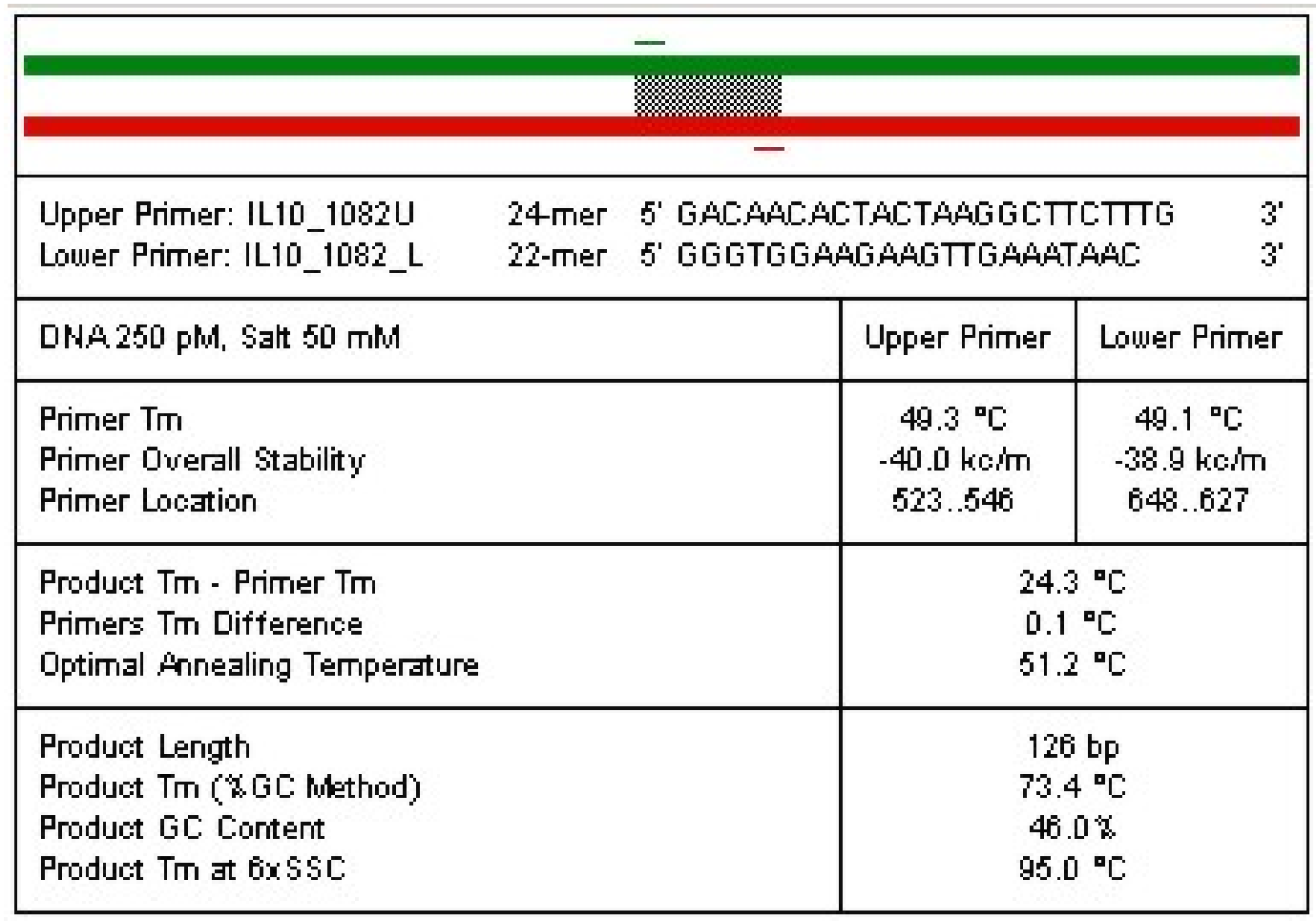

Product Melting Temperature (KGC Method)

\begin{tabular}{|c|c|c|c|c|c|c|}
\hline \multicolumn{3}{|c|}{ Salt } & \multicolumn{4}{|c|}{ Formamide } \\
\hline $\mathrm{m} M$ & $x \operatorname{ssc}$ & XSSPE & $0 \%$ & $10 \%$ & $20 \%$ & $50 \%$ \\
\hline 1 & 0.005 & 0.006 & 45.2 & 38.7 & 32.2 & 12.7 \\
\hline 10 & 0.051 & 0.062 & 61.8 & 55.3 & 48.8 & 29.3 \\
\hline 50 & 0.256 & 0.312 & 73.4 & 66.9 & 60.4 & 40.9 \\
\hline 165 & 0.846 & 1.031 & 82.0 & 75.5 & 69.0 & 49.5 \\
\hline 330 & 1.692 & 2.062 & 87.0 & 80.5 & 74.0 & 54.5 \\
\hline 500 & 2.564 & 3.125 & 90.0 & 83.5 & 77.0 & 57.5 \\
\hline 1000 & 5.128 & 6.250 & 95.0 & 88.5 & 82.0 & 62.5 \\
\hline 195 & 1.000 & 1.219 & 0.0 & formar & $m 83$ & \\
\hline
\end{tabular}

Abb. 45: Amplification summary des Primerpaares IL10 -1087 


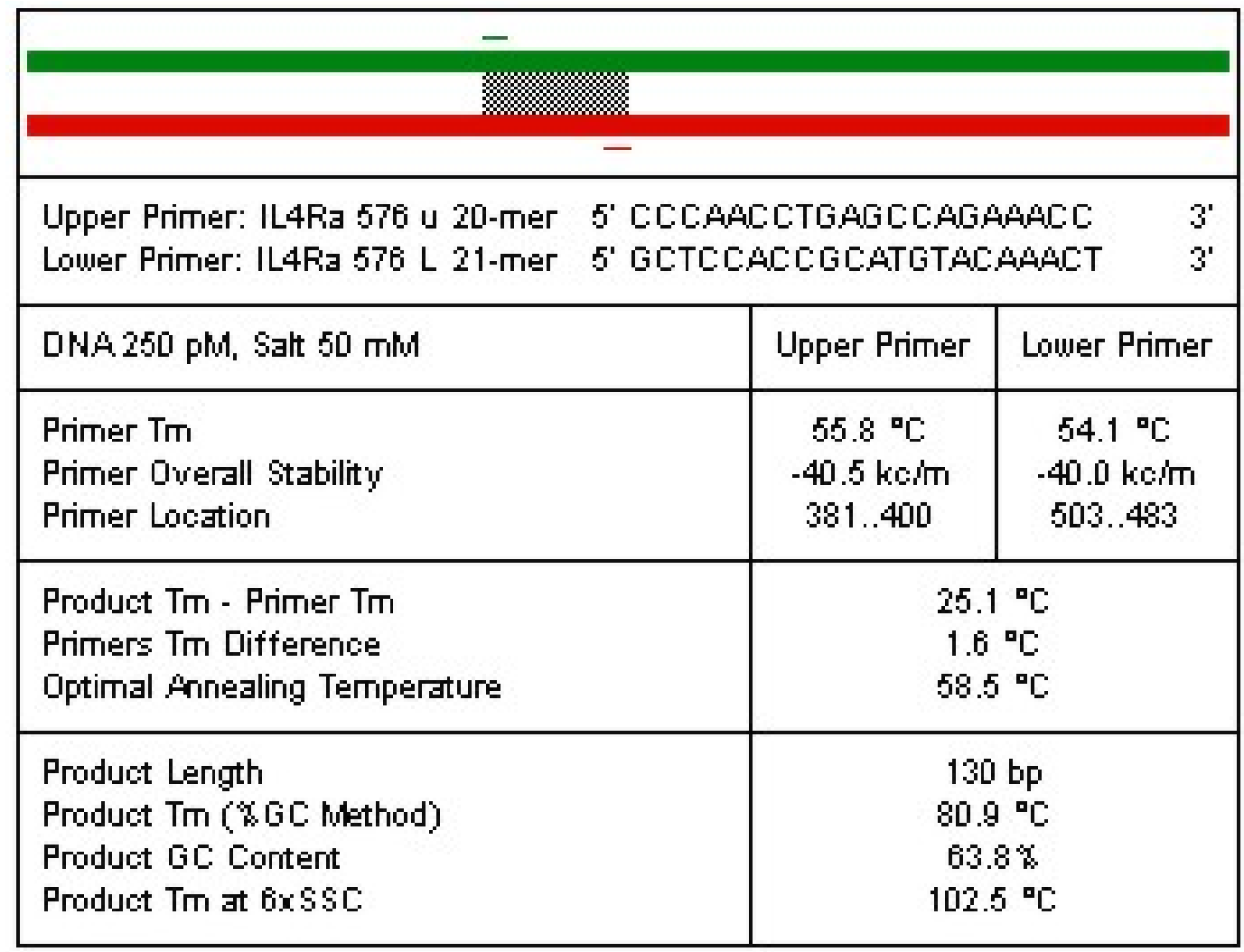

Product Melting Temperature (*GC Method)

\begin{tabular}{|c|c|c|c|c|c|c|}
\hline \multicolumn{3}{|c|}{ Salt } & \multicolumn{4}{|c|}{ Formamide } \\
\hline$m|w|$ & $x \mathrm{SSC}$ & $X S S P E$ & $0 \%$ & $10 \%$ & $20 \%$ & $50 \%$ \\
\hline 1 & 0.005 & 0.006 & 52.7 & 46.2 & 39.7 & 20.2 \\
\hline 10 & 0.051 & 0.062 & 69.3 & 62.8 & 56.3 & 36.8 \\
\hline 50 & 0.256 & 0.312 & 80.9 & 74.4 & 67.9 & 48.4 \\
\hline 165 & 0.846 & 1.031 & 89.5 & 83.0 & 76.5 & 57.0 \\
\hline 330 & 1.692 & 2.062 & 94.5 & 88.0 & 81.5 & 62.0 \\
\hline 500 & 2.564 & 3.125 & 97.5 & 91.0 & 84.5 & 65.0 \\
\hline 1000 & 5.128 & 6.250 & 102.5 & 96.0 & 89.5 & 70.0 \\
\hline 195 & 1.000 & 1.219 & 0.0 & zforma & $\mathrm{Tm}$ & \\
\hline
\end{tabular}

Abb. 46: Amplification summary des Primerpaares IL4Ra 


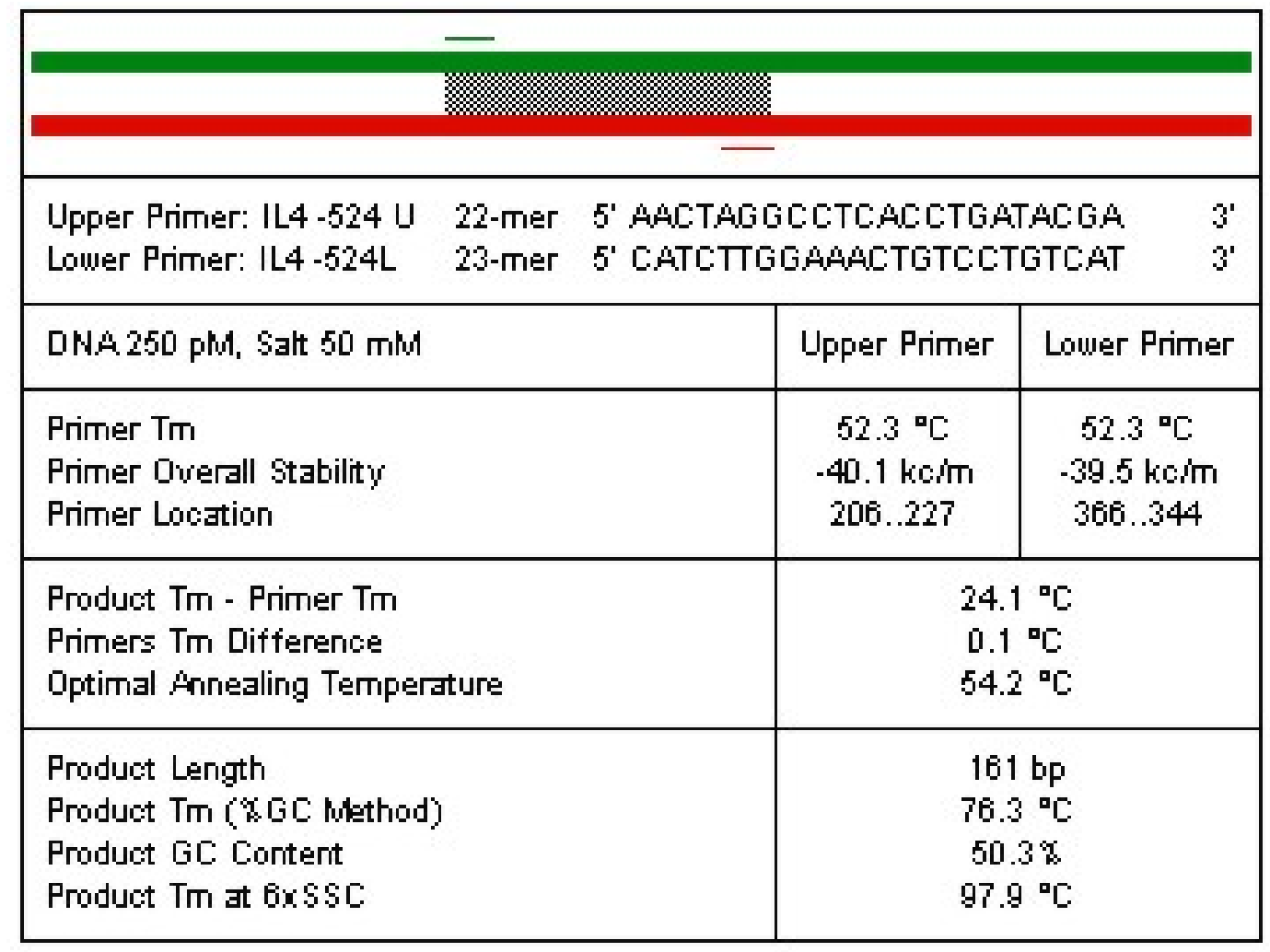

\begin{tabular}{|c|c|c|c|c|c|c|}
\hline \multicolumn{3}{|c|}{ Salt } & \multicolumn{4}{|c|}{ Formamide } \\
\hline$m \mid w 1$ & $x \mathrm{SSC}$ & $X$ SSPE & $0 \%$ & $10 \%$ & $20 x$ & $50 \%$ \\
\hline 1 & 0.005 & 0.006 & 48.1 & 41.6 & 35.1 & 15.6 \\
\hline 10 & 0.051 & 0.062 & 64.7 & 58.2 & 51.7 & 32.2 \\
\hline 50 & 0.256 & 0.312 & 76.3 & 69.8 & 63.3 & 43.8 \\
\hline 165 & 0.846 & 1.031 & 84.9 & 78.4 & 71.9 & 52.4 \\
\hline 330 & 1.692 & 2.062 & 89.9 & 83.4 & 76.9 & 57.4 \\
\hline 500 & 2.564 & 3.125 & 92.9 & 86.4 & 79.9 & 60.4 \\
\hline 1000 & 5.128 & 6.250 & 97.9 & 91.4 & 84.9 & 65.4 \\
\hline 195 & 1.000 & 1.219 & +0.0 & *forman & $\operatorname{Tm} 8$ & \\
\hline
\end{tabular}

Abb. 47: Amplification summary des Primerpaares IL4 -590 


\section{Anhang}

\section{Einheiten und Abkürzungen}

$\begin{array}{ll}\text { 5-Fam } & \text { 5-Carboxylfluorescein } \\ \text { 6-Fam } & \text { 6-Carboxylfluorescein } \\ { }^{\circ} \mathrm{C} & \text { Grad Celsius } \\ \& & \text { und } \\ \% & \text { Prozent }\end{array}$

Abb. Abbildung

AD Anno Domini

aDNA ancient DNA

bp Basenpaare

bidest bidestillata, zweifach destilliert

bzw. beziehungsweise

ca. circa

cm Zentimeter

$\mathrm{cm}^{2} \quad$ Quadratzentimeter

DNA desoxyribonucleic acid, Desoxyribonucleinsäure

dNTP Desoxynucleosidtriphosphat

ddNTP Didesoxynucleosidtriphosphat

Do Dorste, Harz

EDTA Ethylendiamintetraacetat

et al. et alii, und andere

g Gramm

h Stunde

HEX 6-Carboxyl-2 $2^{`}, 4^{`}, 7^{`}, 4,7$-Hexachlorofluorescein

Hrsg Herausgeber

HWE Hardy-Weinberg-Equilibrium

HL Hansestadt Lübeck

Jh. Jahrhundert

Jhs. Jahrhunderts

K Kelvin

kb Kilobasen

l Liter

li. links

M molar 


\begin{tabular}{|c|c|}
\hline $\mathrm{MgCl}_{2}$ & Magnesiumchlorid \\
\hline $\min$ & Minute \\
\hline$\mu \mathrm{l}$ & Mikroliter \\
\hline$\mu \mathrm{M}$ & Mikromolar \\
\hline $\mathrm{mg}$ & Milligramm \\
\hline $\mathrm{ml}$ & Milliliter \\
\hline $\mathrm{mM}$ & Millimolar \\
\hline n.Chr & nach Christi Geburt \\
\hline na & nicht analysiert \\
\hline nd & non determinandum, nicht zu bestimmen \\
\hline ng & Nanogramm \\
\hline nt & Nukleotidposition \\
\hline PAGE & Polyacrylamid-Gelelektrophorese \\
\hline PCR & polymerase chain reaction, Polymerase-Kettenreaktion \\
\hline $\mathrm{pH}$ & potentia hydrogenii, Protonenaktivitätsexponent \\
\hline (®) & rechtlich geschützt \\
\hline pmol & Picomol \\
\hline re. & rechts \\
\hline RFLP & Restriktions-Fragment-Längen-Polymorphismus \\
\hline rfu & relative fluorescent unit, dimensionslose Einheit der Fluoreszenzstärke \\
\hline ROX & 6-Carboxylrhodamin \\
\hline rpm & rotation per minute, Umdrehungen pro Minute \\
\hline RT & Raumtemperatur \\
\hline s. & siehe \\
\hline S. & Seite \\
\hline SBE & single base extension \\
\hline $\mathrm{Si}$ & Silikat \\
\hline S.O. & siehe oben \\
\hline s.u. & siehe unten \\
\hline sec & Sekunde \\
\hline SNP & single nucleotide polymorphism \\
\hline STR & short tandem repeat \\
\hline Tab. & Tabelle \\
\hline Taq-Polymerase & Thermus aquaticus-DNA-Polymerase \\
\hline TBE & Tris-Borat-EDTA \\
\hline $\mathrm{TE}$ & Tris-EDTA \\
\hline$T M$ & Trademark \\
\hline
\end{tabular}




$\begin{array}{ll}\text { U } & \text { unit, Einheit für Enzymaktivität } \\ \text { u. a. } & \text { und andere } \\ \text { üN } & \text { über Nacht } \\ \text { UV } & \text { Ultraviolett } \\ \text { V } & \text { Volt } \\ \text { v. Chr. } & \text { vor Christi Geburt } \\ \text { vgl. } & \text { vergleiche } \\ \text { W } & \text { Watt } \\ \text { w/v } & \text { weight per volume } \\ \text { z. B. } & \text { zum Beispiel }\end{array}$

\section{Geräte}

ABI PRISM ${ }^{\circledR}$ 373Stretch Genetic Analyzer, Applied Biosystems mit AbiPrism ${ }^{T M}$ 672 Collection Software und AbiPrism ${ }^{T M}$ GeneScan Software 2.1 zur FragmentlängenAnalyse,

ABI PRISM@310 Genetic Analyzer, Applied Biosystems mit ABI PRISM@310 Collection Software und 310 GeneScan-Analysis Software (Version 3.1.1) zur Fragmentlängen-Analyse sowie 310 Sequencing-Analysis Software zur Sequenzanalyse Demineralisationsanlage Typ LAB-UPW, TKA Wasseraufbereitungsanlage GmbH Dentalbohrmaschine (Typ K10, KaVo)

DNA-Extraktor Biorobot Ez1, Qiagen

DNA Thermal Cycler Typ TC1, Perkin Elmer Cetus

DNA-Thermal Cycler Typ Mastercycler ${ }^{\circledR}$ gradient, Eppendorf

DNA-Thermal Cycler Typ Mastercycler ${ }^{\circledR}$ personal, Eppendorf

DNA-Thermal Cycler Typ Mastercycler ${ }^{\circledR}$, Eppendorf

Elektrophoresekammer Horizon 1060 BD $58(5 \times 8 \mathrm{~cm})$, Gibco BRL

Elektrophoresekammer Horizon 1060 BD 11-14 $(11 \times 14 \mathrm{~cm})$, Gibco BRL

Gel Jet Imager \& Analyser mit Software IntasGel Capture, Intas

Glaskapillaren 310 Genetic Analyzer Capillaries $47 \mathrm{~cm} \times 50 \mu \mathrm{m}$ i.d., $5 \mathrm{p} / \mathrm{kg}$,

Kugelschwingmühle Typ MM2, Zirkonium-Mahlbecher, Retsch

Polaroid $^{T \mathrm{M}}$-Film, ISO3000 ${ }^{\circ}$ Typ 667, Polaroid ${ }^{\mathrm{TM}}$

Polaroid $^{\mathrm{TM}}$-Kamera, MP4 Land Camera, Polaroid ${ }^{\mathrm{TM}}$ mit Orangefilter, Typ 15 für

Ethidiumbromidfärbung, Polaroid ${ }^{\mathrm{TM}}$

Power Macintosh 7100/66, Apple Computer Inc.

Power Macintosh G3, Apple Computer Inc.

Power Macintosh G4, Apple Computer Inc.

Präzisionswaage excellence, Typ E1200S, Sartorius

Quadra 650, Apple Computer Inc.

Stromversorgung, Typ ST606 Electrophoresis Power Supply, Gibco BRL

Test-tube-Rotator, Fa Snijders

Thermomixer, Typ 5437, Eppendorf 
Transilluminator, Typ IL-350K, 254nm, Bachofer Varipetten, Typ4810, 0,5 $\mu \mathrm{l}-10 \mu \mathrm{l}, 2-20 \mu \mathrm{l}, 10-100 \mu \mathrm{l}, 100-1000 \mu \mathrm{l}$, Eppendorf Wasser-Destilliergerät, Typ Muldestor, Wagner \& Munz

Zentrifuge, Typ 5402, Eppendorf

Zentrifuge, Typ 5415C, Eppendorf

Zentrifuge, Typ 5415R, Eppendorf

\section{Chemikalien und Kits}

- 1KB DNA-Leiter (Molekulargewichtslängenstandard), Life Technologies

- ABI PRISM ${ }^{\circledR}$ SNaPshot ${ }^{\circledR}$ Multiplex Kit, Applied Biosystems

- Acrylamid/Bisacrylamid 29:1, 40 \% w/v, Rotiphorese ${ }^{\circledR}$, Roth

- Agarose Roti ${ }^{\circledR}$ garose, Roth

- Alconox (Detergenz), Aldrich

- Alkaline Phosphatase, Shrimp, Roche

- Ammoniumpersulfat (APS) 98+\%, Aldrich

- AmpFlSTR Profiler Plus ${ }^{\top M}$ Primer Set, Perkin Elmer Applied Biosystems

- Ampuwa ${ }^{\circledR}$ (steriles Wasser), Fresenius

- AmpliTaqGold ${ }^{\circledR}$ DNA-Polymerase $(5 \mathrm{U} / \mu \mathrm{l})$, Perkin Elmer Cetus

- ApaL I, rekombinantes Restriktionsenzym, 10.000 U/ml, New England BioLabs

- Aqua bidestillata, eigene Herstellung

- BigDye ${ }^{T M}$ Terminator v1.1 Cycle Sequencing Kit, Applied Biosystems

- Borsäure, p.a., Merck

- Bromphenolblau Natriumsalz p.a., Serva

- Chelex ${ }^{\circledR} 100$ Resin, BioRad

- dATP, dCTP, dGTP, dTTP, Sigma

- Dextran-Blau, Fluka

- EDTA: Titriplex ${ }^{\circledR}$ III, Merck

- Ethanol

- Ethidiumbromid, wässrige Lösung $1 \%$ w/v, 10 mg/ml, Serva

- Extran ${ }^{\circledR}$ Typ AP13 alkalisch mit Detergenzien, Merck

- EZ1 DNA Tissue Kit, Qiagen

- Formamid, Fluka 
- GeneAmp ${ }^{\circledR} 10 \times$ PCR Buffer II und $\mathrm{MgCl}_{2}$ solution $(25 \mathrm{mM})$, PE Applied Biosystems

- Glasmilk ${ }^{\circledR}$ Typ Ultra Clean ${ }^{\circledR}, 15$ Ultra Bind, Bio 101, QbioGene

- GeneScan ${ }^{T M} 500$ ROX Standard Kit (spurinterner Standard, Loading Buffer), Applied Biosystems

- GeneScan ${ }^{\top \mathrm{M}} 120$ LIZ Standard (spurinterner Standard), Applied Biosystems

- Harnstoff Rotiphorese ${ }^{\circledR}$, Roth

- HiDiFormamid

- Isopropanol, p.a., Merck

- LiChrosolv ${ }^{\circledR}$, HPLC-Wasser zur Chromatographie, Merck

- Mineralöl NUJOL, Perkin Elmer Cetus

- Natriumhydroxyd, p.a., Merck

- NEB2-Puffer, New England BioLabs

- NEB3-Puffer, New England BioLabs

- NEB4-Puffer, New England BioLabs

- NucleoSeq Kit Dye Terminator Removal, Macherey-Nagel

- Oligonucleotide, salt-free oder HPLC-grade, Operon

- Oligonucleotide (SNaPshot-Primer 30 bis 45 nt) salt-free, Applied Biosystems

- Oligonucleotide (SNaPshot-Primer ab 45 nt) HPLC-grade, Applied Biosystems

- $\mathrm{POP}^{\mathrm{TM}}$ (performance optimized polymer), Applied Biosystems

- POP6 $6^{\mathrm{TM}}$ (performance optimized polymer), Applied Biosystems

- Proteinase K, DNA purification grade, Qiagen

- Salzsäure rauchend, $\mathrm{HCl}, 37$ \%, p.a., Merck

- TEMED (Tetramethylethylendiamin), BioRad

- Tris (Tri[hydroxymethyl]aminoethan), Trizma ${ }^{T M}$ Base, p.a., Sigma

- SNaPshot Multiplex Kit, Applied Biosystems

- Qiagen ${ }^{\circledR}$ Multiplex PCR Kit, Qiagen

- QIAquick Purification Kit, Qiagen

\section{Einwegmaterialien und Hilfsmittel}

- Dental-Diamantsägeblätter Typ Diaflex-T H 350 220, Horico

- Einmaluntersuchungshandschuhe, Safeskin Satin Plus, Powder-free, KimberleyClark ${ }^{\circledR}$ 
- Eppendorf Reaktionsgefäße (0,5 ml) safe-lock, Eppendorf

- Eppendorf Reaktionsgefäße (2,0 ml) safe-lock, Eppendorf

- Gesichtsmasken: Surgine face mask, Johnson \& Johnson

- Kimwipes ${ }^{\circledR}$ Lite, Kimberley-Clark ${ }^{\circledR}$

- Parafilm ${ }^{\circledR} \mathrm{M}$, American National Clan $^{\mathrm{TM}}$

- PE-Zentrifugationsgefäße, BlueMax ${ }^{\top M}$

- Pipettenspitzen: gelbe Spitzen $(100 \mu \mathrm{l})$, blaue Spitzen(1ml), Sarstedt

- Pipettenspitzen: Standardtips $(10 \mu \mathrm{l})$, Eppendorf

- Wägepapier $10 \times 13 \mathrm{~cm}$, neoLab

\section{Längenstandards}

1Kb-Leiter (Agarose-Gel) $75-134-154-201-220-298-344-396-506$ $-517-1018$ - $1636-2036-3054-4072-5090-6108-7126-8144-9162-$ $10180-11198-12216$

(Längen in bp)

GeneScan500 ROX (PAA-Gel- und Kapillarelektrophorese) 35 - 50 - 75 $100-139-150-160-200-250-300-340-350-400-450-490-500$ (Längen in bp)

GeneScan120 LIZ (Kapillarelektrophorese) $\quad 15-20-25-35-62-80-110$ $-120$

(Längen in bp) 


\section{IUB-Code}

Tab. 62: IUB-Code

\begin{tabular}{lllll}
\multicolumn{1}{l}{ Nucleotide } & & \multicolumn{3}{c}{ Aminosäuren } \\
A Adenin & A & Ala & Alanin \\
B nicht A & B & Asx & Aspartat oder Asparagin \\
C Cytosin & C & Cys & Cystein \\
D nicht C & D & Asp & Aspartat \\
G Guanin & E & Glu & Glutamat \\
H nicht G & F & Phe & Phenylalanin \\
K G oder T & G & Gly & Glycin \\
M A oder C & H & His & Histidin \\
N A, C, G, oder T & I & Ile & Isoleucin \\
R & A oder G & K & Lys & Lysin \\
S C oder G & L & Leu & Leucin \\
T & Thymin & M & Met & Methionin \\
U & Uracil & N & Asn & Asparagin \\
V nicht T & P & Pro & Prolin \\
W A oder T & Q & Gln & Glutamin \\
Y C oder T & R & Arg & Arginin \\
& & S & Ser & Serin \\
& & T & Thr & Threonin \\
& & V & Val & Valin \\
& & W & Trp & Tryptophan \\
& & beliebige & Aminosäure \\
& & & & Tyrosin \\
& & Glx & Glutamat oder Glutamin
\end{tabular}




\section{Danksagung}

Mein Dank gilt

Herrn Prof. Dr. B. Herrmann für die Bereitstellung des Themas und des Arbeitsplatzes sowie für seine Hilfestellung und Diskussionsbereitschaft in fachlichen Fragen.

Frau Dr. S. Hummel für die umfangreiche Betreuung, die anregenden Gespräche und die Vermittlung ihres Wissens zur aDNA-Analyse.

Der ganzen Belegschaft des Anthropologischen Institutes für die gute Zusammenarbeit, für die vielen Gelegenheiten des gemütlichen Beisammenseins und der anregenden Gespräche, die ich sehr vermissen werde.

Meinen Mit-Doktoranden Lars Fehren-Schmitz und Rebecca Renneberg sei gedankt für inzwischen fünf Jahre des gemeinsamen Arbeitens, fachlichen und privaten Austauschs sowie der gegenseitigen Hilfestellung im Labor.

Sandra Melchisedech, Susanne Schliehe-Dieks, aber ganz besonders natürlich meinem HiWi Stefanie Huhn danke ich für ihre zuverlässige Arbeit im Labor.

Jenni Schawacht, Carolin Fromm-Dornieden, Anke Liebert, Dorothee Suray, Rabea Kleindorp, Verena Seidenberg, Katharina Schmücker für manch kleinen und großen Gefallen.

Carolin Fromm-Dornieden danke ich außerdem für heiß Wasser, Teebeutel und die gut gefüllte Keksdose, die mich aus mancher Notlage gerettet hat.

Den Stadtgängern sei für die mittägliche Verpflegung gedankt!

PD Dr. D. Kube danke ich für die Überlassung der Rezentdaten und für seine zahlreichen Anregungen.

Jingky Lozano for her special patience in teaching me the statistics and keeping a watchful eye on my calculations.

Dem Graduiertenkolleg für die Unterstützung und das lehrreiche Ausbildungsprogramm.

Der Truppe "Alternative Seminarreihe" für die vielen schönen Stunden im GRK und privat. Besonders danke ich Diana Pinkert-Leetsch, Annett Kühne und Valerie Honndorf für ihre Freundschaft, für ihre fachliche Unterstützung und den Zugriff auf die vielen Artikel.

Meiner Familie für die Unterstützung, ihren Glauben an mich und ihre aufmunternden Worte. Meinem Mann danke ich ganz besonders dafür, wie er mir in den letzten Monaten beigestanden und den Rücken freigehalten hat, für seine Geduld und den Adlerblick bei der Fehlersuche. Meinem Sohn danke ich, daß er unbeeindruckt des Stresses mit mir durch die Endphase der Dissertation gegangen ist und selbst seinen Geburtstermin bedingungslos in die Zeitplanung eingefügt hat. 


\section{Lebenslauf}

\section{Persönliche Daten}

Jutta Pepperl, geb. Pollmann

geb. am 02.07.1976 in Wuppertal-Elberfeld

Verheiratet, ein Sohn (1 Monat)

\section{Schulausbildung}

$1983-1987$
$1987-1993$
$1993-1994$
$1994-1996$

Grundschule in Remscheid-Hasten

Gymnasium in Remscheid

High-School in St. Louis, MO, USA, Auslandsjahr

Gymnasium mit Abitur in Solingen

\section{Berufsausbildung}

1996 - 1999

Ausbildung zur examinierten Krankenschwester an der staatlich anerkannten Krankenpflegeschule der Kaiserswerther Diakonie Abschluß als examinierte Krankenschwester

\section{Wissenschaftlicher Werdegang}

$1999-2001$

Biologie (Diplom) an der Heinrich-Heine-Universität Düsseldorf Erwerb des Vordiploms (4 Sem.)

$2001-12004$

Biologie (Diplom) an der Georg- August-Universität (6 Sem.) Abschluß als Diplom Biologin

2004

Diplomarbeit in der Abteilung für historische Anthropologie und Humanökologie zum Thema: „Zerstörungsfreie DNA-Extraktion an historischen Skelettelementen"

$2005-2008$

Promotionsstipendiatin des DFG-Graduiertenkolleg 1034 cancer pharmacogenomics "Die Bedeutung genetischer Polymorphismen in der Onkologie: Von den Grundlagen zur individualisierten Therapie"

Doktorandin in der Abteilung Historische Anthropologie und Humanökologie, Universität Göttingen im Projekt:

"Molekulargenetische Untersuchung immungenetischer Marker an degradierter DNA aus genetischen Archiven"

Titel der Arbeit: Molekulargenetische Analyse von single nucleotide Polymorphismen immungenetischer Rezeptoren und Interleukine in historischen Bevölkerungen

Göttingen, im März 2008 